
Magia daemoniaca, magia naturalis, zouber 


\section{Episteme in Bewegung}

Beiträge zu einer transdisziplinären Wissensgeschichte

Herausgegeben von Gyburg Uhlmann im Auftrag des Sonderforschungsbereichs 980

„Episteme in Bewegung.

Wissenstransfer von der Alten Welt

bis in die Frühe Neuzeit"

Band 2

2015

Harrassowitz Verlag · Wiesbaden 


\title{
Magia daemoniaca, magia naturalis, zouber
}

Schreibweisen von Magie und Alchemie in Mittelalter und Früher Neuzeit

\author{
Herausgegeben von \\ Peter-André Alt, Jutta Eming, Tilo Renz \\ und Volkhard Wels
}

\section{5}

Harrassowitz Verlag · Wiesbaden 
Die Reihe „Episteme in Bewegung“ umfasst wissensgeschichtliche Forschungen mit einem systematischen oder historischen Schwerpunkt in der europäischen und nicht-europäischen Vormoderne. Sie fördert transdisziplinäre Beiträge, die sich mit Fragen der Genese und Dynamik von Wissensbeständen befassen, und trägt dadurch zur Etablierung vormoderner Wissensforschung als einer eigenständigen Forschungsperspektive bei.

Publiziert werden Beiträge, die im Umkreis des an der Freien Universität Berlin angesiedelten Sonderforschungsbereichs 980 „Episteme in Bewegung. Wissenstransfer von der Alten Welt bis in die Frühe Neuzeit" entstanden sind.

Herausgeberbeirat:

Eva Cancik-Kirschbaum (Freie Universität Berlin)

Anne Eusterschulte (Freie Universität Berlin)

Kristiane Hasselmann (Freie Universität Berlin)

Andrew James Johnston (Freie Universität Berlin)

Jochem Kahl (Freie Universität Berlin)

Klaus Krüger (Freie Universität Berlin)

Tilo Renz (Freie Universität Berlin)

Wilhelm Schmidt-Biggemann (Freie Universität Berlin)

Gedruckt mit freundlicher Unterstützung der Deutschen Forschungsgemeinschaft (DFG).

Abbildung auf dem Umschlag:

Musaeum Hermeticum Reformatum Et Amplificatum. Frankfurt a. M. 1678, S. 323.

Abbildung mit freundlicher Genehmigung der SLUB Dresden / Deutsche

Fotothek (Inv.-Nr.: Chem.360; Aufnahme: Dresdner Digitalisierungszentrum, 2008)

Bibliografische Information der Deutschen Nationalbibliothek

Die Deutsche Nationalbibliothek verzeichnet diese Publikation in der Deutschen

Nationalbibliografie; detaillierte bibliografische Daten sind im Internet

über http://dnb.dnb.de abrufbar.

Bibliographic information published by the Deutsche Nationalbibliothek

The Deutsche Nationalbibliothek lists this publication in the Deutsche

Nationalbibliografie; detailed bibliographic data are available on the internet

at http://dnb.dnb.de.

Informationen zum Verlagsprogramm finden Sie unter

http://www.harrassowitz-verlag.de

(c) Otto Harrassowitz GmbH \& Co. KG, Wiesbaden 2015

Das Werk einschließlich aller seiner Teile ist urheberrechtlich geschützt.

Jede Verwertung außerhalb der engen Grenzen des Urheberrechtsgesetzes ist ohne

Zustimmung des Verlages unzulässig und strafbar. Das gilt insbesondere

für Vervielfältigungen jeder Art, Übersetzungen, Mikroverfilmungen und

für die Einspeicherung in elektronische Systeme.

Gedruckt auf alterungsbeständigem Papier.

Druck und Verarbeitung: Hubert \& Co., Göttingen

Printed in Germany

ISSN 2365-5666

ISBN 978-3-447-10495-1

e-ISBN PDF 978-3-447-19412-9 


\title{
Zum Geleit
}

\author{
Andrew James Johnston und Gyburg Uhlmann
}

Der an der Freien Universität Berlin angesiedelte Sonderforschungsbereich 980 „Episteme in Bewegung. Wissenstransfer von der Alten Welt bis in die Frühe Neuzeit", der im Juli 2012 seine Arbeit aufgenommen hat, untersucht anhand exemplarischer Problemkomplexe aus europäischen und nicht-europäischen Kulturen Prozesse des Wissenswandels vor der Moderne. Dieses Programm zielt auf eine grundsätzliche Neuorientierung wissensgeschichtlicher Forschung im Bereich der Vormoderne ab. Sowohl in der modernen Forschung als auch in den historischen Selbstbeschreibungen der jeweiligen Kulturen wurde das Wissen der Vormoderne häufig als statisch und stabil, traditionsgebunden und autoritätsabhängig beschrieben. Dabei waren die Stabilitätspostulate moderner Forscherinnen und Forscher nicht selten von der Dominanz wissensgeschichtlicher Szenarien wie dem Bruch oder der Revolution geprägt sowie von Periodisierungskonzepten, die explizit oder implizit einem Narrativ des Fortschritts verpflichtet waren. Vormodernen Kulturen wurde daher oft nur eine eingeschränkte Fähigkeit zum Wissenswandel und vor allem zur - nicht zuletzt historischen - Reflexion dieses Wandels zugeschrieben. Demgegenüber will dieser SFB zeigen, dass vormoderne Prozesse der Wissensbildung und -entwicklung von ständiger Bewegung und auch ständiger Reflexion geprägt sind, dass diese Bewegungen und Reflexionen aber eigenen Dynamiken unterworfen sind und in komplexeren Mustern verlaufen, als es eine traditionelle Wissensgeschichtsschreibung wahrhaben will.

Um diese Prozesse des Wissenswandels fassen zu können, entwickelte der SFB 980 einen Begriff von ,Episteme', der sich sowohl auf ,Wissen' als auch ,Wissenschaft' bezieht und das Wissen als ,Wissen von etwas' bestimmt, $d$. h. als mit einem Geltungsanspruch versehenes Wissen. Diese Geltungsansprüche werden allerdings nicht notwendigerweise auf dem Wege einer expliziten Reflexion erhoben, sondern sie konstituieren sich und werden auch reflektiert in Formen der Darstellung, durch bestimmte Institutionen, in besonderen Praktiken oder durch spezifische ästhetische oder performative Strategien.

Zudem bedient sich der SFB 980 eines speziell konturierten Transfer-Begriffs, der im Kern eine Neukontextualisierung von Wissen meint. Transfer wird hier nicht als Transport-Kategorie verstanden, sondern vielmehr im Sinne komplex verflochtener Austauschprozesse, die selbst bei scheinbarem Stillstand iterativ in Bewegung bleiben. Gerade Handlungen, die darauf abzielen, einen erreichten 
Wissensstand zu tradieren, zu kanonisieren, zu kodifizieren oder zu fixieren, tragen zum ständigen Wissenswandel bei.

Gemeinsam mit dem Harrassowitz Verlag hat der SFB die Reihe „Episteme in Bewegung. Beiträge zu einer transdisziplinären Wissensgeschichte“ ins Leben gerufen, um die Ergebnisse der Zusammenarbeit zu präsentieren und zugänglich zu machen. Die Bände, die hier erscheinen, werden das breite Spektrum der Disziplinen repräsentieren, die im SFB vertreten sind, von der Altorientalistik bis zur Mediävistik, von der Koreanistik bis zur Arabistik. Publiziert werden sowohl aus der interdisziplinären Zusammenarbeit hervorgegangene Bände als auch Monographien und fachspezifische Sammelbände, die die Ergebnisse einzelner Teilprojekte dokumentieren.

Allen ist gemeinsam, dass sie die Wissensgeschichte der Vormoderne als ein Forschungsgebiet betrachten, dessen Erkenntnisgewinne von grundsätzlichem systematischen Interesse auch für die wissensgeschichtliche Erforschung der Moderne sind. 


\section{Inhalt}

Peter-André Alt, Jutta Eming, Tilo Renz, Volkhard Wels

Einleitung

Almut-Barbara Renger

Von Pythagoras zur arabischen Alchemie? Über Longue-Durée-

Konstruktionen und Wissensbewegungen im Mittelmeerraum

Mireille Schnyder

Der vierte Sohn Noahs und die Magie der Künste

Jutta Eming

Aus den swarzen buochen. Zur Ästhetik der Verrätselung von Erkenntnis und Wissenstransfer im Parzival

Antje Wittstock

Transmutation und Veredelung in Gottfrieds Tristan

Sandra Linden

Zauber der Minne - Zauber der Tugend. Zur Verbindung von Magie

und Tugendlehre in spätmittelalterlichen Minnereden

Jan-Dirk Müller

Magie, Erotik, Kunst. Zur Vorgeschichte einer frühneuzeitlichen

Problemfigur

Frank Fürbeth

Magische Texte in mittelalterlichen Bibliotheken

Tobias Bulang

Satirische, dämonologische und wissensvermittelnde Schreibweisen

über die Alchemie im Werk Johann Fischarts

Marina Münkler

Epistemische Figurationen. Überlegungen zum Status von Magiern und Alchemisten in der Wissensordnung der Frühen Neuzeit 
Volkhard Wels

Die Alchemie der Frühen Neuzeit als Gegenstand der Wissensgeschichte ...

Stefanie Stockhorst

Satirische Erbauungsalchemie. Zum Verhältnis von

Humanistenschalk, Laborpraxis und Gotteserkenntnis in

Johann Rists Philosophischem Phoenix (1638)

Jost Eickmeyer

Hexenflug und Hagelzauber. Zum poetischen Umgang mit Magie in

neulateinischen Gedichten aus Humanismus und Barock ...

Simon Zeisberg

Paradoxe Perspektiven. Zur Funktion des Wunderbaren in

Grimmelshausens Wunderbarlichem Vogel-Nest (1672/75)

Michael Lorber

Alchemia oeconomica. Johann Joachim Bechers (1635-1682)

Sozialutopismus am Schnittpunkt von Projektemacherei,

alchemischer Naturphilosophie und Staatsräson

Sven Dupré

Über die Schwierigkeit der Beschreibung alchemischer Techniken.

Johannes Kunckels Übersetzung der Arte vetraria von Antonio Neri

Harald Haferland

Eine kurze Theoriegeschichte der alchemistischen multiplicatio und der

Vorbothe der am philosophischen Himmel hervorbrechenden Morgenröthe des

Johannes de Monte Raphaim (Amsterdam 1703)

Bernd Roling

Virgula divinatrix. Frühneuzeitliche Debatten über die Wünschelrute zwischen Magie und Magnetismus

Farbabbildungen 


\title{
Einleitung
}

\author{
Peter-André Alt, Jutta Eming, Tilo Renz, Volkhard Wels
}

Der vorliegende Band fasst die Ergebnisse einer Tagung zusammen, welche die Herausgeber im Rahmen des Sonderforschungsbereichs 980 Episteme in Bewegung im November 2013 an der Freien Universität Berlin veranstaltet haben. Der Sonderforschungsbereich verfolgt das Ziel, den Wissenswandel in der Vormoderne in seinen eigengesetzlichen strukturellen Ausprägungen und prozessualen Dimensionen anhand heterogener Wissenskulturen herauszuarbeiten. Die Arbeit des Forschungsverbunds besteht zum einen darin, in einzelnen Teilprojekten an konkretem Material Szenarien dieses Wissenswandels zu beschreiben und in ihren Formierungen transparent zu machen. Von den Teilprojekten ausgehend werden zum anderen solche Formierungen miteinander verglichen, um mögliche Grundmuster zu erfassen. Schließlich geht es um die Möglichkeit einer Metareflexion durch übergreifende kategoriale Ordnungen, die ihrerseits klären soll, inwiefern Wissenswandel vor der Moderne neue Strukturen der Verzeitlichung und Historisierung, des Bewusstseins und der kulturellen Identität schaffen kann. Es gehört zu den schwierigsten Aufgaben des Sonderforschungsbereichs, seine Gegenstände und Quellen so zu erschließen, dass ihre Spezifik jenseits der konventionellen modernen Perspektiven erkennbar wird und in ihren dynamischen Prozessen für die Konstitution der Wissensgeschichte dennoch systematisch erfasst werden kann. Zu ermitteln sind dafür Indikatoren, die Wandlungsprozesse auf epistemischen Feldern der Vormoderne in ihrer Eigenständigkeit beschreibbar und zugleich begrifflich zugänglich machen. $\mathrm{Zu}$ solchen Prozessen zählen etwa Vorgänge der Überlagerung und Adaption, der Abstoßung und Verschmelzung, synkretistische und heterodoxe Bildungen, Kontinuitätssuggestionen, Imitation und Agon, Paradoxie-Entfaltungen, Autoritätswechsel und versteckte Neuerungen.

Die vormoderne Magie und Alchemie bieten als weitgehend nicht-orthodoxe, nicht-kanonische Formen des Wissens mit oftmals subkutanen Formen der Rezeption und epistemischen Bündnissen, die es methodisch unkonventionell eingehen kann, ideale Untersuchungsfelder für diese Anliegen. Gegen die theologischen Schulen des Mittelalters und die Enzyklopädik der Frühen Neuzeit stehen Magie und Alchemie als beispielhafte Bereiche für ein unorthodoxes Verfahren der Wissenserzeugung und -weitergabe, welche die anerkannten Formen der Wissensverwaltung kontinuierlich herausfordern und mit denen diese je neu in ,Verhandlungen' eintreten. Zu ihren spezifischen Merkmalen lassen sich etwa 
rechnen: die Überschreitung der Grenzen zwischen Theorie und Praxis, die Deutung der Natur als Raum der vita activa, die emphatische Definition der Möglichkeit intellektueller Erfahrung, die Annahme einer prinzipiell verwandlungsfähigen Materie, die Konstruktion eines arkan-exklusiven Raums von Wissen, Lernen und Überlieferung, die Bestimmung des Geheimnisses als Element der Wissensordnung, die antischolastische Tendenz ihrer Organisation.

Es wäre sicherlich falsch, zur allgemeinen Beschreibung dieser Konstellationen den Begriff des esoterischen Wissens zu bemühen. Denn dieser unterstellt eine vereinfachende Opposition zwischen akademischem und nicht-akademischem Wissen, zwischen religiöser und paganer Diskurspraxis, zwischen Inspiration und Regel, Vernunft und Offenbarung, die der intellektuellen Situation von Mittelalter und Früher Neuzeit nicht entspricht. Wer sich mit dem Ensemble eines aus moderner Sicht nicht-rationalen Wissens befasst, kann auf den Esoterikbegriff zudem aus systematischen Gründen schwerlich zurückgreifen, denn er enthält die Vorannahme einer wissenschaftsexternen Stellung, die für Mittelalter und Frühe Neuzeit nirgends gegeben war. Zwar schloss die arkane Praxis magischer und alchemischer Denk- und Verfahrensweisen eine schulhafte Verbreitung an den Universitäten weitgehend aus, jedoch partizipierten sie in weitaus stärkerem Maße, als das der Esoterikbegriff nahelegt, an verbreiteten Wissensordnungen. Solche Interaktion zwischen ,geheimen' und ,akademischen' Erkenntnismethoden begründet die hohe Komplexität der mittelalterlichen und frühneuzeitlichen Episteme, die durch moderne Beschreibungskategorien nicht annähernd erfasst werden.

Sinnvoller und angemessener für magisch-alchemische Diskurskonfigurationen scheint uns dagegen die von Martin Mulsow entwickelte Schlüsselkategorie des "prekären Wissens“. ${ }^{1}$ Sie bezeichnet ein noch unsicheres Wissen, wie es gerade für das 15. bis 17. Jahrhundert typisch ist: heterodox, nicht durch Autoritäten abgesichert; unerprobt, nicht im Kanon verankert; subversiv, nicht durch geregelten Transfer vermittelt. Belegt wird die Bedeutung dieses „prekären Wissens" für die frühneuzeitliche Epistemologie bei Mulsow an zahlreichen Feldern (Wunderglauben, Abwehrzauber, Numismatik, Kameralistik). So entsteht ein vielschichtiges Bild, zu dem überlieferte Wissensformationen ebenso gehören wie Elemente frühaufklärerischer Empirie. Ein übergreifendes Merkmal bleibt die eklektische Komponente, in der sich eine Abkehr von der scholastischen Wissensordnung mittelalterlicher Prägung bekundet. Ungesichertes Wissen stellt produktive multidirektionale Bündnisse her, die Innovationen in Zeiten programmatischer Traditionsbeharrung ermöglichen.

Was alchemische und magische Wissenspraktiken miteinander teilen, ist vor dem Hintergrund der Mulsowschen Kategorie des Prekären nicht zuletzt die Gefährdung, die sie als latent ketzerische Formen der Gelehrsamkeit für den

1 Vgl. Martin Mulsow: Prekäres Wissen. Eine andere Geschichte der Frühen Neuzeit. Frankfurt a.M. 2012, S. 14-18. 
Einzelnen bedeuten. Wer sich mit ihnen einließ, war zu manchen Zeiten massiv bedroht und setzte sich der Gefahr aus, als Anhänger des Teufels, als Häretiker und Irrgeleiteter betrachtet zu werden. Andererseits existierten in der mittelalterlichen Gesellschaft auch zahlreiche Nischen, die es erlaubten, magische und alchemische Wissenschaften zu praktizieren, ohne dass sogleich Ausstoßung, Vertreibung und Bestrafung drohten, und auch der intellektuellen Auseinandersetzung mit Bereichen des Wissens, die heute als magisch zu erachten sind (Astrologie), wurde Raum gegeben.

In „Die Ordnung der Dinge“ schreibt Michel Foucault über die epistemische Ordnung im Zeitalter der Ähnlichkeiten, dem 16. und frühen 17. Jahrhundert:

Die Welt drehte sich in sich selbst; die Erde war die Wiederholung des Himmels, die Gesichter spiegelten sich in den Sternen, und das Gras hüllte in seinen Halmen die Geheimnisse ein, die dem Menschen dienten. Die Malerei imitierte den Raum, und die Repräsentation, war sie nun Fest oder Wissenschaft, gab sich als Wiederholung: Theater des Lebens oder Spiegel der Welt, so lautete der Titel jeder Sprache, ihre Art, sich ankündigen, und ihr Recht auf Sprache zu formulieren. ${ }^{2}$

Was Foucault hier in romantisierendem Duktus beschwört, ist, wie kritisch angemerkt werden kann, weniger Bild der frühneuzeitlichen Episteme als vielmehr Reflex eines Teildiskurses der wissenschaftlichen Ordnung, eben der Magie und Alchemie. Dazu passt, dass seine Hauptgewährsleute für die Beschreibung der wesentlichen Merkmale des Denkens in Ähnlichkeiten sämtlich Vertreter nichtorthodoxer Denksysteme sind: Agrippa von Nettesheim, Paracelsus und Giambattista della Porta. Man könnte also sagen: Nicht die Signatur der ganzen Epoche, sondern einer besonderen Diskurskonstellation hat Foucault in seinem überaus folgenreichen Werk erfasst.

Mit Magie und Alchemie verbindet sich in der Tat ein "Analogiezauber" (Novalis), der ihre Dynamik, ihre methodischen Allianzen und praktischen Implikationen bestimmt. Auch aus diesem Grund ist das magisch-alchemische Diskursfeld ein vorzügliches Studienobjekt für jene Transferprozesse, die sich der Sonderforschungsbereich zu untersuchen vorgenommen hat. Gerade weil die Regeln für die epistemische Konstruktion dieser beiden Schlüsselbereiche veränderlich sind, bieten sie sich für Umdeutungen und Transfers von Wissen zwischen verschiedenen Bereichen an. Nicht zuletzt ermöglichen sie literarische Aneignungen, an denen die Dichtung sich als Medium epistemischer Umbrüche profilieren kann. Martin Opitz bemerkt 1624, die Natur habe sich im Altertum durch die Sprache der Dichter offenbart, die einen schein sonderlicher propheceiungen vnd geheimnisse von sich gaben und den einfältigen leute[n] den Eindruck

2 Michel Foucault: Die Ordnung der Dinge. Eine Archäologie der Humanwissenschaften. Frankfurt a.M. 1997, S. 46. 
boten, als stecke etwas göttliches in jhnen. ${ }^{3}$ Genau dieser Übergang des arkanen Wissens in die Dichtung begründet einen Wirkungsanspruch, der mehr als nur die Popularisierung von gelehrter Praxis bedeutet. Hinter ihm steckt das Konzept einer Reorganisation des Wissens selbst, das durch die Dichtung nicht einfach nur transportiert, sondern umgeformt und diskursiv neu geordnet wird. Das magische und alchemische Wissen ist immer auch ein Handlungswissen mit dem Anspruch auf Heilung, Veränderung, Eingriff in die Natur. Glaubt den werken, nit den worten, so formuliert Paracelsus. ${ }^{4}$ Die Dichtung greift dieses dynamische Konzept des Wissens auf, indem sie es nochmals in Bewegung setzt - mit produktiven Effekten für ihre eigenen Textordnungen.

\section{Schwierigkeiten der Begriffsbestimmung: Was ist Magie, was Alchemie?}

Der prekäre Status des magischen und alchemischen Wissens dürfte auch dafür verantwortlich sein, dass sich eine überhistorische Definition von Magie und Alchemie nicht finden lassen wird. Selbst für den hier zur Debatte stehenden Zeitraum wird es schwerlich möglich sein, Gemeinsamkeiten aller Phänomene $\mathrm{zu}$ benennen und festzumachen. Schon ein Blick in das Inhaltsverzeichnis dieses Bandes zeigt, wie divergent die Erscheinungsformen der mittelalterlichen und frühneuzeitlichen Magie und Alchemie sind. Der Band versammelt sowohl Beiträge zur Hexerei und, volkstümlichen' Zauberei wie zur gelehrten Magie, er präsentiert Beiträge zur Alchemie als Goldmacherkunst, als Pharmazeutik, als ökonomischem Wissen und als Glasmacherkunst, er enthält Beiträge zu Magie und Alchemie als spezifischen Wissensformen, zu ihren literarischen Darstellungsweisen und zur ihrem Gebrauch als poetologischer Metapher.

Angesichts dieser vielfältigen Erscheinungsformen von Magie und Alchemie ist erklärungsbedürftig, dass wir beide Wissensbereiche mit diesem Band in eine enge Verbindung bringen. So selbstverständlich die Kombination der beiden Begriffe vielleicht in der populären Kultur der Gegenwart ist, so fragwürdig ist sie in historischer Perspektive. Dennoch ergeben sich auch aus der Perspektive der (insbesondere literaturwissenschaftlichen) Mediävistik und Frühneuzeitforschung verschiedene Verbindungslinien zwischen beiden Bereichen: Da ist zunächst der bereits beschriebene prekäre Status beider Wissensfelder, eine in beiden vorausgesetzte Existenz und vergleichbar systematisierte kosmologische Ordnung aus Ähnlichkeiten und Korrespondenzen, sodann die Produktivität, die Transfers aus beiden Feldern gleichermaßen in die Dichtung nach sich gezogen haben, und es sind schließlich die vielfältigen Verbindungen und Überlagerungen beider Wissensbereiche, zu denen die Aufnahme magischer und alche-

3 Martin Opitz: Buch von der deutschen Poeterey. In ders.: Gesammelte Werke. Hrsg. von George Schulz-Behrend. Bd. II.1. Stuttgart 1978, S. 331-416, hier S. 345.

4 Paracelsus: Das Buch Paragranum. In ders.: Sämtliche Schriften. Bd. I.8: Schriften aus dem Jahre 1530, geschrieben in der Oberpfalz, Regensburg, Bayern und Schwaben. München 1924, S. 31-125, hier S. 89. 
mischer Elemente in literarische Texte geführt hat. Auf die literarische Dimension der Wissensfelder Magie und Alchemie, die für diesen Band zentral ist, kommen wir später noch genauer zu sprechen.

Die Alchemie des Mittelalters und der Frühen Neuzeit ist keineswegs per se eine Kunst oder ein Wissen, das es mit übernatürlichen oder okkult-verborgenen Kräften zu tun hat. ${ }^{5}$ Versteht man die Alchemie im weitesten Sinne als ein Wissen um die Verwandlungsfähigkeit natürlicher Substanzen, dann gibt es deshalb auch zwischen Alchemie und Religion eigentlich keine Konflikte, ja kaum Berührungspunkte.

Der prekäre Status, den die Alchemie in der Vormoderne hat, ist kein Indiz für ein ,okkultes' Wissen, sondern viel eher eine Folge ihrer mangelnden Institutionalisierung, das heißt der Tatsache, dass die Alchemie weder an den Schulen und Universitäten verankert noch als Handwerk anerkannt war. Infolgedessen prägt der herumziehende Alchemiker, der den Fürsten die Herstellung von Gold verspricht und sich dann als Betrüger aus dem Staub macht, nicht erst das moderne Bild der Alchemie. Schon lange vor der Aufklärung wird der Alchemiker wechselweise als Scharlatan oder Narr diffamiert. Man spüert wol jn der alchemy I [...] Was falsch/ ond bschiss vff erden sy, heißt es 1494 in Sebastian Brants Narrenschiff. ${ }^{6}$

Der eigentliche Gegner der Alchemie ist deshalb weniger die Theologie als die ökonomische Vernunft, und mehr noch sind es die polizeilichen und juristischen Autoritäten. Allerdings war die sogenannte Transmutationsalchemie mit dem Ziel der Herstellung von Gold zwar immer eine besonders prominente Form der Alchemie, aber nie die einzige. Insbesondere die Pharmazeutik bedient sich schon lange vor Paracelsus alchemischer Verfahren zu pharmazeutischen Zwecken. Daneben können sich Abhandlungen zur Schmelztechnik oder zur Glasherstellung des Begriffs der Alchemie bedienen, genauso wie am anderen Ende des Spektrums Texte, die metaphorisch Läuterungsprozesse der Seele bezeichnen, wie in der Aurora consurgens, und damit an die Praktiken der Mystik gemahnen. Dazu gehört auch die Tatsache, dass es immer schon einen mehr

5 Wir bevorzugen deshalb auch die von Joachim Telle eingeforderte Begriffsbildung ,alchemisch' im Gegensatz zu dem sprachlich inkonsequenten Begriff , alchemistisch'. Die Begriffe ,alchemistisch' und ,Alchemist' suggerieren einen Bruch zwischen einem ,alchemistischen' Wissen der Vormoderne, das per se ,mystisch' oder ,okkult' sein soll, und dem ,chemischen' Wissen der Moderne, das ,wissenschaftlich' ist. Uns kommt es dagegen darauf an, neben den Diskontinuitäten auch gerade die Kontinuitäten des chemischen Wissens zu betonen. Mit ganz ähnlicher Intention haben Lawrence M. Principe und William R. Newman: Some Problems with the Historiography of Alchemy. In: Secretes of Nature. Astrology and Alchemy in Early Modern Europe. Hrsg. von Anthony Grafton und William R. Newman. Cambridge 2001, S. 385-430 den Begriff ,chymistry' als Vermittlung zwischen einer vormodernen ,alchemy' und einer modernen ,chemistry' vorgeschlagen. Nicht alle Beiträger des Bandes teilen diese Vorbehalte.

6 Sebastian Brant: Das Narrenschiff. Hrsg. von Manfred Lemmer. Berlin, New York 2004, Kap. 102, S. 269. 
oder weniger großen Unterschied zwischen einer ,theoretischen' und spekulativen Alchemie und einer praktischen Alchemie gab, die sich als Labortechnik verstand, in der Tradition etwa der Summa perfectionis Pseudo-Gebers. Joachim Telle hat diese Schwierigkeit einer Begriffsbestimmung auf den Punkt gebracht, indem er formulierte, dass es die Alchemie nicht gibt, sondern nur eine Vielzahl von Alchemien. ${ }^{7}$

Die Alchemie muss deshalb im Mittelalter und in der Frühen Neuzeit nicht per se theologisch heterodoxe Positionen implizieren. In Johann Hartliebs Puch aller verpoten kunst (1455/56) wird die Alchemie mit keinem Wort erwähnt. Mehr noch, ausgerechnet in dem Handbuch der Magie schlechthin, nämlich Agrippas von Nettesheim De occulta philosophia (1510/1533), spielt die Alchemie keine in irgendeiner Form bedeutsame Rolle, ja wird die Möglichkeit der Transmutation ausdrücklich bestritten. ${ }^{8}$ Ein ähnlicher Befund gilt auch für den anderen großen frühneuzeitlichen Theoretiker der Magie, Marsilio Ficino. Obwohl Ficino sehr schnell in den Ruf eines Alchemikers geraten ist, behandelt er die Alchemie in seinen Werken, wenn er sie überhaupt behandelt, eher skeptisch. In den De vita libri tres (1480/89), der Gründungsurkunde der frühneuzeitlichen magia naturalis, wird die Alchemie namentlich nicht erwähnt, auch wenn es durchaus Berührungspunkte gegeben hätte. ${ }^{9}$

Die Subsumption der Alchemie unter die ,okkulten', magischen Künste erscheint unter den skizzierten Voraussetzungen deshalb für die Zeit vor dem 16. Jahrhundert als grundsätzlich fragwürdig. Aber auch für die Zeit nach 1500 gilt, dass diese Subsumption zumindest für weite Teile der Alchemie zweifelhaft ist. Soweit man in der Frage, wann und wo die Alchemie in den Ruch des ,Okkulten' kommt, überhaupt etwas sagen kann, scheint es Paracelsus und mehr noch der Paracelsismus zu sein, der in der zweiten Hälfte des 16. Jahrhunderts die Alchemie mit einem magischen Anspruch versieht und sie damit in einen Gegensatz zur akademischen Theologie bringt, ${ }^{10}$ prominent etwa in Heinrich Khunraths Amphitheatrum sapientiae aeternae solius verae, christiano-kabalisticum, divino-magicum, nec non physico-chymicum, tertriunum, catholicon von 1595/1609. ${ }^{11}$

7 Joachim Telle: Art. Alchemie II. In: Theologische Realenzyklopädie Bd. 2 (1978), S. 199-227; vgl. auch Bernhard Dietrich Haage und Wolfgang Wegner: Deutsche Fachliteratur der Artes in Mittelalter und Früher Neuzeit. Berlin 2007, S. 106-126.

8 Wolf-Dieter Müller-Jahncke: The Attitude of Agrippa von Nettesheim (1486-1535) towards Alchemy. In: Ambix 22 (1975), S. 134-150.

9 Peter Forshaw: Marsilio Ficino and the Chemical Art. In: Laus Platonici Philosophi: Marsilio Ficino and His Influence. Hrsg. von Stephen Clucas, Peter J. Forshaw und Valerie Rees. Leiden 2011, S. 249-271.

10 Grundlegend zum Paracelsismus ist die ausführlich kommentierte und eingeleitete Edition: Corpus Paracelsisticum. Dokumente frühneuzeitlicher Naturphilosophie in Deutschland. Hrsg. und erläutert von Wilhelm Kühlmann und Joachim Telle. Tübingen 2001-2013. Vgl. daneben insbesondere Wilhelm Kühlmann: Der ,Hermetismus' als literarische Formation. Grundzüge seiner Rezeption in Deutschland. In: Scientia Poetica 3 (1999), S. 145-157.

11 Das Werk liegt jetzt in einer neuen Ausgabe vor, mit wertvollen Kommentaren und Einfüh- 
Hier ist die Verbindung von Alchemie und Magie im Zeichen ,okkulter' Künste schon im Titel vollzogen.

Nicht nur der Begriff der Alchemie ist als Klassifikation einer Vielzahl, teilweise stark divergierender Erscheinungen allerdings problematisch, sondern auch der Begriff der Magie. Wer diesen Begriff definieren oder auch nur näher bestimmen will, steht vor mehreren grundsätzlichen Problemen.

Erstens gilt auch für die Magie, dass sie keinen per se theologisch problematischen Status besitzt, wie es die gängigen Vorstellungen von Magie als Teufelswerk nahelegen. Frank Fürbeth hat im Gegenteil darauf hingewiesen, dass die Magie in den Wissenschaftsklassifikationen des Mittelalters (den sogenannten divisiones philosophiae) als scientia gilt, mithin als akademisch anerkannte Wissensform. ${ }^{12}$ Die Diffamierung dieser Wissensform als Teufelswerk und dämonische Magie vollzieht sich erst im Zuge jenes groß angelegten Feldzugs der Theologen gegen den Aristotelismus im 13. Jahrhundert, der in der Pariser Verurteilung von 1277 gipfelt. Die Unterscheidung zwischen einer magia naturalis auf der einen Seite, die sich als Naturphilosophie und Praxis der Naturbeherrschung versteht, und einer magia daemoniaca auf der anderen Seite, die sich dämonischer Hilfe bedient, ist eine späte Erscheinung. ${ }^{13}$ Neben Marsilio Ficino im dritten Buch seiner De vita libri tres wären Agrippa von Nettesheim mit seiner Occulta philosophia und später Giambattista della Porta mit seiner Magia naturalis (1558) prominente Beispiele für diese Ausdifferenzierung.

Problematisch ist zweitens die Unterscheidung zwischen einer sogenannten Gelehrtenmagie und einer sogenannten volkstümlichen Magie, also der alltäglich praktizierten Zauberei als einer ,Volksfrömmigkeit'. Mit letzterer wird etwa an Abwehr- oder Schadenszauber, an Fluchformeln und Verhexungen gedacht, an Liebeszauber genauso wie an das ganze Spektrum der im weitesten Sinne ,medizinischen' Zauberei, vom Besprechen von Warzen bis zur Austreibung von Dämonen bei psychischen Erkrankungen, schließlich an die Dämonenbeschwörungen der Clavicula Salomonis oder des Arbatel. Neuere Studien haben zu zeigen versucht, dass diesen Formen von ,Volksfrömmigkeit' große Bedeutung zukommt und dass es sich hier keinesfalls um marginale Formen von Religiosität handelt. ${ }^{14}$ Dabei ist allerdings zu bedenken, dass die Unterscheidung selbst seit

rungen. Vgl. Heinrich Khunrath: Amphitheatrum Sapientiae Aeternae-Schauplatz der ewigen allein wahren Weisheit. Vollständiger Reprint des Erstdrucks von [Hamburg] 1595 und des zweiten und letzten Drucks 1609. Hrsg. von Carlos Gilly, Anja Hallacker, HannsPeter Neumann und Wilhelm Schmidt-Biggemann. Stuttgart-Bad Cannstatt 2014.

12 Vgl. Frank Fürbeth: Die Stellung der Artes magicae in den hochmittelalterlichen, divisiones philosophiae'. In: Artes im Mittelalter. Hrsg. von Ursula Schaefer. Berlin 1999, S. 249-262.

13 Stellvertretend vgl. Brian P. Copenhaver: Natural Magic, Hermetism, and Occultism in Early Modern Science. In: Reappraisals of the Scientific Revolution. Hrsg. von David C. Lindberg und Robert S. Westman. Cambridge u.a. 1990, S. 261-301 und ders.: The Occultist Tradition and Its Critics. In: The Cambridge History of Seventeenth Century Philosophy. Hrsg. von Daniel Garber und Michael Ayers. Cambridge 1998, S. 454-512.

14 Vgl. Johannes Dillinger: Hexen und Magie. Eine historische Einführung. Frankfurt, New 
frühchristlicher Zeit, namentlich seit Augustinus, von der christlichen Gelehrtenkultur eingeführt und vertreten worden ist, um das Christentum von seiner paganen Umwelt abheben und es in seinem Umfeld behaupten zu können. ${ }^{15}$ Diese Strategien setzen sich, wie insbesondere Christoph Daxelmüller gezeigt hat, zum einen in der weiteren historischen Entwicklung bis zum spätmittelalterlichen Vorgehen gegen ketzerische Gruppen fort, zum anderen öffnen die Abgrenzungsbemühungen gegenüber der Dämonologie das Zauberwesen bereits im Hochmittelalter für gelehrte, proto-naturwissenschaftliche Spekulationen. ${ }^{16}$ Versuche, magische Praktiken als Teil einer so genannten ,Volksfrömmigkeit' zu beschreiben, stehen darüber hinaus stets vor dem Problem, wie diese jenseits der Bestimmungsversuche christlich-gelehrter Autoren erfasst werden können.

Eng mit der Differenzierung von ,volkstümlicher' und ,gelehrter' Magie ist die wiederum problematische Unterscheidung von Magie und Religion verbunden, wie sie insbesondere aus der älteren Religionswissenschaft und Ethnologie mehr oder weniger unreflektiert übernommen wurde. Bernd-Christian Otto hat neuerdings auf die Vorannahmen hingewiesen, die mit dieser Unterscheidung verknüpft sind, darunter eben an erster Stelle die Dichotomie von volkstümlicher Magie und dem Christentum als Religion und Theologie. ${ }^{17}$ Dem gegenüber ist etwa darauf hinzuweisen, dass die magischen Texte des Mittelalters und der Frühen Neuzeit zu einem guten Teil von Klerikern und Akademikern stammen, die - bis auf wenige Ausnahmen, wie etwa Giordano Bruno-ihre magischen Interessen nicht als Gegensatz zu ihrem christlichen Glauben wahrgenommen haben. Kritisch ist gegen Ottos instruktive rezeptionsgeschichtliche Studie einzuwenden, dass sie den Magie-Diskurs des Mittelalters nur bis zu den - fraglos einschlägigen-Schriften des Augustinus und seiner Grundlegung der PaktTheorie behandelt. Albertus Magnus und Thomas von Aquin, um nur die bekanntesten Namen zu nennen, hätten jedoch mindestens ebenso in seine Abhandlung gehört, um ein abgerundetes Bild der Auseinandersetzung mit der Magie bzw. solchen Praktiken und Lehrmeinungen, die wir heute so bezeichnen würden, herzustellen. ${ }^{18}$ Otto verhandelt den Umgang mit Magie in Spätantike bzw. Frühmittelalter zudem unter dem Aspekt der ,Ausgrenzung', ${ }^{19}$ dabei lässt

York 2007, der S. 26 die "Gelehrtenmagie“ als ein „extremes Minderheitenphänomen“ bezeichnet, das nicht mit der, Volksmagie' vermengt werden dürfe.

15 Vgl. Christoph Daxelmüller: Zauberpraktiken. Eine Ideengeschichte der Magie. Zürich 1993, S. 74-94; sowie Richard Kieckhefer: Magie im Mittelalter. München 1995, S. 50-55.

16 Vgl. Daxelmüller: Zauberpraktiken (Anm. 15), S. 110-123, S. 97f.

17 Bernd Christian Otto: Magie. Rezeptions- und diskursgeschichtliche Analysen von der Antike bis zur Neuzeit. Berlin 2011.

18 Vgl. dazu auch die Rezension von Wouter J. Hanegraaff in: Aries 14 (2014), S. 114-120, insbesondere S. 116f.

19 Vgl. den Unterabschnitt „Augustinus: Die Vollendung des Magiebegriffs als Ausgrenzungskategorie", S. 309-311. 
sich derselbe Prozess auch unter dem Aspekt der Integration von Magie beschreiben. ${ }^{20}$

\section{Poetische Schreibweisen von magischem und alchemischem Wissen}

Nicht nur aufgrund der skizzierten heterogenen Diskursformationen ist es den Veranstaltern der Tagung weniger um eine Bestimmung dessen gegangen, was im Mittelalter und in der Frühen Neuzeit überhaupt unter Magie und Alchemie verstanden worden ist. Vielmehr interessierte sie spezifisch die Frage, welche Rolle literarische Darstellungsformen für magisches und alchemisches Wissen spielen. In diesem Zusammenhang kommt die Bandbreite der historischen gelehrten Diskurse allerdings wieder zur Geltung. Denn unzweifelhaft gibt es eine Wahlverwandtschaft zwischen Magie und Alchemie auf der einen und poetischen Darstellungsformen und Schreibweisen im weitesten Sinne auf der anderen Seite.

Angefangen mit der mythischen, dem Hermes Trismegistos zugeschriebenen Tabula smaragdina, die eine Art Gründungsurkunde der Alchemie darstellt, über die Turba philosophorum, die Schrift De compositione alchemiae, die Aurora consurgens und dem Rosarium Philosophorum bis hin zu den berühmten Alchemica der Frühen Neuzeit, etwa der Atalanta fugiens Michael Maiers oder Johann Valentin Andreaes Chymischer Hochzeit Christiani Rosenkreutz, gibt es zahlreiche Beispiele für alchemisches Wissen in poetischen Formen. Erst die sogenannte Moderne zieht einen scharfen Trennstrich zwischen einer Alchemie, die sich literarischpoetischer Formen bedient, und einer Chemie, die sich einer chemischen Formelsprache bedient. Insbesondere für die wissenschaftsgeschichtlichen Darstellungen gilt, dass für diese oft genug der Unterschied zwischen einer ,okkulten Alchemie und einer modernen Chemie gerade in der sprachlichen Form liegt. Je stärker man vom modernen Ideal einer ,Wissenschaft' geprägt ist, desto schwerer scheint es vorstellbar, dass technisches Wissen auch in poetischen Formen transferiert werden kann.

Das gilt in verstärktem Maße für das magische Wissen, das sich im Gegensatz zum alchemischen Wissen nicht wenigstens partiell in eine Chemie als ,Wissenschaft' retten konnte, sondern in überwiegendem Maße in Okkultismus oder Dichtung zum Ausdruck kommt. Die enge Verbindung von Magie und Dichtung reicht dabei bis in die Anfänge schriftsprachlicher Überlieferung zurück. In zahlreichen Kulturen gehören Zaubersprüche und Fluchformeln zu den ältesten überlieferten Dokumenten. Dazu zählen ebenso die Merseburger Zaubersprüche wie das noch ältere jüdische Schemhamphorasch oder das auf arabische Wurzeln zurückgehenden Abrakadabra. Man muss darüber diskutieren, welcher Art genau die Verbindung von Schrift und Zauberei ist, aber dass es sie gibt, steht außer Frage. An der damit nur angedeuteten, grundsätzlichen Verbindung von Magie

20 Dies ist der Ansatz der Studie von Valerie I. J. Flint: The Rise of Magic in Early Medieval Europe. Princeton 1991. 
und Zauberei auf der einen und poetischen Darstellungsformen auf der anderen Seite ändert sich bis in die Frühe Neuzeit hinein, ja bis in die Gegenwart kaum etwas.

$\mathrm{Ob}$ es sich bei der spätantiken Vita des Zauberers und Magiers Apollonius von Tyana, die Philostrat für den römischen Kaiserhof verfasste, um einen Roman oder einen historischen Bericht behandelt, kann nur fragen, wer den grundsätzlichen exemplum-Charakter eines solchen Lebensberichts nicht in Betracht zieht. Was für die Apollonius-Vita aus dem dritten Jahrhundert gilt, betrifft genauso noch den berühmtesten Lebensbericht eines Zauberers und Magiers aus der Frühen Neuzeit, die Historia von D. Johann Fausten. Die Liste ließe sich problemlos fortsetzen, angefangen von der Zauberin Kirke aus der Odyssee über die Feengestalten der höfischen Literatur bis hin zu Tassos Armida und den Hexen Shakespeares, weiter über die Hexenfiguren aus den Märchen der Brüder Grimm bis hin zum Herr der Ringe oder Harry Potter.

Die Beispiele zeigen, wie eng Artikulation und Transfer magischen Wissens an poetische Ausdrucksmuster gebunden sind, ja von ihnen, wie in den Zauberformeln, mitunter gar nicht gelöst werden können. Außerdem wird magisches Wissen in vielgestaltiger Weise in literarische Texte im eigentlichen Sinne aufgenommen. Angesichts der immer schon poetischen Form magischen Wissens kann man hier - in Anlehnung an ein Wort Gérard Genettes - von Magie auf zweiter Stufe sprechen. ${ }^{21}$ Magische Phänomene bilden ein großes Reservoir für literarische Texte. Sie werden in die Literatur allerdings in der Regel in stark veränderter Form aufgenommen und zeigen sich hier beispielsweise als das Wunderbare. Eine der größten Kontroversen um Elemente von Magie in der Literatur lautet dabei, ob magisches Wissen als solches aufgefasst oder literarisch dergestalt rekontextualisiert und metaphorisch verschoben wird, dass es $\mathrm{zu}$ einem spezifischen Ausdrucksmedium, beispielsweise für psychologische Zustände, wird. Die intensive literaturwissenschaftliche Diskussion um den Status des ,Liebestranks' in der Geschichte von Tristan und Isolde steht im Zeichen genau dieser Frage: ${ }^{22}$ Der Umstand, dass dieser Trank auf der Ebene der Diegese ursächlich für die Liebe ist, lässt sich eigentlich nicht übersehen. Angesichts der hoch elaborierten Form dieser sogenannten Tristanminne fiel es der Forschung jedoch schwer, diesen ,banalen' Umstand, der ebenso gut eine andere Paarkonstellation hätte treffen können - und dafür ja auch ursprünglich vorgesehen war-anzuerkennen. In der Abwertung des magischen Mittels spielen auch wissenschaftsgeschichtliche Entwicklungen, wie die Annahme eines diachronen Paradigmenwechsels von der Magie über die Religion zur Wissenschaft oder die Vorstellung einer sukzessiven ,Entzauberung der Welt', die man heute

21 Vgl. Gérard Genette: Palimpseste. Die Literatur auf zweiter Stufe. Frankfurt a.M. 2001.

22 Einen Überblick über die Forschung bieten: Tomas Tomasek: Gottfried von Straßburg. Stuttgart 2007, S. 195-204; Christoph Huber: Gottfried von Straßburg: Tristan. 3., neu bearbeitete und erweiterte Aufl. Berlin 2013, S. 90f. 
in viel geringerem Maße als kulturgeschichtlichen Hintergrund ansetzt als noch vor einigen Jahrzehnten, eine Rolle.

Die Herausgeber sind der Auffassung, dass sich diese Fragen nicht vorab generalisierend klären lassen, sondern mit Blick auf die Dichtungen je neu zu ermitteln sind. In vielen Fällen ist gerade ein Changieren zwischen eigentlichen und metaphorischen Bedeutungsfacetten des Magischen in literarischen Texten des Mittelalters produktiv geworden. ${ }^{23}$

Wenn die Problematik, der die Beiträge dieses Bandes gewidmet sind, damit auch sicherlich nur sehr grob umrissen ist, dürfte zumindest deutlich geworden sein, dass diese Problematik nicht auf bestimmte Textgattungen im modernen Sinne eingeschränkt werden durfte, die schon mit ihrer Unterscheidung von ,poetischen' oder ,literarischen' und ,wissenschaftlichen' Gattungen das Untersuchungsfeld unzulässig eingeschränkt hätten. Der Begriff der Schreibweisen reflektiert auf diese Problematik. Schreibweisen bezeichnen in der Gattungstheorie eine Struktur, die historische Textgruppen übersteigt. ${ }^{24}$ Mit dem Begriff ist eine Ebene der Konvergenz von Phänomenen angesprochen, die einen genrespezifisch je eigenen Ort haben. Im Unterschied zur gattungstheoretischen Verwendung dient der Terminus in diesem Band nicht dazu, Gemeinsamkeiten zwischen disparaten Textformen zu behaupten oder einzelne Texte als Realisationen transhistorischer Ausdrucksformen zu bestimmen. Produktiv für die Analyse magischen und alchemischen Wissens erscheint die Rede von Schreibweisen den Herausgebern aber, indem sie es möglich macht, konkrete Textzeugnisse über ihre gattungshistorische Einbettung hinaus in Relation zu setzen. Literarische Formen ganz unterschiedlicher Texte können im Hinblick auf formale Merkmale analysiert und aufeinander bezogen werden. Dabei kommen Transferprozesse in den Blick, die magisches und alchemisches Wissen und dessen spezifische Darstellungsformen durchlaufen haben.

Es ging den Herausgebern also weniger um Einflussforschung und Rezeptionsgeschichte, als vielmehr im Sinne des Sonderforschungsbereichs 980 um spezifische Fragen der Wissensgeschichte, das heißt um Transferprozesse zwischen den historischen Wissensformen Magie, Alchemie und Literatur, um die Verschiebungen, Veränderungen und Entwicklungen, die magisches und alchemisches Wissen in literarischen und im engeren Sinne wissensgenerierenden Texten in Mittelalter und Früher Neuzeit erfährt, um die Auswirkungen genrespezifischer Konfigurationen auf die Gegenstände des Wissens, um die Frage nach dem historischen Wandel, dem Wissensformen im Kontext gattungsbezo-

23 Vgl. Jan-Dirk Müller: Höfische Kompromisse. Acht Kapitel zur höfischen Epik. Tübingen 2007, S. 418-478, hier S. 420.

24 Vgl. Klaus W. Hempfer: Art. Schreibweise ${ }^{2}$. In: Reallexikon der deutschen Literaturwissenschaft Bd. 3. Hrsg. von Jan-Dirk Müller u.a. Berlin, New York 2003, S. 391-393; sowie ders.: Gattungstheorie. Information und Synthese. München 1973, S. 27. 
gener Austausch- und Transferprozesse unterworfen sind, genauso wie um eine Relationierung unterschiedlicher Textgattungen als Generatoren von Wissen.

Dass die einzelnen Beiträge des Bandes einander widersprechende und zum Teil sogar gegensätzliche Positionen vertreten, ist den Herausgebern bewusst diese sind bereits in den Diskussionen der Tagung und dann erneut im Laufe der Redaktion des Bandes deutlich geworden. Die Herausgeber haben nicht versucht, diese Differenzen einzuebnen, sondern möchten ganz im Gegenteil, dass sie als eigene Forschungsperspektiven sichtbar werden und weiter produktiv gemacht werden können.

\section{Die Beiträge des Bandes}

Den Band eröffnet ein Beitrag von Almut-Barbara Renger, der paradigmatisch die ästhetische Faszinationskraft von Magie und Alchemie illustriert. Wie keine andere Figur verkörpert Pythagoras die mythische Herkunft des magischen Wissens aus dem Orient. Als Grenzfigur zwischen Mythos und Historie wird Pythagoras als ,altehrwürdiger Verwalter von Wissen' funktionalisiert und verbürgt die Kontinuität und Stabilität magischen und alchemischen Wissens. Die griechische Faszination für die alten Kulturen des Orients macht aus Pythagoras zudem einen Vermittler zwischen östlicher und westlicher Episteme. Auch magisches und alchemisches Wissen wird so nachhaltig ,orientalisiert', dass die Reise in den Orient $\mathrm{zu}$ einer Art Bildungsreise wird, die der Initiation in die Magie dient.

Mit der Rezeptionsgeschichte des Jonitus, des vierten Sohns Noahs, im Mittelalter und in der Frühen Neuzeit rekonstruiert Mireille Schnyder, ähnlich wie Renger, eine Herkunftsgeschichte von Astronomie und Astrologie, aber auch der Künste (artes) im umfassenden Sinne. Jonitus wird in Petrus Comestors Historia scholastica (um 1170), Rudolfs von Ems Alexanderroman (Mitte des 13. Jahrhunderts) und Hartmann Schedels Weltchronik (1493) erwähnt. Auf ihn werden besonders Formen abstrakten Arkanwissens ohne handlungspraktische Komponente zurückgeführt. Nach Darstellung der analysierten Texte sind es die Ismaeliten, welche die Macht des mit besonderem Wissen ausgestatteten Geschlechts des Jonitus brechen. In der Überlieferungsgeschichte verliert sich die Spur des Jonitus allerdings erst in der Frühen Neuzeit.

In volkssprachlichen literarischen Texten des Mittelalters gehen dämonologisches Wissen und ein Wissen, das nach zeitgenössischem Verständnis als wissenschaftlich gelten kann, häufig ineinander über und erweisen so ihre ästhetische Produktivität. Wie umstrittenes und nicht allgemein verfügbares Wissen in Verfahren poetischer Verrätselung integriert wird, zeigt sich prominent in Wolframs von Eschenbach Parzival. Jutta Eming analysiert die von Verwunderung geprägte Situation am Hof des Gralkönigs Anfortas, in die unter anderem naturkundliches und alchemisches Wissen eingegangen ist. Durch beider Reorganisation im Zeichen des Wunderbaren entsteht nicht nur Fiktion, sondern auch neu konfiguriertes Wissen. Ausgehend von der Verwunderung am Gralhof führt das 
Verhältnis von Wissenserwerb und Erkenntnisgewinn im Parzival allerdings nicht zu einer reinen Akkumulation von Wissen, sondern wird Mittel der Darstellung seiner Unverfügbarkeit. Durch den Umstand, dass er gerade durch magischem Denken entlehnte Darstellungsmuster die Möglichkeit von Erkenntnis konsequent problematisiert, positioniert sich Wolfram von Eschenbach im aktuellen zeitgenössischen Diskurs über das Verhältnis von Magie und Theologie.

Antje Wittstock geht in ihrem Beitrag zu Gottfrieds von Straßburg Tristan der Frage nach, inwiefern alchemische Praktiken und Konzepte - insbesondere die Transmutation -, die sich bereits in frühen Schriften wie dem Text De compositione alchemiae (1144) fassen lassen, als Deutungshorizont für die Reflexion poetischer Verfahren in der Literatur um 1200 aufgegriffen werden. In diesem Zusammenhang liest Wittstock die Szene der Hirschbast, die das Zerlegen und Wiederzusammenfügen des Tiers auf einer höheren Ebene beschreibt, als Rekurs auf die alchemische Transmutation. Zudem zeigt ein Vergleich von Ausführungen über das Pfropfen im Literaturexkurs des Tristan und in zeitgenössischen alchemischen Schriften, dass damit durchaus mehr gemeint sein kann als ein Imitieren der Natur, nämlich die Herstellung von etwas Neuem.

Der Literarisierung magischen Wissens in mittelalterlichen Minnereden widmet sich Sandra Linden. Ausgehend von Hartmanns von Aue Klage und am Beispiel einzelner Minnereden des Spätmittelalters kann sie zeigen, dass sowohl die Macht der Minne als auch die Verknüpfung unterschiedlicher Tugenden mit dem Darstellungsregister der Magie gefasst werden. Ziel ist es, Tugenden in einer Art magischer Rezeptur so zu mischen, dass Minneglück erreicht werden kann. Dabei kommen in den Texten allegorisierende Verfahren ebenso wie Personifikationen zum Einsatz. Eine epistemische Modifikation, die mit dem Transfer magischen Wissens in den literarischen Zusammenhang einhergeht, besteht darin, für alle Personen Handlungsmacht zu behaupten, die in der Lage sind, ihre Tugenden in der minne in der beschriebenen Weise miteinander zu verbinden.

Im Unterschied zur grundsätzlich positiven Bewertung von Magie in den Minnereden wird der Begriff des Zaubers im Roman und in der Romankritik des 16. und 17. Jahrhunderts mit Vorstellungen von Kunst und erotischer Verführung verbunden und negativ konnotiert. In der Historia von D. Johann Fausten (1587) wird, wie Jan-Dirk Müller zeigt, die Zauberei zur letzten Stufe einer dämonischen Verführung zum Abfall von Gott. Zauberei ist ein Medium radikal verdammungswürdiger Neugier und Wollust. In ähnlicher Weise wird den Amadis-Romanen eine Verquickung von sexueller Ausschweifung und Zauberei attestiert. Die teuflische Verführung, so lautet der Vorwurf, wird in ästhetischer Einkleidung verborgen. Das Beispiel zeigt, dass Elemente des Wissens über Magie in einen ästhetischen Diskurs über die Kräfte der Literatur überführt werden können, der in der Folgezeit durchaus auch mit positiven Bewertungen 
einhergehen kann. Der poetischen Form können dabei selbst dämonische und ,bezaubernde' Wirkungen zugeschrieben werden.

Die supponierte Macht des magischen Wissens ist dafür verantwortlich, dass im Mittelalter der Besitz magischer Bücher im Allgemeinen verboten ist. Diese Restriktionen machen die statistische Auswertung von mittelalterlichen Bibliothekskatalogen und wissenssystematisierenden Schriften, wie sie Frank Fürbeth unternimmt, für den gegebenen Zusammenhang interessant. Johann Hartliebs puch aller verpotten kunst (1456) zeigt gleichsam mit einer Auflistung verbotener Bücher, was man alles hätte besitzen können. Die Analyse der Kataloge mittelalterlicher Bibliotheken bietet dagegen ein ganz anderes Bild: Kaum eines dieser Werke ist dort verzeichnet. Wenn ausgerechnet das als besonders gefährlich geltende Buch Picatrix in keiner anderen Bibliothek als in der Kaiser Maximilians I. zu finden ist, dürfte dies darauf zurückzuführen sein, dass der Kaiser wohl der einzige war, der durch den Besitz dieses Buches keine Verfolgung zu befürchten hatte.

Tobias Bulang nimmt in seinem Beitrag die Forschungskontroverse um die Frage auf, ob es sich bei Johann Fischart um einen überzeugten Alchemiker handelt oder seine Editionen alchemischer Schriften stattdessen vor allem auf kommerziellen Erfolg angelegt sind. Gegen solche einander ausschließende Oppositionen zeigt Bulang, dass Fischarts Auseinandersetzung mit der Alchemie gleichermaßen durch wissensvermittelnde, dämonisierende und satirisch-parodistische Schreibweisen gekennzeichnet sind, die auf frühneuzeitliche Pluralisierungsphänomene verweisen und damit verschiedene und auf den ersten Blick gegensätzliche Wissens- und Darstellungsformen in den Schriften eines Autors vereinen. In diesem Sinne könnte Fischart gleichzeitig an der Begründung einer deutschen Fachsprache arbeiten und sich über die Dunkelheit der alchemischen Sprache lustig machen, ohne dass zwischen beidem ein Widerspruch entstehen müsste.

Dass Magie und Alchemie im 16. Jahrhundert noch an tradierte Wissensordnungen gebunden bleiben, ist zentrale These des Beitrags von Marina Münkler. Sie versteht den Magier und den Alchemisten als ,epistemische Figurationen', die diskursive Praktiken verkörpern. Beide fungieren dabei als Repräsentanten der Naturbeherrschung: Der Magier bemüht sich um die Beherrschung der Geister, der Alchemist um die der Elemente. Doch gründen beide ihr Wissen auf eine Konzeption von Erfahrung, die sich im Spannungsfeld von experientia und experimentum verorten lässt. Mit diesem Erfahrungsbegriff deutet die Alchemie des 16. Jahrhunderts nach Auffassung von Münkler nicht auf einen epistemischen Bruch, sondern erweist sich als Teil einer vormodernen ,Episteme der Ähnlichkeit’ im Sinne Foucaults.

Volkhard Wels betont in seinem Beitrag dagegen gerade den handwerklichen Charakter des alchemischen Wissens, dessen Arkansprache vor allem dem Schutz eines unmittelbar ökonomisch relevanten Wissens diente. Diese Arkansprache verliere allerdings in der Frühen Neuzeit zusehends ihre fachsprach- 
liche Relevanz und gewinne ein poetisches Eigenleben, das auf die Faszinationskraft der alchemischen Bildlichkeit zurückgeht. Gleichzeitig entsteht in der Frühen Neuzeit eine chemische Fachsprache, die ausdrücklich auf Metaphern und Allegorien verzichtet. Wels zeigt an diesen Verschiebungen, welche Erkenntnisse eine Wissensgeschichte der frühneuzeitlichen Alchemie für die Genese der spezifisch modernen Begriffe von Wissenschaft und Dichtung erbringen kann.

Poetische Funktionen der alchemischen Arkansprache schon in der Frühen Neuzeit stehen auch im Mittelpunkt des Beitrags von Stefanie Stockhorst zum Philosophischen Phoenix (1638) von Johann Rist. Anweisungen zur praktischen Alchemie und deren Labortechnik verknüpft Rist mit poetischen Bildern und inszeniert so eine Konkurrenz von alchemischem und theologischem Wissen. Rist gibt den mit der Laboralchemie verbundenen Aufwand der Lächerlichkeit preis und stellt stattdessen die Gedankenarbeit als Tugend eines guten Christen in den Vordergrund. Die kontemplative Betrachtung der Natur führt effektiver als die Alchemie zur Erkenntnis der Natur als einer Schöpfung Gottes.

Jost Eickmeyer geht auf Formen des Umgangs mit Hexen und Zauberei in der neulateinischen Dichtung ein. Dabei fällt an erster Stelle auf, dass - trotz antiker Vorbilder - das Hexenwesen kaum thematisiert wird und dass von den antiken Vorbildern zum zeitgenössischen Hexenwesen kaum eine Brücke geschlagen wird. Während Conrad Celtis mit Zauberei und Hexerei spöttischironisch umgeht und Paul Schede Melissus aus der Perspektive des Opfers die Zauberei verwünscht, zeigt sich bei dem Jesuiten Johannes Bisselius, wie dieser als militant-konformer Verfechter der institutionellen Hexenverfolgung die Dichtung als Warnung vor dem zauberischen Unwesen instrumentalisiert.

In seinem Aufsatz zu Grimmelshausens Wunderbarlichem Vogel-Nest (1672/75) geht Simon Zeisberg von einer Bestimmung des Wunderbaren im frühneuzeitlichen Wissenszusammenhang aus, die Lorraine Daston vorgenommen hat. Das Wunderbare liegt nach Daston in der Frühen Neuzeit zwischen dem naturphilosophisch Zugänglichen und dem Übernatürlichen im christlichen Sinne, in einem Bereich, der stetig wächst und der häufig mit Magie und anderen obskuren Praktiken in Verbindung gebracht wird. Grimmelshausens unsichtbar machendes Vogelnest ist an diesem Ort zu situieren, und es erhält die Funktion, auf den literarischen Status des Textes zu reflektieren. Von besonderer Bedeutung hierfür ist das Verfahren der Paradoxie im Rahmen der satirischen Schreibweise des Romans.

Der Beitrag von Michael Lorber führt wieder zur Alchemie zurück. Er zeigt am Beispiel von Johann Joachim Becher, wie die Alchemie in der zweiten Hälfte des 17. Jahrhunderts die Abgeschlossenheit des Labors überwindet und in die politische Öffentlichkeit tritt. Mit seinen zahlreichen Projekten liefert Becher einerseits wichtige und anschlussfähige Impulse für die funktionelle Ausdifferenzierung von Wissen in moderne Einzeldisziplinen, andererseits bleibt er in seinen Schriften einem universalwissenschaftlichen Reformdenken verpflichtet. Insbesondere die sozialutopischen Aspekte speisen sich dabei, trotz aller Mo- 
dernität, immer noch maßgeblich aus eschatologischen Vorstellungen. Die Alchemie bildet den maßgeblichen Bezugspunkt, insofern sie die Hintergrundfolie abgibt, auf der Becher seine heterogenen Tätigkeiten zusammenführt. Mit dieser ,sozialpolitischen' Instrumentalisierung der Alchemie steht Becher in einer Tradition, die sich bis zu Paracelsus zurückverfolgen lässt: Die der Alchemie zugeschriebene transformative Kraft soll für die Vervollkommnung der sozialen Gemeinschaft eingesetzt werden, die wiederum Voraussetzung ist für die Prosperität des Staates.

Auch der folgende Beitrag von Sven Dupré markiert eine Etappe in der zunehmenden Ökonomisierung und Technisierung alchemischen Wissens. Anhand von Johann Kunckels deutscher Übersetzung der Ars Vitraria Experimentalis (1612) des Alchemikers Antonio Neri zeigt Dupré, wie Kunckel in dieser Praktischen Glasmacherkunst das technische Vokabular, das diese benötigt, erst erschaffen muss. Gleichzeitig inkorporiert Kunckel, der zu dieser Zeit Glasmacher in Brandenburg ist, gezielt lokale Materialien und Arbeitsbedingungen in das Werk Neris, sodass die Übersetzung gleichermaßen Prozesse des Lesens, Übertragens und der Neuschöpfung reflektiert.

Als Engführung experimenteller und sprachlicher Verfahrensweisen charakterisiert Harald Haferland den Vorbothen der am philosophischen Himmel hervorbrechenden Morgenröthe (1703) des Johannes de Monte-Raphaim. Der alchemische Prozess der multiplicatio, der die Streckung von Edelmetallen bezeichnet, wird hier mit einer ,Streckung der Sprache' im Zuge der Schilderung alchemischer Praktiken parallelisiert. Mit dem Verweis auf die sprachlich-geistige, ingeniöse Leistung des Menschen stellt Johannes de Monte-Raphaim heraus, dass in der multiplicatio neben dem eigentlich alchemisch-experimentellen ein geistiger Prozess abläuft, der dem experimentellen nicht äußerlich sei.

Die Entwicklung des magischen Wissens vom späten Mittelalter bis zum Beginn der Moderne spiegelt sich prismatisch in der zunehmenden Verwissenschaftlichung der Wünschelrute, wie sie Bernd Roling beschreibt. Bis in die Mitte des 17. Jahrhunderts verbinden sich in den Versuchen, die Funktionsweise der Wünschelrute zu erklären, magisch-okkulte und naturphilosophische Wissensbestände, wobei es bei Paracelsus, Basilius Valentinus, Georg Philipp Harsdörffer und Athanasius Kircher jeweils zu spezifischen Schwankungen zwischen beiden Erklärungsmöglichkeiten kommt. Erst im 18. Jahrhundert werden dämonologische und magische Argumentationen endgültig suspendiert. Als aufschlussreich für die Frage nach dem Verhältnis von wissensvermittelnden Texten zu literarischen Strategien erweist sich dabei Johann Gottfried Zeidlers Pantomysterium (1700). Hier werden zahlreiche zuvor erwogene Erläuterungen der Wünschelrute aufgegriffen und so sehr überspitzt, dass sie in die Persiflage münden.

Bis auf den Beitrag von Antje Wittstock gehen alle hier versammelten Aufsätze auf die Vorträge zurück, die auf der Berliner Tagung gehalten worden sind. Die Herausgeber haben sehr von der konstruktiven Zusammenarbeit mit den Auto- 
rinnen und Autoren profitiert, die nicht zuletzt einen relativ zügigen Abschluss des Manuskripts ermöglicht hat. Der SFB 980 hat durch finanzielle und personelle Unterstützung die Veranstaltung der Tagung ebenso wie die Veröffentlichung der Beiträge ermöglicht. Eine besondere Freude ist uns in diesem Zusammenhang, den zweiten Band zur neu gegründeten Schriftenreihe „Episteme in Bewegung. Beiträge zu einer transdisziplinären Wissensgeschichte" des SFB beisteuern zu dürfen. Bei der Vorbereitung der Tagung konnten wir auf die tatkräftige Hilfe von Sylwia Bräuer zurückgreifen, für die Herstellung des Satzes auf das Können von Rebecca Pruß. Ihnen allen sei an dieser Stelle sehr herzlich gedankt.

Berlin, im Juli 2015

Peter-André Alt, Jutta Eming, Tilo Renz, Volkhard Wels 
(C) 2015, Otto Harrassowitz GmbH \& Co. KG, Wiesbaden ISBN Print: 9783447104951 - ISBN E-Book: 9783447194129 


\section{Von Pythagoras zur arabischen Alchemie? \\ Über Longue-Durée-Konstruktionen und Wissensbewegungen im Mittelmeerraum}

Almut-Barbara Renger, Berlin

Es ist eine weit verbreitete Strategie schon antiker Kulturen, Wissensbestände durch Vergangenheitsbezüge von großer historischer Tiefe als konstant und stabil zu beschreiben und unter Verweis hierauf Anspruch auf Zuerkennung von Autorität und/oder Wahrheit zu erheben. Paradigmatisch deutlich machen das z.B. die jüdischen und christlichen Apologeten in ihren Diskussionen, ob (ihrem Dafürhalten nach) einschlägiges Wissen auf Mose oder griechische Dichter und Philosophen zurückzuführen sei. ${ }^{1}$ Philon von Alexandria z.B. schloss nach einem Rekurs auf Demokrit, Epikur, die Stoiker, Aristoteles, die

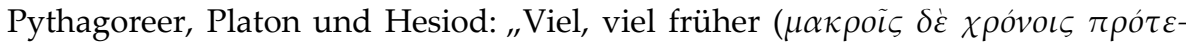
$\rho o v)$ sagte Mose, der Gesetzgeber der Juden, dass der Kosmos entstanden und unvergänglich sei, in heiligen Schriften. “2 Und Justin, einstmals platonischer Wanderphilosoph unter Antoninus Pius, bekehrt sich nach längerer Wahrheitssuche zum Christentum als „der allein verlässigen und nutzenbringenden Philo-

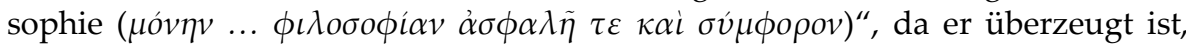

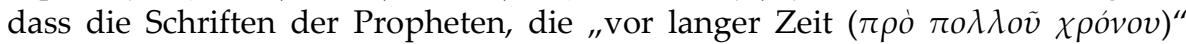
lebten und „älter ( $\pi \alpha \lambda \alpha \iota o ́ \tau \varepsilon \rho \circ \iota)$ " sind als alle sogenannten Philosophen, vom Heiligen Geist erfüllt, die ältere und zuverlässigere Wahrheit enthielten. ${ }^{3}$

Referenzen dieser Art, in denen Verweise auf Alter und Ansprüche auf Autorität, u.U. in Form von Wahrheit, miteinander Hand in Hand gehen, über-

1 Vgl. zum Problem Peter Pilhofer: Presbyteron Kreitton. Der Altersbeweis der jüdischen und christlichen Apologeten und seine Vorgeschichte. Tübingen 1990.

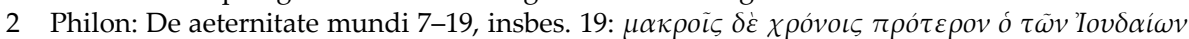

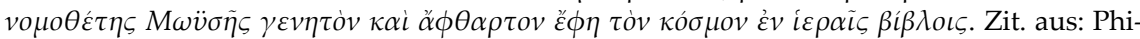
lonis Alexandrini opera quae supersunt, Bd. 6. Hrsg. von Leopoldus Cohn und Sigofredus Reiter. Berlin 1915, S. 78. - In diesem Beitrag wird bei bloßen Angaben griechischer und lateinischer Textstellen die für den jeweiligen Text gängige Zitierweise verwendet. Einer interdisziplinären Leserschaft Rechnung tragend, werden bei längeren Zitaten zudem die benutzten Ausgaben und Übersetzungen (sofern letztere nicht von der Verf. stammen) vermerkt und bei Fragmenten die Ausgaben genannt, in denen sie sich finden.

3 Justin: Dialogus cum Tryphone 3,1-8,2 (Zitate aus 7,1 und 8,1). Zit. aus: Justin: Dialog mit dem Juden Tryphon. Übers. von Philipp Haeuser. Neu hrsg. von Katharina Greschat nach der Ausg. Kempten 1917. Wiesbaden 2005, S. 11-13. 
sehen oder verschweigen häufig, dass es keine lebenden Kulturen gibt, die sich nicht wandelten, und Wandel zu den natürlichen Bedingungen auch jeder lebenden Wissenskultur gehört. Wissen ist, wie u.a. Thomas Luckmann in Anknüpfung an Alfred Schütz dargestellt hat, wesentlich sozial vermittelt. ${ }^{4}$ Es wird in einer Triangulation von Akteur (Einzelnen, Gruppen, Institutionen), Objekt (Gegenstand des Wissens, materieller Kultur, Texten, Medien) und Umwelt bzw. Kontext (sozial, politisch, religiös; physisch/materiell, mental/ intellektuell) gewonnen und verteilt. ${ }^{5}$ Als das, was in einer bestimmten Gesellschaft als Wissen gilt, ist es immer an Kommunikation gebunden und erfährt mit jedem neuen Wissensträger, ob personal oder apersonal, kleinere oder größere, unmerkliche oder deutlich sichtbare Veränderungen, die durch Wechselwirkungen zwischen den involvierten Parteien der sozialen Vermittlung (Akteuren, Gruppen, Institutionen, Kulturen) bedingt sind. ${ }^{6}$ Der Bestand lebender Wissenskulturen ist mithin immer in Bewegung und relational. Er wird in vielfältigen Beziehungen zwischen Akteur, Objekt, Kontext und Umwelt konstituiert und kommuniziert, simplifiziert und differenziert, de- und neukontextualisiert und im Zuge sowie infolge seines Transfers in verschiedenen Zusammenhängen diversifiziert. Folglich ist immer dort, wo es um Wissensbestände geht, die dem Anspruch nach lang überliefert sind, die Möglichkeit in Betracht zu ziehen, dass Transferprozesse $\mathrm{zu}$ nicht unerheblichem Wandel von Wissen geführt haben und die Person oder Gestalt, die als Stifter bzw. Archeget vorliegender Wissensbestände gilt, inhaltlich nur wenig oder gar nichts mit diesen zu tun hat. Ein solcher Ansatz freilich steht der im Eingangssatz beschriebenen Strategie entgegen, mit dem Rekurs auf das hohe Alter von Wissensbeständen auch deren Stabilität zu behaupten und auf diese Weise Zweifel an ihrer Geltung auszuräumen.

Pythagoras von Samos, der im 6. Jahrhundert v. Chr. eine Lebensgemeinschaft in Kroton gründete und nach Umsiedlung innerhalb Süditaliens in Metapont gestorben sein soll, ist eine antike Gestalt, die bis heute als altehrwürdige Vergangenheitsreferenz zum Zwecke der Legitimierung, Authentifizierung und Autorisierung verschiedenster Wissensformen und -bestände aufgerufen wird. Er selbst, seine Schüler und Anhänger sowie die auf ihn zurückgeführten Lehren sind für die Frage nach Wissensbewegungen in vormodernen Kulturen von besonderem Wert: Das dem Samier zugerechnete Wissen, das schon in der Anti-

4 Vgl. Thomas Luckmann: Wissen und Gesellschaft. Ausgewählte Aufsätze 1981-2002. Hrsg., teilw. übers. und eingeleitet von Hubert Knoblauch. Konstanz 2002.

5 Vgl. hierzu z.B. Günter Abel: Knowledge Research: Extending and Revising Epistemology. In: Rethinking Epistemology, Bd. 1. Hrsg. von Günter Abel und James Conant. Berlin, Boston 2012, S. 1-52.

6 Eine wesentliche Rolle spielen hierbei Prozesse der Professionalisierung, in denen Wissensformen und -bestände verschiedentlich institutionell spezialisiert und sozial auf sehr unterschiedliche Weise verteilt werden. Vgl. hierzu z.B. Hubert Knoblauch: Wissensstruktur und Sozialstruktur: Die soziale Verteilung des Wissens. In ders.: Wissenssoziologie. Konstanz 2005, S. 285-301. 
ke mit dem Gütesiegel der Anciennität versehen wurde, hat im Zuge räumlicher und zeitlicher Transferprozesse zahlreiche Veränderungen erfahren - nicht nur innerhalb des antiken Pythagoreismus vom 6. bis zum 4. Jahrhundert v. Chr., sondern auch nach dessen Schwinden, zumal seit dem Entstehen des Neupythagoreismus im 1. Jahrhundert v. Chr., sowie von der griechischen Spätantike in das arabische Mittelalter hinein. An diesen zahlreichen Prozessen, die sich über kürzere und längere, teils mehrere Jahrhunderte umfassende Zeiträume erstreckten und verschiedene geographische Räume einschlossen, waren Transfers in vielfältige soziale und kulturelle Zusammenhänge beteiligt: Vermittlungen in verschiedene Sprachen und Denkweisen, Argumentationszusammenhänge und Bildungskonzeptionen, soziale Zusammenschlüsse und Institutionen sowie Text- und Kunstgattungen, nicht zuletzt in solche, die magisches und alchemisches Wissen beinhalteten.

Ergebnis dieser komplexen sozial vermittelten Bewegungen in unterschiedliche Medien, Kontexte und Umwelten hinein ist eine immense Diversität und Pluralität von Wissensbeständen, die auf Pythagoras bezogen sind. Seit der Antike wurde immer wieder versucht, sie durch systematisierende Darstellungen epistemisch zu ordnen und zu sichern. Zugleich kam es, unter Bildung immer neuer Relationen zwischen Akteuren, Objekten und Kontexten, zu weiteren Aneignungen und Umformungen, Erweiterungen und Erfindungen. Bis in die Gegenwart hinein werden Pythagoras und der Pythagoreismus, werden Seelenlehre und Lebensvorschriften, Kosmologie, Musik und Zahlenlehre von zahllosen individuellen und überindividuellen Akteuren in einer Fülle von Darstellungsmodi und -medien thematisiert, in Literatur, Kunst und Musik, in Philosophie und Wissenschaften, sowie in Okkultismus und Esoterik. ${ }^{7}$ Häufig geschieht dies gerade dort, wo wir es mit Fälschungen alten Wissens, Erfindungen oder Veränderungen bis zur Unkenntlichkeit zu tun haben, unter Verweis auf die Anciennität und/oder Divinität von Pythagoras' Person und Lehrinhalten und den Verweis auf seine Ipse-dixit-Autorität (griech. $\alpha \hat{v} \tau \dot{c} \varsigma \check{\varepsilon} \phi \alpha$ : „Er selbst [Pythagoras] hat es gesagt" ${ }^{\prime \prime}$ ).

7 Ein Überblick findet sich in Almut-Barbara Renger und Roland Alexander Ißler: Pythagoras. In: Historische Gestalten der Antike. Rezeption in Literatur, Kunst und Musik (Der Neue Pauly, Supplemente 8). Hrsg. von Peter von Möllendorff, Annette Simonis und Linda Simonis. Stuttgart 2013, Sp. 798-818. - Drei Beispiele für rezente esoterisierende Funktionalisierungen des Pythagoras finden sich unten (in der Schlussbemerkung) in Anm. 136.

8 Antike Belege sind zusammengestellt in M. Tulli Ciceronis de natura deorum liber primus. Hrsg. von Arthur Stanley Pease. Cambridge (Mass.) 1955, S. 149-150. - Nicht selten ist es gerade diese Ipse-dixit-Autorität des Pythagoras, die in ,invented traditions“ im Sinne Hobsbawms und Rangers aufgerufen wird: in "erfundenen Traditionen“, die Akteure in ihrer jeweiligen Gegenwart unter Rückprojizierung in die Vergangenheit konstruiert haben, um die dargestellten Inhalte und an sie gebundene Werte und Normen zu legitimieren und zu festigen. Zum Konzept siehe Eric Hobsbawm und Terence Ranger: The Invention of Tradition. Cambridge 1992. 
Der vorliegende Beitrag geht in Ausschnitten auf diese komplexe Geschichte der Wissensbewegung im Mittelmeerraum ein. Er führt ausgewählte Beispiele an, die das Ziel so vieler Pythagorasbezüge exemplarisch verdeutlichen: zu zeigen, dass gegenwärtiges Wissen altüberliefert sei bzw. mit altem Wissen übereinstimme oder in Kohärenz stehe, und so seinen epistemischen Status zu begründen oder zu festigen. Zahlreiche textuelle Rekurse auf Pythagoras, und so paradigmatisch auch die hier angeführten, sind mit epistemischen Geltungsansprüchen auf Basis der Annahme, Je älter die Tradition, desto größer die Wahrscheinlichkeit, dass das Bewährte zutrifft' verbunden. Beständigkeit erscheint in ihnen als Bewahrung und Bewährung von Wissen. Es ist verlockend, aufgrund dieser Stabilitätsansprüche, die sich in Selbst- ebenso wie Fremdbeschreibungen finden, anzunehmen, es gäbe eine ungebrochen lebendige Tradition von Pythagoras bis hin zum arabischen Kulturkreis, nach Byzanz und in die Renaissance hinein; und es ist in der Tat für eine kontinuierliche Tradierung bestimmter fester Wissensbestände plädiert worden, die von Unteritalien nach Ägypten, von Pythagoras und der Orphik über den „Pythagoreer“ Bolos von Mendes im Nildelta bis hin zu den arabischen alchemischen Texten des Mittelalters geführt habe. ${ }^{9}$

Solchen Longue-Durée-Konstruktionen gegenüber suchen die hier angestellten Überlegungen gerade nicht, Kontinuität von Wissen seit Pythagoras nachzuweisen, die auf einer „esoteric transmission“ quer durch den Mittelmeerraum beruhe, und damit esoterische Argumentationsweisen $\mathrm{zu}$ verdoppeln, wie sie uns vermehrt seit der Frühen Neuzeit, teils in Anknüpfung an die Florentiner Academia Platonica, teils unabhängig von ihr, begegnen. Anliegen dieses Beitrags ist es vielmehr, an Ansätze der Geschichts- und Kulturwissenschaften anzuschließen, die dafür plädieren, Frakturen, Lücken und Abbrüche in der Entwicklung der Geschichte als solche bestehen zu lassen und in ihrer Historizität ernst zu nehmen. ${ }^{10}$ Der nachfolgende Gang durch die vielschichtige Transferge-

9 So insbesondere Peter Kingsley: From Pythagoras to the Turba philosophorum: Egypt and the Pythagorean Tradition. In: Journal of the Warburg and Courtauld Institutes 57 (1994), S. 1-15; ders.: Ancient Philosophy, Mystery, and Magic. Empedocles and the Pythagorean Tradition. Oxford 1995, S. 233-391; ders.: A Story Waiting to Pierce You: Mongolia, Tibet and the Destiny of the Western World. Point Reyes, CA 2010 (in diesem jüngsten Werk Kingsleys führen die esoterischen Wege der Überlieferung u.a. bis in die Mongolei). Kingsley betrachtet es, wie seiner Homepage zu entnehmen ist, als seine "Lebensaufgabe“, die „besondere mystische Tradition wieder zum Leben zu erwecken und zugänglich zu machen, die vergessen direkt an den Wurzeln unserer modernen, westlichen Welt" liege. Diese „,in ihrer Unmittelbarkeit und Direktheit" „ungemein stark[e]“, Tradition sei „vor Tausenden von Jahren“ als "Methode“ entwickelt worden, "die Erfahrung der Wirklichkeit zu ermöglichen". Sie bedeute „für uns heute mehr, als wir uns vorstellen können“, denn sie enthalte in sich „das Geheimnis - die ursprüngliche Bedeutung und den heiligen Zweck - der Welt, in der wir leben“. Siehe https://www.peterkingsley.org/deutsch.cfm (01.07.2014).

$10 \mathrm{Vgl}$. hierzu z.B. Hartmut Bergenthum: Geschichtswissenschaft und Erinnerungskulturen. Bemerkungen zur neueren Theoriedebatte. In: Erinnerung, Gedächtnis, Wissen. Studien zur 
schichte der Pythagorasfigur will Diskontinuitäten der Überlieferung mithin nicht überwinden, sondern einmal mehr darauf hinweisen, dass es schon in der Vormoderne vielfach darum ging, Überlieferungslücken zu schließen. Wenn sich seit der klassischen Antike überhaupt ein Moment der Kontinuität im Umgang mit der Gestalt Pythagoras ausmachen lässt, so liegt es in ihrer aneignenden und umdeutenden Funktionalisierung für Zwecke der Traditionskonstruktion und/oder der Wissensautorisierung. Geltungsansprüche, die Bewährung und Bewahrung, Beständigkeit und normative Richtigkeit oder gar Wahrheit in ein Kongruenzverhältnis setzen, finden sich in der Pythagorasüberlieferung immer wieder, allen Unterbrechungen und Frakturen zum Trotz.

Im Folgenden werden Beispiele für verschiedenste Autoren und Textformen beigebracht, die Pythagoras zum Mittler oder gar Archegeten bedeutender, von ihnen vermittelter Lehrinhalte stilisierten, um Anspruch auf Anciennität und/ oder Divinität des in ihnen dargestellten Wissens zu erheben. Angeführt werden auch und insbesondere Texte, die Reisen des Pythagoras zu Inhalt haben. Darstellungen dieser Reisen erzählen von diachronen und diaspatialen Bewegungen von Wissen, das als stabil charakterisiert wird, und versehen das Wissen, das sie präsentieren, mit Geltungsansprüchen. Sie binden es an Pythagoras zurück und behaupten, dieser habe seine Kenntnisse aus geographisch weit entfernten Gebieten und/oder der Verbindung mit dem Bereich der Götter gewonnen und in eigener Filterung transferiert. Pythagoras erscheint in diesen Texten als Grenzen transzendierende Integrationsfigur: als personaler Wissensträger, in dem - infolge horizontaler und vertikaler Wissensbewegungen zwischen Griechen und „Orient" sowie Göttern und Menschen - althergebrachtes Theorie- und Praxiswissen verschiedenster Provenienz konvergiert. Dass die Texte Grenzen errichten, indem sie das Wissen, das sie präsentieren, als Bezugspunkt einer Gemeinschaft oder Schule, Gesellschaft oder Kultur ausstellen und zugleich von der Transgression solcher Grenzen durch Pythagoras künden, macht sie zu einem besonderen Zeugnis der Dynamik von Stabilität und Veränderung.

Meine Darstellung erfolgt in vier Abschnitten. An knappe Bemerkungen zur Überlieferungsgeschichte schließen Beispiele an, die Pythagoras als Wissensstifter und Leitfigur aufrufen (1.), sowie Ausführungen zu Texten, die seine Gravität durch Einspielung von Bildungsaufenthalten in Ägypten und anderen frühen Hochkulturen zu untermauern suchen (2.). Als Fallbeispiel der Engführung dieser beiden Formen der Überhöhung dient Jamblichs De vita Pythagorica, ein Text, der Pythagoras als vielgereisten, mit göttlichem Übungswissen ausgestatteten Mittler stilisiert und maßgeblich zur Orientalisierung des ,Wissens des Pythagoras' beitrug (3.). In Auseinandersetzung mit seinerzeit vorliegenden Quellen ${ }^{11}$ schrieb der syrische Autor das Pythagorasbild einer asketisch ausge-

kulturwissenschaftlichen Gedächtnisforschung. Hrsg. von Günter Oesterle. Göttingen 2005, S. $121-162$.

$11 \mathrm{Zu}$ den in der Forschung wechselnden Meinungen, um welche Quellen es sich handelt, vgl. 
richteten, in uralte Geheimnisse orientalischer Weisheit und Magie eingeweihten Führungsgestalt fest, deren Leben und Lehre sich übend anzuverwandeln er seinen Lesern dringend anempfahl. Umrisse einer solchen Führungsgestalt erkennen wir schon in vorangehenden Texten der Kaiserzeit, etwa in Hippolyts Refutatio omnium haeresium oder in Porphyrios' Pythagorasvita, aber auch in späteren Testimonien wie der Turba Philosophorum. Um diese geht es im vierten Abschnitt meines Beitrags (4.). Im Geiste der intensiven arabisch-islamischen Erschließung griechischen Wissens verfasst, ${ }^{12}$ ist die Turba ein wichtiges Zeugnis der Wirkungsgeschichte antiker Philosophie im arabischen Kulturraum. Wie Jamblichs Text macht sie paradigmatisch deutlich, wie fundamentalen Veränderungen vormodernes Wissen durch De- und Rekontextualisierung, Aneignung und Integration unterworfen sein konnte.

\section{Am Anfang war Pythagoras: Der Samier als Wissensstifter und Leitfigur}

Die Anfänge der multiplen Inanspruchnahme des Pythagoras reichen weit in die Antike zurück. Bereits in vorplatonischer Zeit schlug sich seine Bekanntheit in zahlreichen Bezugnahmen nieder, die uns in Fragmenten erhalten sind. Da er selbst vermutlich keine Schriften hinterließ (und auch seine unmittelbaren Schüler und Nachfolger nichts zu seiner Lehre verfasst zu haben scheinen), avancierte er bald zu einer Referenzfigur, die sich je nach Wissensansprüchen flexibel stilisieren ließ, und es nahmen ihn seit der klassischen Ära verschiedenste religiöse, philosophische und wissenschaftliche Richtungen und Anschauungen für eigene Zwecke in den Dienst - mit besonderer Nachhaltigkeit Platon und die Alte Akademie mit ihrer stark platonisierenden Pythagoras-Deutung. ${ }^{13}$ Pythagoras, an dem noch sein Gegner Heraklit Wissen-Sammlerei und Vielwisserei ${ }^{14}$ kritisiert hatte, fungierte hierbei als Gestalt autoritativer Ehrwürdigkeit, und der Blick auf die historische Person und ihre Lehre wurde erheblich verstellt. Hinzu

z.B. Gregor Staab: Pythagoras in der Spätantike. Studien zu De Vita Pythagorica des Iamblichos von Chalkis. München 2002, S. 217-237.

$12 \mathrm{Vgl}$. hierzu z.B. Gotthard Strohmaier: Antike Naturwissenschaft in orientalischem Gewand. Trier 2007.

13 Vgl. hierzu z.B. Charles H. Kahn: Pythagoras and the Pythagoreans: A Brief History. Indianapolis 2001, S. 63-71; Christoph Riedweg: Pythagoras. Leben, Lehre, Nachwirkung. München 22007 (12002), S. 152-157; Detlef Thiel: Die Philosophie des Xenokrates im Kontext der Alten Akademie. München 2006, S. 31-136; Carl Huffman: Plato and the Pythagoreans. In: On Pythagoreanism. Hrsg. von Gabriele Cornelli, Richard McKirahan und Constantinos Macris. Berlin 2013, S. 237-270.

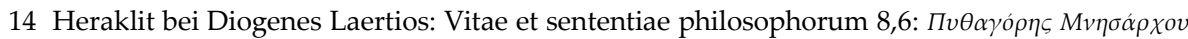

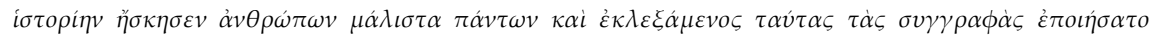

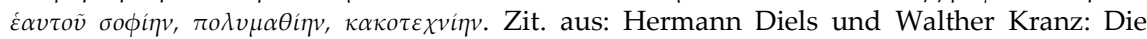
Fragmente der Vorsokratiker. Berlin 1901 (hinfort abgekürzt: DK), 22 B 129. Übers. von Laura Gemelli Marciano: Die Vorsokratiker, Bd. 1. Düsseldorf 2007, S. 293: „Pythagoras, der Sohn des Mnesarchos, hat von allen Menschen am meisten Forschung getrieben; und indem er eine Auswahl aus diesen Schriften machte, schuf er sich seine eigene Weisheit, Vielwisserei, Betrügerei." 
kam seit dem Hellenismus eine reiche Pseudepigraphie - echte Fragmente der Pythagoreer Philolaos und Archytas sind hiervon zu unterscheiden -, die vorgibt, auf Pythagoras oder seinen Schülerkreis zurückzugehen; sie erschwerte eine Trennung von ursprünglichen Lehrinhalten des Pythagoras, Auffassungen von Pythagoreern und Fremdzuschreibungen durch Außenstehende zusätzlich. ${ }^{15}$

In der Kaiserzeit schließlich, nachdem es zu einer Erneuerung des Pythagoreismus durch die Römer gekommen war, ${ }^{16}$ erfolgte in verherrlichenden Darstellungen eine systematische Ausschmückung des Lebens und Wirkens Pythago-

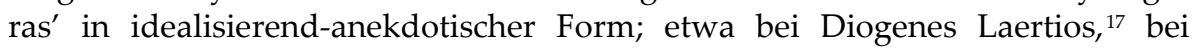
Porphyrios in der einzig erhaltenen Vita aus seiner Philosophiegeschichte, worin Pythagoras porträtiert wurde, ${ }^{18}$ und in der Darstellung der pythagoreischen Lebensform des Jamblich, ${ }^{19}$ der mit Porphyrios in engem Kontakt stand und mit ihm aus gemeinsamen Quellen schöpfte (z.B. aus Nikomachos' Schrift über Pythagoras und den Pythagoreismus). Eine wirkmächtige Ausgestaltung erfuhr in diesen Texten die Verbindung rational-wissenschaftlicher mit religiösen Aspekten, die schon Aristoteles dem Samier unter Verweis auf den Mythographen und Kosmologen Pherekydes von Syros, der als ein Lehrer Pythagoras' gilt, bescheinigt hatte: „Pythagoras, der Sohn des Mnesarchos, erarbeitete sich zuerst die

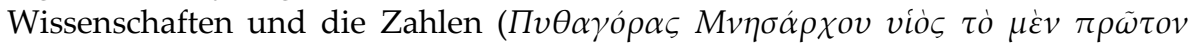

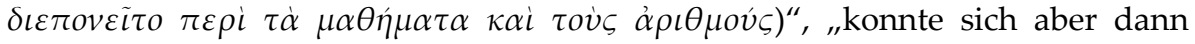

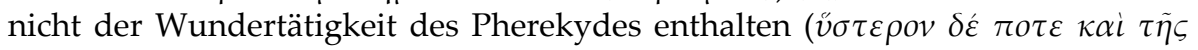

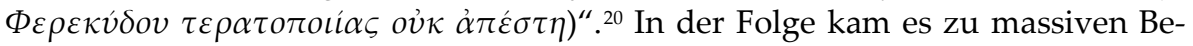

15 Vgl. hierzu u.a. Walter Burkert: Hellenistische Pseudopythagorica. In: Philologus 105 (1961), S. 16-43, 226-246; Holger Thesleff: An Introduction to the Pythagorean Writings of the Hellenistic Period. Åbo 1961; ders.: The Pythagorean Texts of the Hellenistic Period. Åbo 1965; Walter Burkert: Zur geistesgeschichtlichen Einordnung einiger Pseudopythagorica. In: Entretiens sur l'antiquité classique 18 (1972): Pseudepigrapha I, S. 23-55; Bruno Centrone: Introduzione a I Pitagorici. Rom 1996, S. 148-163; Kahn: Pythagoras and the Pythagoreans (Anm. 13), S. 74-79.

16 Cicero: Timaeus 1 behauptet, Publius Nigidius Figulus habe im 1. Jahrhundert v. Chr. „die erloschene Lehrtradition (disciplina extincta)“ der alten Pythagoreer, die „über Jahrhunderte in Italien und Sizilien in Blüte gestanden (aliquot saecla in Italia Siciliaque viguisset)" habe, „erneuert (renovaret)“. Zit. aus: M. Tulli Ciceronis scripta quae manserunt omnia. Fasc. 46 De divinatione/ De fato/ Timaeus. Hrsg. von Wilhelm Ax. Stuttgart ${ }^{21965, ~ S . ~ 154-155 . ~ D i e s ~}$ schließt, ohne dass zuverlässig von einer durchgängigen Weiterführung der Tradition nach dem 4. Jahrhundert v. Chr. gesprochen werden könnte, vereinzelte Aktivitäten in Italien im 3. und 2. Jahrhundert v. Chr. nicht aus; vgl. hierzu z.B. Cornelia J. de Vogel: Pythagoras and Early Pythagoreanism. Assen 1966, S. 28-51.

17 Diogenes Laertios: Vitae et sententiae philosophorum 8,1.

18 Porphyrios: Vita Pythagorae.

19 Jamblich: De vita Pythagorica.

20 Aristoteles: Fr. 191 Rose. In: Aristotelis qui ferebantur librorum fragmenta. Hrsg. von Valentinus Rose. Stuttgart 1968, S. 153. Dem Pherekydes wurden zahlreiche Wunder, wie etwa das Vorhersagen eines Erdbebens, eines Schiffbruchs und der Einnahme von Messene, zu- 
wegungen und Veränderungen in zahlreichen Wissensbereichen, wobei Pythagoras und das ihm attribuierte Wissen in einer Fülle produktiver Missverständnisse immer wieder neu und anders dar- und ausgestellt wurden.

Wer also tatsächlich der historische Pythagoras und welcher Art sein Wissen war, lässt sich nicht mit Gewissheit sagen. Darstellungen seines Lebens gelten in ihrem Quellenwert weitgehend als problematisch und auch sonst liegen gesicherte Zeugnisse über seine Lehre und sein Wirken nicht hinreichend vor. ${ }^{21}$ Mögen Quellenkritik und die Arbeit mit Fragmenten auch die Herausarbeitung eines historischen Kerns pythagoreischer Wissensbestände ermöglichen, ist dieser Kern doch klein, und es lässt sich nur annähernd erschließen, wann und von wem er mit eigenen Gedanken und Lehrinhalten angereichert und im Kontext eigener Fragestellungen verändert wurde. Sicher wissen wir indessen, dass gerade der Mangel verbürgter originärer Pythagoras-Testimonien bei zugleich proliferierender Legendenbildung über die Spätantike, das lateinische Mittelalter und den arabisch-islamischen Raum bis in die Frühe Neuzeit zu einer komplexen Pythagoras- und Pythagoreismusrezeption mit ungezählten Fälschungen, Innovationen und Umgestaltungen alter Inhalte geführt hat, und dass Pythagoras gerade hierdurch ein wichtiger Stellenwert in verschiedenen Wissenskulturen und Disziplinen zukommt.

Unzweifelhaft ist zudem, dass Rekurse auf Pythagoras im Rahmen der Selbstbeschreibung jener Wissenskulturen und Disziplinen regelmäßig eine historische Tiefendimension evozieren, indem sie ihn als Urheber oder zumindest autoritativen Träger lange tradierter Wissensbestände aufrufen. In diesen vielen verschiedenen Referenzen - sei es auf ihm beigemessene Entdeckungen wie den "Satz des Pythagoras" $a^{2}+b^{2}=c^{2}$, wie er sich bei Euklid findet, ${ }^{22}$ oder die Gesetzmäßigkeiten von Proportionen in Mathematik und Musik, sei es auf religiöse Lehrinhalte wie die Unsterblichkeit und Wanderung der Seele oder Übungen für die Lebensführung - fungiert Pythagoras regelmäßig als Autoritätsfigur an der Grenze von Mythos und Historie. Ob als religiöser Führer, als Mystiker, Magier und/oder Schamane einerseits, ob als Denker, als Philosoph und Wissenschaftler andererseits aufgefasst: Er tritt uns als ein in mythischen Glanz gehüllter Stifter oder zumindest altehrwürdiger Verwalter von Wissen entgegen, nicht selten mit Eigenschaften, die in den Bereich des Göttlichen wei-

geschrieben (siehe z.B. Diogenes Laertios: Vitae et sententiae philosophorum 1, 116-122). Nach Cicero: Tusculanae disputationes 1,16,38 soll er als erster die These der Unsterblichkeit der Seele vertreten haben; laut Porphyrios: De antro Nympharum 31 war damit das Konzept der Seelenwanderung verbunden. Hiermit hängt wohl die Angabe zusammen, er sei der Lehrer und/oder Freund des Pythagoras gewesen; vgl. hierzu Kurt von Fritz: Pherekydes (Mythograph). In: Pauly-Wissowa RE 19,2. Stuttgart 1938, Sp. 2025-2033, hier Sp. 20272028; Hermann S. Schibli: Pherekydes of Syros. Oxford 1990, S. 11-13.

21 Vgl. hierzu z.B. Walter Burkert: Lore and Science in Ancient Pythagoreanism. Cambridge (Mass.) 1972, S. 97-120.

22 Euklid: Elementa geometriae planae 1,47. 
sen. Von gelegentlicher Kritik und Diffamierung seiner Person als Schwindler oder Scharlatan ${ }^{23}$ abgesehen, genießt Pythagoras in dieser Position durch die Jahrhunderte hindurch große Anerkennung.

Schon die antike Philosophiegeschichte und Doxographie vermittelt ein solches Bild. Das Beispiel von Diogenes Laertios' Zusammenstellung Leben und Lehren der Philosophen ist geeignet, dies exemplarisch zu verdeutlichen. Diogenes schreibt dem Pythagoras im Proöm unter Berufung auf den Platonschüler Hera-

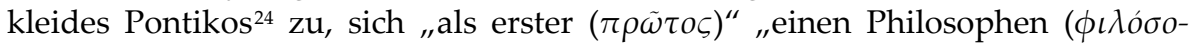

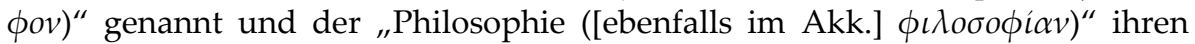
Namen gegeben zu haben. ${ }^{25}$ Am Beginn von Buch 8 stellt Diogenes den Samier zudem der italischen Philosophie, deren Sukzession in Epikur ihren letzten Vertreter findet, als Begründer voran. Sie habe mit Pythagoras „begonnen“ ( $\tilde{\eta} \rho \xi \varepsilon)$, „der nach Hermipp Sohn des Graveurs Mnesarchos aus Samos war.“26

Auch der Neuplatonismus, mit dem sich u.a. die pythagoreische Lehre von den Zahlen als Prinzipien des Seienden und dem Einen als dem Urgrund verband, wollte Pythagoras als Stiftergestalt verstanden wissen. Die Vitentradition, die von Porphyrios ausgeht, macht eine ungebrochene Sukzession von Pythagoras als Archegeten der Philosophie über Platon bis hin zu Plotin und dessen Nachfolgern geltend und stellt den Samier dabei als nachahmenswertes Idealbild eines Philosophen dar. ${ }^{27}$ Jamblich geht besonders weit. Im Proöm seiner Darstellung des pythagoreischen Lebens erklärt er die pythagoreische Philosophie als eine Gabe „von den Göttern $(\dot{\varepsilon} \kappa \theta \varepsilon \tilde{\omega} v)$ “ und Pythagoras, ihren „Stifter $(\dot{\alpha} \rho \chi \eta \gamma o ́ v)$ “ und "Vater $(\pi \alpha \tau \dot{\varepsilon} \rho \alpha)^{\text {", }}$, zum „Leiter $(\eta \gamma \varepsilon \mu o ́ v \alpha)$ " seines Unterfangens, diese göttliche Weisheit zu vermitteln. ${ }^{28}$

Verweise auf spezifisches Wissen und Können unterstreichen diese Zurechnungen von Anciennität und Divinität. So galt Pythagoras als Meister psychophysischer Reinigungsmethoden und Übungen zur Steigerung mentaler Kapazität und Erkenntnisfähigkeit, die auf medizinisch-diätetischem und magischrituellem Wissen beruhten und mit zahlreichen Ge- und Verboten verbunden waren. ${ }^{29}$ Zudem wurde er als Erfinder der Tetraktys und der Musik(theorie)

23 Vgl. z.B. die Anspielung in Herodot: Historiae 4,95.

24 Herakleides Pontikos: Frg. 88. In: Fritz Wehrli: Herakleides Pontikos. Basel ${ }^{2} 1969$.

25 Diogenes Laertios: Vitae et sententiae philosophorum 1,12. Zit. aus: Diogenes Laertius: Lives of Eminent Philosophers. Hrsg. von Tiziano Dorandi. New York 2013, S. 73.

26 Diogenes Laertios: Vitae et sententiae philosophorum 8,1 (Anm. 25), S. 601.

27 Vgl. hierzu z.B. Staab: Pythagoras in der Spätantike (Anm. 11), S. 109-143.

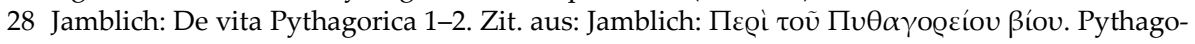
ras: Legende, Lehre, Lebensgestaltung. Eingeleitet und mit interpretierenden Essays versehen. Hrsg. von Michael von Albrecht u.a. Darmstadt 2002, S. 32-33. Der griechische Text wird hinfort aus dieser Ausgabe zitiert.

29 Vgl. hierzu z.B. Riedweg: Pythagoras (Anm. 13), S. 47-58. 
gehandelt, ${ }^{30}$ was u.a. in der sogenannten Schmiedelegende ${ }^{31}$ zur Darstellung kommt, sowie in platonisierenden Theorien zur Sphärenharmonie, die zu hören Pythagoras als Einziger imstande gewesen sei. ${ }^{32}$ Hieran knüpft später die lateinische Schultradition des Mittelalters an: Vermittelt über Boethius, der unter Berufung auf Pythagoras die Notwendigkeit der vier mathematischen Disziplinen Arithmetik, Geometrie, Musik und Astronomie für die Vollendung in der Philosophie betont, ${ }^{33}$ sieht sie ihn als Meister, teils sogar Erfinder der artes liberales.

\section{Ex Oriente Lux: Pythagoras als Vermittler altbewährten Wissens orientalischer Hochkulturen}

Viele Referenzen auf den Sonderstatus des ,Ältesten' (oder zumindest eines der ältesten Akteure) der Philosophie- und/oder Wissenschaftsgeschichte sind mit Hinweisen auf Reisen verknüpft, auf denen Pythagoras Zugang zu erprobten Wissensbeständen alter Hochkulturen erhalten habe. Antike und spätantike Testimonien ,berichten' von Bildungsfahrten des Pythagoras nicht nur innerhalb Großgriechenlands, sondern auch in den Nahen und Mittleren Osten: nach Ägypten, wo er Ägyptisch gelernt habe, und nach Phönizien, des Weiteren u.a. nach Babylonien, Persien und Indien. ${ }^{34}$ Von diesen Expeditionen in die Fremde brachte er, so der Anspruch der Texte, altes, lange bewährtes Wissen mit und gab es nach verschiedenen Zwischenstationen in Süditalien weiter. Als Wissensvermittler nennen die Quellen religiöse Spezialisten wie ägyptische Priester und persische Magier oder gar Zarathustra selbst, arithmetisch bewanderte Phönizier, sternkundige Chaldäer sowie, im Bereich der Traumdeutung, Juden, und sogar Kelten und Iberer. ${ }^{35}$

30 Zur Tetraktys siehe z.B. Jamblich: De vita Pythagorica 150; zur Musik siehe schon Xenokrates: Frg. 9. In: Richard Heinze: Xenokrates. Darstellung der Lehre und Sammlung der Fragmente. Leipzig 1892.

31 Z.B. in Nikomachos von Gerasa: Encheiridion 6; Jamblich: De vita Pythagorica 115-121.

32 Siehe z.B. Nikomachos von Gerasa: Frg. 1. In: Die Fragmente der griechischen Historiker (hinfort abgekürzt: FGrHist). Hrsg. von Felix Jacoby. Leiden 1923-1999, N. 1063; Porphyrios: Vita Pythagorae 30-31; Jamblich: De vita Pythagorica 65.

33 Siehe Boethius: De institutione arithmetica 1,1.

34 Quellenangaben zu den Reisen finden sich u.a. in Eduard Zeller: Die Philosophie der Griechen in ihrer geschichtlichen Entwicklung, I,1: Allgemeine Einleitung. Leipzig 1919, S. 381392; Armand Delatte: La Vie de Pythagore de Diogène Laërce. Édition critique avec introduction \& commentaire. Brüssel 1922, S. 150-154 (unter Bezug auf S. 104-106); Theodor Hopfner: Orient und griechische Philosophie. Leipzig 1925, S. 3-6, 11-13; Isidore Lévy: Recherches sur les sources de la légende de Pythagore. Paris 1927, S. 20-26; Peter Gorman: Pythagoras: A Life. London 1979, S. 43-68; Riedweg: Pythagoras (Anm. 13), S. 20-21; Leonid Zhmud: Pythagoras and the Early Pythagoreans. Oxford 2012, S. 83-91.

35 Siehe etwa, um nur einige Beispiele anzuführen, Diodoros von Eretria: Frg. 1. In: FGrHist, N. 1103; Aristoxenos: Frg. 13. In: Fritz Wehrli: Aristoxenos. Basel 1945; Hermippos von Smyrne: Frg. 21. In: FGrHist, N. 1026; Valerius Maximus: Factorum et dictorum memorabilium 8,7; Flavius Philostratos: Vita Apollonii 8,7; Diogenes Laertios: Vitae et sententiae philo- 
Es ist diese Behauptung vielfältiger Wissensbewegungen durch den Mittelmeerraum, insbesondere von Ost nach West, die Pythagoras zu einem noch im arabisch-islamischen Kulturraum vielfach aufgerufenen Verwalter und Vermittler altehrwürdiger Wissensbestände westlicher und östlicher Provenienz gemacht hat - eine Behauptung, zu der es nicht zufällig kam. Die Geschichte des Wissenstransfers zwischen dem sogenannten Orient und Kulturräumen westlich hiervon, dem sogenannten Okzident, setzt nicht erst mit dem Zugriff der Christen auf antikes Wissen ein, das, im Europa des beginnenden Mittelalters verlorengegangen, die Araber bei der Reconquista in Handschriften zurückließen. ${ }^{36}$ Das griechische Festland stand fast während des gesamten 2. Jahrtausends nicht nur mit Kreta und Zypern, sondern auch mit dem Vorderen Orient und, vermittelt über Rezeptionen in der Levante und Syrien, mit Mesopotamien in regem Kontakt, und, wie die Mythologie, entwickelte sich auch die Philosophie der Griechen in Auseinandersetzung mit Theogonien und Kosmogonien der orientalischen Hochkulturen. ${ }^{37}$ Viele Philosophen - in Anlehnung an Platon, der orientalische Wissensbestände in sein Werk integrierte, zumal die Platoniker - beschäftigten sich mit der „Weisheit" der „Barbaren“, um sie in ihre eigenen Entwürfe einzuarbeiten. ${ }^{38}$

Ein Grund hierfür bestand darin, dass die Griechen vom großen Alter der benachbarten Kulturen beeindruckt waren und, wie paradigmatisch Herodot in seinen Historien, Analogien zwischen ihnen und der eigenen Kultur durch Übernahme aus jenen erklärten. Dabei kam es zu einer Fülle von Ableitungskonstruktionen und Verherrlichungen; wurde doch die Rückführung eines Kulturbestands auf z.B. ägyptische Wurzeln ähnlich positiv bewertet wie etwa die genealogische Rückbindung von Geschlechtern an Helden z.B. der Ilias. ${ }^{39}$ Eine erhebliche Intensivierung erfuhr der schon in vorhellenistischer Zeit beobachtbare ori-

sophorum 8,2-3; Porphyrios: Vita Pythagorae 6; 11-12; Jamblich: De vita Pythagorica 19; 151; 154; Lactantius: Divinarum Institutionum 1,2; Eusebios: Praeparatio Evangelica 10,4.

36 Vgl. zur Thematik z.B. Franz Rosenthal: Das Fortleben der Antike im Islam. Zürich 1965 (engl.: The Classical Heritage in Islam. London 1975, neu aufgelegt 1994 bei Routledge, Arabic Thought and Culture); John Freely: Platon in Bagdad. Wie das Wissen der Antike zurück nach Europa kam. Stuttgart 2012.

37 Vgl. hierzu insbes. Walter Burkert: The Orientalizing Revolution. Near Eastern Influence on Greek Culture in the Early Archaic Age. Cambridge (Mass.) 1992; ders.: Die Griechen und der Orient. Von Homer bis zu den Magiern. München 2003; Martin L. West: The East Face of Helicon. West Asiatic Elements in Greek Poetry and Myth. Oxford 1997; Robert Rollinger: Antikes Griechenland und Alter Orient. Historisch-kritische Untersuchungen zur Interaktion der beiden Kulturräume mit besonderer Berücksichtigung der Zeit vom 8. bis zum 5 . Jahrhundert v. Chr. Innsbruck 1999 (Habilitationsschrift).

38 Vgl. hierzu z.B. Udo Reinhold Jeck: Platonica Orientalia. Aufdeckung einer philosophischen Tradition. Frankfurt a.M. 2004, S. 19-171.

39 Vgl. hierzu z.B. Christian Froidefond: Le Mirage égyptien dans la littérature grecque d'Homère à Aristote. Aix-en-Provence 1971. Für die Haltung Herodots gegenüber Ägypten siehe Joseph Vogt: Herodot in Ägypten. Ein Kapitel zum griechischen Kulturbewusstsein. Stuttgart 1929. 
entalisierende Trend, der aus vielfältigen interkulturellen Kontakten Griechenlands mit Vorderasien, und insbesondere Ägypten, resultierte, durch die Aktivitäten Alexanders des Großen. Zum einen gründete er 331 v. Chr. Alexandria, eine von Beginn an ausgeprägt multiethnische Stadt, in der u.a. Griechen und Makedonen, Ägypter, Juden und Syrer wohnten und die sich bald zu einem der wichtigsten kulturellen und wissenschaftlichen Zentren der hellenistischen Welt entwickelte. Zum anderen dehnte er durch seinen Eroberungsfeldzug die Grenzen des Reiches bis an den indischen Subkontinent aus und trug so maßgeblich auch in dieser Richtung zu einem nachhaltigen Kulturaustausch bei. Spätestens seit jener Zeit gehörte es für Dichter, Philosophen und Gelehrte bzw. ihre Lebensbeschreibungen gleichsam zum ,guten Ton', mindestens eine Reise an die Ränder des östlichen Mittelmeerraums und in angrenzende Gebiete unternommen zu haben (ob sie nun tatsächlich stattgefunden hatte oder nicht). Antike Biographien erklären das besondere Wissen eines Intellektuellen daher regelmäBig mit Unterweisungen in östlichen Teilen der antiken Welt - eine Tendenz, die sich in der römischen Kaiserzeit und Spätantike, im Osten des Imperium Romanum mitunter motiviert durch affektive Haltungen der eigenen Heimat gegenüber, noch verstärkte.

Die Einspielung von Reisetopik in Darstellungen des Pythagoras und seines Wissens ist vor diesem Hintergrund zu verstehen: als hellenistische ,Modeerscheinung', in der eine ältere Neigung zum Durchbruch kam. Die Tendenz der Griechen, ihre Glaubensvorstellungen und philosophischen Lehren auf östlich gelegene Kulturen zurückzuführen, zeigt sich in der Literaturgeschichte schon früh. Herodot leitet im zweiten Historien-Buch eine Fülle griechischer Vorstellungen und Sitten von der Hochkultur der Ägypter ab, auf deren Alter auch Platon verweist - beispielhaft in seiner breiten Ägyptendarstellung im Einleitungsgespräch des Timaios. ${ }^{40}$ Diese Haltung Ägypten gegenüber kehrt in späterer Literatur topisch wieder, zumal bei Autoren, die sich selbst im Nilland aufhielten; Pythagoras wird hierbei regelmäßig ins Spiel gebracht.

Ein prominentes Beispiel bilden die Aigyptiaka des Hekataios von Abdera, der während der Regierung Ptolemaios' I. Soter in Ägypten lebte. Seine idealisierende Darstellung des Nillandes besagte, alle Kultur habe dort ihren Ursprung, und stellte die griechische als der ägyptischen Kultur unterlegen dar. Hekataios listete zahlreiche berühmte griechische Gestalten aus Mythos und Geschichte auf, die alle auf Reisen nach Ägypten ihr Wissen von den dortigen Weisen erhalten hätten (FGrHist 264 F 25,69-98) - unter ihnen Pythagoras, der die kultischen Vorschriften, die Wiedergeburtslehre und die geometrischen und arithmetrischen Theoreme von den Ägyptern gelernt habe (FGrHist $264 \mathrm{~F}$ 25,98,2). Das Werk diente u.a. Diodorus Siculus, der sich 60-57 v. Chr. in Ägypten aufhielt, als Quelle für seine eigenen Berichte über Ägypten in der Bibliotheca

40 Siehe Platon: Timaeus 21E-25D. 
Historica ${ }^{41}$ Diodor referiert darin mehrfach, unter Berufung auf die (Bücher der)

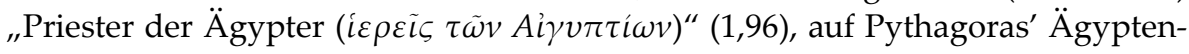
reise. ${ }^{42}$ Er reiht den Samier in den Kreis der Einsichtsvollsten und Gebildetsten unter den Griechen ein: in eine Riege altehrwürdiger Gestalten wie Orpheus, Musäus, Melampus und Dädalus, Homer und Lykurg von Sparta, Solon, Demokrit und Platon. Sie alle seien eifrig darum bemüht gewesen, „zwecks Teilhabe

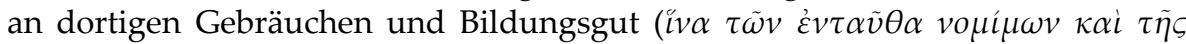
$\tau \alpha \iota \delta \varepsilon i \alpha \varsigma \mu \varepsilon \tau \alpha \dot{\alpha} \sigma \chi \omega \sigma \iota v)^{\prime \prime}$ nach Ägypten zu reisen - obwohl „das Land einstmals

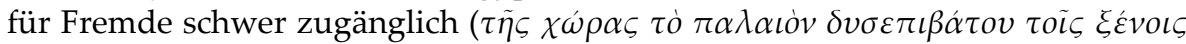

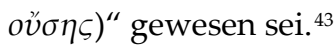

In den anekdotisch-idealisierenden Lebensdarstellungen des Pythagoras, wie sie aus der Kaiserzeit, beispielhaft von Diogenes Laertios, Porphyrios und Jamblich, erhalten sind (vgl. im Übrigen auch die Fragmente der Pythagorasvita des Apollonios von Tyana, Zuschreibung umstritten ${ }^{44}$ ), kommt die Reisetopik zu einer besonderen Entfaltung. Das Wissen des Pythagoras, den schon der kongeniale Empedokles als „Mann von überragendem Wissen ( $\dot{\alpha} v \dot{\eta} \rho \tau \varepsilon \rho \iota \omega ́ \sigma \iota \alpha \varepsilon \dot{\varepsilon} \delta \omega \varsigma)$ “ beschrieb, ${ }^{45}$ erscheint hier deswegen als überragend, weil es das Ergebnis komplexer grenzüberschreitender Transferprozesse ist, die mehr als geographischer Art sind: Sie schließen verschiedene Formen der Überwindung, Aufhebung oder Verschiebung religiöser, kultureller und gesellschaftlicher Barrieren und Grenzen ein, so auch die sozialer Ordnungen der Wissensvermittlung. Diese Markierung des Über-Hinaus erfolgt qua Ausschmückung früherer Quellen, denen zufolge Pythagoras in der Fremde der Einweihung und Unterweisung durch besondere Spezialisten auf den Gebieten von Religion, Philosophie und Wissenschaft teilhaftig wurde: In die Texte eingetragen wird ein Sonderstatus des Pythagoras, der impliziert, dass es sich bei seinem Wissen um exklusives Wissen

41 Siehe Diodor: Bibliotheca Historica 1,10-98.

42 Diodor: Bibliotheca Historica 1,69,3-4; 1,96,2; 1,98,1. Zit. aus: Diodorus of Sicily. Hrsg. von Charles Henry Oldfather. London, Cambridge (Mass.) 1933, Bd. 1, S. 326.

43 Auf ähnliche Weise ,berichtet' Plutarch: De Iside et Osiride 10,354D-E, dass „die Weisesten

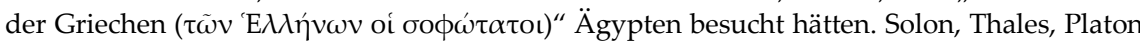
und Eudoros, einigen Angaben zufolge auch Lykurg, und so auch Pythagoras, seien alle

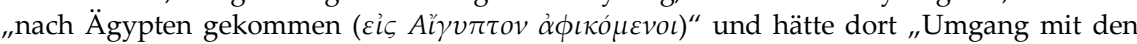

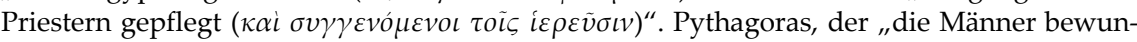

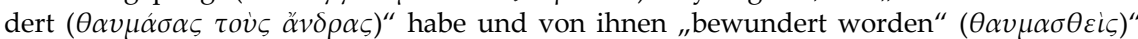
sei, sei von einem heliopolitanischen Priester namens Oenuphis unterwiesen worden und habe die symbolische und mysteriöse Ausdrucksweise der Ägypter nachgeahmt, indem er seine Lehren in Rätsel gehüllt habe. Zit. aus: Plutarch's De Iside et Osiride. Hrsg. von John Gwyn Griffiths. Cambridge 1970, S. 130-132.

44 Porphyrios: Vita Pythagorae 2 und Jamblich: De vita Pythagorica 254 berufen sich auf die heute verlorene Pythagoras-Biographie des Apollonios, scheinen also noch Zugriff auf sie gehabt zu haben.

45 Empedokles: Frg. DK 31 B 129. Es ist auch Parmenides als derjenige, den Empedokles mit seinem Lob meinte, gesehen worden. Vgl. Staab: Pythagoras in der Spätantike (Anm. 11), S. 52-53. 
handelte, das von den Spezialisten, die über es verfügten, eigentlich nur innerhalb der Sozial- und Organisationsstrukturen ihrer Kulturen, in denen sie wirkten, und in diesen nur an sehr wenige weitergegeben wurde.

Mit besonderem Nachdruck hebt die Schwierigkeit des Wissenserwerbs in der Fremde Porphyrios hervor. Für den neuplatonischen Philosophen und Gelehrten gehörte der weitläufig gebildete Pythagoras zu den großen Autoritätsfiguren der Vergangenheit, die ein besonderes Verhältnis zu Logos und Wahrheit hatten. Auf Pythagoras' Orientreisen geht er in den Kapiteln 6-8 ein, in denen er die Herkunft der Lehrinhalte erläutert. Bei Ägyptern, Chaldäern und Phönikern habe Pythagoras sich gründlich Wissenschaften ",aus alten Zeiten $(\dot{\varepsilon} \kappa \pi \alpha \lambda \alpha \iota \tilde{\omega} v$ $\chi \rho o ́ v \omega v)^{\prime \prime}$ angeeignet, bei den Magiern Kenntnisse „über den Gottesdienst ( $\pi \varepsilon \rho i$ $\tau \dot{\alpha} \varsigma \tau \tilde{\omega} v \theta \varepsilon \tilde{\omega} v \alpha \gamma \iota \sigma \tau \varepsilon \dot{\varepsilon} \alpha \varsigma)^{\prime \prime}$ und „das Übrige, was die Lebensbetätigungen betrifft

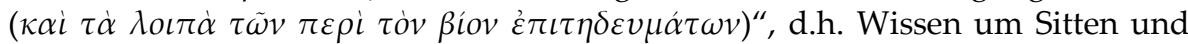
Bräuche, wie sich der Mensch vor den Göttern und in seinem Privatleben zu verhalten habe. In Ägypten, so fährt Porphyrios fort, seien dem Pythagoras, um ihn abzuschrecken, besonders harte Regeln auferlegt worden. Durch ihre Einhaltung habe er sich aber die Bewunderung der Priester erworben, so dass er "die Erlaubnis bekommen ( $\dot{\varepsilon} \xi o v \sigma i \alpha v \lambda \alpha \beta \varepsilon \tilde{\mathcal{l}} v)^{\text {“ }}$ habe, "den Göttern zu opfern $(\theta \dot{v} \varepsilon \iota v$

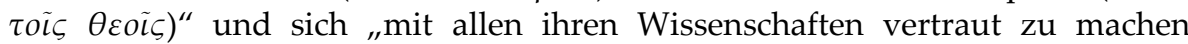

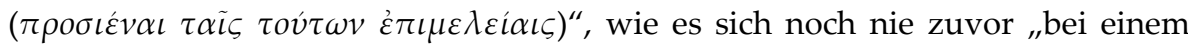

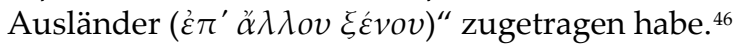

Solche soziokulturell bedeutsamen Aspekte der Grenzüberwindung ergänzen etliche antike Quellen um eine transzendente Dimension, so dass der Samier uns als eine Figur der Wissensbewegung durch Entgrenzung in Horizontal- und Vertikalverläufen entgegentritt: als Integrationsgestalt vielfältiger Wissensformen und -bestände über Grenzen sowohl zwischen Griechen und „Barbaren“, d.h. „Okzident" und „Orient", als auch zwischen Göttern und Menschen, Lebenden und Toten, Himmel und Erde hinweg. Dabei schöpfen viele Textpassagen aus einem breiten Repertoire von Topoi der Besonderung und Entgrenzung, die verdeutlichen sollen, dass eine Person aus dem Horizont des gewöhnlichen Menschseins herausfällt. Solche Topoi (Redewendungen, Metaphern, Beschreibungsmuster etc.) finden sich nicht nur im Feld und Umfeld antiker griechischer und römischer Mythen und Legenden, sondern kulturübergreifend im euroasiatischen Raum. Sie haben den Zweck, das Wirken, Wissen und Können der Person bzw. Figur, um die es geht, in Ausdrücken und Bildern einer dem geographischen Raumsinn übergelagerten Form der übernatürlichen Befähigung des Menschen darzustellen. ${ }^{47}$ In Pythagoras' Fall gehören hierzu, um

46 Porphyrios: Vita Pythagorae 6-8. Zit. aus: Porphyre: Vie de Pythagore. Lettre a Marcella. Hrsg. von Édouard des Places. Paris 1982, S. 38-39.

47 Systematisch angeführt werden solche Topoi in der (kontrovers rezipierten) Arbeit von Ludwig Bieler: $\Theta E I O \Sigma$ ANHP. Das Bild des „göttlichen Menschen“ in Spätantike und Frühchristentum. Darmstadt 1976 (zuerst Wien 1935-1936); siehe des Weiteren z.B. auch Hans Dieter Betz: Gottmensch II (Griechisch-römische Antike und Urchristentum). In: Reallexikon 
nur drei Beispiele zu nennen: der Topos der Bilokation, Pythagoras' Fähigkeit, an zwei Orten gleichzeitig zu sein; ${ }^{48}$ der Totenkontakt durch Katabasis: die Hadesreise des Pythagoras; ${ }^{49}$ und der Hinweis auf frühere Inkarnationen, ${ }^{50}$ an die sich Pythagoras habe erinnern können. ${ }^{51}$

Viele Pythagoras-Darstellungen dieser Art, in der sich Horizontalität und Vertikalität der Erweiterung und Entgrenzung von Wissen verbinden, sind topisch unterfüttert durch Mirabilien, „wunderbare Taten $(\theta \alpha v \mu \alpha \sigma \tau \dot{\alpha} \varepsilon \text { है } \gamma \alpha)^{\prime \prime}$, wie Jamblich (De vita Pythagorica 130) schreibt, Ereignisse und Zeichen, die ebenfalls dazu dienen, Pythagoras' Autorität als Ausnahmemenschen zu markieren. Sie weisen ihm die Gabe der Divination zu, setzen ihn zu Apollon in Beziehung oder dem Gott gar gleich und berichten von außerordentlicher Nähe zu und Gewandtheit im Umgang mit der Natur. So wird etwa berichtet, der Fluss Kosa habe ihn bei der Überquerung gegrüßt und von einer giftigen Schlange heißt es, Pythagoras habe sie durch einen Biss getötet. Aufschluss darüber, ob Pythagoras sein Wissen einstmals tatsächlich zu gewichtigen Anteilen in verschiedenen Gebieten des Orients erwarb, erteilen solche Darstellungen nicht. Die Häufung der Mirabilien erregt eher den Verdacht, dass - in ähnlicher Weise wie in Darstellungen des Apollonios von Tyana, des klassischen Beispiels eines literarisch stilisierten ,Wundertäters ${ }^{52}$ - Pythagoras' vielbeschworene Leuchtkraft zum Scheinen gebracht werden sollte, um Mangel an historischer Sicherheit wettzumachen und Akteure, die an Wundertaten, Bilokation, Reinkarnation u.ä. glaubten, dazu anzuhalten, auch den Reisen Validität zuzumessen. Tatsächlich lässt

für Antike und Christentum 12 (1983), S. 234-312; David S. du Toit: THEIOS ANTHROPOS. Zur Verwendung von theios anthrôpos und sinnverwandten Ausdrücken in der Literatur der Kaiserzeit. Tübingen 1997; (für die byzantinische hagiographische Literatur) Thomas Pratsch: Der hagiographische Topos: griechische Heiligenviten in mittelbyzantinischer Zeit. Berlin, New York 2005.

48 Siehe z.B. Porphyrios: Vita Pythagorae 27; Jamblich: De vita Pythagorica 134.

49 Siehe z.B. Hieronymos von Rhodos Frg. 42. In: Fritz Wehrli: Hieronymos von Rhodos. Kritolaos und seine Schüler. Basel 21969 = Diogenes Laertios: Vitae et sententiae philosophorum 8,21; Hermipp = Diogenes Laertios: Vitae et sententiae philosophorum 8,41; später auch Tertullian: De anima 28. - Parallelen zwischen den pythagoreischen und den jüdischen Katabaseis (u.a. des Mose) sind bei Isidore Lévy zu finden: Isidore Lévy: La légende de Pythagore de Grèce en Palestine. Paris 1927, S. 154-170 (allgemein zum Vergleich PythagoreismusJudentum vgl. S. 211-263; zu Pythagoras und den Essenern S. 264-293; zu Pythagoras und Jesus S. 295-331).

50 So z.B. bei Ovid: Metamorphoseon libri 15,158-164; Diogenes Laertios: Vitae et sententiae philosophorum 8,4-5; Porphyrios: Vita Pythagorae 26-27; Jamblich: De vita Pythagorica 63.

51 So etwa Ovid: Metamorphoseon libri 15,160-164; Diogenes Laertios: Vitae et sententiae philosophorum 8,5; Jamblich: De vita Pythagorica 134.

52 An Apollonios von Tyana haben sich ebenfalls zahlreiche Legenden, u.a. auch von Reisen in den Orient, geheftet, und es gelten nur wenige biographische Details und Lehrinhalte als gesichert (Philostrats Apollonios-Biographie ist als Quelle umstritten). $\mathrm{Zu}$ den fiktiven Reisen des Apollonios im Kontext der Legendenbildung vgl. John Elsner: Hagiographic Geography: Travel and Allegory in the Life of Apollonius of Tyana. In: The Journal of Hellenic Studies 117 (1997), S. 22-37. 
die derzeitige Quellenlage keinerlei Sicherheit darüber zu, dass Orientfahrten des Pythagoras jemals stattfanden bzw. dass, wenn es denn eine oder mehrere Reisen gegeben haben sollte, es Studienreisen waren. Bemerkungen zu den Orientbesuchen begegnen in vorhellenistischer Zeit extrem selten, betreffen allein Ägypten $^{53}$ und haben überdies eine erkennbar legendäre Note, die, wie Leonid Zhmud überzeugend dargelegt hat, ${ }^{54}$ die Orientthese genauso wenig verifiziert wie z.B. der Hinweis des römischen Kaiserzeitautors Aelian, Pythagoras habe Hosen getragen ${ }^{5}$ (oder, so ließe sich hinzufügen, ikonographische Zeugnisse ab dem 2. Jahrhundert n. Chr., die Pythagoras mit orientalisierendem Turban zeigen $^{56}$ ). Nach Verknüpfungen pythagoreischer Lehrinhalte mit Ägypten bei Herodot $^{57}$ findet sich die früheste konkrete Angabe $\mathrm{zu}$ einer Ägyptenreise in der klassischen Ära bei Isokrates in einer Rede auf den mythischen ägyptischen König Busiris: ${ }^{58}$ Dort heißt es, Pythagoras habe, „nachdem er nach Ägypten

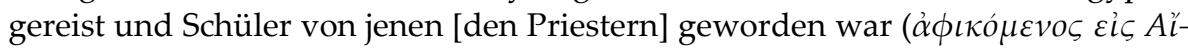

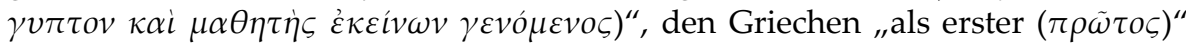

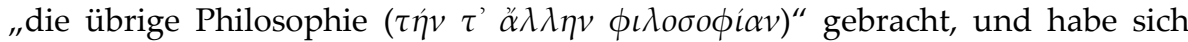
mehr als andere besonders ernsthaft für "Opfer und Reinigungszeremonien ( $\tau \dot{\alpha}$

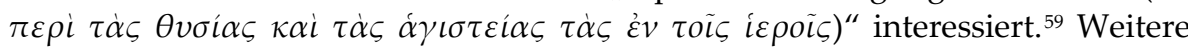
Beispiele aus klassischer Zeit gibt es nicht. Erst im Hellenismus und vor allem in der Kaiserzeit nehmen Angaben zu Reisen des Pythagoras zu und avancieren

53 Siehe Isokrates: Busiris 28; FGrHist, N. 264 F 25,96 und 98; von Herodot: Historiae 2,81 wohl vorausgesetzt.

54 Siehe Leonid Zhmud: Wissenschaft, Philosophie und Religion im frühen Pythagoreismus. Berlin 1997, S. 61-64.

55 Siehe Aelian: Varia Historia 12,32.

56 Eine Bronzebüste im Archäologischen Nationalmuseum in Neapel, die in der Villa dei Papiri in Herculaneum gefunden wurde, sowie eine Marmorherme in den Kapitolinischen Museen in Rom sollen nach Annahme Karl Schefolds sehr wahrscheinlich Pythagoras darstellen. Dafür spreche die turbanartige Kopfbedeckung des Philosophen, ein Bestandteil orientalischer Tracht, der an die Legende von der Indienreise des Pythagoras erinnern solle. Von der Bronzebüste, die um 360-350 v. Chr. entstanden ist, sind sieben Repliken erhalten. Die Herme wird von Schefold um 120 n. Chr. datiert: ders.: Die Bildnisse der antiken Dichter, Redner und Denker. Basel 1997, S. 152-155, 344-345. (Abb. 69 Bronzebüste mit orientalisierendem Turban aus der Villa dei Papiri in Herculaneum aus dem 1. Jahrhundert n. Chr.; Abb. 217 Herme mit Turban, um 120 n. Chr., nach frühaugusteischem Vorbild); Gisela M.A. Richter: The Portraits of the Greeks, Bd. 1. London 1965, S. 79-80.

57 Siehe Herodot: Historiae 2,81; 2,123.

58 Isokrates: Busiris 28. Zit. aus: Isocrates opera omnia. Hrsg. von Basilius Mandilaras. München, Leipzig 2003, S. 278.

59 Eine zweite konkrete Angabe ist in dem oben erwähnten Fragment des Hekataios überliefert, in dem er unter Berufung auf die heiligen Bücher der Ägypter von Ägyptenbesuchen legendärer Gestalten wie Orpheus, Musaios, Daidalos und Homer erzählt und für Pythagoras hinzufügt, er habe von den Ägyptern einen Hieros Logos, die Lehre der Metempsychose und geometrische Theoreme übernommen (FGrHist 264 F 25, 96 und 98). 
unter beträchtlicher Ausschmückung und Expansion der Reiseroute zu einem integralen Bestandteil der Lebensdarstellung des Pythagoras. ${ }^{60}$

\section{Zwischen Göttern und Menschen: Pythagoras als Mittlerfigur von Übungswissen mit soteriologischer Funktion}

Mit besonderer Sinnfälligkeit kommt die kulturell-geographische und spirituellkosmische Dimension der Wissensvermittlung an und durch Pythagoras in Jamblichs Darstellung der pythagoreischen Lebensform zum Ausdruck. Über das py-

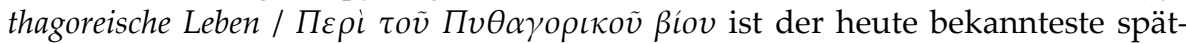
antike Text über Pythagoras. Mit Hilfe einer Fülle von Topoi der oben skizzierten Art spannt er an den Vorsokratiker zurückgebundenes Wissen in ein religiös aufgeladenes Koordinatensystem von ausgeprägter Horizontalität und Vertikalität. Aufbereitet wird das Wissen in einübenden Wiederholungsstrukturen, die es den Adressaten einprägen und qua Rekapitulation systematisch vertiefen sollen.

Der Text bildet den als erstes Buch konzipierten Teil eines vermutlich auf zehn Bücher angelegten Kompendiums. Er führt in die verschiedenen Mathemata/ $\mu \alpha \theta \eta \mu \alpha \tau \alpha$ sowie weitere Bereiche des Pythagoreismus und zugleich in ein komplexes Programm einer geregelten philosophischen Ausbildung ein, das der Autor selbst für seine Schüler (und generell Anfänger) in der platonischen Philosophie entwarf. ${ }^{61}$ Unter den drei weiteren erhaltenen Büchern sind ein „Aufruf

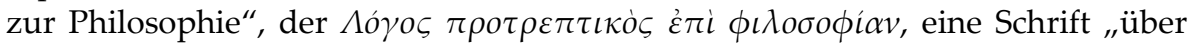

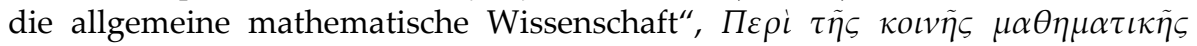
$\dot{\varepsilon} \pi \iota \sigma \tau \eta \mu \eta \varsigma$, und ein Kommentar zur „Einführung in die Arithmetik des Niko-

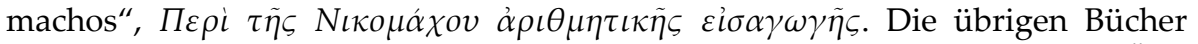
behandelten Physik, Ethik, Theologie, Geometrie, Musik und Astronomie. Über das pythagoreische Leben wirbt für eine Nachahmung des pythagoreischen Lebens und präsentiert zu diesem Zweck - in Form einer protreptisch-propädeutischen Aufforderung zur Tugendübung um Heilserlangung willen - eine Erlösungslehre des Autors, die den Anspruch erhebt, bei konsequent einübender Umsetzung zur Schau des wahren Seienden und Göttlichen und dadurch zur Glückseligkeit führen zu können.

Literaturtypologisch handelt es sich bei Jamblichs Schrift um eine abgewandelte Form der antiken Biographie, die zahlreiche Bezüge zur Schematik und Topik der Lobrede aufweist und romanhafte sowie protreptische, programmatische und erbauliche Elemente miteinander verbindet. ${ }^{62}$

60 Vgl. hierzu auch Zhmud: Wissenschaft, Philosophie und Religion (Anm. 54), S. 60-61.

61 Ausführlich Staab: Pythagoras in der Spätantike (Anm. 11), S. 193-202.

62 Vgl. hierzu z.B. Michael von Albrecht: Das Menschenbild in Jamblichs Darstellung der

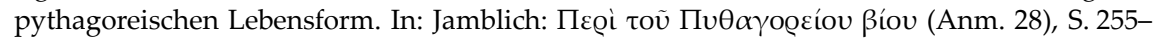
259; David S. du Toit: Heilsbringer im Vergleich. Soteriologische Aspekte im Lukasevange-

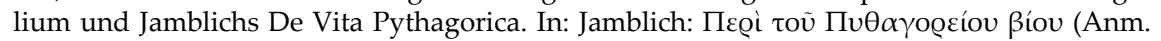
28), S. 275-294, hier S. 291-292; Staab: Pythagoras in der Spätantike (Anm. 11), S. 441-447. 
Schon der biographische Teil (3-32) ${ }^{63}$ macht deutlich, dass die pythagoreische Lebensform in der Konzeption des Autors ein Übungsweg ist, in dem religiöses und wissenschaftliches Streben im Sinne philosophischer Tugendübung untrennbar miteinander verbunden sind. Integrale Bestandteile dieses Weges, wie ihn Pythgaoras vorgelebt habe, sind "Gottesdienste $(\theta \rho \eta \sigma \kappa \varepsilon i \alpha \iota \varsigma)$ ", "Wis-

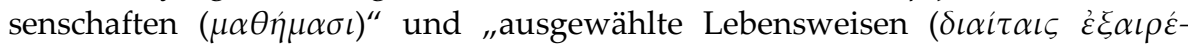
$\tau o \iota \varsigma)^{\prime \prime}(10) . \mathrm{Zu}$ den $\theta \rho \eta \sigma \kappa \varepsilon i \alpha \iota$ des Pythagoras gehörten Götterglaube und die Ausübung kultischer Frömmigkeit, die sich im Streben nach möglichst vielen Initiationen in Geheimkulte und göttliche Mysterien äußerten (14). Seine Übung in $\mu \alpha \theta \eta \mu \alpha \tau \alpha$ zielte auf eine möglichst umfassende Bildung (9-10). Und die von

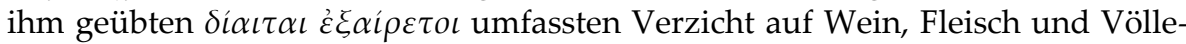
rei zugunsten leicht verdaulicher Kost. Begründet wird der einübend-asketische Lebensstil diätetisch: Er habe bei Pythagoras zu geringem Schlafbedürfnis, Seelenreinheit und unerschütterlicher körperlicher Gesundheit geführt (13).

Der Hauptteil der Schrift (33-240) nimmt Details aus Pythagoras' Lebensgeschichte, die im biographischen Teil präsentiert wird, auf und bindet sie, elaborierend, in die systematische Darstellung eines Erziehungsprogramms ein (33-57: exoterische Paideia/ $\pi \alpha \iota \delta \varepsilon i \alpha$; 58-133: esoterische Paideia; 134-240: pythagoreisches Leben und Erziehung als Tugendbetätigung). Dessen Ablauf wird in einübender Form präsentiert, vermittels nachvollziehender Darlegung, wie Pythagoras seinen Schülern den Weg zur Schau des Intelligiblen und zur Einung mit Gott immer wieder aufs Neue gewiesen habe. Dabei wird wiederholt auf die Hauptpfeiler der Tugendübung eingegangen und deutlich gemacht, dass es, um Seelenreinheit zu erlangen, großer Beharrlichkeit der Übung und strenger Kontrolle bedarf. In einem Abschnitt zur esoterischen philosophischen Paideia, in

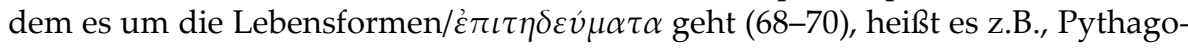
ras habe darauf geachtet, dass die Läuterung des Denkens und der ganzen Seele

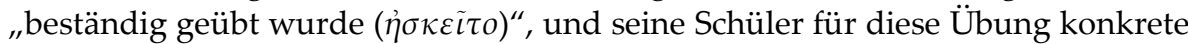
Mittel gelehrt, wie reduzierte vegetarische Ernährung, Enthaltung von Wein, Beschränkung von Schlaf, Schweigen, Verzicht auf Ruhm und Reichtum, neidlo-

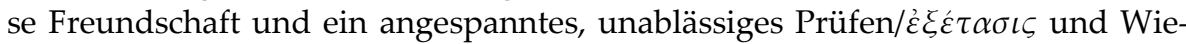
derholen/ $\dot{\alpha} v \alpha \dot{\alpha} \lambda \eta \psi \iota \varsigma$ der schwierigsten Theoreme (68-69). Ähnliche Passagen finden sich in der systematischen Darstellung des pythagoreischen Lebens und der pythagoreischen Paideia als Betätigung der Tugenden (134-240). In mehreren Schritten wird dort ein Tugendschema präsentiert, das es diszipliniert übend umzusetzen gilt.

Insofern als die Verknüpfung dieser Tugenden mit Pythagoras Antiquität und göttliche Autorität dokumentieren soll, ${ }^{64}$ sagt uns die Schrift sehr viel mehr

63 Vgl. zum Aufbau Michael Lurje: Die Vita Pythagorica als Manifest der neuplatonischen

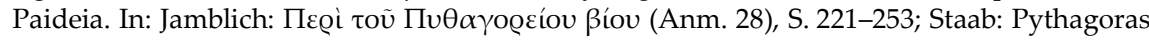
in der Spätantike (Anm. 11), S. 238-242.

64 Vgl. hierzu auch du Toit: Heilsbringer im Vergleich (Anm. 62), S. 293. 
über die Autorintention, das Platonismusverständnis Jamblichs und die epistemischen Geltungsansprüche in einer Zeit miteinander konkurrierender paganer und christlicher Erlösungsvorstellungen aus als über die historische Gestalt des Pythagoras selbst. Dieser erscheint, auf Basis des ethischen Menschenbildes des Autors, ${ }^{65}$ als programmatische Gründerfigur eines letztlich religiös verstandenen Platonismus, als Archeget eines als Heilsmittel begriffenen Übungswissens, dessen Zusammenspiel von Theorie und Praxis Aspekte der Lebensführung, Charakterformung und intellektuellen Bildung integrativ umschließt. Vieles spricht dafür, dass Jamblich, der vermutlich selbst eine philosophische Schule platonischer Ausrichtung unterhielt, ${ }^{66}$ den Pythagoras, von Interessen der Eigenwerbung geleitet, als Idealbild eines trefflichen Lehrers und als Mittlerfigur von Übungswissen mit soteriologischer Funktion modellierte: als Führungspersönlichkeit, die nie aufhörte, ihren Wissensstand $\mathrm{zu}$ erweitern, und auf Grundlage dieser Haltung durch soziale Vermittlung der göttlichen Philosophie die Vertikalkluft zwischen Göttern und Menschen zu überbrücken und die Seele des Menschen dem Göttlichen vertraut zu machen vermochte.

Integrationen von Reisenarrativen bei gleichzeitiger Betonung der Verbundenheit mit dem Göttlichen unterstreichen die Mittlerrolle. ,Berichte' über Pythagoras' Lehrjahre in Syrien, seine Einweihung in Mysterien durch phönizische Hierophanten, die wunderbare Überfahrt nach Ägypten sowie Lehrjahre ebendort und in Babylon ${ }^{67}$ weisen ihm eine $\dot{\varepsilon} \tau \iota \sigma \tau \eta \mu \eta ~ \delta \alpha \iota \mu o v i \alpha \mathrm{zu}$, „übermenschliches Wissen", wie es in den Aufzeichnungen der Pythagoreer bezeugt sei (157158), und kennzeichnen ihn, wie schon der biographische Teil, als "guten Daimon ( $\dot{\alpha} \gamma \alpha \theta o ́ v \tau \iota v \alpha \delta \alpha i \mu o v \alpha)$ “ zwischen Göttern und Menschen (30-31; vgl. auch 10): als eines der höheren Wesen, die, wie in De mysteriis ausgeführt (I 18

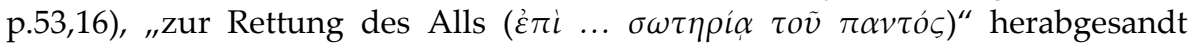
sind. ${ }^{68}$ Jamblich geht sogar so weit zu behaupten, Pythagoras stamme aus dem Geschlecht des Zeus selbst (3) und schon seine Geburt - nach Weissagung der Pythia die Geburt eines Helfers der gesamten Menschheit (5) - habe auf einer Reise stattgefunden: im phönizischen Sidon an der östlichen Mittelmeerküste (7; 13). Verwendung finden so zwei Topoi (göttliche Abstammung, Geburt in der Fremde), die in antiken Lebensbeschreibungen zur Kennzeichnung eines göttlichen oder heiligen Menschen und seiner Ausnahmestellung von Geburt an die-

65 Vgl. hierzu von Albrecht: Das Menschenbild in Jamblichs Darstellung (Anm. 62), S. 255-274.

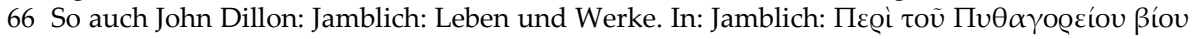
(Anm. 28), S. 11-21, hier S. 17-19.

67 Auf die Reisen wird in zahlreichen Stellen verwiesen, nicht nur in Jamblich: De vita Pythagorica 13-19.

68 Vgl. Jamblique: Les Mystères d'Égypte. Hrsg. von Édouard des Places. Paris 1966, S. 70. Vgl. zur Einteilung der immateriellen Welt in "Götter, Heroen und Dämonen“ (wie zitiert in Jamblich: De vita Pythagorica 146) auch Jamblich: De mysteriis I 3 p.8,15-p.9,1 (hier kommen in der Aufzählung die psychai hinzu). Zur Schrift De mysteriis siehe auch die Angaben weiter unten in Anm. 76. 
nen. ${ }^{69}$ Zugleich trägt der syrische Autor mit der Angabe, Pythagoras sei in der Levante zur Welt gekommen, Lokalkolorit in den Text ein: Der Verweis auf Sidon als Geburtstätte stellt Nähe des Pythagoras zur syrischen Heimat Jamblichs aus - zu seinem Geburtsort und seiner Wirkungsstätte.

Zusammenfassend lässt sich feststellen, dass Pythagoras bei Jamblich als Konvergenzgestalt erscheint, in der nicht nur alle Mathemata und Episte$\mathrm{mai} / \dot{\varepsilon} \tau \iota \sigma \tau \tilde{\eta} \mu \alpha \iota$, deren er, über kulturelle Grenzen hinweg, teilhaftig wurde (1821), zusammenliefen, sondern auch eine übermenschliche Lehrgabe (60-62) angelegt war, die der Vermittlung einer allumfassenden Bildung diente (28). In dieser Funktion, als - „in Menschengestalt ( $\dot{\varepsilon} v \dot{\alpha} v \theta \rho \omega \pi i v \eta \mu \rho \rho \phi \tilde{\eta})$ “ erschienener (30) - Mittler philosophischer Erkenntnis qua Paideia wies Pythagoras, in der Darstellung Jamblichs, zwei vorbildliche Eigenschaften auf: eine in allem „unerschütterliche ( $\dot{\alpha} \tau \dot{\alpha} \rho \alpha \chi o v)$ " asketisch-beharrliche Geisteshaltung (17) und einen „unstillbaren Wissensdurst". ${ }^{70}$ Ihre Kombination war es, die Pythagoras, Jamblichs ,Porträtierung' zufolge, zu einem begnadeten Lehrer, der streng auf Übung insistierte, werden ließ, nachdem sie ihn als unermüdlichen Schüler zu Pherekydes und Thales, Phöniziern, Ägyptern und bis nach Babylon getrieben und keine Belehrung, keine Initiation in Mysterien und magische Praktiken hatte versäumen lassen (18): Am Ende seiner Reisen war Pythagoras in alles Göttliche eingeweiht, beherrschte den gesamten wissenschaftlichen Fächerkanon mit Astronomie und Geometrie, Arithmetik und Musik (18-19) - und erst das qualifizierte ihn zum Hegemon für den Aufstieg der Seele. Denn die Beschäftigung mit jenem Kanon war es, aus der, nach Jamblich, die Paideia, die zur "Schau $(\theta \varepsilon \omega \rho i \alpha)^{\prime \prime}$ des wahrhaft und ewig seienden Schönen führen sollte, bestand. Nur durch sie konnte die Seele gereinigt und auf das Intelligible hin gewendet werden - ein Prozess, in dem es beständiger Übung und Betätigung der Tugend bedurfte, galt doch die ethische Vervollkommnung des Menschen als unabdingbare Voraussetzung, um zum theoretischen Erkennen, zur schauenden Philosophie zu gelangen (71-79).

Dass Pythagoras bei alledem „unter der Führung Apollons ( $\dot{\alpha} \pi \dot{o} \tau \tilde{\eta} \varsigma$

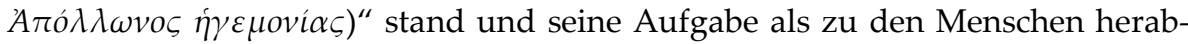
gesandte Seele erfüllte, hebt Jamblich gleich zu Beginn des Buches hervor (8). Damit nimmt der Text, wie an zahlreichen nachfolgenden Stellen, die Erklärung des Proöms auf, der zufolge die pythagoreische Lehre - und damit auch Jamblichs eigene Philosophie - „gottgegeben ( $\dot{\kappa} \kappa \theta \varepsilon \tilde{\omega} v[\ldots] \pi \alpha \rho \alpha \delta o \theta \varepsilon i \sigma \eta \varsigma)^{\prime \prime}$, d.h. wahr und unbezweifelbar ist. Mit anderen Worten: Das Wissen, um das es im

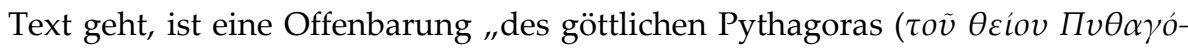

69 Analogien finden sich z.B. in den Evangelien der neutestamentlichen Schriften der christlichen Bibel in Berichten der Geburt Jesu' auf einer Reise seiner Eltern in Bethlehem (Matthäus 2,1; 2,5-6; 2,8; Lukas 2,4; 2,11; 2,15; Johannes 7,42). Vgl. hierzu auch Bieler: $\Theta E I O \Sigma$ ANHP (Anm. 47), S. 28-29.

70 von Albrecht: Das Menschenbild in Jamblichs Darstellung (Anm. 62), S. 257. 
$\rho o v)^{\prime \prime}(1)$. Wer sich eingehender mit ihm beschäftigen wolle, solle „die von den Pythagoreern verfassten Hypomnemata ( $\tau \dot{\alpha} \gamma \rho \alpha \phi \varepsilon \dot{\varepsilon} \tau \alpha$ viò $\tau \tilde{\omega} v \Pi v \theta \alpha \gamma o \rho \varepsilon i \omega v$

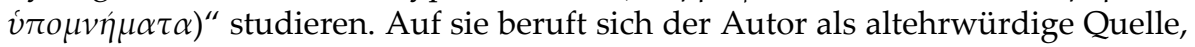

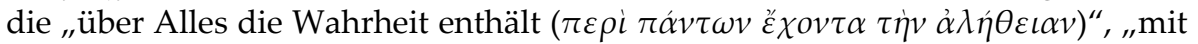
übermenschlichem Wissen in höchstem Maße durchdacht ist $\left(\mu \varepsilon \tau^{\prime} \dot{\varepsilon} \pi \iota \sigma \tau \eta \dot{\eta} \mu \eta \varsigma \delta \dot{\varepsilon}\right.$

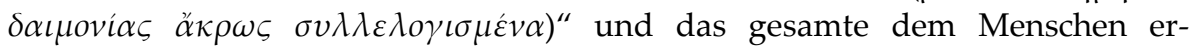
mittelbare „Wissen über das (durch das intelligible Vermögen) Erkennbare und

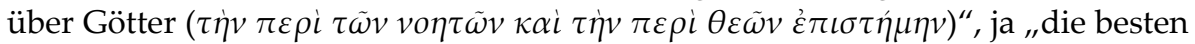

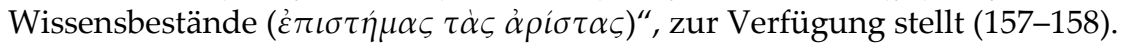

Es gehört zur didaktisch-iterativen Struktur des Buches, dass Jamblich nicht müde wird, Teile des offenbarten und von ihm zwecks Transfers aufbereiteten Wissens im Fortgang seiner Ausführungen immer wieder zu beschreiben. Das Fundament dieser Elaborationen legt er am Übergang des biographischen zum unterweisenden Teil der Schrift. Schon hier sucht er, im Leser Appetit auf mehr zu wecken, indem er einen großen Bogen schlägt: Es handele sich bei Pythago-

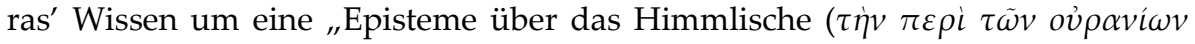
$\varepsilon \dot{\tau} \iota \sigma \tau \eta \dot{\mu} \eta v)^{\prime \prime}(27)$, ein Wissen „über Götter, Heroen, Daimonen und den Kosmos, über sämtliche Bewegungen der Sphären und Planeten, über deren Umläufe, Finsternisse und Anomalien, sowie über deren Exzentrizitäten und Epizyklen", mehr noch, es sei ein Wissen „über alles, was es auf der Welt gibt: über Himmel, Erde und all die dazwischenliegenden Naturbereiche, sowohl die offenbaren $(\dot{\varepsilon} \kappa \delta \dot{\eta} \lambda \omega v)$ als auch die verborgenen ( $\dot{\alpha} \pi \circ \kappa \rho v \dot{\phi} \omega v)^{\prime \prime}(31)$. Kurzum, es ist ein Wissen, wie es nur ein göttlicher Dämon im Gefolge der olympischen Götter besitzen kann, dessen Aufgabe es ist, aus dem Reich der Götter „der sterblichen Natur den rettenden Funken der Philosophie zu schenken ( $\left.\varepsilon^{\prime} v \alpha v \sigma \mu \alpha \chi \alpha \rho i \sigma \eta \tau \alpha \iota \tau \tilde{\eta} \theta v \eta \tau \tilde{\eta} \phi \hat{v} \sigma \varepsilon \iota\right)^{\prime \prime}$ (30). Dieses Wissen des Pythagoras umfasst mit dem Kosmos zugleich, so resümiert David du Toit, "die ganze Palette rationaler Erkenntnis und wissenschaftlicher Aktivitäten der Griechen": ${ }^{71}$,zu lernende Wissensbestände $(\mu \alpha \theta \eta \mu \alpha \tau \alpha)$ ", "Anschauung $(\theta \varepsilon \omega \rho \dot{\alpha} \alpha)^{\text {" }}$ und "alles Wißbare ( $\tau \dot{\alpha} \dot{\varepsilon} \pi \iota \sigma \tau \eta \mu о \nu \iota \kappa \dot{\alpha} \tau \dot{\alpha} v \tau \alpha)^{\prime \prime}$, was der Seele Augen verleiht und die Vernunft von der Verblendung durch andere Beschäftigungen reinigt, so dass sie die wirklichen Prinzipien und Urgründe des Alls zu "durchdringen $(\kappa \alpha \tau \iota \delta \varepsilon \tilde{v} v)$ " vermag (31). Nicht zuletzt sind darunter einzuübende Epistemai wie Musik, Heilkunst (insbes. Diätetik) und Mantik (163-164), in denen propositionales und praktisches Wissen besonders eng miteinander verwoben sind.

Jamblichs Schrift führte zu einer Umprägung des Neuplatonismus, die sich auf seine Rezeption sowohl innerhalb der griechischen Philosophie als auch in Ju-

71 du Toit: Heilsbringer im Vergleich (Anm. 62), S. 287. 
dentum, Christentum und Islam auswirkte: ${ }^{72}$ Indem der Text eine Fülle von Versatzstücken aus der Überlieferung zum Wissen des Pythagoras und der Pythagoreer in das philosophische Erziehungsprogramm des Autors integrierte, ${ }^{73}$ vollzog er die schon lange angebahnte Gleichsetzung von Platonismus und Pythagoreismus. ${ }^{74}$ Eine maßgebliche Wendung gegenüber Plotin und Porphyrios

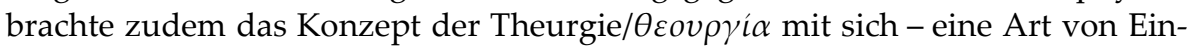
wirkung auf die höheren Mächte, durch die sich der Mensch mittels symbolischritueller Handlungen göttlichem Einfluss öffnet und die Rettung seiner weltverhafteten Seele bewirken kann. ${ }^{75}$ Diese Innovation in Form der Verbindung von Philosophie und religiöser Praxis, u.a. eine Reaktion auf die christliche Betonung des Wunderwirkens des heiligen Mannes, wurde für den spätantiken Neuplatonismus repräsentativ und verstärkte seine Rivalität mit dem Christentum.

Auf besonders eindrückliche Weise prägt das Konzept der Theurgie die oben erwähnte, dem Jamblich zugewiesene Schrift De mysteriis von der Wende des 3. zum 4. Jahrhundert v. Chr., die eine methodische Unterscheidung von Philosophie, Theologie und Theurgie (I 2 p.7,2-6) vornimmt und von profunder Kenntnis spätägyptischer Religion zeugt. ${ }^{76}$ Unter dem ägyptisierenden Pseudonym Abamon ägyptische Verwurzelung suggerierend, äußert sich der Autor darin zu der Möglichkeit der Kontaktaufnahme mit dem göttlichen Bereich. Er reagiert damit auf eine kritische Anfrage des Porphyrios, der seinerseits selbst auf ein theurgisches Lehrwerk, das unter dem Namen des Anebo, eines ägyptischen Hierogrammateus, lief, reagiert zu haben scheint. In seiner Antwort auf Porphyrios' Fragen bezeichnet sich Jamblich bzw. der Textautor als Lehrer des Anebo und tritt unter Berufung auf chaldäische und ägyptische Wissensbestände für die „wahre“ Theurgie ein. Dabei verortet er sich selbst im Kontext des

72 Vgl. hierzu z.B. Platonismus im Orient und Okzident. Neuplatonische Denkstrukturen im Judentum, Christentum und Islam. Hrsg. von Raif Georges Khoury und Jens Halfwassen. Heidelberg 2005.

73 Vgl. hierzu z.B. Lurje: Die Vita Pythagorica als Manifest der neuplatonischen Paideia (Anm. 63); Staab: Pythagoras in der Spätantike (Anm. 11).

74 Vgl. hierzu z.B. Charles Kahn: Pythagoras and the Pythagoreans (Anm. 13).

75 Vgl. hierzu Ilinca Tanaseanu-Döbler: Theurgy in Late Antiquity: The Invention of a Ritual Tradition. Göttingen 2013.

76 Der Text trug ursprünglich den Titel Vom Meister Abammon, Antwort auf den Brief des Porphyrios an Anebo und Auflösung der darin befindlichen Fragestellungen; erst Renaissanceausgaben haben ihn Über die Geheimlehren der Ägypter, Assyrer ... (kurz De mysteriis) betitelt. Siehe zur Thematik z.B. Beate Nasemann: Theurgie und Philosophie in Jamblichs De mysteriis. Stuttgart 1991; Thomas Stäcker: Die Stellung der Theurgie in der Lehre Jamblichs. Frankfurt a.M. 1995: Andrew Smith: Iamblichus' Views on the Relationship of Philosophy to Religion in De mysteriis. In: The Divine Iamblichus. Philosopher and Man of Gods. Hrsg. von Henry J. Blumenthal und E. Gillian Clark. London 1993, S. 74-86; ders.: Iamblichus, the First Philosopher of Religion? In: Habis 31 (2000), S.345-353; Joachim Friedrich Quack: Spuren ägyptischer Opfertheologie bei Jamblich? In: Transformations in Sacrificial Practices. From Antiquity to Modern Times. Hrsg. von Eftychia Stavrianopoulou, Axel Michaels und Claus Ambos. Berlin 2008, S. 241-262. 
traditionellen ägyptischen Tempelkultes und geht ausführlich auf die Opferpraxis und damit verbundene Vorschriften und Zwecke ein.

Jamblich schrieb in einer Zeit, in der sich die Bedeutung von einerseits Magie/ $\mu \alpha \gamma \varepsilon i \alpha$ (bis zur griechischen Klassik integraler Teil der religiösen Tradition)

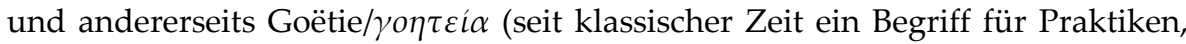
die auf Kontakt mir der Totenwelt basieren) einander angenähert hatten, wobei die Goëtie in noch stärkerem Maße als die Magie zu anrüchiger Nebenbedeutung (im Sinne von Scharlatanerie) kam. ${ }^{77}$ Offiziell aus der religiösen Tradition ausgeschlossen - Agrippa ließ 33 v. Chr. „die Astrologen und die Scharlatane

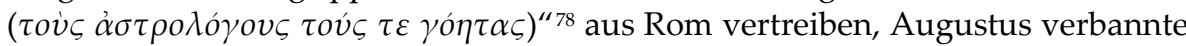
28 den Pythagoricus et magus Anaxilaos von Larissa nicht nur aus Rom, sondern ganz Italien (urbe Italiaque) ${ }^{79}-$, waren Magie und Zauber im römischen Reich, wenn auch durch alle Jahrhunderte weitverbreitet, äußerst negativ besetzt. In der Spätantike setzten sich daher Akteure, die Theurgie als eine Art sakraler Magie praktizierten, vehement von den Goëten ab.

Auch Jamblich grenzte die Theurgie scharf von der Goëtie ab, da diese das Göttliche verfehle und Trugbilder erzeuge. In Über das pythagoreische Leben kommt diese Abgrenzung u.a. in Rekursen auf die volkstümliche Gestalt des Abaris (90-93; 135-136; 140-141; 215-221) zum Ausdruck, einen legendären Reinigungspriester des Gottes Apollon, den zuerst Pindar ${ }^{80}$ und Herodot ${ }^{81}$ erwähnen. Abaris repräsentiert im Text eine Irrationalität, die es zu überwinden gilt. Erzählt wird, wohl unter Rückgriff auf Herakleides Pontikos' Ausgestaltung der Abarislegende, ${ }^{82}$ wie der Hyperboreer zu Pythagoras gekommen, sich diesem als Hörer unterstellt, über den göttlichen Bereich und die Zusammenhänge des Kosmos habe belehren und zum Theurgen umschulen lassen. Pythagoras' Belehrungen darüber, wie alles vom Walten des Himmels abhänge und sich eben dies an der Wirksamkeit von Opfern zeige, führen Abaris zu dem Schluss, Pythagoras sei nicht etwa ein "Zauberschwindler $(\gamma o ́ \eta \tau \alpha)$ ", weil er solches lehre, sondern über die Maßen bewundernswert, „als sei er ein Gott ( $\omega \varsigma$ äv $\theta \varepsilon o ́ v)^{\prime \prime}$ (216). Magi-

77 Vgl. Fritz Graf: Gottesnähe und Schadenzauber. Die Magie in der griechisch-römischen

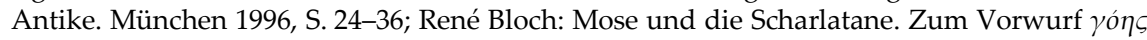

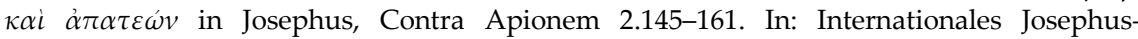
Kolloquium Brüssel 1998. Hrsg. von Jürgen U. Kalms und Folker Siegert. Münster 1999, S. 142-157.

78 Cassius Dio: Historiae Romanae 49,43,5. Zit. aus: Dio's Roman History, Bd. 5. Hrsg. von Earnest Cary nach der Version von Herbert Baldwin Foster. London, Cambridge (Mass.) 1955, S. 428-429.

79 Eusebios: Hieronymi Chronicon ad annum 28 a. Chr. Zit. aus: Eusebius: Werke, Bd. 7: Die Chronik des Hieronymus. Hrsg. von Rudolf Helm. Mit einer Vorbemerkung von Ursula Treu. Berlin ${ }^{3} 1984$, S. 163-164.

80 Siehe Pindar: Frg. 270. In: Pindari carmina cum fragmentis. Hrsg. von Henricus Maehler. Leipzig ${ }^{4} 1975$.

81 Siehe Herodot: Historiae 4,36.

82 Ähnlich wie Porphyrios: De vita Pythagorae 28-29; Jamblich: De vita Pythagorica 90-93. 
sches Handeln wird auf diese Weise in die Philosophie zurückgeholt, mit epistemischen Geltungsansprüchen verbunden und Pythagoras vor dem Vorwurf der Zauberei, mit der er wiederholt, z.B. in den Sillen des Timon von Phleius, in Verbindung gebracht wurde, in Schutz genommen. ${ }^{83}$

\section{Pythagoras Arabicus: Wissenstransfer in die arabisch-islamische Welt}

Jamblichs Pythagoras-Stilisierung schrieb sich dem Neuplatonismus unverbrüchlich ein. ${ }^{84}$ Wir wissen, dass der Autor z.B. auf Syrian in Athen, dem noch Jamblichs Pythagoreismus-Kompendium in allen Büchern vorlag, und damit auf dessen Schüler und engen Freund Proklos, der sein Nachfolger als Scholarch der neuplatonischen Philosophenschule in Athen wurde, maßgeblichen Einfluss ausübte. Auch ist bekannt, dass Schriften Jamblichs - über Werke wie die von Dionysios Areopagita sowie byzantinische Autoren wie Michael Psellos und schließlich über Marsilio Ficinos Übersetzungen - einen wirkungsreichen Transfer in den Westen Europas erfuhren. Einen maßgeblichen Beitrag zu Pythagoras' Eingang ins lateinische Mittelalter leistete-neben Autoren wie Ovid, Justin, Hieronymus, Augustinus und Cassiodor ${ }^{85}$ - der im Neuplatonismus geschulte Boethius. Er widmete den vier, von ihm mit dem Terminus quadruvium belegten, mathematischen Disziplinen Arithmetik, Geometrie, Musik und Astronomie je ein eigenes Lehrwerk und betonte ihre Notwendigkeit für die Vollendung in der Philosophie. ${ }^{86}$ Eine weitere wichtige Schaltstelle ins lateinische Mittelalter bilden Isidors Etymologiae, die viele Jahrhunderte lang Studenten als StandardNachschlagewerk diente, mit den ersten drei Büchern über die artes liberales. Auch sie betonen Pythagoras' breite Bildung und würdigen ihn als Begründer der ars musica und der numeri disciplina, sowie für die Schweigepraxis und als Erfinder des Buchstabens Y und des Namens "Philosophie“" ${ }^{87}$

Es war die so eindrücklich dargestellte Gelehrtheit, die dem Pythagoras in der Zeit des Mittelalters nicht nur im christlichen, sondern auch im arabischislamischen Raum große Bekanntheit einbrachte. Zwar erfuhr Pythagoras von

83 Vgl. hierzu auch Staab: Pythagoras in der Spätantike (Anm. 11), S. 411-418. - Siehe auch

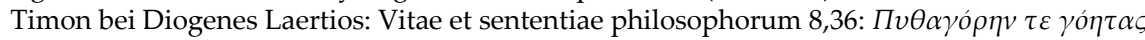

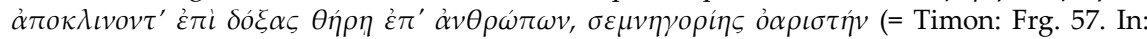
Timone di Fliunte: Silli. Hrsg. von Massimo Di Marco. Rom 1989). Übers. von Laura Gemelli Marciano: Die Vorsokratiker, S. 113 (Anm. 14): „Und Pythagoras, der der Zauberei zuneigt, um Menschen zu jagen, vertraut mit feierlichen Reden."

84 Vgl. hierzu z.B. Dominic O'Meara: Pythagoras Revived: Mathematics and Philosophy in Late Antiquity. Oxford 1989.

85 Siehe Ovid: Metamorphoseon libri 15, 40-478; Justin: Epitome 20,4; Hieronymus: Epistula adversus Rufinum 39-40 und Adversus Iovinianum 1,42; Augustinus: De civitate dei 8,2; 8,4; 18;37; Cassiodor: Institutiones 2,4,1;2,5,1-2.

86 Siehe Boethius: De arithmetica 1,1.

87 Isidor von Sevilla: Originum seu etymologiarum libri 1,3,7; 3,2,1; 3,16,1; 8,6,2-3; 14,6,31. Zit. aus: Isidori Hispalensis episcopi etymologiarum sive originum. Hrsg. von Wallace Martin Lindsay. Oxford 1957 (o. arab. S.zahlen). 
christlicher Seite Kritik insbesondere wegen des mit kirchlichen Doktrinen unvereinbaren Seelenwanderungstheorems, das zugunsten der Lehre von der Auferstehung des ganzen Menschen abgelehnt wurde ${ }^{88}$ (Ausnahmen bildeten u.a. die Katharer und der spätbyzantinische Philosoph Plethon $\left.{ }^{89}\right)$. Es ist aber zu beobachten, dass ihm, bei aller christlichen Kritik an paganen Lehren, durchaus Achtung zuteil wurde, etwa bei Clemens von Alexandria ${ }^{90}$ oder Hippolyt von Rom. Letzterer bezog sich ausführlich auf Pythagoras in der oben erwähnten Refutatio omnium haeresium, einer Kampfschrift insbesondere gegen die Gnostiker. Sie geht davon aus, dass "alle Häresien“ eine Verarbeitung und Verfälschung von weitaus älteren und gotteswürdigeren philosophischen Lehren seien; die valentinianische Gnosis z.B. führt der Autor auf Platon, Pythagoras und die Ägypter, von denen beide ihr Wissen erhalten hätten, zurück. ${ }^{91}$ Das erste Buch wurde bald aus dem Gesamtkorpus herausgelöst und diente möglicherweise als Lehrbuch der Philosophie; die doxographisch ausgerichtete Darstellungsweise Hippolyts trug dazu bei, dass er zu einer Quelle der Araber wurde.

Dass Pythagoras - unter dem Namen Fītāgàuras, oder Fūtāgūuras (selten Būtāā gūras oder andere Transliterationen) im arabisch-islamischen Kulturgebiet Bekanntheit genoss, überrascht nicht. ${ }^{92}$ Arabische Intellektuelle des Mittelalters bezogen große Teile ihres Wissens aus Doxographien und Gnomologien, die Lebensbeschreibungen und Anekdoten, Ansichten und Äußerungen antiker Philosophen enthielten, und Pythagoras spielte in ihnen in der Regel eine prominente Rolle. ${ }^{93}$ Teils handelte es sich um ursprünglich auf Griechisch verfasste

88 Vgl. Wolfgang Maaz: Metempsychotica mediaevalia. Pictagoras redivivus. In: PsychēSeele - anima. Festschrift für Karin Alt. Hrsg. von Jens Holzhausen. Stuttgart, Leipzig 1998, S. 385-416.

89 Vgl. hierzu Helmut Zander: Geschichte der Seelenwanderung in Europa. Alternative religiöse Traditionen von der Antike bis heute. Darmstadt 1999, S. 200-233.

90 Z.B. in Stromateis 1,14,61-65; 1,15,66-70; 4,23,151.

91 Hippolyt beginnt seine Darstellung im ersten Buch mit einer Übersicht über die Lehrmeinungen der griechischen Philosophen, dann folgten in zwei Büchern (leider verlorene) Darstellungen der griechischen Mysterien sowie, in einem weiteren Buch (Anfang verloren), von Astrologie, Astronomie und Magie. Hieran schließt, ab Buch 5, die eigentliche Widerlegung an, u.a. von den Gnostikern, Valentinus, Basilides und Markion (Bücher 5-7) sowie den Doketen, Montanisten und Quartodezimanern (Buch 8). Ziel ist es zu zeigen, dass die Häretiker nicht Christi Lehre folgen, sondern den paganen Anschauungen, die sie plagiierten. Das letzte Buch enthält eine Epitome der vorgetragenen Lehrmeinungen (10,9-29), denen der Autor seine eigene - wahre - christliche Überzeugung $(10,30-34)$ gegenüberstellt.

$92 \mathrm{Zu}$ Pythagoras im arabisch-islamischen Raum siehe z.B. auch Franz Rosenthal: Some Pythagorean Documents Transmitted in Arabic. In: Orientalia, N.S. 10 (1941), S. 105-115, 383-395; ders.: Fīthāghūras. In: Encyclopaedia of Islam, Second Edition, Bd. 2: C-G. Hrsg. von Bernhard Lewis u.a. Leiden 1965, S. 929-930; Gotthard Strohmaier: Pythagoras in Islam. In: The Oxford Encyclopedia of Philosophy, Science, and Technology in Islam, Bd. 2. Hrsg. von Ibrahim Kalin u.a. Oxford 2014, S. 148-152.

93 Vgl. hierzu z.B. Dimitri Gutas: Greek Wisdom Literature in Arabic Translation: a Study of the Graeco-Arabic Gnomologia. New Haven 1975; Gotthard Strohmaier: Ethical Sentences and Anecdotes of Greek Philosophers in Arabic Tradition. In: Von Demokrit bis Dante. Die 
Werke (so [Pseudo-Plutarchs] Placita Philosophorum wahrscheinlich von Aetius, die in der Übersetzung des bekannten Qustạ ibn Lūqā vorlagen, ${ }^{94}$ und die neuplatonisch inspirierte Doxographie des Pseudo-Ammonios, die u.a. auf Hippolyts Refutatio fußte ${ }^{95}$ ), teils um doxographische und gnomologische Sammlungen, die auf Arabisch verfasst waren (wie z.B. von al-Mubaššir ibn Fātik und Ibn Abī Ușaibi'a). Übersetzer wie Ibn Mațar, Ḥunain ibn Isḥāq und Qustāa ibn Lūqā bewirkten im 9. und 10. Jahrhundert eine umfängliche Adaption griechischen Bildungsgutes im Reich der Kalifen. ${ }^{96}$ Sie brachten zahlreiche Werke aus dem Griechischen ins Arabische; daneben wurden etliche Schriften von Arabern selbst über griechische Philosophie verfasst, so auch zu Pythagoras und pythagoreischen Lehrinhalten. Wer sich hierüber informieren wollte, konnte dies folglich mit Hilfe von zahlreichen Werken tun. Sie enthielten Angaben zu Pythagoras' Leben, seinen Anhängern und der pythagoreischen Lehre, u.a. in Form von Zusammenfassungen, wie sie aus der einflussreichen Philosophiegeschichte des Porphyrios bekannt waren. ${ }^{97}$ Arabischsprachige Gelehrte des Mittelalters kannten den namhaften Gelehrten, der sie durch seine außergewöhnliche Bildung beeindruckte, als Furfūriyūs; etliche seiner Werke - u.a. die Isagoge, AristotelesKommentare und der Brief an Anebo - lagen in, zum Teil stark umgestaltender, Übersetzung vor, so auch die Pythagorasvita. ${ }^{98}$

Die Wertschätzung, die Pythagoras in der arabisch-islamischen Welt wider den Mainstream des aristotelischen Rationalismus erfuhr, war maßgeblich seiner

Bewahrung antiken Erbes in der arabischen Kultur. Hrsg. von Gotthard Strohmaier. Hildesheim u.a. 1996, S. 44-52.

94 Vgl. hierzu Hans Daiber: Aetius Arabus: die Vorsokratiker in arabischer Überlieferung. Wiesbaden 1980.

95 Vgl. hierzu Ulrich Rudolph: Die Doxographie des Pseudo-Ammonios: ein Beitrag zur neuplatonischen Überlieferung im Islam. Stuttgart 1989.

96 Vgl. hierzu z.B. Moritz Steinschneider: Die arabischen Übersetzungen aus dem Griechischen (11897). Graz ${ }^{2} 1960$.

97 Vgl. hierzu Richard Walzer: Porphyry and the Arabic Tradition. In: Entretiens sur l'antiquité classique 12 (1966): Porphyre, S. 275-297, hier S. 282-283; Hans Daiber: Hellenistischkaiserzeitliche Doxographie und philosophischer Synkretismus in islamischer Zeit. In: Aufstieg und Niedergang der römischen Welt II,36,7 (1994), S. 4974-4992, hier S. 4978 mit Anm. 25; Emily Cottrell: Notes sur quelques-uns des témoignages médiévaux relatifs à

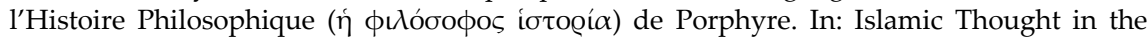
Middle Ages. Studies in Text, Transmission and Translation, in Honour of Hans Daiber. Hrsg. von Anna Akasoy und Wim Raven. Leiden u.a. 2008, S. 523-555 (mit detaillierten Ausführungen zu den doxographischen Pythagoras-Zeugnissen).

98 Die Pythagorasvita in arabischer Sprache weist gegenüber der Darstellung in der Philosophiegeschichte des Porphyrios etliche Umstellungen, Hinzufügungen und Auslassungen auf. Vgl. zum Thema Franz Rosenthal: Arabische Nachrichten über Zenon den Eleaten. In: Orientalia, N.S. 6 (1937), S. 21-67, hier S. 43-56 (deutsche Übersetzung der auf Porphyrios zurückgehenden arabischen Pythagorasvita); Richard Walzer: Porphyry and the Arabic Tradition (Anm. 97); Porfirio: Vita di Pitagora. Testo greco e arabo a fronte. Hrsg. von Angelo Raffaele Sodano und Giuseppe Girgenti. Mailand 1998; Staab: Pythagoras in der Spätantike (Anm. 11), S. 117-121. 
neuplatonisch-neupythagoreischen Stilisierung geschuldet. Er wurde als weiser Philosoph, Beispiel ethischer Autorität und Träger renommierten Wissens angesehen, der nach Reisen in den Orient die Musiktheorie begründet sowie Arithmetik, Geometrie und metaphysische Lehrinhalte unter den Griechen verbreitet habe. ${ }^{99}$ Das enzyklopädische Kitāb al-Fihrist („Index; Katalog“) des Ibn an-Nadīm, ein Buchhändlerkatalog, in dem der Verfasser alle ihm bekannten arabischsprachigen Bücher auflistete, zeigt, dass es zahlreiche Bücher gab, in denen es um Pythagoras ging. Diskutiert wurde z.B. die Frage, ob und inwiefern er die Philosophie begründet habe, ${ }^{100}$ und es gab unter seinem Namen ein Kitāb alQur'a über Divination. ${ }^{101}$ In Harrān, das aus spätantiken syrischen Quellen als multiethnisches Zentrum des Paganismus bekannt ist, verehrten ihn die Sabier im Rahmen ihres altbabylonischen, mit neuplatonischer Theologie und Hermetismus amalgamierten Gestirnkults, u.a. neben Hermes, als Propheten. ${ }^{102}$ Unter Muslimen wurden seine asketischen Übungen und Regeln als Richtlinien für ein Allāh gefälliges Leben verstanden, ${ }^{103}$ wie die Verbreitung pythagoreischer Texte in arabischer Übersetzung bezeugt, unter ihnen ein Kommentar zum Carmen Aureum, das, nach Aussage seines Autors angeblich auf Jamblich zurückgeht und Anweisungen für die Einübung einer in jeder Hinsicht maßvollen Lebensführung gibt, die u.a. dadurch strukturiert ist, dass abendlich Leistungen und Versäumnisse des Tages bilanziert werden. ${ }^{104}$

In der Figur des Fītāgāuras verschmolzen mithin religiöse und wissenschaftliche Aspekte und Perspektiven, die zwischen Sichtbarkeit und Unsichtbarkeit

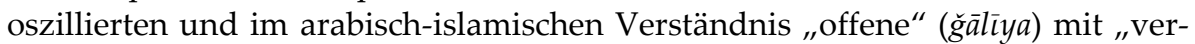
borgenen“ (hăfìya) Wissenschaften verbanden. ${ }^{105}$ Eben dieses amalgame Moment dürfte arabische Autoren, die ein Interesse an Alchemie hatten, dazu angeregt haben, sich (wider den Rat etwa des Maimonides, keine Zeit an „alte Philosophie“ zu verschwenden ${ }^{106}$ ) mit dem Vorsokratiker zu befassen oder ihn zumin-

99 Vgl. hierzu z.B. Rosenthal: Fìthāghūras (Anm. 95); Strohmaier: Pythagoras in Islam (Anm. 92); Anna Izdebska: The Attitudes of Medieval Arabic Intellectuals towards Pythagorean Philosophy: Different Approaches and Ways of Influence, in: Cultures in Motion. Studies in the Medieval and Early Modern Periods. Hrsg. von Adama Iczdebski und Damian Jasiński. Krakau 2014, S. 25-44.

100 Siehe Muhạmmad ibn Ishạa Ibn an-Nadīm: Kitāb al-Fihrist. Hrsg. von Gustav Flügel. Leipzig 1871, S. 245.

101 Siehe Ibn an-Nadìm: Fihrist (Anm. 100), S. 314.

102 Vgl. hierzu: Tamara M. Green: The City of the Moon God. Religious Traditions of Harran. Leiden 1992, S. 182, 216.

103 Vgl. hierzu Rosenthal: Some Pythagorean documents transmitted in Arabic (Anm. 92), S. 105-115, 383-395; ders.: Das Fortleben der Antike im Islam (Anm. 36), S. 165-168.

104 Siehe die Ausgabe Neuplatonische Pythagorica in arabischem Gewande. Der Kommentar des Iamblichus zu den Carmina aurea. Ein verlorener griechischer Text in arabischer Überlieferung. Hrsg. von Hans Daiber. Amsterdam 1995.

105 Zur Unterscheidung vgl. z.B. Manfred Ullmann: Die Natur- und Geheimwissenschaften im Islam. Leiden 1972.

106 So Moses Maimonides unter Bezug auf Empedokles, Pythagoras, Hermes und Porphyrios 
dest als nobilitierende Referenzfigur zu verwenden und durch Bezugnahme auf ihn epistemische Geltungsansprüche zu unterstreichen. Ähnlichkeiten und Berührungspunkte alchemischen Wissens und Wirkens mit Wissensbeständen und Unterweisungsformen, die Fītāgāuras zugeschrieben wurden, legten eine Assoziation seiner Person mit der Alchemie nahe. Zudem ließ sich der Name des berühmten Vorsokratikers zur Steigerung des Ansehens der Alchemie nutzen.

Die Verbindung zwischen Alchemie und Pythagoras herzustellen drängte sich zumal deshalb auf, weil die Alchemie den Umgang mit Apparaturen, die der Vervollkommnung unedler Metalle (meist durch Umwandlung in Gold oder Silber) dienten, mit einer theoretisch-esoterischen Komponente verknüpfte ${ }^{107}$ und auch Pythagoras mit einer solchen assoziiert wurde. Mit dem Pythagorasbild eines „vom Geheimnis umgebenen göttlichen“ Mannes, asketisch lebenden Wundertäters und Mathematikers ${ }^{108}$ hatte sich zum einen die Reisetopik durchgesetzt, der zufolge er große Teile seiner Kenntnisse Wissensträgern in Ägypten und Vorderasien, insbesondere Priestern, verdankt habe. Zum anderen herrschte die Vorstellung, er habe seine Unterweisungen an initiationsartige Vorbereitungen und einzuübende Lebensvorschriften gebunden und zur Vermittlung seiner Lehre eine besondere soziale Organisationsform gewählt (ob sie als enger religiöser Bund mit Geheimlehre und Tabus ${ }^{109}$ oder als lockerer Zusammenschluss Einzelner ${ }^{110} \mathrm{zu}$ denken ist, wird kontrovers diskutiert). Die Vermittlungsweise der Alchemie ließ sich mit dieser legendenumrankten Sozialform leicht in Verbindung bringen. Wurden doch Lehren der Alchemie in der Regel im engen Kreis von Schülern weitergegeben und in sprachlich verschlüsselter Form.

Die These, dass Pythagoras eine "esoterische“ Vermittlungsstruktur von den Ägyptern übernommen und adaptiert habe, klingt zuerst explizit im Pythagoraskapitel des ersten Buchs der Refutatio Hippolyts an, das als Spezifikum dieser Adaption die Schweigeübung nennt: Hippolyt überliefert, der Samier habe „die Zahlen und die Maße bei den Ägyptern ( $\tau$ ov̀ $\varsigma \dot{\varepsilon} \dot{\alpha} \rho \iota \theta \mu o \dot{\varsigma} \kappa \alpha i \tau \dot{\alpha} \mu \dot{\varepsilon} \tau \rho \alpha \pi \alpha \rho^{\prime}$ Ai $\gamma v \pi \tau i \omega v)^{\prime \prime}$ "gelernt $(\mu \alpha \theta \varepsilon \tilde{\imath} v)^{\prime \prime}$; und er habe, "tief beeindruckt von der gut begründeten, phantasiereichen und schwer enthüllbaren Weisheit der ägyptischen

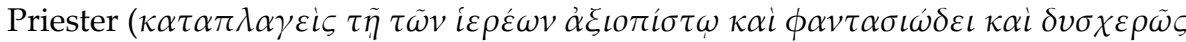

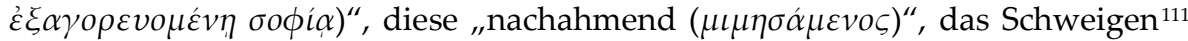

in einem Brief an seinen Übersetzer Samuel ibn Tibbon; siehe Moritz Steinschneider: Die hebräischen Übersetzungen des Mittelalters und die Juden als Dolmetscher. (Nachdr.) Graz 1956, S. 42.

107 Zur Frage, ob und wie das Konzept der Erlösung der Materie und das der Läuterung und Vervollkommnung der Seele des Alchemisten ineinanderspielten, siehe (für die Antike) z.B.: André-Jean Festugière: La révélation d'Hermès Trismégiste. Paris 1944-1954 (4 Bde.), Bd. 1: L'astrologie et les sciences occultes, S. 260-274; Garth Fowden: The Egyptian Hermes. A Historical Approach to the Late Pagan Mind. Cambridge 1986, S. 116-125.

108 Lurje: Die Vita Pythagorica als Manifest der neuplatonischen Paideia (Anm. 63), S. 252.

109 Vgl. z.B. Burkert: Lore and Science in Ancient Pythagoreanism (Anm. 21), S. 112-192.

110 Vgl. z.B. Zhmud: Wissenschaft, Philosophie und Religion (Anm. 54), S. 75-91.

111 In Kapitel 2 der ersten Buchs der Refutatio heißt es auch, Pythagoras habe seine Schüler in 
eingeführt und seine Schüler dazu angehalten, in unterirdischen Räumen „ein zurückgezogenes Leben zu führen $(\eta \rho \varepsilon \mu \varepsilon \tilde{\varepsilon} v)^{\prime \prime} .{ }^{112}$ Des Weiteren berichtet Hippolyt, Pythagoras habe zwei Klassen von Schülern gehabt: die „Esoteriker ( $\dot{\varepsilon} \sigma \omega \tau \varepsilon$ $\rho \iota \kappa o v \varsigma)$ “ bzw. "Pythagoreer" und die „Exoteriker ( $\dot{\xi} \xi \omega \tau \rho \iota \kappa o v \varsigma)$ “ bzw. Pythagoristen; ersteren habe er die „vollkommeneren Wissensgebiete $(\tau \varepsilon \lambda \varepsilon \omega \tau \varepsilon \rho \alpha \mu \alpha \theta \dot{\eta}$ $\mu \alpha \tau \alpha)^{\prime \prime}$ zugetraut, letzteren die "gewöhnlicheren $(\mu \varepsilon \tau \rho \iota \omega \tau \varepsilon \rho \alpha)^{\prime \prime} .{ }^{113}$

Es war mithin Ägypten, welches in der Vorstellung derjenigen, die Alchemie und Pythagoras zusammendachten, das entscheidende verbindende Glied bildete: Hier, in jenem Kulturraum, der den Griechen als Ursprung und Modell aller Geheimreligion galt und in den sie Teile ihrer Mysterien und platonisierenden ,Mystik' hineinzuprojizieren pflegten, ${ }^{114}$ hatte - traditionsgängig gewordener Reisetopik nach-der Vorsokratiker im Feld und Umfeld von Tempelkulten gewichtige Anteile seines Wissen erworben. Hier verortet schon Zosimos im griechischen Corpus der Alchemie ihre Ursprünge und verbindet sie mit alter ägyptischer Weisheit. ${ }^{115}$ Und hier setzte sich, vermutlich in Tempelwerkstätten, bei der hellenistisch gebildeten Priesterschaft, die Alchemie tatsächlich durch. ${ }^{116}$

einer ersten Unterweisungsphase angewiesen, aus Ehrfurcht vor der Weltordnung und da sie zur Welt gekommen seien, um sich in die Geheimnisse des Alls einweihen zu lassen, Stillschweigen zu üben, und habe ihnen erst dann wieder zu reden gestattet, wenn sie genügend Wissen über die Gestirne und die Natur erworben hätten (Hippolyt: Refutatio omnium haeresium 1,2,18).

112 Hippolyt: Refutatio omnium haeresium 1,2,18. Zit. aus: Hippolytus: Refutatio omnium haeresium. Hrsg. von Miroslav Marcovich. Berlin, New York 1986, S. 61-62.

113 Hippolyt: Refutatio omnium haeresium 1,2,4-5. Zit. aus: Hippolytus: Refutatio omnium haeresium (Anm. 115), S. 58. Hippolyt nimmt damit auf die Unterscheidung von „Akusmatikern" und "Mathematikern" Bezug, die explizit terminologisch zuerst bei Clemens von Alexandria belegt ist: Stromata 5,59,1. Sie besagt, dass letztere vor allem auf Mathemata, also wissenschaftlich, ausgerichtet waren, während sich erstere primär an religiösphilosophischen Lehren in Form mündlicher Unterweisung durch Pythagoras orientierten, der ihnen offenbar als unfehlbare Ipse-dixit-Autorität im Sinne des „Er selbst [Pythagoras] hat es gesagt" erschien. Die "Akousmata“, "das Gehörte“, die Pythagoras zugewiesen wurden, enthielten u.a. Lebensregeln und Sprüche mit einem tieferen verborgenen Sinn.

114 Vgl. hierzu Jan Assmann: Ägypten und der Ursprung der Esoterik. Zur Geschichte und Genese eines Mythos. In: Constructing Tradition. Means and Myths of Transmission in Western Esotericism. Hrsg. von Andreas B. Kilcher. Leiden u.a. 2010, S. 373-393.

115 Festugière: La révélation d'Hermès Trismégiste (Anm. 107), Bd. 1, S. 363-368.

116 Aus dem 2. und 3. Jahrhundert n. Chr., also der griechisch-römischen Zeit Ägyptens, datieren eine Reihe alchemischer Schriften, die unter den Namen Hermes, Thoth, Agathodaimon, Kleopatra, Moses, Solomon, Maria, Jesus, Demokrit (oder Demokrates), Zarathustra, Astanes u.a. verbreitet wurden - Texte, deren Inhalte zu Beginn des 4. Jahrhunderts im Werk des griechischen Alchemisten Zosimos aus Panopolis (= Akhıīm) verbunden wurden, der, in Oberägypten geboren, in Alexandria lehrte. Ausführungen hierzu finden sich z.B. bei Edmund O. von Lippmann: Entstehung und Ausbreitung der Alchemie, Bd. 1. Berlin 1919; Arthur John Hopkins: Alchemy, Child of Greek Philosophy. New York 1934; F. Sherwood Taylor: The Origins of Greek Alchemy. In: Ambix 1 (1937), S. 3047; Jack Lindsay: A Survey of Greek Alchemy. In: Journal of Hellenic Studies 50 (1930), 
Kurzum, mag die Alchemie auch erst viele Jahrhunderte nach Pythagoras entstanden sein, galt doch als Raum, in dem sie gedieh, derselbe Raum, von dem es hieß, dass dort einstmals der Samier (nach Jamblich 22 Jahre lang) geweilt habe, und in dem griechische Autoren wie Bolos von Mendes (mit Arbeiten über die okkulten Eigenschaften und Kräfte in der organischen Natur und Sympathien und Antipathien zwischen Menschen, Tieren, Pflanzen, Steinen und Metallen) ${ }^{117}$ wirkten, die wichtige Anstöße für die Entstehung der Alchemie gaben.

Vor diesem Hintergrund verwundert es nicht, dass Pythagoras mehr als einmal zum Träger alchemischen Wissens gemacht wurde und hierbei für epistemische Lehrinhalte stand (wie z.B. den Aufbau der Stoffe aus Materie und Form, ihre Zusammensetzung aus den vier Elementen Erde, Wasser, Luft und Feuer und die Möglichkeit der Umwandlung der Materie ineinander), die aus der griechischen Philosophie in die Alchemie übernommen wurden. Der berühmte Abū Bakr Muhammad ibn Zakarīyā' ar Rāz̄̄, latinisiert als Rhazes bekannt, hielt Pythagoras (wie auch Demokrit, Platon und Aristoteles) für einen, der sich auf die Kunst verstand. Aț-Ṭugrā' $\overline{1}$ zitiert mehrfach ein Kitāb fì $l-A$ 'dād at-țabì '̌ya („Die natürlichen Zahlen“) alchemistischen Inhalts, das von Pythagoras stamme, und das Gāair-Korpus enthielt ein Werk mit dem Titel Musaḥhahāt Fìt $\underline{a} \bar{g} \dot{g} \bar{u} r a s$ („Berichtigungen des Pythagoras“). ${ }^{118}$ Im Fihrist ist der Name des Pythagoras unter Namen von Philosophen aufgelistet, die sich mit der Alchemie

S. 109-139; ders.: The Origins of Alchemy in Graeco-Roman Egypt. London 1970. Die alchemischen Schriften sind schlecht erhalten und verderbt bis entstellt überliefert; die Collection des anciens alchimistes grecs. Hrsg. von Marcellin Berthelot in Zusammenarbeit mit Charles E. Ruelle. Paris 1887-1888 (3 Bde.) gilt als unzuverlässig, ein Editionsprojekt zu einem Teil der griechischen Handschriften wurde von Michèle Mertens begonnen.

117 Siehe Bolos von Mendes: Frg. DK 68 B 300 und 78. - Bolos' Rolle innerhalb der Alchemie wird seit einiger Zeit diskutiert; dabei überwiegen Zweifel, dass er alchemische Schriften verfasst hat; vgl. hierzu zuletzt Matteo Martelli: The Four Books of Pseudo-Democritus. London 2014, S. 36-48. Eine ausgiebige Diskussion des status quaestionis findet sich auch bei Patricia Gaillard-Seux: Un pseudo-Démocrite énigmatique: Bolos de Mendès. In: Transmettre les savoirs dans les mondes hellénistique et romain. Hrsg. von Frédéric Le Blay. Rennes 2009, S. 223-243.

118 Siehe hierzu Paul Kraus: Jābir Ibn Ḥayyān. Contribution à l'histoire des idées scientifiques dans l'Islam (1942-43). (Nachdr.) Hildesheim 1988, Bd. 1: Le corpus des écrits Jābiriens, S. 45; Bd. 2: Jābir et la science grecque, S. 94; weitere Erwähnungen finden sich auch bei Manfred Ullmann: Die Natur- und Geheimwissenschaften im Islam. Leiden 1972, S. 152153. Bei Kraus (S. 292-302) sind zudem ausführliche Belege für die Popularität des Neupythagoreers Apollonios von Tyana zusammengestellt, der, im arabisch-islamischen Raum u.a. als Bālīnās oder Balīnūs bekannt, als șāhib aṭ-țilasmāt, "Herr der Talismane“, galt und in der arabischen okkultistischen Literatur einen wichtigen Stellenwert als Meister der Alchemie und Verfasser, Entdecker, Empfänger, Übermittler und Übersetzer okkulter Schriften hatte. Die bekannteste und umfangreichste unter seinem Namen verbreitete Schrift war das Kitāb Sirr al-ḩalīqa, „Buch über das Geheimnis der Schöpfung“, eine umfassende naturphilosophische Erklärung der Beschaffenheit des Universums. Siehe hierzu auch Ursula Weisser: Das Buch über das Geheimnis der Schöpfung von PseudoApollonios von Tyana. Berlin 1980, S. 1-8, 22-41. 
auseinandergesetzt hätten; und im Verzeichnis alchemischer Büchertitel ebendort findet sich, neben z.B. Schriften des Hermes, an 16. Stelle Das Buch des Pythagoras und an 43. Stelle des Titelverzeichnisses Das große Buch des Pythagoras, das von den Ansichten in der Kunst handelt aufgeführt. Es ist angenommen worden, dass dieses im Fihrist erwähnte Große Buch des Pythagoras ein Vorläufer der Turba Philosophorum, eines der bedeutendsten lateinischen Texte der Alchemie, sei oder diese selbst bezeichne. ${ }^{119}$ Die Turba, um die es im Folgenden geht, wurde wohl um 900 (möglicherweise von einem Autor aus Ägypten) verfasst und allerspätestes im 13. Jahrhundert aus dem Arabischen übersetzt; unter den Arabern war sie als Werk des Aršilāwus al-Fītāàgūrì („des Pythagoräers Archelaos“) bekannt. Im Arabischen sind nur Fragmente erhalten sowie Exzerpte, Anklänge und andere Hinweise in verschiedenen Testimonien; das Original mit eventuell dem Titel Muṣhaf al-ğamā'a (,Kodex der Gruppe“, ,Buch der Gemeinschaft" o.ä.) gilt als verloren. Eine vollständige Fassung liegt infolge von Übersetzung ins Lateinische vor. ${ }^{120}$

Die Turba ist ein besonders faszinierendes Zeugnis der komplexen Bewegungen und Transferprozesse von Wissen im Mittelmeerraum. Sie gehört nicht nur zu den ältesten alchemischen Texten in lateinischer Sprache, die in der Geschichte der Alchemie im europäischen Kulturraum einflussreich waren, sondern ist auch das älteste datierbare arabische Testimonium, das griechische Alchemie in kosmologischer Fundierung als islamische Wissenschaft für den Buchmarkt fruchtbar zu machen sucht. In dem Text laufen theologische und philosophische Vorstellungen und Ansichten insbesondere paganer griechischer, aber auch jüdischer, christlicher und islamischer Provenienz ineinander, die sich u.a. in doxographisch ausgerichteten Texten nachweisen lassen. Vieles ist, wie die For-

119 Zum Fihrist siehe auch Johann W. Fück: The Arabic literature on alchemy according to An-Nadīm (A.D. 987). A Translation of the Tenth Discourse of the Book of the Catalogue (Al-Fihrist) with Introduction and Commentary. In: Ambix 4 (1951), S. 81-144 (nachgedr. in ders.: Arabische Kultur und Islam im Mittelalter. Ausgewählte Schriften, hrsg. von Manfred Fleischhammer. Weimar 1981, S. 31-92).

120 Ausführlicher hierzu: Julius Ruska: Turba philosophorum. Ein Beitrag zur Geschichte der Alchemie. Berlin 1931 (kritische Edition der lateinischen Übersetzung eines nur teilweise erhaltenen arabischen Turba-Originals nach alten Drucken und einigen Handschriften); Martin Plessner: The Place of the Turba Philosophorum in the Development of Alchemy. In: Isis 45 (1954), S. 331-338; ders.: Vorsokratische Philosophie und griechische Alchemie in arabisch-lateinischer Überlieferung. Studien über Text, Herkunft und Charakter der Turba Philosophorum. Wiesbaden 1975; Ulrich Rudolph: Christliche Theologie und vorsokratische Lehren in der turba philosophorum. In: Oriens 32 (1990), S. 97-123. Knapp zusammenfassend z.B.: Manfred Ullmann: Die Natur- und Geheimwissenschaften im Islam (Anm. 118), S. 213-215; Joachim Telle: Turba Philosophorum. In: Verfasserlexikon - Die deutsche Literatur des Mittelalters, Bd. 9: Slecht, Reinbold - Ulrich von Liechtenstein. Berlin und New York 1995, Sp. 1151-1157. - Der lateinische Text der Turba mit deutschen Übersetzungen wird hinfort aus der Ausgabe Ruskas zitiert (unter Angabe der "Sermones“). Meine Darstellung des Inhalts stützt sich weitgehend auf die Ergebnisse Plessners und Rudolphs. 
schung herausgefunden hat, griechisch vorgebildet, nicht nur der Rahmen: Es finden sich Anleihen aus Vorsokratik, Alchemie und Patristik, vornehmlich aus der Hippolyt zugeschriebenen Refutatio, die dem Turba-Autor als Sammlung kosmologischer und theologischer Sätze gedient hat. ${ }^{121}$ Als historisches Vorbild der Versammlung, als deren Protokoll sich der Text gibt, sind, neben den kirchlichen Synoden die philosophischen Dialoge der Antike sowie die gelehrten Disputationen des Mittelalters ausgemacht worden. Der islamische Anstrich durch Einstreuung von Koranzitaten hatte vermutlich den Zweck, die grundsätzliche Übereinstimmung der Alchemie mit der offenbarten Religion des Islam zu untermauern und so auch den Absatz des Buches zu fördern.

Das in dem Text präsentierte Wissen wird in der literarischen Darstellungsform eines Versammlungsberichtes dem Pythagoras und anderen antiken Wissensautoritäten, griechischen Philosophen und Alchemisten, dialogisch in den Mund gelegt. Teils halten sie Reden, teils antworten sie auf Fragen der übrigen Gesprächsteilnehmer. Darstellungsziel ist es, alchemistisches mit kosmologischem Wissen in dem Sinne in Einklang zu bringen, dass die Welt des Schöpfers Allāh aus einer einheitlichen Natur besteht und alle Kreaturen der oberen und unteren Welt aus den vier von Allāh geschaffenen Elementen Wasser, Erde, Feuer und Luft zusammengesetzt sind. Zu diesem Zweck wird zunächst (Sermones 1-9) kosmologisches Wissen, dann, in einem sehr viel umfangreicheren Teil (Sermones 9-72), alchemistisches Wissen ausgestellt, das die Ausführungen des kürzeren Teils detailreich untermauert und ergänzt. Querbeziehungen zwischen den beiden Debattenteilen verweisen auf ihren inneren Zusammenhang und die Einheit von Kosmologie und Alchemie. Den Nachweis der Einheit führt der Text performativ, indem er nicht etwa Lehren von Philosophen des ersten Teils in Parallele zu Lehren bekannter Alchemisten setzt, sondern den Philosophen als Theoretikern der Alchemie das Wort erteilt. Ihre (infolge mehrfacher Transkription teilweise stark entstellten) Namen sind Anaximander, Anaximenes, Anaxagoras, Empedokles, Archelaos, Leukippos, Ekphantos, Pythagoras und Xenophanes. ${ }^{122}$ Schriftführer ist Archelaos (Arisleus, Umschrift von arab.

121 Auf vorsokratische Philosophie wird bereits bei den griechischen Alchemisten referiert, etwa in den alchemischen Schriften, die Olympiodor zugeschrieben werden; dort finden sich doxographische Darstellungen antiker Vorsokratiker, deren Positionen explizit mit solchen der frühesten griechischen Alchemisten verglichen werden. Pythagoras wird bei Olympiodor nicht erwähnt. Vgl. hierzu Cristina Viano: Olympiodore l'Alchimiste et les présocratiques: une doxographie de l'unité (De arte sacra, § 18-27). In: Alchimie. Art, histoire et mythes. Actes du 1er Colloque international de la Société d'étude de l'histoire de l'alchimie. Hrsg. von Didier Kahn und Sylvain Matton. Paris u.a. 1995, S. 95-136.

122 Die obige Identifikation der Namen durch Plessner weicht in drei Fällen von der durch Ruska ab: Er korrigiert Eximedrus zu Anaximenes, Anaximenes zu Xenophanes und Locustor zu Ekphantos: 1. Eximedrus $=$ Anaximander; 2 . Eximedrus $=$ Anaximenes, 3 . Anaxagoras, 4 . Pandolfus $=$ Empedokles, 5 . Arisleus $=$ Archelaos, 6 . Lucas $=$ Leukippos, 7 . Locustor $=$ Ekphantos $($ nach Ruska: Bacoscus $=$ Paxamos), 8. Pythagoras, 9. Eximenus $=$ Xenophanes. 
Aršilāwus; gemeint ist der Schüler des Anaxagoras), weshalb er im Arabischen als Autor figuriert.

Den Vorsitz der Versammlung führt Pythagoras - als Hauptredner und, wie es in der Einführung heißt, besonderer "Schüler aus der Schülerschaft des Hermes Trismegistos (discipulus ex discipulis Hermetis gratia triplicis)“", seit dessen Wirken (post Hermetem) niemand ein so großes „Geschenk Gottes und der Weisheit (donum Dei et sapientiae)" besessen habe wie er. In der Versammlung selbst breitet er seine Kenntnisse über die vier Elemente aqua, terra, ignis, aër sowie daran gebundene „[in ihnen verborgene] Geheimnisse und Wissenschaften (arcanis et scientiis, quae [in]sunt)" (Sermo 8) eingehend aus. Pythagoras nimmt einen Deus ante omnia, einen ursprünglich allein existierenden Gott an, der die Elemente auf einmal und vor den Geschöpfen geschaffen habe. Die Geschöpfe selbst will er, abhängig von der Zahl der bei ihrer Erschaffung verwendeten Elemente, in einer Stufenfolge verstanden wissen: Die Engel bestünden aus nur einem Element (dem Feuer), Himmel und Sterne seien aus zwei Elementen (der Himmel: aus Wasser und Luft; Sonne, Mond und Sterne: aus Feuer und Luft) geschaffen, Pflanzen und Tiere aus drei und nur der Mensch - „unser Vater Adam und seine Kinder (pater noster Adam et filii eius)" aus allen vier Elementen. Unsterblich seien allein die Engel, da nur das, was "Gott aus einer einzigen Substanz geschaffen hat (ex una creavit Deus essentia)", nicht sterbe; alle übrigen Geschöpfe seien sterblich - sei doch "die Definition des Todes (mortis... definitio)" "die Scheidung des Zusammengesetzten (compositi disiunctio)". ${ }^{123}$ Die Rede wird beschlossen durch den Wunsch der Versammelten, Gott möge Pythagoras beim jüngsten Gericht belohnen. Das darauf folgende Angebot, noch mehr zu den Elementen zu sagen, das Pythagoras auf Archelaos' Drängen hin, es werde "für die Künftigen (futuris)“ nichts Nützlicheres geben als seine „Definitionen der Elemente (definitionibus elementorum)", macht, schlägt die Versammlung (mit dem Vorschlag, entsprechende Ergänzungen an geeigneter Stelle später beizubringen), höflich, aber deutlich aus.

Es ist ein markanter Zug des Textes, dass Pythagoras' Autorität in der Versammlung nicht unhinterfragt ist. Mag sein Sermo im ersten Teil auch den meisten Raum einnehmen, und mag er selbst anfänglich als Haupt der einzelnen Debatten erscheinen, macht doch der Verlauf der einzelnen Vorträge und Aussprachen deutlich, dass ihm eine solche Zuerkennung nicht durchgängig zuteil wird. Die Versammelten sprechen zwar über ihn und mit ihm in Ehrerbietung, erweisen ihm als "Meister (magister)“ der Kunst Respekt und beziehen sich in ihren Argumentationen auf ihn und seine Arbeiten, etwa auf ein wichtiges Buch der Alchemie, das von ihm stamme (Sermo 55). Doch er erfährt auch Wider-

123 Ulrich Rudolph: Christliche Theologie (Anm. 120), S. 112-114, hat gezeigt, dass Vorlage der ersten zwei Drittel von Sermo 8 die Skizzierung der „wahren“ christlichen Lehre im zehnten Buch der Refutatio Hippolyts ist. Es wurden zwei größere Partien aus dieser herausgelöst und, unter Anpassung an die Erfordernisse der dialogischen Form, umgestaltet. 
spruch, wird als neidisch hingestellt, und die vielen Fragen, die er als Zweifel und Gegnerschaft deutet, verärgern ihn: "Ihr habt gezweifelt (dubitastis)", „ihr alle mit euren Meinungen (omnes opiniones habentes)", ", und seid dazu gekommen, mir zu widersprechen (et adversarii facti estis)"; wenn ihr die Elemente „wahrheitsgemäß (veraciter)“ wüsstet, „würdet ihr dies nicht in Abrede stellen (haec non negaretis)".

Dieser Befund ist bemerkenswert, da die Einleitung Pythagoras, den „Meister der Weisen und Haupt der Seher (sapientum magister <et> vatum caput)", als Vorsitzenden einführt, in dessen Auftrag die Versammlung durch seinen Schüler Archelaos einberufen wurde: Er habe veranlasst, die zahlreichen Vertreter der Alchemie, die in allen Ländern zerstreut leben, $\mathrm{zu}$ „versammeln (congregare)“, um mit ihnen die Richtlinien der Kunst „für die nachwachsenden Generationen (post se venturis)" festzulegen. Dementsprechend ist er es, der den ersten Rednern das Wort erteilt, der kritisiert und erläutert, tadelt und lobt. So etwa in Sermo 3, worin er den "Söhnen der Lehre (filii doctrinae)", die bislang gesprochen haben, bescheinigt, eine gute Beschreibung „der vier Elemente (harum naturarum quatuor)", "aus denen Gott alles geschaffen hat (e quibus Deus omnia creavit)", gegeben zu haben. Auch an späterer Stelle wird auf diese Position hingewiesen, etwa in Sermo 49, worin Pythagoras auf die Bemerkung hin, dass er über viel Wissen „von den Alten ( $a b$ antiquis)“ verfüge, erklärt, er habe die Versammlung einberufen, damit sie die "Dunkelheiten (tenebras)", "die sich in jenen alten Büchern befinden (quae in illis sunt libris)", beseitige.

Doch der Führungsanspruch, mit dem Pythagoras einleitend vorgestellt wird, wird im Lauf der Versammlung nicht eingelöst, zumindest nicht im herkömmlichen Sinne des antiken Ipse dixit, das nicht von komplexen interpersonellen Aushandlungsprozessen von Wissen, sondern von einseitiger Vermittlung durch die Führungsperson ausgeht. Anders als der griechische Pythagoras, wie ihn Cicero und Autoren vor allem der Kaiserzeit zeichneten, erfährt der arabisch überformte Pythagoras der Turba keineswegs uneingeschränkt Bestätigung als Autorität, sondern eine Depotenzierung. Jener war nach Darstellung paganer Autoren, mythisierend überhöht, umringt von einer eingeschworenen Gemeinschaft, die ihren Meister als übermenschliches Wesen verehrte und so sehr an seine Unfehlbarkeit glaubte, dass bei ihnen das personenbezogene Autoritätsargument „Er selbst hat es gesagt $\left(\alpha \dot{v} \tau \dot{c} \varsigma \varepsilon^{\prime} \phi \alpha\right)$ “ galt. ${ }^{124}$ Der Pythagoras der Turba dagegen wird von den Mitversammelten als einer unter vielen Debattenteilnehmern behandelt, die gemeinsam an einem Wissen teilhaben, das aus Beziehungen zwischen ihnen ebenso hervorgeht wie es sie herstellt. So wird ihm widersprochen und, wenn auch höflich, über gebührliche Länge zu reden untersagt; und nicht er ist es, der die kosmologische in die alchemistische Debatte überführt, sondern sein Nachredner Xenophanes in Sermo 9. Martin Plessner hat diesen Befund dahingehend gedeutet, dass es Xenophanes ist, der ans Ziel ge-

124 Siehe Cicero: De natura deorum 1,10. 
lange, indem er erstens „den koranischen, in seiner Bewußtheit und Aktivität dem Alchemisten vergleichbaren Schöpfergott" einführe, zweitens mit seiner „konsequent monistischen[n] Lehre“ das Fundament der „,alchemistischen Stoffverwandlung" lege und drittens mit dem Nachweis der „Ubiquität der vier Elemente“ maßgeblich die ",allgemeine Naturanschauung“ der Alchemie stabilisiere, wie sie ihren Ausdruck in der Tabula Smaragdina gefunden hatte. Pythagoras sollte in der Turba, so schließt Plessner, gleichsam wie ein „Ehrenpräsident der Alchemistischen Gesellschaft“ porträtiert werden, „während die wirkliche Leitung in den Händen Jüngerer liegt, die selbständige Gedanken aufbringen wollen". ${ }^{125}$ Diese Schlüsse Plessners, zumal der Verweis darauf, dass Sermo 9 den vorangehenden Darstellungen gegenüber in besonderer Weise die koranische Schöpfungsvorstellung zur Geltung bringt, ${ }^{126}$ legen die Annahme nahe, dass wir es in der Turba mit einer strategischen Depotenzierung der paganen Überhöhung des Vorsokratikers zu tun haben.

\section{Ausblick in die Frühe Neuzeit und Schlusswort}

Es ist hier nicht der Ort, Plessners Thesen detailliert zu prüfen; deutlich ist, dass sich die Turba dem Pythagoras als einem Traditionalisten gegenüber ambivalent zeigt, ihn aber als bedeutenden Wissensträger grundsätzlich anerkennt. Auch tat die Turba der Popularität des Pythagoras, der im arabisch-islamischen Raum gegenüber dem aristotelischen Mainstream als Projektionsfläche für alternative Ansätze diente, keinen Abbruch. Durch ihre Übersetzung ins Lateinische behauptete sie sich als ein Hauptwerk europäischer Alchemie und genoss - mit Pythagoras als antiker Gestalt, die Wissen aus dem griechischen und dem orientalischen Kulturraum integrierte - noch im Zeitalter des Paracelsus Anerkennung. In Europa war sie bereits um die Mitte des 12. Jahrhunderts verbreitet. Sie wurde von einflussreichen Gestalten wie Alanus ab Insulis, Albertus Magnus und dem Grafen Bernhard von Tarvis geschätzt. Als erste Druckausgabe erschien sie in Auriferae artis, quam chemiam vocant, antiquissimi authores, sive Turba philosophorum im Jahre 1572. Die erste deutsche Übersetzung stammt von Paul Hildenbrandt, der sie 1597 in Frankfurt bei Nicolaus Basse veröffentlichte. ${ }^{127}$

Mit der Geburt der neuzeitlichen Esoterik verfestigte sich die Wahrnehmung des Pythagoras als Integrationsgestalt griechischen und orientalischen Wissens, wobei die antike Reisenarrativik mit Sukzessionsnarrativen in Form personaler Wissensgenealogien verbunden wurde, wie sie schon in der Kaiserzeit aufgetreten waren, als in Verbindung mit Pythagoras' Ägyptenreise die historische Fiktion zu begegnen begann, der zufolge griechische Dichter und Philosophen ihre

125 Plessner: Vorsokratische Philosophie (Anm. 120), S. 90-91, 111.

126 Siehe auch Plessner: Vorsokratische Philosophie (Anm. 120), S. 84-85.

127 Avriferae artis das ist der goldtkunst: die man chemiam nennt uhraelteste authores und anfaenger. oder: turba philosophorum. Frankfurt a.M. 1597. 
Weisheit Mose verdankten. ${ }^{128}$ Maßgeblich in dieser Richtung wirkten Theorien und Spekulationen des Renaissancehumanismus, insbesondere solche, die Topoi der Philosophia perennis aufgriffen. Deren Grundaussage, dass bestimmte philosophische Einsichten über Zeiten und Kulturen hinweg perennieren und gültiger Maßstab wahren Erkenntnisstrebens seien, hatte Theologie und Philosophie von der christlichen Spätantike an geprägt. Eusebios etwa griff in der Praeparatio Evangelica das berühmte, auch bei Clemens von Alexandria ${ }^{129}$ überlieferte Zitat des Pythagoreers Numenios auf: „Was ist Platon anderes als Mose, der attisch spricht?" (fr. 8 des Places), ${ }^{130}$ das auf der Vorstellung basiert, es gebe eine einzige göttliche Weisheit, an der wie Pythagoras auch Propheten alter Zeit, Brahmanen, Juden, Magoi und Ägypter Anteil gehabt hätten. ${ }^{131}$ Sie wurde durch die Jahrhunderte mittels zahlreicher Longue-Durée-Konstruktionen mehr und mehr ausgebaut und erwies sich im Florentiner Neuplatonismus als besonders wirkmächtig. Pagane griechisch-römische, ägyptische und arabische Philosophie und Tradition wurden hier mit Elementen der christlichen und jüdischen Schöpfungs- und Geschichtstheologie in Konstellation gebracht und Pythagoras zusammen mit anderen prominenten Wissensträgern antiker Kulturen in die fiktive Tradition einer universalen Theologie integriert. ${ }^{132}$

Entscheidend vorangetrieben wurde diese Entwicklung u.a. von Marsilio Ficino, der auf der Suche nach der ,alten Weisheit' - dem ,Urwissen' - war und eine Einheit aus theologischen und philosophischen Weltdeutungen anstrebte. ${ }^{133}$ Ficino machte sich vor allem dadurch einen Namen, dass er mit seinen Überset-

128 Siehe z.B. Pseudo-Iustinos: Cohortatio ad Graecos 14,2.

129 Siehe Clemens von Alexandria: Stromata 1,22,150.

130 Eusebios: Praeparatio Evangelica 9,6. Zit. aus: Eusèbe de Césarée: La préparation évangélique. Livres VIII-IX-X. Livres VIII und X hrsg. von Guy Schroeder und Édouard des Places, livre IX von Édouard des Places. Paris 1991, S. 210-211.

131 Siehe Eusebios: Praeparatio Evangelica 9,7.

132 Vgl. hierzu Wilhelm Schmidt-Biggemann: Philosophia perennis. Historische Umrisse abendländischer Spiritualität in Antike, Mittelalter und Fruher Neuzeit. Frankfurt a.M. 1998.

133 Stärker noch als Ficino setzte sich Giovanni Pico della Mirandola, der sich explizit als „Pithagoricus“ bezeichnete (Brief an Marsilio Ficino, o.J. In: Opera omnia. Lugduni 1557, $64 \mathrm{v}$.$) , für die synkretistische Vereinigung philosophischer und religiöser Lehren ver-$ schiedener Zeiten und Kulturkreise des Mittelmeerraums und östlich hiervon ein. In seiner berühmten Rede De hominis dignitate (verfasst 1486, Erstausgabe 1496) bezieht er in dem Bestreben, Wissen und Glauben, Philosophie und Theologie miteinander zu versöhnen, zum Zwecke einer pax philosophica im Zeichen der Einheit der Wahrheit zahlreiche ihm bekannte Bereiche der Philosophie, sowie die Theologie, die Magie und die Kabbala ein, nicht nur die griechisch-römische Antike, sondern auch das geistige Erbe der Chaldäer, Araber und Hebräer. Zur Stützung seiner Ansicht, dass die Philosophie zur glückseligen Anschauung Gottes führe, bezieht er sich auf Mose, Zoroaster, Pythagoras, Platon und Aristoteles, die Delphischen und Chaldäischen Orakel sowie die Kabbala; als erste Quelle der philosophisch-theologischen Weisheit, aus der Pythagoras' Philosophie erwachsen sei, nennt er Orpheus. 
zungen und Kommentaren Platons und des Platonismus, Neuplatonismus und Pythagoreismus, u.a. pythagoreischer Pseudepigrapha, dem lateinischsprachigen Publikum seiner Zeit griechische Texte zugänglich machte. Unter den Werken, die er übersetzte, waren, neben der erwähnten Schrift De mysteriis, auch die Traktate, die das Corpus Hermeticum, nach Renaissanceverständnis eine Paralleloffenbarung zur biblischen Schöpfungsgeschichte, bilden. Als Verfasser dieser Schriften religiös-philosophischen, astrologischen, alchemistischen, magischen und medizinischen Inhalts, die er als eine ägyptische Variante der platonischen Weisheitslehre ansah, galt traditionell der mythische Hermes Trismegistos, der mit Thot, dem ägyptischen Gott der Weisheit und Schreibkunst, gleichgesetzt wurde - eine Identifikation, aufgrund derer die Texte als Zeugnisse uralten Wissens angesehen wurden, das älter als das Offenbarungswissen des Mose sei. ${ }^{134}$ Im Vorwort der Übersetzung (hrsg. 1471) drückt Ficino seine Vorstellung von der uralten Überlieferung außerbiblischer Wahrheit durch Konstruktion einer sechsgliedrigen Kette von prisci theologi aus (Opera, Basel 1576, S. 1836), an deren erster Stelle Hermes Trismegistos als Begründer der prisca theologia, der alten, vorchristlichen Theologie steht. Auf ihn folgen Orpheus und Aglaophemus, dann Pythagoras, Philolaos und Platon; in der Platonica Theologia 17,1 (1482) setzt Ficino an den Anfang dieser Traditionskette Zoroaster. ${ }^{135}$

Ficino ebnete mit seinem Ansatz einer esoterischen Pythagorasrezeption den Weg, die den Kosmos in einem ganzheitlichen, monistischen oder holistischen, Sinn konstruieren. Bis heute wird Pythagoras von Vertretern solcher Weltdeutungen regelmäßig als besondere geistige Autorität im Kosmos - als Träger ,geheimen', ,höheren', ,uranfänglichen' Sonderwissens von mythischer Strahlkraft aufgerufen. Infolge seiner Anciennität wird ihm eine besondere Nähe zum ,eigentlichen', , absoluten' Wissen beigemessen: zur ,ursprünglichen Wahrheit', die sich esoterischem Dafürhalten nach in Formen und Beständen verborgenen bzw. okkulten Wissens manifestiert und $\mathrm{zu}$ der Zugang $\mathrm{zu}$ finden einem besonderen Kreis von Akteuren vorbehalten ist. ${ }^{136}$

134 Vgl. hierzu Paul Oskar Kristeller: Die Philosophie des Marsilio Ficino. Frankfurt a.M. 1972, S. 13. Festugière: La révélation d'Hermès Trismégiste (Anm. 107), Bd. 1, S. 89-308.

135 Vgl. hierzu Claudio Moreschini: Ancora alcune considerazioni su Marsilio Ficino e l'ermetismo. In: Marsilio Ficino: Fonti, testi, fortuna. Hrsg. von Sebastiano Gentile und Stéphane Toussaint. Rom 2006, S. 89-120; hier S. 94-97; Christopher Celenza: Pythagoras in the Renaissance: The Case of Marsilio Ficino. In: Renaissance Quarterly 52 (1999), S. 667-711.

136 Aus der Fülle von Beispielen aus dem großen Bereich alternativer Religion und populärer Spiritualität der Gegenwart, die Pythagoras in esoterisierender Weise funktionalisieren, mögen drei Beispiele genügen: Bhagwan Shree Rajneesh: Philosophia Perennis, Bd. 1: Speaking on the Golden Verses of Pythagoras (1978). Puna 1981 (= Osho, Philosophia Perennis, Bd. 1: Talks on Pythagoras, the Philosopher and Mystic. Mumbai 2009); Alfried Lehner: Die Esoterik der Pythagoreer. Der pythagoreische Orden der Antike. In: Tattva Viveka. Zeitschrift für Wissenschaft, Philosophie \& Spirituelle Kultur 44 (Aug. 2010), S. 17-23; Auszug online: http://www.tattva.de/die-esoterik-der-pythagoreer-3 (01.07.14); 
Pythagoras-Funktionalisierungen dieser Art zeigen auf besonders anschauliche Weise, dass Pythagoras eine Figur von hoher mythischer Qualität ist, die, in ähnlicher Weise, wie von Hans Blumenberg 1979 in seiner wegweisenden Untersuchung Arbeit am Mythos dargelegt, mitsamt ihrer Lehre „immer schon in Rezeption übergegangen" ist. ${ }^{137}$ Beide, Figur und Lehre, sind nur in zahlreichen individuellen und kulturspezifischen Modellierungen und Auffächerungen verfügbar. Einen ursprünglichen ,Einheitsmodus des Pythagoreischen', in dem Pythagoras, sein Wissen, seine Regeln und Übungen fassbar wären, hat es nie gegeben. Dementsprechend ist auch die Transferstruktur des pythagoreischen Könnens und Wissens eine Struktur der Ausdifferenzierung und Heterogenität. Sie bildet ein vielschichtiges, in sich verzweigtes Beispiel dafür, dass vormoderne Wissensformen und -bestände mit einem besonders hohen Auffächerungsgrad durch Transferprozesse gerade dann, wenn erhebliche Umgestaltungen, Erfindungen und Fälschungen im Spiel sind, eine besonders nachhaltige Bedeutungsanreicherung und Einschreibung ins kulturelle Bewusstsein erfahren. Die enorme Beachtung, die Pythagoras, pythagoreischen Lehrinhalten und Übungsanweisungen durch die Jahrhunderte zuteil geworden ist, ihr Sonderstatus, erklärt sich aus dieser Nähe zum Mythos im Sinne Blumenbergs.

Letztlich fassbar ist uns das dem Pythagoras zugeschriebene Wissen - sei es, wie bei Jamblich, asketisch fundiertes Übungswissen mit Anspruch auf Heilsrelevanz, sei es kosmologisch-alchemistisches Wissen, wie es die Turba präsentiert - in seiner Vielfalt und Vielschichtigkeit nur, wenn wir bei seiner Prozeduralität und Relationalität ansetzen; wenn wir es als das anerkennen, was es ist, anstatt ihm, vereinfachend, eine esoterische Wirkungsmacht zuzuschreiben: als ständig sich neu und umbildendes Wissen, das von komplexen Beziehungen abhängt, aus ihnen hervorgeht, in ihnen angesiedelt ist und sie herstellt. Es sind dies Beziehungen in der Triangulation zwischen: erstens Akteuren (Pythagoras, seinen Lehrern und Schülern, späteren (Neu-) Pythagoreern und Außenstehenden), zweitens Wissensbereichen (Seelenlehre und Lebensvorschriften, Kosmologie, Musik und Zahlenlehre, später auch Alchemie und Magie) sowie Medien ihrer Darstellung (Texten, Bildern, Artefakten, Architektur und Ritualen) und drittens sozialen Feldern und kulturellen Zusammenhängen rund ums Mittelmeer. Diese Relationalität lässt sich als prototypische Konfiguration einer komplexen Episteme in Bewegung begreifen, die zahlreiche Formen von Übung, Wissen und Wissenschaft in diachroner und diaspatialer Verflechtung umfasst.

Nicholas Kardaras: How Plato and Pythagoras Can Save Your Life: The Ancient Greek Prescription for Health and Happiness. San Francisco 2011.

137 Hans Blumenberg: Arbeit am Mythos. Frankfurt a.M. 1990, insbes. S. 133 und 294-299.

* Ich danke den Organisatoren und Teilnehmern der Tagung „Magia daemoniaca, magia naturalis, zouber. Schreibweisen von Magie und Alchemie in Mittelalter und Früher Neuzeit" für wertvolle Anregungen und Hinweise. Besonderen Dank schulde ich zudem Regula Forster, Matteo Martelli, Alessandro Stavru und Gotthard Strohmaier, die den Text kommentiert und korrigiert haben. 


\title{
Der vierte Sohn Noahs und die Magie der Künste
}

\author{
Mireille Schnyder, Zürich
}

Die im Mittelalter weit verbreitete und bekannte Geschichte der Erfindung der Künste (artes) durch die Nachkommen Kains und ihrer Überlieferung und Wiederaufnahme durch das Cham-Geschlecht nach der Sintflut ist - wie ich andernorts dargestellt habe - wirkmächtige Folie für die Diskursivierung der Künste. ${ }^{1}$ In dem heilsgeschichtlichen Narrativ stehen dem Gott zugewandten, in einer Segensbeziehung stehenden Abel- und Seth-Geschlecht die Nachkommen Kains und Chams gegenüber als die Erfinder der handwerklich-mechanischen Künste, aber auch der septem artes liberales. Ich habe die These aufgestellt, dass sich in diesem heilsgeschichtlich legitimierten Narrativ die spezifisch christliche KunstIdee im Sinne einer göttlich inspirierten Bild-Kunst (non manu-factum) gegenüber einer immer dämonisch-teuflisch infizierten Täuschungs- und Blendungskunst wirkmächtig etabliert.

In der Geschichte eines vierten Noah-Sohns, der als von Gott inspirierter Weiser in die lateinisch-westliche Tradition tritt, findet sich nun aber scheinbar ein Anti-Narrativ zu der Genealogie der Kains- und Cham-Künste. Gleichzeitig scheint er auch eine Konkurrenzfigur zu Zoroaster zu sein, der gern auch als ,Erfinder der artes' gezeigt wird. ${ }^{2}$ Denn hier wird eine göttliche Herkunft der artes etabliert und diese werden in eine Art Inspirationslehre eingebunden.

Die Idee des vierten Sohnes von Noah stammt ursprünglich aus syrischen Schriften des frühen Christentums und ist über die Rezeption der seit dem 8. Jahrhundert vorliegenden lateinischen Übersetzungen der in Syrien entstandenen Revelationes des Ps.-Methodius in den lateinisch-sprachigen Westen aufgenommen $^{3}$ und über enzyklopädische Werke des 12. und 13. Jahrhunderts

1 Mireille Schnyder: Heidnisches Können in christlicher Kunst. In: Literarische Säkularisierung im Mittelalter. Hrsg. von Susanne Köbele und Bruno Quast. Berlin 2013, S. 159-173. Mireille Schnyder: Die Verfügbarkeit des Teufels und die Kunst. In: Paragrana 21/2 (2012): UnVerfügbarkeit. Hrsg. von Ingrid Kasten. Berlin 2012, S. 47-59.

2 Vgl. dazu Schnyder: Die Verfügbarkeit (Anm. 1), S. 52f. und Anm. 17.

3 Zum Motiv des vierten Sohnes von Noah in frühen syrischen Texten sowie der Textgeschichte der fälschlich dem Heiligen Methodius von Olympus (3./4. Jh.) zugeschrieben Revelationes mit ihren Übersetzungen ins Lateinische und Griechische vgl. Stephen Gero: The Legend of the Fourth Son of Noah. In: The Harvard Theological Review 73 (1980), S. 321330; Ernst Sackur: Sibyllinische Texte und Forschungen. Pseudomethodius, Adso und die tiburtinische Sibylle. Halle a.S. 1898; v.a. aber das Vorwort von Willem J. Aerts in: Die Apokalypse des Pseudo-Methodius. Die ältesten griechischen und lateinischen Übersetzungen. 
verbreitet worden. ${ }^{4}$ So findet sich die Geschichte auch in volkssprachigen Texten wie dem Alexanderroman von Rudolf von Ems. ${ }^{5}$ Dieser, ein Erzähler, der auch produktiver, kreativer und breit interessierter Kompilator ist, folgt in seinem ausführlichen Exkurs zu Jonitus eng der Darstellung in der Historia scholastica des Petrus Comestor, der seinerseits nahe am Text von Ps.-Methodius erzählt. ${ }^{6}$ Wenn ich im Folgenden der Darstellung der Geschichte von Jonitus bei Rudolf von Ems folge, ist dies also auch die Geschichte, wie sie über Petrus Comestor verbreitet wurde und im Wesentlichen bei Ps.-Methodius erzählt wird. Auf die wenigen Abweichungen zu diesem weise ich hin.

\section{Die Geschichte des Jonitus}

Nach der Sintflut, die Noah mit seinen drei Söhnen und deren Frauen überlebte, bebauen sie das Land und prosperieren. Hundert Jahre nach der Sintflut wird Noah ein vierter Sohn geschenkt: Jonitus. ${ }^{7}$ Nach Noahs Tod teilen sich die Söhne die Welt auf, wobei Jonitus, wie von seinem Vater bestimmt, in das Land Êotham (Eoam) im äußersten Osten zieht - bei Methodius ist es auch Heliochoros rsp. die regio solis. ${ }^{8}$ In diesem Land erhält er direkt von Gott so wîsen rât, dass er als erster die Kunst (list) der Astronomie beherrscht (V. 17100ff.). ${ }^{9}$

Nimrod, der Erbauer Babylons, wird zu seinem Schüler, wobei Nimrod gegen die biblische Tradition, gemäß derer er ein Nachkomme von Cham ist, bei Rudolf zum Sohn des Jonitus wird (V. 17117), bei Ps.-Methodius zu einem Nachkommen von Sem. ${ }^{10}$ Er lernt bei Jonitus nicht nur die Astrologie und das

Hrsg. von Willem J. Aerts und Gorgius A. A. Kortekaas. 2 Bde. (Corpus Scriptorum Christianorum Orientalium 569-70, subsidia 97-98). Louvain 1998. Zur Datierung und Forschungsgeschichte vgl. Bernard McGinn: Visions of the End. Apocalyptic Traditions in the Middle Ages. New York 1979, S.70-73. Zur Rezeption des Methodius-Textes vgl. auch Charlotte d'Evelyn: The Middle-English Metrical Version of the Revelations of Methodius. With a Study of the Influence of Methodius in Middle-English Writings. In: Modern Language Association of America 33/2 (1918), S. 135-203, hier S. 187. Zur Tradition dieses vierten Sohns von Noah siehe Suzanne Conklin Akbari: Idols in the East. European Representations of Islam and the Orient 1100-1450. Cornell 2009.

4 Vgl. Francis J. Carmody: Latin Sources of Brunetto Latini's World History. In: Speculum 11/3 (1936), S. 359-370, hier S. 361-362.

5 Rudolf von Ems: Alexander. Ein höfischer Versroman des 13. Jahrhunderts. Hrsg. von Victor Junk. Leipzig 1928/1929 (Nachdruck Darmstadt 1970).

6 Petrus Comestor: Historia Scholastica, liber Genesis, cap. 37, in: PL 198, Sp. 1087D-1088C.

$7 \mathrm{C}$ autem anno de terciam chiliadam natus est Noe filius secundum ipsius similitudinem et vocavit nomen eius Ionitum. CCC vero tempore de trium milium annorum dedit Noe donationes filio suo Ionito et demisit eum in terram Eoam. Ps.-Methodius: Apokalypse (Anm. 3), Rec. 1, Kap. [3], 2 (S. 81). Rudolf von Ems: Alexander (Anm. 5), V. 17085-17091.

8 Ionetus autem, filius Noe, introivit in Eoam usque ad mare, qui vocatur, Hiliu Chora', id est, Regio Solis', in quo solis ortum fit, et habitavit ibidem. Ps.-Methodius: Apokalypse (Anm. 3), Kap. [3], 4 (S. 83).

9 Alle Versangaben im Text beziehen sich auf Rudolf von Ems: Alexander (Anm. 5).

10 Hic Ionitus accipit a Deo donum sapientiae, qui non solum hoc tantum, sed et omnem astronomiae articulum factusque inventor. Ad hunc discendens Nebroth, qui fuit gigans, et eruditus ab eo accipit 
artes-Wissen, sondern auch die Herrschaftsführung. ${ }^{11}$ Und mit seiner Herrschaft beginnt eine Abfolge von vier Weltreichen, wie ihm das Jonitus in einem Brief voraussagt. ${ }^{12}$ Nimrod und seine Nachkommen besiegen denn auch in mehr oder weniger direktem Auftrag von Jonitus das Geschlecht Chams, löschen es fast ganz aus, und Nimrod wird der erste große Weltherrscher (V. 17151-17154). ${ }^{13}$

Ein anderer Nachfahre von Jonitus, Samsab, erobert den dritten Teil Indiens und dringt in Arabien nach Sabaa ein (V. 17189-17197). ${ }^{14}$ Hier aber stellen sich ihm die Ismaeliten entgegen, so dass sich Samsab, dem von seiner Genealogie her das Epitheton wîse gegeben ist, kaum retten kann (V. 17201-17204). Die bis dahin klar installierte Machthierarchie zwischen dem Cham-Geschlecht und den Jonitus-Nachkommen wird hier gestört durch eine Macht, die erklärungsbedürftig ist, da sie sozusagen aus dem mythischen Nichts auftaucht. Es handelt sich, wie Rudolf von Ems dann auch ausführt, um die Nachkommen von Ismael, dem Sohn Abrahams, den dieser mit seiner Dienerin Agar gezeugt hatte. Aus seinem Geschlecht sind dreißig Stämme hervorgegangen, zu denen auch Gog und Magog gehörten. Bis zu der Konfrontation mit Samsab hatten sie zurückgezogen in der Wüste gelebt, überrannten dann aber nach ihrem Sieg alle umgebenden Länder (V. 17238-17244). Damit werden die Angehörigen der minderen Linie der Nachkommen Abrahams, denen die „wahrhaftigen“ Kinder (gewæriu kint, V. 17218) der Linie Isaaks gegenübergestellt werden, zu den die Welt erobernden Feinden, deren Charakterisierung mit allen Ingredienzien des Barbarendiskurses erfolgt, Maßlosigkeit, Unreinheit, Bestialität und eine sich vor allem im Umgang mit der Nahrung zeigende Unzivilisiertheit. ${ }^{15}$

Nach dem Sieg über Samsab, den Jonitus-Nachkommen, wählt sich dieses wilde Volk vier Könige, deren Namengebung das Wüstenvolk wieder in das biblische Narrativ einfügt: Es sind die Namen der von Gideon mit Gottes Hilfe besiegten vier midianitischen Fürsten. ${ }^{16}$

ab illo consiliom, in quibus regnare coepisset. $\mathrm{Hi}<\mathrm{c}>$ autem Nebroth ex filiis discendebat hiroum; qui fuit filius Sem et ipse primus regnavit super terram. Ps.-Methodius: Apokalypse (Anm. 3), Kap. [3], 5 (S. 83).

11 Sackur: Sibyllinische Texte und Forschungen (Anm. 3), S. 64; Ps.-Methodius: Apokalypse (Anm. 3), Kap. [3], 5 (S. 83).

12 Scripsit ergo Ionitus epistolam ad Nebroth ita quia "Regnum filiorum Iaphedi, hic incipiet delere regnum filiorum Cham. Ps.-Methodius: Apokalypse (Anm. 3), Kap. [3], 8 (S. 87).

13 Bei Rudolf wird ein Friedensvertrag zwischen Nimrod und Cham erwähnt, der Jonitus nicht passt, sodass er Nimrod befiehlt, diesen Vertrag aufzulösen, was dann die Kriege provoziert, vgl. Rudolf von Ems: Alexander (Anm. 5), V. 17131-17136.

14 Vgl. Ps.-Methodius: Apokalypse (Anm. 3), Kap. [5], 1-2 (S. 91/93).

15 Diz liut was al gemeine / unmæzec und unreine, / ir leben was unmenschlich, / in vihes wîs sie nerten sich, / ir munt deheine spîse schiet, / dehein dinc man sôt noch briet / wan daz die spîse nôz der man / als er sî möhte komen an. I In was niht ungemeine / noch z ezzenn unreine, / swaz sie vunden, daz was gar / ir spîs und ir lîpnar, / die vogel und die slangen. (V. 17245-17257). Erant autem quasi locustae et incidebant nudo corpore et edebant carnes camellorum conposite in utribus et bibebant sanguinem iumentorum in lacte mixto. Ps.-Methodius: Apokalypse (Anm. 3), Kap. [5], 3 (S. 93).

16 Vgl. Ôreb, Zeb, Zebeê und Salmanâ. Richter 7,25 / 8,21. Die Midianiter sind ihrerseits Ab- 
Nach der vernichtenden Niederlage gegen Gideon, heißt es nun, wuchsen die Überlebenden langsam wieder zu einem großen Volk heran. Als Alexander der Große dann ihr Land eroberte, erkundigte er sich nach ihrer Geschichte und, als er die unreinekeit ihres Tuns und Lassens erfahren hatte, deportierte er sie in den hohen Norden (in Ubera Aquilônis). ${ }^{17}$ Hier schloss er sie - wie schon vorher die zehn Stämme der Juden (V. 17316) - zwischen Bergen ein. Auch da vermehren sie sich wieder kontinuierlich, bis sie am jüngsten Tag dann ausbrechen werden - ein Narrativ, über das das Geschlecht von Ismael, zu dem ja vorhin schon Gog und Magog gezählt wurden, mit dem Antichrist zusammengebracht wird (V. 17276-17318). ${ }^{18}$ Entsprechend ist dieses Ereignis, wie Rudolf hier mit explizitem Bezug auf Methodius sagt, dann Zeichen des kommenden Weltendes.

Diese Schreckensherrschaft wird, wie Methodius von Gott unterrichtet weiß, schließlich durch einen neuen christlichen Herrscher des römischen Reiches beendet. Dieser wird nach seinem Sieg über die Heiden seine Macht dem Kreuz auf Golgatha opfern und seine Krone ans Kreuz hängen (V. 17496-17535). Damit installiert sich das in Babylon durch die Traumdeutung Daniels prophezeite irdische Reich (V. 17539-17546), bevor dann aus dem Stamm Ismaels der Antichrist auftaucht: nâch ir ende in kurzer vrist / wirt geborn der Endekrist / von Ismahêles künne (V. 17557-1759).

Jonitus - bei Methodius als Ebenbild Noahs bezeichnet ${ }^{19}$ - ist also Urvater eines im Osten siedelnden, auserwählten, direkt von Gott inspirierten Geschlechts, dessen Mitglieder das Epitheton wîse tragen. Mächtiger noch als das ChamGeschlecht, werden seine Nachkommen nur von den Ismaeliten besiegt, die so an die Stelle der gottinspirierten Joniten treten und mit ihrer Welteroberung das baldige Weltende anzeigen. Die schon im syrischen Text des 7. Jahrhunderts angelegte Lesart der arabischen Eroberungen als Zeichen des kommenden Weltendes macht den Text in seiner lateinischen Übersetzung für die Zeit der Kreuzzüge interessant und bewirkt dann auch eine starke Rezeption der Revelationes

kömmlinge aus der zweiten Ehe Abrahams mit Ketura. Die Söhne aus dieser Verbindung hat Abraham zu Ismael geschickt. So verbinden sich hier die Abrahamslinien, die ,nicht die wahrhaftigen Kinder' sind. Gleichzeitig sind die Midianiter definiert durch ihre Feindschaft den Israeliten gegenüber (vgl. 1. Mos 25). Ps.-Methodius: Apokalypse (Anm. 3), Kap. [5],6 (S. 97).

17 Rudolf von Ems: Alexander (Anm. 5), V. 17305.

18 War schon die exegetische Ausdeutung des antiken Geschehens mit der Identifikation der eingeschlossenen Völker mit den verlorenen Stämmen der Juden eine in den christlichheilsgeschichtlich geprägten Kulturdiskurs eingreifende Erweiterung des Narrativs, wird hier nun, in offener Parallelisierung der Episoden, die Deutung der mit Gog und Magog in Verbindung gebrachten eingeschlossenen Völker auf die Ismaeliten, die mit den Midianitern gleichgesetzt sind, bezogen.

19 Vgl. Ps.-Methodius: Apokalypse (Anm. 3), Kap. [3],2 (S. 81). Vgl. auch Gero: The Legend of the Fourth Son of Noah (Anm. 3), S. 325. 
des Ps.-Methodius im Kontext der Türkengefahr in der Frühen Neuzeit. ${ }^{20}$ Denn es ist ein prophetisches Narrativ, das sich immer neu aktualisierend überschreiben lässt, so wie der Endkaiser, der seine Krone am Kreuz in Jerusalem aufhängt, immer neu figuriert werden konnte. ${ }^{21}$

\section{Störungen: Falsche Genealogien und legitimierte Gewaltherrschaft}

Mit dem Rückgriff auf den vierten Noah-Sohn werden die die Heilsgeschichte bestimmenden dichotomen Verhältnisse (verflucht - gesegnet) kompliziert. Dieser vierte Sohn von Noah bringt die biblisch begründete Ordnung und Semantik der Weltregionen und Geschlechter durcheinander. So ist es hier nicht mehr das Geschlecht des Cham, des Urvaters allen Übels, das sich durch die Erfindung der artes sowie der Astrologie auszeichnet, sondern dieses Wissen wird, als von Gott gegeben, dem Geschlecht des vierten Sohnes übermittelt. Dabei handelt es sich um ein Arkanwissen, das genauso den Herrschaftsverlauf und die Herrschaftsführung betrifft wie die Sternkunde. Praktisches, technisches Wissen jedoch gehört nicht in diesen Bereich der arkanen Erkenntnis. Denn, wie es bei Ps.-Methodius heißt, Jonitus kann seine Bauten nicht selber errichten, sondern braucht dafür die Nachkommen des Japhet. Seine Stadt, Ionitum (auch Heliopolis), ist von semitischen und japhetitischen Fremdarbeitern (Handwerkern und Ingenieuren) gebaut worden.22 Damit wird das Wissen von Jonitus aus dem Handwerklichen ausgeklammert und in die Abstraktion der arkanen Erkenntnis gestellt.

Dieses gottinspirierte Wissen wird aber nicht von Jonitus selber, sondern über die Figur des Nimrod verbreitet. Dieser, eigentlich zum Cham-Geschlecht gehörig, negativ konnotiert als erster Gewaltherrscher, Erbauer von Babel und Riese, muss für diese Funktion des positiven Wissensträgers entweder zu einem Nachkommen (oft Sohn) des Jonitus (Rudolf von Ems), oder einem Nachkommen von Sem (Ps.-Methodius) gemacht werden. Im Egerton-Manuskript 1894, einer illustrierten Genesis aus dem letzten Drittel des 14. Jahrhunderts, wird das sehr deutlich (vgl. Farbabbildung S. 440).

Die jeweils in vier Bilder eingeteilten Seiten zeigen auf fol. 5a zuerst Nimrod als ersten Gewaltherrscher, Riesen und Feueranbeter. Er wird explizit im Verweis auf Methodius und gegen die Tradition als Enkel von Sem bezeichnet. ${ }^{23}$

20 Vgl. zu den Pamphleten mit Auszügen aus den Revelationes während der Belagerung von Wien 1683: Ps.-Methodius: Apokalypse (Anm. 3), S. 35.

21 Bei Rudolf von Ems ist der Hoffnungsträger der Staufer Friedrich II., in dem MethodiusDruck von Aytinger, dann Sebastian Brant, ist es dann Ende des 15. Jahrhunderts Maximilian I. (vgl. dazu unten).

22 Vgl. Sackur: Sibyllinische Texte und Forschungen (Anm. 3), S. 65.

23 Egerton Ms. fol. 4. Konsultiert nach: Illustrations of the Book of Genesis. Being a complete Reproduction in Facsimile of the Manuscript British Museum, Egerton 1894, with an Introduction by M. R. James. Oxford 1921, S. 15: 27. De Cam le filz Noe vint Nemroth si come dit le mestre / destoirs. Mais Metodie dit sicome mesme le mestre re/herce qe cestui Nemroth vint de hiron 
Darauf sieht man die Nachkommen des Cham-Geschlechts und des JaphetGeschlechts und zuletzt Noah, der Jonitus in den Osten schickt und - in einem Simultanbild damit zusammengeschlossen - Jonitus, der Nimrod sein Wissen vermittelt.

Das hat nicht nur zur Folge, dass das Wissen, in erster Linie die Astrologie, vom Ruch der Sünde befreit, ja sogar mit einer spezifischen Gottesnähe ausgestattet wird, sondern auch, dass der erste Weltherrscher, Nimrod, in ein besseres Licht gerückt wird. Seine Herrschaft ist durch Jonitus legitimiert, folgt einem göttlichen Ordnungsmuster, und er wird zum Sieger über die aufmüpfigen Cham-Nachfolger, die er in die Schranken weist.

Die über Nimrod in die Welt hineinwirkende Macht des durch Wissen ausgezeichneten Geschlechts von Jonitus wird erst durch die Ismaeliten gebrochen, die ihrerseits aus der bisherigen Heils-Logik der Geschlechter herausfallen. Denn sie sind einerseits als Nachkommen Abrahams Teil des Seth-Geschlechts, sind anderseits aber, als Dienerinnen-Kinder und nicht dem ,wahren' Geschlecht Abrahams zugehörig, in einem gefährlichen Graubereich angesiedelt, der in seiner Prosperität einerseits unter Gottes Schutz steht, anderseits aber - von der ,rechten' Linie ausgeschieden - gerade durch diese Prosperität eine heilsgeschichtliche Funktion als Geißel Gottes erhält.

\section{Zentrale Randfigur}

Die Figur dieses über ein arkanes Wissen verfügenden Jonitus, der im Kontext von Endzeit-Prophetien steht und durch Briefe den Sieg der Japhetiten über die Cham-Nachkommen vorhergesagt hat, ist durch unzählige Handschriften der lateinischen Übersetzung der Revelationes verbreitet worden; bekannt sind ca. 220 lateinische Handschriften und unzählige volkssprachige Übersetzungen. ${ }^{24}$ Die Geschichte ist in allen großen enzyklopädischen Werken des 12. Jahrhunderts präsent, wo Jonitus als Erfinder der Astrologie und mit göttlichem Wissen ausgestattet als Bewohner der regio solis, des heliochoros, des äußersten Teils von Indien auftaucht. So auch in dem 1120 fertiggestellten Liber floridus des Lambert von St. Omer. ${ }^{25}$ In der Handschrift aus der Mitte des 12. Jahrhunderts, die in Wolfenbüttel liegt, ist auf der Weltkarte auch das Land von Jonitus verzeichnet: Insula solis, direkt neben dem Paradies (vgl. Farbabbildung S. 441).

Wird im 12. und 13. Jahrhundert die Idee des fernen Lands von Jonitus, das, wie gezeigt, auch in die Kartographie Eingang gefunden hat, ${ }^{26}$ durch die Hoff-

le filz sem. De le quel sem / come dit Alquyn auindrent vint et sept parenties et il oue / les soens occupia Asie la tierce partie du siecle.

24 Vgl.: Ps.-Methodius: Apokalypse (Anm. 3), Einführung.

25 Lambert von Saint-Omer: Liber floridus, Cod. Guelf. 1 Gud. lat., fol. 69v-70r (ca. 1180); Wolfenbüttel Katalog-Nr. 4305. Hier ist Jonitus dann auch als Entdecker der Astronomie unter den ,Erfindern' auf der 1. Seite aufgeführt. Vgl. Akbari: Idols in the East (Anm. 3), S. 86.

26 Vgl. zu dem vierten Erdteil die Tradition der Beatuskarten. In den Beatuskarten von Osma und Ona ist explizit ein „Sonnenland“ eingezeichnet, auch wenn es (zumindest auf der Os- 
nungsfigur des Priester Johannes überlagert, ${ }^{27}$ taucht die Figur von Jonitus interessanterweise in der Frühen Neuzeit im Umfeld der ersten Drucke wieder auf. Das hängt vor allem mit der Rezeption der prophetischen Schrift des Ps.Methodius zusammen, die gerade im Kontext der Türkengefahr neu bedeutsam reflektiert wurde. Anderseits ist Petrus Comestors Historia scholastica immer noch ein gern konsultiertes Werk. Hinter der Schedelschen Weltchronik, in der Jonitus als Erfinder der Astrologie und Prophet sowie Experte in Herrschaftsfragen erscheint, stehen wohl beide Quellen (vgl. Farbabbildung S. 442).

Ionichus der vierdt sun noe ist geporn in dem drittē iar nach der süntfluß. des geschweigt moyses. Diser hat zů erst die kunst des gestirns lauffs erfunden $v \bar{n}$ òttlich künftig ding fürsehen. $v \bar{n}$ da im der vater gab gegeben

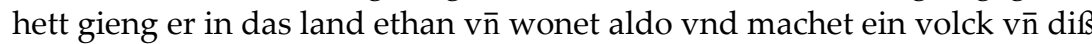
ist die erde (der sunnen erd genant) do hin sich òtlich fürtreffenlich mañ

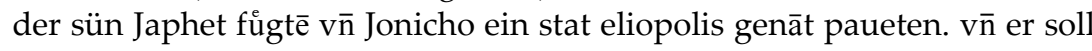

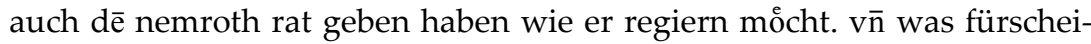
nender sin̄reichigkeit. vnd ein grosser erkenner des gestirns. der den lauff $v \bar{n}$ eigenschafft aller stern erschauet vnd dardurch den vrsprung v $\bar{n}$ auch den vndergang der vier fürnåmlichen reiche vor erken̄et v̄ leret. do er starb ward sein sun cosdron sein nachkommen. ${ }^{28}$

Auch hier ist Jonitus kein Mechaniker, kein Bauherr, kein Architekt, sondern dafür sind die Söhne Japhets zuständig. Er ist eine Figur des Wissens, die das Handeln andern überlässt.

\section{Astrologisches Wissen vs. magische Praktik}

Wie eng das Schicksal des Jonitus über die Revelationes mit der Hoffnung eines Siegs über die Ismaeliten verknüpft ist, wird auch in dem von Sebastian Brant veröffentlichten, neu mit Holzdrucken illustrierten Druck der Revelationes deutlich, 1498 in Basel bei Michael Furter erschienen. ${ }^{29}$

ma-Karte) nicht mit Jonitus in Beziehung gesetzt wird. Zu den Beatuskarten, aber leider nicht zu dem vierten Erdteil darauf, vgl. Ingrid Baumgärtner: Visualisierte Weltenräume. Tradition und Innovation in den Weltkarten der Beatustradition des 10. bis 13. Jahrhunderts. In: Tradition, Innovation, Invention. Fortschrittsverweigerung und Fortschrittsbewusstsein im Mittelalter. Hrsg. von Hans-Joachim Schmidt. Berlin, New York 2005, S. 231-276; Ingrid Baumgärtner: Graphische Gestalt und Signifikanz. Europa in der Weltkarte des Beatus von Liébana und des Ranulf Higden. In: Europa im Weltbild des Mittelalters. Kartographische Konzepte. Hrsg. von Ingrid Baumgärtner und Hartmut Kugler. Berlin 2008, S. 81-134.

$27 \mathrm{Zu}$ der Verbindung der Jonitus- und der Priester Johannes-Figur vgl. Akbari: Idols in the East (Anm. 3), S. 87.

28 Hartmann Schedel, Georg Alt und Hieronymus Münzer: Das buoch Der Croniken unnd geschichten mit figuren vnd pildnussen von Anbeginn der welt biß auff diese onsere Zeÿt. Augsburg, 1496.09.18. Seite 30, URL: http://daten.digitale-sammlungen.de/ db/0009/ bsb00092409/image_30 (05.02.2015).

29 Erstdruck der Ausgabe von Brant in Basel 1498. Brant hat die von Wolfgang Aytinger ver- 
Hier wird nicht nur der Sieg der Nachkommen des Nimrod über die Söhne Chams gezeigt [Abb. 1], sondern auch, wie die aus dem zivilisatorischen Nichts (aus der arabischen Wüste) auftauchenden Ismaeliten das Heer des Jonitus besiegen und die Völker und das gelobte Land erobern [Abb. 2], bevor sie durch Gideon besiegt werden [Abb. 3]. Als die Ismaeliten dann aber ein zweites Mal aus ihrer Wüste herauskommen, erobern sie den ganzen Erdkreis [Abb. 4], wie das Methodius vorhergesagt hat. Bis schließlich diese Macht (hoc est turcos) besiegt wird durch einen König der Japhetiten (Römischen König), der seine Krone in Jerusalem am Kreuz opfert, was als Zeichen des Weltendes gesehen wird und als Erfüllung der Prophezeiung des Methodius. Deutlich wird hier die Aktualisierung der Prophetie auf die Türkengefahr hin. ${ }^{30}$

Jonitus wird hier, als direkt von Gott instruierter Weiser, zur Figur des Astrologen, nach dessen Berechnungen sich die Weltreiche ablösen und dessen Arkanwissen vom Rand der Welt stammt, dessen Wissen ihm aber nicht die Handlungs-Macht über die Völker gibt. In der Ausgabe von 1500 ist interessanterweise an den Anfang, sozusagen als Gegenbild, eine Darstellung der aus dem Geschlecht des Kain stammenden Erfinder der dämonischen Künste, der Magier und teuflischen Astrologen gesetzt [Abb. 5].

Die ganz am Anfang des Methodius-Traktats angelegte Gegenüberstellung von zwei entgegengesetzten Wissens- und Machtdiskursen (göttlich vs. teuflisch) wird über die Bilder in dieser Ausgabe verstärkt. Die Erfinder der schlechten Künste stehen dem göttlich inspirierten Astrologen gegenüber, dessen Wissen den ersten Gewaltherrscher Nimrod legitimiert. Denn dessen Herrschaft ist nicht nur von diesem Wissen getragen, sondern folgt auch einem göttlichen Plan. Jonitus ist so nicht nur der Erfinder der Astrologie, sondern auch der Begründer einer sanktionierten Gewaltherrschaft. Deutlich ist Jonitus aber von der malignen Prognostik, magischen Kunst und Astrologie abgegrenzt.

fasste, mit einer Vorrede und einem Traktat ergänzte Fassung der Revelationes verwendet, die 1496 in Augsburg bei Johann Froschauer gedruckt wurde. Vgl. dazu Walther Ludwig: Eine unbekannte Variante der Varia Carmina Sebastian Brants und die Prophezeiungen des Ps.-Methodius. In: Daphnis 26 (1997), S. 263-299, hier S. 275-282. Zu den Hintergründen und den vielen Paralleldrucken dieser Ausgabe vgl. Sackur: Sibyllinische Texte und Forschungen (Anm. 3), S. 3-5. Die hier verwendete Ausgabe ist: Methodius, Revelationes Divinae, zusammengebunden mit Wolfgang Aytinger: Tractatus super Methodium. Basel bei Michael Furter. 1500. Online-Ausg. Düsseldorf: Universitäts- und Landesbibliothek, 2011, URL: http://digital.ub.uni-duesseldorf.de/ihd/content/titleinfo/3362436 (24.10.2014).

$30 \mathrm{Zu}$ dieser Aktualisierung des Textes auf die Gegenwart und die damaligen politischen Verhältnisse hin vgl. Ludwig: Eine unbekannte Variante (Anm. 29). 


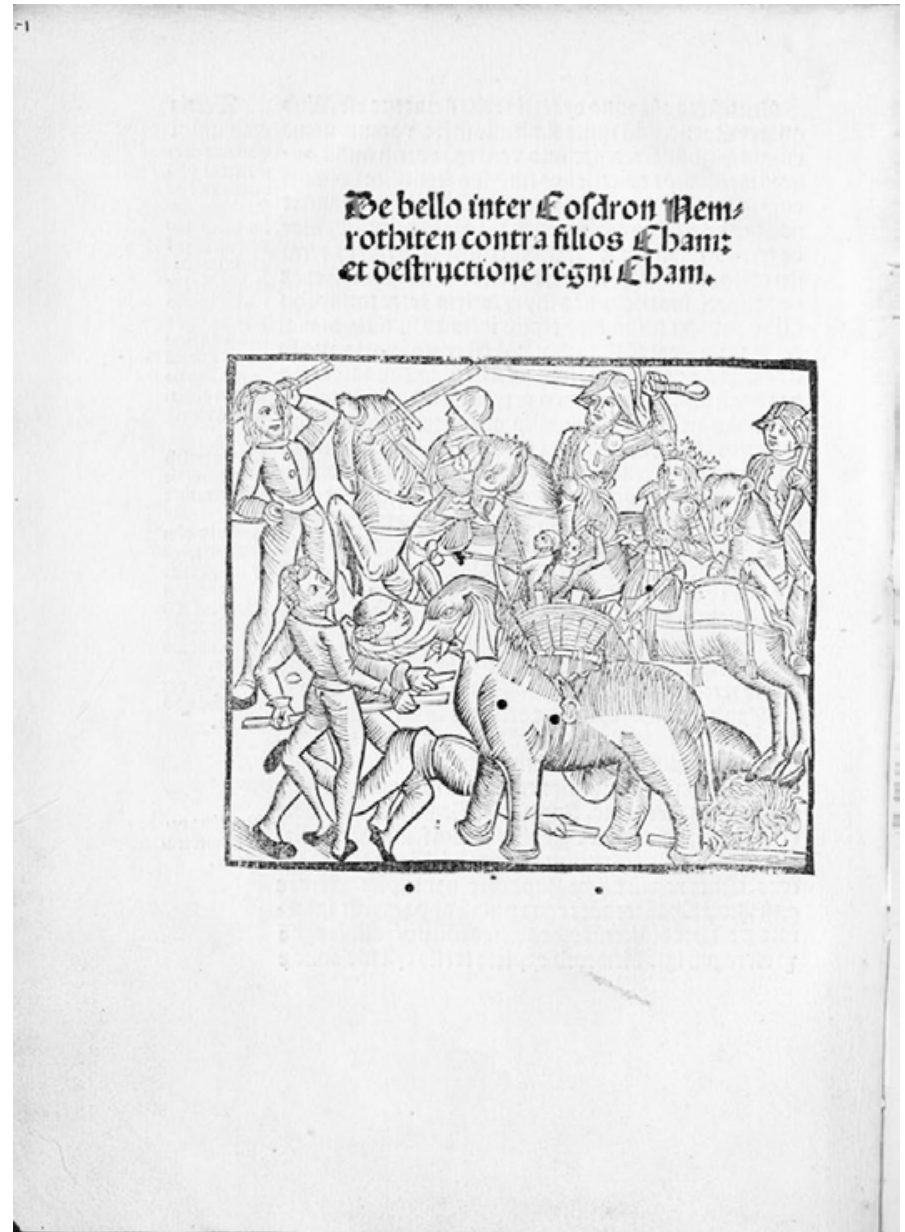

Abb. 1: Sieg der Nachkommen Nemrots über die Cham-Nachkommen. Methodius: Revelationes Divinae (Anm. 29), S. 16, URL: http://digital.ub.uniduesseldorf.de/ihd/content/pageview/3362453 (24.10.2014). 


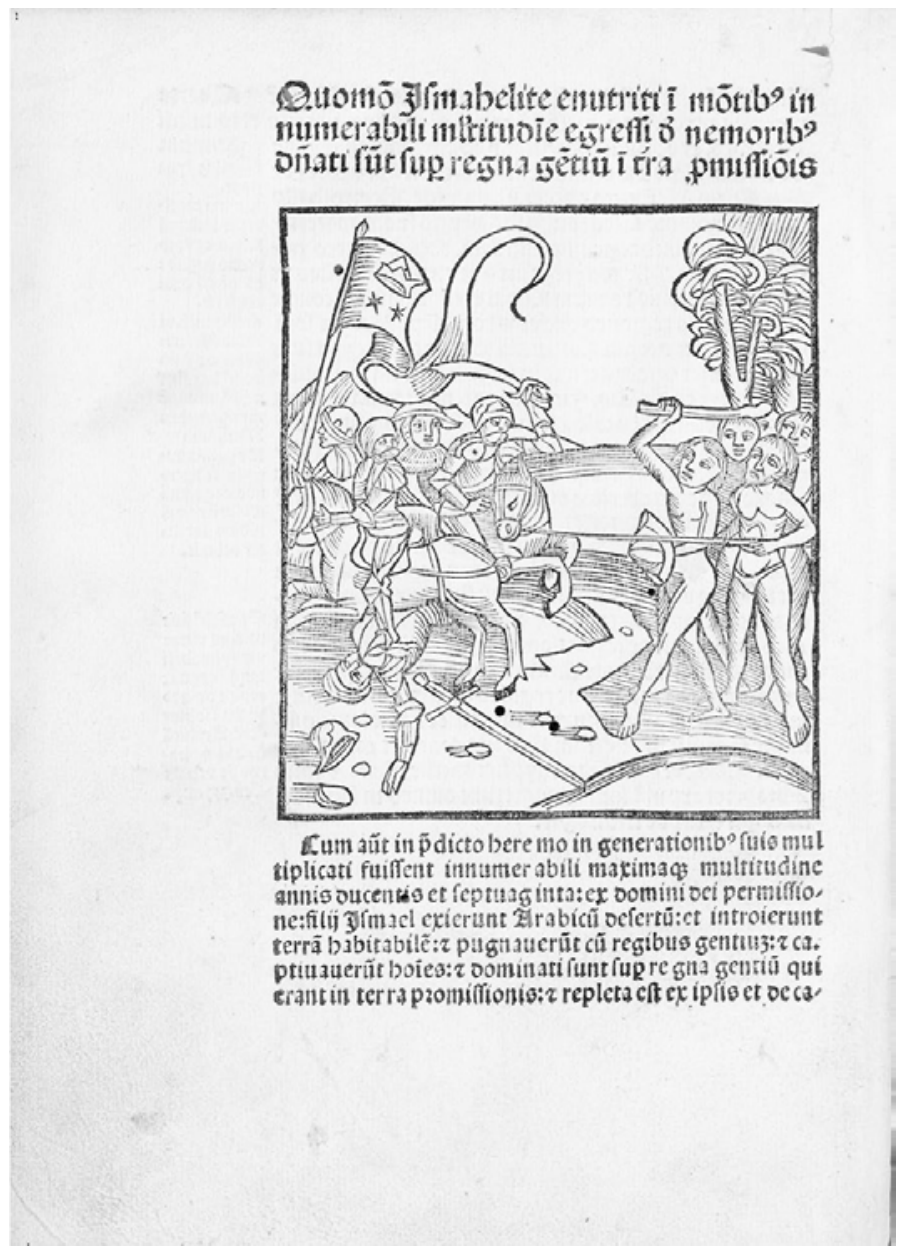

Abb. 2: Der Sieg der Ismaeliten über die Joniten.

Methodius: Revelationes Divinae (Anm. 29), S. 18, URL: http://digital.ub.uniduesseldorf.de/ihd/content/pageview/3362455 (24.10.2014). 


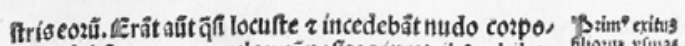

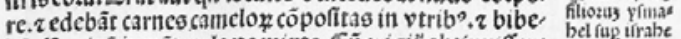

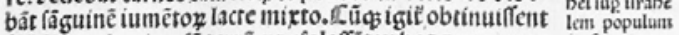

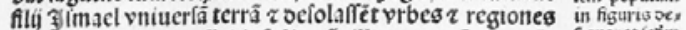

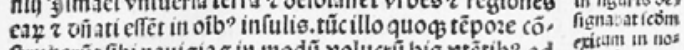

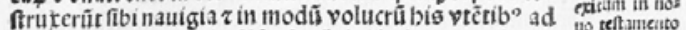

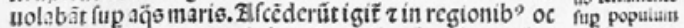

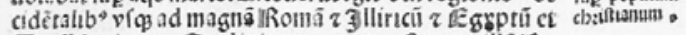

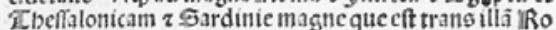
mam.er ooninati funt terre in annis feraginta.et fecerunt in ca quecung; volucrunt

Quó Bedeo foztifim? pugnatoz hberas uert filios if abel oe funtute tfrisbelitaz

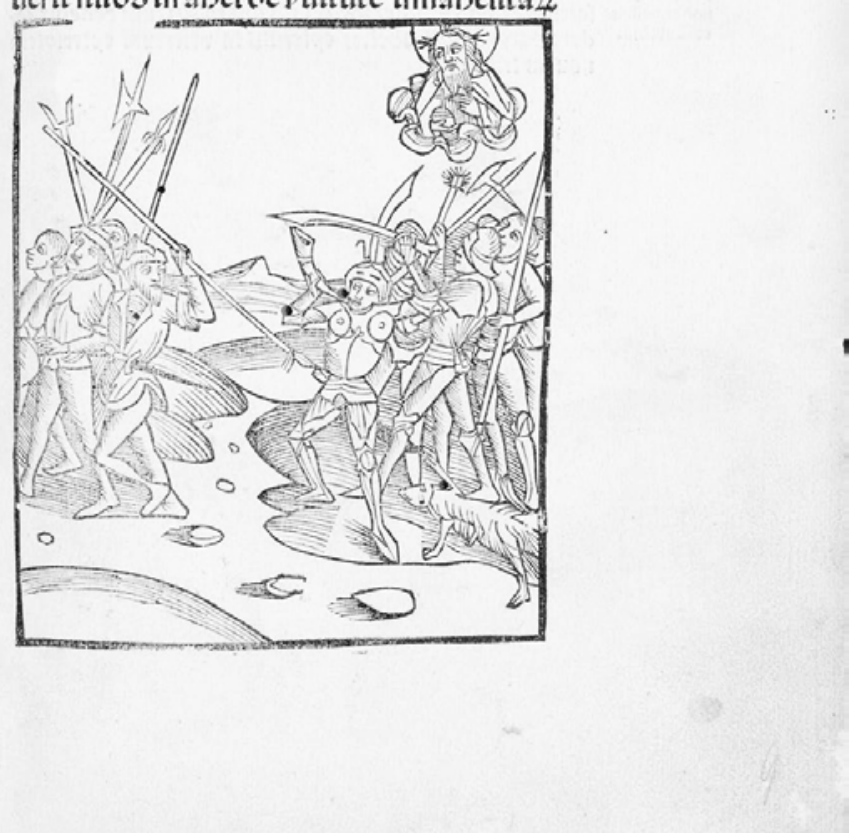

Abb. 3: Sieg Gideons über die Ismaeliten.

Methodius: Revelationes Divinae (Anm. 29), S. 19, URL: http://digital.ub.uniduesseldorf.de/ihd/content/pageview/3362456 (24.10.2014). 


\section{Quontodofili ylimael exetnt be Deferto et obtinent totum osbem}

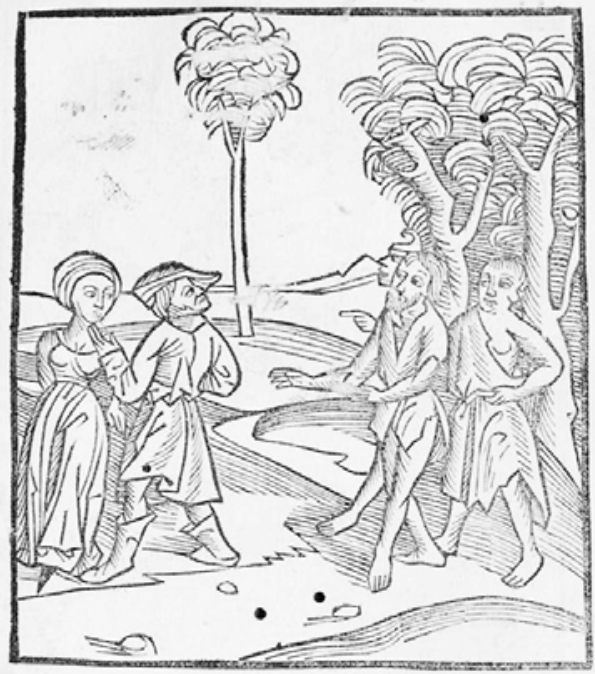

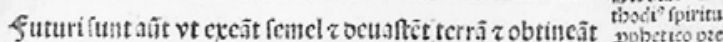

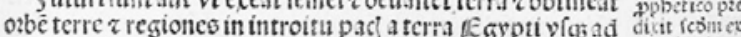

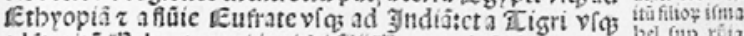

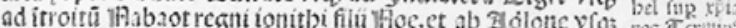

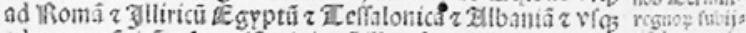

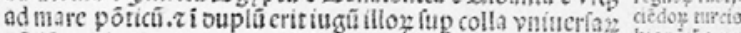

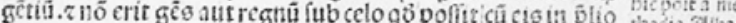

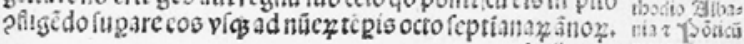
marc,

Abb. 4: Die Eroberung der ganzen Welt durch die Isameliten. Methodius: Revelationes Divinae (Anm. 29), S. 21, URL: http://digital.ub.uniduesseldorf.de/ihd/content/pageview/3362458 (24.10.2014). 


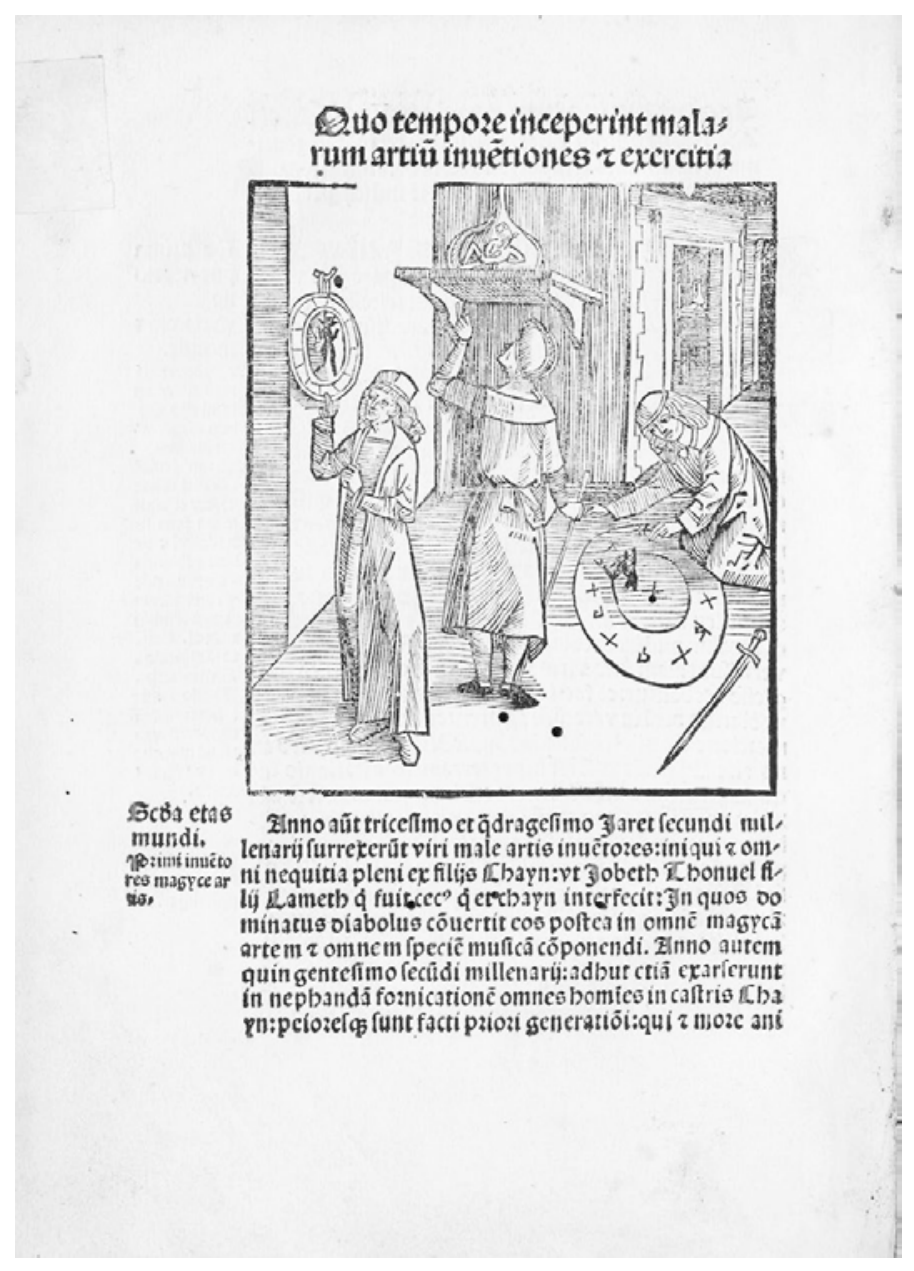

Abb. 5: Die Erfinder der schwarzen Künste.

Methodius: Revelationes Divinae (Anm. 29), S. 12, URL: http://digital.ub.uniduesseldorf.de/ihd/content/pageview/3362449 (24.10.2014). 


\section{Vermittlungen: Nimrod}

Die grundsätzlich irritierende Verbindung von Nimrod mit Jonitus führt zu einer eigenen Entwicklung der Nimrodfigur. Bei Methodius ist Nimrod Schüler des Jonitus und damit ein mit göttlichem Wissen ausgestatteter Tyrann - und großer Astronom. Und als solcher macht er dann auch seine eigene Karriere im Westen.

Im 10. Jahrhundert taucht ein astronomischer Traktat unter dem Namen von Nimrod auf und damit die Idee, dass der Gigant Nimrod ein erstklassiger Astrologe, wenn nicht der Erfinder dieser Kunst war. ${ }^{31}$ Denn in diesem Text, der in Form eines Dialogs zwischen Nemroth und Ioanton abgefasst ist, hat sich das Lehr-Verhältnis umgekehrt und geht Jonitus zu Nimrod in die Schule. ${ }^{32}$ Und das vorliegende astrologische Lehrbuch ist das Ergebnis dieses Unterrichts, wie es unter anderem in dem wohl fälschlich Albertus Magnus zugeschriebenen Speculum Astronomie zu lesen ist, wie es aber auch Hugo von St. Victor berichtet. ${ }^{33}$ Bei Michael Scotus liest man im Prohemium seines Liber Introductorius sogar die ganze Geschichte, wie es zu dieser Wissensvermittlung kam: Cham, heißt es da, sei der Erfinder der Astrologie gewesen, was der sozusagen orthodoxeren Tradition entspricht. Sein Wissen hat er dann seinem Sohn Chanaan weitergegeben, der noch geschickter und begabter darin war und seinerseits sein Wissen seinem Sohn Nimrod vermittelte, aufgeschrieben in dreißig Büchern. Diese verbrannten nach Chanaans Tod, doch konnte Nimrod das Wissen rekonstruieren. Nimrod nun hatte einen Schüler namens Ioanton, dem er alles vermittelte, was er wusste. Und dabei schrieb er ein Buch über die Astronomie. ${ }^{34}$ Damit ist die Genealogie des Buches von Nimrod gegeben, eines Buches, das wohl im lateinischen Westen entstanden ist. ${ }^{35}$

Im Kontext dieser Wissenstradition ist Nimrod wieder Teil des ChamGeschlechts, damit auch in die Linie der mit gefährlicher Magie Handelnden gestellt. Und Jonitus ist nicht mehr als erwählte Figur Begründer einer eigenen Wissenstradition, sondern bester Schüler des Nimrod. Damit aber ist er aus sei-

31 Vgl. zu der Datierung, der Zuschreibung und der Tradition in erster Linie Steven J. Livesey, Richard H. Rouse: Nimrod the Astronomer. In: Traditio 37 (1981), S. 203-266.

32 Charles Homer Haskins: Nimrod the Astronomer. In: The Romanic Review 5 (1914), S. 203212, hier S. 207 und Anm. 10 und 11.

33 Aiunt quidam Nemrod gigantem summum fuisse astrologum, sub cuius nomine etiam astronomia invenitur. Zitiert in: Haskins: Nimrod the Astronomer (Anm. 32), S. 205. Im Speculum Astronomie heißt es: Ex libris ergo qui est libros geometricos et arithmeticos invenitur apud nos scripti super his, primus tempore compositionis est liber quem edidit Nemroth gigas ad Iohathonem discipulum suum, qui sic incipit: Sphera celi, etc. in quo est parum proficui et falsitates nonnulle; sed nihil est ibi contra fidem, quod sciam. Zitiert nach: ebd. S. 205.

34 Et docendo illum ei conposuit librum tocius artis astronomie quid dicitur Nemroth in quo libro sunt magnalia cum rotis et figuris. Zitiert in: Livesey, Rouse: Nimrod the Astronomer (Anm. 31), S. 243-244.

35 Livesey und Rouse vertreten diese These einer westlich-lateinischen Entstehung des Buches gegen die von Haskins aufgestellte Behauptung eines syrischen Ursprungs. 
ner Insel-Stellung herausgeholt und in den Kontext astrologischer (chaldäischer) Wissenstradition gebracht. Dadurch steht er im Zusammenhang mit einem Wissen, das eng an die verfluchten Geschlechter gekoppelt ist, in deren Reihen auch Zoroaster - oft mit Cham identifiziert ${ }^{36}$ - aufgenommen ist, als Erfinder der magischen Künste und der septem artes liberales. ${ }^{37}$

Auch wenn die Tradition des Nimrod-Astrologen und seines Textes im Vergleich zur Wirkmacht des Ps.-Methodius und seiner Jonitus-Figur gering ist, wird darüber Jonitus in die chaldäisch-chamitische Astrologie eingereiht. Und Jonitus tritt im astrologischen Diskurs der Frühen Neuzeit dann als Gründervater der Astrologie auf - auch einer praktischen Astrologie, wie sie die Ärzte für nützlich erachten. Entsprechend erscheint er auf der Ärzte- und AstrologenTabelle von Jacob Ruf aus Zürich, der seine Liste durch Holzdrucke von Heinrich Vogtherr d. Ä. (1490-1546) illustrieren und bei Eustachius Froschauer drucken ließ [Abb. 6]. ${ }^{38}$ Jonitus ist hier als Astrologe gezeigt, eine Säulchensonnenuhr in der Hand, und in der Beischrift wird er bezüglich des Wissens graduell von seinen Brüdern abgesetzt:

Jonichus der vierd sun Noe

Hat gliebt acht ghebt der kunst vil mee

Mit dem verstand und so̊lchem flyß

Dann ander siner brůder gwüß.

\section{Verschwindende Figur}

Der hier ganz kurz skizzierte Prozess der Assimilation einer durch göttliches Wissen ausgezeichneten Figur in die Tradition eines (ambivalenten) AstrologieWissens führt zu dem Verschwinden von Jonitus. Diese aus dem praktischen Wissen (auch den mechanischen Künsten) ausgeklammerte Weisheits-Figur hat in der Frühen Neuzeit keinen Ort mehr. Die insula solis, Heliochoris, wandelt sich zu den utopischen Regionen, in denen über die Gesetze der Natur Gott

36 Cham-Zoroaster als Erfinder der schwarzen Magie u.a. bei Hugo von St. Victor: Adnotationes elucidatoriae in Genesim 10-11, PL 175, Sp. 48-50 und Comestor: Historia scholastica (Anm. 6), Genesis c16, PL 189, Sp. 1070. Für weitere Belege vgl. Arno Borst: Der Turmbau von Babel. Geschichte der Meinungen über Ursprung und Vielfalt der Sprachen und Völker. 4 Bde. München 1995 (Unveränderter Nachdruck der Ausgabe 1957-1963), S. 652, 735-36, $789,815$.

37 Pico della Mirandola (1486) ist es, der Zoroaster den Ruch des Dämonisch-Magischen nimmt, indem er ihn unter die Philosophen aufnimmt und den Begriff ,Magier' im Persischen als ,Dolmetscher des Göttlichen' erklärt. Pico della Mirandola: De hominis dignitate, 1486. Hinweis bei Borst: Der Turmbau von Babel (Anm. 36), S. 980.

38 Vgl. dazu Max Geisberg: The German single-leaf woodcut: 1500-1550. 4 Bde. New York 1974, 4. Bd., S. 1384-1386. Zu diesen Tafeln im Speziellen sowie ihrem Entstehungshintergrund vgl. Hildegard Elisabeth Keller: Astrologentafel. In dies.: Jacob Ruf, Werke 1545-1549. Kritische Gesamtausgabe, Teil 2, S. 79-116, hier S. 110. 


\section{Zonidus Sex vierd fun tioe \\ Bat gliebt adbt ghebt Jer Funft vil mee \\ Wit $\mathrm{gem}$ verftand vnd foldem fly $\bar{\beta}$ Dann ander finer Băder groüb.}

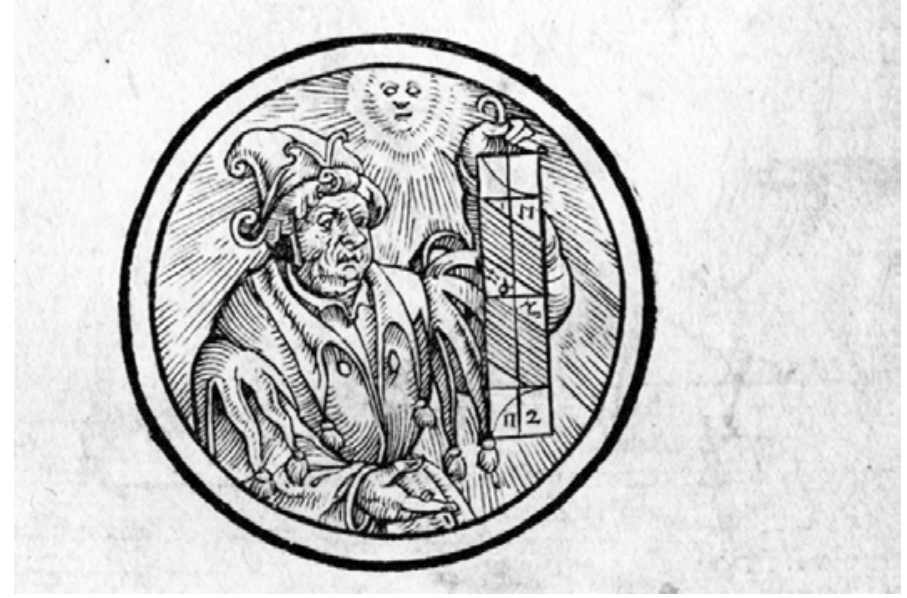

Abb. 6: Ausschnitt aus: Astrologen-Tabelle von Jacob Ruf aus Zürich, Holzdrucke von Heinrich Vogtherr d.Ä. (1490-1546), (Anm. 37).

realisiert und erkannt wird und Gesellschaften wohnen, in denen das Wissen handelnd umgesetzt wird. ${ }^{39}$ Ganz verschwunden ist Jonitus dann im 18. Jahrhundert, wenn im Rahmen einer Suche nach der Wahrheit hinter den Fabeln Jonitus mit Cham identifiziert wird. So in dem 1776 erschienenen [A] New System. Or An Analysis of Ancient Mythology: Wherein an Attempt is made to divest Tradition of Fable and to reduce the Truth to its Original Purity von Jacob Bryant, ${ }^{40}$ in dem auch der Turm zu Babel als Observatorium erklärt ist.

Deutlich wird in diesem kurzen Überblick zur Jonitus-Figur, dass das Konzept, das hinter der Idee dieses vierten Noah-Sohns steht, das Konzept eines

39 Vgl. z.B. Francis Bacon: New Atlantis. In ders.: The advancement of learning and New Atlantis. Hrsg. von Thomas Case. Oxford 1974. Interessant wäre in diesem Zusammenhang, die Rezeption der arabischen philosophischen Erzählung von Hayy ibn Yaqzan genauer anzuschauen. Ibn Tufayl: Hayy ibn Yaqzān. Translated with an Introduction and Notes by Lenn Evan Goodman. Chicago 2009.

40 Jacob Bryant: A New System: Or An Analysis of Ancient Mythology: Wherein an Attempt is made to divest Tradition of Fable and to reduce the Truth to its Original Purity. Bd. 3. London 1776. Die Stelle zum Turm zu Babel: S. 375. 
reinen, göttlichen Wissens, von prophetischem Welt-Wissen ohne handlungspraktische Komponente nicht bestehen kann. Es braucht den Vermittler (Nimrod), der dann aber auch die Stelle des Jonitus einnehmen kann. Oder die ,reine Wissensfigur wird von der sozusagen weltlich gebundenen, damit aber auch (handlungs-)relevanten Wissensfigur überschrieben: Cham.

Als Figur, in der sich göttliches Wissen mit Herrschaftswissen verbindet, die aber außerhalb heilsgeschichtlicher Haupterzählungen eine Leerstelle im Großnarrativ bildet, ist die Figur des Jonitus dann aber auch attraktiv für Zuschreibungen in Ursprungsmythen, gerade auch herrschafts-genealogischer Art. ${ }^{41}$ Doch diese Metamorphosen der Jonitus-Figur können hier nicht weiter verfolgt werden. Denn die Geschichte des nach Italien gekommenen Jonitus (mit Janus identifiziert), ist eine andere, die nicht zuletzt in einem der ganz großen gefälschten Texte, den Schriften des Berosus von Annius von Viterbo ihre Wirkkraft entfaltete. ${ }^{42}$

41 Vgl. dazu u.a. Thomas D. Hill: The Myth of the Ark-Born Son of Noe and the West-Saxon Royal Genealogical Tables. In: The Harvard Theological Review 80 (1987), S. 379-383.

$42 \mathrm{Zu}$ Annius von Viterbo vgl. u.a.: Anthony Grafton: Defenders of the Text. The Tradition of Scholarship in an Age of Science. 1450-1800. Cambridge (Mass.). London 1991, S. 76-103. 
(C) 2015, Otto Harrassowitz GmbH \& Co. KG, Wiesbaden ISBN Print: 9783447104951 - ISBN E-Book: 9783447194129 


\section{Aus den swarzen buochen \\ Zur Ästhetik der Verrätselung von Erkenntnis und \\ Wissenstransfer im Parzival}

Jutta Eming, Berlin

In Gottfrieds von Straßburg Tristan-Roman ist anlässlich der Beschreibung von Tristans Schwertleite eine als ,Literaturexkurs' oder ,Dichterrevue' bekannt gewordene theoretische Passage inseriert, in der prominente Dichter der höfischen Literatur hinsichtlich ihrer Erzählkunst miteinander verglichen werden. Den Anfang macht eine Laudatio auf einen Meister des klaren Ausdrucks, Hartmann von Aue, von dem kontrafaktisch in einer längeren Passage - der längsten des Exkurses - andere, nicht namentlich genannte Autoren abgehoben werden, die mit Sprachakrobatik und befremdlichen Fabeln nur Oberflächen-Effekte erzeugten. $\mathrm{Ob}$ diese vindære wilder mære ${ }^{1}$ auch Wolfram von Eschenbach einschließen, ist in der germanistischen Mediävistik noch immer umstritten. ${ }^{2}$ Neben vielem anderen ist ein Argument für eine solche Identifizierung mit dem Verfasser des Parzival aus dem Umstand zu gewinnen, dass dieser über magisches und alchemisches Wissen verfügt und dass Gottfried sich im Literaturexkurs kritisch darüber äußert.

In Gottfrieds poetologischer Invektive wird dieses Wissen metaphorisch zur ironischen Kritik an einem ,dunklen' Erzählstil gewendet, gleich jenen, die golt von swachen sachen / den kinden kunnen machen (V. 4669f.), also vermeintliches Gold für Kinder (oder kindliche Gemüter) herstellen, eine denunziatorische und verkürzende - Anspielung auf das Kerngeschäft der Alchemie. ${ }^{3}$ Für Gottfried sind die Geschichten der wilderære (V. 4683) ${ }^{4}$ aus sich nicht verständlich; ein Versuch, sie zu deuten, würde jedoch eine eben solche Verschwendung be-

1 Gottfried von Straßburg: Tristan und Isold. Hrsg. von Walter Haug und Manfred Günter Scholz. Mit dem Text des Thomas, herausgegeben, übersetzt und kommentiert von Walter Haug. Band I. Berlin 2012, V. 4665. Im Folgenden erscheinen die Versangaben aus dieser Ausgabe direkt im laufenden Text.

2 Dies wird verbreitet angenommen, obwohl auch Gegenstimmen verlauteten. Vgl. dazu jetzt wieder ausführlich den Kommentar von Scholz in der gemeinsam mit Haug herausgegebenen Werkausgabe: Haug und Scholz: Tristan und Isold (Anm. 1). Band II. Berlin 2012, S. 367-377.

3 Vgl. auch Scholz: Kommentar (Anm. 2), S. 376.

4 Der Plural hat, wie Scholz vermerkt, Deutungen der Passage gestützt, die keine eindeutige Referenz auf Wolfram annehmen, vgl. Scholz: Kommentar (Anm. 2), S. 374. 
deuten wie die, daz wir die glôse suochen / in den swarzen buochen (V. 4689f.), das heißt in Zauberbüchern Sinn suchen zu wollen.

Mit seiner Rhetorik würde Gottfried also einerseits Wolframs Erzählstil und Wirkungsintention zu diskreditieren versuchen und ihm eine ernstzunehmende Sinndimension seiner Werke absprechen und andererseits Formen zeitgenössischen Wissens, mit denen er arbeitet, zumindest in einigen Bereichen angreifen. ${ }^{5}$ Es ist diese Engführung von magischem und alchemischem Wissen mit Ästhetik, die im Folgenden interessiert. Nicht nur als Spitze gegen den Status von Wolframs Quellen ist Gottfrieds Kommentar bemerkenswert, ${ }^{6}$ sondern auch und vielleicht mehr noch durch den Umstand, dass diese Quellen metaphorisch zur Kennzeichnung der Spezifik von Wolframs Erzählen herangezogen werden.

In Gottfrieds Kritik ist eine Relation auf den Punkt gebracht, welche weiter reicht, als seine Anspielungen auf ,faulen Zauber' es vermuten ließen: die Affinität des Parzival zu magischen und alchemischen Denkweisen, Narrationen und Motiven, die bereits vielfach nachgewiesen wurde, aber keineswegs erschöpfend diskutiert worden ist. Wie im Folgenden gezeigt werden soll, liegt dies auch am Verständnis von Magie, das dabei jeweils unterstellt, und am Bezug auf literarische Texte, der dazu angenommen wird. Damit geht es auch um die Bestimmung des Verhältnisses von Literatur und Wissen.

\section{Gelehrte und populäre Magie}

Bereits für Wolframs wichtigste literarische Quelle, den Perceval von Chrétien de Troyes, ist die Frage nach dem epistemologischen Status magischen Denkens einschlägig. Vor einigen Jahren ist dies im Rahmen eines groß angelegten literaturtheoretischen Entwurfs auch in grundlegender Weise auf ästhetische Verfahren bezogen worden: in der Studie zum Phantastischen in der französischen Literatur des Mittelalters von Francis Dubost. ${ }^{7}$

Mit dieser Untersuchung schien sich eine neue, mancherorts als überfällig empfundene Möglichkeit zu eröffnen, literaturästhetische Phänomene zu erfassen, die vorher eher provisorisch und vorbegrifflich als ,geheimnisvoll', ,atmosphärisch' und ,rätselhaft' bezeichnet worden waren. Dubost konzeptualisiert

5 Aus Gottfrieds Tristan eine generelle Kritik an Magie abzuleiten dürfte angesichts der Minnetrank-Episode, aber auch hinsichtlich der Episode um das Hündchen Petitcreiu schwerfallen, die ebenfalls mit magischen Traditionen operiert. Vgl. zur alchemischen Metaphorik im Tristan ferner den Beitrag von Antje Wittstock im vorliegenden Band.

6 Tobias Bulang spricht von „inkriminierenden Vermutungen über die Herkunft seines Wissens". In ders: Enzyklopädische Dichtungen. Fallstudien zu Wissen und Literatur in Spätmittelalter und Früher Neuzeit. Berlin 2011, S. 37. Vgl. zu Formen des Wissens im Parzival jetzt Martin Baisch: Ästhetisierung und Unverfügbarkeit. Strategien der Inszenierung von Wissen bei Wolfram und Chrétien. In: Wolfram-Studien XXIII. Wolframs Parzival-Roman im europäischen Kontext. Tübinger Kolloquium 2012. In Verbindung mit Susanne Köbele und Eckart Conrad Lutz herausgegeben von Klaus Ridder. Berlin 2014, S. 207-250.

7 Vgl. Francis Dubost: Aspects fantastiques de la littérature narrative médiévale (XIIèmeXIIIème siècles). L'Autre, l'Ailleurs, l'Autrefois. Paris, Genf 1991. 
die dezidiert für die Moderne eingeführte Kategorie des Phantastischen im Rückgriff auf klassische Theorieansätze dafür als einen Moment der Unbestimmtheit, des Zweifels und vor allem der Angst bezüglich der metaphysischen Referenz eines Phänomens oder eines Vorgangs in einem literarischen Text. ${ }^{8}$ Im phantastischen Moment hält das Erzählen inne, weil die Bedeutung einer Handlung nicht sinnfällig wird. Emblematisch vertritt dieses Prinzip die blutende Lanze, welche den Auftakt der Gralprozession in Chrétiens de Troyes Perceval bildet. Dubost beschreibt die sich dabei entfaltende Rätselhaftigkeit wie folgt: „l'écoulement du sang ininterrompu est incompréhensible, inexplicable [...] pourquoi la lance saigne-t-il alors qu'elle n'a ni sang ni veines?" ${ }^{\prime 9}$ Angst oder Verunsicherung entsteht nach Dubost dadurch, dass die einem Helden und/oder dem Textrezipienten zur Verfügung stehenden Bezugssysteme, insbesondere christliche Deutungsmuster, für ein gegebenes Phänomen zumindest prima vista nicht greifen. Eine solche Situation transzendenter Verunsicherung könne im christlichen Horizont allerdings nur kurz und augenblickshaft auftreten.

Dubosts Studie ist nicht nur in der Romanistik breit rezipiert worden. Mit dem Ansatz, über die Kategorie des Phantastischen solche Szenarien von epistemischer Verunsicherung, Angst und Horror in der Literatur des Mittelalters beschreiben zu können, die sich nicht ohne weiteres mit christlicher Jenseitsfurcht erklären lassen, ist er einem Desiderat begegnet, das in der Germanistik vor allem von Walter Haug identifiziert worden war. ${ }^{10}$ Doch es hat auch Kritik an Dubosts Untersuchung gegeben, so hinsichtlich seiner nicht klaren Differenzierung von Figuren- und Rezipientenperspektive und der Frage, in welchem Maße die skizzierte Verunsicherung als Element des Erzählens selbst manifest wird. ${ }^{11}$ Diese Aspekte müssen hier nicht vertieft werden; allerdings ist ein Problem der Arbeit mit Blick auf die kulturgeschichtliche Begründung für die Rätselhaftigkeit des phantastischen Moments anzusprechen.

Während die Ästhetik des Phantastischen in der Moderne eine metaphysisch , aufgeräumte' Welt voraussetzt, in der das ,Ding auf der Schwelle ${ }^{\prime 12}$ Grauen erzeugt, weil es für unmöglich erklärt worden war, verhält sich dies in der spirituell fundierten Kultur des Mittelalters in ganz grundsätzlicher Hinsicht anders. Die Rätselhaftigkeit ist Dubost zufolge eine vorläufige oder scheinbare. Denn das Befremdliche des phantastischen Moments wird auf einer sekundären Ebene

8 Vgl. Dubost: Aspects fantastiques (Anm. 7), S. 125.

9 Dubost: Aspects fantastiques (Anm. 7), S. 5.

10 Vgl. vor allem Walter Haug: Das Fantastische in der späteren deutschen Artusliteratur. In: Spätmittelalterliche Artusliteratur. Ein Symposion der neusprachlichen Philologien auf der Generalversammlung der Görres-Gesellschaft Bonn, 25.-29. September 1982. Hrsg. von Karl Heinz Göller. Paderborn, München, Wien und Zürich 1984, S. 133-149.

11 Vgl. insbesondere Friedrich Wolfzettel: Das Problem des Phantastischen im Mittelalter. Überlegungen zu Francis Dubost. In: Das Wunderbare in der arthurischen Literatur. Probleme und Perspektiven. Hrsg. von dems. Tübingen 2003, S. 3-21.

12 Nach H. P. Lovecrafts Erzählung The Thing on the Doorstep (zuerst 1937). 
entweder durch Elemente des Dämonischen oder über Semantiken aus älteren, im christlichen Horizont des Hochmittelalters nicht mehr unmittelbar verständlichen Vorstellungen und Glaubensinhalten konstituiert, darunter solche magischer Provenienz. Dubost nimmt damit eine Position auf, die auch schon von Jacques Le Goff vertreten worden war. ${ }^{13}$ Die Ästhetik des Phantastischen konstituiert sich dem zufolge über Sedimente älterer, nicht- oder vorchristlicher Glaubensinhalte, die aus dem gelehrten Diskurs verbannt worden sind und nicht mehr verstanden werden, oder, wie Friedrich Wolfzettel formuliert hat, „Reste eines folkloristisch magischen Weltbilds" darstellen, die verdrängt worden sind. ${ }^{14}$ Das Phantastische der Literatur würde sich also unter anderem aus den Residuen einer nicht mehr als Wissen verfügbaren, beinahe schon überwundenen, fiktionalisierten, unheimlich gewordenen Magie speisen.

Wissensgeschichtlich ist die Vorstellung einer überkommenen folkloristischen Magie, die auch in der Volkskunde lange vertreten wurde, ${ }^{15}$ aus mehreren Gründen nicht haltbar. Zum einen befassen sich im Mittelalter in erster Linie klerikale Eliten mit Magie, eine Popularisierung lässt sich erst für das Spätmittelalter nachweisen. ${ }^{16}$ Zum anderen setzt die Beschäftigung mit Magie in Form astrologischen, medizinischen oder naturphilosophischen Schrifttums an den Kathedralschulen und Universitäten zur Zeit der Entstehung von Parzival - und Perceval - gerade wieder neu an. ${ }^{17}$ In Folge der Reconquista wird das intellektuelle Europa im 12. Jahrhundert mit arabischen Schriften aus den islamischen Wissenschaften geradezu überschwemmt. Bereits zu Beginn des 13. Jahrhunderts wird unter dem Titel Asclepius die lateinische Übertragung eines fragmentarischen griechischen Traktats bekannt, das zum Corpus Hermeticum gehört. Damit treten christliche Religion und Theologie schließlich nicht - wie in Dubosts Entwurf angenommen - an die Stelle von Denkformen und Praktiken, welche sich als magisch bezeichnen lassen. Historisch kommt es vielmehr in einigen Bereichen $\mathrm{zu}$ einer Verflechtung von religiösen mit magisch-alchemischen Vorstellungsgehalten.

13 Vgl. Jacques Le Goff: Das Wunderbare im mittelalterlichen Abendland. In ders.: Phantasie und Realität des Mittelalters. Stuttgart 1990, S. 39-63, hier S. 60-62.

14 Wolfzettel: Das Problem des Phantastischen (Anm. 11), S. 17.

15 Vgl. Frank Fürbeth: Zum Begriff und Gegenstand von Magie im Spätmittelalter. Ein Forschungsproblem oder ein Problem der Forschung? In: Jahrbuch der Oswald von Wolkenstein-Gesellschaft 12 (2000), S. 411-422, hier S. 414.

16 Dezidiert Christoph Daxelmüller: Zauberpraktiken. Eine Ideengeschichte der Magie. Zürich 1993. Vgl. auch Helmut Birkhan: Magie im Mittelalter. München 2010, S. 115ff. Eine vermittelnde Position vertritt demgegenüber Richard Kieckhefer, der schon im Hochmittelalter Beispiele verbreiteter magischer Praktiken sieht, vgl. ders.: Magie im Mittelalter. München 1995, S. 70ff. Vgl. zu diesem Problem auch den Beitrag von Marina Münkler im vorliegenden Band.

17 Diese große, Übersetzungsbewegung' ist viel beschrieben worden. Ich verweise hier nur auf Kieckhefer: Magie im Mittelalter (Anm. 16), S. 136ff. Zur Zeit vor 1100 vgl. insbesondere Valerie I. J. Flint: The Rise of Magic in Early Medieval Europe. Princeton 1991. 
Magie zeigt als Weltverhältnis, ${ }^{18}$ das von sympathetischen Strukturen zwischen Mikro- und Makrokosmos ausgeht und diese in unterschiedlichen Praktiken nutzen kann, grundsätzlich hinreichende Parallelen zur Religion. In der Theologie des Mittelalters ist dies zwar nicht so formuliert worden, doch wurden nur Handlungen, welche eindeutig der Evokation des Teufels bedurften, einhellig abgelehnt, der Dämonenlehre zugeordnet - und überhaupt als magisch bezeichnet. ${ }^{19}$ Theorien und Fertigkeiten aus den Bereichen der Bau- und Handwerkskunst, der Heilkunde oder Astrologie, die ebenfalls unter der Voraussetzung okkulter Kräfte operierten, waren dagegen entweder Teil der mittelalterlichen Systematisierung in ars und scientia oder sie besaßen einen ,prekären' Status und wurden - was etwa an der Diskussion über die Verfertigung von Talismanen nachvollziehbar ist ${ }^{20}$ - mit Blick auf ihren Geltungsanspruch unter theologischer und philosophischer Perspektive stets neu diskutiert. ${ }^{21}$ Magie und Religion gehen somit teils ineinander über, teils treten sie in Spannung zueinander, und nicht zuletzt deshalb ist die theologische Abgrenzung von der Magie weniger eindeutig dogmatisch abgesichert als permanenter Anlass der Überprüfung und Reflexion. ${ }^{22}$ Mit Blick auf das Interesse an Magie und Alchemie innerhalb der gelehrten Schichten Europas sind die Beziehungen zur volkssprachigen Literatur also anders anzusetzen, als Dubost dies vorschlägt.

Wolframs Umgang mit Elementen magischen und alchemischen Denkens ist in der Parzival-Forschung früh untersucht und als teilweise höchst subtiles Spiel der Allusionen und Strukturmuster auf unterschiedlichen textuellen Ebenen beschrieben worden. ${ }^{23} \mathrm{Im}$ Allgemeinen geht Wolfram mit diesen Elementen über die Chrétiensche Vorlage hinaus. Bereits der Umstand, dass er Erzählpartien, die im Orient - als dem Raum der Herkunft und der Vermittlung magischen und

$18 \mathrm{Zu}$ diesem Weltverhältnis als zentraler Episteme der Vormoderne nach Michel Foucault vgl. auch den Beitrag von Marina Münkler im vorliegenden Band.

19 Vgl. Fürbeth: Zum Begriff und Gegenstand von Magie (Anm. 15).

$20 \mathrm{Zu}$ den erlaubten und verbotenen Umgangsformen mit Talismanen vgl. am Beispiel des Picatrix von 1256 die populärwissenschaftlich aufbereitete, gleichwohl lesenswerte Untersuchung von Karl-Heinz Göttert: Magie. Zur Geschichte des Streits um die magischen Künste unter Philosophen, Theologen, Medizinern, Juristen und Naturwissenschaftlern von der Antike bis zur Aufklärung. München 2001, S. 124-132. Noch Marsilio Ficino setzt sich im dritten Buch von De vita libri tres (1489) ausführlich mit der heiklen Frage der Talismane auseinander, vgl. Marsilio Ficino: De vita libri tres / Drei Bücher über das Leben. Herausgegeben, übersetzt, eingeleitet und mit Anmerkungen versehen von Michaela Boenke. München 2012, S. 205-395, passim. Vgl. zur deutschen Rezeption des Picatrix auch den Beitrag von Frank Fürbeth im vorliegenden Band.

21 Zum Begriff des prekären Wissens vgl. Martin Mulsow: Prekäres Wissen. Eine andere Ideengeschichte der Frühen Neuzeit. Berlin 2012.

22 Dies gilt weniger für den Bereich der Dämonenlehre, über deren verwerflichen Charakter man sich einig ist, als für das Verhältnis zu Astrologie, Heilkunde oder Naturphilosophie. Vgl. bereits ausführlich Flint: The Rise of Magic (Anm. 17).

23 Speziell zur Astrologie vgl. bereits Wilhelm Deinert: Ritter und Kosmos im Parzival. Eine Untersuchung der Sternkunde Wolframs von Eschenbach. München 1960. 
alchemischen Denkens - situiert sind, neu in seine Geschichte integriert, könnte eine Rolle spielen, und es dürfte nicht zufällig mehrfach um die spanische Stadt Toledo gehen, die um 1200 einen „Knotenpunkt“24 für Transfers griechischer, arabischer und hebräischer Schriften, speziell der Astronomie und Kosmologie, der Heilpraktiken und arabischer Hermetik und Nigromantik darstellt. In wissens- und wissenschaftsgeschichtlicher Hinsicht bilden die Nachweise solcher Einflüsse Argumente für die lange in Frage gestellte umfassende Gelehrsamkeit Wolframs, die umso beeindruckender ist, als sie eine sehr frühe Rezeption bezeugen, die voraussetzt, dass er zu exklusiven intellektuellen Zirkeln Zugang hatte. Doch mehr als das: Sie zeigen, dass Wolfram mit dem Parzival in einen Prozess der ,Verhandlungen' eines historisch zu diesem Zeitpunkt weitgehend randständigen, ,gefährlichen' Wissens eingetreten ist, das in theologischer Hinsicht potentiell verwerflich ist und zudem - wie die Kritik Gottfrieds von Straßburg zeigte - mit Leichtigkeit zur Zielscheibe solcher zeitgenössischer Literaten werden kann, die ihr Metier als seriös begreifen. Es ist deshalb sowohl danach $\mathrm{zu}$ fragen, ob der Status magischen und alchemischen Denkens tendenziell dadurch eine Aufwertung erfährt, dass es im literarischen Medium inszeniert wird, als auch danach, welchen poetischen Gewinn die Dichtung umgekehrt daraus bezieht, dass sie dieses Denken integriert.

\section{Rekontextualisierung: Das Wunderbare}

Neben dem Versuch, rätselhafte Phänomene nicht nur des Parzival, sondern der mittelalterlichen Literatur generell, mit Dubost als Ästhetisierung nicht mehr verstandener Spuren eines folkloristischen Magischen aufzufassen oder sie im Sinne einer Einfluss- oder Diskursgeschichte auf historische Wissensbewegungen zu beziehen, lassen sich weitere Beschreibungsebenen konstituieren. Dafür wären sie als Elemente spezifisch literarischer Konfigurationen zu beschreiben. Eine solche Ebene ist die des Wunderbaren. Unter dem Wunderbaren verstehe ich rekurrente Darstellungsmuster in der fiktionalen Literatur des Mittelalters seit dem 11. Jahrhundert, in welche verschiedene Wissensdiskurse eingegangen sind, um in Beschreibungen des Orients, der Antike und affiner Anderswelten Erfahrungen kultureller und historischer Alterität zu gestalten. Die entsprechenden Wissensbereiche betreffen Historiographie, Theologie, Naturgeschichte oder Medizin, ihre Überschneidungen in verschiedenen Diskursen und schließlich magisches und alchemisches Wissen, das historisch allerdings zumindest zu Teilen als scientia oder ars bezeichnet worden wäre. Im literarischen Text werden diese Wissenstraditionen medien- und gattungsspezifisch in immer neuen Kontexten re-organisiert und ästhetisiert. Das Wunderbare meint in diesem Zusam-

24 Peter Strohschneider: Sternenschrift. Textkonzepte höfischen Erzählens. In: Wolfram-Studien XIX. Text und Text in lateinischer und volkssprachiger Überlieferung des Mittelalters. Freiburger Kolloquium 2004. In Verbindung mit Wolfgang Haubrichs und Klaus Ridder hrsg. von Eckart Conrad Lutz. Berlin 2006, S. 33-58, hier S. 51. 
menhang nicht nur einen Objektbereich - mirabilia wie Magnetberge oder Wundervölker - und auf Seiten eines wahrnehmenden Subjekts nicht nur die emotional-intellektuelle Haltung des Staunens, sondern es bezieht sich auf einen umfassenden Zusammenhang erzählerischer Inszenierung, zu dem rhetorische Stilisierungen durch descriptiones und Ekphrasen ebenso gehören wie Erzählerkommentare und Fokalisierungen, Handlungsvollzüge und Erfahrungen, Emotionen und Reflexionen sowie atmosphärische Effekte.

Das Wunderbare ist mit Formen des Magischen oder Alchemischen nicht identisch, aber es nimmt, um Narrative und literarische Konfliktkonstellationen zu motivieren und Topographien und Figuren zu bebildern, Anleihen bei ihrer Sprache, bei ihren Denkmustern, Metaphern und Symbolen. In der Ausarbeitung zum Wunderbaren entsteht auf diese Weise nicht nur etwas Neues - fiktionale Literatur -, sondern auch dezidiert wieder Wissen, ${ }^{25}$ das durch spezifisch literarische Mittel konfiguriert ist. Außerdem werden in den Darstellungsmustern des Wunderbaren Probleme von Wissen und Nichtwissen, Erfahrung und Unverfügbarkeit ständig mit verhandelt und können bis zu regelrechten Krisen der Erkenntnis führen. In poetologischer Hinsicht sind solche ,Verhandlungen' mit einem tendenziell transgressiven, den Horizont zulässiger Intellektualität verlassenden Wissens auf ihre Funktion für den Roman zu befragen.

Joachim Bumke schätzt die Bedeutung des Wunderbaren in Form der Parallelität zweier andersweltlich gestalteter Burgen (Gralburg und Schastel marveile), zweier dort wirkender Wunderobjekte (Gral und Wundersäule), zweier Erlöserfiguren (Parzival und Gawein) und zweier zentraler Verursacher (Anfortas und Clinschor) für den Bauplan des Parzival mittlerweile höher ein als die "Auflösung" der Artusstruktur hin zum Gralroman. ${ }^{26}$ Die Frage, welche magischen oder alchemischen Wissenstraditionen sich im Wunderbaren entfalten, verfolgt er nicht. Vielen bereits nachgewiesenen Wissenstransfers wäre jedoch hinsichtlich ihrer speziell poetologischen Funktion noch genauer nachzugehen. ${ }^{27}$ Im Parzival lassen sich zum Beispiel Bezeichnungen von Heilmitteln für die Wunde des Gralkönigs identifizieren, welche auf das Drachentier Ouroboros verweisen, ${ }^{28}$ ein alchemisches Symbol für die Dynamik von Destruktion und

25 Zuletzt hat Ursula Kocher auf das Phantastische in der Frühen Neuzeit als Form des Wissens hingewiesen, allerdings ohne systematische Abgrenzung vom Wunderbaren, vgl. Ursula Kocher: Frühe Neuzeit. Deutschland. In: Phantastik. Ein interdisziplinäres Handbuch. Hrsg. von Hans Richard Brittnacher und Markus May. Stuttgart, Weimar 2013, S. 19-23.

26 Vgl. Joachim Bumke: Wolfram von Eschenbach. 8. völlig neu bearb. Aufl. Stuttgart, Weimar 2004, S. 186f. Von einer „Auflösung“ des Artusromans bzw. seiner Struktur spricht Walter Haug: Die Symbolstruktur des höfischen Romans und ihre Auflösung bei Wolfram von Eschenbach. In: Deutsche Vierteljahrsschrift für Literatur und Geistesgeschichte 45 (1971), S. 668-705.

27 Vgl. zu diesem Ansatz auch den Beitrag von Antje Wittstock im vorliegenden Band.

28 Über Anspielungen auf die Ouroboros-Symbolik in der Beschreibung der Wurzel trachontê $(483,6)$ in Verbindung mit der Formulierung des trachen umbevart $(483,12)$ ist im Anschluss an die Forschungen von Arthur Groos viel gehandelt worden. Vgl. Bernhard Dietrich Haa- 
Erneuerung ${ }^{29}$ und zugleich für die als Iatrochemie bekannte Verwendung von Verfahren der Sublimation und Destillation zum Zwecke der Gewinnung von Substanzen. ${ }^{30}$ Der Drache ist jedoch auch ein eingeführtes Element des Wunderbaren. ${ }^{31}$ Er vertritt in der weltlichen Literatur eine archaische Dimension der Bedrohung von Herrschaft und bietet zugleich Chancen des Erwerbs von Macht und Ruhm; im Parzival steht er damit in Binnenbezügen zu anderen Episoden des Textes, insbesondere zum ,Drachentraum' von Parzivals Mutter Herzeloyde. Welche Deutungsebenen über die Möglichkeit der Erneuerung des Gralgeschlechts über solche internen Bezüge und spezifisch literarische Formen der Vernetzung errichtet und welche Aussagen über Formen der Reproduktion von Herrschaft zugleich damit getroffen werden, wäre erst noch zu untersuchen. ${ }^{32}$

Im Folgenden möchte ich zeigen, dass sich auch die zentrale Problematik der Erkenntnis im Parzival über das Wunderbare entfaltet und dabei bereits auf Darstellungsmustern vorgängiger Romane aufbaut. ${ }^{33}$ Wolfram arbeitet mit Elementen des Wunderbaren, um die semireligiöse Atmosphäre auf der Gralburg zu entwickeln und um Möglichkeiten, Bedingungen und Grenzen des Wissens zu thematisieren. ${ }^{34}$

Die Auseinandersetzung mit dem Motivrepertoire des Wunderbaren im Parzival wird im Folgenden also unter besonderer Berücksichtigung von Elementen magischen und alchemischen Denkens mit Blick auf die Frage untersucht, wie die Ebene des ,Dunklen' und Geheimnisvollen konstituiert wird, die bereits

ge: Alchemie im Mittelalter. Ideen und Bilder - von Zosimos bis Paracelsus. Düsseldorf, Zürich 1996, S. 107, ausführlich ders.: Medizin im Parzival Wolframs von Eschenbach in ihrem Bezug zur "Schule von Chartres". Ein Forschungsbericht. In: Begegnung mit Literaturen. Festschrift für Carola L. Gottzmann zum 65. Geburtstag. Hrsg. von Petra Hörner und Roswitha Wisniewski. Berlin 2008, S. 173-198; ferner Michael Horchler: Die Alchemie in der deutschen Literatur des Mittelalters. Ein Forschungsbericht über die deutsche alchemistische Fachliteratur des ausgehenden Mittelalters. Baden-Baden 2005, S. 340-343.

29 Vgl. Haage: Alchemie (Anm. 28), S. 95-104.

30 Vgl. Horchler: Alchemie in der deutschen Literatur des Mittelalters (Anm. 28), S. 343 et passim.

31 Die klassische Studie verfasste Claude Lecouteux: Der Drache. In: Zeitschrift für deutsches Altertum und deutsche Literatur 108 (1979), S. 13-31.

$32 \mathrm{Zu}$ religiösen Bezügen vgl. Helmut Brall-Tuchel: Wahrnehmung im Affekt. Zur Bildsprache des Schreckens in Wolframs Parzival. In: Wahrnehmung im Parzival Wolframs von Eschenbach. Actas do Colóquio Internacional 15 e 16 de Novembro 2002. Hrsg. von John Greenfield. Porto 2004, S. 67-104.

33 C. Stephen Jaeger hat vor einiger Zeit die Auffassung vertreten, dass Wolfram das Wunderbare im Parzival nur setze, um es dann mittels einer Rationalisierung aufzulösen. Zu diesen Formen der Rationalisierung zählte er Wissenselemente, die - den Vorstellungen des 12./13. Jahrhunderts gemäß - als ,wissenschaftlich' zu bezeichnen seien, wie Heilkunde oder Astrologie. Vgl. C. Stephen Jaeger: Wunder und Staunen bei Wolfram und Gottfried. In: Inszenierungen von Subjektivität in der Literatur des Mittelalters. Hrsg. von Martin Baisch u.a. Königstein 2005, S. 122-139, hier S. 134ff.

34 Zum narrativen Umgang mit Aspekten von Wissen im Parzival vgl. zuletzt Baisch: Ästhetisierung und Unverfügbarkeit (Anm. 6). 
Gottfried aufgefallen sein könnte, ohne dass er sie geschätzt hätte. Den Auftakt bildet die klassische Szene aus Anlass von Parzivals erstem Besuch auf der Gralburg. Im Anschluss geht es um die Frage, welche Schreibweisen des Wunderbaren ausgehend von dieser Szene im Roman entwickelt werden. In diesem $\mathrm{Zu}$ sammenhang wird auch auf die Frage eingegangen, inwiefern die alchemische Lehre der substantiellen und spirituellen ,Läuterung' als Modell für die Veränderung der Hauptfigur gedient hat.

\section{Diffusion der Zeichen I: vröude und Trauer}

Parzival ist auf genau die Burg geleitet worden, auf der er dringlich erwartet wird, was er nicht weiß. Auf der Burg soll er das Siechtum des Gralkönigs Anfortas durch einen Sprechakt beenden, ein wunder, ${ }^{35}$ was ihm ebenfalls nicht bekannt ist. Dadurch - sowie durch frühere, bereits vor dem Besuch liegende Ereignisse, was ihm noch weniger bewusst ist - lädt er Schuld auf sich und wird für den Rest seines Weges durch den langen Roman dazu verurteilt sein, diese Schuld wiedergutzumachen.

Wie schwer einsichtig der Zusammenhang für Parzival ist, wird dem Publikum in intern fokalisierten Textpassagen nahe gebracht und zugleich durch Erzählerkommentare perspektivisch gebrochen, die zumindest einen Teil an Information über die Vorgänge abgeben. Das klärt diese Vorgänge allerdings nicht eigentlich auf, sondern hebt die Verstrickung des Helden nur umso mehr hervor. Schon den Einstieg in die Episode bildet ein Erzählerkommentar, der die Exzeptionalität dessen, was mit Parzival geschehen wird, in gewisser Weise ankündigt, dieses zugleich jedoch in ein vertrautes Prinzip einbettet: die âventiure. Damit wird der Kontext höfischen Erzählens aufgerufen und ein Erwartungshorizont konstituiert:

Swer ruochet hœren war nu kumt

den âventiur hât ûz gefrumt, der mac grôziu wunder

35 Wolfram von Eschenbach: Parzival. Studienausgabe. Mittelhochdeutscher Text nach der sechsten Ausgabe von Karl Lachmann. Übersetzung von Peter Knecht. Einführung zum Text von Bernd Schirok. Berlin, New York 1998, 239,9. Im Folgenden erscheinen die Zitatnachweise direkt im Fließtext. Inwiefern es sich hier um einen transzendenten Vorgang handelt, ist umstritten. Dies rührt unter anderem daher, dass Parzival das Wunder durch eine Frage auslöst und über es dadurch mit verfügt. Ulrich Ernst spricht in diesem Zusammenhang von "quasi magisch", vgl. Ulrich Ernst: Wolframs Gral und der Schatz der Templer. Theokratie, Heterotopie und Imagologie im Parzival. In: Artushof und Artusliteratur. Hrsg. von Matthias Däumer, Cora Dietl und Friedrich Wolfzettel. Berlin, Boston 2010, S. 191-214, hier S. 194. Jan-Dirk Müller: Percevals Fragen - oder ein ,Parzival' ohne Mitleidsfrage? In: Wolfram-Studien XXIII (Anm. 6), S. 21-49, hier S. 41, zufolge wird Magie im Parzival minimalisiert. Vgl. auch die Diskussion bei Walter Haug: Die ,Theologisierung' des höfischen Romans in Wolframs von Eschenbach ,Parzival' und in der ,Queste del Saint Graal'. In ders.: Positivierung von Negativität. Letzte kleine Schriften. Hrsg. von Walter Haug und Ulrich Barton. Tübingen 2008, S. 157-171. 
merken al besunder.

lât rîten Gahmuretes kint.

swâ nu getriwe liute sint,

die wünschn im heils: wan es muoz sîn

daz er nu lîdet hôhen pîn,

etswenne ouch freude und êre.

$(224,1-9)$

Die alles entscheidende Episode auf der Gralburg wird über die Semantik höfischen Erzählens (âventiure, triuwe, freude und êre) konventionell eingeleitet. Der Umstand, dass diese Semantik religiös tingiert ist (wunder, heil), stört den Eindruck nicht, sondern komplettiert ihn. In prägnanter Subjekt-Objekt-Verkehrung wird indessen das Prinzip der âventiure des höfischen Romans, die dem Ritter zu-fällt, zugespitzt: Es ist die âventiure, welche den Ritter sucht, nicht umgekehrt. ${ }^{36}$ Aus der Erzählervorausdeutung geht außerdem hervor, dass Parzivals Scheitern und seine damit verbundene Unbill (pîn) von Anfang an nicht nur Teil des Plans, sondern notwendige Voraussetzung für Parzivals Erwählung war (wan es muoz sîn).

Die ältere Parzival-Forschung neigte dazu, das Unverständnis gegenüber den Geschehnissen auf der Gralburg auf ein Defizit in der Figur zurückzuführen; dies kristallisierte sich in einer intensiven Diskussion über Sünde und Schuld. ${ }^{37}$ Unter welchen Prämissen Parzivals Fehlverhalten - auf der Gralburg und früher - aber als ,Schuld' aufzufassen ist, ist ein immenses Problem. Parzival ist an den Vorgängen derart unbeteiligt, dass selbst die Kategorie des Tragischen wiederholt in Erwägung gezogen wurde. ${ }^{38}$ In der jüngeren Forschung wurde außerdem die Konstellation auf der Gralburg zunehmend problematisiert und gefragt, was Parzival unter den gegebenen Bedingungen eigentlich hätte verstehen können. ${ }^{39}$

36 Vgl. zu diesem Zu-Fall auch Mireille Schnyder: Sieben Thesen zum Begriff der âventiure. In: Im Wortfeld des Textes. Worthistorische Beiträge zu den Bezeichnungen von Rede und Schrift im Mittelalter. Hrsg. von Gerd Dicke, Manfred Eikelmann und Burkhard Hasebrink. Berlin, New York 2006, S. 369-375.

37 Diese ist letztlich überdeterminiert, vgl. den Überblick bei Bumke: Wolfram von Eschenbach (Anm. 26), S. 126-130.

38 Zuletzt von Regina Toepfer: Höfische Tragik. Motivierungsformen des Unglücks in mittelalterlichen Erzählungen. Berlin, Boston 2013, S. 123-160, zur Forschungsdiskussion ebd., S. $142-152$.

39 Vgl. insbesondere Bernd Schirok: Die Inszenierung von Munsalvaesche. Parzivals erster Besuch auf der Gralburg. In: Literaturwissenschaftliches Jahrbuch 46 (2005), S. 39-78. Vgl. außerdem die resümierende Feststellung von Cornelia Schu: Vom erzählten Abenteuer zum Abenteuer des Erzählens. Überlegungen zur Romanhaftigkeit von Wolframs Parzival. Frankfurt a.M. u.a. 2002, hier S. 287: „Die Eindeutigkeit der Schuldfrage bei Chrétien hat sich in ein mehrstimmiges Geflecht von Schuldzuweisungen aufgelöst, welches eine eindeutige Beurteilung der Frage nach Parzivals Schuld im Text verweigert." 
Dafür wird - im Mindesten $-^{40}$ die Figurenperspektive von einer allgemeinen Beobachterperspektive und diese vom Erzähler analytisch unterschieden, und der avisierte Wahrnehmungs- und Erkenntnisprozess wird nicht mehr nur mit Blick auf rationale, sondern auch auf emotionale Komponenten untersucht. Parzivals ausgebliebene Frage ist unter dieser Voraussetzung vielleicht als Unvermögen zu adäquatem Mit-Leiden zu verstehen. ${ }^{41}$

Die Interdependenz zwischen der Reaktion des Helden und der besonderen Form der Inszenierung, mit der er konfrontiert wird, könnte sich aber auch so darstellen, dass - pointiert gesagt - die Möglichkeit, dass er eine Erlösungsfrage stellt, geradezu verhindert wird. Damit geht es um die Einrichtung der Szene und um ihre Wahrnehmungs- und Rezeptionsangebote auf intradiegetischer Ebene.

Die Inszenierung des Gralaufzugs ist mit Blick auf diesen Zusammenhang bereits als theatralisch bezeichnet worden, ${ }^{42}$ als hyperbolisch, ${ }^{43}$ aber auch als mystifizierend. ${ }^{44}$ Dies sind in allen Fällen Distanzkategorien, insofern sie eine Zuschauerperspektive auf einen Vorgang implizieren (Theatralik), welcher schwer verständlich ist, weil er zu viele Sinnangebote zugleich macht (Hyperbolik) oder weil seine Intention darin liegt, Rätsel aufzugeben (Mystifizierung). Von Parzival wird jedoch eine empathische Reaktion erwartet. Deshalb lässt sich fragen, ob die Szene simultan Appell- und Verrätselungsstrukturen exponiert, welche sich in der Konsequenz wahrnehmungshalber wechselseitig blockieren.

In der Forschung ist es üblich, diesem Zusammenhang auch im Vergleich mit Chrétiens de Troyes Perceval nachzugehen. Wie Bumke erklärt hat, steht der Held des deutschen Romans im Vergleich zum französischen Prätext insofern vor einer viel schwereren Aufgabe als der des französischen, ${ }^{45}$ als Wolfram aus einer ,Neugier- eine Mitleidsfrage' gemacht $^{46}$ und die gemeinsame Präsentation von Gral und Lanze in Chrétiens Perceval auf zwei unterschiedliche Szenen ver-

$40 \mathrm{Zu}$ Parzival als multiperspektivischem Roman im Sinne Bachtins vgl. grundsätzlich die Untersuchung von Schu: Vom erzählten Abenteuer (Anm. 39).

41 Katharina Mertens Fleury: Leiden lesen. Bedeutungen von compassio um 1200 und die Poetik des Mit-Leidens im ,Parzival' Wolframs von Eschenbach. Berlin 2006, versteht dies als eine sukzessive Annäherung an die Figur der Sigune und zugleich eine Form der Mimesis an die Passion Christi. Vgl. ebd., S. 195.

42 Vgl. Uta Störmer-Caysa: Mitleid als ästhetisches Prinzip: Überlegungen zu Romanen Hartmanns von Aue und Wolframs von Eschenbach. In: Höfische Literatur \& Klerikerkultur. Wissen - Bildung - Gesellschaft. Xth Triennial Conference der Internationalen Gesellschaft für höfische Literatur (ICLS). Berlin 2002, S. 64-93, hier S. 91.

43 So Mireille Schnyder: Überlegungen zu einer Poetik des Staunens im Mittelalter. In: Wie gebannt. Ästhetische Verfahren der affektiven Bindung von Aufmerksamkeit. Hrsg. von Martin Baisch, Andreas Degen und Jana Lüdtke. Freiburg, Berlin und Wien 2013, S. 95-113, hier S. 110.

44 Vgl. Ernst: Wolframs Gral (Anm. 35), S. 197.

45 Vgl. Bumke: Wolfram von Eschenbach (Anm. 26), S. 130.

46 So die Unterscheidung bei Bumke: Wolfram von Eschenbach (Anm. 26), S. 138. 
teilt habe. Jan-Dirk Müller sieht dagegen die Szeneneinrichtung bei Chrétien in viel höherem Maße verrätselt und verdunkelt, eine Tendenz, die er - teils im Anschluss an die französische Romanistik - als ,magisch' bezeichnet. ${ }^{47}$ Was also sieht Parzival?

Im Festsaal der Gralburg trifft Parzival auf den Gralkönig Anfortas bzw. er trifft ihn wieder: Es handelt sich um den kostbar gekleideten, aber unglücklich aussehenden Fischer, der ihm den Weg zur Burg gewiesen hatte. Abgesehen von dieser ersten Begegnung hatte Parzival kaum Gelegenheit festzustellen, dass mit der Stimmung auf der Burg irgendetwas besonders ist, und anders als im Rahmen höfischen Erzählens zu erwarten wäre. ,Kaum' heißt: Er hat vielleicht verstanden, dass es sich nicht um einen Hof als konventionellem Ort der vröude handelt. So erblickt er bereits bei seinem Eintritt in den Burghof kurzes grünes Gras, was ein Zeichen dafür ist, dass hier schon lange keine Ritterspiele mehr veranstaltet worden sind:

selten frœlîchiu werc

was dâ gefrümt ze langer stunt:

in was wol herzen jâmer kunt.

wênc er des gein in enkalt.

$(227,14-17)$

Diese Stelle ist unter anderem deshalb schwierig zu deuten, ${ }^{48}$ weil sie suggeriert, dass hier einerseits etwas für Parzival zu erkennen ist und andererseits nicht, weil der Erzählerkommentar also seine Wahrnehmung referieren könnte - oder auch nicht. Zum einen bemerkt Parzival vielleicht die fehlenden Anzeichen höfischer Festlichkeit, zum anderen heißt es sofort, dass man ihn ,wenig' darunter leiden lasse.

Hier ist die Formulierung als Hinweis auf den Versuch relevant, Parzival angemessen höflich zu behandeln, obwohl der Zustand des Hofes das eigentlich nicht erlaubt. Entscheidend ist mit Blick auf die involvierte emotionale Ebene, den höflichen Umgang nicht als Formalität aufzufassen, sondern als Bemühen darum, dass Parzival sich buchstäblich willkommen fühlt, dass er also vom schlechten Zustand des Hofes nicht befremdet, verunsichert, abgestoßen oder negativ affiziert wird. Entscheidend ist ferner, dass die Dichtung zwischen höfischem Zeremoniell, vröude und der höfischen Prachtentfaltung, welche noch

47 Müller: Percevals Fragen (Anm. 35) spricht von Magischem metaphorisch als von einer "dunklen, unbegreiflichen Wirkung", vgl. S. 33.

48 Nach Auffassung von Elisabeth Schmid: Da staunt der Ritter, oder der Leser wundert sich. Semantische Verunsicherungen im Wald der Zeichen. In: Das Wunderbare (Anm. 11), S. 7994, hier S. 89, sollen hier nur die Rezipienten auf die Stimmung im Inneren eingestellt werden, nicht auch Parzival. Das ist nicht eindeutig, weil es ja heißt, dass man ihn das ,wenig spüren lasse. Vgl. zur Stelle und ihrer Interpretation auch Maike Retzer: Mythische Strukturen in Wolframs von Eschenbach Parzival. München 2007, S. 80f. 
folgt, einen konventionellen Konnex errichtet, dem der Ausnahmezustand des Hofes nicht entspricht.

Die Emotionskategorie vröude bezeichnet in erster Linie die Hochgestimmtheit aller Angehörigen des Hofes und ist als solche Ausdrucksform einer intakten Herrschaft, ja einer intakten Welt: „Die courtoise Harmonie wird als sinnerfüllte Ordnung (ordo) vorgestellt, als universelle Sinnfiguration, in der alle Wertvorstellungen und Handlungsformen des höfischen Adels fundiert sind. " ${ }^{49}$ Das Gegenteil des freudig gestimmten ist der trauernde und dadurch krisenanfällige Hof, der als Macht- und Repräsentationsraum nur noch begrenzt funktioniert, keine Turniere veranstaltet und keine Feste ausrichtet. Dies wäre folglich auch ein Hof, der keine Gäste mehr empfängt. Wenn, wie der Erzählerkommentar festhält, man sich darum bemüht, den jâmer vor Parzival zu verbergen, kann sich dies also gerade dadurch vollziehen, dass ihm ein festlicher Empfang bereitet wird.

Der luxuriös ausgestattete Saal, in den Parzival dafür geführt wird, ist deshalb keine Hintergrundkulisse, sondern ein Raum der ,Gestimmtheit' (Hermann Schmitz), ${ }^{50}$ ein Raum mit einer durch spezielle Arrangements und von Menschen und Objekten erzeugten festlichen Atmosphäre, welche den Gast potentiell positiv ,ergreifen’ kann: „Das Fest (hôhgezîte) vermittelt adliges Hochgefühl (vroide) durch Anschauung und Teilhabe, durch reiche Bilder für die Augen, bunte Klänge für die Ohren, durch Speisen und Getränke, Düfte und Gerüche“ ${ }^{\text {" }}{ }^{1}$ Der Saal der Gralburg verspricht die gastliche Aufnahme in einer geordneten, mächtigen und zudem um Schönheit als Tugend zentrierten Gemeinschaft: Hundert Kronleuchter und weitere Kerzenhalter an den Wänden lassen Kerzen erstrahlen, an einhundert Ruhebetten sitzen jeweils vier Leute, drei viereckige Feuerstellen aus Marmor beheizen den Raum mit großen Feuern. Erst als die Rede auf den Hausherrn kommt, der sich genau an der mittleren Feuerstelle niedergelassen hat, wird ein Moment der Dissonanz vernehmlich:

der wirt sich selben setzen bat

gein der mitteln fiwerstat

ûf ein spanbette.

ez was worden wette

zwischen im und der vröude:

er lebte niht wan töude.

$(230,15-20)$

49 Horst Wenzel: Hören und Sehen, Schrift und Bild. Kultur und Gedächtnis im Mittelalter. München 1995, S. 181.

50 Vgl. Hermann Schmitz: Der Leib, der Raum und die Gefühle. Bielefeld, Basel 2009.

51 Wenzel: Hören und Sehen (Anm. 49), S. 180. 
Der Erzähler rückt vröude explizit in einen Kontrast zum elenden Zustand des Königs; unklar bleibt, ob dies der Perspektive Parzivals entspricht. ${ }^{52}$ Als die Ritter vollzählig versammelt sind, tritt ein Knappe mit einer Lanze auf, von deren Spitze Blut herunter läuft und die im Saal eine laute Klage auslöst:

der truog eine glævîn

(der site was ze trûren guot):

an der snîden huop sich pluot

und lief den schaft unz ûf die hant,

deiz in dem ermel wider want.

dâ wart geweinet unt geschrît

ûf dem palase wît:

daz volc von drîzec landen

möhtz den ougen niht enblanden.

$(231,18-26)$

Wenn es einen Moment mit Appellcharakter und einen Anlass für eine Mitleidsfrage gibt, dann hier. Vor Parzivals Augen entfaltet sich eine ritualisierte Trauer, die alle Angehörigen des Hofes einbezieht und die Parzival, hätte er nach ihrem Grund gefragt und sich an ihr beteiligt, in den Rang eines Mitglieds der Gralgesellschaft erhoben hätte. Die Funktion der ostentativen Trauer liegt - in Anlehnung an die Totenklage - in der Aktualisierung eines Verlusts, ${ }^{53}$ der die gesamte Gemeinschaft betrifft und im vorliegenden Fall zudem die Gefährdung des gesamten Hofes in Szene setzt. Mit Blick auf die ritualisierte Form der Klage ließe sich fragen, ob an Parzival eine Unkenntnis eines solchen Rituals exemplifiziert werden soll oder ob er als Figur konzipiert ist, die soziales Wissen um die Situationsadäquatheit eines Emotionsausdrucks erst erwerben muss. ${ }^{54}$

Wie bereits erläutert, liegt eine Schwierigkeit des Arrangements jedoch darin, dass die Klage im Rahmen eines Festes virulent wird, in dem Parzival gerade als Gast aufgenommen wurde. Hatte es bei seiner Ankunft am Hof noch geheißen, dass Trauer möglichst von ihm fernzuhalten sei, hat sich der Umgang damit inzwischen komplett verkehrt: Jetzt soll Parzival sie bemerken und sogar von ihr affiziert werden. Die beiden Szenen kontrastieren in dieser Hinsicht deutlich miteinander.

In der Verschränkung der Ausdrucksmodi von Trauer und Schmerz mit einer Szene festlicher vröude und damit zweier gegenläufiger, ebenso rational wie

52 Anders Müller: Percevals Fragen (Anm. 35), S. 29, für den die Szene von Beginn an „,[...] im Zeichen des jâmer [steht]".

53 Vgl. dazu Elke Koch: Die Vergemeinschaftung von Affekten in der ,Klage'. Mit Untersuchungen zur Semantik von verklagen und klagen helfen. In: 11. Pöchlarner Heldenliedgespräch. Mittelalterliche Heldenepik - Literatur der Leidenschaften. Hrsg. von Johannes Keller und Florian Kragl. Wien 2011, S. 61-82.

$54 \mathrm{Zu}$ diesem Punkt vgl. jetzt wieder Baisch: Ästhetisierung und Unverfügbarkeit (Anm. 6), S. 216-228. 
emotional determinierter sozialer Praktiken, werden Zeichen hybridisiert. Dies erzeugt einen Widerspruch, der für Parzival nicht mehr aufzuheben ist, und der womöglich eine Erklärung für seine wie paralysiert wirkende Haltung bietet, für die Tatsache, dass er, anstatt sich affizieren zu lassen, in einer passiven Position verharrt. ${ }^{55}$ Als weitere Schwierigkeit für die Einstimmung auf eine Mitleidshaltung tritt hinzu, dass die Möglichkeit unmittelbarer Affizierung durch Trauer nur kurze Zeit gegeben ist. Nachdem das Memorialzeichen der Lanze wieder aus dem Saal herausgetragen wird, verstummt die Klage der Angehörigen des Hofes.

\section{Diffusion der Zeichen II: Mitleid und Verwunderung}

Die eigentliche Gralprozession entfaltet einen enormem Luxus und wird durch feierliches Gebaren eines einerseits eindeutig höfischen, andererseits exotisch anmutenden Personals begleitet. ${ }^{56}$ Ich gebe nur eine Kernstelle wieder, in der die Gralkönigin den Gral trägt:

ir antlütze gap den schîn,

si wânden alle ez wolde tagen.

man sach die maget an ir tragen

pfellel von Arâbî.

ûf einem grüenen achmardî

truoc si den wunsch von pardîs,

bêde wurzeln unde rîs.

daz was ein dinc, daz hiez der Grâl,

erden wunsches überwal.

$(235,16-24)$

Die Beschreibung von Repanse de Schoye folgt Mustern des synkretistischen Wunderbaren, das sich in frühhöfischen und höfischen Romanen bereits etabliert hat und beim intradiegetischen Betrachter ein Spektrum von Reaktionen hervorrufen kann, die von Staunen und Neugier über admirative Identifikation bis zu Angst reichen. ${ }^{57}$ Dabei werden Vorstellungsbereiche zu Luxus und Exotik

55 In der Forschung ist die Verschränkung von wunder und Trauer bereits besprochen und so interpretiert worden, dass Parzival gerade durch den scharfen Kontrast zu einer Frage hätte angeregt werden müssen. Vgl. die resümierende Diskussion bei Schirok: Die Inszenierung von Munsalvaesche (Anm. 39), S. 49-62. Meines Erachtens sind die emotionalen Appelle der Szene jedoch nicht zu unterschätzen. Parzival soll Mitleid artikulieren, keine Rätsel lösen.

$56 \mathrm{Zu}$ Luxus als einer synästhetischen Konfiguration in der Literatur des Mittelalters vgl. Jutta Eming: Luxurierung und Auratisierung von Wissen im Straßburger Alexander. In: Fremde Luxus - Räume. Konzeptionen von Luxus in Vormoderne und Moderne. Hrsg. von Jutta Eming, Gaby Pailer, Franziska Schößler und Johannes Traulsen. Berlin 2015, S. 63-83.

57 Staunen wird im klerikalen Diskurs komplex motiviert, und es zieht unterschiedliche Reaktionen nach sich, vgl. Caroline Walker Bynum: Metamorphosis and Identity. New York 2005, S. 37-75. Zu antiken Theorien des Staunens, die durch eine Polarität der Konzepte von Platon und Aristoteles bestimmt sind, und ihrer Rezeption in der mittelalterlichen Theolo- 
des Orients aufgerufen und mit Anklängen an Glanz und Glück des Paradieses überblendet; weibliche Schönheit erscheint als Attribut wie als Mediatorin emotionaler Valenzen. Der Gral bildet dabei ein Element unter vielen, wenn auch ein herausragendes.

Anders als im Perceval ist der Gral bei Wolfram ein Stein namens lapsit exillîs $(469,7),{ }^{58}$ eine Bezeichnung, auf deren Entschlüsselung viel Energie verwandt worden ist, ohne dass ein Vorbild gefunden werden konnte. Inzwischen wird eher von einer bewussten Verrätselung ausgegangen. ${ }^{59}$ Er steht in der Tradition eines Verständnisses von Edelsteinen als Vermittlern von Immanenz und Transzendenz, das in magischen Denkmustern und Praktiken verbreitet ist. ${ }^{60}$ Einige der von Wolfram gewählten Umschreibungen für den Gral, nämlich dinc sowie die paradoxale Formel wurzel unde rîs (Wurzel und Spross) entsprechen alchemischen Decknamen für den Stein der Weisen. ${ }^{61}$ Sie bieten damit ein Beispiel für eine maximale Annäherung alchemischer und literarischer Schreibweisen, das den mit den Lehren der ars nova vertrauten Rezipienten des Parzival einen wichtigen Anhaltspunkt für das Verständnis des heilsgeschichtlichen Status' des Grals geben würde. ${ }^{62}$ Auf den Umstand, dass der Gral ein Medium religiöser Kommunikation darstellt, ${ }^{63}$ wird jedoch nur angespielt (wunsch von pardîs), eindeutig ist es nicht. Auch die Dimension des Lichts wirkt nicht (auf)klärend. Die Bezüge zur Geheimlehre und zu magischen Praktiken konstituiert in Verbindung mit der religiös gefärbten Beschreibungssprache eine eher diffuse Transzendenz. ${ }^{64}$

gie, sowie zur Eigendynamik des Staunens in der höfischen und legendarischen Literatur des Mittelalters vgl. auch Stefan Matuschek: Über das Staunen. Eine ideengeschichtliche Analyse. Tübingen 1991.

58 Einem Vorschlag von Harald Haferland zufolge ist ferner in Erwägung zu ziehen, dass es sich um ein Elixier handelt, vgl. ders.: Die Geheimnisse des Grals. Wolframs Parzival als Lesemysterium? In: Zeitschrift für deutsche Philologie 113 (1994), S. 23-51, hier S. 48-49.

59 Vgl. zusammenfassend Bumke: Wolfram von Eschenbach (Anm. 26), S. $139 f$.

60 Vgl. dazu Damaris Gehr: Luxus und Luxusdiskurse in der gelehrten lateinischen Magie des 12. bis 14. Jahrhunderts. In: Fremde - Luxus - Räume (Anm. 56), S. 147-165.

61 Vgl. Haage: Alchemie (Anm. 28), S. 159f., Horchler: Alchemie in der deutschen Literatur des Mittelalters (Anm. 28), S. 346f.

$62 \mathrm{Zu}$ ars nova als hochmittelalterlicher Bezeichnung für die neuen alchemischen Lehren vgl. Haage: Alchemie (Anm. 28), passim.

63 Vgl. dazu die systemtheoretisch angelegte Untersuchung von Susanne Knaeble: Höfisches Erzählen von Gott. Funktion und narrative Entfaltung des Religiösen in Wolframs Parzival. Berlin, Boston 2010.

64 Zur „\#̈̈sthetik des In-der-Schwebe-Lassens“ dort, wo höfisches Erzählen religiös überformt wird, vgl. Uta Störmer-Caysa: Grundstrukturen mittelalterlicher Erzählungen. Raum und Zeit im höfischen Roman. Berlin, New York 2007, S. 224-230, hier S. 228. Vgl. zu Licht im Parzival auch Titus Knäpper: Ex oriente lux. Neues zum Orientalischen im Parzival. In: Artusroman und Mythos. Hrsg. von Friedrich Wolfzettel, Cora Dietl und Matthias Däumer. Berlin, Boston 2011, S. 271-286, mit weiteren Literaturangaben. 
Die Gralprozession folgt also den Konventionen einer im höfischen Roman häufiger mit dem Wunderbaren verknüpften Überwältigungsästhetik. Überwältigend wirkt hier insbesondere die Verbindung von strahlender Schönheit und ritualisiertem Verhalten, deren Hintergrund sich dem nicht eingeweihten Betrachter nicht erschließs - der Sinn des Aufzugs wird nicht klar. ${ }^{65}$ Im Sinne klerikaler Konzepte von Staunen als einem Affekt, der nach Auflösung strebt, aber auch gemäß der literarischen Konvention des Erzählens vom Wunderbaren könnte Parzival nun mit Verwunderung oder mit Neugier reagieren, er könnte Näheres wissen wollen oder er könnte vom Glanz des Auftritts ergriffen sein; es könnte ihm, wie dem Helden des Straßburger Alexander, förmlich das Herz überfließen und sein Staunen und Begehren zum Ausdruck bringen. ${ }^{66}$ Tatsächlich entsteht als Reaktion auf die Gralprozession bei Parzival ein Frageimpuls:

wol gemarcte Parzivâl

die rîcheit und daz wunder grôz:

durch zuht in vrâgens doch verdrôz.

$(239,8-10)$

Aus der berühmten Stelle zum Schweigen des Helden geht hervor, ${ }^{67}$ dass er etwas Ungewöhnliches wahrgenommen hat, doch in Rücksicht auf bestimmte Regeln höfischen Verhaltens (zuht) davon absieht, ihm durch eine Frage nachzugehen. Allerdings gehört die Offenheit der Bezüge dieser Aussage zu den Problemen des Textes, dem entsprechend gibt es unterschiedliche Ansichten zur Referenz von wunder groz. ${ }^{68}$ Wonach genau möchte Parzival fragen, was empfindet er als Wunder? Nach der Bedeutung der geheimnisvollen Prozession, nach dem Grund für das Leiden des immer noch anwesenden Anfortas oder danach, wie beides zusammen passt?

Uta Störmer-Caysa hat die Textstelle vor einiger Zeit im Kontext theologischer misericordia diskutiert und dafür inmitten einer imaginären Runde von mittelalterlichen Dogmatikern Augustinus die Möglichkeit erwägen lassen, „ob sich nicht Parzival, getäuscht durch die theatralische Situation, einem lebenden, leidenden Menschen gegenüber verhalten habe, wie es nur gegenüber einem Schauspieler angemessen wäre, der das Leiden nur spielt: mit ästhetischer Distanz. ${ }^{69}$ Mit der hier entwickelten Lesart, dass der Gralaufzug auf ritualisiertem

65 Vgl. auch die Diskussion bei Knaeble: Höfisches Erzählen von Gott (Anm. 63), dass der Gral diese Vermittlerrolle nur mit Blick auf seine Bezugsgesellschaft einnimmt, S. 214 et passim.

66 Vgl. Eming: Luxurierung und Auratisierung (Anm. 56), S. 78f.

67 Mireille Schnyder: Topographie des Schweigens. Untersuchungen zum deutschen höfischen Roman um 1200. Göttingen 2003, S 146, interpretiert die Stelle so, dass sie ein „,in Gedanken verlorenes" Schweigen markiere. Ob Parzival hier einen regelrechten Reflexionsprozess durchläuft oder eher augenblickshaftes Wahrnehmen aus der Passage spricht, bleibt jedoch offen, vgl. auch unten zu 236, 12-25.

68 Schirok: Die Inszenierung von Munsalvaesche (Anm. 39), S. 59 f.

69 Störmer-Caysa: Mitleid als ästhetisches Prinzip (Anm. 42), S. 91. 
Handeln beruht, ist Störmer-Caysas These, dass er sich in einem Als-Ob-Modus vollziehe, zwar nicht zu vereinbaren. Wichtig ist jedoch der Hinweis, dass Parzival möglicherweise eine ästhetische Haltung einnimmt.

Die Bezeichnung wunder für das, was Parzival in der Szene wahrnimmt, wäre unter dieser Voraussetzung Kennzeichen für eine primär ästhetische Einstellung gegenüber den beobachteten Abläufen um den Gral und seine Herrlichkeit. Ästhetische Haltungen gegenüber dem Wunderbaren werden im (früh-)höfischen Roman insbesondere in Relation mit der Entfaltung des räumlich, zeitlich oder kulturell Anderen konstituiert (Eneasroman, Herzog Ernst oder Straßburger Alexander). Der Besuch auf der Gralburg erhält auch mit Blick auf diese Tradition seine Konturen, als Aufenthalt in einer Anderswelt, die über Semantiken von Luxus, Magie und Schönheit zur Geltung kommt. ${ }^{70}$ Dieser Erzähltradition des Wunderbaren folgend hätte Parzival in der unterdrückten Frage Genaueres über den blendenden Gegenstand erfahren wollen, über die Bedeutung des Aufzugs oder den Sinn der Zusammenkunft. ${ }^{71}$ Der Umstand, dass über den gesamten Ablauf der Passage, in welcher die Gralprozession und ihre Wirkung auf Parzival beschrieben werden, nicht mehr von Anfortas die Rede ist, ließe sich in diesem Zusammenhang als ein Beispiel für eine Psychonarration werten, in welcher die Erzählhaltung kurzfristig Mimikry an die Bewusstseinslage eines Romanhelden betreibt. ${ }^{72}$

Die eingangs gestellte Frage danach, was Parzival sieht - oder wahrnimmt setzt also eine Reihe wichtiger interpretatorischer Entscheidungen voraus. Die Stelle 236,12-25:
dez mære giht das Parzivâl
dicke an si sach unt dâhte,
diu den grâl dâ brâhte:
er het och ir mantel an.

lese ich in diesem Zusammenhang als Bestätigung des früher erläuterten Texteindrucks, dass Parzival in Gedanken versunken auf Repanse de Schoye starrt. ${ }^{73}$ Die Begründung, die der Kommentar dafür gibt - dass er ja auch ihren Mantel anhabe -, betrachte ich als einen für diesen Erzähler typisch hintergründigen Hinweis auf eine offenkundige äußerliche Verbindung, die eine geheime innere Verbindung - dass auch Parzival zum Gralgeschlecht gehört - schon andeutet.

70 Vgl. auch die Überlegungen zum Status von Anderswelten als einem Element des Wunderbaren im höfischen Roman bei Störmer-Caysa: Grundstrukturen (Anm. 64), S. 202-214.

71 Vgl. auch Schnyder: Topographie (Anm. 67), S. 186: „Das Staunen vor dem Wunder müsste durch das Wort gebrochen werden."

72 Zur Psychonarration vgl. Gert Hübner: Erzählform im höfischen Roman. Studien zur Fokalisierung im Eneas, im Iwein und im Tristan. Tübingen, Basel 2003, S. 47-48.

73 Schnyder: Überlegungen (Anm. 43), S. 108, versteht, der anders interpungierten Ausgabe von Nellmann folgend, den letzten Vers als Wiedergabe eines Gedankensprungs Parzivals und schließt gerade auf eine Störung der betrachtenden Aufmerksamkeit. 
Dass eine Frage zu stellen ist, aus der Mitleid mit dem leidenden Burgherrn spricht, versteht Parzival nach meiner Lektüre der Vorgänge selbst dann noch nicht, als die Erzählperspektive nach der Beschreibung der Gralprozession wieder zu Anfortas schwenkt, der Parzival mit den Worten sein Schwert als Geschenk überreicht, dass dieses ihm gute Dienste geleistet habe, bevor er von Gott so sehr bestraft worden sei (vgl. 239,25-27).

Diese zweite Szene, in der offensichtlich an das Mitleid des Gastes appelliert wird, ist erneut zugleich mit Symbolen feudalen Ehrerhalts und Konventionen höfischer Gastlichkeit in einer Weise verschränkt, die eine Nachfrage nicht nahelegt. Die Freigiebigkeit des Herrschers, der einem Gast dadurch Ehre erweist, dass er ihm sein kostbares Schwert zum Geschenk macht (dessen erfolgreiche Handhabung eine Grundlage seiner splendiden Existenz geschaffen haben dürfte), evoziert nach den Prinzipien höfischer Reziprozität den Ausdruck von Freude oder Wertschätzung. Die Verschränkung mit einem Appell an das Mitgefühl des Gastes wirkt vor dem Hintergrund dieser Tradition höfischer Interaktion hingegen befremdlich. ${ }^{74}$

Unter der Voraussetzung der hier vorgeschlagenen Interpretation kommt Parzival also aus dem Grund weder die Frage nach dem Gral noch nach dem Leid des Königs über die Lippen, weil die Inszenierung auf der Gralburg auf der Überblendung von zwei gegenläufigen Elementen beruht: dem auf Überwältigung setzenden, durch diffuse transzendente Bezüge bereits potentiell rätselhaften wunder mit einem mit Affizierung und Partizipation rechnenden Trauerritual. Ebenso gegenläufig sind die rational-emotionalen Involvierungen, welche sie nach sich ziehen: Überraschung, Staunen oder Bewunderung einerseits; Einsicht und Empathie andererseits.

\section{Von Erkenntnis zu Offenbarung}

Die innertextuelle Auflösung der Rätsel, denen Parzival auf der Gralburg begegnet war, macht den Kern seiner nun folgenden Geschichte aus. Dabei kommen unterschiedliche Formen des Wissens und unterschiedliche Modi der Wissensvermittlung zur Geltung: Wissen um religiöse Fundamente des Christentums ebenso wie Wissen um adäquate soziale Interaktion oder Wissen um Herkunft und Genealogie, das Parzival durch Gespräche, Belehrungen, Erfahrungen und Emotionen zuteil wird.

Nach seinem Besuch auf der Gralburg wird Parzival zunächst von seiner Cousine Sigune, dann - unter für ihn äußerst beschämenden Bedingungen - von der hässlichen, zauberkundigen Gralbotin Kundrie und schließlich von dem

74 Mertens Fleury: Leiden lesen (Anm. 41) zufolge tragen Lanze und Schwert in der Gralszene „einen imperativen Anstoß zum affectus compassionis in sich, und stehen damit in einem Spannungsverhältnis zum höfischen Gebot maßvollen Schweigens“ (S. 195). Zu ergänzen ist: Sie stehen aber auch in einem spannungsvollen Verhältnis zur curiositas angesichts von Wundern. 
Einsiedler Trevrizent über die Umstände der Vorgänge auf Munsalvaesche und die Ursachen der Leiden des Anfortas belehrt.

Die Begegnung mit Sigune, die unmittelbar nach Parzivals Weggang von der Gralburg erfolgt, ist gleich in mehrfacher Hinsicht aufschlussreich. Sie illustriert, dass Parzival in der Lage ist, Mitgefühl zu empfinden und zu artikulieren, wenn die Zeichen der Trauer stimmig sind. Angezogen durch Sigunes Klagelaute, die er von Ferne wahrnimmt, findet er sie in Pietà-förmiger Haltung im Wald, den einbalsamierten Geliebten im Schoß, und nimmt in seiner Begrüßung sofort auf ihre Trauer Bezug: ${ }^{75}$

Parzivâl si gruozte unde sprach

,frouwe, mir ist vil leit

iwer senelîchiu arebeit.'

$(249,26-28)$

Im Gespräch mit ihr erklärt er dann, auf der Gralburg rîcheit $(250,15)$ wahrgenommen zu haben: grœzlîch wunder ich dâ sach, I unt mange frouwen wol getân $(251,26 f$.$) . Er erfährt von Sigune erstmals, wo er gewesen ist und was von ihm$ erwartet worden war, und er hört, dass er nicht einfach zurückkehren kann, um seinen Fehler zu korrigieren. Auf die Gralburg kommt niemand, der sie sucht: ez muoz unwizzende geschehen $(250,29) .{ }^{76}$ Seine Äußerungen gegenüber Sigune unterstützen den Eindruck, dass es vor allem der Luxus der Gralburg war, der auf ihn wirkte, nicht das Leiden des Burgherrn. ${ }^{77}$

Die dritte Figur, die gegenüber Parzival die Geschehnisse auf der Gralburg nachträglich und diesmal umfassend kommentiert, ist der Einsiedler Trevrizent. Seine Erklärungen stellen die Ereignisse retrospektiv in einen komplexen transzendenten Zusammenhang, in dessen Konstruktion sich religiöse und magischalchemische Traditionen - insbesondere solche der gelehrten Kosmogonie -

75 Vgl. auch Störmer-Caysa: Mitleid als ästhetisches Prinzip (Anm. 42), S. 86f. Auch Schirok: Die Inszenierung von Munsalvaesche (Anm. 39) sieht den ersten Aufenthalt auf der Gralburg in enger Verbindung zur anschließenden Begegnung mit Sigune, vgl. ebd., S. 65f.

76 Die abschließende Rede von Sigune, 255, bindet selbstverständlich beide Elemente zusammen, die ich für die Analyse getrennt hatte, wunder changiert dabei zwischen Gral, Gralprozession und Gottesstrafe.

77 Vgl. Mertens Fleury: Leiden lesen (Anm. 41), S. 138f. Beim Einsiedler Trevrizent offenbart Parzival, dass er derjenige sei, der das Unglück Anfortas' gesehen habe, aber aus der Formulierung $(488,17)$ geht nicht klar hervor, ob dies sein tatsächliches Erleben auf der Gralburg wiedergibt oder nicht, ob in die Formulierung nicht vielmehr das mittlerweile erworbene Wissen eingeht. Anders Mertens Fleury, vgl. S. 143. Vgl. auch Schu: Vom erzählten Abenteuer (Anm. 39), S. 278: „Seine Wahrnehmung war so eingeschränkt auf rîcheit, wunder und zuht, daß er die Trauer der Versammlung nicht registrieren konnte." Vgl. zu den Prozessen der Wahrnehmung während des ersten Besuches auf Munsalvaesche außerdem Kenneth J. Northcott: Seeing and Partly Seeing: Parzival's Encounters with the Grail. In: Spectrum medii aevi. Essays in Early German Literature in Honor of George Fenwick Jones. Hrsg. von William C. McDonald. Göppingen 1983, S. 409-428. 
ineinander verflechten. Durch Trevrizent erfährt Parzival von der Natur des Grals als einer Gnadengabe Gottes, von der Struktur der Gralgesellschaft und der Geschichte ihres Königs, aber auch von seiner Wunde, die in Abhängigkeit vom Stand der Sterne mehr oder weniger schmerzt; er hört, dass die Gralberufung in Form einer Schrift erfolgt, die in Abhängigkeit von Planetenkonstellationen auf dem Gral erkennbar wird; er hört weiter, dass die Geschichte des Gral selbst in einer Sternenschrift am Himmel erschienen ist und in dieser arkanen Form vom Heiden Flegetanis kopiert wurde. ${ }^{78}$

Während sich die astrologischen Dependenzen, die Trevrizent erläutert, relativ leicht auf magische Denkmuster hin transparent machen lassen, sind die Bezüge zur Alchemie weniger offensichtlich und infolgedessen diskussionsbedürftig. Unter der Voraussetzung, dass der alchemische Prozess der ,Läuterung' im Mittelalter mit spirituellen und Erkenntnis-Prozessen korreliert oder analogisiert wurde, bildet die Form der Belehrung, die Parzival durch Trevrizent zuteil wird, ein Beispiel: Sie zeigt Parallelen zur Lehrer-Schüler-Konstellation, die in einigen Texten des Corpus Hermeticum überliefert ist; Trevrizent würde demnach Züge des Hermes Trismegistos tragen. ${ }^{79}$ In eine verschlüsselte Quellenangabe, mit der sich im Kontext der Trevrizent-Episode an markanter Stelle der Erzähler einschaltet, sind eventuell die Motive der alchemischen Geheimschrift und Auffindungslegende eingegangen. ${ }^{80}$ Harald Haferland sieht in der Inserierung hermetischer Motive in den Parzivalroman Hinweise darauf, dass der geheime Charakter der Wirkweisen des Grals unterstrichen werden sollte. ${ }^{81}$

Mich interessieren diese Verrätselungsstrategien dagegen auf der Ebene, die speziell den Wissenszuwachs der Hauptfigur in Relation zu Schreibweisen des Wunderbaren betrifft. Als Ansatzpunkt dient mir die These von Bernhard Haage, dass Trevrizent „den Protagonisten zur inneren Läuterung [bringt], und zwar auf hermetisch-gnostischem Wege durch Erkenntnis seiner selbst, des Mikro- wie des Makrokosmos. "82 Das (al-)chemische Konzept der Läuterung und

78 - indem er, so die Lesart von Peter Strohschneider, sich an der Materialität der Schrift orientierte, ohne ihren Zeichenwert zu verstehen, vgl. ders.: Sternenschrift (Anm. 24), S. 53-55. Vgl. auch die dazu noch etwas weiter gefassten Überlegungen zur Auratisierung des Textes in: Peter Strohschneider: Höfische Textgeschichten. Über Selbstentwürfe vormoderner Literatur. Heidelberg 2014, S. 54-56.

79 Diese Auffassung vertritt insbesondere Haage: Alchemie (Anm. 28), vgl. S. 159f. In welchem Umfang Alchemie als Praxis der Metallverwandlung mit religiösen oder geheimwissenschaftlichen Lehren in Verbindung verbunden war, ist umstritten, vgl. dazu den Artikel "Alchemie I. Religionsgeschichtlich" von Sven S. Hartmann. In: Theologische Realenzyklopädie 2 (1978), S. 195-199. Joachim Telle macht für das Mittelalter vornehmlich einen Doppelcharakter der Alchemie zwischen naturphilosophischer scientia und praxisbezogener ars geltend, vgl. ders.: Alchemie II. Historisch. In: Theologische Realenzyklopädie 2 (1978), S. 199-227, hier S. 202f.

80 Vgl. Haferland: Geheimnisse des Grals (Anm. 58), S. 41f.

81 Vgl. Haferland: Geheimnisse des Grals (Anm. 58), S. 49.

82 Haage: Alchemie (Anm. 28), S. 82f. 
Erkenntnis arkaner Zusammenhänge variiert die These der ,inneren Umkehr', die in der älteren Parzival-Forschung als Sinn der Trevrizent-Begegnung galt, inzwischen aber vielfach in Frage gestellt wird. Zwar besteht an der magischkosmologischen Ausrichtung von Trevrizents Belehrungen kein Zweifel, doch bleibt - so hat insbesondere Bumke zu bedenken gegeben - völlig unklar, wieviel von diesen Belehrungen grundsätzlich bei Parzival ,ankommt'. ${ }^{83}$ Die Berechtigung eines Bezugs zur alchemischen ,Läuterung' müsste sich folglich in irgendeiner Weise an einer Veränderung in Parzivals Verhalten erhärten lassen.

Parzival verhält sich nach anfänglichen Widerständen dialogbereit, was sein Verhältnis zu Gott betrifft, ${ }^{84}$ aber er zeigt sich nach dem Besuch auf der Gralburg weder umkehrwillig, noch einsichtig oder regelrecht wissbegierig. Die Kenntnisse über den Hintergrund seiner Erlebnisse werden ihm allmählich durch die Erzählungen der anderen meist ungefragt zuteil. ${ }^{85}$ Dies ist umso auffälliger, als er als Kind und Heranwachsender als durchaus neugierig gezeichnet wird. ${ }^{86}$

Anders als sein alter ego, der komplementär konzipierte Romanheld Gawein, der immerhin einen Zauberbann löst, wird Parzival kontinuierlich nur darin aktiv, dass er sich in ritterlichen Kämpfen engagiert. ${ }^{87}$ In Reaktion auf Trevrizents lange Erzählung über die Templeisen, den Gral, seinen heilsgeschichtlichen Status und die Umstände der Gralbotschaft äußert Parzival erstmals eine Ahnung über seine Zugehörigkeit zur Gralgesellschaft - doch er tut es in einer Weise, welche die religiösen Lehren, die ihm gerade zuteil geworden sind, beinahe vollständig ausblendet und stattdessen, einigermaßen deplaziert, seine Freude am ritterlichen Kampf akzentuiert:

ist got an strîte wîse,

der sol mich dar benennen,

83 Vgl. Bumke: Wolfram von Eschenbach (Anm. 26), S. 92 f.

84 So auch Schu: Vom erzählten Abenteuer (Anm. 39), S. 294ff., welche zentrale Argumente dafür versammelt, dass Parzival nach dem Besuch bei Trevrizent mit dem gleichen ,Programm' ausgestattet sei wie früher. Dazu gehöre auch, dass „Parzival weiterhin wahllos gegen jeden kämpft, der ihm begegnet" (S. 294).

85 John Greenfield hat herausgearbeitet, dass Parzival während seines Aufenthalts bei Trevrizent mehr Fragen stellt als an irgendeiner anderen Stelle des Romans, insgesamt 10 Fragen. Vgl. ders.: sîner frâge maht and the Question in the Quest. Verfügbarkeit of the Grail in Wolfram's Parzival? In: Unverfügbarkeit. Hrsg. von Ingrid Kasten (Paragrana 21/2; 2012), S. 132 147, hier S. 142. Dies ist summarisch fraglos richtig, doch mit Blick auf die Länge der Belehrungen Trevrizents immer noch sehr wenig, zudem es sich um sehr unterschiedliche Fragen handelt. Und, wie Greenfield hervorhebt, keine der Fragen kann die Natur des Gral aufklären-gerade durch diese Unverhältnismäßigkeit erscheint er als unverfügbar. Vgl. ebd., S. 146.

86 Dies betont jetzt Baisch: Ästhetisierung und Unverfügbarkeit (Anm. 6), S. 228 et passim.

87 Vgl. auch Schu: Vom erzählten Abenteuer (Anm. 39), S. 295ff., jetzt auch Müller: Percevals Fragen (Anm. 35). 
daz si mich dâ bekennen:

mîn hant dâ strîtes niht verbirt.

$(472,8-11)^{88}$

Auch nach seinem Besuch bei Trevrizent zeigt er „kaum Reaktionen, die von einer wirklichen Erkenntnis zeugen. "89 Zwar wird ihm allmählich ein immenses Wissen zugänglich, das über die Vorgänge auf der Gralburg hinaus die Kenntnis seiner art betrifft sowie seiner Verwandtschaft, ihrer Lebensgeschichten und Konflikte. Am Ende des Romans ist ein äußerst engmaschiges Netz von Verwandtschaftsbeziehungen um Parzival offengelegt; durch die Integration des Bruders Feirefiz werden Orient und Okzident versöhnt und Parzival hat Wesentliches über die verborgenen Beziehungen von Mikro- und Makrokosmos erfahren; aber inmitten dieser weltumspannenden Bezüge steht er bis zum Schluss scheinbar passiv, "gelenkt und abhängig von den Aussagen des Grals, von Gottes Hand, von der Setzung durch den Erzähler". ${ }^{90}$ Wenn eine ,Läuterung' im Stile der alchemischen Praktik und Geheimlehre für Parzivals Erkenntnisweg Modell gestanden haben sollte, dann bleibt das Rezept verschlüsselt. ${ }^{91}$ Abgesehen von dem - allerdings entscheidenden - Fakt, dass er bei seinem zweiten Besuch auf der Gralburg alles richtig macht und seinen initialen Fehler ,korrigiert', werden weder Wissensdrang noch Erkenntniszuwachs von ihm in einer irgendwie erkennbaren, konventionellen Form reflektiert, ausgesprochen oder verkörpert. ${ }^{92}$

Parzivals ,Schuld', so formulierte Bernd Schirok vor einiger Zeit forciert, sei nichts als das Resultat einer Projektion vom Wissen anderer, eines Wissens, das

88 Diese Orientierung am Rittertum ist, wie Müller: Percevals Fragen (Anm. 35), S. 44 betont, im Horizont höfischen Erzählens allerdings ganz folgerichtig. Aus dem Umstand, dass Wolfram zeigt, dass der ritterliche Kampf mit Schuld verbunden ist, werde kein Vorwurf abgeleitet.

89 Annette Gerok-Reiter: Individualität. Studien zu einem umstrittenen Phänomen mittelhochdeutscher Epik. Tübingen, Basel 2006, S. 142. Das "Ziel der Selbsterkenntnis“, so GerokReiter, dränge zwar an die „Textoberfläche“ (S. 142), werde jedoch nicht wirklich dargestellt.

90 Gerok-Reiter: Individualität (Anm. 89), S. 144.

91 Dies widerspricht nicht unbedingt der Möglichkeit, dass der Aufenthalt bei Trevrizent vom asketischen Modell der Buße geprägt ist, wie es Marina Münkler diskutiert hat, vgl. dies.: Buße und Bußhilfe. Modelle von Askese in Wolframs von Eschenbach Parzival. In: Deutsche Vierteljahrsschrift für Literaturwissenschaft und Geistesgeschichte 86 (2010), S. 131-159.

92 Anders jetzt Elisabeth Lienert: Können Helden lernen? Wissen und Subjektkonstitution in europäischen Parzivalromanen. In: Wolfram-Studien XXIII (Anm. 6), S. 251-267. Lienert begründet ihre These, dass Parzival nach dem Besuch auf der Gralburg durchaus lernfähig sei, vor allem mit dem Argument, dass er Trevrizents Lehren nicht einfach reproduziere, sondern in seinem Verhalten in einigen Punkten von diesen abweicht. Vgl. ebd., S. 265f. Mir scheint dies eine Lernfähigkeit, welche in letzter Instanz die Rede „in einem beinahe modernen, individualisierten Sinne von Subjektkonstitution" rechtfertigt (vgl. ebd., S. 266), jedoch nicht hinreichend stützen zu können. Und auch Lienert hält fest: „Durch Parzivals unerwartete Berufung zum Gral werden die Wissenden kompromittiert.“ (ebd., S. 265). 
er selbst nicht haben konnte. ${ }^{93}$ Aus moderner Perspektive muss es so erscheinen, doch kommt man nicht daran vorbei, dass der Text es anders möchte: Der Roman arbeitet konsequent mit der Unterstellung, dass Parzival eine Frage hätte stellen müssen und folglich hätte stellen können. Obwohl er auf seinem weiteren Weg kein Wissen erwirbt, welches sich klar auf ein ,Fehlverhalten' im Sinne einer habituell-empathischen Defizienz oder einer fehlenden Einsicht in die Geheimnisse des Grals beziehen ließe, affirmiert der zweite Besuch auf der Gralburg, auf dem er alles richtig macht, die Berechtigung der initialen Erwartung.

Dies legt den Schluss nahe, dass sich die Struktur des Umgangs mit Wissen selbst, vor allem die Wege seiner Vermittlung und seiner Applikation verschoben haben. In Wolframs Parzival fällt Wissen der Figur zu, für die es vorgesehen ist, von der es aber weder unmittelbar angeeignet noch gesucht werden kann. Eine Möglichkeit zur Erkenntnis ist prinzipiell gegeben, doch die Umstände des Erkennens werden äußerst verkompliziert und in Abhängigkeit von Konstellationen gerückt, die der Protagonist nicht beeinflussen kann. Diese Logik wird bis an die Grenzen des Paradoxen getrieben: Das Wissen, um das es geht, ist exklusives Wissen, es wird einem Berufenen zuteil, dieser Berufene ist jedoch nicht der Begabte, sondern der tumbe. Tumbheit ist in diesem Kontext Reflexionsfigur des Umstands, dass der Transfer von Wissen konsequent verrätselt wird.

Dadurch wird auch die an Parzival exemplifizierte Korrektur einer Verfehlung zum Prozess, den er kaum aktiv vorantreibt. Eine Parallele zu alchemischmagischem Denken sehe ich deshalb auch darin, dass sein Wissenserwerb auf den Offenbarungen verborgener Zusammenhänge durch verschiedene Figuren beruht und sich bei Trevrizent einer regelrechten kosmologischen Initiation annähert. Die Darstellung von Parzivals Erkenntnisprozess zeigt dadurch Analogien zum Erzählen von Geheimwissen.

Dies radikalisiert eine Tendenz, die im Wunderbaren immer schon angelegt war, nämlich etwas zu sein, was dem Ausgezeichneten zufällt. ${ }^{94}$ In letzter Instanz verändert Wolfram damit auch das Helden- und Aventiureschema des höfischen Romans: Nicht nur die âventiure fällt dem Helden zu, sondern auch Wissen.

Ich lese Wolframs Parzival ausgehend von der Gralszene also im Kontext der Kontinuität eines Erzählens vom Wunderbaren im mittelalterlichen Roman. Die Gralszene bildet das zentrale Beispiel für ein Erzählen, das aus verschiedenen Archiven zeitgenössischen Wissens schöpft und sie dann in einer Form rekontextualisiert, welche sich als das Wunderbare begreifen lässt. Dies habe ich anschließend insbesondere an den Modi der Vermittlung weiter verfolgt, die Parzival über die Hintergründe des Vorgangs erhält. Magisch-alchemisches Wissen beeinflusst die Inhalte dieser Schreibweise: durch Trevrizents Lehren von Mikround Makrokosmos, aber auch durch die Verflechtung von magischen und reli-

93 Schirok: Die Inszenierung von Munsalvaesche (Anm. 39), S. 73.

94 Vgl. Schmid: Da staunt der Ritter (Anm. 48), S. $93 f$. 
giösen Motiven in den Vorgängen um den Gral, durch die sich Wolfram in der zeitgenössischen Diskussion um beider Verhältnis zueinander eigens positioniert. Durch Verbindungen zwischen Magischem und Religiösem, die sein Erzählen inszeniert, wird das Unverfügbare zugleich in die Erzählung eingeholt und konsequent verrätselt.

Magisch-alchemische Wissenstraditionen prägen den Roman darüber hinaus in seiner Struktur. Analog scheint mir insbesondere das Prinzip, den Helden einerseits sukzessive in ein immer komplexeres Netz von Bezügen zu rücken das Netz aus Verwandtschaft, genealogischer Folge und Position, Konflikten und Geschichten, in denen das Gralgeschlecht steht - und die Möglichkeit, ihm Zugang zum Wissen um diese Bezüge zu gewähren, zugleich konsequent zu problematisieren. Durch die nachträglichen, sukzessiven und teilweise widerrufenen Erläuterungen ebenso wie durch die bis zum Ende des Romans nicht zu entscheidende Frage, was überhaupt in Parzivals Bewusstsein gedrungen ist, wird der Status eines Arkanwissens auch für Zusammenhänge behauptet, die Parzivals Verwandtschaft und Identität betreffen. Es ist ein Wissenstransfer, der sich kaum in Handlungsvollzügen niederschlägt. Am Ende geht es um ein Aufdecken, gleichsam Freilegen von Bezügen, aber nicht um Erkenntnis, und erst recht nicht um Abenteuer.

Wissen und Erkenntnis werden im Parzival in dieser Weise in ihren Vollzugsund Erwerbsformen zum Geheimnis und in ihren Inhalten zur Offenbarung. An Parzival wird exemplarisch, dass Wissen verborgen ist, aber für den, dem es zugänglich wird, umfassende Kenntnisse über Ich und Gesellschaft, Gott und die Welt bereithält. Den modernen Interpreten bereitet diese Verschlüsselung unabsehbare Probleme. Im Roman entfaltet das Geheimnis über die Darstellungsmodi des Wunderbaren hingegen einen verführerischen Glanz. Magie und Alchemie sind durch die literarische Inszenierung ebenso partiell ent-dämonisiert und $\mathrm{zu}$ ästhetischen Phänomenen verschoben, wie sie die höfische Dichtung mit einer neuen Sphäre des Unverfügbaren aufladen. Gattungsgeschichtlich hat sich die Konfiguration des Wunderbaren als einer Möglichkeit, Wissen zu erlangen, damit in einer Weise verschoben, die im sogenannten nachklassischen Roman teilweise Schule machen wird: im Wigalois Wirnts von Gravenberc und in den sogenannten Wunderketten der Crône Heinrichs von dem Türlin. In ihnen kehrt eben die Passivität angesichts einer verrätselten Bilderfülle wieder, die sich in Parzivals paralysierter Haltung auf der Gralburg angekündigt hat. ${ }^{95}$ Es ist vielleicht kein Zufall, dass für genau diese Wunderketten bereits der Begriff des Phantastischen geltend gemacht worden ist. ${ }^{96}$

95 Vgl. dazu zuletzt Matthias Däumer: Stimme im Raum und Bühne im Kopf. Über das performative Potenzial der höfischen Artusromane. Bielefeld 2013, S. 214-218.

96 Von Johannes Keller: Fantastische Wunderketten. In: Das Wunderbare (Anm. 11), S. 225248. 
(C) 2015, Otto Harrassowitz GmbH \& Co. KG, Wiesbaden ISBN Print: 9783447104951 - ISBN E-Book: 9783447194129 


\title{
Transmutation und Veredelung in Gottfrieds Tristan*
}

\author{
Antje Wittstock, Mannheim
}

Dixit ei Calid: „Quenam est ista res?" Ac iste respondit: „Audivi iam a multis quod tu es homo qui incessanter perquirere non desinis opus quod apud philosophos maius opus nuncupatur. Et ego faciam te scire hoc cum quodam homine romano qui est heremita in montibus Ierosolimitanis, nam suum locum iam bene cognovi. Et iste in unoquoque anno multum aurum Ierosolimam transmittit.."

(„Was ist das für eine Neuigkeit?“, fragte Khalid. Und jener antwortete: „Von vielen habe ich gehört, dass du derjenige bist, der unaufhörlich nach dem Verfahren sucht, das die Philosophen das Große Werk nennen. Ich werde dir zu diesem Wissen durch einen gewissen Römer verhelfen, der als Einsiedler in den Bergen von Jerusalem lebt und dessen Wohnort ich sehr gut kenne. Jedes Jahr schickt er große Mengen an Gold nach Jerusalem.")

In einem Lehrgespräch zwischen dem arabischen Prinzen Khalid und dem Mönch Morienus weiht dieser ihn in die Geheimnisse des ,Großen Werks' ein, das neben der Herstellung von Gold mittels des Steins der Weisen auch die Beschreibung anderer alchemistischer Verfahren und Weisheiten verhandelt. Dieser Text, der in der lateinischen Übersetzung des Robert von Chester von 1144 als De Compositione alchemiae vorliegt, gilt als die erste bekannte Übertragung eines alchemistischen Textes ins Lateinische und markiert damit den Anfang der nachweisbaren Rezeption der Alchemie aus dem Arabischen. Zahlreiche Übersetzungen sowie dann eine stetig zunehmende Produktion alchemistischer Tex$\mathrm{te}^{2} \mathrm{ab} 1200$ belegen ein immenses Interesse an dieser ars nova. Hierzu trug sicher-

* Die folgenden Überlegungen zum Tristan stellen einige exemplarische Lesarten zur Diskussion, die im Zusammenhang einer größeren laufenden Arbeit stehen. Für Hinweise und kritische Anmerkungen danke ich besonders Thomas Cramer, Jutta Eming, Katharina Philipowski und Tilo Renz sowie den Diskutanden des Mediävistischen Colloquiums der Humboldt Universität zu Berlin unter der Leitung von Hans Jürgen Scheuer.

1 Zit. nach: Testament of Alchemy. Being the Revelations of Morienus, ancient adept and hermit of Jerusalem to Khalid ibn Yazid ibn Mu'Awiyya, King of the Arabs, of the divine secrets of the Magisterium and Accomplishment of the Alchemical Art. Edited and Translated from the Oldest Manuscripts, with Commentary by Lee Stavenhagen. Hanover, New Hampshire 1974, S. 4. Übersetzung von mir.

2 In der ersten Hälfte des 13. Jahrhunderts wächst das lateinische Schrifttum der Alchemie stark an: Neben den Übersetzungen aus dem Arabischen ist auf die eigenständig auf Latein 
lich die Zwischenstellung der Alchemie im bisherigen Wissenschafts- und Denksystem der artes bei, die durch ihre sowohl praxisorientierten als auch philosophisch-spekulativen Anteile zwischen ars und scientia oszillierte und bei ihrer Rezeption je unterschiedlich gewertet und verortet wurde. ${ }^{3}$ Sicherlich war es auch das alchemistische Anliegen der Goldherstellung und des Veredelns von Stoffen, insbesondere von Metallen, das faszinierte und die Rezeption anregte und damit von Anfang an auch den Vorwurf des Betrügerischen mit sich brachte. ${ }^{4}$ Dies ist die Wahrnehmung, die die Alchemie auch bis heute wesentlich prägt und die sie lange nach ihrer Verurteilung im Zuge der Aufklärung noch nicht ganz aus der ,Schmuddelecke' des Anrüchigen und Versponnenen herausholen konnte.

Darauf fokussiert, bleibt jedoch ein zentraler Aspekt der Alchemie weitgehend ausgeklammert, der für die Rezeption um 1200 ganz wesentlich berücksichtigt werden muss: Denn zu den Grundthemen der Alchemie gehören vor allem die Annahme einer Entsprechung von organischer und anorganischer Natur; das heißt die Idee, dass die Prozesse des Organischen auch im Anorganischen ablaufen (auch Metalle zum Beispiel, wachsen nach') und es hier gleiche Prozesse, wie Zeugung, Geburt, Heranreifen und Tod gibt. Auf der Grundlage tradierten Wissens und nach festgelegten Regeln will Alchemie in diese Prozesse eingreifen mit dem Ziel, diese zu beschleunigen bzw. die Materie zu verwandeln

verfassten Texte mit einer Vielzahl von Pseudo-Schriften zu verweisen, wie z.B. von Albertus Magnus, Thomas von Aquin oder Raymundus Llullus, deren Zuordnung nicht abschließend zu klären ist. Auch findet neben reich vorhandener Rezeptliteratur die ars nova Aufnahme in die großen Enzyklopädien von Thomas' von Cantimpré Liber de natura rerum, Bartholomaeus Anglicus' De proprietatibus rerum und Vincentius' von Beauvais Speculum maius. Schließlich ist auf die ,alchemistische Autorität' des Mittelalters zu verweisen, den sog. Geber latinus oder Pseudo-Geber, der um 1300 auftritt und dessen Texte (vgl. insbes. Summa perfectionis magisterii) für die Folgezeit prägend sind.

3 Albertus Magnus hielt die Alchemie z.B. für eine Abteilung der Gesteinskunde, andere bezogen die Metallurgie mit ein; auch die technologische Chemie in Gestalt der Färbertechnik und der Glasmacherei wurde bisweilen zur Alchemie gerechnet. Roger Bacon spricht von Medizinbereitung, die heute in den Bereich der Pharmazie fallen würde. Der Standort innerhalb des Systems der artes war also nicht fix. Vgl. Hans-Werner Schütt: Auf der Suche nach dem Stein der Weisen. Die Geschichte der Alchemie. München 2000, bes. Kap. „Ars oder Scientia", S. 378-382. Zum Alchemiebegriff und seiner Geschichte vgl. auch die umfangreiche Literatur von Joachim Telle; einschlägig z.B. sein Lexikonartikel: Joachim Telle: Alchemie. II. Historisch. In: Theologische Realenzyklopädie. Bd. 2. Hrsg. von Gerhardt Krause und Gerhard Miller. Berlin, New York 1977, S. 199-227.

4 Die Alchemie als zwielichtige Goldmacher- und Fälscherkunst ist vielfach dargestellt und diskutiert worden. Einen Einblick gibt z.B. die Einführung zur Geschichte der Alchemie von Schütt: Auf der Suche nach dem Stein der Weisen (Anm. 3), bes. S. 382-390, der für das Mittelalter insbesondere auf die Verbote der Alchemie am Ende des 13. Jahrhunderts hinweist. So verbot das Generalkapitel der Dominikaner 1287 in mehrfachen Beschlüssen die Ausübung der Alchemie, 1317 erließ Papst Johannes XXII. seine Bulle Spondent quas non exhibent. Schütt zufolge richteten sich diese Verbote weniger gegen die naturphilosophischen und spekulativen Aspekte der Alchemie, sondern wurden ökonomisch begründet. 
oder genauer: zu veredeln. Während dieser Aspekt der Transmutation, der sich vorrangig auf die Umwandlung unedler Metalle in Gold oder Silber bezog, ${ }^{5}$ der Alchemie vorbehalten war, stehen die Fragen nach der Regelhaftigkeit und Gesetzmäßigkeit durchaus im Zusammenhang mit Themen, die auch die Naturphilosophie der sog. Schule von Chartres beschäftigte. Zur Frage der ,entdeckten Natur' und den Begründungsversuchen einer scientia naturalis im 12. Jahrhundert heißt es bei Speer:

An die Stelle der symbolisch-spekulativen Interpretation der Natur, die in hermeneutischer Parallele zum Buch der Schrift ebenfalls als „Buch“ gelesen wurde mit Bezug auf Gott als den Autor beider Bücher, durch welche der Mensch gleichermaßen den Schöpfer zu erkennen vermag, tritt zunehmend ein originäres Interesse an der Struktur, Konstitution und Eigengesetzlichkeit der physisch-physikalischen Realität, welche die Vernunft ohne Rückgriff auf traditionelle, theologisch bestimmte Deutungsmuster als in sich sinnvolle Größe zu erfassen vermag. ${ }^{6}$

Zwar taucht der Begriff der Alchemie nicht explizit in den Texten der Schule von Chartres auf, jedoch wird bereits am Beispiel des ,Buchs der Natur' sichtbar, dass sich die Fragestellungen im Kern sehr ähneln: Sowohl die Naturphilosophie der Chartrenser als auch die auf Erfahrung und Experiment ausgerichtete Alchemie des 12. und 13. Jahrhunderts ${ }^{7}$ gehen - in Abgrenzung von einem spekulativ-religiösen Ansatz ${ }^{8}$ - von Regeln und Gesetzmäßigkeiten der natürlichen Dinge aus, die es aufzufinden gilt. Während die Naturauffassung der Vertreter der Schule von Chartres jedoch als „Natur ohne Buch“9 $\mathrm{zu}$ resümieren wäre,

5 Der Transmutationsgedanke ließ sich theoretisch durch die aristotelische Elementen- und Transmutationslehre begründen, die jedoch in dem entscheidenden Punkt modifiziert wurde, dass die Urmaterie in Substanz isoliert werden konnte. Bei dem hieraus abgeleiteten Transmutationsprozess mussten zunächst geeignete Ausgangsstoffe auf die Urmaterie zurückgeführt werden, die dann Schritt für Schritt durch Zuführung der erforderlichen Eigenschaften derart verändert werden musste, bis die Stufe des Silbers oder des Goldes erreicht war. Den Erfolg des Prozesses glaubte man daran ablesen zu können, dass dabei eine bestimmte Folge von Farben durchlaufen wurde.

6 Andreas Speer: Die entdeckte Natur. Untersuchungen zu Begründungsversuchen einer ,scientia naturalis' im 12. Jahrhundert. Leiden 1995, S. 1.

7 Bereits die arabische Alchemie hatte sich im Gegensatz zur griechisch-ägyptischen durch eine Tendenz zur ,Verwissenschaftlichung' und deutlicher Hinwendung zu Erfahrung und Experiment ausgezeichnet; eine Tendenz, die mit der lateinischen Alchemie weiter ausgebaut wurde.

8 Vgl. hierfür Alanus ab Insulis: omnis mundi creatura / quasi liber et pictura / nobis est et speculum. In: Alani de insulis doctoris universalis opera. Accurante Jacques Paul Migne. Paris 1855, Reprint Turnhout 1965, Bd. 210, 579a.

9 Der Ausdruck "la nature sans livre“ stammt von Jean Jolivet: Les Quaestiones naturales d'Adélard de Bath ou la nature sans le Livre. In: Études de civilisation médiévales. Poitiers 1974, S. 437-446, hier zitiert nach Speer: Die entdeckte Natur (Anm. 6), S. 35. 
wird das ,alchemistische Lesen' im ,Buch der Natur' geradezu zu einer Metapher für alchemistische Theorie und Praxis. ${ }^{10}$

Der vorangegangene Exkurs in zentrale Grundannahmen der Alchemie zeigt, dass sie im Zusammenhang mit naturphilosophischen Fragestellungen und Themen steht, die im 12. und 13. Jahrhundert beschäftigten, und die in durchaus nennenswertem Umfang rezipiert wurden. Dass sie heute in der mediävistischen Forschung dennoch so wenig als ,Folie' für das 13. Jahrhundert präsent ist, dürfte vor allem dem spezifischen wissenschaftsgeschichtlichen Fokus bisheriger Forschung geschuldet sein. Dabei bringt das um 1200 rezipierte alchemistische Wissen Themen ein, die bestehende Denksysteme ergänzen konnten, und zu denen insbesondere der Aspekt des Verwandelns und Veredelns gehört oder ,alchemistisch' formuliert: die Transmutation. Inwiefern dieses Konzept auch für die Literatur um 1200 produktiv gemacht wird, ist im Folgenden am Beispiel von Gottfrieds von Straßburg Tristan zu fragen. Diesem Ansatz liegen folgende Überlegungen zugrunde:

1. Angesichts der Überlieferungssituation wird davon ausgegangen, dass zu Beginn des 13. Jahrhunderts alchemistische Texte kursierten, wie insbesondere die bereits genannte Übersetzung von Morienus' De Compositione Alchemiae, die als mögliche Quelle für alchemistisches Wissen um 1200 gelten kann. ${ }^{11}$ Auch wenn dies durchaus noch Desiderat bei der Aufarbeitung des Themas wäre, liegt das Abgleichen von relevanten Quellen im Zuge eines historisierendpositivistischen Zugangs nicht im Interesse des vorliegenden Beitrags. Gleichzeitig liegen Untersuchungen vor, die die Bedeutung fachwissenschaftlichen Wissens für Gottfrieds literarisches Werk und seine Verortung im zeitgenössischen naturphilosophischen Diskurs belegen. ${ }^{12}$

2. Auch geht es in den folgenden Überlegungen nicht darum, eine alchemistische Symbolik im Tristan zu dokumentieren, ${ }^{13}$ wie dies bereits von Clark /

10 Vgl. dazu Helmut Gebelein: Alchemie. München 2000, bes. S. 119.

11 Auf die generelle Problematik von Text- und Wissenstransfer sowie die Schwierigkeit einer stichhaltigen Nachweisbarkeit kann hier nicht weiter eingegangen werden. Exemplarisch zu dieser Diskussion vgl. Antje Wittstock: Melancholia translata - Marsilio Ficinos Melancholiebegriff im deutschsprachigen Raum des 16. Jahrhunderts. Göttingen 2011, bes. S. 11-29.

12 Für den hier vorliegenden Zusammenhang nach wie vor einschlägig ist die Studie von Christoph Huber: Die Aufnahme und Verarbeitung des Alanus ab Insulis in mittelhochdeutschen Dichtungen. Untersuchungen zu Thomasin von Zerklaere, Gottfried von Straßburg, Frauenlob, Heinrich von Neustadt, Heinrich von St. Gallen, Heinrich von Mügeln und Johannes von Tepl. München 1988, bes. S. 79-135.

13 Dass alchemistische Symbolik in literarischen Texten des Hochmittelalters präsent und bedeutsam ist, ist auch für andere Beispiele belegt, insbesondere für den Parzival von Wolfram von Eschenbach sowie die Spruchdichtung. Im Überblick dazu Horchler, der die Literatur des Hochmittelalters jedoch nur in einem knappen Seitenblick streift und daher nur bedingt aussagekräftig ist, vgl. Michael Horchler: Die Alchemie in der deutschen Literatur des Mittelalters. Ein Forschungsbericht über die deutsche alchemistische Fachliteratur des aus- 
Wasserman ${ }^{14}$ und Ober $^{15}$ unternommen worden ist, deren Beiträge aus den 1970er und 80er Jahren stammen und - soweit ich ersehen kann - in der wissenschaftlichen Diskussion bislang folgenlos geblieben sind. Sie lesen die im Roman vorhandene Zahlensymbolik und die Metallvergleiche sowie vor allem die unio von Tristan und Isolde in der Minnegrotte vor dem Hintergrund alchemistischer Lehren: Die unio der Liebenden entspräche demnach der unio oppositorum, also der Vereinigung der Gegensätze im alchemistischen Prozess, während die Beschreibung der Grotte bis ins Detail denen einer alchemistischen Retorte gleiche.

3. In Abgrenzung zu den eben skizzierten Zugängen soll es mit den folgenden Überlegungen vielmehr darum gehen, den Zusammenhang von Alchemie und Poetologie zu untersuchen, eine Frage, der bisher nur in vereinzelten Ansätzen nachgegangen wurde. ${ }^{16}$ Dass die Alchemie Denkansätze bietet, die poetologisch neue Perspektiven eröffnen, wird von Gert Hübner in Der künstliche Baum ${ }^{17}$ angerissen: Am Beispiel des künstlichen Vogelbaums im Trojanerkrieg Konrads von Würzburg und der Frage nach der Rolle von ars und natura weist

gehenden Mittelalters. Baden-Baden 2005; zum Parzival vgl. z.B. Bernhard D. Haage: Das Ourobouros-Symbol im Parzival. In: Würzburger medizinhistorische Mitteilungen 1 (1983), S. 5-22; ders.: Studien zur Heilkunde im Parzival Wolframs von Eschenbach. Göppingen 1992; ders.: Die Schlange ,Ecidemon' im Parzival Wolframs von Eschenbach. In: De l'aventure épique à l'aventure romanesque. Festschrift für André de Mandach. Hrsg. von Jaques Cocheyras. Bern 1997, S. 257-268. Auch gibt es Versuche, den Erec Hartmanns von Aue im Hinblick auf alchemistische Symbolik zu interpretieren. Vgl. Helmut Gebelein: Alchemistisches im Roman Iwein, der Ritter mit dem Löwen von Hartmann von Aue. In: Xenja von Ertzdorff. Die Romane von dem Ritter mit dem Löwen. Unter redaktioneller Mitarbeit von Rudolf Schulz, Amsterdam 1994, S. 313-330; zur Spruchdichtung, bes. zu Heinrich von Mügeln Der meide kranz, vgl. den Forschungsüberblick in Horchler: Die Alchemie des deutschen Mittelalters (Anm. 13), S. 358-368.

14 Susan L. Clark, Julian N. Wasserman: The Poetics of Conversion. Number Symbolism and Alchemy in Gottfried's Tristan. Bern 1977.

15 Peter C. Ober: Alchemy and the Tristan of Gottfried von Straßburg. In: Monatshefte 57 (1965), S. 321-335.

16 Ein Zusammenhang zu Literatur und Sprache des Mittelalters (die spätmittelalterliche Fachliteraturforschung ausgenommen) wurde bislang nur vereinzelt formuliert: Ansätze, die die Alchemie als verbale Kunst herausstellen (Brian Vickers), den Zusammenhang von Alchemie zu biographischen Mustern konstatieren (Harald Haferland), sowie im Fall von Walthers zweitem Reichsspruch deren Funktion im Kontext eines Assoziations-, Denk- und Verstehensvorgangs bestimmen (Thomas Cramer), wurden bislang nicht weiter aufgegriffen. Vgl. Brian Vickers: Alchemie als verbale Kunst: die Anfänge. In: Chemie und Geisteswissenschaften. Versuch einer Annäherung. Hrsg. von Jürgen Mittelstraß und Günter Stock. Berlin 1992, S. 17-34; Harald Haferland: Alchemie und Literatur. In: Mediävistik und Kulturwissenschaften. Mediävistik und Neue Philologie. Akten des X. Internationalen Germanistenkongresses Wien 2000, Bd. 5., S. 183-188; Thomas Cramer: „Ich sach swaz in der welte was." Die Ordnung des Kosmos in Walthers zweitem Reichsspruch. In: Zeitschrift für deutsche Philologie 104 (1985), S. 70-85.

17 Gert Hübner: Der künstliche Baum. Höfischer Roman und poetisches Erzählen. In: PBB 136,3 (2014), S. 415-471, hier S. 429. 
er darauf hin, dass mit der Alchemie eine Einschätzung vorhanden war, nach der ars die Perfektionierung des natürlichen Vorbilds übernehmen konnte. ${ }^{18}$

Im Folgenden soll der These nachgegangen werden, dass alchemistisches Wissen um 1200 Denkmodelle und Darstellungsmuster zur Verfügung stellt, die literarisch produktiv gemacht werden und (neue) Spielräume poetologischer Reflexion eröffnen.

\section{Transmutation I: Fälschung und Veredelung}

1. In der Forschung zum Tristan wird insbesondere Gottfrieds Kritik an der Alchemie als Goldmacher- und Fälscherkunst herausgestrichen. ${ }^{19}$ Diese wird zum Beispiel darin gesehen, dass Marke einer Minne unterliegt, die sich ihm gestreichet unde gestrichen nähert und er ihrer goldenen Täuschung - in alchemistischer Terminologie läge hier eine Tingierung bzw. Färbung vor - auf den Leim geht:

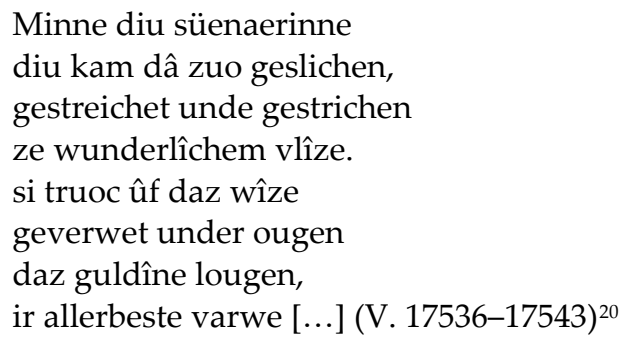

Ein ähnlicher Fall wird darin gesehen, dass Isolde und Brangäne im Brautnachtbetrug mit Gold und Messing verglichen werden, wobei Gold als das hochwertige und ,originale', Messing als das minderwertige Metall aufgefasst wird, ${ }^{21}$ das Einsatz findet, um Gold vorzutäuschen:

18 „Wenn jeder künstliche Herstellungsprozess das Prinzip der natürlichen Entstehungsprozesse nachahmt, kann ars natura eigentlich nicht überbieten. Eine davon abweichende Einschätzung war indes in der Alchemie verbreitet. So heißt es beispielsweise um 1260 in einem Roger Bacon zugeschriebenen Traktat, dass ars potentior sei als natura." Hübner: Der künstliche Baum (Anm. 17), S. 429.

19 Vgl. dazu Horchler: Die Alchemie in der deutschen Literatur des Mittelalters (Anm. 13), S. 370-373; Lambertus Okken: Kommentar zum Tristan-Roman Gottfrieds von Strassburg. Amsterdam 1984, S. 239ff; Sigrid Müller-Kleimann: Gottfrieds Urteil über den zeitgenössischen Roman. Ein Kommentar zu den Tristanversen 4619-4748. Stuttgart 1990, bes. S. 171175.

20 Mhd. Text und nhd. Übersetzungen sind hier und im Folgenden zitiert nach der Ausgabe: Gottfried von Straßburg. Tristan. Nach dem Text von Friedrich Ranke, neu hrsg., ins Neuhochdeutsche übersetzt, mit einem Stellenkommentar und einem Nachwort von Rüdiger Krohn. 3 Bde. Stuttgart 1986 u.ö.

21 Vgl. dazu den Kommentar von Krohn in Gottfried von Straßburg: Tristan (Anm. 20), Bd. 3, S. 187. Ein ähnlicher Vergleich findet sich in V. 12666-12671. 
ich wil mich ouch des wol versehen,

daz ez ê selten sî geschehen,

daz ie sô schoene messinc

vür guldîniu teidinc

ze bettegelte würde gegeben.

deiswâr ich sazte es wol mîn leben,

daz sît Âdâmes tagen

als edel valsch nie wart geslagen

noch nie sô gaebiu trügeheit

an mannes sîten wart geleit. (V. 12605-12614)

In der Forschung wird diese Stelle als ein Beleg für Markes reduzierte Wahrnehmungsfähigkeit aufgefasst ${ }^{22}$ und der Vergleich von Messing und Gold mit der Idee der Fälschung als betrügerischer alchemistischer Tätigkeit verbunden. Gleichzeitig aber streicht der Erzählerkommentar heraus, dass Brangäne als das ,Falschgeld aus Messing' mitnichten als minderwertige Braut abqualifiziert wird. ${ }^{23}$ Es scheint hier also weder um eine (moralische) Bewertung des Tatbestandes der Fälschung noch um die Qualität des vermeintlich gefälschten Metalls zu gehen.

Eine andere Lesart wird möglich, wenn man den Metallvergleich vor dem Hintergrund der Alchemie sieht: Diese kennt die Idee der Fälschung im eigentlichen Sinne nicht, denn entgegen des Vorwurfs einer betrügerischen Intention will die Alchemie primär Ersatzstoffe herstellen. Hierbei kommt es im Wesentlichen auf die Imitation des Farbtons an: „Ein künstlicher Smaragd galt als perfekt imitiert, wenn er die durchsichtig leuchtende Farbe des echten Edelsteins besaß. Die Härte und andere Eigenschaften waren dabei, wenn auch nicht völlig unwichtig, so doch sekundär." 24

In diesem Sinne wird auch Messing nicht als Fälschung gefasst, sondern zählt als Legierung zusammen mit Bronze zur "großen Familie des Goldes", 25 die der Alchemie bekannt ist, und die im Wesentlichen über die Farbe bestimmt wird. Die Legierung wird dabei als eigenständiges Metall aufgefasst, indem etwas anders Gemachtes oder etwas Neues erschmolzen wird. Angesichts eines quasi identischen Aussehens besteht eine Unterscheidungsmöglichkeit nur mit der Flammenprobe, die Klarheit über das jeweils vorliegende Metall zu ver-

22 So z.B. im Kommentar von Krohn: „Daß Marke keinen Unterschied bemerkt zwischen seinen beiden Partnerinnen, bestärkt jene Interpreten, die das Vergehen des Königs in seiner undifferenzierten Sinnengier sehen." Gottfried von Straßburg: Tristan (Anm. 20), Bd.3, S. 188.

23 So z.B. bei Christoph Huber: Gottfried von Straßburg. Tristan. Berlin 2001, S. 87.

24 Schütt: Auf der Suche nach dem Stein der Weisen (Anm. 3), S. 32. Es geht dabei nicht um die Imitation des Prozesses, sondern um die Imitation des Ergebnisses. So zielt die alchemistische Erzeugung von Purpur nicht auf die Verarbeitung eines anderen Kriechtiers anstelle der eigentlichen Purpurschnecke ab, sondern auf die Imitation des Farbtons.

25 Vgl. dazu Schütt: Auf der Suche nach dem Stein der Weisen (Anm. 3), S. 39. 
schaffen vermag. Ansonsten gilt der Farbton als wichtigster Indikator für den Zustand der Materie.

Das hier im Tristan anzitierte und aus der Literatur hinlänglich bekannte Motiv der ,untergeschobenen Braut' dient also nicht als moralisches Exempel, sondern es wird vielmehr mittels des Gold- und Legierungsbeispiels der Alchemie eine Verbindung zum mittelalterlichen Diskurs der imitatio hergestellt. ${ }^{26}$ Die besondere Stoßrichtung von Gottfrieds Text innerhalb dieser breit geführten Diskussion ergibt sich dabei aus dem Aspekt der Fälschung und ihrer diskurskritischen Funktion. ${ }^{27}$ Denn es geht hier weniger darum, über das gefälschte Objekt zu reflektieren und die Frage ,echt' oder ,falsch', ,wahr' oder , simuliert' (das stellt der Text klar aus), sondern vielmehr um das diskurskritische Potential, das Fälschungen innewohnt. Hierzu heißt es bei Doll:

Fälschungen schärfen „den Blick auf die Bedingtheiten von Erkenntnissen, Erfahrungen und Diskurspraktiken“ und bringen „mitunter einen grundlegenden Dissens gegenüber vorgefundenen Ordnungen, wie Wissen verteilt, oder allgemein, wie reagiert wird, zur Artikulation [...], mit dem Effekt, ansatzweise deren jeweilige Verunsicherung und Veränderung zu bewirken. " 28

Eine Fälschung also existiert nur bis zu ihrer Entdeckung und wird auch nur dadurch als solche konstituiert - im Falle von Isolde / Brangäne wird der Betrug durch den Erzähler aufgedeckt, während er Marke und dem Hof auf der Handlungsebene zunächst unentdeckt bleibt. Auf der Erzählebene hingegen wird ein Raum für Irritation geschaffen, indem die Fälschung „,nach ihrer Entlarvung das Selbstverständnis, mit dem man zu wissen glaubt, was als wahr, echt, authentisch, original oder autorisiert gilt, “ irritiert und „mitunter auch gesicherte Vorstellungen, was eine Fälschung ist, ins Wanken geraten. “29

Durch die Einbeziehung des Aspekts der Fälschung wird der Blick damit auf die diskurstheoretischen Implikationen und auf den kontextuellen Rahmen, in dem die ,Fälschung' Isolde / Brangäne steht, gelenkt.

26 Ein Forschungsreferat, das einen angemessenen Überblick über den Begriff der imitatio und dessen Verwendung im Mittelalter liefern würde, kann im hier gebotenen Rahmen nicht geleistet werden; zur Einführung in den Begriff vgl. den Eintrag „,imitatio“ von Dina DeRentiis und Nicola Kaminski in: Historisches Wörterbuch der Rhetorik. Hrsg. von Gert Ueding. Bd. 4. Tübingen 1998, Sp. 235-303, mit weiterführender Literatur.

27 Ich greife hier Überlegungen auf, die für den Bereich der Moderne in Anschlag gebracht werden. Vgl. dazu Martin Doll: Fälschung und Fake. Zur diskurskritischen Dimension des Fälschens. Berlin 2012; Fälschungen. Zu Autorschaft und Beweis in Wissenschaften und Künsten. Hrsg. von Anne-Kathrin Reulecke. Frankfurt a.M. 2006, bes. Einleitung S. 7-31; Das Spiel mit der Wahrheit - Fälschungen in Literatur, Film und Kunst. Hrsg. von Barbara Potthast. Berlin 2012.

28 Doll: Fälschung und Fake (Anm. 27), S. $12 \mathrm{f}$.

29 Doll: Fälschung und Fake (Anm. 27), S. 12. 
2. Klar im poetologischen Zusammenhang steht die Angabe über die vindaere wilder maere und deren betrügerisches Vermögen im Literaturexkurs, in dem Gottfried bekanntlich am Beispiel der zeitgenössischen Literatur bzw. deren Vertreter Grundfragen der Poetologie diskutiert und dazu auch das alchemistische Bild von der Transmutation, hier das des Gold- und Perlenmachens, aufruft:

vindaere wilder maere,

der maere wildenaere,

die mit den ketenen liegent

und stumpfe sinne triegent,

die golt von swachen sachen

den kinden kunnen machen

und ûz der bühsen giezen

stoubîne mergriezen. (V. 4665-4672)

Wieder verweisen das Herstellen von Gold und Perlen auf die alchemistische Praxis der Transmutation, die sich prinzipiell auch der Gießtechnik bediente und bei der auch Perlen aus Körnchen von Kalziumoxyd künstlich hergestellt wurden. ${ }^{30}$ Im Gegensatz aber zum Legierungsbeispiel Isolde / Brangäne kann das alchemistische Imitat hier seine Funktion nur bedingt erfüllen: Die Fälschungen vermögen nur die naiven Gemüter (stumpfe sinne und kinden) zu verführen und die stoubine mergriezen assoziieren weder den $\mathrm{zu}$ imitierenden Perlmuttglanz der Perle noch ihre Formbeständigkeit.

Auch hier also dient das Verfahren der Alchemie zur Diskussion poetologischer Inhalte, wobei durchaus Kritik an der Fälschung geübt wird - dieser Aspekt des Alchemie-Diskurses findet also durchaus Eingang in die Dichtung. Der Text zeigt aber im weiteren Verlauf, dass die Frage der Fälschung (erneut) nicht im Fokus steht, da dieser nun vor allem auf die Regellosigkeit gelenkt wird, die die vindaere wilder maere auszeichnet: Denn entscheidend für die ,richtige Dichtung' ist die Technik und das kalkulierte Eingreifen, alles andere sind die maere wildenaere, die kunstlosen Jäger (eigentlich ,Wilderer' von Erzählungen), ${ }^{31}$ wo nur noch die Magie mit ihren Ausdeutern der swarzen buochen (V. 4690) zu einer vorläufigen Sinnkonstitution verhelfen können.

Diese Bedeutung des kalkulierten Eingriffs, der die Eigengesetzmäßigkeiten der Natur kennt und planvoll manipuliert, zeigt sich auch bei Heinrich von Veldeke und dem berühmten Vergleich seiner Dichtungsleistung mit der Gärtnertechnik des Pfropfens:

30 Vgl. z.B. die Anleitung zur Herstellung von ,runden Perlen' (,Méthode pour confectionner la perle ronde“) in Marcelin Berthelot: Collection des anciens alchimistes grecs. Publié sous les auspices du Ministère de L'instruction Publique par M. Berthelot. Avec la Collaboration de Charles-Emile Ruelle. Paris 1887. Nachdruck London 1963, Bd. II, S. 349-356.

31 Siehe auch noch später beim Hirschbast. 
er inpfete daz êrste rîs

in tiutischer zungen.

dâ von sît este ersprungen,

von den die bluomen kâmen,

dâ sî die spaehe ûz nâmen

der meisterlîchen vünde. (V. 4738-4743).

Dass nach mittelalterlichem Selbstverständnis des Autors dieser sein Amt in der Regel nicht im Erfinden, sondern im Auffinden eines überlieferten poetischen Stoffes sieht, gilt als gesichertes Wissen in der Mediävistik, ${ }^{32}$ denn - so zum Beispiel der Kommentar zum Komplex der vindaere im Literaturexkurs - „das Mittelalter kannte noch nicht die Forderung nach künstlerischer Originalität", sodass auch die bei Gottfried erwähnten vindaere nur "Auf-Finder", nicht „ErFinder" seien. ${ }^{33}$ Ganz in diese Richtung geht auch die Interpretation der Stelle von Seggewiß, der herausstellt, dass es sich bei der Idee des Pfropfens lediglich um eine Kulturtätigkeit handle, Natur und Kultur im Tristan stets nur in Harmonie miteinander gebracht werden könnten. ${ }^{34}$

Dass das Pfropfen in der theoretischen Reflexion nicht nur auf eine kultivierende Tätigkeit reduziert wurde, die der ,Natur auf die Sprünge' helfen sollte, ${ }^{35}$ sondern durchaus mehr impliziert, zeigt hingegen die Tatsache, dass das Bild des Pfropfens auch im Kontext alchemistischer Argumentation herangezogen wurde, um die Frage der imitatio naturae zu diskutieren: Eine der Kernfragen, die im 12. Jahrhundert erörtert wurden, richtete sich auf das Problem, ob nur die akzidentiellen Eigenschaften bei der Transmutation zu ändern seien oder auch die substantiellen, und damit die Frage, ob der Mensch Dinge schaffen kann, die die Natur (noch) nicht hervorgebracht hat.

Im Liber Hermetis, einem kurzen alchemistischen Text, der im Zusammenhang mit De compositione alchemiae von Morienus überliefert wurde, ${ }^{36}$ werden dazu nicht nur die bereits bekannten Thesen zur imitatio angeführt, nach denen das Imitierende dem Imitierten durchaus vergleichbar sei, ${ }^{37}$ sondern am Beispiel

32 Nach wie vor einschlägig zu diesem Thema ist Thomas Cramer: Solus creator est deus. Der Autor auf dem Weg zum Schöpfertum. In: Daphnis 15 (1986), S. 261-276; Franz-Josef Worstbrock: Wiedererzählen und Übersetzen. In: Mittelalter und Frühe Neuzeit. Übergänge, Umbrüche und Neuansätze. Hrsg. von Walter Haug. Tübingen 1999, S. 128-142.

33 Gottfried von Straßburg: Tristan (Anm. 20), Bd. 3, S. 97.

34 Michael Seggewiß: ,Natur' und ,Kultur' im Tristan Gottfrieds von Straßburg. Heidelberg 2012, S. 158.

35 So Seggewiß: ,Natur' und ,Kultur' im Tristan Gottfrieds von Straßburg (Anm. 34), S. 158. Zur Metapher des Pfropfens und der Baumsymbolik mit ähnlicher Diskussion der Stelle vgl. Müller-Kleimann: Gottfrieds Urteil über den zeitgenössischen Roman (Anm. 19), S. 307-312.

36 Datierung und Zuschreibung des Textes sind unklar. Ich verweise hierfür auf die Dokumentation bei Newman: The Summa Perfectionis of Pseudo-Geber. A critical edition, translation and study by William R. Newman, Leiden 1991, S. 7-10.

37 Vgl. das bereits oben dargestellte Problem von Fälschung und Legierung bzw. Messing und Gold. 
der Vergleichbarkeit von gepfropftem Baum (arbor insita artificialis) und ,natürlichem' (arbor spontanea naturalis) konstatiert, dass der menschliche Eingriff die essentiellen Eigenschaften der Substanz verändern und damit Neues herstellen kann:

Imo opera humana cum naturalibus multimode eadem sunt, ut in igne et aere, aqua, terra, mineris, arboribus et bestiis ostendemus. Nam et ignis fulgoris naturalis et ignis de lapide eiectus uterque ignis est. Aer continens naturalis est et aer ex decoctione artificialis uterque aer. Terra substituens naturalis et terra ex reservatione aque artificialis utraque terra est. Sal vero viride et dragantum et thutia et sal armoniacus et naturalia et artificialia sunt. Immo et artificialia naturalibus potiora sunt, quod qui de mineriis sciunt non contradicunt. Arbor spontanea naturalis et arbor insita artificialis utraque arbor est. Apes naturales et apes ex tauro artificiales utreque apes sunt. Nec ars hec omnia facit, sed naturam facientem adiuvat. ${ }^{38}$

(Menschliche Werke sind auf vielerlei Art wie natürliche, wie wir am Beispiel von Feuer, Luft, Wasser, Erde, Mineralien, Bäumen und Tieren zeigen werden. Denn das Feuer eines natürlichen Blitzes und das Feuer, das durch einen Stein geschlagen wird, sind beides Feuer. Die natürliche Luft und die künstliche Luft, die durch Kochung erzeugt wird, sind beides Luft. Die natürliche Erde, auf der wir stehen, und die künstliche oder durch Kompostierung entstandene Erde sind beides Erde. Grünes Salz, Vitriol, Tutia und Ammoniumchlorid sind künstlich und natürlich. Aber die künstlichen sind sogar noch besser als die natürlichen, was jeder, der sich mit Mineralien auskennt, bestätigen wird. Der natürliche wilde Baum und der künstlich gepfropfte sind beide Bäume. Natürliche Bienen und künstliche Bienen aus einem verwesenden Stier sind beide Bienen. Nicht die Kunst macht alle diese Dinge, sondern sie hilft der Natur dabei, sie zu machen.)

Das Pfropfen wird im Tristan damit als poetologische Metapher genutzt, die vor dem Hintergrund alchemistischer Auffassungen über die gemeinhin gebräuchliche Referenz auf eine gärtnerische Kulturleistung weit hinausgeht und auf den Kern alchemistischer Reflexion über das Verhältnis von ars und natura und das Vermögen des Adepten zielt.

3. Die Verbindung von Transmutationsverfahren der Alchemie und den klassischen Inspirationstopoi erscheint im Literaturexkurs bei Gottfried selbst: Bereits ein Tropfen aus den Quellen des Helikon könne wie ein Katalysator wirken und - nachdem die Verwirrung von Zunge und Geist wieder in rechte Bahnen

38 Newman: The Summa Perfectionis of Pseudo-Geber (Anm. 36), S. 53f. Übersetzung von mir. 
gelenkt sei - Gottfrieds Worte, gleichwie in einer Retorte (den vil liehten tegel), zu arabischem Gold veredeln:

der selbe trahen der eine

der ist ouch nie sô cleine,

er enmüeze mir verrihten,

verrihtende beslihten

beidiu zungen unde sin,

an den ich sus entrihtet bin.

diu mînen wort muoz er mir lân

durch den vil liehten tegel gân

der camênischen sinne

und muoz mir diu dar inne

ze vremedem wunder eiten,

dem wunsche bereiten

als golt von Arâbe. (V. 4883-4895).

Auch hier steht der Gedanke des Regelhaften und Geordneten im Vordergrund, der jedoch in Form von Musenquelle und Retorte durch zwei der Kontrolle enthobene Instanzen ergänzt wird.

Christoph Huber stellt zum Literaturexkurs fest, dass dieser "antike und christliche Inspirationsgaranten übereinander schichtet ${ }^{\prime \prime}, 39$ und betont die damit implizierte Qualitätsänderung der Topoi von diesseitiger zu jenseitiger Welt. Dabei aber erscheint wichtig zu ergänzen, dass mit dem Pfropfen und dem Schmelzen von Gold im Tiegel auch Techniken und Bilder alchemistischer Praxis aufgenommen sind, die - an zentraler Stelle - den Blick auf die Prozesshaftigkeit des Dichtungsvorgangs lenken, indem sie alchemistische und poetische Bildlichkeit ineinander verschränken. Anstelle eines ,Übereinander-Schichtens von Topoi wird so eher ein nebeneinander geordnetes Panorama abgeschritten und ein ,Laboratorium des Erzählens' präsentiert, mit dem Komponenten literarischer Produktion durchgespielt werden.

\section{Transmutation II: solve et coagula}

Auch bei der folgenden Textstelle, für die ich eine ,alchemistische Lesart' vorschlagen möchte, dem Hirschbast (V. 2759-3080), handelt es sich um eine Kernstelle von Gottfrieds Poetologie. Die Szene ist bekannt: Nach seiner Entführung irrt Tristan heimatlos durch Cornwall und trifft eine Jagdgesellschaft mit Hirsch. Wieder einmal ist er derjenige, der eine Kunst-hier die des Zerlegens des Hirschs - perfekt und über die allgemeinen Kenntnisse hinaus beherrscht und damit Aufsehen erregt; seine besondere Fertigkeit, vielleicht auch deren Inszenierung, ist die ,Eintrittskarte' zum Marke-Hof.

39 Christoph Huber: Gottfried von Straßburg. 3., neu bearbeitete und erweiterte Auflage, Berlin 2013, S. 68. 
Besonders herausgestellt wird die Zerlegung des Hirschs (die eigentliche Jagd und Tötung ist in knappen Worten erledigt), der Bast fällt als unbekannte Kunst, als list (V. 2816) auf. Handwerksmetaphern wie entwaeten (V. 2873) und entnaen (V. 2874) betonen das Handwerkliche des Vorgangs. ${ }^{40}$ Gleichzeitig ist der Bast ein zeremoniell-kultischer Akt: ${ }^{41}$ Unter den Augen der Jagdgesellschaft bereitet sich Tristan minutiös auf die Handlung vor, schlägt die Ärmel hoch, streicht das Haar zurück. ${ }^{42}$ Und: Das Entbästen wird den anderen Anwesenden als komplizierter Vorgang vorgeführt, bei dem Worte und Gesten von Tristan in die fremde Kunst einführen. Auf Wunsch des Jägermeisters erteilt Tristan der Jagdgesellschaft eine Lektion:

entriuwen, vriunt [Tristan], du enzeiges $\operatorname{mir}^{\prime} z$, sone weiz ich, waz enbesten ist.

ez enweiz nieman disen list

in disem künicrîche hie.

sone gehôrte in ouch genennen nie

von kunden noch von gesten.

trût kint, waz ist enbesten?

als guot du sîs, nu zeige mir'z.

gâ her, enbeste disen hirz! (V. 2814-2822)

Nach vollendetem Entbästen, bei dem der Hirsch von Tristan entsprechend seiner Anatomie zerlegt wird, gipfelt der Bast in einem zweiten, nun ,kompositorischen' Akt, bei dem Tristan die Teile in der ,richtigen Weise' (prîsantet in ze rehte, V. 3057) in einer Zeremonie bei der Hofgesellschaft einziehen lässt (ze hove nâch hovelîchem site, V. 3053).

In der Forschung ist die Stelle vielfach mit dem allgemeinen Tenor diskutiert worden, in dem Bast - neben dem fachliterarischen Inhalt - vor allem eine poetologische Dimension zu sehen. ${ }^{43}$ Dabei steht das Verfahren als solches - das

40 Hierauf weist besonders Schmid hin; vgl. Elisabeth Schmid: Natur und Kultur in der Jagdszene von Gottfrieds Tristan. In: Der Tristan Gottfrieds von Straßburg. Symposion Santiago de Compostela. 5. bis 8. April 2000. Hrsg. von Christoph Huber und Victor Millet. Tübingen 2002, S. 153-166, hier S. 163.

41 Dazu auch Burkhardt Krause: Die Jagd als Lebensform und höfisches ,spil'. Mit einer Interpretation des ,bast' in Gottfrieds von Straßburg Tristan. Stuttgart 1996, S. 172-174.

42 Gottfried von Straßburg: Tristan, V. 2843-2849. Krause spricht bei dem Bast von einem digressiven Moment der Handlung, das den Ablauf des Geschehens entdramatisiert und diesem den Charakter souveräner Bedachtsamkeit und distanzierender Beherrschtheit verleiht, vgl. Krause: Die Jagd als Lebensform und höfisches ,spil' (Anm. 41), S. 141.

43 Vgl. Krause: Die Jagd als Lebensform und höfisches ,spil' (Anm. 41); Ernst S. Dick: The Hunted Stag and the Renewal of Minne: Bast in Gottfried's Tristan. In: Tristania 17 (1996), S. 1-25; Hans Jürgen Scheuer: Die Signifikanz des Rituals. Zwei Tristan-Studien. In: Beiträge zur Geschichte der deutschen Sprache und Literatur 121 (1999), S. 406-439; Katharina Philipowski: Die Ordnungen des Erzählens und ihre Entblößung. Formalismus und Verfremdung als Selbstreflexion von Erzählstrategien. In: Das fremde Schöne. Dimensionen 
Zerlegen und Wiederzusammenfügen-im Vordergrund. Beides folgt einer bestimmten Ordnung und ermöglicht das Wiederherstellen des Hirschs zu einer neuen und intakten Einheit, was einer Exposition wider dessen natürliche Ordnung - wie ein Schwein ${ }^{44}$ - und dem brachialen Zerhauen (spalten, V. 2801) des Tiers in vier gleich große Teile ${ }^{45}$ (wir erinnern uns an die wilderaere aus dem Literaturexkurs) entgegengestellt wird. Widerspruch an dieser Lesart meldet allein Elisabeth Schmid an, die keine Einheit oder gar einen ,Mehrwert' nach der Zusammenfügung der Teile erkennen will, wenn sie betont, dass der Hirsch nach dem Bast schließlich „mausetot" sei. ${ }^{46}$ Für meine Überlegungen schließe ich mich dem Befund von Ernst Dick an: „The end result is the deer, the object of the hunt, transformed also into something new: a composite figure, reflecting a natural order restored through art." ${ }^{47}$

Erst dieser ,neue Hirsch', der in der Prozession Hirschkörper und Gesellschaftskörper vereint, bindet auch Tristan darin ein und ermöglicht damit seinen Eintritt in die neue Ordnung des Marke-Hofes.

Dass Körper zerlegt und wieder zusammengesetzt werden, ist zum Beispiel aus dem Mythos bekannt: ${ }^{48}$ Der Gott Dionysos wird getötet, zerstückelt, in einen Kessel geworfen und gekocht - Zeus erweckt ihn wieder zum Leben, indem er die Glieder einsammelt und wieder zusammenfügt. ${ }^{49}$ Im Falle des ebenfalls zerteilten und als Mahl zubereiteten Pelops, von dessen Schulter Persephone gedankenverloren bereits ein Stück gegessen hatte, fehlt nach der Wiederzusam-

des Ästhetischen in der Literatur des Mittelalters. Hrsg. von Manuel Braun und Christopher Young. Berlin 2007, S. 195-224; Andreas Kraß: Der fragmentierte Körper. Politik und Poetik im Tristan Gottfrieds von Straßburg. In: Fragmentarität als Problem der Kultur- und Textwissenschaften. Hrsg. von Kay Malcher, Stephan Müller, Katharina Philipowski und Antje Sablotny. München 2013, S. 117-131.

$44 \mathrm{Nu}$ daz der hirz gevellet wart,

der da jêgermeister was,

der stracte in nider $\hat{u} f$ daz gras

$\hat{u} f$ alle viere alsam ein swîn [...] (V. 2788-2891)

45 Gottfried von Straßburg: Tristan (Anm. 20), V. 2798-2806.

46 Schmid bezieht ihre Argumentation jedoch auf die Leiblichkeit des Hirsches, der - und da muss man ihr Recht geben - nach dem Bast in der Tat , mausetot' ist. Damit bleibt die zweite, für die poetologische Interpretation der Stelle bedeutsame Lesart jedoch unbeachtet.

47 Ernst S. Dick: The Hunted Stag and the Renewal of Minne: Bast in Gottfried's Tristan. In: Tristania 17 (1996), S. 1-25, hier S. 8.

48 Weitere Beispiele wären Pelias, der auf Wirken der Medea unter der Lüge, er könnte dadurch verjüngt werden, von seinen Töchtern zerstückelt und gekocht wird; Prokne, die ihrem Gatten Fereus den gemeinsamen Sohn als Gericht vorsetzt, sowie v.a. der ägyptische Gott Osiris, der von seinem Bruder getötet und zerstückelt, von Isis gesucht und wiederbelebt wird.

49 Schütt weist auf die Bedeutung der Mysterienkulte und die besondere Rolle des Dionysoskults für die Alchemie hin; vgl. Schütt: Auf der Suche nach dem Stein der Weisen (Anm. 3), S. 87-94. 
mensetzung zwar ein Körperteil, das jedoch durch eine elfenbeinerne Prothese ersetzt (und durch diese Artifizialität noch verbessert?) wird. Während also der Gedanke der Transmutation im Mythos durch Vorstellungen von De- und Rekomposition verankert ist, ${ }^{50}$ scheint der Fokus im Tristan anders ausgerichtet zu sein. $\mathrm{Zu}$ auffällig ist der Stellenwert des planvollen Zerlegens, das den natürlichen Gesetzmäßigkeiten folgt, und der Wert, der auf die Verwandlung in einen ,neuen Hirsch' gelegt wird: Erst die planvolle Zerlegung und die kalkulierte Fragmentierung des Körpers ermöglichen die Transformation zu einer neuen Einheit auf höherem Niveau. Hierfür werden in der Forschung verschiedene Lesarten diskutiert, die alle an der poetologischen Funktion der Bastszene ansetzen, diese jedoch interpretatorisch unterschiedlich kontextualisieren. ${ }^{51}$

Ich möchte vorschlagen, den Bast vor der Folie alchemistischer Denkmuster zu lesen. Denn das dem Hirschbast zugrunde liegende Muster des Zerteilens und Wiederzusammenfügens ist auch das Grundprinzip der Transmutation in der Alchemie: Es ist das Prinzip des solve et coagula, des Lösens und Wiederverbindens von Stoffen.

Gleichgültig, ob es sich um die alchemistischen Verfahren der Destillation, Sublimation, Calcination, Assation oder Kochung, Reverberation, Dissolution, Descension oder Coagulation handelt, steht dahinter letztlich ein und derselbe Effekt des Zerteilens, der eine Verbindung auf neuer und höherer Ebene - und damit die Transmutation und Veredelung - ermöglicht. Dieses Konzept der Zerteilung, wie auch die anderen oben genannten Operationen und Vorgänge, werden im Kontext alchemistischer Grunddisposition und deren genereller Af-

50 Weitere Parallelen und Interpretationsansätze in Verbindung mit der Alchemie würden sich im Bereich des Mysterienkults, des Initiationsritus' sowie der Vorstellung der Erlösung ergeben. Sie können hier jedoch nicht weiter verfolgt werden.

51 Krause schlägt gleich zwei ,Lektüren’ des Basts als poetologischer Metapher vor: „Das Ganze und die Teile“ sowie eine "Interpretatio platonica“, bei der er mit einer Parallele zu Platons Phaidros argumentiert, in der Sokrates die gelungene Rede mit einem lebendigen Wesen vergleicht, das über einen geordneten Körperbau verfüge, vgl. Krause: Die Jagd als Lebensform und höfisches ,spil' (Anm. 41), S. 151-188 und S. 177-188. Kraß sieht den Hirsch als Allegorie der politischen und poetischen Ordnung, der zunächst waidgerecht in seine Einzelteile zerlegt und dann wieder kunstvoll zusammengesetzt wird, und dessen Zurichtung das hierarchische bzw. stratifikatorische Prinzip ,verkörpert', vgl. Kraß: Der fragmentierte Körper (Anm. 42), S. 127-130; Dick schlägt eine metanarrative Lesart vor und sieht im Jäger ein Bild des Künstlers, vgl. Ernst S. Dick: Tristan the Hunter: Toward a Metanarrative Reading of Gottfried's Stag Ritual. In: Fide et amore. Festschrift für Hugo Bekker. Hrsg. von William C. McDonald. Göppingen 1990, S. 41-69. Philipowski nennt den Bast im Zusammenhang mit der Selbstreflexivität von Literarizität und streicht den Aspekt von Machtausübung und Herrschaft bei der kunstgerechten Formung des Hirschs heraus, an dem sich das formale Ordnungsprinzip und die Kohärenz höfischen Erzählens spiegeln, vgl. Philipowski: Die Ordnungen des Erzählens und ihre Entblößung (Anm. 42), S. 7-9. Scheuer untersucht die Ritualität der Szene und fragt nach dem erzählerischen Modus, nach dem Rituale oder ritualisierte Handlungen zum Gegenstand des Erzählens werden, vgl. Scheuer: Die Signifikanz des Rituals (Anm. 43), S. 438. 
finität zur Bildlichkeit, nach der auch Stoffe als Figuren oder Personen gedacht werden, ebenfalls bildlich und oft körperlich imaginiert. ${ }^{52}$ Ikonographisch umgesetzt finden sich diese körperlich inszenierten Vorgänge in den ab dem Spätmittelalter einsetzenden bildlichen Darstellungen, wie ein Beispiel aus einem Exemplar der breit überlieferten alchemistischen Bilderhandschrift Splendor solis oder Sonnenglanz (um 1530) ${ }^{53}$ zeigt, das den chemischen Vorgang der ,Zerstückelung' ins Bild setzt (vgl. Farbabbildung S. 443).

Doch auch alchemistische Texte selbst operieren mit einer körperlich inszenierten Bildlichkeit. Ein Beispiel liefert der Text Über die Kraft des altägyptischen, auch im Hochmittelalter bekannten ${ }^{54}$ Autors Zosimos aus Panapolis (spätes 3. bis frühes 4 . Jahrhundert), einem der einschlägigen alchemistischen Texte aus dem griechisch-alexandrinischen Kontext. In einer in einen Traum eingebetteten Vision erhält der Erzähler Auskunft über unterschiedliche alchemistische Vorgänge und Naturprozesse, wie hier die ,Entstehung der Wässer ${ }^{4}{ }^{55}$

Und indem ich dieses sprach, schlief ich ein, und ich sah einen Priester vor mir stehen oben auf dem Altar, der die Form einer flachen Schale hatte. [...] Er aber antwortete mir mit feiner Stimme und sprach: - Ich bin Ion, der Priester der innersten verborgenen Heiligtümer, und ich unterziehe mich einer unerträglichen Strafe. Denn es kam einer um die Morgenfrühe in eilendem Laufe, der überwältigte mich und zerteilte mich mit dem Schwert, indem er mich durchbohrte, und zerriß mich entsprechend der Zusammensetzung der Harmonie. Und er zog die Haut meines Kopfes ab mit dem Schwert, das von ihm mit Macht gehandhabt wurde, und er fügte die Knochen mit den Fleischstücken zusammen und verbrannte das Ganze der Kunst entsprechend auf dem Feuer, bis ich wahrnahm, wie mein Körper verwandelt und zu Geist wurde. Und dieses ist meine unerträgliche Qual. - Und wie er mir dies noch erklärte, und ich ihn mit Gewalt zwang, mir Rede zu stehen, da geschah es, daß seine Augen wurden wie Blut. Und er spie all sein eigenes Fleisch aus. Und ich sah, wie er sich in einen verstümmelten Homunculus, in seine eigene Umkehrung, ver-

52 Untersuchungen zu alchemistischer Ikonographie und speziellen Bildhandschriften gibt es zahlreiche; theoretische Ansätze zu Alchemie und Bildlichkeit liegen hingegen nur wenige vor, vgl. Mino Gabriele: Alchimia e Iconologia. Udine 1997.

53 Zum Splendor solis im Überblick vgl. Joachim Telle: Splendor Solis. In: Lexikon des Mittelalters, VII. München 1995, Sp. 2126-2127. Zum Cod. 78 D 3 konkret vgl. Jörg Völlnagel: Splendor solis oder Sonnenglanz. Studien zu einer alchemistischen Bilderhandschrift. Cod. 78 D 3 des Berliner Kupferstichkabinetts. München, Berlin 2004.

54 Auf die Werke und Aussagen des Zosimos wird auffallend häufig in Robert Chesters Übersetzung De compositione alchemiae von Morienus (s. Anm. 1) verwiesen. Ob dies jedoch auch eine genaue Kenntnis seiner Texte impliziert, kann nur vermutet werden.

55 Nach Schütt handelt es sich bei diesen ,Wässern' um Wandlungswässer (Theia hydrata), die aus der Prima materia durch Dekomposition herausgezogen werden sollten, vgl. Schütt: Auf der Suche nach dem Stein der Weisen (Anm. 3), S. 83. 
wandelte. Und mit seinen eigenen Zähnen zerfleischte er sich und sank in sich zusammen.

Voller Furcht erwachte ich aus dem Schlafe, und ich erwog bei mir: ,Ist dies nicht etwa die Zusammensetzung der Wässer?' Ich meinte fest überzeugt zu sein, daß ich wohl verstanden hätte. Und ich schlief wieder ein... ${ }^{56}$

Während es sich nach Holmyard in diesem Text im ersten Abschnitt um eine Beschreibung der "Zerstörung eines Metalls durch Hitze und seine Umwandlung in Pulver [handelt], dann vielleicht gefolgt von der Wiederherstellung des Metalls durch Erhitzen des Pulvers mit Kohle", ${ }^{57}$ verweist die Darstellung neben der bildlich und körperlich imaginierten Transmutationsszene vor allem auf die Verschlüsselung und Arkanisierung des Wissens, das sich nur dem Eingeweihten durch die Vermittlung des Geheimwissens verbunden mit experimentellem Nachvollzug bzw. Partizipation (der Erzähler sieht den Transmutationsvorgang im Traum) mitteilt. Dass der Aspekt der Arkanisierung mit ihrer Idee von Exklusivität in dieser Form nicht nur für den Hirschbast, sondern auch für den gesamten Tristan-Roman und dessen anvisierten Rezipientenkreis der edelen herzen weiterzudenken wäre, kann hier nur angedeutet werden. Eine Vertiefung dieses Aspekts würde den Rahmen des vorliegenden Beitrags übersteigen und muss weiterer Untersuchung vorbehalten bleiben.

Dass Gottfrieds Tristan im Spannungsfeld unterschiedlicher intellektueller und kultureller Strömungen situiert ist, ist Ausgangspunkt und Grundlage fast jeder Beschäftigung mit diesem Text. Ebenso vielzitiert und grundlegend ist seine Vielschichtigkeit und sein Charakter des Heterogenen und Widersprüchlichen, der nach wie vor zu literaturwissenschaftlicher Auseinandersetzung auffordert. $\mathrm{Zu}$ den zentralen Themenkomplexen und Fragen gehören dabei die im Text ausgestellte Problematik der Artifizialität und des Kunstwerks sowie die Rolle von Natur und Kultur. ${ }^{58}$ Fragen nach der Darstellung und Funktion der Mehrdeutigkeit von Zeichen ${ }^{59}$ lenken den Blick neben der Problematik der Arbitrarität ${ }^{60}$ auch auf die Themen von Experimentalität ${ }^{61}$ und kalkulierter Unbestimmt-

56 Zosimos aus Panapolis: Über die Kraft („Die Visionen des Zosimos“), Übersetzung zitiert nach Carl Gustav Jung: Von den Wurzeln des Bewußtseins. Studien über den Archetypus. Zürich 1954, S. 139-141.

57 Eric John Holmyard: Alchemy. Harmondsworth 1957, Reprint New York 1990, S. 29.

58 Vgl. u.a. Karina Kellermann: ,und vunden vür ir herren da einen zestucketen man'. Körper, Kampf und Kunstwerk im Tristan. In: Der Tristan Gottfrieds von Straßburg (Anm. 40), S. 131-152; Seggewiß: ,Natur' und ,Kultur' im Tristan (Anm. 34).

59 Vgl. u.a. Christoph Huber: Wort-Ding-Entsprechungen. Zur Sprach- und Stiltheorie Gottfrieds von Straßburg. In: Befund und Deutung. FS Hans Fromm. Hrsg. von Klaus Grubmüller u.a. Tübingen 1979, S. 268-308.

60 Vgl. u.a. Irene Lanz-Hubmann: ,Nein unde jâ'. Mehrdeutigkeit im Tristan Gottfrieds von Straßburg. Ein Rezipientenproblem. Frankfurt a.M., Bern u.a. 1989. 
heit. ${ }^{62}$ Und schließlich zeigt der Text die Thematik und Struktur der Fragmentarität, die auch die (erzählte) propagierte Ganzheit als eine künstliche ausweist. ${ }^{63}$

Artifizialität, Experiment, Fragmentarität: Dies sind auch Muster und Strukturen, die für die Alchemie konstitutiv sind. Die vorangegangenen exemplarischen Lektüren ausgewählter Stellen des Tristan haben versucht aufzuzeigen, dass die Alchemie Denkmodelle und Darstellungsmuster bietet, um die literarischen Spezifika des Tristan neu zu verorten und bekannte Problemkomplexe in einen neuen Deutungszusammenhang zu stellen.

Für den Bereich der Moderne ist die Bedeutung der Alchemie für die Poetologie hinlänglich bekannt und dokumentiert: Interdisziplinäre Ansätze, wie die Ausstellung Kunst und Alchemie - das Geheimnis der Verwandlung, betonen die Parallele von künstlerischer und alchemistischer Produktion; ${ }^{64}$ literatur- und kunsttheoretische Überlegungen des 20. Jahrhunderts wie Alchemie und Sprache von Michel Butor setzen Alchemie parallel zu literarischer und philologischer Tätigkeit und verstehen das Hervorbringen eines literarischen Werks selbst als auch dessen Rezeption bzw. Dechiffrierung als alchemistischen Prozess. ${ }^{65}$ In literarischen Beispielen wie Texten von Walter Benjamin und Marcel Proust ist Alchemie eine Folie der literaturtheoretischen Reflexion und Bildspeicher der eigenen literarischen Tätigkeit. ${ }^{66}$

Am Beispiel des Tristan zeigt sich, dass Alchemie auch in mittelalterlicher Literatur Freiräume für poetologische Reflexion eröffnet, indem sie unter anderem die Diskussionen um das Verhältnis von ars und natura sowie die Konzeptualisierungen von imitatio in erweiterte Perspektiven einzustellen vermag. Dabei geht es im literarischen Verfahren nicht um das Zitieren, die Aufnahme alchemistischer Symbolik oder einen simplen Vergleich: Mit dem Brautnachtbetrug wird weder allein die gelungene Vertauschung der Frauen Isolde und Brangäne erzählt, noch geht es einzig um den Aspekt des Goldfälschens in der Alchemie.

61 Vgl. u.a. Horst Wenzel: Negation und Doppelung. Poetische Experimentalformen von Individualgeschichte im Tristan Gottfrieds von Straßburg. In: Wege in die Neuzeit. Hrsg. von Thomas Cramer. München 1988, S. 229-251.

62 Anna Mühlherr: Unstimmigkeit als Kalkül. Gottfrieds Rühmen und Schelten zu Beginn des poetologischen Exkurses. In: Der Tristan Gottfrieds von Straßburg (Anm. 40), S. 317-326.

63 Kellermann: Körper, Kampf und Kunstwerk im Tristan (Anm. 58), S. 152.

64 Die Ausstellung, die vom 05.04.2014-20.08.2014 im Düsseldorfer Museum ,Kunstpalast' stattfand, wurde realisiert in Zusammenarbeit vom Max-Planck-Institut für Wissenschaftsgeschichte (Berlin), der Stiftung Museum Kunstpalast / Quadriennale Düsseldorf 2014 und der Chemical Heritage Foundation. Vgl. dazu den Ausstellungskatalog Kunst und Alchimie. Das Geheimnis der Verwandlung. Hrsg. von Beat Wismer, Dedo von Kerssenbrock-Krosigk und Sven Dupré. München 2014.

65 Michel Butor: Die Alchemie und ihre Sprache. Essays zur Kunst und Literatur. Hrsg. von Helmut Scheffel. Frankfurt a.M., Paris 1984, S. 13-24.

66 Vgl. Helmut Kaffenberger: Orte des Lesens - Alchimie - Monade. Studien zur Bildlichkeit im Werk Walter Benjamins. Würzburg 2011. 
Vielmehr wird durch die Einbeziehung der alchemistischen Legierungsthematik der Blick auf die Problematik der imitatio eröffnet, die durch den Aspekt der Fälschung in einen neuen, diskurskritischen Zusammenhang gestellt ist. Anstelle eines bloßen Vergleichs wird so eine übergeordnete Aussageebene eröffnet und-dem Verfahren der Transmutation ähnlich-eine neue Sinndimension generiert. Ähnlich dem alchemistischen Werk, das sich dem Adepten nur im Zusammenspiel von chiffriert überlieferter Lehre und experimentellem Nachvollzug zu offenbaren verspricht, präsentiert auch der Text keine faktische Setzung, sondern stellt die Prozesshaftigkeit der Deutung und den Deutungsprozess selbst als poetologisches Prinzip aus. 
(C) 2015, Otto Harrassowitz GmbH \& Co. KG, Wiesbaden ISBN Print: 9783447104951 - ISBN E-Book: 9783447194129 


\title{
Zauber der Minne - Zauber der Tugend
}

\author{
Zur Verbindung von Magie und Tugendlehre \\ in spätmittelalterlichen Minnereden
}

\author{
Sandra Linden, Tübingen
}

\section{Vorbemerkungen: Liebe und Magie}

Als Diotima in Platons Symposion eine Beschreibung des Eros liefern soll, holt sie weit aus, erklärt seine Eigenschaften genealogisch über das Erbe seines Vaters Poros und bietet gleich eine Fülle teilweise widersprüchlicher Deutungszugänge: Eros strebt nach dem Schönen, er ist ein tapferer findiger Jäger, ein eifriger Philosoph, aber eben auch ein Zauberer, ein Giftmischer und Sophist. ${ }^{1}$ Die griechischen Begriffe goes und pharmakeus schreiben hier eine folgenreiche Verbindung von Liebe und Magie in die philosophische Tradition ein, die von Plotin in den Enneaden ${ }^{2}$ aufgenommen wird, die sich aber auch in anderen Diskursen niederschlägt; das Spektrum reicht von der philosophischen Definition der Liebe als kosmogonischem Prinzip bis hin zu konkreten Praktiken einer Liebesmagie.

Magie möchte ich dabei in einem ganz grundlegenden Sinn verstehen als eine Form der Einflussnahme, die sich Methoden bedient, die nicht jedem gleichermaßen zugänglich sind, sondern in einem arkanen Bereich liegen und sich nicht-institutioneller Formen der Wissenserzeugung bedienen. Und die Liebe scheint nun ein Bereich zu sein, der eine besondere Affinität zur Magie mitbringt, ein Bereich, in dem sich der Einzelne höheren Mächten ausgeliefert sieht und trotzdem sein Schicksal aktiv gestalten möchte. Verwiesen sei hier auf die

1 Vgl. Platon: Symposion. In ders.: Hippias minor. Symposion. Phaidon. Griechisch und Deutsch. Nach der Übersetzung Friedrich Schleiermachers, ergänzt durch Übersetzungen von Franz Susemihl und anderen. Hrsg. von Karlheinz Hülser. Frankfurt a.M., Leipzig 1991 (Sämtliche Werke in zehn Bänden. IV), 203b-204a.

2 Vgl. Plotins Schriften [Enneaden]. Übersetzt von Richard Harder, fortgeführt von Rudolf Beutler und Willy Theiler. Bd. IIa: Die Schriften 22-29 der chronologischen Reihenfolge. Text und Übersetzung. Hamburg 1962, IV,4,40 (Schrift 28 der ,chronologischen' Reihenfolge), S. 344/345, Übersetzung nach Harder: „die wahre Magie nämlich ist ,die Freundschaft' [philia] und ,der Streit' [neixos], die im All sind, das ist der oberste Zauberkünstler [goes] und Hexenmeister [pharmakeus]. Ihn kennen die Menschen gar wohl und brauchen seine Kräutlein und Formeln wider einander. Denn weil die Menschen von Natur zur Liebe fähig sind und die Liebe erregenden Stoffe sie zueinander zwingen, findet die Kunst des magischen Liebeszwanges statt, bei der man verschiedenen Personen verschiedene magische Substanzen beibringt, die sie durch Kontakt zusammenführen, weil ihnen Liebeskräfte innewohnen." 
Thesen Malinowskis, ${ }^{3}$ nach dem die Magie als Reaktion auf überwältigende Gefühle entsteht und aus der Konfrontation mit einem komplexen, nicht genau kontrollierbaren menschlichen Inneren ein Handlungsmodell entwirft.

Wie tragfähig Platons Verknüpfung von Eros und Magie ist, belegt die Vielfalt, in der die Praxis der Liebesmagie schon früh in varianten Diskursen begegnet. ${ }^{4} \mathrm{Zu}$ denken ist an Circe oder Medea, ${ }^{5}$ Vergil lässt die verzweifelt liebende Dido in der Aeneis Zuflucht zum Zauberlied einer massylischen Priesterin nehmen, ${ }^{6}$ bei Horaz bereitet die Hexe Canidia in der fünften Epode ein Liebesmittel aus Mark und Leber eines eingegrabenen Knaben, ${ }^{7}$ in Vergils achter Ekloge wird der untreue Geliebte Daphnis mit Kräutern eines Zauberers zurückgebracht. ${ }^{8}$ Auch der naturkundliche Diskurs zieht mit, so liefert etwa Plinius in der Naturalis historia Rezepte, nach denen man mit Körperteilen der Hyäne hantieren muss, um schöne Frauen anzuziehen. ${ }^{9}$

3 Vgl. Bronislaw Malinowski: Magie, Wissenschaft und Religion und andere Schriften. Übersetzt von Eva Krafft-Bassermann (1948). Frankfurt a.M. 1973.

4 In einer rezeptionsgeschichtlichen Perspektive bedenkt diesen Zusammenhang Mary Frances Wack: From Mental Faculties to Magical Philters: The Entry of Magic into Academic Medical Writing on Lovesickness, 13th-17th Centuries. In: Eros and Anteros: The Medical Traditions of Love in the Renaissance. Hrsg. von Donald A. Beecher und Massimo Ciavolella. Toronto 1992, S. 9-31. Vgl. auch Richard Kieckhefer: Erotic Magic in Medieval Europe. In: Sex in the Middle Ages. A Book of Essays. Hrsg. von Joyce E. Salisbury. New York 1991, S. 30-55.

5 Vgl. Irmgard Müller: Liebestränke, Liebeszauber und Schlafmittel in der mittelalterlichen Literatur. In: Liebe - Ehe - Ehebruch in der Literatur des Mittelalters. Hrsg. von Xenja von Ertzdorff und Marianne Wynn. Gießen 1984, S. 71-87, hier S. 71.

6 Vgl. Vergil: Aeneis. Lat. - Dt. Hrsg. und übersetzt von Johannes Götte. München 1988, IV, 478-493.

7 Vgl. [Horaz: Epoden] Horace: The Odes and Epodes. Hrsg. von Charles Edwin Bennett. London, Cambridge, MA 1964, Epode 5, V. 29-40: Der Knabe wird bis zum Hals eingraben; als er verhungert und verdurstet ist, kann die Hexe aus den getrockneten Organen bestimmte liebeswirksame Zauberstoffe gewinnen. Zur Canidiafigur bei Horaz vgl. Frank Wittchow: Prekäre Gemeinschaften. Inklusives und exklusives Lachen bei Vergil und Horaz. In: Lachgemeinschaften. Kulturelle Inszenierungen und soziale Wirkungen von Gelächter im Mittelalter und in der Frühen Neuzeit. Hrsg. von Werner Röcke und Hans Rudolf Velten. Berlin 2005, S. 85-110, hier S. 95f.

8 Vgl. [Vergil: Bucolica] Vergil: Landleben. Catalepton. Bucolica. Georgica. Hrsg. von Johannes und Maria Götte. Vergil-Viten. Hrsg. von Karl Bayer. Lateinisch und deutsch. 5. Aufl. München 1987, Ekloge 8,64-109, mit der mehrfach wiederholten Beschwörungsformel ducite ab urbe domum, mea carmina, ducite Daphnim, Übersetzung: „Führt mir heim von der Stadt, oh meine Beschwörungen, führt mir Daphnis her."

9 Vgl. Gaius Plinius secundus der Ältere: Naturkunde. Lateinisch-Deutsch. Buch XXVIII. Medizin und Pharmakologie. Heilmittel aus dem Tierreich. Hrsg. und übersetzt von Roderich König in Zusammenarbeit mit Gerhard Winkler. Darmstadt 1988 (Gaii Plinii secundi Naturalis Historiae libri XXXVII), Kap. 27, § 101, wo es über die Hyäne heißt: pilos rostri admotos mulierum labris amatorium esse, Übersetzung nach König: „die Haare der Schnauze, an die Lippen der Frau gebracht, seien ein Liebesmittel“. Vgl. auch $\S 106$ : eiusdem cavernam sinistro lacerto alligatam, si quis mulierem prospiciat, amatorium esse tam praesens, ut ilico sequatur, 
Christliche Magieverbote, die auf Formen nicht-christlicher Ritualpraxis zielen, hindern diese Stoffe nicht daran, ihren Weg ins Mittelalter zu finden. Betrachtet man jedoch medizinische Schriften über die Liebeskrankheit, die etwa von Constantinus Africanus oder Avicenna beeinflusst sind, ${ }^{10}$ sucht man die naturphilosophische Verbindung von Magie und Liebe oder auch einen Rekurs auf historische Praktiken des Liebeszaubers vergeblich, was wohl damit zu erklären ist, dass in diesem aristotelisch-galenisch geprägten Diskurs die Konzentration auf eine streng logische Kausalität magische Denkformen unterdrückte. ${ }^{11}$ Erst ab dem späten 13. Jahrhundert, vor allem durch die vermehrte Beschäftigung mit der Imaginationslehre, die etwa erklärt, wie allein der Anblick von Schönheit Liebe verursachen kann, wird plötzlich auch im medizinischwissenschaftlichen Schrifttum über die Wirksamkeit magischer Hilfsmittel, Zaubertränke usw. diskutiert; die Magie wird für die Theoretiker der Liebe, die mit enzyklopädischer Akribie alles über die Liebeskrankheit versammeln wollen, zu einem Faktor in ihrem Kalkül. Jedoch verläuft die Übernahme nicht unkritisch, schließlich warnt schon Ovid in der Ars amatoria:

Viderit, Haemoniae siquis mala pabula terrae

Et magicas artes posse iuvare putat.

Ista veneficii vetus est via; noster Apollo

Innocuam sacro carmine monstrat opem.

$[\ldots]$

Quid te Phasiacae iuverunt gramina terrae,

Cum cuperes patria, Colchi, ${ }^{12}$ manere domo?

Quid tibi profuerunt, Circe, Perseides herbae,

Cum sua Neritias abstulit aura rates? ${ }^{13}$

Übersetzung nach König: „das Mastdarmende <des Tieres>, an den linken Arm gebunden, sei ein so rasch wirkender Liebesreiz, daß, wenn jemand eine Frau nur ansehe, sie $<$ ihm $>$ sogleich folge".

10 Zum lateinischen Diskurs über die Liebeskrankheit vgl. Alfred Karnein: Amor est passio. Untersuchungen zum nicht-höfischen Liebesdiskurs des Mittelalters. Hrsg. von Friedrich Wolfzettel. Triest 1997, sowie Mary Frances Wack: Lovesickness in the Middle Ages. The Viaticum and Its Commentaries. Philadelphia, PA 1986.

11 Vgl. hierzu und zum Folgenden die aufschlussreiche Studie von Wack: From Mental Faculties to Magical Philters (Anm. 4).

12 Mit der Colcherin ist Medea gemeint.

13 Ovid: Remedia amoris. Hrsg. von John Henry Mozley. Cambridge, London 1985, Buch 2,98113. Übersetzung: „Wenn jemand meint, dass die schädlichen Kräuter aus Hämonien und die Künste der Magie ihm helfen können, so möge er selbst sehen. Das ist der alte Weg der Giftmischerei. Unser Gott Apollo gibt unschädliche Hilfe mit heiligem Gesang. [...] Was nützten dir die Gräser des Phasischen Landes, Colcherin, als du zu Hause in deinem Vaterland bleiben wolltest? Was nützten dir, Circe, persische Kräuter, als die Winde das Schiff des Neritiers wegtrugen?“ Zur Rezeption der ovidischen Liebeskonzeption im deutschsprachigen Mittelalter vgl. immer noch grundlegend Rüdiger Schnell: Ovids Ars amatoria und die höfische Minnetheorie. In: Euphorion 69 (1975), S. 132-159. 
An die Stelle magischer Rezepturen tritt bei Ovid die eigene Dichtung, wird der heilige Gesang des Apoll zur wahren Liebesmagie. Er wendet das Argument ins Poetologische und nutzt das Verlangen nach wirksamen Zaubermitteln, um die eigene Dichtung zu propagieren.

In der Naturphilosophie wird die platonische Verbindung von Liebe und Magie im 15. Jahrhundert im Zuge der Symposion-Rezeption wieder aktuell. So vertritt Ficino eine positive Sicht der Magie, versteht den Magier als eine Art Sachverständigen des Kosmos, der die im ordo wirkenden Kräfte erkennt und verstärkt. ${ }^{14}$ Die Bezeichnung des Eros als Magier wird von Ficino in seinem Symposion-Kommentar De amore (1466) ausgebaut und zu einer Theorie der magia naturalis als Basis einer philosophischen Liebestheorie verdichtet. In direktem Bezug auf die Bezeichnung des Eros als goes bei Platon bzw. Plotin heißt es dort: Sed cur magum putamus amorem? Quia tota vis magice in amore consistit. Magice opus est attractio rei unius ab alia ex quadam cognatione nature..$^{15}$ Er vergleicht den Kosmos in seinem liebenden Zusammenhang zwischen allen Elementen mit dem Menschen, dessen Körperteile ein harmonisches Ganzes ergeben. ${ }^{16}$ Schließlich konkretisiert Ficino die magischen Wirkweisen des Eros: Quapropter ne/mini dubium est quin amor sit magus, cum et tota vis magice in amore consistat et amoris opus fascinationibus incantationibus veneficiis expleatur. ${ }^{17}$ Wenn die Magie auf dem liebenden Zusammenhalt aller Elemente des ordo beruht, hat im Umkehrschluss die Liebe ihre Wirk- und Ausdrucksform in magischen Praktiken.

\section{Liebeszauber als literarisches Motiv}

Um den Fokus zu verengen, wird im Folgenden die volkssprachige Literatur des Mittelalters auf die skizzierte Verbindung von Liebe und Magie befragt, wobei vor allem zu zeigen ist, wie dieser Konnex in der spätmittelalterlichen Gattung der Minnereden fruchtbar gemacht wird. Das Konzept der höfischen idealen Minne, die den wehrlosen Menschen als eine radikale und absolute Macht er-

14 Zur Verbindung von Magie und Eros bei Ficino vgl. Bernd-Christian Otto: Magie. Rezeptions- und diskursgeschichtliche Analysen von der Antike bis zur Neuzeit. Berlin, New York 2011, S. 426-431.

15 Marsilio Ficino: Über die Liebe oder Platons Gastmahl. Übers. von Karl Paul Hasse. Hrsg. von Paul Richard Blum. Lat. - dt. Hamburg 2004, Oratio 6, Kap. 10, S. 242. Übersetzung nach Hasse: „Weshalb aber wird Eros Zauberer genannt? Weil alle Macht der Zauberei auf der Liebe beruht. Die Wirkung der Magie besteht in der Anziehung, welche ein Gegenstand auf einen anderen auf Grund einer bestimmten Wesensverwandtschaft ausübt."

16 Vgl. Ficino: Über die Liebe (Anm. 15), Oratio 6, Kap. 10, S. 244: Ex communi cognatione communis innascitur amor, ex amore, communis attractio. Hec autem vera magicae est. Übersetzung nach Hasse: „Aus dieser allgemeinen Verwandtschaft entspringt gemeinsame Liebe, aus dieser die gegenseitige Anziehung: und dies ist die wahre Magie."

17 Ficino: Über die Liebe (Anm. 15), Oratio 6, Kap. 10, S. 246. Übersetzung nach Hasse: „Darum besteht kein Zweifel daran, daß Eros ein Zauberer ist; denn alle magischen Kräfte beruhen auf der Liebe, und das Wirken des Liebesgottes vollzieht sich gewissermaßen durch Zauberblicke, Zaubersprüche und Zaubertränke." 
fasst, lädt schon in seiner Grundkonzeption zur Verknüpfung mit magischen Denkformen ein. Entweder versteht man die Minne selbst als magisch, dann personifiziert man sie wie etwa in der Blutstropfenepisode in Wolframs Parzival als übernatürliche Frau Minne, ${ }^{18}$ oder man überträgt die magischen Anziehungskräfte auf das Objekt der Liebe, etwa im Minnesang auf die ideale Dame, die den Minnediener wie eine mächtige Zauberin an sich bindet. Eine weitere Möglichkeit besteht darin, die minnebetroffenen Personen angesichts der gewaltigen Kraft der Minne zu magischen Hilfsmitteln greifen lassen, weil ihre regulären Handlungsoptionen nicht ausreichen.

Die magisch-dämonische Macht der Dame hat im Minnesang vor allem Heinrich von Morungen gestaltet, der das magisch-gebannte und selbstverlorenstaunende Stehen vor der Dame - etwa im Elbenlied oder auch in Vil süeziu senftiu toeterinne - besonders ausdifferenziert hat. ${ }^{19}$ Bereits mit einer ironischen Volte findet sich das Bild der zaubermächtigen Dame in Walthers von der Vogelweide Lied Mich nimt immer wunder, ${ }^{20}$ wenn der Sänger fragt, warum die Dame gerade ihn als Ziel für ihre Zauberkünste ausgewählt hat, wo es doch geeignetere Kandidaten gäbe. ${ }^{21}$ Walthers letzte Strophe klärt auf, worin der Zauber der Dame besteht: Lât iu sagen, wiez umbe ir zouber stât (L 116,25). Ihre Zauberwirkung gründet nicht in einem Geheimwissen, sondern in natürlichen Fähigkeiten, und so wandelt sich die Magieexplikation über das Frauenlob zur Magiekritik:

sie ist ein wîp, die schoene und êre hât,

dâ bî liep und leit.

Daz sie iht anders kunne,

des sol man sich gar bewegen (L 116,27-30).

Das Ich warnt, man möge nur ja nicht glauben, dass seine Geliebte noch iht anders, nämlich geheime Künste könne. Die Dame ist keine Zauberin, sondern einfach zauberhaft.

Wie Elemente des Wunderbaren und auch der Magie zu einem wesentlichen Bestandteil der Poetologie des höfischen Romans werden, hat Jutta Eming wie-

18 Vgl. Wolfram von Eschenbach: Parzival. Nach der Ausgabe Karl Lachmanns revidiert und kommentiert von Eberhard Nellmann. Übertragen von Dieter Kühn. Frankfurt a.M. 1994, 287,9-294,30 (Blutstropfenepisode) oder auch der dritte Minneexkurs 584,25-587,14.

19 Vgl. Des Minnesangs Frühling. Unter Benutzung der Ausgaben von Karl Lachmann und Moriz Haupt, Friedrich Vogt und Carl von Kraus hrsg. von Hugo Moser und Helmut Tervooren. Bd. 1: Texte, 38., erneut revidierte Aufl., mit einem Anhang: Das Budapester und Kremsmünsterer Fragment. Stuttgart 1988, MF 126,8 und MF 147,4.

20 Vgl. Walther von der Vogelweide: Leich, Lieder, Sangsprüche. 14., völlig neubearbeitete Aufl. der Ausgabe Karl Lachmanns hrsg. von Christoph Cormeau. Berlin, New York 1996, L 115,30 .

21 Über die Behauptung, von ihr willentlich verzaubert worden zu sein, hat das Ich auf raffinierte Weise eine Bindung zwischen sich und der Dame gesetzt, ihr die Aktivität in der Minnebindung zugewiesen, während es sich selbst als auserwähltes Ziel des Zaubers bescheiden zurücknehmen kann. 
derholt gezeigt. ${ }^{22}$ Dabei ist der Zauber einerseits als übernatürliche Kraft keiner Erklärung zugänglich und eröffnet innerhalb des Erzählens einen beliebig abrufbaren Raum des Arkanen, andererseits wird er immer wieder als eine ars, also als etwas, das man lernen kann, rationalisiert und einzelnen Figuren als spezifische Könnerschaft zugewiesen. ${ }^{23}$ Auch hier zeigt sich eine signifikante Verknüpfung von Magie und Minne, ${ }^{24}$ wobei in der höfischen Epik die minnebetroffenen Protagonisten meist nicht selbst mit den liebesmagischen Rezepten hantieren, sondern die magischen Dienstleistungen meist auf Nebenfiguren ausgelagert sind:25 Thessala, die zauberkundige Amme der Fenice, verhilft in Chrétiens Cligès mit einem Zaubertrank dazu, dass der ungewollte Ehemann die Ehe nur im Traum vollziehen kann. ${ }^{26}$ Auch die Zauberin, die Dido mit ihrem astronomischen Wissen vom Liebeskummer befreien soll, begegnet in Veldekes Eneasroman wieder, ${ }^{27}$ und in Gottfrieds Tristan hat Isoldes Mutter den folgenreichen Liebestrank bereitet. ${ }^{28}$ Die Helferfiguren leisten ihre mehr oder weniger günstigen magischen Dienste und verschwinden schnell wieder von der Bildfläche, ohne dass man die Protagonisten mit Figurenmerkmalen des Magiers belasten muss. ${ }^{29}$ Als radikale Macht reizt die Minne dazu, auf das Darstellungsregis-

22 Vgl. grundlegend Jutta Eming: Funktionswandel des Wunderbaren. Studien zum Bel Inconnu, zum Wigalois und zum Wigoleis vom Rade. Trier 1999.

23 Vgl. Matthias Meyer: Struktureller Zauber. Zaubersalben und Salbenheilungen in der mittelhochdeutschen Literatur. In: Zauberer und Hexen in der Kultur des Mittelalters. III. Jahrestagung der Reineke-Gesellschaft. Hrsg. von Danielle Buschinger und Wolfgang Spiewok. Greifswald 1994, S. 139-151, vor allem S. 140: „Zauber ist so nicht etwas Über- oder besser Nebennatürliches, sondern ein schlichtes Arkanum, ein Bereich, der einerseits ausgegrenzt, andererseits durchaus in bestimmte Gesetze der Erklärbarkeit und der Logik eingebunden ist."

24 Den Zusammenhang von Magie und Minne in der mittelhochdeutschen Epik nicht nur für die Blutstropfenepisode im Parzival, sondern auch für weitere Beispiele verhandelt Ulrich Ernst: Wolframs Blutstropfenszene. Versuch einer magiologischen Deutung. In: Beiträge zur Geschichte der deutschen Sprache und Literatur 128 (2006), S. 431-466, vor allem S. 453-466.

25 Zur Figur des Zauberers in der mittelhochdeutschen Literatur vgl. etwa Stephan Maksymiuk: The Court Magician in Medieval German Romance. Frankfurt a.M. u.a. 1996; Helmut Brall: Die Macht der Magie: Zauberer in der hochmittelalterlichen Epik. In: Artes im Mittelalter. Hrsg. von Ursula Schäfer. Berlin 1999, S. 215-229, und Sandra Linden: Clinschor und Gansguoter. Zwei Romanfiguren im Spannungsfeld von Gelehrsamkeit und Magie. In: Literaturwissenschaftliches Jahrbuch der Görres-Gesellschaft 49 (2008), S. 9-32.

26 Vgl. Chrétien de Troyes: Cligès. Auf der Grundlage des Textes von Wendelin Foerster übersetzt und kommentiert von Ingrid Kasten. Berlin, New York 2006, V. 2962-2970 sowie Thessalas Selbsteinschätzung in V. 2988-2991. Zur Thessala-Figur im Cligés vgl. auch Laine E. Doggett: Love Cures: Healing and Love Magic in Old French Romance. Pennsylvania (PA) 2009, S. 39-73.

27 Vgl. Heinrich von Veldeke: Eneasroman. Die Berliner Bilderhandschrift. Mit Übersetzung und Kommentar hrsg. von Hans Fromm. Frankfurt a.M. 1992, 73,38-74,26 (V. 2264-2292).

28 Vgl. Gottfried von Straßburg: Tristan und Isold. Hrsg. von Friedrich Ranke. Text. 15., unveränderte Aufl. Dublin, Zürich 1978, V. 11429-11444.

29 Eine Ausnahme bilden freilich die Feengeschichten, vgl. etwa Konrads von Würzburg Partonopier und Meliur oder den Friedrich von Schwaben. 
ter des Magischen zurückzugreifen, doch als Ideal höfischer Wert- und Tugendvorstellungen will man das Thema zugleich von wie auch immer gearteten dämonischen Kräften fernhalten, da die von Magie beeinflusste Minne immer die Gefahr birgt, das für die Protagonisten aufgestellte Minneideal negativ zu beeinträchtigen. So beklagt etwa Heinrich von Veldeke in einem Lied Tristran muose sunder sînen danc (MF 58,35), ,0 dass Tristan Isolde ja nur liebe, weil ihn das poisûn dazu gezwungen habe, und nutzt die Tristangeschichte, um seine eigene, echte Minne zur besungenen Dame von der minderwertigen Trankliebe abzusetzen. ${ }^{31}$ Eine rationale Kritik an der Liebesmagie in dem Sinne, dass sie einfach nicht funktioniert, findet sich in den literarischen Entwürfen kaum, denn schließlich kann die Fiktion die von der Magie bewirkten Resultate beliebig umsetzen.

Anders sieht es in stärker lehrhaften Zusammenhängen aus: Im Folgenden soll für die Gattung der Minnereden, die Glier als „pragmatisch-didaktische Variante der Minnedichtung “32 bezeichnet hat, gefragt werden, wie sich in dieser vielfältigen Textgruppe mit offenen Rändern das Motiv des Minnezaubers, der ja auch auf ein Handhabbar- und Verfügbarmachen des Minneerfolgs zielt, fortschreibt und wie es diskursiviert wird. Ausgangspunkt ist der Kräuterzauber in der Klage Hartmanns von Aue, sodann wird am Beispiel von vier Minnereden analysiert, inwiefern Hartmanns Vorgabe zu einem wichtigen Orientierungspunkt dafür wird, wie die Minnereden mit dem Thema Magie umgehen.

\section{Der Kräuterzauber in der Klage Hartmanns von Aue}

Hartmanns Klage, ${ }^{33}$ wohl um 1180 entstanden, ist von der Forschung wiederholt als Vorform der sich erst später herausbildenden Gattung der Minnerede gesehen worden. ${ }^{34}$ In einem Streitgespräch ${ }^{35}$ diskutieren die Personifikationen Herz

30 Vgl. Minnesangs Frühling (Anm. 19), 58,35-59,2: Tristran muose sunder sînen danc, / staete sîn der küneginne, / wan in daz poisûn dar zuo twanc / mêre dann diu kraft der minne. Nicht nur die Chronologie, sondern auch die Namensform „Tristran“ lässt vermuten, dass Heinrich sich hier auf Eilharts Version der Tristangeschichte bezieht.

31 Eine solche Kritik an der Tristanminne, die eben nicht am Ehebruch, sondern an der Trankliebe ansetzt, begegnet im Minnesang mehrfach (z.B. Bernger von Horheim MF 112,1) und ist immer auch im Sinne einer Gattungskritik zu lesen. Vgl. zum Trankmotiv Otfrid Ehrismann: Isolde, der Zauber, die Liebe - der Minnetrank in Gottfrieds Tristan zwischen Symbolik und Magie. In: Ergebnisse und Aufgaben der Germanistik am Ende des 20. Jahrhunderts. Festschrift für Ludwig Erich Schmitt zum 80. Geburtstag. Hrsg. von Elisabeth Feldbusch. Hildesheim 1989, S. 282-301.

32 Ingeborg Glier: Artes amandi. Untersuchungen zu Geschichte, Überlieferung und Typologie der deutschen Minnereden. München 1971, S. 16.

33 Vgl. Das Klagebüchlein Hartmanns von Aue und das zweite Büchlein. Hrsg. von Ludwig Wolff. München 1972.

34 Vgl. Glier: Artes amandi (Anm. 32), S. 20, sowie in direkter Reaktion auf Gliers Kategorisierung der Vorformen Dietrich Huschenbett: Minne als Lehre. Zur Bedeutung der "Vorläufer" der Minnereden für die Literaturgeschichte des 12. und 13. Jahrhunderts. In: Liebe in der deutschen Literatur des Mittelalters. St. Andrews-Colloquium 1985. Hrsg. von Jeffrey Ashcroft, Dietrich Huschenbett und William Henry Jackson. Tübingen 1987, S. 50-60. Vgl. auch 
und Leib über das Für und Wider eines Minnedienstes, was schließlich in ein versöhnliches Einlenken des Leibes mündet, sodass am Ende eine Liebesbotschaft an die Dame formuliert wird. Die perspektivische Komplexität der Innendarstellung ist wiederholt analysiert worden, ${ }^{36}$ doch ist dies hier nicht das vorrangige Thema. Vielmehr soll die Analyse auf den in V.1275 angekündigten zouberlist fokussieren, den das Herz aus Kärlingen (V. 1280, Frankreich) importiert hat und der als Lehre des Herzens eine Schlüsselstellung in der Argumentation einnimmt. ${ }^{37}$

Das Herz stellt zu Beginn des Abschnitts noch einmal fest, dass der Leib zwar zuvor jeglichem Zauber abgeschworen habe, ${ }^{38}$ dass er für diesen guten Zauber aber eine Ausnahme machen müsse, da es sich um einen zouberlist handele, der benamen guot ist (V. 1275). Die ersten drei Zutaten für den Kräuterzauber sind nicht einfach verfügbar, man kann sie weder anbauen noch kaufen, der endarft dîu aber niht warten / in deheines mannes garten, / ouch envindet sîniemen veile (V. 1287-89). Sie werden vielmehr gnadenhaft von Gott verliehen. Schließlich werden die Zutaten genannt; es sind keine botanischen Kräuter, sondern die Tugenden milte, zuht und diemuot (V. 1303)-das vermeintliche Zauberrezept wird ins Allegorische zu einem Tugendzauber verschoben. Die Tugendmischung wird als einzig rechtmäßiger Zauber ausgewiesen:

Ronald Michael Schmidt: Studien zur deutschen Minnerede. Untersuchungen zu Zilies von Sayn, Johann von Konstanz und Eberhard von Cersne. Göppingen 1982, S. 17-30.

35 Dass sich Hartmann hier einer gelehrt-klerikalen Form bedient, bedenkt Volker Mertens: Factus est per clericum miles cythereus. Überlegungen zu Entstehungs- und Wirkungsbedingungen von Hartmanns >Klage-Büchlein ‘. In: Hartmann von Aue. Changing Perspectives. Hrsg. von Timothy McFarland und Silvia Ranawake. Göppingen 1988, S. 1-19.

36 Vgl. Francoise Salvan-Renucci: Selbstentwurf als Utopie im >Büchlein In: Gesellschaftsutopien im Mittelalter. Hrsg. von Danielle Buschinger und Wolfgang Spiewok. Greifswald 1994, S. 101-117, sowie Susanne Köbele: Der paradoxe Fall des Ich. Zur Klage Hartmanns von Aue. In: anima und sêle. Darstellungen und Systematisierungen von Seele im Mittelalter. Hrsg. von Katharina Philipowski und Anne Prior. Berlin 2006, S. 265283, mit weiterer Literatur, die S. 266 die „perspektivische Komplexität" der Innendarstellung hervorhebt. Ob der Disput zwischen Herz und Leib in eine Harmonie führt (vgl. Katharina Philipowski: sêle und herz in geistlichen und höfischen Dialoggedichten des Mittelalters. In: anima und sêle [s.o.], S. 299-319), oder ob trotz der formalen Einigung eine unterschwellige Spannung zwischen beiden Gesprächspartnern bestehen bleibt (Köbele: Der paradoxe Fall des Ich), steht hier nicht zur Diskussion.

37 Vgl. Marie-Sophie Masse: der rehte zouberlist aus Karlingen. Ältere und neuere Überlegungen zu Hartmanns `Klageく. In: Mertens lesen. Exemplarische Lektüren für Volker Mertens zum 75. Geburtstag. Hrsg. von Monika Costard, Jacob Klingner und Carmen Stange. Göttingen 2012, S. 89-106, die auf S. 92 den Kräuterzauber in der Klage als Kern der Lehre einschätzt, der dann zur Versöhnung der beiden Instanzen führt.

38 Vgl. V. 1271f.: ich hôrt dich zouber versprechen: / daz gelübede muost dû brechen. Tatsächlich hatte der Leib zuvor versprochen, auch einen leidvollen Minnedienst zu erdulden und sämtliche Ratschläge zu befolgen, solange sie nicht auf Zauberei und Mord ausgehen, vgl. V. 11201123: âne zouber und âne mort / und daz an die triuwe gât / so verwirfe ich deheinen rât, / ichn leiste in durch ir êre. 
ezn ist kein zouber sô guot:

swelich sæliger man

diu driu krût tempern kan

dar nâch als in gesetzet ist,

daz ist der rehte zouberlist. (V. 1304-1308)

Es ist nicht ausreichend, die richtigen Kräuter einfach zusammenzufügen, sondern man muss sie im richtigen Verhältnis mischen (tempern) - hier kommt über den nicht genauer spezifizierten Vorgang des richtigen Mischens eine leichte alchemische Note in die Anweisung -, und zwar muss man sie so mischen, wie es ihnen gesetzet ist, d.h., wie es ein höherer ordo vorsieht. Als weitere Zutaten dienen Treue, Beständigkeit, Keuschheit, Schamhaftigkeit und gewislîchiu manheit. ${ }^{39}$ Wenn man alle Tugenden beisammen hat, was durchaus als ein nicht selbstverständlicher Gelingensprozess beschrieben wird, fehlt noch das passende Gefäß:

und swem alsô gelinget

daz er sî zesamen bringet,

der sol sî schütten in ein vaz:

daz ist ein herze âne haz (V. 1319-1322).

Das Gefäß, in dem der Leib die Tugenden versammeln soll, ist sein Gesprächspartner, das Herz. Beide müssen zusammenwirken, wenn der Zauber gelingen soll.

Es folgt eine Bewertung des Zaubers, die in Erinnerung ruft, dass der Leib ja eigentlich dem Zauber abgeschworen hatte, und eine Differenzierung zwischen gutem Tugendzauber und schlechtem dämonischem Zauber einführt: Den Tugendzauber kann man ohne Laster und ohne Sünde vollziehen, zudem bringt er weltliche und geistliche Ansprüche zum Ausgleich: ez ist bêdenthalp ein gewin, / got und diu werlt minnet in (V. 1345f.). Allein den Tugendzauber lässt das Herz im Minnedienst gelten, alle anderen Zaubermittel nicht, und es folgt eine massive Kritik an den Anhängern solcher Praktiken, d.h., der eigene gute Zauber wird von den üblen Betrügereien der anderen abgesetzt:

wan daz wær misselungen,

würde ein wîp betwungen

mit zouberlîchen dingen

$[\ldots]$

got gebe im immer leit

der sîn von êrste began! (V. 1351-1363)

39 Vgl. V. 1309-1318: ouch hœrent ander würze derzuo / ê daz man im rehte tuo, / triuwe unde stæte: / swer die dar zuo niht hæte, / sô müese der list belîben: / ouch muost dî dar zuo trîben / beide kiuscheit unde schame: / dannoch ist ein krûtes name / gewislîchiu manheit: / sô ist der zouber gar bereit. 
Als Mittel, wie man Minneleid in Minneglück verwandelt, rät Hartmanns Klage also zur tugendhaften Vervollkommnung des Minnedieners, was zunächst einmal nicht weiter verwunderlich ist, und so sind auch die gewählten Tugenden im Kanon höfischen Minnedienstes verortet. Interessant ist aber die Form, die Präsentation der Tugendlehre als zouberlist. Auf den ersten Blick sieht das aus wie ein augenzwinkernder Trick, eine schöne und aufmerksamkeitsträchtige Verpackung für eine eher konventionelle Tugendlehre. Aber was sich mit den Zentraltugenden Mildtätigkeit, Anstand, demütige Bescheidenheit und den fünf weiteren Tugendkräutern zunächst so glatt liest, wird problematisch, wenn man nach der logischen Motivierung des Zaubers fragt. Eigentlich ist der Leib nach den anfänglichen Anklagen nämlich durchaus zur Versöhnung mit dem Herzen und ausdrücklich zur Unterordnung unter seine Führung bereit, denn er formuliert unmissverständlich: Nû leiste ich gerne swaz dî wil (V. 1173). Als attraktiven Köder, um den Leib zum Einlenken zu überreden, braucht das herze den Kräuterzauber in der Gesprächslogik gar nicht, und so wird die Zauberbildlichkeit zu einem überschüssigen Argument, an dem die Deutung ansetzen kann.

In Hartmanns Konzeption des Kräuterzaubers sind zwei Elemente hervorzuheben, die für die späteren Minnereden relevant werden, nämlich 1.) die Unterscheidung eines richtigen und eines falschen Zaubers, d.h. die Reflexion darüber, welche Formen magischen Handelns im Minnediskurs zulässig sind, und 2.) die Öffnung des Zaubermotivs hin zur Tugendallegorie, die Verschiebung von den botanischen Kräutern hin zu den Tugendkräutern im menschlichen Herzen. Bedenkt man dabei, dass das mittelhochdeutsche Substantiv tugent neben der ethischen Tugend zunächst einmal eine grundsätzliche Tauglichkeit und Kraft meint, die einer Person oder auch einem Ding zukommen kann, ist die Verbindung zu magischen Kräften naheliegend, und so können etwa die magischen Eigenschaften eines Steins ganz gängig als tugent bezeichnet werden. ${ }^{40}$ Für

40 Vgl. beispielsweise Wirnt von Grafenberg: Wigalois. Text der Ausgabe von J.M.N. Kapteyn. Übersetzt, erläutert und mit einem Nachwort versehen von Sabine Seelbach und Ulrich Seelbach. Berlin, New York 2005, V. 1477-79, wenn der Blick des Protagonisten auf den magischen Stein vor dem Artushof fällt: b̂̀ einer linden er dô sach / ligen einen breiten stein, / des tugent im inz herze schein. Vgl. auch Rudolf von Ems: Barlaam und Josaphat. Hrsg. von Franz Pfeiffer. Leipzig 1843. Neudruck Berlin 1965, wenn es im Gespräch zwischen dem als Kaufmann verkleideten Barlaam und dem Erzieher Josaphats über den angebotenen Edelstein heißt, 39,1-4 (V. 1500-1504), doch hân ich her von kindes jugent / alsô gelebet, daz ich die tugent / vernam von steine nie sô rich. / im wart nie steines kraft gelîch, und der Edelstein später zum Gleichnis für die christliche Lehre wird, mit der die Tugenderziehung des Josaphat zu leisten ist. Vgl. dazu Uwe Ruberg: >Wörtlich verstandene scher erzählender Dichtung von Veldeke bis Wickram. In: `Sagen mit Sinneく. Festschrift für Marie-Luise Dittrich zum 65. Geburtstag. Hrsg. von Helmut Rücker. Göppingen 1976, S. 205-220, hier S. 208-210. Auch die von den vier Elementen ausgehenden Kräfte können als tugent bezeichnet werden, vgl. die gleichnishafte Auslegung der Schlange im Barlaam, 119,37-40 (V. 4737-4740): Der vier slangen houbet sint / vier tugende, von den al diu kint, / diu von menschen sint bekomen, / lîp und leben hânt genomen. 
die Tugendkräuter der Klage wird in der Übertragung auf eine innere Eignung des Menschen die Plötzlichkeit der Zauberwirkung, der magische Automatismus in eine vom Menschen abhängige Prozessualität der tugendhaften Bewährung überführt: Nicht nur das Zusammenfügen der Zutaten, sondern das - nicht näher beschriebene - richtige Mischen derselben, das durchaus eine Phase des Ausprobierens und der schrittweisen Vervollkommnung vorsieht, entscheidet über den Erfolg. Das schnelle, garantiert wirkende Zauberrezept wird durch einen zeitlich ausgedehnten Prozess ethischer Vervollkommnung und die Steigerung der eigenen Tauglichkeit ersetzt, was sich besser zum Konzept eines prinzipiell auf die Ewigkeit ausgerichteten Minnedienstes fügt.

In einen stärker lehrhaften Kontext übertragen, wird die Verknüpfung von Minne und Magie, wie sie für die höfische Epik und den Minnesang skizziert wurde, nicht einfach weitergeschrieben, sondern transformiert. Hartmann macht aus dem Zaubertrank eine Tugendmagie, das minnebetroffene Ich ist nicht mehr auf die Hilfe eines zwielichtigen Zauberers angewiesen, sondern kann über eine entsprechende Ethik seine Handlungsmacht im Bereich der Minne behaupten. Dass Hartmann damit ein Bild entwirft, das für die Gattung der Minnereden attraktiv wird, sollen einige Textbeispiele verdeutlichen.

\section{Minnereden}

Das Corpus der rund 600 Texte, das nun im Heidelberger Minnereden-Handbuch von Ludger Lieb und Jacob Klingner besser verfügbar ist, ${ }^{41}$ demonstriert eindrucksvoll die Beliebtheit der Gattung Minnerede im Spätmittelalter. Thema ist immer noch die ideale Minne als radikale Kraft, wie sie die höfische Literatur als Konzept entwickelt hat, doch wird sie in den Minnereden in den Formen eines stärker lehrhaften, verbindlichen Sprechens fortgeführt und so auf eine neue Diskussionsebene gestellt. ${ }^{42}$ Die komplexen Reflexionen des hochhöfischen Minnediskurses werden heruntergebrochen auf die Frage nach dem richtigen Umgang mit der Minne. Dabei präsentieren sich die Minnereden häufig, wenn auch nicht im konkreten Anspruch, so doch im kommunikativen Gestus als Verhaltenslehren, die das Phänomen der Minne einerseits handhabbar machen und andererseits als Faszinosum erhalten wollen. Es zeigt sich das verstärkte Bemühen, bestimmte Grundwerte der Minne in Variation immer wieder gedanklich zu umkreisen und festzuschreiben, sodass sich die Poetik der Minnereden zentral über die Faktoren Wiederholung und Serialität erschließt. ${ }^{43}$ Die Ich-

41 Vgl. Jacob Klingner, Ludger Lieb: Handbuch Minnereden, mit Beiträgen von Iulia-Emilia Dorobanțu, Stefan Matter, Martin Muschick, Melitta Rheinheimer und Clara Strijbosch. Berlin, Boston 2013.

42 Einen frühen - freilich nicht unumstrittenen Versuch - einer Gattungsbestimmung unternimmt Tilo Brandis: Mittelhochdeutsche, mittelniederdeutsche und mittelniederländische Minnereden. München 1968, S. 8-12. Bereits Glier: Artes amandi (Anm. 32), S. 10, spricht für die Minnereden von einem "gleitenden System von Gattungsmerkmalen“.

43 Vgl. Ludger Lieb: Eine Poetik der Wiederholung. Regeln und Funktionen der Minnerede. In: 
Rede der Gattung ist, was die Betroffenheit des Ichs von der Minne angeht, übergängig zum Minnesang, zugleich setzen sich Redetraditionen aus der Spruchdichtung fort, in denen sich ein nichtbetroffenes Ich lehrhaft-autoritativ über ein Thema äußert. ${ }^{44}$ Stärker als der Minnesang zeigen die Minnereden das Bedürfnis, ein Wissen über die Minne verfügbar zu machen und Verhaltensratschläge zu formulieren, um den Verlauf der Minne lenkbar und kontrollierbar zu machen.

Freilich erreichen die meisten Minnereden nicht das Reflexionsniveau von Hartmanns Klage, argumentieren deutlich einfacher, als es das komplizierte psychologische Arrangement zwischen Herz und Leib vorgibt. Vielleicht etwas plakativ lässt sich dies an der Minnerede B 70 demonstrieren, die eine Reihe von Liebesklagen zusammen überliefert. Die Ablehnung eines magischen Minnezaubers ist ähnlich strikt wie bei Hartmann, und das Argument einer Wirkungslosigkeit des Zaubers bringt bereits Ovid in seiner Schelte auf die via veneficii, ${ }^{45}$ aber die Magiekritik wird in der Minnerede deutlich handfester und schnörkelloser formuliert:

Ich muz den olden wiben

sprechen an ir ere,

daz sie den tober [= Zauber - S.L.] triben.

und van iren tromen sagen mere.

wär ez myr nach denen tromen ergangen.

ich hette tuzent werbe mein allerliebste umvangen. ${ }^{46}$

Die Liebeszauber sind ehrlos, weil sie nicht funktionieren, und die Träume der alten Frauen versprechen Liebeserfüllung, die aber ausbleibt.

Zwar lehnt man magische Tricks ab, um Liebeserfolg zu erlangen, aber auf einem anderen Feld, das der Minnerede ein besonderes Anliegen ist, sind die magischen Hilfsmittel dann wieder zulässig, nämlich wenn es darum geht, sich mit Zaubermitteln Zugang zu einem Arkanbereich der Minne zu verschaffen und Wissen über sie zu erlangen. So kann die Sprecherin in der Minnerede Das

Text und Kultur. Mittelalterliche Literatur 1150-1450. DFG-Symposion 2000. Hrsg. von Ursula Peters. Stuttgart, Weimar 2001, S. 506-568.

44 Wie die Minnereden den Anspruch auf Lehrautorität und die persönliche Minnebetroffenheit des Sprechers in der Ich-Rolle austarieren, habe ich gezeigt in: Sandra Linden: Lieben lernen? Lehrhafte Vermittlung und ihre Problematisierung in Minnereden. In: Lehren Lernen - Bilden. XXIII. Anglo-German Colloquium (Nottingham 2013). Hrsg. von Henrike Lähnemann, Nicola McLelland und Nine Miedema, im Druck.

45 Vgl. das Zitat aus der Ars amatoria im ersten Teil dieses Beitrags.

46 Erasmus Nyerup: Symbolae ad literaturam Teutonicam antiquiorum ex codicibus manu exaratis qui Havniae asservantur ed. sumtibus Petri Friderici Suhm. Havniae 1787, S. 93 102, hier S. 93, Str. 3. 
Zauberkraut (B 407) ${ }^{47}$ mit einem magischen Kraut plötzlich das Problem der Ausdrucksverstellung umgehen und allen Männern direkt ins Herz blicken. ${ }^{48}$ Das nutzt sie aber nicht etwa, um einen geeigneten Partner zu finden, wie es sich die Minnesänger gelegentlich ausmalen, ${ }^{49}$ sondern um endlich eine aufrichtige Antwort auf die sie schon lange umtreibende Frage zu bekommen, ob die treue Liebe zu einer Frau oder der Dienst für viele Frauen für Männer attraktiver ist. Sie führt eine Diskussion mit einem Ritter, in dessen Herz sie mehrere Frauen erblickt hat und der ihr, nachdem sie ihm die Zauberwirkung des Krauts eröffnet hat, auch aufrichtig Rede und Antwort steht. Die Magie ist hier an ein Requisit gebunden, ihre Funktionsweise bleibt im Unklaren, aber sie wird akzeptiert, weil sie im Dienste des Wissenserwerbs über die Minne nützlich ist und hilft, einen theoretischen Minnekasus argumentativ zu entfalten. Eine ähnliche Funktion hat ein Brief in der Minnerede Die alte und neue Minne (B 451), der unsichtbar macht und den Besitzer alle Wege finden lässt. ${ }^{50}$ Die Sprecherin bekommt den Brief von der personifizierten alten, rechtmäßigen Minne verliehen und nutzt das magische Ding, um zur neuen, treulosen Minne zu reisen, sich ausführlich über sie zu informieren, um dann am Ende für die alte Minne zu votieren. Das Zauberkraut und der Brief verschwinden, sobald sie ihre Funktion, den Wahrnehmungs- und Wissensbereich des Sprechers zu erweitern, erfüllt haben: Das Zauberkraut landet in einem Bach, und das Tarn- und Wegebrieflein wird einfach gar nicht mehr erwähnt.

\section{4. a Walther von Griven: Weiberzauber (B 391)}

In direkter Rezeptionslinie zu Hartmanns Klage steht wohl um 1300 Walther von Griven, dessen Minnerede Weiberzauber (B 391)51 mit sechs erhaltenen Handschriften verhältnismäßig breit überliefert ist. ${ }^{52}$ In der Rezeption wird nun nicht

47 Vgl. Mittelhochdeutsche Minnereden II. Die Heidelberger Hss. 313 und 355; die Berliner Hs. ms. germ. fol. 922. Auf Grund der Vorarbeit von Wilhelm Brauns hrsg. von Gerhard Thiele. Berlin 1938, S. 87-97, Nr. 16.

48 Vgl. V. 18-35: do brach ich uff dem anger wit / meng crut das mir was unerkant. / Do ward mir ains in min hant / do von mir groß aubentúr geschach. / als bald ich das crútlin ie abgebrach, / do sach ich vor mir alle man / wer zü der minn ie kain müt gewann, / und hort och all ir red wol, / der ich doch gar nit sagen sol, / und wúst och allen irn gedannck. / [...] / do merckt ich erst das daz crúttelin / an im selbes hett die crafft. Sowie V. 75f.: ich hön ain crüt in miner hant, / das tüt mir gantz din hertz bekant.

49 Vgl. etwa Ulrich von Liechtenstein: Frauendienst. Hrsg. von Reinhold Bechstein. Leipzig 1888, Lied XIV Ouwê daz ich bî den wolgemuoten alsô, Str. 4.

50 Vgl. Lieder-Saal. Sammlung altdeutscher Gedichte. Hrsg. von Joseph Freiherr von Lassberg. Bd. 3. Neudruck Hildesheim 1968, S. 83-95, Nr. 182, vor allem die Beschreibung der Wirkung des Briefs, V. 168-173: Si sprach nim hin daz brifelin / Und slissz ez in du hant din / So sint dir allu weg bechant / Wie ser du wilt in dú lant / Dé wort dar an hant soelich phligt / Wenn du wilt dich nieman sicht.

51 Vgl. Liederbuch der Clara Hätzlerin. Hrsg. von Carl Haltaus. Quedlinburg, Leipzig 1840, S. 217 (Nr. 50).

52 Zur Überlieferung vgl. Klingner, Lieb: Handbuch Minnereden (Anm. 41), Bd. 1, S. 614. Eine 
etwa der sophistisch-scharfsinnige Wortwechsel zwischen Herz und Leib produktiv, sondern Walther übernimmt mit deutlicher intertextueller Markierung ausschließlich den Kräuterzauber. Die Minnerede baut die Kräuter-TugendAllegorie aus, wobei die Rezeptstruktur in der Kombination verschiedener Tugenden der Vorliebe der Gattung Minnerede für Tugendaufzählungen und Systematisierungen entgegenkommt. Hartmanns acht Tugendkräuter hat Walther auf zehn erweitert und sie auch variiert, weil sich sein Zauber an Frauen richtet, die damit ein unliebsames Verhalten ihrer Ehemänner korrigieren können. Die Überschriften variieren, die Fassung im Liederbuch der Clara Hätzlerin überschreibt den kurzen Text Von krewtern, damit frawen ir mann bezaubern, und auch die anderen Handschriften haben sämtlich das Signalwort ,Zauber' in der Überschrift. ${ }^{53}$ Das Ich inszeniert sich als Ratgeber für die Frauen:

Ich hör die frawen dick sagen

Vnd aine der andern not clagen,

Was ir Ir man laides tů.

Da kan ich schön list zů,

Die sind zu Baris erdacht,

Von dannen hab ichs her pracht,

Damit frawen zaubern ir mann

Als ich eüch wol gesagen kan. (V. 1-8)

Während die ersten drei Tugenden, die wie bei Hartmann eine Einheit bilden, mit Demut, weiblicher Güte und Sanftheit ein gängiges weibliches Verhaltensideal beschreiben, wendet sich die Reihe mit den weiteren Zutaten in einer gewissen Überzeichnung zu einer Lehre, die die männliche Dominanz über die Frau mehr als in den Minnereden üblich betont: Die Frau soll alles für gut halten, was ihr Mann tut, sie soll seine Seitensprünge nicht tadeln, sich vielmehr unwissend stellen, trotzdem stets guter Laune sein usw.

Während die Fassung der Minnerede, die im Liederbuch der Hätzlerin überliefert ist, den Frauen kurz und lakonisch zucht vnd er (V. 48) verspricht, gibt sich die Langfassung in der Heidelberger Handschrift (cpg 384) etwas versöhnlicher und formuliert - möglicherweise ironisch ${ }^{54}$ - als Ziel: Dise zawbernisch hab ich den frawen geben / Daz ir man dester paz mit in leben. ${ }^{55}$ So wird zum Ende eher das von

genaue Analyse der intertextuellen Bezüge bietet Thomas Bein: Hartmann von Aue und Walther von Grieven im Kontext: Produktion, Rezeption, Edition. In: editio 12 (1998), S. 38 54.

53 Vgl. Ditz mere ist wie die wip ir man / Mit zouber gewinnen dan (Co); Ditz ist wie die wip ir man / Mit zouber gewunnen han (He 6) und Ain hubsche zauberlist den frawen (Lo 4). Zur Überlieferung vgl. Klingner, Lieb: Handbuch Minnereden (Anm. 41), Bd. 1, S. 614f.

54 Deutlich für eine ironische Lesart der Fassung in cpg 384 votiert Bein: Hartmann (Anm. 3), S. 53.

55 Eine Transkription der Fassung in cpg 384 findet sich in der Einleitung zum Liederbuch der Clara Hätzlerin (Anm. 51), Einleitung, S. XXXVII, V. 57f. 
Gott eingerichtete Miteinander von Mann und Frau als die vermeintliche Bezwingung des Mannes betont. Was als magische Korrektur eines Fehlverhaltens der Männer angekündigt wurde, wandelt sich über den Kräuterzauber zu einer Tugendlehre für die Frau, die jedoch im Vergleich zu Hartmann die Anforderungen bewusst überzeichnet und eine ernsthafte Auseinandersetzung mit der Klage der Frauen verweigert. Ohne das rahmende Streitgespräch von herze und lîp wird der Kräuterzauber hier zu einer ironischen Kritik an denjenigen, die für alles einen bequemen Zauber haben und nicht zuerst das eigene Verhalten verändern wollen.

\section{4.b Der Stern der Treue (B 432)}

Die gut 500 Verse umfassende Minnerede Der Stern der Treue (B 432) ${ }^{56}$ erzählt primär davon, wie das Ich der personifizierten Treue hilft, am Himmel ihren Stern $\mathrm{zu}$ entdecken, doch wird die umfangreiche Sternallegorie durch einen etwa 80versigen Kräuterzauber der Tugenden unterbrochen (V. 298-381). Für den vorliegenden Zusammenhang ist relevant, wie sich der Kräuterzauber hier zu einem medizinisch-heilkundlichen Diskurs hin öffnet, denn der Gedanke einer Heilung des Liebesleids durch Tugenden wird nun in ein Handlungsarrangement der Personifikationen überführt. Die Kräuter werden nicht mehr wie bei Hartmann im allegorischen Verweiszusammenhang mit den einzelnen Tugenden gleichgesetzt, sondern die Tugenden werden personifiziert und führen jeweils ein heilendes Kraut mit sich, aus dem sie dem Liebeskranken einen wirksamen Verband bereiten. Als medizinische Helfer eilen die Tugenden Triuwe, Staetekeit, Mâze usw. zu dem von Minne verletzten Herzen, um die Wunde zu heilen: Die kennent gütte krütter wol, / da mit man es verpinden sol (V. 309f.). Es folgt eine Auflistung der hilfreichen Kräuter; einige sind reale Pflanzen wie etwa Vergissmeinnicht (V. 317) und Wegwarte (V. 319), andere wie die Pflanzen hoche[r] muit (V. 317) und ain aid (V. 312) haben eine allegorische Bedeutungsebene. Auch hier kommt es wie schon bei Hartmann auf die richtige und sorgfältige Zubereitung der Kräutermixtur an, muss man die guten Kräuter vom Unkraut trennen, denn: belib ye dar under ain klain torn, / alle arbait ist verlorn (V. 325f.). Die Pflanze Falsch (V. 323), die sich gern einschleicht, muss man auslesen, und auch zagel hail (V. 328), was man wohl nicht als zagelholz (= Wipfelholz) lesen kann, sondern eher wörtlich als ,Schwanzglück' übersetzen muss, wird verboten. Aus dieser Mischung wird dann dem Herzen von den Tugenden ein Verband angelegt, und zwar vorsorglich ein dreifacher, damit kein Zweifel mehr durch den Verband schlagen kann (V. 340-345).

Das Motiv des Kräuterzaubers ist hier über den Kunstgriff der Personifikation in ein lebendiges Handlungsarrangement überführt, die magische Wirkung der Tugenden ist in der belebten Szene durch die konkrete Heilwirkung der

56 Vgl. Mittelhochdeutsche Minnereden I. Die Heidelberger Hss. 344, 358, 376 und 393. Hrsg. von Kurt Matthaei. Berlin 1913. Neudruck Dublin, Zürich 1967, S. 134-143, Nr. 13. 
Kräuter, die die personifizierten Tugenden eifrig herbeischaffen, ersetzt, wobei die konkrete Arzneiwirkung zum Teil wieder ins Allegorische überführt wird. Das Magisch-Übernatürliche ist hier in das Reich der Personifikationen verlegt. Was auf der Darstellungsebene der Personifikationshandlung als ein realistisch anmutender heilkundlicher Vorgang gestaltet wird, ist, wenn man aus dem Sonderbereich der Personifikationen herausgeht, wie bei Hartmann eine durch Tugenden herbeigeführte Besserung des Herzens, und so mag man hier eine Variante des Kräuterzaubers ansetzen. ${ }^{57}$

\section{4.c Die Zauberin (Z 51)}

Vom konkreten Kräuterzauber öffnen die beiden folgenden Beispiele die Perspektive auf eine etwas allgemeinere Verbindung von Magie und Tugenden in der Gattung Minnerede. Die gut 500 Verse lange Minnerede Die Zauberin (Z 51) ist in der dünnen Berliner Minneredenhandschrift 115 überliefert und bislang unediert. ${ }^{58}$ Die Handschrift ist um 1590 im bayerischen oder österreichischen Raum entstanden, die Minnerede selbst ist aber wohl früher zu datieren, da fehlende Reime auf Textverlust und somit auf eine vorgängige Überlieferung schließen lassen und auch die übrigen Minnereden der Handschrift eher ins 15. Jahrhundert weisen. Es handelt sich um einen Schönheits- und Tugendpreis, der, indem die Minnedame als allmächtige Zauberin ausgewiesen wird, über einen Liebeszauber motiviert wird. Ein Sprecher präsentiert eingangs die Zauberei in Minneangelegenheiten nicht mehr als außerordentliche Begebenheit, sondern als das Schicksal vieler, und er selbst ordnet sich unterschiedslos in die große Gruppe der Opfer ein:

57 Einen Einfluss bei dieser Variation des Motivs mögen die in der Gattung gängigen Pflanzenallegoresen haben, die so funktionieren, dass in einer Liste einzelne Pflanzen auf ihre Bedeutung in der Minne hin ausgelegt werden, so dass sich eine Art Blumensprache der Liebe ergibt und z.B. Eichenblätter Festigkeit bedeuten. Jacob Klingner hat gezeigt, dass man bei diesen Pflanzenallegoresen immer auch damit rechnen muss, dass mit dem Tragen bestimmter Blumen oder Blätter dann wieder die Funktion eines Liebeszaubers verknüpft wird, dass also die getragene Blume den bezeichneten Zustand erst herbeiführt, vgl. Jacob Klingner: Gattungsinteresse und Familientradition. Zu einer wieder aufgefundenen Sammelhs. der Grafen von Zimmern. (Lana XXIII D 33). In: Zeitschrift für deutsches Altertum 137 (2008), S. 204-228, hier S. 212.

58 Die Zauberin (Z 51). Berlin, SBB-PK, Hs. 115, f. 15r-19r. Vgl. die Beschreibung und Inhaltszusammenfassung in Klingner, Lieb: Handbuch Minnereden (Anm. 41), Bd. 1, S. 1045-1047, sowie Tilo Brandis: Eine späte Minneredenhandschrift. In: Codices Manuscripti 9 (1983), S. 19-25. Ich danke Ludger Lieb und Iulia-Emilia Dorobanțu (Heidelberg) herzlich, dass sie mir aus der Heidelberger Materialiensammlung des Handbuch Minnereden-Projekts Bilder und Transkription der Handschrift zur Verfügung gestellt haben. Ein Digitalisat der Handschrift ist mittlerweile auch online verfügbar: http://digital.staatsbibliothek-berlin.de/ werkansicht/?PPN=PPN622669508\&LOGID=LOG_0001 (07.08.2014). Um einen schnellen Einstieg in den bisher nicht edierten Text zu ermöglichen, erfolgt die Analyse mit ausführlicher Zitation, zum besseren Verständnis wird die Transkription mit Interpunktion versehen. 
Ich hör dikh von zaúbereÿ sagen, manigen grossen kumer klagen, den er von zaúbrer leidet.

derselb mich auch nicht meidet. (V. 1-4)

Der Grund ist einfach: Er hat sich in ein Minnedienstverhältnis zu einer Zauberin begeben, doch anders als Walther von der Vogelweide in seinem Lied Mich nimt immer wunder (L 115,30) scheint das Ich der Minnerede sein Schicksal selbst gewählt, sich eigenverantwortlich für eine Werbung bei der gefährlichen Dame entschieden zu haben:

ich warb ain zaúberin, die hat all ir sin

an zaúbern list gewendet.

damit aúch sÿ verendet

von mir, was so sÿ wil.

zaúberei list kan si vill. (V. 5-10)

Selbst in räumlicher Distanz, wenn er sechzig Meilen weit von der Dame weg reitet, kann er sich ihrem magischen Einfluss nicht entziehen, und wenn er sie fangen will, ist sie plötzlich nicht mehr da. Trotz dieser kritischen Distanznahme zu ihren Zauberkünsten beginnt der Sprecher direkt im Anschluss mit dem Tugendpreis: Sie ist schön, hat tugent manigualt (V. 21), ist weise und klug, was nicht unbedingt typische Eigenschaften einer Minnedame sind. Zugleich geht das Minneleid des Werbers weit über das übliche Maß hinaus; eine Erklärung liegt wieder in der Zauberei:
daúon so was ich nahent todt
und laid von schmerzen soliche not,
das mir es niemandt glaúbt.
das ich so war betaúbt,
so war, das múest von zaúberÿ sein,
das sÿ hilfft der fraúen main. (V. 41-46)

Immer wieder hält der Sprecher mit solchen kurzen Bemerkungen bewusst, dass die Dame Zauberkraft besitzt und diese gezielt gegen ihn einsetzt. ${ }^{59}$ Obwohl das Ich ganz genau weiß, dass es sich um magische Verstrickungen handelt, formuliert es dennoch ein recht inniges Frauenlob, wenn es das zarte und feine Lächeln der Dame über das Bild des Sonnenscheins beschreibt. ${ }^{60}$ Aber in die liebe-

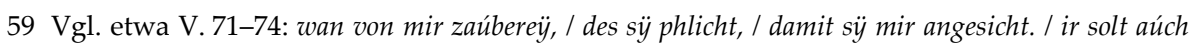
wissen sonder wan, I mein herz khain rúe haben kan, oder V. 103f.: zwar das múes von zaúbereÿ komen, / das sü sich hat angenomen.

60 Vgl. V. 124-132: ach gott, wie zart und wie fein / ist mir das súnlain des lachen! / wie súes khan es sich machen / in meinem herzen grúndt! / gelob sü der stúndt, / wo es mir ie kúndt wart. / es wart 
vollen Worte ist eine Ebene eingezogen, die das Zwanghaft-Gefährliche dieser Minne reflektiert, wenn etwa in die Schönheitsbeschreibung plötzlich der Gedanke hereinbricht, dass der Liebende für dieses Lächeln auch verschmerzen würde, wenn sie ihm alle Freunde erschlagen und ihm selbst den Tod bringen würde. ${ }^{61}$ Wiederholt gibt der Sprecher zu bedenken, dass alles nur Zauberei ist: so sües ist mir <ir> güezen, / wer es nicht von zaúbereÿ list, / des sü pflicht zu aller frist (V. 139-141). Nach der beschreibenden Bestandsaufnahme setzt er zur Erklärung an (nú wil ich eúch wissen lan, / wie das zaúberÿ ist gethan, V. 142f.), und es folgt eine Tugend- und Schönheitsbeschreibung der Dame - auch sie zaubert wie schon Walthers Dame mit natürlichen Mitteln.

Hier spricht ein Ich, das zwar vom Zauber der Dame gefangen ist, aber noch recht rational darüber reflektieren und die Minnemagie in ihrem Wirken für den Rezipienten wenn auch nicht erklären, so doch an sich selbst diagnostizieren und auf variante Weise besprechen kann. Wie eingangs gesagt wird, hält der Sprecher den Einsatz von Magie in der Minne für ein Problem, das viele angeht, und er scheint sich vorgenommen zu haben, trotz der eigenen Betroffenheit die Umstände und Bedingungen eines minnemagischen Verhältnisses darstellen und für ein Publikum lehrhaft objektivieren zu wollen. Zugleich wird die gebetsmühlenartig wiederholte Versicherung, dass es sich um Zauberei handeln muss, zu einem Erklärungsmodell für die Minnewirkung der Dame, die das Ich als so radikal empfindet, dass es seiner Einschätzung nach nicht mit rechten Dingen zugehen kann.

\section{4.d Von einem Schatz (B 392)}

Das letzte Beispiel, die Minnerede Von einem Schatz (B 392), ${ }^{62}$ die in 207 Titurelstrophen verfasst ist, integriert das Zaubermotiv in eine Artes-Reihe und reagiert produktiv auf die in gelehrten Diskursen des Mittelalters immer wieder verhandelte Frage nach einer Integration der artes magicae in einen Kanon der Künste. ${ }^{63}$ Bei der Minnerede handelt es sich um eine Minnereflexion im dunklen Stil, die assoziativ und bildreich eine allegorische Ausdeutung des Schatzes bietet, den man zwar nicht ganz widerspruchsfrei, aber doch für weite Passagen des Textes stimmig mit der Minnedame identifizieren kann.

mir lieb so súes so zart / so ir minigleicher leib, / sü vil rain súes selig weib.

61 Vgl. V. 135-138: het süe mir alle die erschlagen, / die solt von schúlden khlagen, / darzúe mich in den todt vertraút, I des wirt vergessen so zú stúndt.

62 Vgl. Von einem Schatz. Eine mittelhochdeutsche Minneallegorie. Edition und Übersetzung von Michael Mareiner. Bern 1988.

63 Wie die gelehrte Diskussion verläuft, analysiert Frank Fürbeth: Die Stellung der artes magicae in den hochmittelalterlichen Divisiones philosophiae. In: Artes im Mittelalter. Hrsg. von Ursula Schäfer. Berlin 1999, S. 249-262. vgl. auch - allerdings in einer breiteren Perspektive Karl-Heinz Göttert: Magie. Zur Geschichte des Streits um die magischen Künste unter Philosophen, Theologen, Medizinern, Juristen und Naturwissenschaftlern von der Antike bis zur Aufklärung. München 2001. 
Das Ich beschreibt in einem allegorischen Arrangement die positiven Eigenschaften des Schatzes, nähert sich ihm in immer neuen Beschreibungen an und bezieht in knapp 30 Strophen auch eine Reihe von Artes auf den Schatz. Zusammen mit Arithmetik, Geometrie, Musik und Astronomie gehören zu den zehn beschriebenen Künsten auch drei magische, d.h., die artes magicae haben in dieser Reihe einen ungewöhnlich hohen Anteil, ihnen wird im allegorischen Wissenschaftskanon der Minne eine besondere Bedeutung zugesprochen.

So wünscht das Ich seiner Dame die Fähigkeiten der Nigromantie: Ich wöllt, dem schatz wär by / nigromanci die kunst; / alles wyssen wär im fry (Str. 144). Und dieses magisch erworbene Wissen soll den Schatz dann befähigen, die Treue des Minnedieners $\mathrm{zu}$ erkennen und entsprechend $\mathrm{zu}$ belohnen: so weßt ich wol, ich hett gantz gar sin gunst (Str. 144). Da die Dame diese Kunst noch nicht beherrscht, bleibt das Ausdrucksdilemma aber bestehen und der Dienst unbelohnt. Eine weitere magische Kunst, die der Dame bereits zugänglich ist, die sich aber weitaus weniger günstig für den Sprecher auswirkt, ist die Alchemie, denn mit ihrer Hilfe kann die Dame einen Bindezauber ausüben:
Alchamy ir krafft
haut mit dem schatz gethayllt.
ich empfind an sim hafft,
wen er verwundt, das der niht bald erhaylt (Str. 151).

Der alchemische Gedanke einer Transmutation hier des betroffenen Liebenden ist über das Bild einer dauerhaften Verwundung ausgeführt. Auffällig ist, dass gerade die Kunst der Alchemie eine besondere Treue des Adepten zu fordern scheint, denn das Ich verspricht, das kain untruw by mir niht wurd erfunden, / die offt die kunst vernichtet / und schaidt von schätzenn mängen unnder stunden (Str. 152). Das Ich ist zwar vom Zauber getroffen, aber es ist nicht ganz wehrlos, denn es verfügt über die Kunst Notaria (Str. 164) bzw. Notoria, wie es richtiger in der Wiener Handschrift steht. Dabei handelt es sich um eine auf Salomon zurückgeführte Praxis, sich mit Beschwörungen und Anrufungen Gottes oder anderer höherer Kräfte Wissen anzueignen, ohne dafür die Mühen eines Studiums auf sich nehmen zu müssen. ${ }^{64}$ Der Sprecher führt aus, wie man mittels der Kunst Notoria durch göttliche Gnade von sieben Geistern, die den sieben Künsten zugeordnet sind, auf magische Weise belehrt wird, so dass man das Wissen nicht vergisst und gut kombinieren kann:

Notaria die kunst

kompt von den siben gaisten.

wem würd von gott die gunst,

der siben kunst yeder sins thaylß erweiste,

64 Vgl. Lynn Thorndike: A History of Magic and Experimental Science. 8 Bde. New York, London 1923-1958, Bd. 2, S. 279-89, vor allem S. 281. Vgl. auch den Beitrag von Frank Fürbeth in diesem Band. 
so das er blyb dar inne unvergessen

und möcht yeder besonnder,

mit ain annder gepruchen oder niessen. (Str. 164)

In der folgenden Strophe wird diese Kunst - zumindest im Präteritum - dem Ich zugeschrieben, ${ }^{65}$ und es folgen anders als bei den übrigen Künsten längere Ausführungen über den Nutzen der ars notoria für den Minnedienst. Sie ist für den treuen und beständigen Minnediener ein erlaubtes Hilfsmittel im Werben um die Dame:

Wer lept in truwer liebe stätteklich, der darff wol bitten umb der gaiste lere, das er thü wol besorgen sins schatzes dinst, sin tugent, lob unnd ere (Str. 166).

In einem System, in dem die Dame über alchemisches Wissen und potentiell über die Nigromantie verfügt, kann auch der Werber ohne moralische Bedenken die ars notoria nutzen. Hier wird-zumindest im Modus eines allegorischen Sprechens über den Schatz - in einem gegenseitigen magischen Aufrüsten der beiden Minnepartner der klassische Beschwörungszauber wieder für die Minne salonfähig gemacht. Und so scheinen gerade die magischen Wissenschaften in der Reihe für den Minnedienst besondere Relevanz zu haben: Die Nigromantie könnte der Dame helfen, das Aufrichtigkeitsdilemma in der Minne zu umgehen, mit der Alchemie kann sie den Werber dauerhaft an sich binden, und mit der ars notoria bekommt auch der Werber ein Instrument an die Hand, mit dem er Dienst, Tugend, Lob und Ehre der Dame auf angemessene, nämlich übernatürliche Weise mehren kann. Die Verbindung von Minne und Magie wird über die Einordnung in eine Artes-Reihe mit wissenschaftlichem Anspruch versehen, und die magischen Künste werden zumindest in der allegorischen Konstruktion eines Minnedienstes für den Schatz als gleichberechtigtes oder vielleicht sogar wirkungsvolleres Instrument neben die regulären artes gesetzt.

\section{Minnezauber - Tugendzauber. Ein kurzes Fazit}

Der Kräuterzauber in Hartmanns Klage (Kap. 3) hat für die Gattung der Minnereden, was die Verbindung von Magie und Minne angeht, ein innovatives Potential und wird in der Rezeption mehrfach produktiv aufgenommen. Im Weiberzauber des Walther von Griven (4a) liegt ein markierter intertextueller Bezug auf Hartmanns Klage vor, der den Kräuterzauber aus dem Streitgespräch isoliert und in eine - stellenweise ironisch überzeichnete-Wertelehre für die Frauen überführt. Dass der Gedanke eines Kräuterzaubers offen zum heilkundlichmedizinischen Diskurs ist, zeigt die Minnelehre Stern der Treue (4b), wo die abstrakten Tugenden in ein konkretes Personifikationshandeln überführt werden

65 Vgl. Str. 165: Ich hab ir wol empfunden / lang zit in minem hertzen. 
und die magische Tugendwirkung als reale Heilwirkung einzelner, zum Teil wieder allegorisierter Kräuter umgesetzt wird. In der Minnerede über die Dame als Zauberin (4c) wird die vom Ich negativ bewertete Zauberkraft der Dame mit ihrer Tugend und Schönheit gekoppelt. Dabei laufen im Sprecher-Ich die beiden Perspektiven des betroffenen Liebeswerbers und der objektiven Lehrinstanz zusammen. Eine Art wissenschaftliche Legitimation erfährt die Verbindung von Minne und Magie schließlich in der Minnelehre über den Schatz (4d), die in eine Zehnerreihe der Artes mit Nigromantie, Alchemie und ars notoria drei magische Künste integriert. Dabei ist nicht nur die Dame zauberkundig, sondern die ars notoria rangiert als ein probates Mittel, das der Werber im Minnedienst einsetzen kann.

Hartmanns Idee, den Liebeszauber zu einem Tugendzauber zu allegorisieren, ist kein einmaliger innovativer Entwurf, sondern wird, wie die Rezeption zeigt, für die Gattung der Minnerede zu einer attraktiven Gedankenform. Die mit der Zauberwirkung verbundene Dynamik des Zustandswechsels wird in den Minnereden für die Tugendlehre produktiv gemacht, und so wird die Verbindung von Magie und Liebe, vor allem aber die von Hartmann eingeführte Innovation des Tugendzaubers der Minne auf vielfältige Weise aufgenommen und variiert. Der Tugendzauber liefert nämlich einen Zugang dazu, was die Minnereden, wenn auch nicht in der realen Anwendung, so doch zumindest im lehrhaften Gestus als ihr kommunikatives Ziel vorgeben: Sie wollen die Tugenden des Menschen so tempern und mischen, dass der Mensch durch sie eine magische Wirkung erfährt und aus eigener Kraft sein Minneglück finden kann. Zwar wird der Mensch von der radikalen Kraft der Minne schicksalhaft erfasst, doch kann er aktiv damit umgehen, wenn er seine Minnetugenden richtig entwickelt - die Minnereden, die die Tugenden und Werte in immer neuer Systematisierung zusammenfügen, sind ihm dabei eine Art magische Rezeptur zum Glück. Wendet man das Ganze ins Poetologische, so avancieren die Minnereden selbst zum Zauberbuch, in dem man die magische Formel für das Liebesglück in Form einer wirksamen Tugendlehre findet, die man aber im eigenen Verhalten wie ein Zauberrezept auch selbst ins Werk setzen muss.

Die mit der Magie verknüpfte Dynamik der Wirkung kommt dem Selbstverständnis der Minnereden entgegen und hilft auch, die immense Popularität der Gattung im Spätmittelalter zu erklären: Sie will keine trockene Ethik und abstrakte Verhaltenslehre mit erhobenem Zeigefinger sein, sondern im Lebensbereich der Minne einen Zauber der Tugenden vermitteln, und zwar nicht so sehr in der konkreten außerliterarischen Anwendung, sondern als literarischästhetisches Spiel mit dem, was die hochhöfische Literatur im Modell der idealen Minne vorgibt. Die Minnereden antworten auf die radikale Emotion der Minne mit einem magischen Faszinations- und Wirkpotential der Tugenden. Dieses Verständnis der Tugenden als magischem Potential des Menschen ist als Programm durchaus ernstzunehmen: Mit ihren Tugenden kann die Dame das liebende Ich verzaubern, und umgekehrt kann der Werber mit seinen Tugenden 
das Wunder einer gelungenen Minnebindung ins Werk setzen. Die Minnereden wollen weniger Minnedidaxe als vielmehr Minnezauber sein, sie propagieren Ethik nicht als mühsamen Zwang, sondern als faszinierende Magie und entwickeln dabei eine Begeisterung für ethische Systematisierungen, die man heute nur noch bedingt nachvollziehen kann. Dass sie dabei als meist anonyme Dichtung, die wohl hauptsächlich von interessierten Gelegenheitsdichtern geübt wurde, nicht die inhaltliche Komplexität und stilistische Qualität so mancher hochhöfischer Minneliteratur erreichen, ist leicht zugestanden, tut aber der grundsätzlichen Ausrichtung der Texte auf eine Diskursivierung von Verhaltensformen der Minne keinen Abbruch.

Nur vor der Hand kommt in den Variationen des Kräuterzaubers die in der lehrhaften Literatur verbreitete Strategie der Arzneimetapher zur Anwendung, die die bittere Medizin, d.h. die abstrakte Verhaltenslehre, in eine süße, attraktive Hülle verpackt, um die Aufnahmebereitschaft der Rezipienten zu erhöhen. Die Magie ist nicht nur trickreiche Verpackung der Tugendlehre, sondern ein ernst gemeintes moraldidaktisches Konzept, das die Tugenden als ein magisches Potential des Menschen etabliert und erstrebenswert macht. Er ist in seinen Minnenöten nicht mehr auf die zweifelhafte Wirksamkeit dämonischer Liebestränke, die ihm dubiose Mittlerfiguren zusammenbrauen, angewiesen, sondern wird selbst zum Magier und kann den Herausforderungen Minne mit seinem eigenen Tugendzauber begegnen. Die Minnereden liefern ihm das Rezept dazu. 


\title{
Magie, Erotik, Kunst \\ Zur Vorgeschichte einer frühneuzeitlichen Problemfigur
}

\author{
Jan-Dirk Müller, München
}

\begin{abstract}
Meine These ist riskant, und ich kann an dieser Stelle nicht mehr als den ersten Schritt zu ihrer Untermauerung tun. Sie lautet, dass der Diskurs über Magie die ästhetische Debatte der Frühen Neuzeit beeinflusst und dass zwischen dem 16. und dem späten 18. Jahrhundert Teile des Diskurses über Magie in einen ästhetischen Diskurs überführt werden.
\end{abstract}

\section{1}

Ich beginne am Endpunkt: In Wielands Agathon (1767) ${ }^{1}$ wird erzählt, wie der sittenstrenge Titelheld der Hetäre Danae verfällt. Die Verführungsgeschichte steht im Zeichen von sinnlichem Begehren, Kunst und Zauber. Natürlich handelt es sich nicht um wirklichen Zauber, sondern um die Bezauberung der Einbildungskraft durch eine verführerische Frau, aber diese funktioniert nicht anders als jener. Sie paralysiert die Willenskraft und macht die Wirkung von erotischer Attraktion unwiderstehlich. Diese Wirkung wird durch die Kunst gesteigert, mit der Danae sich umgibt: durch den Zauber ihrer Gärten, durch die Schönheit der Architektur, durch geistreiche Gespräche, vor allem aber durch Malerei, Drama, Tanz und Musik, die die Sinne überwältigen, indem sie der Einbildungskraft eine höhere Wirklichkeit, die göttliche Welt des Mythos, vorspiegeln.

Die Entdeckung der Sinnlichkeit ist ein notwendiger Schritt in der Entwicklungsgeschichte Agathons, mit dem er den blutleeren Stoizismus seiner Jugend hinter sich lässt. Trotzdem bleibt Verführung Verführung; sie wird den Helden auf einen langen Weg schicken, auf dem Sinnlichkeit und Vernunft zusammengeführt werden sollen, ein Ziel, an dem Wieland lebenslang gearbeitet hat, ohne eine restlos überzeugende Lösung $\mathrm{zu}$ finden. ${ }^{2}$ Doch nicht davon soll hier die Rede sein, sondern von einer Genealogie der Konstellation, die der Episode zugrunde liegt, des Zusammenwirkens der Trias Zauber, Erotik, Kunst.

1 Christoph Martin Wieland: Geschichte des Agathon. Unveränderter Nachdruck der Editio princeps (1767). Bearbeitet von Klaus Schäfer. Berlin 1961. Die folgenden Seitenzahlen aus dieser Ausgabe.

2 Jan-Dirk Müller: Wielands späte Romane. Untersuchungen zur Erzählweise und zur erzählten Wirklichkeit. München 1971, S. 82-96. 
Nur wenige Bemerkungen zum Zusammenhang in Wielands Roman: Der sensualistische Philosoph Hippias hat sich vorgenommen, die kalte Tugend seines Sklaven Agathon zu erschüttern und ihn von seiner Unempfindlichkeit für sinnliche Reize zu heilen. Mittel dazu soll die Hetäre Danae sein. Die Voraussetzungen scheinen günstig. Sein Haus, in das es Agathon als Sklave des Hippias unter dem Namen Kallias verschlagen hat, ist von Gärten umgeben, in denen „die Kunst und der Reichtum alle ihre Kräfte aufgewandt hatten, die einfältige Natur mit ihren eignen und fremden Schönheiten zu überladen“: durch Blumen, exotische Pflanzen, fruchttragende Bäume, kunstvoll angelegte Lauben und Irrgänge, Statuen und Brunnen. Es ist eine Landschaft, die von Zauberinnen wie der Armida des Torquato Tasso geschaffen sein könnte: „Alles dieses machte die Gärten des Hippias den bezauberten Gegenden ähnlich, diesen Spielen einer dichterischen und mahlerischen Phantasie, die man erstaunt ist, ausserhalb seiner Einbildung zu sehen" (S. 36).

Bei aller Schönheit bleibt bei Agathon ein Misstrauen gegen eine Kunst, die sich anmaßt, die „Natur" zu verschönern und sie „ihrer Freyheit und rührenden Einfältigkeit zu berauben" (S. 36). Es sind eben Gärten des Sensualisten Hippias. ${ }^{3}$ Zur Beruhigung des Lesers und zum Ärger Wielands fügte der Verlag eine Fußnote gegen das „Blendwerk“ der hippiasschen Philosophie und sein Evangelium maximalen sinnlichen Genusses ein, die die künftige Widerlegung seiner Ansichten ankündigt (S. 37). ${ }^{4}$ Die Anmerkung erinnert unabsichtlich an die Tradition, in der Agathons Bezauberung steht: „Blendwerk“ ist der übliche Vorwurf gegen Zauberer und die Verführung durch den Teufel. Wieland sieht das anders: Die sinnliche Attraktion mindert es nicht, dass Genuss sich zuletzt als Täuschung erweist.

In der Hetäre Danae ist die Schönheit der Natur durch Kunst geadelt. Danae scheint selbst ein Kunstwerk zu sein. Sie hat „in ihrer ersten Jugend den berühmtesten Mahlern zum Modell gedient“ (S. 80). Um dem Leser eine Vorstellung von der Schönheit ihres Landguts zu verschaffen, appelliert der Erzähler an seine Einbildungskraft: Er solle sich mit Hilfe des „sechzehnten Gesang des befreyten Jerusalems" den Ort ausmalen, "den sich diese griechische Armide zum Schauplaz der Siege auswählte, den [!] sie über unsern Helden zu erhalten hoff-

3 Insofern unterscheidet er sich dann doch vom Garten der Danae und von dieser selbst: Hier werden Kunst und Natur ununterscheidbar.

4 Wieland: Agathon (Anm. 1), S. 37: „Zur Verhütung alles Mißverstandes berichtet der Verfasser, daß, was Hippias hier und forthin scheinbares zur Behauptung des Epicureismus vormahlet, im folgenden Theile, worinn eine der wahren Religion und christlichen Tugend vollkommen günstige Philosophie die Oberhand behält, gründlich wird widerlegt werden; so daß dieses Blendwerk, wo die in den Zeiten des Pericles herrschende Philosophie, nach der historischen Wahrheit, in der Hülle einer Geschichte vorgetragen wird, vor der Wahrheit verschwinden soll, wie der Nebel vor der Sonne." Dazu schreibt der Herausgeber Klaus Schäfer: „Wieland war darüber verärgert und schrieb im Druckfehlerverzeichnis: ,deleatur die sehr überflüssige Anmerkung." Die Vorsicht des Verlages zeigt, wie brisant die durch zauberähnliche Kunst gesteigerte Sinnlichkeit 1767 noch schien. 
te" (S. 103). So wie in Torquato Tassos Gerusalemme liberata Armida die Natur verzaubert, um die Liebe des Ritters Rinaldo zu gewinnen, ${ }^{5}$ hat Danae in diesem Landgut eine Umgebung geschaffen, in der Agathon ihr verfallen soll. Ihr Tanz verbindet höchste Kunst mit der Wahrheit der Natur. Ihrem Zauber verfällt der Held zuletzt, wenn sie selbst im Kreis ihrer Dienerinnen und sie alle überbietend ein allegorisches Tanzspiel aufführt. Im Tanzspiel Apollo und Daphne hatte Agathon die Darstellerin kritisiert, die in ihr Spiel zu viel Kunst und damit Zweideutigkeit gelegt und so den Charakter der vom Gott verfolgten Unschuld verlassen hatte. Die Gesellschaft um Hippias teilte die Kritik nicht, doch Danae schlüpft selbst in die Rolle der Daphne und spielt alles das, was Agathon an der ersten Tänzerin der Daphne vermisst hatte: „Ihr ganzes Spiel drükte die eigenste Idee des Agathon aus, aber mit einer Anmuth, mit einer Zauberey, wovon ihm seine Phantasie keine Idee gegeben hatte“ (S. 93). Was Agathon zuvor, auch schon bei Hippias, als allzu große Künstlichkeit kritisiert hatte, das verschwindet in Danaes Kunst. ${ }^{6}$ In Danaes Kunst verbinden sich "Anmuth" und „Zauberey". Der Zauber der Danae lässt die Bezauberungen durch Schönheit und Luxus im Umkreis des Hippias hinter sich. Kein Wunder, dass Agathon ihr verfallen wird; Danae wird seine Geliebte werden.

Das geschieht in einer Reihe von Inszenierungen, in denen sinnliche Attraktion und Phantasie zusammenwirken. Stimulans ist die Kunst. Wieland entwirft eine Welt, die er mit Hilfe einer anderen Dichtung als Kunstwelt kennzeichnet, mit einem Abschnitt aus der Gerusalemme liberata des Torquato Tasso. Solche literarischen Heterotope hat Wieland immer wieder zur Ausmalung seiner Erzählwelten zitiert. ${ }^{7}$ Doch verweist das Zitat darüber hinaus auf eine Umbesetzung im literarischen Diskurs, die sich zwischen der italienischen Dichtung der Renaissance und der frühklassischen Literatur in Deutschland vollzogen hat. Er betrifft das Verhältnis von Kunst, Magie und Sinnlichkeit. In Danaes verführerischer Schönheit wirken sie zusammen. "Zauber' ist eine Metapher für ihre durch Kunst gesteigerte sinnliche Attraktivität. Dieser Zauber nimmt Agathon eine Zeit lang gefangen, aber er ist, anders als der Verfasser der Fußnote suggeriert, nicht bloß Blendwerk, sondern hilft Agathon, an sich eine Seite zu entdecken, die sein Tugendrigorismus leugnen zu können glaubte. Die Liebe zu Danae, Ergebnis des Zusammenwirkens von Kunst, Magie und Sinnlichkeit, erscheint

5 Torquato Tasso: La Gerusalemme liberata. In: Torquato Tasso: Opere Bd. 1. Mailand 1957; vgl. die Ausgabe a cura di Severino Ferrari. Nuova edizione curata e riveduta da Pietro Papini. Nuova presentazione di Ezio Raimondi. Florenz [1970]; hierzu die Übersetzung Torquato Tasso: Das befreite Jerusalem. Aus dem Italienischen übersetzt von J[ohann] D[ietrich] Gries. Leipzig o.J.

6 Das ist eine weitere Anspielung auf Tassos Armida. Über ihren Garten heißt es in Gerusalemme liberata XVI, 9: L'arte che tutta fa, nulla si scopre. Zu diesem Motiv und zur Bedeutung des Gartens der Armida für Literatur und Kunst bis zur Romantik Mario Praz: Il giardino dei sensi. Studi sul manierismo e il barocco. Mailand 1975; vgl. S. 111.

7 Müller: Wielands späte Romane (Anm. 2), S. 143-145. 
deshalb nicht bloß als Fehltritt (wenn Agathon sie auch überwinden muss), sondern als notwendiger Schritt in seiner Biographie. Eben dies setzt aber eine fundamentale Umbesetzung im Verhältnis und in der Bewertung der drei Komponenten voraus. Der Verlauf dieser Umbesetzung, die in Deutschland mit erheblicher Verzögerung stattfindet, muss weiter ausgreifenden Untersuchungen vorbehalten bleiben. Hier sollen nur einige verstreute Stationen aus ihrer Vorgeschichte berührt werden.

\section{2}

Die intertextuelle Verbindung zu Tassos Zauberin Armida ist aufschlussreich. Ich skizziere kurz die Handlung, wobei die Skizze stark vergröbert ist und ich auf Tassos oszillierende Darstellung von Magie, Erotik und Tugend nicht näher eingehen kann. ${ }^{8}$ Armida ist eine wirkliche Zauberin, die der Teufel gegen das christliche Kreuzfahrerheer aufbietet, um dessen Vordringen gegen Jerusalem zu verhindern. Doch zunächst sind es gar nicht Armidas magische Künste, die sie gegen die Christen einsetzt, sondern ihre erotischen Reize, die den Rittern den Kopf verdrehen und sie ihr Ziel vergessen lassen. ${ }^{9}$ Ihr wichtigstes Opfer ist Rinaldo, der beste Ritter im Heer Gottfrieds von Boullion. Ihm zuliebe schafft sie die Isole Fortunate, indem sie die Natur in einen Zaubergarten verwandelt. Das ist die Welt, die Wielands Leser imaginieren soll. In diesem Zaubergarten wird Rinaldo ihr Geliebter und vergisst seine eigentliche Aufgabe, so lange jedenfalls, bis ihm in einem Zauberspiegel an seinem Bild gezeigt wird, was aus ihm geworden ist. Dann ist der Zauber sofort gebrochen. Rinaldo erinnert sich an seine ritterliche Tapferkeit und verlässt Armida.

Letztlich also erweisen sich Armidas Zauberkunststücke als vergeblich. Das bedeutet jedoch nicht, dass die Wirkung ihrer Schönheit auf Rinaldo verschwindet. Zwar bricht zuletzt die teuflische Magie zusammen, die Ritter kehren zu ihrer Pflicht zurück, doch Armida wird nicht ausgeschlossen. Sie bekehrt sich zum Christentum, entsagt ihren Künsten und unterwirft sich dem geliebten Rinaldo. ${ }^{10}$ Eine Zauberin ist sie nicht mehr, bezaubernd noch immer. Es findet also eine Verschiebung der Semantik von ,Zauber' statt. Es gelingt, die Frau, deren dämonische Kräfte die christliche Ordnung bedrohen, in diese zu integrie-

8 Die Tasso-Forschung hat das längst herausgearbeitet. Ich zitiere nur den Sammelband Torquato Tasso e la cultura Estense. A cura di Gianni Venturi. Florenz 1999; darin besonders: Jo Ann Cavallo: Armida: La Funzione della donna-maga nell' epica Tassiniana, S. 99-114. Remo Fasani: Il racconto di Armida: Dalla finzione a la realtà, S. 115-133; Gianni Venturi: Armida come un paesaggio, S. 203-217.

9 Cavallo: Armida (Anm. 8), S. 107 unter Berufung auf Gerusalemme liberata IV, 23: la nuova seduttrice, Armida, viene presentata come una donna che è pratica delle arti sia femminili che magiche.

10 Mit der marianischen Formel Ecco l'ancilla tua unterwirft sie sich nicht Gott (obwohl ihre Konversion vorausgehen muss), sondern dem Geliebten (vgl. Cavallo: Armida, Anm. 8, S. 108 und 110f. zur Umbesetzung des Verhältnisses von conversio und Liebe). 
ren, doch so, dass ihre Zauberkräfte zur erotischen Attraktivität domestiziert sind. In der Gerusalemme liberata ist das Thema der Zauberei durch den christlichen Kontext des Kreuzzugsepos gerahmt und begrenzt. Armidas Zauberkräfte verwandeln die Natur tatsächlich. Sie beruhen auf teuflischen Gegenkräften und müssen im Dienst der Sache Christi zerstört werden.

Armidas Zauberkünste sind aber nur die andere Seite und die unermessliche Steigerung ihrer sexuellen Verführungskraft. Auch diese muss domestiziert werden, verschwindet aber nicht vollständig. Die erotische Attraktion, die auf Rinaldo nach wie vor wirkt, wird in die Bahnen der Legitimität gelenkt. Das letztendliche Ziel von Zauberei ist zwar Schadenszauber - das christliche Heer soll wehrlos gemacht werden-, ihre Erscheinungsform aber ist „raffinierte Kunst", ${ }^{11}$ die eine ideale Landschaft bewirkt. Es ist, wie Gerhard Regn gezeigt hat, eine hochmoderne Kunst, die Kunst des Manierismus, die Tasso zugleich zitiert und distanziert. Armidas Kunst verwandelt die Natur in einen wunderbaren Zaubergarten. Dieser besitzt

eine klar erkennbare manieristische Faktur. Die manieristische Welt soll faszinieren und sie tut es auch. Gleichwohl ist sie bei Tasso der faule Zauber einer Gegenwelt, die [...] der Vernichtung anheim gegeben werden muss. ${ }^{12}$

Diese manieristische Kunstwelt bleibt zwar „in Tassos Kreuzzugsepos [...] nur Episode" ${ }^{13}$ belegt aber die Affinität des Diskurses über Zauberei und des Diskurses über Kunst. Wieland ist Zeuge, dass man dieses gegenreformatorische Arrangement knapp 200 Jahre später anders lesen konnte, selbst wenn auch bei ihm sich noch ein Vorbehalt gegenüber der künstlichen Zurichtung von Natur findet. ${ }^{14}$

Bei Wieland bleibt von der heidnischen Zauberin nur die verführerische Frau übrig, von ihren Zauberkünsten der bewusste Einsatz ihrer Reize und derjenigen der Kunst. Auffällig ist freilich, wie abundant Wieland auf die Semantik von Zauber anspielt. An die Stelle wirklichen Zaubers tritt die „bezauberte Phanta-

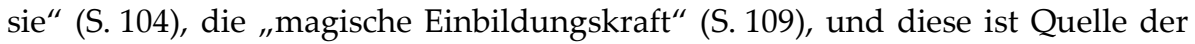
„Liebe“ (S. 105). Die Verführung wirkt durch die „magische Kraft der Musik“ (S. 110) und die "Zaubergewalt" des „Gemähldes“ (der Szene, die sich dem Au-

11 Gerhard Regn: Manierismus: Kritik eines Stilbegriffs. In: Manierismus. Interdisziplinäre Studien zu einem ästhetischen Stiltyp zwischen formalem Experiment und historischer Signifikanz. Hrsg. von Bernhard Huss und Christian Wehr. Heidelberg 2014, S. 19-44; hier S. 34 .

12 Regn: Manierismus (Anm. 11), S. 34.

13 Regn: Manierismus (Anm. 11), S. 35. Regn zeigt, dass das Zauberreich als „manieristische Gegenwelt", eine „Welt artistischer Künstlichkeit” (S. 33) die „unterschiedlichen Seinsordnungen von Kunst und Natur" (S. 34) und damit die Voraussetzungen der klassizistischen Ästhetik der Renaissance kollabieren lässt.

14 Das Thema verdiente nähere Ausarbeitung; vgl. Wieland: Agathon (Anm. 1), S. 36. 
ge darbietet) (S. 111), durch die "Zauberkräfte der Kunst“ (S. 112). Die Magie der Schönheit ist positiviert, wenn auch nicht ohne Rest, denn Danae bleibt eine Hetäre, die Agathon verführt und die er verlässt, als er das entdeckt. Das ist letzter Rest einer Diskreditierung des Zaubers und der Zauberin. Deshalb hat auch Danae einen Bußweg vor sich. ${ }^{15}$ Am Ende soll aber kein Sieg des Glaubens stehen - wie noch bei Tasso-oder stoizistischer Tugend-wie zu Beginn des Agathon -, sondern die Integration und Harmonisierung der unterschiedlichen Kräfte der menschlichen Natur.

Wielands intertextueller Verweis macht auf eine Konstellation aufmerksam, die für die europäische Literaturgeschichte der Frühen Neuzeit zentral ist. In ihrem Zentrum steht Magie, die auf der einen Seite mit erotischer Attraktion (gewertet meist als Verführung) und auf der anderen mit der Erschaffung einer Kunstwelt verknüpft ist. Im 16. Jahrhundert wird ,Zauber' noch proprie verstanden, und diesem wörtlichen Verständnis entsprechend werden die beiden anderen Komponenten religiös und moralisch diskreditiert. Diese Beurteilung scheint Schritt für Schritt abgeschwächt und durch eine ästhetische ersetzt zu werden, die die ursprüngliche Bewertung zweifelhaft macht. Allerdings schwinden Misstrauen und Reserve gegen diese Verbindung nur langsam und nie vollständig. Es wäre reizvoll, Stationen dieses Prozesses, angefangen von Ariosts Orlando Furioso und seiner Alcina zu verfolgen. ${ }^{16}$ Ich kann mich hier nur auf einige anfängliche Konfigurationen der Trias in der gegenüber den Nachbarliteraturen eher rückständigen deutschen Literatur beschränken, und zwar anhand des Faustbuchs und des Amadis sowie deren Rezeption.

\section{3}

Romanhafte Unterhaltungsliteratur hat es in der Frühen Neuzeit nicht leicht. Die Romane sind volkssprachig, sodass der Bildungswert der lateinischen Sprache entfällt. Sie sind nicht in Versen, sondern in Prosa verfasst und liegen damit unterhalb der Wahrnehmungsschwelle der Poetik. Und sie sind Fiktion, also ,erlogen'. Sie bedürfen damit mehrfacher Rechtfertigung: durch die Vorbildlichkeit ihrer Sprache (ein anfangs vor allem für den Amadis gebrauchtes Argument), ${ }^{17}$ durch ihre Annäherung an die historia oder mindestens ihren Anspruch auf Anschließbarkeit an makrohistorische Zusammenhänge und schließlich

15 Vgl. Müller: Wielands späte Romane (Anm. 2), S. 83.

$16 \mathrm{Zu}$ den Zauberinnen im italienischen romanzo Cavallo: Armida (Anm. 8), S. 100-107.

17 Es wurde durch die Amadis-Schatzkammern, die Zetzner (Straßburg) nach französischen Vorbild herausbrachte, gefördert: Schatzkammer / Scho̊ner / zier=licher Orationen / Send= briefen / Gespråchen / Vortrågen / Vermahnungen vnnd dergleichen Auß den vier vnd zwen=tzig Büchern des Amadis von Franckreich zu=samen gezogen, Straßburg 1596); die Schatzkammern wurden mehrfach neu aufgelegt. Vgl. Henrike Schaffert: „Nicht weniger / sondern ja gleich so wol / wo nicht hơher." Der Amadis als stilistisch-ästhetisches Modell. In: Aemulatio. Kulturen des Wettstreits in Text und Bild (1450-1620). Hrsg. von Jan-Dirk Müller, Ulrich Pfisterer u.a. Berlin, Boston 2011, S. 417-448. 
durch die Vermittlung von Sachwissen sowie das bekannte integumentale Modell versteckter Belehrung unter scheinbar anspruchslos-gefälliger Oberfläche. ${ }^{18}$ Die Romankritik hat das nicht zum Verstummen gebracht. Die angebliche sprachliche Vorbildlichkeit wurde in Zweifel gezogen, der Wahrheitsanspruch ridikülisiert und der praktische Nutzen - etwa die Fülle vermittelten Wissens als bloße Schutzbehauptung bestritten. ${ }^{19}$ In dieser Kritik vereinigten sich Gelehrte, Pfarrer, Lehrer, Juristen und sogar Inquisitoren und Hexenverfolger. Zu den bekannten Argumenten kommt im 16. Jahrhundert ein weiterer Vorwurf hinzu: Man wirft der verderblichen Literatur vor, von Zauberdingen zu reden und zur Zauberei anzuleiten. Dieses Argument ist insofern überraschend, als zwar in einigen Texten wie dem Faustbuch und den Amadis-Romanen tatsächlich Zauberei vorkommt, dies aber keineswegs bei der Mehrzahl der übrigen Titel der Fall ist, wenn es auch dort häufig Wunderbares gibt, das die Kritiker auf Dämonenkräfte zurückführen. Handelt es sich bei ,Zauberei einfach um ein Modethema eines „Faustian Century“, eines Jahrhunderts der Hexenverfolgung, der Alchimie, der Versprechen magischer Künste? ${ }^{20}$ Aber auch dann wäre die Übertragung auf die Rezeption fiktionaler Literatur insgesamt erklärungsbedürftig. Meine These ist, dass die Assoziation etwas mit der oben beschriebenen Konfiguration von Zauber, Kunst und Verführung zu tun hat.

Die Lektüre schöner Historien ist eine zweckfreie Beschäftigung, und eben dies weckt den Verdacht. Die Romanlektüre steht im Horizont müßiger curiositas. ${ }^{21}$ Zauberei ist eine Radikalisierung von curiositas, der Beschäftigung mit Dingen, die Gott vorbehalten sind und den Menschen nichts angehen. Diese Dinge lenken den Menschen, wenn er sie zu ergründen versucht, von Gott ab. Zauberei geht aber noch einen Schritt weiter. Sie zielt nicht nur auf die Erkenntnis solcher Dinge, sondern auf ihre Manipulation gegen die von Gott geschaffenen Naturgesetze und ihren Gebrauch gegen ihre ihnen von Gott verordnete Natur. Zauberei pfuscht Gott ins Handwerk, wo curiositas sich damit begnügt, in sein Wissen eindringen zu wollen. Beides aber ist Abfall von Gott. Zauberei ist nur dessen letzte Stufe dämonischer Verführung.

18 Jan-Dirk Müller: Volksbuch/Prosaroman. Perspektiven der Forschung. In: Internationales Archiv für Sozialgeschichte der deutschen Literatur 1 (Sonderheft 1985; Forschungsreferate), S. 1-128; hier S. 75-79. Die angeblichen Lehren sind häufig Banalitäten.

19 Vgl. auch Jan-Dirk Müller: Prosaroman und Enzyklopädie. Zur Spannung zwischen ethischen und ästhetischen Kriterien bei Conrad Gesner, Juan Luis Vives und Antonio Possevino. In: Sammeln, Ordnen, Veranschaulichen: Zur Wissenskompilatorik in der Frühen Neuzeit. Hrsg. von Frank Büttner, Markus Friedrich und Helmut Zedelmaier. Münster 2003, S. 15-31.

20 The Faustian Century. German Literature and Culture in the Age of Luther and Faustus. Hrsg. von James M. van der Laan und Andrew Weeks. Rochester 2013; hierzu meine Rezension in Arbitrium 32 (2014), S. 60-67.

21 Jan-Dirk Müller: Curiositas und erfarung der Welt im frühen Prosaroman. In: Literatur und Laienbildung im Spätmittelalter und in der Reformationszeit. Symposion Wolfenbüttel 1981. Hrsg. von Ludger Grenzmann und Karl Stackmann. Stuttgart 1984, S. 252-271. 
Curiositas hat überdies aber noch eine andere Bedeutung. Als ungeordnetes Begehren ist sie Werkzeug der cupiditas, dient also der Verführung zur Wollust und der Erfüllung rücksichtsloser sinnlicher Begierde. Instrument der cupiditas sind vor allem Frauen, nicht nur dämonische Wesen und Hexen, sondern ebenso verführerische Schönheiten. Ariosts Alcina und Tassos Armida sind beides, Zauberinnen und Verführerinnen, denn Zauberei und Wollust gehören eng zusammen.

\section{4}

Wie das eine Thema das andere nach sich zieht, kann man an der Geschichte des Erzzauberers Faustus beobachten. Dort sind curiositas und cupiditas zwar zwei verschiedenen Rubriken, unterschiedlichen Lebensabschnitten zugeordnet, gehören aber zusammen, auch wenn die Historia sich nicht die Mühe macht, ihren Zusammenhang psychologisch oder handlungslogisch zu entfalten. Der Gelehrte, der alles Wissbare im Himmel und auf Erden wissen will und der darüber zum Magier wird, der den Teufel beschwört, muss auch ein schlimmer Wüstling sein, dem der Teufel immer neue Beischläferinnen verschaffen muss, der im Harem des Sultans Staunenswertes vollbringt und der zuletzt der schönen Helena, dem Urbild verderblicher Verführung, verfällt.

Faustus ist ein Negativexempel, seine Lebensform gilt aber offensichtlich als attraktiv, sodass die, die sich für ihn interessieren, gefährdet sind. Trotz der gut lutherischen Warnung des Faustbuchs vor Magie scheint man mit der Faszination des Gegenstandes gerechnet zu haben. Die Wirkungsästhetik der Zeit unterstellt, dass literarische Texte zur Nachahmung anleiten. Die Überzeugung lectio transit in mores verbindet Humanisten, die daraus den erzieherischen Wert der Lektüre antiker Schriften ableiten, mit Pfarrern und Pädagogen, die vor verderblichen Büchern warnen. Das Erzählen von Zauberei würde demnach die Lust am Zaubern fördern. Das bedeutet, dass man Faustus statt als abschreckendes Exempel auch als Vorbild rezipieren kann. Ein Buch über einen Magier macht seinen Besitzer verdächtig. Wenig bekannt ist, dass der Besitz des Faustbuchs und des Amadis in den Hexenverfolgungen als Verdachtsindiz für Hexerei und Häresie galt. ${ }^{22}$ Einige Juristen hielten die Lektüre bereits für einen hinreichenden Grund für die Folter. ${ }^{23}$

Tatsächlich schließt die „Vorred an den christlichen Leser“ mit der Bemerkung, damit niemand zu Fürwitz vnd Nachfolge mócht gereitzt werden seien im Faustbuch die formae coniurationum ausgelassen worden ond allein das gesetzt / was jederman zur Warnung vnnd Besserung dienen mag. ${ }^{24}$ Die Behauptung, aus

22 Julius Schwering: Amadis und Faustbuch in den Hexenprozessen. In: Zeitschrift für deutsche Philologie 51 (1926), S. 106-116. Schwering unterscheidet leider nicht zwischen Romankritik im Allgemeinen und dem besonderen Vorwurf der Zauberei. Im Folgenden werden einige Spuren, auf die er verwies, verfolgt.

23 Schwering: Amadis und Faustbuch (Anm. 22), S. 115f.

24 Faustbuch. In: Romane des 15. und 16. Jahrhunderts. Nach den Erstdrucken mit sämtlichen 
Sorge um die Tugend des Lesers die Zaubersprüche weggelassen zu haben, mag Teil der Authentifizierungsstrategie des Verfassers sein, der ja behauptet, seine Erzählung sei dokumentarisch beglaubigt: Man besitzt die Beschwörungsformeln, gibt sie aber aus Verantwortungsgefühl nicht weiter. Auch könnte es sich um ein Zugeständnis an die Zensur handeln, um bei diesem gefährlichen Thema Rechtgläubigkeit unter Beweis zu stellen. Jedenfalls rechnet man mit identifikatorischer Lektüre, mit unmittelbarer Applikation des Gelesenen auf die eigene Praxis.

Dabei ist, was Faustus' Zauberei mit Hilfe des Teufels schafft, meist Blendwerk, nicht nur die Streiche, die er Bauern, Juden und anderen spielt, sondern auch die verführerischen Genüsse, die er herbeizaubert: die üppigen Gärten im Winter, das köstliche Essen, von dem man nicht satt wird, die schönen Frauen, mit denen er schläft. Zauberei und sinnliche Ausschweifung liegen eng beieinander, sollen aber im Blick des christlichen Lesers beide gleichermaßen als bloße Phantasmen erscheinen, letztlich leer und nichtig. Die Zauberkunststücke des Faustus bringen den Scheincharakter sinnlichen Genusses heraus, der ihm, auch wo er nicht nur vorgespiegelt ist, sub specie aeternitatis grundsätzlich eignet. Das Phantasma aber ist die negative Erscheinungsform der Phantasie.

Wie eng beide zusammenhängen, zeigt sich an einer meist überlesenen Episode, in der in verzerrter Form eine Verknüpfung von Zauber und sinnlicher Ausschweifung mit Kunst erscheint. Faustus, der spätere Liebhaber der schönen Helena, zaubert diese zum ersten Mal am Weißen Sonntag für seine Studenten herbei. Sie erscheint als eine hinreißend schöne Dirne, deren Reize und anzügliche Blicke den Studenten den Kopf verdrehen. Zwar versichert der Erzähler dem christlichen Leser beruhigend: weil die Studenten es aber für einen Geist achteten / vergienge jhnen solche Brunst leichtlich (S. 948). Das Blendwerk wird also angeblich durchschaut und wirkt nur flüchtig auf die Studenten. Dazu will allerdings nicht recht passen, dass offenbar das Phantasma doch weiter ihre Phantasie beschäftigt, denn sie können, wie es wenig später heißt, der verführerischen Frau wegen, die sie sichtbarlich gesehen haben, nachts nicht schlafen: Hierauß dann zusehen ist / daß der Teuffel offt die Menschen in lieb entzündt vnd verblendt / daß man ins Huren Leben geräth / ond hernacher nit leichtlich widerumb herauß zubringen ist. (S. 949)

Die Studenten bitten Faustus, Helena am nächsten Tag noch einmal zu beschwören, so wolten sie einen Mahler mit sich bringen / der solte sie abconterfeyten (S. 948). Das klingt harmlos: Wenigstens ihr Bild wollen sie besitzen. Doch schlägt Faustus das ab, da er jhren Geist nicht allezeit erwecken kónte. Er bietet jedoch an:

Holzschnitten. Hrsg. von Jan-Dirk Müller. Frankfurt 1990, S. 831-986; hier S. 841; aus dieser Ausgabe die folgenden Zitate; vgl. Marina Münkler: Narrative Ambiguität. Die Faustbücher des 16. bis 18. Jahrhunderts. Göttingen 2011. Sie kommentiert die Stelle S. 45: man fürchtete offenbar, die „Funktionalisierung des Exempels“ könne scheitern. 
Er wollte jhnen aber ein Conterfey darvon zukommen lassen / welches sie die Studenten abreissen mo̊chten lassen / welches dann auch geschahe / vnd die Maler hernacher weit hin vnd wider schickten / dann es war ein sehr herrlich Gestalt eins Weibsbilds. Wer aber solches Gemåld dem Fausto abgerissen / hat man nicht erfahren kơnnen. (S. 948f.)

An die Stelle eines von Menschen geschaffenen Bildes, wie es die Studenten wollten, tritt ein Bild unbekannter Herkunft, vermutlich vom Teufel. Durch das Bild wirkt er auf die Studenten und die Maler, die es kopieren. Die verführerische Illusionierung durch das Blendwerk der Magie setzt sich in der Illusionierung durch das Bild fort. Das Gemälde der herrlich Gestalt überdauert die Beschwörung und ihre Folgen; es hat eine breite Wirkung. Mit dem Bild gelingt es dem Teufel, das verführerische Objekt sündiger Begierde omnipräsent zu machen. Auf versteckte Weise enthält diese Szene damit eine Kritik an den teuflischen Verführungskräften einer Kunst dubiosen, wahrscheinlich dämonischen Ursprungs, die mit Zauber und Wollust einhergeht.

\section{5}

$\mathrm{Zu}$ den immer wiederkehrenden Motiven des Amadis gehören neben unablässigen ritterlichen Kämpfen hauptsächlich außereheliche Liebesverhältnisse und das einmal positive, einmal negative Wirken von Zauberern. ${ }^{25}$ Im kollektiven Gedächtnis geblieben sind dank dem Don Quijote nur die ritterlichen Abenteuer, deren Albernheit und mangelnder Realitätsgehalt auch damals schon auffiel. Die wichtigsten zeitgenössischen Punkte der Kritik am Amadis aber sind sexuelle Ausschweifung und Magie. Die ausführlichste Auseinandersetzung stammt von dem Hugenotten François de la Noue (Lanovius) in seinen Discours politiques et militaires (1586). ${ }^{26}$ In den Discours würde man eigentlich keine Literaturkritik erwarten, Zeichen, für wie wichtig de la Noue diesen Roman in der Adelsdidaxe hält. Der sechste Discours ist überschrieben: Que la lecture des livres d'Amadis n'est moins pernicieuse aux jeunes gens, que celle des livres de Machiavel aux vieux (S. 160). Dieser Vergleich mit dem schlimmsten aller schlimmen Autoren unterstreicht die Gefahr, die de la Noue im Ritterroman wittert. Er habe, sagt de la Noue, sich anfangs von Machiavellis Discorsi und seinem Principe und den darin verhandelten hautes et belles matieres politiques et militaires blenden lassen, bis er genauer

25 Wie Henrike Schaffert gezeigt hat, werden aus diesen drei Ingredienzien, aus denen wiederum einige rekurrente Erzählkerne abgeleitet sind, die seriell angelegten 24 Bände (in der deutschen Ausgabe) generiert; vgl. künftig dies.: Der Amadisroman. Serielles Erzählen in der Frühen Neuzeit. Diss. München 2013 (erscheint 2015 in der Reihe Frühe Neuzeit).

26 François de la Noue: Discours politiques et militaires. Publiés avec une introduction et des notes par F. E. Sutcliffe. Genf, Paris 1967; vgl. Myriam Barakat: Édition commentée des Discours politiques et militaires de François de la Noue (1531-1591), Thèse du doctorat. Montpellier 2011. Das 1586 erschienene Buch wurde bereits 1592 ins Deutsche übersetzt durch Jakob Rathgeb: Discours Oder Beschreibung vnd vßführliches rähtliches bedencken, von allerhandt so wol Politischen, als Kriegssachen. Frankfurt 1592, 6. Discours, S. 163-180. 
zusah und erkannte, wie die verführerischen Gedanken auf voyes de deshonneur et de dommage (S. 160) führten. Als Zeugen ruft er Innocent Gentillets AntiMachiavel auf. ${ }^{27}$ Bis ins 18. Jahrhundert gilt Machiavelli als Zerstörer der Grundlagen einer auf Moral gegründeten politischen Ordnung, und als ebenso gefährlich schätzt de la Noue Les livres d'Amadis ein, die er für „äußerst geeignete Mittel zur Verderbnis der Sitten“ (des instrumens fort propres pour la corruption des moeurs) hält. Er wolle die „unschuldige Jugend“ davor schützen, sich in ihren fein gewebten Netzen zu fangen (S. 162). Der Amadis habe die Nachfolge der alten Romane ${ }^{28}$ angetreten, dem verfeinerten Geschmack einer neuen Zeit angepasst; so beliebt seien die Amadis-Romane unter Heinrich II. gewesen, dass jeder Kritiker angespuckt worden sei. Man lernte Amadiser de paroles (,in der Rede zu ,amadisieren'“), eine Mode, mit deren Süßigkeiten man sich den Magen verderben konnte; jeder wollte taster seulement un petit morceau des friandises [Gaumenkitzel] qui y sont si naivement $\mathcal{E}$ naturellement representées (S. 162). ${ }^{29}$ Doch dann holt er zur Kritik aus. Der Verfasser ist Werkzeug des Teufels:

C'est qu'il me semble [...] que ç'a esté un Magicien courtisan, habile \& accort, ${ }^{30}$ qui les a composez, lequel pour mettre son art en estime, \& rendre ceux qui s'en meslent honnorez \& craints, a dextrement feint mille merveilles, qu'il a couvertes \& envelopees de plusieurs choses plaisantes, desirees, \& en usage, à fin que l'un coulant parmi l'autre, le tout fust mieux receu. (S. 162f.)

Mir scheint, dass es ein Magier bei Hof war, fähig und raffiniert, der sie verfasst hat, um seiner Kunst [der Magie] Anerkennung zu verschaffen und die, sie sich darauf einlassen, geehrt und gefürchtet $\mathrm{zu}$ machen. Er hat 1000 wunderbare Ereignisse erfunden, die er mit zahlreichen angenehmen, erwünschten und allgemein üblichen Dingen verdeckt und verkleidet hat, damit eins aus dem andern fließt und alles desto besser aufgenommen wird. ${ }^{31}$

Sein Ziel, der Zauberei Ansehen zu verschaffen, verfolgt er durch die Erfindung von Wunderbarem, eingekleidet in choses plaisantes, desirees $\mathcal{E}$ en usage. Teuflische Verführung camoufliert sich durch ästhetische Gestaltung.

27 Discours sur les moyens de bien gouverner et maintenir en bonne paix un royaume ou autre principauté [...] contre Nicolas Machiavel. s.l. 1576.

28 Immer schon habe es Leute gegeben, qui ont esté diligens d'escrire \& mettre en lumiere des choses vaines. Er nennt, wie seit Juan Luis Vives üblich, die alten Ritterromane Lancelot, Tristan, Perforest oder Giron le courtois (S. 161f.).

29 Rathgeb: Discours (Anm. 26), ist noch direkter, indem er den Bezug auf das Schmecken von Delikatessen kappt; doch auch bei ihm geht es um sinnliche (leibliche) Genüsse: der Amadis wecke im Leser das Begehren nur ein geringes stücklin der darinnen so artlich / eigentlich / ond leiblich vorgestelten wolluste zu versuchen / vnd zu probieren.

30 Rathgeb: Discours (Anm. 26): ein verschmitzter / subtiler / abgefürter Hoffmann / vnd zumahl grosser Schwartzkuinstler (S. 165).

31 Übersetzung hier und im Folgenden v. V. 
Die übliche integumentale Deutung der literarischen Fiktion - unter gefälliger, wenn auch bloß fingierter Oberfläche Einübung in höfische Sitten zu bieten, Aufmunterung zu Waffentaten, Rat in Liebesdingen - sei nur vorgeschoben. Die Einkleidung sorge weniger dafür, dass die bittere Medizin der Moral besser geschluckt wird, sondern überdecke im Gegenteil das süße Gift der Lektüre. ${ }^{32}$ Wer der Behauptung der Belehrung und Nützlichkeit Glauben schenkt, achtet mehr auf die Schönheit mancher äußerlicher Dinge als auf innere Wahrheit (la beauté de certaines choses exterieures, que la verité des interieures). ${ }^{33}$ Mögen die Lehren und Exempel den Zweck haben pour enseigner à aimer et à combatre, so ist doch die Mehrzahl solcher Liebesgeschichten scham- und sittenlos und fast alle Kämpfe voller Falschheit und Unmöglichkeiten, sodass die Anweisungen in die Irre führen (la pluspart de telles amours sont deshonnestes, $\mathcal{E}$ quasi tous les combats pleins de fausseté, E impratiquables: de sorte que c'est cheminer en erreur, que suyvre telles regles, S. 163). Integumentum bedeutet hier in Wirklichkeit verdeckte Anleitung zum Laster.

Die Verwirrung beginnt damit, dass Zauber verharmlost wird, indem Zauberer ,Weise' (sages) genannt werden und magische Künste Weisheit (parfaite sapience), wenn sie Gutes bewirken. Dadurch sind die klaren religiösen und moralischen Maßstäbe aufgehoben, ${ }^{34}$ denn es gibt keine böse und keine gute Zauberei; Zauberei (ces arts pernicieux, et pleins de fraude et de mensonge) ist immer vom Teufel (S. 165f.).

De la Noue sieht selbst, dass solche Zaubereien niemand glaubt und alle sich darüber lustig machen. Was ihn stört, ist das Vergnügen (plaisir), das man an solchen Geschichten findet und bei dem man die Gefahr vergisst (S. 166). Er warnt, dass in den Amadis-Büchern le succre qui est repandu fait avaller les grands morceaux d'aloes, sans y penser (S. 167); der Zucker ist nicht, wie in traditioneller Didaxe, Mittel, die bittere Lehre zu versüßen, sondern den Geschmack des Giftes (vénin, S. 167) zu überdecken. Er führt zur Selbstvergessenheit und zum Vergessen des religiösen Ernstes. Befriedigt wird der Geschmackssinn: repaistre sa curiosité de telles merveilles. De la Noue beschreibt die absorbierende ästhetische Wirkung:

32 l'intention de l'autheur desdits livres, n'a esté autre que de laisser à la posterité un pourtrait des exercices des cours de son temps, $\mathcal{E}$ forger un aiguillon, pour picquer les jeunes gentils-hommes, $\mathcal{E}$ les inciter à la pratique de l'amour $\mathcal{E}$ des armes. Mais ils jugent trop a la bonne foy (S. 163). Das ist eine Umkehrung des üblichen Arguments, das fabulae rechtfertigen soll: nützliche Wahrheit unter erlogener Oberfläche (vgl. Anm. 18). Nicht die Oberfläche erregt Anstoß, sondern, was unter ihr liegt (vgl. Rathgeb: Discours, Anm. 26, S. 163): vnder solchen hübschen Deckin/ viel grober fehler (S. 165; ähnlich S. 169).

33 Rathgeb: Discours (Anm. 26) übersetzt: die scho̊n vnd zierligkeit außwendig vs. die rechte warheit inwendig (S. 166).

34 Mir scheint es daher unrichtig, wenn Sutcliffe (Anm. 26), S. 164 die guten Zauberer mit weißer Magie zusammenbringt, denn diese liegt jenseits der Romanwelt. 
Plusieurs ne cuident pas qu'il y ait aucun inconvenient à voir \& aprendre choses qui font rire \& esmerveiller. Mais ils n'aperçoyvent pas que ce n'est que le commencement de la farce, \& qu'à la queuë gist le venin. (S. 167)

Viele Leute finden nichts Schlimmes dabei, lächerliche und wunderbare Sachen zu sehen und kennenzulernen. Aber sie merken nicht, dass dies nur am Anfang eine Farce ist und dass am Ende das Gift droht.

Solche Schriften untergraben die Moral, nous servent d'amorces pour nous apprivoiser aux misteres diaboliques (S. 168), sie gewöhnen ans Laster, indem sie den Geschmack kitzeln.

Die zweite Gefahr ist noch offenkundiger als die erste: das Gift der Wollust (poison de volupté, dont plus de gens tastent). ${ }^{35}$ Es ist so fein und wirksam (suptil $\mathcal{E}$ penetratif), dass es der stärksten Gegenmittel bedarf (S. 168). Der Amadis lockt mit plusieurs especes d'amours deshonnestes, die so gut dargestellt sind (si bien depeintes), dass sie die jungen Leute täuschen. Hier kommt nun ein weiterer ästhetischer Aspekt ins Spiel. Die Verführung zur Wollust bedient sich nämlich der Mittel der Kunst. Der Jugend gehe es, führt de la Noue aus, wie den Vögeln, die die gemalten Trauben des Zeuxis - einer Anekdote aus der Historia naturalis des älteren Plinius zufolge - für echte ansahen. Verführt werden Vögel wie junge Leute nicht nur durch das Begehren selbst, die sinnliche Attraktion der Früchte bzw. des anderen Geschlechts, sondern in diesem Fall durch eine Kunst, die den Gegenstand des Begehrens auf besonders reizvolle Weise vortäuscht. De la Noue bindet die verführerische Wirkung ausdrücklich an die vollkommene ästhetische Gestalt. Erst die kunstvolle Ausgestaltung der schlichten spanischen Amadis-Romane durch die französischen Übersetzer hat nämlich den Romanen ihre Verführungskraft verliehen, der der Leser bereitwillig erliegt:

[...] tous les plus beaux ornemens qu'ils ont peu emprunter de la rhetorique, à fin que le nouveau eust plus d'efficace de persuader, ce que plusieurs ne se persuadent que trop volontiers. Et l'ayant rendu fluide \& affetté, il ne faut point demander si son murmure est doux aux aureilles, où apres avoir passé, il va chatouiller les plus tendres affections du coeur, lesquelles il esmeut, plus ou moins, selon que les personnes sont prepares. (S. 168f.) $)^{36}$

[...] der ganze schöne Ornatus, den sie der Rhetorik entlehnen konnten, damit das Neue um so wirksamer von dem überzeugt, von dem sich viele nur zu gerne überzeugen lassen. Und nachdem sie es eingängig und raf-

35 Wieder kommt der Geschmackssinn ins Spiel: kostend ausprobieren.

36 Die fürnemsten / schönesten zierden vnd schmück / auß der Rethoric herfür gesucht / solches newe werck / den Menschen vnd Lesern nur desto angenemer / vnnd vnder dem schein zierlicher sprach / anmüthiger zu machen. (S. 171) 
finiert gemacht haben, muss man nicht fragen, ob die gefällige Rede den Ohren wohltut, wo sie, noch wenn sie vergangen ist, die zärtlichsten Gefühle des Herzen kitzeln wird, sie stärker oder schwächer hervorruft, je nach dem die Personen darauf vorbereitet sind.

Die vollendete Kunst erregt die Sinne und lockt mit dem Reiz des Neuen. Mit ,neu' nennt de la Noue neben dem Wunderbaren, den milles merveiles, eine weitere zentrale Kategorie frühneuzeitlicher Ästhetik. ${ }^{37}$ Zwar sind Magie und sinnliche Ausschweifung vornehmlich gefährliche Erzählgegenstände, die man meiden muss. Doch ihre magische Verführungskraft entfalten sie durch ihre kunstvolle Form. ${ }^{38}$ Und de la Noue malt aus, wie für die jungen Mädchen nicht die Moral, nicht honte et modestie, nicht pudicité attraktiv sind, sondern deren Übertretung, gefasst wieder in Kategorien der Esslust: elles sont contraintes de se jetter par la fenestre, pour aller dans quelque delicieux jardin manger des abricots (S. 169). ${ }^{39}$ Nicht anders die jungen Kavaliere, die unablässig brennen und listiger als ein Fuchs die Vögel herbeilocken avec friandes pipees de volupté (S. 170). Und der Autor bietet all seine Beredsamkeit auf, um zu zeigen, dass darin das Glück besteht, pour donner des mauvaises impressions à la jeunesse delicate (S. 170).

Die außerehelichen Liebschaften enden zwar im Amadis meist in der Ehe, aber erst später; zuerst dominiert die Wollust; auch gibt es andere Helden, die der incontinence (S. 171) Vorschub leisten. Ein Teil der Liebesaffairen hängt wieder direkt mit Zauber zusammen, aber der Zauber vollendet nur, was sich unter den Verliebten, etwa Amadis aus Griechenland und Zahara schon anbahnt:

Car aucuns magiciens voyans qu'ils s'entreregardoyent de bon oeil, encores que cest Amadis fust marié, neantmoins esmeus de pitié de leur passion, \& aussi pour oster la coulpe de l'adultere, ils les enchantment tous deux ensembles en de beaux verger delicieux, où s'oublians eux mesmes, il n'oublierent pas pourtant de forger deus beaux enfans. (S. 172)

Denn manche Zauberer, wenn sie sehen, dass sie sich mit verliebten Blicken anschauen, werden, obwohl Amadis verheiratet ist, auch um sie von

37 An der Ästhetik Johann Jakob Breitingers und Johann Jakob Bodmers wäre dieser Zusammenhang aufzuweisen. wenn die Schweizer auch das in der Dichtung legitime ,Wunderba$\mathrm{re}^{\prime}$ vom ,Abenteuerlichen' unterscheiden, mit dem u.a. die wilden und haltlosen Erfindungen der Ritterromane gemeint sind.

38 Hier unterscheidet sich die deutsche Übersetzung. Rathgeb fügt hinzu: Sie hetten zwar dessen so hoch nit bedorfft / weil der Mensch vorhin von Natur darzu geneigt / daß gut zu lassen / vnd dem bo̊sen zu folgen, Rathgeb: Discours (Anm. 26), S. 171. Sein Misstrauen gegen die schöne Form äußert sich auch, wenn er den kunstvoll gestalteten Roman verdeckt Gifft nennt, vgl. Rathgeb: Discours (Anm. 26), S. 171.

39 Wieder übernimmt der deutsche Übersetzer die Geschmacksmetaphorik nicht: [...] seyen sie als in Lieb hefftig entbrendt / verursacht worden / sich etwan zu einem Fenster hinab zu lassen / vnd im grünn Graß / vnder lustigen Rosenhecken / die Blümchen abzubrechen (S. 172). Blumenbrechen ist eine konventionelle Metapher für den Sexualverkehr; das ist sehr direkt, wo de la Noue von süßen Früchten spricht. 
der Schuld des Ehebruchs zu entlasten, von Mitleid über ihre Leidenschaft gerührt und verzaubern die beiden in einem wunderschönen Garten, wo sie ihrer selbst vergessen, freilich nicht vergessen zwei schöne Kinder zu zeugen.

Die Passion geht dem Zauber voraus, motiviert seine Anwendung und schafft die Voraussetzung für die Selbstvergessenheit, die die Leidenschaft verursacht. Solche Passion ist flüchtig. Es ist wieder eher eine Aussage über die Psychologie der Leidenschaft in der Perspektive rigoristischer Moral: Schwindet der Zauber, dann geht jeder seiner Wege ohne Erinnerung an das, was passiert ist. Das alles ist

une couverte representation du paradis de Mahommet, dont cest autheur vouloit donner quelque petit goust aux crestiens de son temps [...] à fin qu'ils s'accoustumassent à repaistre leurs esprits et leurs corps de pensemens \& d'actes charnels. (S. 171f.)

eine versteckte Darstellung des Paradieses der Muslim, von dem der Autor den Christen seiner Zeit einen kleinen Vorgeschmack geben wollte, um sie daran zu gewöhnen, Seele und Leib mit fleischlichen Gedanken und Akten zu nähren.

Erinnert man sich, dass de la Noue auch in dem der Zauberei gewogenen Verfasser einen Muslim vermutete, ist hinter der Amadis-Kritik das Interesse religiöser Orthodoxie erkennbar, auf allen Ebenen die Unterhaltungsliteratur zu bekämpfen.

Erst mit dem dritten Vorwurf kehrt de la Noue zu seinem eigentlichen Thema politischer und militärischer Didaxe zurück. Er nennt die unablässigen Zweikämpfe, die oft zwischen nahen Verwandten der Ehre wegen oder im Dienst der Damen oder wegen unsinniger Gelöbnisse oder einfach, um sich zu beweisen, stattfinden, mauvaises drogues, ein gefährliches Genussmittel. Die Helden massakrieren sich pour choses frivoles, zum Vergnügen und Zeitvertreib von Königen, Damen, Höfen und Städten (S. 173). Er führt die Händelsucht im Adel darauf zurück, dessen sinnloses Blutvergießen er mit den Tierkämpfen in England vergleicht. Die Polemik gegen Duelle erklärt sich aus dem Bemühen des frühmodernen Staats, das Gewaltmonopol durchzusetzen; sie gehört in den Rahmen frühneuzeitlicher Sozialdisziplinierung. ${ }^{40}$ Überdies macht er sich über die Unglaubwürdigkeit der Kämpfe lustig, die im Adel völlig falsche Vorstellungen wecken, sodass aus Amadis-Lesern nie gute Soldaten werden (S. 174).

De la Noues religiös-moralische Polemik gegen die Sittenlosigkeit und Blutrünstigkeit der Amadis-Serie ist mit latent ästhetischen Argumenten, freilich in verzerrter Form, verknüpft. Die verderblichen Inhalte werden als Nahrung aufgenommen; sie schmeicheln dem Geschmackssinn, einem der niederen Sinne,

40 Gegeninstanz gegen die Unordnung im Adel ist deshalb der König Heinrich II. (S. 176). 
und verderben so den Menschen. Die Annehmlichkeit für den Geschmackssinn ist hier noch eindeutig negativ besetzt. Trotzdem ist die in mehreren Kontexten auftretende Nahrungsmetapher symptomatisch (so wie-ebenso symptomatisch - der deutsche Übersetzer sie tilgt oder abschwächt). Zur Aufwertung des goût ist es noch ein weiter Weg. Doch deutet de la Noues zwanghafte Verwendung von Nahrungsmetaphern schon an, wo er die eigentliche Gefährlichkeit der Romanlektüre sieht. Schattenhaft und in negativer Verkehrung zeichnet sich hier ab, was für ein Sprengpotential man der Gattung Roman dank ihrer Ästhetik zutraut.

\section{6}

Durch Rathgebs Übersetzung wurde, wie bemerkt, de la Noues Discours schon 1592 in Deutschland bekannt. Das Urteil des Calvinisten hat deshalb im lutherischen Deutschland - wie übrigens auch in der katholischen Welt - große Resonanz, wobei sich auch die Verbindung von Romankritik und Magiekritik als erfolgreich erweist. Die Behauptung eines ,sarazenischen' Ursprungs des Romans neutralisiert mögliche konfessionelle Spannungen und macht die Kritik des Calvinisten auch für Lutheraner und Katholiken nachvollziehbar.

Sonst konzentriert sich die Romankritik meist auf die unsinnige Handlung und Nutzlosigkeit der spätmittelalterlichen und frühneuzeitlichen Romane, die seit den Schriften des Juan Luis Vives, die eigentlich auf den französischen Markt bezogen waren, in einem festen Kanon genannt werden mit Titeln, die es z.T. in Deutschland gar nicht gibt. ${ }^{41}$ Ein weiterer Anstoß ist, dass hauptsächlich von Liebe die Rede ist. ${ }^{42}$ Hinter beidem steckt der Teufel. Er sucht mittels gesuchter und absurder Plots, die Menschen von sinnvoller, auf Gott bezogener Tätigkeit abzulenken, gaukelt ihnen Wunschbilder sinnlichen Genusses vor und taucht das Laster so in schönes Licht. Da kommt es gar nicht mehr darauf an, ob ausdrücklich von Zauberei die Rede ist, denn was erzählt wird, hat allemal eine ähnlich verheerende Wirkung. Mit dem Amadis und der prominenten Behandlung von Zauberei erhält die Kritik einen zusätzlichen Akzent. ${ }^{43}$

Johann Valentin Andreae ${ }^{44}$ erweitert die übliche Liste der vanae fabulae mit Tristan, Kaiser Octavian, Melusine, Magelone usw. noch um den Guzman de Alfarache, den Brissonetus, den Don Quixote oder die literati histriones Rabelais und Merlin. Für den Amadis beruft er sich auf de la Noue. Er nennt den Roman einen „berüchtigten Betrüger bei Hof, bei Müßiggängern und besonders beim weibli-

41 Fritz Wahrenburg: Funktionswandel des Romans und ästhetische Norm. Die Entwicklung seiner Theorie in Deutschland bis zur Mitte des 18. Jahrhunderts. Stuttgart 1976; vgl. zu Vives Müller (Anm. 19), S. 19-21.

42 Siegmund Feyerabend bringt eine große Sammlung erfolgreicher Prosaromane unter dem Titel Buch der Liebe heraus.

43 Ich konzentriere mich im Folgenden auf Kritiker, die diesen Akzent hervorheben.

44 Johann Valentin Andreae: Mythologiae Christianae sive Virtutum et vitiorum vitae humanae imaginum Libri III. Straßburg [1619], S. 47. Dort auch alle folgenden Zitate. 
chen Geschlecht" (famosum impostorem in aula et apud otiosos, tum femineum etiam sexum) und setzt ihn von den übrigen fabulae noch einmal als besonders gefährlich ab. Diese sind nämlich - wie die ältere Romankritik betont hatte - bloß geschwätzig und nichts wert, im Angebot von Marktschreiern (nugivendi), und sollten aus den Palästen vertrieben werden. Der Amadis dagegen, das Spitzenwerk der Sittenverderbnis (morum corrumpendorum antesignanum), sollte bei lebendigem Leib verbrannt werden. Durch Spiel und Blendwerk verleite er die Menschen zum Bösen (miris ludibriis animos hominum ad pessima quaeque fascinavit). Besonders gefährlich ist er wieder wegen der Dreiheit Nekromantie, Wollust und eine große Brutalität:

Nam et scelestissimam Necromantiam pro divina sapientia venditabat, et impuris libidinibus virgineum et conjugalem thorum polluebat, et ferocitate bestiali animos generosos imbuebat, et religionis legumque vincula dissolvebat, et vanis fabulis puriorem mentem occupabat.

Er pries nämlich verbrecherischste Nekromantie statt göttlicher Weisheit an [oder auch: „... verkaufte sie für ..."], besudelte mit schmutzigen Begierden jungfräuliche und eheliche Betten und tränkte hochdenkende Seelen mit bestialischer Wildheit; er löste die Bande von Religion und Gesetz auf und besetzte reine Gemüter mit leeren Fabeleien.

Die Amadis-Bücher, von großen Herren gefördert, seien voll von Beschwörungen, Hurereien, Zweikämpfen, leichtfertigen Gelöbnissen ${ }^{45}$ und törichten Phantastereien (incantionibus, lenociniis, duellis, votis frivolis, et stulta imaginatione). Das ist überwiegend auf den Inhalt der Reihe bezogen; doch stulta imaginatio weist über diese Ebene hinaus. Die Einbildungskraft ist zwar töricht, aber sie ist es, die die inkriminierten Gegenstände so verführerisch macht.

Deutlich ist das soziale Ressentiment gegen eine höfische Oberschicht, die nichts $\mathrm{zu}$ tun hat. Um leere Zeit zu füllen und die Melancholie zu vertreiben, empfahlen schon die Vorreden die Amadis-Bücher. ,Muße' ist in den Augen Andreaes nicht Freisetzung von alltäglicher Beschäftigung, sondern Müßiggang, Vermeiden ernsthafter Tätigkeit, damit Einfallstor des Lasters. Wieder trifft man unter negativen Vorzeichen auf eine Bedingung ästhetischen Genießens: die Entlastung von Alltagsgeschäften und -sorgen.

Allgemein gilt die Ansicht, dass die Romane die sittlichen Kräfte schwächen. Insofern steht der Amadis auch in der Nachbarschaft von Schwankbüchern, ${ }^{46}$

45 Gemeint sind die eidlichen Versprechungen, die die Helden unbedacht leisten und die sie $\mathrm{zu}$ unerhörten, manchmal unsinnigen Abenteuern verpflichten.

46 Candorin [Conrad von Höveln]: Des hochlo̊bl: adelen Swanen=Ordens Deutscher Cimber=Swan. Lübeck 1662, der zu Vives' üblichen Titeln Schwankbücher, Hurenlieder, Wahrsagebücher, auch Amadisi grillen aufführt (S. 150-154); Martin Zeiller: Epistolische Schatzkammer bestehend Von Siebenhundert vnd sechs Sendschreiben / Worinnen Allerhand ko̊stliche Schåtze [...] anzutreffen vnd zu finden seind. Ulm 1683, 73. Epistel, S. 304; Johann 
Hurenliedern, Wahrsagetexten und dgl. Christoph Ludwig Dietherr (1689) verhandelt unter dem Titel De libris Amadisiis auch den Eulenspiegel und die Schwanksammlungen Grillenvertreiber, Gartengesellschaft und Rollwagenbüchlein. Er kommt zu dem Ergebnis, solche Schriften enthielten

moribus nociva, honestaeque disciplinae perniciosa, maxime: venena, quae melle condita instillant adolescentibus, blanda quidem, non tamen continent salubria. (S. 34a)

für die Sitten höchst schädliche, für Ehrbarkeit und Selbstzucht höchst verderbliche Gifte, die sie honigsüß gewürzt den jungen Leuten einträufeln, gewiss einschmeichelnd, doch enthalten sie nichts Gesundes.

Es ist die süße Würze (melle condita), der verführerische Geschmack, der so gefährlich ist. Die ungewöhnliche Zusammenstellung zeigt wieder: Unterhaltung und Magie liegen auf einer Linie. ${ }^{47}$

Peter Laurembergs Acerra Philologica (1637) zählt im 3. Buch die übliche Liste schlechter Historien auf zur Belustigung der müssige[n] Jugend (S. 195). Beim Amadis hebt er, de la Noue folgend, die schwarze Kunst, die Teuffels Kunst, hervor, die der Verfasser habe fortpflanzen wollen. ${ }^{48}$ Arnold Mengering stellt den Amadis wieder in eine Reihe mit Gartengesellschaft und Rollwagenbüchlein (S. 769), beliebt bei Studenten und Frauen, insgesamt unreine Bulen-Bücher (S. 768). ${ }^{49}$ Auch bei ihm gibt es das Syndrom Zauberei und Wollust. Zwanghaft zieht das eine das andere nach sich. Wenn er diskutiert, ob Fürsten im Krieg schwarze Kunst anwenden dürfen und als abschreckendes Beispiel dafür den Amadis nennt, verbindet er das nahezu reflexhaft mit einer Polemik gegen die sexuelle Freizügigkeit des Romans:

So hålts auch der Autor des Amadis fưr kein Sůnde / wie denn solches Schandbuch / auf Zauberey / Hurerey und Ehebruch unter dem Schein großer Helden-Thaten und züchtiger Lieb die fưrwitzigen Leser zu verleiten vom Teuffel ausgeheckt worden (S. 390).

Johannes Deckherrs Schrift De scriptis adespotis ${ }^{50}$ hat ein Kapitel, das schon in seinem Titel Romane und Schadenzauber miteinander verknüpft: „De Scriptori-

Jacob Speidel: Speculum iuridico-politico-philosophico historicarum observationum et notabilium. Nürnberg 1657, S. 51 und 431f., setzt sie mit billigen Jahrmarktskünsten gleich.

47 Christoph Ludwig Dietherr: Orbis novus literatorum prae primis jurisconsultorum, detectus sive Continuatio Thesauri practice Besoldiani. Nürnberg 1689.

48 [Peter Lauremberg:] Acerra Philologica. Das ist: Dritte Hundert Außerlesener [...] Historien. Rostock 1637.

49 Arnoldi Mengerings Scrutinium conscientiae catecheticum. Das ist / Sůnden-Auge Nach der Ordnung des Catechismi. Nunmehro auffs neue ubersehen / vermehrt/ vnd mit einer Vorrede gezieret Von Augusto Pfeiffern. 3. Aufl. Frankfurt, Leipzig 1687.

50 Johannes Deckherr: De Scriptis adespotis, pseudoepigraphis et suppositiis coniecturae. 3. Auflage. Amsterdam 1686. Deckherr war Jurist, am Reichskammergericht in Speyer tätig. Ihm geht es folglich vor allem um die Frage, was justiziabel ist. 
bus Fabularum, quae Romanas vocant; et de Maleficis“ (Sectio IX, S. 238ff.). Romane sind Produkte otiosorum ingeniorum für otiosi lectores (S. 237). Seine Kritik des Amadis, dieses liber pestilens, folgt de la Noue, indem er wie dieser als Verfasser einen schlauen, magiekundigen spanischen Hofmann vermutet (Magicae rei callentissimum), der unter der täuschenden Oberfläche Satanskünste verbreiten wollte, einen Mohammedaner oder Sarazenen, einen Dämonenknecht oder Adepten dämonischer Künste (sub hoc involucro artes Diaboli propagare Satagentem, Mahometanum illum vel Saracenum; Daemoniacum et Daemonomaniam professum) (S. 239). Das Urteil ist vernichtend. Er nennt den Amadis ein Werk, „das für die Lüste der meisten Höfe bestimmt sei und sich durch Unzucht mit Hilfe aberwitzigster Gedanken den erbärmlichsten Liebhabern warm empfehle" (Amadisium plerarumque Aularum deliciis sepositum, et ex incestu ineptissimis cogitationibus miserrimis amatoribus commendatissimum) (S. 239). Solche Häufung von Lastern hat strafrechtliche Konsequenzen. Magische und häretische Schriften sind zu verbrennen. Deckher fragt sogar, ob die Lektüre eines solchen Buchs nicht als Grund für die Verhängung der Folter ausreiche. Für das Faustbuch verneint er diese Frage, weil dieses ja mit einem (vermutlich gefälschten) obrigkeitlichen Privileg erschienen sei, das treffe für den Amadis jedoch nicht zu. Damit führt die literarische Kritik zur Erörterung der Frage, wie man Zauberer überführen könne, und so geht das Kapitel über anonyme Romane ganz selbstverständlich in einen Exkurs über malefici über (S. 240ff.). Beides gehört für ihn offenbar zusammen. Nach dieser Abschweifung ruft Deckherr sich zur Ordnung und kehrt zu einer nun überwiegend positiven Erörterung von Romanen (Sophonisbe, Theuerdank, Hercules und Herculiscus, Heldenbuch, S. 246ff.) zurück.

Die katholische Seite argumentiert nicht anders. So geißelt der Jesuit Jeremias Drexel in seinem Nicetas (1628) die obszönen Bücher (impuri et obscoeni libri), die zur Unkeuschheit einladen (incontinentiae invitamentum) und Büchern mit frommen geistlichen Mahnungen vorgezogen würden (S. 26-33). ${ }^{51}$ Auch bei ihm steht der Satz lectio transit in mores im Hintergrund. Er fragt in seinem Plädoyer gegen Unterhaltungslektüre: „Was lese ich viel, wenn ich nicht tun will, was ich gelesen habe. Wenn wir etwas gelesen haben, fangen wir an, so zu sein, wie das Buch es uns lehrt" (Quid multa lego, si facturus non sum quod legi? Post lectionem tales incipiamus esse, quales esse praecipit liber, S. 181f.). Er weitet die Romankritik zur allgemeinen Literaturkritik. Der Amadis steht an der Seite Ovids, des Goldenen Esels und des Faustbuchs (S. 33), denn es ist der böse Geist, der hinter Unkeuschheit ebenso wie hinter der Zauberei steht (S. 32). Schuld ist der Müßiggang (S. 185f.). Die schöne Gestalt dient nur der Verführung.

Auch die Bibliotheca selecta des Antonio Possevino gibt eine Übersicht über die Bücher, die der gute Katholik lesen darf. In der 4. Sectio des 16. Buchs über die humana historia geht es um falsche und verderbliche historiae, darunter über Geschichtsfälschungen, die Werke Machiavellis, Schriften des konfessionellen

51 Jeremias Drexel: Nicetas seu triumphata incontinentia. München 1628. 
Gegners, d.h. vor allem die protestantische Geschichtsschreibung, dann aber auch wieder Geschichten über Magier, die Jesus verdrängen wollen. An diese schließt der Abschnitt De Amadisio et alijs eiusmodi Auctoribus an. ${ }^{52}$ Gemeint sind fiktionale Texte generell, hauptsächlich Romane. Sie sind Werkzeuge des Teufels, otiosiores animi zu verführen mittels libido und fortitudo. Possevino nennt die üblichen Ritterromane, vermehrt um einige andere Schriften wie das Decameron Boccaccios oder den Orlando furioso Ariosts. Zwar tadelt Possevino bei einigen ihre schlechte Qualität; meist jedoch habe der Teufel, um das Gift süßer wirken zu lassen, die Verfasser gerade mit Eloquenz und Erfindungsgabe ausgestattet:

Et plerisque istis omnibus vt suauius venena insiuerint, dedit de spiritu suo Diabolus, eloquentia, et inuentione fabularum ditans ingenia, quae tam miserae suppelectilis officinae fuerunt.

Und den meisten von diesen allen gab der Teufel von seinem Geist, damit sie umso süßer ihr Gift einträufelten, indem er den Geist derer, die als Instrumente solch elenden Geschäfts dienten, mit Beredsamkeit und der Gabe, Fabeln zu erfinden, ausstattete.

Die ästhetische Qualität, das süße Gift, das den Geschmacksnerven schmeichelt, mache diese Schriften so gefährlich. Sein Beispiel ist der Amadis. Nachdem der Teufel mit Hilfe von Luther Deutschland nahezu zu Fall gebracht habe, habe er für eine kunstvolle Übersetzung des Amadis ins Französische gesorgt (eleganter verti) als Lockmittel (illecebra), um den Adel zu ködern (nobilium Aulicorum ingenia) und so auch das solidissimae fidei regnum, nämlich Frankreich, zugrunde zu richten: Sparserat enim in eo libro [...] amores foedos, inauditos congressus equestres, Magicas artes. Es geht ihm also weiterhin um die Dreiheit der Inhalte Wollust, Ritterabenteuer und eben wieder Magie. Ihre Verführungskraft entfalten diese Inhalte dank der teuflischen ästhetischen Mittel. ${ }^{53}$ Die Verharmlosung der Magie einer Urganda und anderer zu einem höheren Wissen, das das Glück des Menschen lenkt (adeo festivum), ist besonders gefährlich, weil sie zur Nachahmung reizt und zur Selbstüberhöhung des Menschen vor Gott, der allein Verehrung verdient, führt.

Als gemeinsamen Nenner kann man die angebliche Sittenlosigkeit der Romane ${ }^{54}$ ausmachen. In den Ritterromanen sind es Wunschwelten und Fluchträume von Liebe und Abenteuer, die vom Ernst eines verantwortlichen christlichen Lebens ablenken, in Fazetiensammlungen, Schwankbüchern und Schelmenromanen derbe, oft obszöne Scherze, die den Rezipienten frommer Wohlan-

52 Antonio Possevino: Societatis Iesu Bibliothecae selectae. De ratione studiorum in Facultatibus qui in pagina sequenti indicantur. Bd. II. Köln 1607, S. 345, dort alle folgenden Zitate. Zu Possevino vgl. Müller (Anm. 19), S. 24-28.

53 Wenn er sagt, dass der Teufel so teils die mentes, teils die corpora in sein Netz lockt, könnte das letztere sich vor allem auf die oft tödlich ausgehenden Zweikämpfe, die duelli, beziehen; beide Male verfallen die Seelen dem ewigen Tod.

54 Weitere Beispiele Schwering: Amadis und Faustbuch (Anm. 22), S. 115. 
ständigkeit entfremden. Nur in einigen der inkriminierten Bücher spielt die Zauberei als Gegenstand eine Rolle. Aber Zauberey ist zu Hurerey und Ehebruch nicht nur der Tropfen, der das Fass sittlicher Entrüstung zum Überlaufen bringt und die Zurückweisung der Romane unwiderlegbar macht, denn der Teufel steckt ebenso hinter ihr wie hinter den Lastern sexueller Ausschweifung und Obszönität. Vor allem gibt es eine Verbindung zwischen dem Teufel und den ästhetischen Qualitäten der Texte. Die Überwältigung durch die Romane erscheint dabei immer noch als teuflische Verführung. In dem Maße, in dem der buchstäbliche Vorwurf der Zauberei in den Hintergrund tritt, kann der Begriff metaphorisiert werden, d.h. Verzauberung und Verhexung bezeichnet nur noch die Verführung durch die verderblichen Inhalte des Romans und schließlich überhaupt den Vorgang der Illusionierung durch fiktionale Welten. Damit gewinnt ,Zauber' eine neue Bedeutung, meint nicht mehr tatsächliche magische Praktiken, sondern die Überwältigung des Denkens, Wollens und Fühlens, sodass man nicht mehr Herr seiner selbst ist.

Ich breche hier ab. Die Geschichte dieser Positivierung kann ich hier nicht weiter verfolgen; ich möchte nur noch einmal an die anfangs zitierte Station erinnern, in der die Trias Zauberei - Erotik - Kunst in einer Konstellation erscheint, die zwischen den frommen Mahnungen der Romankritik und Wielands Versuchsanordnung steht. Armida ist eine der beliebtesten Gestalten der Opernbühne der Frühen Neuzeit. ${ }^{55}$ Bis hin zu Rossini wird die Faszination ihres Zaubers beschworen, wenn dieser auch schließlich exemplarisch überwunden werden muss. Der Sieg der Christenheit und der Tugend ist wieder mit der Zähmung der Zauberin und der Zerstörung von Schönheit erkauft. Zuerst aber wird der Zauber weidlich genossen. Die der Zauberin zugeordnete Musik ist bei weitem kunstvoller und verführerischer als das, was an ihre Stelle tritt. Die entzauberte Natur verwandelt sich in Wüste. Die Tugend siegt zuletzt, doch um welchen Preis. Die Dreiheit Zauberei, erotische Verführung und Kunst als Blendwerk ist erhalten, doch es fragt sich, ob ihre geforderte Vernichtung und Desillusionierung nicht ein Verlust ist. Dieses Motiv verdient nähere Ausarbeitung, wie auch die Begriffe, die die Kritiker der Romane gebrauchen: das Neue, das Wunderbare. Auch bei Wieland ist Danae noch eine Verführerin, doch Verführerin wozu?

55 Ich nenne nur Händel (neben Rinaldo auch Alcina), Jomelli, Gluck, Haydn, Rossini. 
(C) 2015, Otto Harrassowitz GmbH \& Co. KG, Wiesbaden ISBN Print: 9783447104951 - ISBN E-Book: 9783447194129 


\title{
Magische Texte in mittelalterlichen Bibliotheken
}

\author{
Frank Fürbeth, Frankfurt a.M.
}

Der bayerische Hof- und Leibarzt Johann Hartlieb schrieb im Jahre 1456 für den Markgrafen Johann von Brandenburg, genannt "der Alchemist", das Buch aller verpotten kunst, vnglaubens vnd der zaubrey, in welchem er den Markgrafen vor allerhand teuflischen Künsten warnt und eine Reihe von Büchern nennt, vor denen er sich besonders hüten soll. Da heißt es im 35. Kapitel:

,Es ist noch gar ein mercklich püch in der künst nigramancia das hebt sich an , ad laudem dei et gloriosissime virginis Marie', haisst picatrix. das ist das vollkomenst püch, das jch ye gesach jn der kunst. das selp püch ist ainem küng von Hysponia gesambelt worden durch ainen hochen doctorem sunder zweifel, wann er hat die kunst also gerümt mit natürlichen aygenschaft vnd mit sprüchen der hailigen geschrift, das maniger wolgelerter man gantz gelaubt, das es nit sünd sey, das püch verfürt gar vil lewt zu ewiger verdambnuss. vor dem püch sol sich dein fürstlich genad am maisten hütten, wann vnder seinen süssen worten ist der potter gift vermist. das püch Piccatrix ist grösser dann drey psalter, o was hocher list vnd gespenst hat gehabt sathanas, bis er das püch einpläsen hat.' [...]

Trotz solcher Warnungen hat sich das Buch mit dem merkwürdigen Namen Picatrix, von dessen Ursprung man nicht viel mehr wußte, als dass es der spanische König Alfons (,der Weise') für sich hatte schreiben lassen, sehr weit verbreitet. Es gab eine große Reihe von Handschriften davon, Kaiser Maximilian hatte sogar zwei in seiner Bibliothek. ${ }^{1}$

Diese einleitenden Worte stammen aus der Einführung zur deutschen Übersetzung des Picatrix, die 1961 von Hellmut Ritter und Martin Plessner in den Studien der Warburg Bibliothek herausgegeben worden ist. Ritter geht es hier offensichtlich darum, zwei Kronzeugen für die weite Verbreitung dieses nigromantischen Zauberbuchs im Mittelalter anzuführen: zum einen die genannte Schrift

1 Picatrix. Das Ziel des Weisen von Pseudo-Mağrịțī. Translated into German from the Arabic by Hellmut Ritter and Martin Plessner. London 1962, S. XX. Der Hinweis auf die beiden Exemplare in der Bibliothek Maximilians bezieht sich auf Theodor Gottlieb: Die Büchersammlung Kaiser Maximilians I. Mit einer Einleitung über älteren Bücherbesitz im Hause Habsburg. Leipzig 1900, S. 99. Das Inventar nennt unter der Rubrik Nigromantia vnd Arzney außerdem noch die Clauicula Salomonis und die Secreta secretissima Salomonis. 
Hartliebs, ${ }^{2}$ die bis heute immer wieder herangezogen wird, wenn man einen Überblick über magische Praktiken im Spätmittelalter zu gewinnen sucht, ${ }^{3}$ und zum anderen die vermeintlich große Zahl an direkten und indirekten Zeugnissen für die Existenz dieses Zauberbuchs in mittelalterlichen Bibliotheken. Dieser letzten These soll im Folgenden in einem größeren Zusammenhang nachgegangen werden. Es soll danach gefragt werden, welche magischen Texte in mittelalterlichen Buchsammlungen überhaupt und in welcher Zahl vorhanden waren. Anlass für diese Frage ist ein immanenter Widerspruch der beiden Kronzeugen: Wenn nämlich der Picatrix und andere Zauberbücher wirklich so teuflisch sind, dass ihr Gebrauch die Menschen in die ewige Verdammnis führt, wie es Hartlieb behauptet, dann wäre eher zu erwarten, dass man kaum Spuren ihrer Existenz finden würde. Dies also gilt es zu untersuchen, wobei in drei Schritten vorgegangen werden soll: Zuerst soll ein knapper Überblick über die magischen Texte des Mittelalters und ihre Überlieferung gegeben werden, ehe dann am Beispiel des Picatrix auf die Details der handschriftlichen Überlieferung eingegangen wird. Zuletzt wird schließlich das Ergebnis noch in den Kontext weiterer Zeugnisse von magischen Texten in den Buchverzeichnissen des Mittelalters gestellt.

Zuerst aber soll noch einmal in aller Kürze auf das Buch Hartliebs zurückgekommen werden. Hartlieb ordnet seine Liste magischer Bücher und Praktiken nach einem Schema der Magie, das sich schon bei Isidor findet und dann von Hugo von St. Viktor im Didascalicon in eine systematische Ordnung gebracht wurde. Die erste Species der Magie ist die Mantik, die einerseits die Necromantie und andererseits die vier sogenannten „elementischen“ Künste Geomantie, Hydromantie, Aeromantie und Pyromantie umfasst. ${ }^{4}$ Hartlieb folgt dieser Fünfer-Reihe, fügt diesen aber noch die Chiromantie und die Spatulamantie hinzu; er verspricht außerdem Informationen zu allen anderen Täuschungen des Teufels, wozu es aber in diesem Buch nicht mehr gekommen ist. Die Einfügung der Chiromantie und, besonders wichtig, die Umbenennung der Necromantie in Nigromantie bei Hartlieb verdankt sich nun der Rezeption einschlägiger arabischer

2 Johannes Hartliebs Buch aller verbotenen Kunst. Untersucht und hrsg. von Dora Ulm. Halle a.S. 1914. Eine Neuedition nach der Hs. Heidelberg, UB, cpg 478 mit Übersetzung und Kommentar wurde hrsg. von Falk Eisermann und Eckhard Graf: Johannes Hartlieb. Das Buch aller verbotenen Künste, des Aberglaubens und der Zauberei. Ahlerstedt 1989. Zur Abhängigkeit Hartliebs von dem Tractatus de superstitionibus des Nikolaus Magni de Jawor vgl. Frank Fürbeth: Johannes Hartlieb. Studien zu Leben und Werk. Tübingen 1992, S. 88120 .

3 Vgl. etwa Hans Biedermann: Handlexikon der magischen Künste von der Spätantike bis zum 19. Jahrhundert. 3. verbesserte und wesentlich vermehrte Auflage. 2 Bde. Graz 1986, wo Hartlieb in Bd. 1, S. 198 sogar einen eigenen Eintrag erhalten hat.

4 Isidori Hispalensis Episcopi Etymologiarum sive Originum Libri XX. Hrsg. von W. M. Lindsay. 2 Bde. Oxford 1911, Buch VIII, Kap. 9; Hugo von St. Viktor: Eruditionis didascalicae libri septem. In: Migne, PL 176, Sp. 739-812, Buch VII, Kap. 15. Vgl. Frank Fürbeth: Art. Artes magicae. In: Reallexikon der deutschen Literaturwissenschaft. Bd. 1. Berlin, New York 1997, S. 146-149. 
Schriften seit dem 13. Jahrhundert. In der arabischen Wissenssystematik, wie sie durch Dominicus Gundissalinus nach Europa gekommen ist, ${ }^{5}$ wird die Nigromantie allerdings der Naturwissenschaft zugezählt; 6 ein Reflex dieser Zuordnung findet sich bei Hartlieb in seiner Warnung, dass der Picatrix sich angeblich mit natürlichen aygenschaft befasse. ${ }^{7}$ Die in den folgenden Jahrhunderten stattfindenden Systematisierungen ordnen nun diese neue Terminologie in das alte Schema Hugos ein, als Beispiel sei nur die Divisio scientiarum des Arnould de Provence genannt. ${ }^{8}$ Dass Hartlieb in seiner Darstellung der magischen Künste zwischen den alten Katalogen Isidors oder Hugos einerseits und der neuen Systematisierung der Araber andererseits steht, zeigt sich weiter ganz deutlich darin, dass er für die Nigromantie fast nur eine Reihe von Büchern aufzählt, während er für die weiteren sechs Künste ausschließlich magische Praktiken darstellt. Sein Buch, so könnte man sagen, ist damit deutlich zweigeteilt: Im ersten Teil nennt er schriftliche Quellen einer Buchmagie, und im zweiten Teil führt er Verfahrensweisen einer mündlich-praktischen Magie auf, die entweder volksläufig ist oder von entsprechenden Experten ausgeübt wird; bei letzteren nennt er für den Fall der Handlesekunst eine Gruppe von Zigeunern ${ }^{9}$ und für den Fall des Wettermachens eine Hexe, die er in ihrer Kunst ausgeforscht habe. ${ }^{10}$

\section{1}

Für unseren Zusammenhang ist nun wichtig, dass man für alle diese Formen der praktischen Magie keine schriftlichen Zeugnisse in den Bibliotheken finden wird, sieht man einmal von versprengten Niederschriften einzelner Anleitungen $\mathrm{ab}$, denen hier aber nicht nachgegangen wird. $\mathrm{Zu}$ erwarten sind dagegen Texte der Buchmagie, von denen Hartlieb selbst 15 mit Autor oder Titel nennt: sigillum Salomonis, claviculum Salomonis, Jerarchia, Schamphoras, ${ }^{11}$ püch Kyrammdorn, ${ }^{12}$ Thebit, Ptholomeus, Luipoldus de Austria, Arnoldus, Arnoldus de noua uilla, ${ }^{13}$ das gesegent

5 Dominicus Gundissalinus: De divisione philosophiae. Über die Einteilung der Philosophie. Lateinisch, Deutsch. Hrsg., übers., eingeleitet und mit Anmerkungen versehen von Alexander Fidora und Dorothée Werner. Freiburg, Basel und Wien 2007, S. 76, über die acht Teile der Naturwissenschaft (scientia de nigromantia secundum physicam; etwas unspezifisch übersetzt als „die Wissenschaft der Weissagung gemäß der Physik“, Dominicus Gundissalinus, S. 77).

6 Vgl. Frank Fürbeth: Die Stellung der Artes magicae in den hochmittelalterlichen, divisiones philosophiae'. In: Artes im Mittelalter. Hrsg. von Ursula Schaefer. Berlin 1999, S. 249-262.

7 Ulm: Johannes Hartliebs Buch (Anm. 2), S. 24.

8 Quatre introductions à la philosophie au XIIIe siècle. Textes critiques et étude historique. Hrsg. von Claude Lafleur. Montréal, Paris 1988, S. 295-347, hier S. 317-321.

9 Ulm: Johannes Hartliebs Buch (Anm. 2), S. 61.

10 Ulm: Johannes Hartliebs Buch (Anm. 2), S. 22-23.

11 Alle Ulm: Johannes Hartliebs Buch (Anm. 2), S. 16.

12 Ulm: Johannes Hartliebs Buch (Anm. 2), S. 16.

13 Alle Ulm: Johannes Hartliebs Buch (Anm. 2), S. 17. 
puch, ${ }^{14}$ Liber Raselis, ${ }^{15}$ piccatrix, ${ }^{16}$ ein püch der hailigen drey küngen ${ }^{17}$ und die pücher Pittagoras. ${ }^{18}$

Es sind dies zum größten Teil Werke der arabischen Astrologie, Magie und Mantik, die man ab dem 13. Jahrhundert in lateinischen Übersetzungen in den europäischen Bibliotheken findet. Eine systematische Erfassung der Überlieferung dieser Texte ist bis heute noch nicht geleistet worden; ausführliche Informationen zu ihren Verfassern, ihrer Entstehungszeit und zu ihrem Gegenstand findet man zwar in den Editionen und der Forschungsliteratur ${ }^{19}$ sowie in den einschlägigen Überblickswerken ${ }^{20}$ und Handbüchern, ${ }^{21}$ eine überlieferungsgeschichtliche Untersuchung, die insbesondere auch die von Ritter postulierte ,sehr weite Verbreitung' verifizieren würde, steht allerdings noch aus. Hier kann daher für einen ersten Überblick nur das Incipit-Verzeichnis von Lynn Thorndike und Pearl Kibre ${ }^{22}$ sowie ergänzend die History of Magic and Experimental Science von Lynn Thorndike ${ }^{23}$ und die Bibliographie von Francis Carmody ${ }^{24}$ ausgewertet werden, wobei die methodischen Bedenken angesichts des Frageziels vernachlässigbar erscheinen. ${ }^{25}$

14 Ulm: Johannes Hartliebs Buch (Anm. 2), S. 18.

15 Ulm: Johannes Hartliebs Buch (Anm. 2), S. 19.

16 Ulm: Johannes Hartliebs Buch (Anm. 2), S. 24.

17 Ulm: Johannes Hartliebs Buch (Anm. 2), S. 24.

18 Ulm: Johannes Hartliebs Buch (Anm. 2), S. 33.

$19 \mathrm{Vgl}$. dazu im Einzelnen unten.

20 Vgl. etwa Richard Kieckhefer: Magie im Mittelalter. München 1992; Christoph Daxelmüller: Zauberpraktiken. Eine Ideengeschichte der Magie. Zürich 1993; Christa Habiger-Tuczay: Magie und Magier im Mittelalter. München 1992.

21 Vgl. etwa Biedermann: Handlexikon (Anm. 3), s.v. Arnaldus Villanovanus, Jezîrah, Picatrix, Ptolemaios, Salomo, Zauberbücher.

22 Lynn Thorndike und Pearl Kibre: A Catalogue of Incipits of Mediaeval Scientific Writings in Latin. Revised and augmented Edition. Cambridge 1963.

23 Lynn Thorndike: A history of Magic and Experimental Science. Bd. 1-2. The first thirteen centuries. Bd. 3-4. Fourteenth and fifteenth centuries. New York 1923-1934.

24 Francis J. Carmody: Arabic Astronomical and Astrological Sciences in Latin Translation. A Critical Bibliography. Berkeley, Los Angeles 1956.

25 Die Bedenken richten sich einerseits auf die Unvollständigkeit des Verzeichnisses, die nicht nur daraus resultiert, dass seit dem Erscheinungsjahr der erweiterten Auflage die Handschriftenerschließung und damit auch der Nachweis weiterer Texte und Textzeugen weltweit qualitativ und quantitativ erheblich zugenommen hat, sondern auch daraus, dass es Thorndike/Kibre primär darum ging, die Werke, nicht die gesamte Überlieferung nachzuweisen. Eine Auswertung gerade bezüglich der Überlieferung wird also immer mit mehr oder minder großen Lücken zu rechnen haben. Andererseits war es der Ansatz von Thorndike/Kibre, alle Incipits zu verzeichnen, also auch diejenigen, die aus fragmentarischer Überlieferung oder aus Hinzusetzung oder Weglassung eines Prologs oder anderer Textteile entstanden sind. Dies führt dazu, dass die Zahl der verzeichneten Incipits grundsätzlich höher ist als die der sich dahinter verbergenden Werke. Gleichwohl können für die vorliegende Untersuchung diese Bedenken vernachlässigt werden, weil es zuerst einmal nicht um die absolute Zahl der nachgewiesenen Werke und Handschriften geht, sondern um einen Ver- 
Insgesamt können so 314 Texte gezählt werden, die sich im weitesten Sinne mit magischen Verfahren beschäftigen, wovon der größte Teil, nämlich 240 Texte, anonym überliefert ist. ${ }^{26}$ Im Vergleich zu der Gesamtzahl der bei Thorndike/ Kibre verzeichneten Werke, die auf etwa 8000 bis 9000 geschätzt werden kann, ${ }^{27}$ macht dies gerade einmal 3,5 Prozent aus. 237 dieser magischen Texte lassen sich durch Titel und Inhalt eindeutig der spätmittelalterlichen Systematisierung der artes magicae zuordnen, ${ }^{28}$ wie sie auch von Hartlieb verwendet wird. Auffällig sind drei Punkte: Erstens sind die Chiromantie mit $40^{29}$ und die Geomantie mit 95 Texten $^{30}$ überproportional vertreten; dies ist meines Erachtens darin begründet, dass es sich meistens um recht kurze und theorieferne Texte handelt, die also einerseits rasch und mit wenig Platzbedarf abgeschrieben werden können und sich so auch immer wieder in umfangreichen Sammelhandschriften finden. Zum anderen sind sie auf die Anwendung orientiert und von daher ebenfalls von größerem Interesse. Zweitens sind Hydromantie und Aeromantie jeweils nur mit einem Text, Pyromantie und Spatulamantie ${ }^{31}$ jeweils nur mit zwei Texten vertreten; dies zeigt, dass Hartlieb hier tatsächlich keine buchmagischen Texte zur Verfügung standen, auf die er hätte zurückgreifen können, ${ }^{32}$

gleich der Überlieferungshäufigkeit von magischen und sonstigen Werken und um die Gruppenbildung innerhalb der magischen Werke.

26 Vgl. die Liste im Anhang.

27 Die Schätzung resultiert aus einer Auszählung des Autoren- und Werkindex auf Sp. 17171935, wobei durchschnittlich 40 Werke pro Spalte aufgeführt werden, was insgesamt 8760 Werke ergeben würde.

28 Nicht berücksichtigt wurden solche Texte, die über Thorndike bzw. Carmody nicht eindeutig identifiziert werden konnten und deren Incipit nicht eindeutig erkennen lässt, ob es sich um eine magisch-mantische Anleitung oder im Gegenteil um eine kritische Auseinandersetzung mit solchen Praktiken handelt. Dies betrifft ausschließlich die anonym überlieferten Texte insbesondere zur Dämonologie, Divination und Magie.

29 Darunter sind 28 anonym. Zur Überlieferung der Chiromantie im Mittelalter vgl. Manuali medievali di chiromanzia. Hrsg. von Stefano Rapisarda. Rom 2005; Frank Fürbeth: Das Johannes Hartlieb zugeschriebene Buch von der hand im Kontext der Chiromantie des Mittelalters. In: ZfdA 136 (2007), S. 449-479.

30 Darunter sind 75 anonym. Zur Überlieferung der Geomantie im Mittelalter vgl. a. Thérèse Charmasson: Recherches sur une technique divinatoire: la géomancie dans l'occident médiéval. Geneve, Paris 1980.

31 Zur Spatulamantie im Sinne der Vorhersage aus den Schulterknochen großer Tiere im Mittelalter vgl. Charles Burnett: Magic and Divination in the Middle Ages. Texts and Techniques in the Islamic and Christian World. Aldershot 1966, Nr. XII („,Scapulimancy“), XIII (,,Arabic divinatory texts and Celtic folklore: a comment on the theory and practice of scapulimancy in Western Europe“), XV („An Islamic divinatory technique in medieval Spain: An editon of the earliest Latin Scapulimancy ").

32 Die drei artes magicae der Aeromantie, Hydromantie und Pyromantie verdanken ihr Leben in der Magie des Mittelalters offensichtlich nicht der Tradierung einschlägiger Praktiken und der entsprechenden Texte, sondern ihrer Nennung und Systematisierung als elementische Künste bei Isidor und Hugo von St. Viktor. Erwähnt werden sie vor allem in superstitionskritischen Werken des Mittelalters. So meint Michael Scotus in seiner Introductio in astrologiam, dass die Hydromantie darin bestehe, dass bei der Opferung für die Dämonen Blut 
wobei zudem noch zu bedenken ist, dass sich allein vier dieser Texte in einer Handschrift des späten 15. Jahrhunderts finden, in der sie unter dem wohl fingierten Autornamen Almadel als Liber de firmitate sex scientiarum zu Pyro-mantie, Aeromantie, Hydromantie, Augurium, Geomantie und Chiromantie zusammengefasst werden. ${ }^{33}$ Die Informationen, die Almadel hier zu Pyromantie, Aeromantie und Augurium - unter dem er eine Form der Wettervorhersage versteht - gibt, sind ebenso allgemeiner Natur wie bei Hartlieb und beruhen daher wohl nicht auf älteren Quellen, sondern sind erst im Rahmen und zur Erfüllung dieser gängigen Systematisierung zusammengestellt worden.

Damit bin ich bei dem dritten Punkt, der zeitlichen Verteilung. Der Großteil der Handschriften stammt aus dem 14. und 15. Jahrhundert. Dies ist nicht weiter verwunderlich, da bekanntermaßen der weitaus größte Teil der erhaltenen mittelalterlichen Handschriftenproduktion in diesen Jahrhunderten erfolgt ist. ${ }^{34}$ Umso auffälliger ist dann allerdings, dass die Geomantie schon mit acht Handschriften aus dem 13. Jahrhundert vertreten ist, dies erinnert daran, dass es ein geomantischer Text mit Angabe von Incipit und Explizit ist, der auf der Lektüreund Diskussionsverbotsliste des Bischofs Tempier für die Pariser Artisten von

mit Wasser vermischt werde (Thorndike, Anm. 23, Bd. II, S. 321f.), und in dem Albertus Magnus zugeschriebenen Speculum astronomiae werden die vier elementischen Künste nach der Nigromantie aufgeführt, weil sie mit dieser dieselbe Wortendung teilen; Hydromantie wasche das Fleisch der Tiere und inspiziere die Muskelfasern, Pyromantie sage aus dem Feuerschein voraus (ebd., S. 701f.). Weitere Erwähnungen von Aeromantie, Hydromantie oder Pyromantie finden sich in der Klassifikation der artes magicae bei Thadeus von Parma aus dem Jahr 1318 (ebd. Bd. III, S. 12), in Nicolaus Oresmes De divinationibus (ebd., S. 421), bei Gerd Groot (ebd., S. 512), Nicolaus Eymeric (ebd., S. 514), Jacques Le Grand (ebd., Bd. IV, S. 278), Johannes Gerson (ebd., S. 117), Giovanni da Fontana (ebd., S. 172) und Bernard Basin (ebd., S. 492). Immer handelt es sich um mehr oder minder allgemein gehaltene Beschreibungen in magiekritischen Werken; Textkenntnis scheint nicht vorhanden gewesen zu sein. Nur Johannes Calderia kündigt, ähnlich wie Hartlieb am Ende von dessen Buch, in seinem um 1440 entstandenen Liber canonum astrologie an, dass er noch Weiteres über Hydromantie, Aerimantie, Pyromantie, Geomantie und Chiromantie schreiben wolle, hat dies aber nicht ausgeführt (ebd., Bd. IV, S. 165). Bezeichnenderweise schreibt auch Hugo von Santalla in seiner Geomantie, dass er danach auch noch die Hydromantie behandeln wolle, dass er aber keinerlei Bücher zur Aeromantie oder zur Pyromantie gefunden habe (ebd., Bd. II, S. 86).

33 Vgl. Lynn Thorndike: Alfodhol and Alamadel. Hitherto unnoted mediaeval books of magic in Florentine manuscripts. In: Speculum 2 (1927), S. 326-331; ders.: Alfodhol and Alamadel once more. In: Speculum 20 (1945), S. 88-91.

34 Vgl. Uwe Neddermeyer: Von der Handschrift zum gedruckten Buch. Schriftlichkeit und Leseinteresse im Mittelalter und in der frühen Neuzeit. Quantitative und qualitative Aspekte. 2 Bde. Wiesbaden 1998, Bd. 1, S. 217-307, bes. S. 305f. Neddermeyer geht davon aus, dass ab dem Jahr 1370 aus verschiedensten Gründen eine erhebliche Intensivierung der Manuskriptproduktion eingesetzt hat. Unter Ansatz einer erschlossenen Verlustquote von $93 \%$ geht er davon aus, dass in Mitteleuropa vom ausgehenden 14. bis zum Ende des 15. Jahrhunderts 2,5 Millionen Handschriften entstanden sind. Vgl. Neddermeyer: Von der Handschrift zum gedruckten Buch, S. 929. 
1277 ganz oben steht; erst danach folgt ein summarisches Verbot jener libros, rotulos seu quaternos nigromanticos aut continentes experimenta sortilegiorum, invocationes demonum, sive conjurationes in periculam animarum..$^{35}$

Die hier genannten nigromantischen Werke können nach dem im Mittelalter Albertus Magnus zugeschriebenen Speculum Astronomiae ${ }^{36}$ in drei Gruppen eingeteilt werden. Das Speculum geht von einer engen Nähe der Nigromantie, die es als scientia imaginum bezeichnet, ${ }^{37}$ zur Astrologie aus und kennt deshalb neben zwei verwerflichen Species der Nigromantie, die eindeutig nur mit Hilfe der Dämonen zu ihren Ergebnissen komme, eine licite dritte, welche imagines astronomicarum herstelle, deren Kraft allein von den figurae caelesti herrühre. ${ }^{38}$ Als herausragende Bücher dieser Species nennt das Speculum den Liber Thebit filii Chorat (Thabit ibn Qurra) und ein Opus imaginum Ptolemaei. ${ }^{39}$ Allerdings seien auch diese Bücher nicht zu dulden, wenn ihre imagines unter nigromantischen Bedingungen hergestellt würden. Bei den anderen beiden Species gehe es zum einen um die Herstellung von Talismanen, die Opferung und Invokation (der Dämonen) verlange, ${ }^{40}$ das Speculum nennt hier die Bücher von Toz dem Griechen, Balenus (Belenus) und Hermes, wobei dies die schlimmste Art der Idolatrie sei. ${ }^{41}$ Zum anderen gehe es um die Einschreibung von magischen Figuren (inscriptio characterum) bei gleichzeitiger Exorzierung gewisser Namen (per quaedam nomina exorcizandum); zu den Büchern dieser Species zählt das Speculum das Buch Almandal Salomonis und den Liber Raziel. ${ }^{42}$

Alle Bücher der Magie im Mittelalter, die handschriftlich überliefert sind und die sich nicht mit Geomantie oder Chiromantie befassen, gehören diesen drei Species der nigromantischen scientia imaginum an; wie nicht anders zu erwarten, stammen mit einer Ausnahme ${ }^{43}$ auch die von Hartlieb aufgeführten nigroman-

35 item librum Geomantie, qui sic incipit: Estimaverunt Indi, et sic terminatur: Ratiocinare ergo super eum, et invenies etc., item libros, rotulos seu quaternos nigromanticos aut continentes experimenta sortilegium, invocationes demonum, sive conjurationes in periculum animarum, seu in quibus de talibus et similibus fidei orthodoxe et bonis moribus evidenter adversantibus tractatur. Aufklärung im Mittelalter? Die Verurteilung von 1277. Das Dokument des Bischofs von Paris übersetzt und erklärt von Kurt Flasch. Mainz 1989, S. 90.

36 Paola Zambelli: The Speculum Astronomiae and its Enigma. Astrology, Theology and Science in Albertus Magnus and his Contemporaries. Dordrecht, Boston und London 1992 (mit einer Edition des Textes und einer engl. Übersetzung).

37 Zambelli: The Speculum Astronomiae (Anm. 36), S. 240.

38 Zambelli: The Speculum Astronomiae (Anm. 36), S. 246.

39 Zambelli: The Speculum Astronomiae (Anm. 36), S. 248.

40 Zambelli: The Speculum Astronomiae (Anm. 36), S. 240. Ein solches ,Handbuch eines Nigromanten' hat Richard Kieckhefer ediert und kommentiert: Forbidden Rites. A Necromancer's Manual of the Fifteenth Century. Stroud 1997.

41 Zambelli: The Speculum Astronomiae (Anm. 36), S. 240.

42 Zambelli: The Speculum Astronomiae (Anm. 36), S. 240.

43 Der von Hartlieb genannte Luipoldus de Austria hat kein nigromantisches Buch geschrieben, es handelt sich wohl um den um 1271 tätigen Leopold de Austria, der eine aus den ver- 
tischen Bücher aus diesen drei Species ${ }^{44}$ und sind zum Teil mit denen im Speculum astronomiae genannten identisch. Es wäre daher zu fragen, ob die durch das Speculum und durch Hartlieb zugewiesene Bedeutung der genannten Werke sich auch in einer entsprechend breiten Überlieferung widerspiegelt. Auch wenn Thorndike/Kibre nicht die gesamte handschriftliche Überlieferung verzeichnen, sondern sich meistens mit der Angabe eines oder zweier Textzeugen begnügen, fallen umso mehr diejenigen Texte auf, bei denen eine größere Anzahl von Handschriften aufgeführt wird. Ich nenne hier nur die Fälle mit mehr als fünf Textzeugen: Ptolemäus, De imaginibus (7 Handschriften); Thabit ibn Qurra, De imaginibus (8 Hss); Zahel, De imaginibus (6 Hss) und die ,Kyraniden' (6 Hss). Nach Ausweis der bei Thorndike/Kibre verzeichneten Überlieferung kann also gesagt werden, dass es die Werke der ersten, am wenigsten verwerflichen nigromantischen Species sind, also die Anleitungen zur Herstellung von imagines nach stellaren Einflüssen, die im Mittelalter am beliebtesten sind; dazu kommen als Einzelwerke unter den Geomantien noch die Texte von Gerhard von Cremona (10 Hss) und von Wilhelm von Moerbeke (7 Hss) sowie unter den Chiromantien diejenigen von Adelard von Bath (9 Hss), Ps.-Aristoteles (8 Hss) und Johannes von Sevilla (9 Hss). Es ist allerdings immer daran zu denken, dass dies nicht alle heute bekannten Textzeugen sind, dass also unter Umständen durch die Hinzuziehung der einschlägigen Forschung sowie durch weitere Handschriftenfunde sich das Bild verschieben könnte; auf der anderen Seite sollte gleichfalls auch

schiedensten arabischen Autoren zusammengestellte Compilatio de astrorum scientiae verfasst hat. Vgl. Carmody: Arabic Astronomical and Astrological Sciences (Anm. 24), S. 170, Nr. 38.

44 Die einzelnen Werke sind identifiziert bei Eisermann und Graf: Johannes Hartlieb (Anm. 2) und finden sich auch in der Liste im Anhang, wobei der Liber Raselis und das gesegent puch unter dem Namen $\rightarrow$ Salomons verzeichnet sind. Einige Ergänzungen zu Eisermann und Graf seien angeführt: Bei Arnoldus de noua uilla wird es sich um die Übersetzung des Liber de ligaturis physicis von $\rightarrow$ Costa ben Lucca handeln. Das Buch Schamphoras soll nach Eisermann und Graf: Johannes Hartlieb (Anm. 2), S. 151, entweder eine nicht erhaltene Ars notaria meinen oder ein Buch Semiphoras, das allerdings „nicht vor 1686 greifbar wird“, Eisermann und Graf: Johannes Hartlieb (Anm. 2), S. 151. Wahrscheinlicher bezieht sich Hartlieb hier auf das Buch Semmaforas des $\rightarrow$ Johannes von Barro, das man allerdings auch nur aus einer Erwähnung bei Jean Gerson in dessen Trilogium astrologiae theologizatae kennt. Demnach hatte Johannes von Barro, der Arzt und Astrologe am Hof der Herzöge von Burgund war, dieses Buch geschrieben, das aber zusammen mit ihm 1398 in Paris, wo ihm der Prozess wegen Hexerei gemacht woren war, verbrannt wurde. Vgl. dazu Jan Riepke Veenstra: Magic and Divination at the Courts of Burgundy and France. Text and Context of Laurens Pignon's Contre les devineurs (1411). Leiden, New York und Köln 1997, S. 68f., das Zitat von Jean Gerson mit der Nennung des Buchs als Semmaphoras S. 344, Anm. 4. Da auch die von Hartlieb genannte Jerarchia (,Hierarchie'), nach Eisermann und Graf, S. 145, nicht nachweisbar ist, was jetzt durch die Untersuchung der Überlieferung der magischen Texte bestätigt wird, die ebenfalls keinen Textzeugen bietet, und da weiterhin das von ihm genannte püch der hailigen drey küngen ebenfalls nicht verifizierbar ist, wäre einmal grundsätzlich zu fragen, ob Hartlieb die von ihm aufgeführten Werke überhaupt aus eigener Anschauung kannte oder ob er sich nicht hier einer Verbotsliste bediente, wie man sie aus anderen superstitionskritischen Werken (vgl. dazu Anm. 32) kennt. 
bedacht werden, dass im Vergleich mit der gesamten Handschriftenproduktion der Zeit, die auf mehr als 2,5 Millionen geschätzt wird, ${ }^{45}$ die Rezeption der artes magicae nur einen marginalen Bruchteil der gesamten Textüberlieferung ausmacht und in der Tat eine Angelegenheit von (geheimen?) Eliten ist. Dies zeigt sich im Übrigen auch daran, dass im 15. Jahrhundert bis auf wenige Ausnahmen keines dieser Werke in den Druck gelangt. ${ }^{46}$ Diese Fragen sollen nun genauer an Beispiel des Picatrix untersucht werden.

\section{2}

Bei dem Picatrix ${ }^{47}$ handelt es sich um die lateinische Übersetzung des arabischen Buchs Das Ziel der Weisen (Ghāyat al-ḥakīm) von Ps.-Al-Majrịṭ̂, das 1256 für König Alfons von Kastilien zuerst ins Spanische übertragen wurde; der Autorname Picatrix ist ein Missverständnis aus dem arabischen Namen Buqrāṭīs oder überhaupt nur fingiert. Das Werk ist in vier Bücher geteilt, wobei das erste eine Definition und Behandlung der Magie und der Talismane im Kontext von Kosmologie, Astronomie und Naturphilosophie gibt. Das zweite Buch beschäftigt sich mit den Sternbildern und den Planeten sowie ihren Eigenschaften und gibt Anleitungen, die stellaren Emanationen in Form von Talismanen einzufangen. Im dritten Buch wird dies weiter ausgeführt, ehe dann im vierten Buch zu den Verfahren der Anrufung der Planeten und ihrer Pneumata übergegangen wird.

Der Picatrix ist in 31 Handschriften überliefert, ${ }^{48}$ wobei allerdings der Großteil (elf Handschriften aus dem 16. und zehn aus dem 17. und 18. Jahrhundert) nicht aus dem Mittelalter stammt. Die Überlieferung setzt, wenn man von einem kleinen Exzerpt in einer Handschrift des 14. Jahrhunderts absieht, ${ }^{49}$ überhaupt erst im 15. Jahrhundert mit einer vollständigen Abschrift aus dem ersten Drittel des Jahrhunderts ein; ${ }^{50}$ der in der Chronologie nächste Textzeuge, der den Pica-

45 Vgl. oben Anm. 34.

46 Vgl. dazu Frank Fürbeth: Selektion und Transformation. Formen des Wissenstransfers von lateinischen zu deutschsprachigen Diskursen des Spätmittelalters. In: Translationes. Dekontextualisierung und Rekontextualisierung in vormoderner Literatur (Daphnis 40, 1-2). Hrsg. von Sabine Seelbach und Alexander Schwarz. Amsterdam, New York 2011, S. 6-38.

47 Picatrix. The Latin version of the Ghāyat al-hakīm. Hrsg. von David Pingree. London 1986. $\mathrm{Zu}$ einzelnen Aspekten des Werks und seiner Geschichte vgl. zuletzt: Images et Magie. Picatrix entre Orient et Occident. Hrsg. von Jean-Patrice Boudet, Anna Caiozzo und Nicolas Weill-Parot. Paris 2011.

48 Eine Auflistung der Handschriften mit Abdrucken der Exzerpte geben Pingree: Picatrix (Anm. 47), S. xvi-lxix, und Vittoria Perrone Compagni: Picatrix latinus. In: Medioevo 1 (1975), S. 237-337. Zu ergänzen sind: Krakau, BJ, 610 (Exzerpte); Krakau, BJ, 3411 (fragmentarisch, nur Illustrationen); Oxford, Bodl., 499 (Exzerpt). Von Pingree, S. xxiii, genannt, aber nicht eingesehen ist Weimar, Anna Amalia-Bibliothek, Oct 95.

49 Mailand, BiBl. Ambrosiana, M. 28. sup., f. 92rv. Vgl. Pingree: Picatrix (Anm. 47), S. li-liii („Excerpt VI“), A. d'Agostino, Frammento ambrosiano del Picatrix. In: Studi medievali, 3. Ser., 20 (1979), S. 255-260.

50 Weimar, Anna Amalia-Bibliothek, Oct 95 (1401/33). Die Angabe von Jean-Patrice Boudet, Anna Caiozzo und Nicolas Weill-Parot: Picatrix. Au carrefour des savoirs et pratiques ma- 
trix vollständig enthält, stammt aus dem Jahr $1466 .{ }^{51}$ Ginge man also nur von diesen erhaltenen Handschriften aus, hat Hartlieb mit großer Wahrscheinlichkeit nie ein Exemplar des Buches zu Gesicht bekommen. Wie auch immer: Auffällig ist auch hier, dass die integrale Überlieferung überhaupt erst im 15. Jahrhundert beginnt. Dazu kommen noch weitere Punkte: Nur in drei der zehn Handschriften des 15. Jahrhunderts ist der Picatrix vollständig überliefert, ${ }^{52}$ in einer bricht die Abschrift im zweiten Buch ab, ${ }^{53}$ in weiteren vier finden sich nur Exzerpte, ${ }^{54}$ in einer nur Illustrationen, ${ }^{55}$ und in einer gar nur kurze Zitate, in denen der Picatrix als sentenzenhafte Autorität der Magie dient. ${ }^{56}$ Die Textzeugen der vollständigen Abschriften überliefern in zwei Fällen den Picatrix monographisch, ${ }^{57}$ in dem anderen Fall steht er zusammen mit anderen Werken; letzteres gilt selbstverständlich auch für die Fragmente und Exzerpte sowie für die Kurzzitate.

Von besonderem Interesse ist nun einerseits die Frage, welche Textpartien aus dem Picatrix ausgezogen und abgeschrieben werden, und andererseits, in welchen Werkkontexten die Exzerpte wie auch die nicht-monographische Abschrift stehen. Alle Sammelhandschriften haben einen astronomisch-astrologischen Textkern; neben Tafeln zur Bewegung der Planeten und Sterne sowie zu ihren Konjunktionen ${ }^{58}$ stehen kanonische Texte wie Albubathers De nativitatibus, ${ }^{59}$ Ps.-Alkindis De planetis, ${ }^{60}$ Albumasars Electiones planetarum, ${ }^{61}$ Messahalahs De revolutione annorum mundi ${ }^{62}$ oder die von Hartlieb der Nigromantie zugerechnete Compilatio de astrorum scientia des Leopold von Österreich. ${ }^{63}$ Drei Hand-

giques. In dies.: Images et Magie (Anm. 47), S. 13-24, hier S. 13, Anm. 4 („Le plus ancien codex latin daté est le manuscrit 793 de la Bibliothèque Jagellone ${ }^{\prime \prime}$ ) ist entsprechend zu korrigieren.

51 Wien, ÖNB, 3317 (1466)

52 Weimar, Anna Amalia-Bibliothek, Oct 95; Wien, ÖNB, 3317; Paris, BN, lat. 10272 (1494).

53 Krakau, BJ, 793 (1458/59).

54 Florenz, BiBl. Laurenziana, 89 sup., Cod. 38 (15. Jh.); Krakau, BJ, 610 (1440/77); London, Wellcome Inst., 128 (1487); Rom, Vat., Pal. lat. 1354 (1463/64).

55 Krakau, BJ, 3411. Vgl. dazu Grażyna Rosińska: Scientific Writings and Astronomical Tabels in Cracow. A Census of Manuscript Sources (XIVth-XVIth Centuries). Wrocław [u.a.] 1984, S. 444, Nr. 2315.

56 Oxford, Bodl., 499 (15. Jh.).

57 Wien, ÖNB, 3317; Paris, BN, Lat. 10272.

58 Weimar, Anna Amalia-Bibliothek, Oct 95, f. 183v-185r (Kurzbeschreibungen von 28 Sternbildern); Krakau, BJ, 610, f. 1r-289v, 317r-346v, 350v-357v (diverse Tabulae).

59 Krakau, BJ, 793, f. 1r-33v. Vgl. Carmody: Arabic Astronomical and Astrological Sciences (Anm. 24), S. 136f.

60 Krakau, BJ, 793, f. 47v-48v. Vgl. Carmody: Arabic Astronomical and Astrological Sciences (Anm. 24), S. 81f.

61 Krakau, BJ, 793, f. 53v-59r. Vgl. Carmody: Arabic Astronomical and Astrological Sciences (Anm. 24), S. 96.

62 Krakau, BJ, 793, f. 157r-158r. Vgl. Carmody: Arabic Astronomical and Astrological Sciences (Anm. 24), S. 25f.

63 Krakau, BJ, 793, f. 153r (fragm.); Rom, Vat. Pal. lat. 1354, f. 169ra-233rb. Vgl. Carmody: Arabic Astronomical and Astrological Sciences (Anm. 24), S. 170f. 
schriften enthalten fast ausschließlich solche astronomisch-astrologischen Wer$\mathrm{ke}^{64}$ in zwei anderen Handschriften lagern sich an diesen Kern Texte unterschiedlicher Fachzugehörigkeit an. Dies sind einmal medizinische Werke wie die Urindiagnostik von Wilhelm Anglicus, der Liber de medicorum astrologia Wilhelms von Moerbeke oder mehrere Texte zur Veränderung der Luft und zur Verursachung der Pest durch die intemperentia planetarum, ${ }^{65}$ dazu aber auch mehrere geomantische Anleitungen ${ }^{66}$ sowie eine Reihe von astrologischnigromantischen Texten wie Thabits ibn Qurra De imaginibus, Ps.-Albertus Magnus' Secretum de sigillo Leonis sowie Ps.-Ptolemäus' De imaginibus und De lapidibus pretiosis et sigillis. ${ }^{67}$ Die zweite Handschrift enthält Anleitungen zur Visierkunst, Euklids Elemente und Ausführungen über den Aderlass, ${ }^{68}$ aber ebenfalls auch Ps.-Ptolemäus' De imaginibus. ${ }^{69}$ Nur eine Handschrift stellt sich als rein magisch-nigromantische Sammlung ohne Texte mit anderer Thematik dar; sie enthält einen anonymen Tractatus de imaginibus, Ps.-Ptolemaeus' De imaginibus, eine Ars invocandi spiritus, mehrere Texte zu den Nomina et virtutes spirituum, die Clavicula Salomonis, eine Scientia Magicalis, einen anonymen Tractatus de coniurationibus und dergleichen mehr. ${ }^{70}$

Die Exzerpte aus dem Picatrix entsprechen nun genau der so zu erschließenden Charakteristik der einzelnen Handschriften in ihrer Zusammensetzung mit anderen Textgattungen. In den beiden rein astronomischen Handschriften finden sich Auszüge aus Buch I, 4 zu den Mondstationen ${ }^{71}$ und aus Buch II, 12 zu den Figuren der Sternzeichen, ${ }^{72}$ in der astronomisch-mathematisch-medizinischen Sammelhandschrift kommt zu den 28 Mondstationen noch eine Anleitung, wie man einen Talisman zur Erzeugung und Erhaltung der Liebe machen soll (was, ohne diese Auswahl überstrapazieren zu wollen, durchaus auch eine medizinische Indikation haben könnte), ${ }^{73}$ und in der magisch-nigromantischen Handschrift findet sich außer den ebenfalls abgeschriebenen Mondstationen noch ein Auszug aus Buch III, 6, wo es um die spiritus der Planeten geht. ${ }^{74}$ Es

64 Weimar, Anna Amalia-Bibliothek, Oct 95; Krakau, BJ, 610; London, Wellcome Inst., 128.

65 Krakau, BJ, 793, f. 44r-46r, 107v-109v, 153r-155r.

66 Krakau, BJ, 793, f. 63r-85v (vier geomantische Texte), 87v-103v (Bernhard Silvestris, Experimentarius).

67 Krakau, BJ, 793, f. 61r-63r, 63v, 139rv, 139v-140v, 140v-143v.

68 Rom, Vat. Pal. lat. 1354, f. 2va-30v (De arte visorandi cubica), 98vb-99va (Euklid, Elementa, Auszüge), 121ra-126rb (De phlebotomia).

69 Rom, Vat. Pal. lat. 1354, f. 58v-59v.

70 Florenz, BiBl. Laurenziana, 89 sup., Cod. 38.

71 Krakau, BJ, 610, 312v-316r.

72 London, Wellcome Inst., 128, f. 14-17. Abgedruckt als Exzerpt IX bei Pingree: Picatrix (Anm. 47), S. lxii-lxvi.

73 Rom, Vat., Pal. lat. 1354, f. 243va-246rb. Abgedruckt als Exzerpt V bei Pingree: Picatrix (Anm. 47), S. xlvi-li.

74 Florenz, BiBl. Laurenziana, 89 sup., Cod. 38, f. 18-23 u. 27-30. Abgedruckt als Exzerpt IV bei Pingree: Picatrix (Anm. 47), S. xxxviii-xlvi. 
wird deutlich, dass der Picatrix, gerade weil er in seiner besonderen eklektischen Art verschiedenste Quellen philosophischer, naturkundlicher, astronomischastrologischer und magischer Art ausschreibt, für die unterschiedlichsten Rezeptionsperspektiven offen ist, die sich fallweise nur der interessierenden Partien bedienen oder vielleicht auch, wenn sie den gesamten Text abschreiben, nur die interessierenden Partien lesen. Insofern ist die Warnung Hartliebs vor dem $\mathrm{Pi}$ catrix zwar berechtigt, denn mit seinen Anleitungen für die Herstellung von Talismanen und zur Invokation der Planetengeister fällt das Buch genau unter die beiden im Speculum astronomiae verbotenen Species der Nigromantie; der handschriftliche Kontext wie auch die Exzerpierungen, deren Schwerpunkt auf der Liste mit den 28 Mondstationen liegt, legen jedoch die Vermutung nahe, dass der Picatrix hier eher als Vertreter der dritten, erlaubten, weil astrologischen Species der Nigromantie gelesen wurde. Es ist nun abschließend zu fragen, ob solch eine ,naturwissenschaftliche' Rezeptionsperspektive auch für die anderen nigromantischen Texte vermutet werden kann, wozu nun in einem dritten Teil auf deren Vorkommen in den mittelalterlichen Bibliotheken eingegangen werden soll.

\section{3}

Ich beschränke mich dazu in Auswahl auf die Editionen in den Mittelalterlichen Bibliothekskatalogen Deutschlands, der Schweiz und Österreichs; ${ }^{75}$ da dieses Editionswerk auf die Zeit bis etwa 1500 wie auch auf den südlichen Teil des deutschsprachigen Raum beschränkt ist sowie die Quellen des norddeutschen Raums nicht berücksichtigt sind, sollen für diesen ersten Überblick die Büchersammlungen außerhalb dieser zeitlichen und geographischen Grenzen außer Betracht bleiben. ${ }^{76}$ In den MBK sind Kataloge, Inventare, Schenkungen und ähnliches zu 295 Buchsammlungen ediert, unter deren Besitzern sich 88 Klöster, 25 Pfarrkirchen, 14 Domkapitel, drei Universitäten, drei Rats- und sechs Spitalbibliotheken sowie 97 Kleriker, 15 Gelehrte und 40 weitere Privatpersonen befinden; vier Sammlungen sind hinsichtlich des Besitzers nicht bestimmbar. Wie nicht anders zu erwarten, dominieren also insgesamt die kirchlichen, insbesondere klösterlichen Sammlungen; zählt man den Buchbesitz der Kleriker dazu, der in den meisten Fällen durch Schenkung oder testamentarische Verfügung in die Biblio-

75 Mittelalterliche Bibliothekskataloge Deutschlands und der Schweiz. Bearb. von Paul Lehmann u.a. Bd. Iff. München 1918ff. (MBKD); Mittelalterliche Bibliothekskataloge Österreichs. Bearb. von Theodor Gottlieb u a. Bd. Iff. Wien 1915ff. (MBKÖ).

76 Zum Editions- und Forschungstand vgl. Ladislaus Buzas: Deutsche Bibliotheksgeschichte des Mittelalters. Wiesbaden 1975; ders.: Deutsche Bibliotheksgeschichte der Neuzeit (15001800). Wiesbaden 1976; Frank Fürbeth: Privatbibliotheken des Spätmittelalters und der frühen Neuzeit. Forschungsstand und -perspektiven. In: Zur Erforschung mittelalterlicher Bibliotheken. Chancen - Entwicklungen - Perspektiven. Hrsg. von Michael Embach und Andrea Rapp. Frankfurt a.M. 2009, S. 185-208. Insgesamt zähle ich etwa 1200 Bibliotheksverzeichnisse bis zum Jahr 1600 im deutschen Raum. 
thek der Mutterinstitution gelangt, kommt man so auf 224 klerikale Sammlungen, denen 61 weltliche Sammlungen gegenüberstehen. Wie viele Bücher insgesamt in diesen Bibliotheken vorhanden waren, kann nicht gesagt werden, die Größe der einzelnen Sammlungen variiert beträchtlich. Hatte etwa das Kloster St. Gallen schon im 9. Jahrhundert einen Bestand von 428 Büchern, ${ }^{77}$ so besaß das Kloster Echenbrunn im Jahr 1487 nur 30 Bände. ${ }^{78}$ Auch bei den privaten Besitzern ist die jeweilige Büchersammlung von sehr unterschiedlicher Größe und reicht im 15. Jahrhundert von meist wenigen Exemplaren ${ }^{79}$ bis zu über 250 Büchern. ${ }^{80}$ Eine Durchschnittszahl ist also kaum zu schätzen, aber selbst wenn man den Besitz der klerikalen Sammlungen vorsichtig auf nicht mehr als 100 Bücher und den der Privatbesitzer auf nicht mehr als zehn Bücher ansetzen würde, käme man schon auf eine Gesamtzahl von 12700 und 1520, zusammen also 14220 Bücher. Da in jedem Buch, sofern es sich um eine Handschrift handelt, üblicherweise mehrere Texte enthalten waren, ist die Zahl der Bücher noch mit einem hier nicht zu bestimmenden Faktor zu vervielfachen.

Dies sei nur deshalb angeführt, um die Gesamtzahl der in diesen 295 Sammlungen vorhandenen magischen Texte einordnen zu können. Diese beläuft sich auf insgesamt 98 Werke, ${ }^{81}$ die in 16 Sammlungen zu finden sind. ${ }^{82}$ Machen die

77 MBKD I, S. 16-20.

78 Buzas: Bibliotheksgeschichte des Mittelalters (Anm. 76), S. 35.

79 Vgl. etwa Frank Fürbeth: Literatur in Frankfurter Privatbibliotheken des 15. und 16. Jahrhunderts. In: Frankfurt im Schnittpunkt der Diskurse. Strategien und Institutionen literarischer Kommunikation im späten Mittelalter und in der frühen Neuzeit. Hrsg. von Robert Seidel und Regina Toepfer. Frankfurt a.M. 2010, S. 54-80.

80 So etwa die Bibliothek des Südtiroler Adligen Anton von Annenberg; vgl. Frank Fürbeth: Die spätmittelalterliche Adelsbibliothek des Anton von Annenberg: ihr Signaturensystem als Rekonstruktionshilfe. In: Sources for the History of Medieval Books and Libraries. Hrsg. von Jost M. M. Hermans, M. Hoogvliet und Rita Schlusemann. Groningen 2000, S. 61-78.

81 Ich habe auch die Nennungen der Introductio scientiae astrorum des Leopold von Österreich aufgenommen, da Hartlieb sie unter den Büchern der Nigromantie verzeichnet.

82 Bücherverzeichnis des Gallus Kemli, St. Gallen, um 1470 (MBKD I, S. 121-135); Verzeichnis des Schatzes des Klosters Pfäfers, 1155 (MBKD I, S. 485f.); Katalog des Amplonius Rating, Erfurt, 1410-1412 (MBKD II, S. 7-96), Verzeichnis der Wohltäter des Collegium Maius, Erfurt, 1407 (MBKD II, S. 109-116); Standortregister des Collegium Universitatis, Erfurt, um 1497 (MBKD II, S. 135-179); Bibliothekskatalog der Karthause Salvatorberg vom Ende des 15. Jh.s, Erfurt (MBKD II, S. 239-593); Benediktinermönch Veit Bild, St. Ulrich und Afra, Augsburg, Bücherwünsche, 1514 (MBKD III, S. 114f.); Bücherschenkung des Pfarrers Gerungus von Reimlingen, Anfang des 14. Jh.s, an das Cistercienserkloster Kaisheim (MBKD III, S. 135); Katalog des Augustinerchorherrnstifts Rebdorf, 15./16. Jh. (MBKD III, S. 265316); Bibliothekskatalog des Benediktinerklosters St. Ägidien, Nürnberg, Ende d. 15. Jh.s (MBKD III, S. 432-569); Kirchenbibliothek im Pfarrhof von St. Sebald, Nürnberg, Ende d. 15. Jh.s (MBKD III, S. 685-690); Sigismund Meisterlins Katalog der Kirchenbibliothek von St. Sebald, Nürnberg, 1486-1502 (MBKD III, S. 693-729); Katalog der Bibliothek Hartmann Schedels, Nürnberg, 1498/1507 (MBKD III, S. 807-839); Katalog des Benediktinerklosters St. Emmeran, Regensburg, 1500/01 (MBKD IV, S. 188-388); Katalog des Benediktinerklosters Reichenbach, 1585 (MBKD IV, S. 485, Anm. 13); Katalog des Zisterzienserklosters Walden- 
magischen Texte so weniger als ein Prozent des Gesamtbestandes aus, so konzentrieren sie sich in kaum einem Zwanzigstel der Sammlungen. Dieses Bild ist nun noch weiter zu differenzieren, indem gefragt wird, in welchem Sammlungstyp diese Texte vor allem zu finden sind. Die Schwerpunkte der Überlieferung liegen bei privaten Bibliotheken von Gelehrten und Klerikern (wobei auch bei den Klerikern des 15. Jahrhunderts fallweise ein gelehrter Hintergrund aufgrund eines Studiums angenommen werden kann), während in Rats-, Dom- und Spitalbibliotheken überhaupt kein magischer Text $\mathrm{zu}$ finden ist. Allerdings gibt es bei den Klerikern und den Gelehrten mit Gallus Kemli, Amplonius Rating und Hartmann Schedel drei aufgrund der Größe ihres Buchbesitzes untypische Vertreter dieser Gruppe, die zwar die Statistik verfälschen, gleichwohl aber signifikant sind; darauf wird noch zurückzukommen sein. Bereinigt um diese Ausreißer ergäbe sich folgendes Mittel: In 13 Sammlungen sind 32 Texte der Magie vorhanden, im Durchschnitt also etwas mehr als zwei Texte, wobei auch solche Texte mitgezählt wurden, die aufgrund der Angaben in den Inventaren sicher oder wahrscheinlich eher dem Bereich der Magiekritik zuzurechnen sind.

Dieses Bild kann und muss nun noch weiter aufgeschlüsselt werden, indem gefragt wird, um welche Texte es sich dabei jeweils handelt. Ich beginne mit den Klöstern: In der Kartause Salvatorberg findet sich die Verteidigung der Magie des Apuleius, allerdings in einer Apuleius-Handschrift mit mehreren seiner Werke, außerdem ein Werk De cognicione daemonum und eine Ars notoria; ${ }^{83}$ das Kloster St. Mang in Füssen verleiht 1515 die Chiromantie des Ambrosius Alantsee an Veit Bild, Mönch in St. Ulrich und Afra in Augsburg; ${ }^{84}$ der Katalog des Augustinerchorherrenstifts Rebdorf des ausgehenden 15. Jahrhunderts verzeichnet einen Tractatus de cyromantia und einen Tractatus De incantatricibus, wlgariter unholden; ${ }^{85}$ im Kloster St. Ägidien in Nürnberg findet sich ebenfalls am Ende des 15. Jahrhunderts eine Handschrift mit Experimenta secretissima vera et a multis approbata; ${ }^{86}$ im Katalog von St. Emmeran in Regensburg aus dem Jahr 1500 stehen der Tractatus de ymaginibus Thebit Benchorat, die Introductoria astronomie leopoldi de Austria, De celesti ierarchia des Dionisius Areopagita, außerdem ein Text De sortilegiis und eine Liste De nominibus, id est magis, incantatoribus, auruspicibus et ceteris talibus. ${ }^{87}$ Die ,Einführung' des Leopold von Österreich findet sich

bach, 1511/12 (MBKD IV, S. 523-563); Bücherkäufe des Prämonstratenserklosters Windberg, 1478-1497 (MBKD IV, S. 583-592); Schenkung des Johannes de Gmunden an die artistische Fakultät der Universität Wien, 1443 (MBKÖ I, S. 475-477).

83 MBKD II, S. 514, 19; 501,20; 244, 26. Bei den Artes notoriae kann es sich allerdings auch immer um Briefsteller und dergleichen handeln; wo aufgrund der Inventarumgebung eher davon ausgegangen werden kann, habe ich diese Texte nicht aufgenommen.

84 MBKD III, S. $114 f$.

85 MBKD III, S. 274, 30; 291, 5. Das Kloster besitzt außerdem den Malleus maleficarum (293, 34), einen Tractatus contra demonum invocatores $(276,15)$ und Reuchlins Libri de arte cabalistica $(289,16)$.

86 MBKD III, S. 496, 25; 524, 35.

87 MBKD IV, S. 258, 2858; 309, 4896; 257, 2832; 282, 3882; 261, 3006. 
außerdem im Kloster Reichenbach im Jahr 1533,88 die Kyraniden im Zisterzienserkloster Walderbach im Jahr 1511/12 ${ }^{89}$ und schließlich zwei Traktate De sortibus domini Troili und De incantacionibus im Prämonstratenserkloster Windberg. ${ }^{90}$

Ich gehe über zum Privatbesitz der Kleriker und Gelehrten. Der Pfarrer Gerungus von Reimlingen schenkt anfangs des 14. Jahrhunderts dem Zisterzienserkloster Kaisheim einen Liber Sigillorum. ${ }^{91}$ Allerdings lassen das Schenkungsjahr und der Adressat es eher unwahrscheinlich erscheinen, dass es sich um ein magisches Werk handelt, zumal es in einer Reihe mit grammatischen Werken und antiker Literatur erscheint. Der berühmte Astronom Johannes von Gmunden überlässt der artistischen Fakultät der Universität Wien ein Exemplar der ,Einführung' des Leopold von Österreich;92 ein anderes Exemplar dieses Werkes wird von Magister Geraldus aus Göttingen dem Collegium universitatis in Erfurt geschenkt. ${ }^{93}$ Dieses besitzt außerdem noch einen Text De sigillis gemmarum, bei dem es sich um eine Anleitung zur Herstellung von Talismanen handeln könnte; es ist allerdings unter die Bücher der praktischen Medizin eingereiht. ${ }^{94}$ Bis hierhin könnte zusammengefasst gesagt werden, dass ein Schwerpunkt von Werken über Dämonenbeschwörung und Hexerei gebildet wird; allerdings ist hier nur aufgrund des jeweiligen Katalogeintrags nicht immer zu entscheiden, ob es sich um magische Anleitungen oder um Werke der kirchlichen Superstitionenkritik handelt. Den zweiten Schwerpunkt machen Texte der astrologischen Nigromantie aus, wobei es wiederum genau diejenigen Werke sind, vor denen Hartlieb zur gleichen Zeit warnt: die Kyraniden, Thabits De imaginibus, Anleitungen zur Herstellung von Talismanen, die Einführung in die Astrologie des Leopold von Österreich und Werke zur Chiromantie. Wie diese Texte in die Klöster kommen, kann nur vermutet werden, anzunehmen ist, dass sie von Mönchen von der Universität in das Kloster mitgebracht worden sind. Ich werde dies an einem Beispiel zum Schluss noch genauer zeigen.

Davor komme ich zu den drei statistischen Ausreißern. Es handelt sich dabei um die prominenten und auch in ihrer Zeit außergewöhnlichen Büchersammler Gallus Kemli, Amplonius Rating de Bercka und Hartmann Schedel. Kemli, der ein unstetes Wanderleben geführt hatte, ehe er 1470 zurück in das Kloster St. Gallen kam, ${ }^{95}$ hatte sich mit eigener Hand eine kleine Privatbibliothek zusam-

\footnotetext{
88 MBKD IV, S. 485, Anm. 13.

89 MBKD IV, S. 538, 594.

90 MBKD IV, S. 590, 331; 586, 189.

91 MBKD III, S. 133, 14.

92 MBKÖ I, S. 476, 34.

93 MBKD II, S. 115, 12.

94 MBKD II, S. 156, 9.

95 Vgl. zu ihm Arne Holtorf: Art. Kemli, Gallus. In: 2VL 4 (1983), Sp. 1107-1112. Zu ergänzen ist Josef Nadler: Wittenweiler? In: Euphorion 27 (1926), S. 172-184, wo Nadler die (von der Forschung nicht weiter verfolgte) These vertritt, dass Kemli statt Wittenwiler Autor des Ring gewesen sei.
} 
mengeschrieben, deren Handschriften dadurch gekennzeichnet sind, dass sie jeweils Texte höchst unterschiedlicher Thematik enthalten. So findet sich in einem Codex eine Abschrift der Legenda aurea (Historia lombardica) zusammen mit einem Exorcismus et coniurationes super demoniacos; ${ }^{96}$ eine andere Handschrift, die er als Diversarius multarum materiarum benennt, enthält neben Kalendarien, geometrischen, medizinischen, logischen und theologischen Schriften auch eine Ars Cyromancie und einen Liber sortis vel sorcium. ${ }^{97}$ Die hohe Zahl von magischen Texten in seiner Sammlung kommt allerdings dadurch zustande, dass in einem weiteren libello multifario allein 33 Benediktionen zu finden sind, die unter anderem zur Austreibung von Würmern aus dem Wein, gegen das Fieber, gegen kranke Augen oder den Zahnschmerz dienen. Hier wäre grundsätzlich zu fragen, ob diese Segnungen in der Auffassung der Zeit überhaupt als magisch gelten würden; bei einer Benediccio ad omnia que volueris wäre dies allerdings wohl zu vermuten. ${ }^{98}$

Die Sammlungen von Amplonius Rating de Bercka und Hartmann Schedel sind zur Genüge bekannt, ${ }^{99}$ sodass hier nur kurz auf die jeweiligen Sachordnungen eingegangen werden soll. Das Inventar, das Amplonius Rating anlässlich seiner Bücherstiftung an das Collegium universitatis 1410 erstellt hatte, ist von ihm nach der Abfolge und dem Studienprogramm der universitären Fakultäten geordnet, wobei das alte Quadrivium der Artes liberales durch die hochmittelalterliche Wissenssystematisierung der Philosophie in philosophia practica (hier: philosophia moralis) und philosophia theorica (hier: Mathematik, Philosophia naturalis und Metaphysik) ersetzt ist. ${ }^{100}$ Bei dem fast hundert Jahre jüngeren Inventar Hartmann Schedels ist diese Ordnung ebenfalls noch zu erkennen, ${ }^{101}$ wobei er

96 MBKD I, S. 122, 20.

97 MBKD I, S. 125, 40; 126, 37.

98 MBKD I, 130, 33-132, 29.

99 Zu Schedel vgl. Béatrice Hernad und Franz-Josef Worstbrock: Art. Schedel, Hartmann. In: 2VL 8 (1992), Sp. 609-621; zu Amplonius Bercka von Rating vgl. die Beiträge in: Die Bibliotheca Amploniana. Ihre Bedeutung im Spannungsfeld von Aristotelismus, Nominalismus und Humanismus. Hrsg. von Andreas Speer. Berlin, New York 1995; Der Schatz des Amplonius. Die große Bibliothek des Mittelalters in Erfurt. Begleitbuch zur gleichnamigen Ausstellung der Stadt- und Regionalbibliothek Erfurt und des Angermuseums Erfurt vom 2. September bis 4. November 2001. Hrsg. von Kathrin Paasch und Eckehart Döbler. Erfurt 2001.

100 Vgl. dazu Frank Fürbeth: Die medizinischen Werke in der Bibliothek des Amplonius Rating de Bercka: von der Studienbibliothek zur bibliophilen Sammlung. In: Die Bibliothek des Mittelalters als dynamischer Prozeß. Hrsg. von Michael Embach, Claudine Moulin und Andrea Rapp. Wiesbaden 2012, S. 177-190, und allgemein zu den Sachordnungen ders.: Sachordnungen mittelalterlicher Bibliotheken als Rekonstruktionshilfe. In: Rekonstruktion und Erschließung mittelalterlicher Bibliotheken. Neue Formen der Handschriftenpräsentation. Hrsg. von Andrea Rapp und Michael Embach. Berlin 2008, S. 87-103.

101 Vgl. dazu Franz-Josef Worstbrock: Hartmann Schedels Index librorum. Wissenschaftssystem und Humanismus um 1500. In: Studien zum 15. Jahrhundert. Festschrift für Erich Meuthen. Hrsg. von Johannes Helmrath und Heribert Müller. München 1994, S. 697-715. 
sich von Amplonius dadurch unterscheidet, dass er Astronomie und Astrologie nicht der philosophia naturalis zuordnet, wie es üblich wäre, sondern mit der Mathematik zusammenfasst, und dass er ein neues Fach einfügt, nämlich das der ars humanitatis. Ein Nachtrag folgt ebenfalls, wenn auch mit reduzierter Fachanzahl, dieser Ordnung. $\mathrm{Zu}$ fragen ist nun, welche Texte der Magie in welchen Fächern und mit welchem handschriftlichen Kontext zu finden sind. Ich beginne chronologisch mit Amplonius Rating.

Unter allen Sammlungen finden sich hier in insgesamt 26 Handschriften die meisten einschlägigen Texte. 24 Handschriften sind in der Rubrik Mathematica inventarisiert, nicht, wie man nach den Wissenssystematisierungen in der Nachfolge des Dominicus Gundissalinus erwarten würde, in der Philosophia naturalis. Dies könnte ein Reflex darauf sein, dass bei Hugo von St. Viktor und den auf ihn aufbauenden Magiesystematiken zwischen mantica und mathematica unterschieden wird; letztere umfasst die Vorhersagen aus natürlichen Zeichen. Wahrscheinlicher aber ist, dass es hier nach Auffassung der Zeitgenossen um Praktiken geht, die mit naturwissenschaftlich-mathematischen Verfahren aus der Stellung der Sterne schließen und handeln. Dafür spricht, dass im Großteil der Handschriften die magischen Texte wie schon bei dem Großteil der Textzeugen des Picatrix mit astrologisch-iudicialen Texten zusammen stehen, bei diesen Handschriften etwa mit dem Introductorius des Albumasar in der Übersetzung des Johannes von Sevilla oder auch mit dessen Ptolemaeus-Übertragung. Auf der anderen Seite unterscheidet aber Amplonius wieder zwischen solchen astrologisch-iudicialen Texten einerseits und Texten im engeren nigromantischen Sinne andererseits, von denen er eine Handschrift ausschließlich mit diesen Werken besitzt. ${ }^{102}$ Da gerade diese Handschrift nicht erhalten ist, kann auch nicht gesagt werden, was sich im Einzelnen hinter den jeweiligen tractatus in nigromancia verbirgt; aus den identifizierbaren Texten ist aber zu schließen, dass es insgesamt um Dämonenbeschwörung und um die Herstellung von Talismanen und Siegeln geht. Als solche fasst er die Texte insgesamt als volumen nigromanticum zusammen. Noch deutlicher ist seine Haltung bei einer Abschrift der Ars notoria Salomonis; hier merkt er ausdrücklich an, dass der Text nicht den Ungelehrten gezeigt werden darf.

Nimmt man noch die Abschrift einer weiteren ars notoria hinzu, die wohl wegen ihrer Textumgebung in die Naturphilosophie eingeordnet ist, ${ }^{103}$ so ergibt sich die Gesamtzahl von 25 Handschriften magisch-nigromantischen oder mantischen Inhalts. ${ }^{104}$ Darin enthalten sind 51 Werke der Nigromantie und der astrologisch-iudicialen Vorhersage: fünf artes notoriae, zum Teil cum figuris, ${ }^{105}$ sieben

102 MBKD II, S. 29, 17-24.

103 MBKD II, S. 40, 18.

104 MBKD II, S. 21-31, Hss.nrr. 8, 9, 11, 12, 13,14, 15, 22, 23, 29, 35, 38, 42, 47, 49, 50, 53, 54, 59, $64,66,67,69,72,73$. Dazu kommt noch eine Handschrift innerhalb der Theologie mit errores Alkindi magicae artis (ebd., S. 80, 43).

105 MBKD II, S. 21, 28; 22, 15; 22, 35; 28, 31; 40, 18. 
Traktate de imaginibus, darunter einmal derjenige des Hermes und dreimal der von Thabit ibn Qurra, ${ }^{106}$ eine Anleitung zur Verfertigung von magischen Siegeln, ${ }^{107}$ zwei Exemplare der Einführung in die Astrologie Leopolds von Österreich, ${ }^{108}$ vor allem aber 17 Geomantien, ${ }^{109}$ vier Chiromantien ${ }^{110}$ und, immerhin, eine Pyromantie. ${ }^{111}$ Damit liefert die Bibliothek des Amplonius einen recht getreuen Spiegel der gesamten Überlieferung nigromantisch-mantischer Werke im Mittelalter.

Das gleiche Bild, wenn auch in kleinerem Maßstab, zeigt sich ebenfalls bei Hartmann Schedel. Auch er ordnet die einschlägigen Texte in die Rubrik Mathematica, die er allerdings als Libri astronomie, astrologie et mathematici ${ }^{112}$ bzw. als Libri naturales et mathematici ${ }^{113}$ explizit mit den astronomischen und astrologischen Büchern zusammenfasst. Auch bei ihm stehen sie in fast identischen handschriftlichen Zusammenstellungen, so etwa mit dem astrologischen Werk des Messahalah. ${ }^{114}$ Insgesamt finden sich bei ihm allerdings mit 13 Texten ${ }^{115}$ weniger nigromantisch-mantische Werke als bei Amplonius, wobei es sich aber im Kern um dieselben Texte handelt. Schedel besitzt ebenfalls die Einführung in die Astrologie des Leopold von Österreich und die Clavicula Salomonis, und auch bei ihm überwiegen mit einer Chiromantie und sechs Geomantien diese mantischen Texte, wobei bei letzteren für die jeweilige Gebrauchsfunktion aufschlussreich ist, dass Schedel zwischen einer sciencia geomantiae ${ }^{116}$ und einer practica geomantiae $^{117}$ unterscheidet. Im Übrigen scheint Schedel von dem naturwissenschaftlichen Charakter der jeweiligen Verfahren überzeugt zu sein, was sich nicht nur daran zeigt, dass er sie unter die libri naturales rechnet, sondern dass er gleichzeitig auch Ulrich Molitoris' De lamiis et phitonicis mulieribus und den Mal-

106 MBKD II, S. 21, 38; 21, 41 (Hermes); 21, 42; 23, 42; 26, 14 (Thabit); 27, 30 (Thabit); 30, 36 (Thabit).

107 MBKD II, S. 22, 20.

108 MBKD II, S. 21, 28; 23, 22

109 MBKD II, S. 21, 28; 22, 15; 22, 15; 23, 17-18 (fünf Geomantien); 26, 35; 28, 19 (Wilhelm von Moerbeke); 28, 20; 28, 30 (Wilhelm von Moerbeke); 30, 16 (Abdallah); 30, 27 (Gerhard von Cremona); 30, 40 (zwei Geomantien); 31, 12 (Basilegus); 31, 18.

110 MBKD II, S. 22, 12; 25, 2; 31, 17; 31, 22.

111 MBKD II, S. 31, 18.

112 MBKD IV, S. 808, 14.

113 MBKD IV, S. 831, 26.

114 MBKD IV, S. 832, 1-3 (Liber mathematicus, in quo liber iudiciorum Messahala, methodus archani sublimis Die et certum iudicium secundum scienciam geomantie, puncta astrologorum de arte sigillandi).

115 MBKD IV, S. 808, 33 (Geomantie); 808, 15 (Leopold von Österreich, De astrorum scientia); 809, 11 (dass.); 812, 30 (Apuleius; Apologia magiae); 832, 2 (Geomantie); 832, 3 (Ars sigillandi); 832, 4 (zwei Geomantien); 832, 7 (Michael Scot, Nigromancia); 832, 12 (Gerhard von Cremona, Geomantie); 832, 14 (Geomantie); 833, 1 (Chiromantie); 833, 1f. (Clavicula Salomonis).

116 MBKD IV, S. 832, 3.

117 MBKD IV, S. 832, 4. 
leus maleficarum besitzt, welche er unter die Sacri codices historie sancte theoloice veritatis einordnet. 118

Ich fasse an dieser Stelle zusammen. Der Durchgang durch die Überlieferung und die Bibliothekskataloge zeigt, dass es sich bei den schriftlich festgehaltenen Texten zum größten Teil um nigromantische Texte astrologischer und dämonologischer Art sowie um geomantische und chiromantische Anleitungen aus der arabischen Tradition handelt. Auch wenn alle diese Verfahren aus der Perspektive der kirchlichen Superstitionenkritik als dämonisch galten und deshalb verboten waren, gehören sie gleichwohl zum Kanon der naturwissenschaftlichen Studien und wurden daher nicht als superstitiös wahrgenommen, auch wenn bei explizit talismanischen und dämonologischen Schriften die Besitzer sich der potentiellen Gefährlichkeit bewusst sind und vor unbefugtem Gebrauch warnen. Es fällt allerdings in diesem Zusammenhang auf, dass gerade das Buch, vor dem Hartlieb am dringlichsten warnt, der Picatrix, nicht nur im 15. Jahrhundert handschriftlich nur schwach überliefert ist, sondern auch in keiner der untersuchten Buchsammlungen nachweisbar ist. Dem soll noch zuletzt in einem kurzen Ausblick am Beispiel des Picatrix nachgegangen werden, der vielleicht auch verstehen lässt, wie die einzelnen nigromantischen Texte in klerikalen und klösterlichen Besitz gekommen sind.

Bei den Handschriften des Picatrix aus dem 15. Jahrhundert ist nur in drei Fällen die Provenienz festzustellen, wobei diese Handschriften alle im Umkreis einer Universität entstanden sind. ${ }^{119}$ Einer der Besitzer war der Emmeraner Mönch ,Fridericus Astronomus', ${ }^{120}$ hinter dem sich vielleicht Fridericus Ammann verbirgt, ${ }^{121}$ der nach einem Studium in Leipzig seit 1427 vielleicht 1464 in das Regensburger Kloster eingetreten war und dort 1472 starb; seine während des Studiums hergestellten Bücher hat er mit in das Kloster gebracht. Sechs seiner astronomischen Handschriften sind bis heute erhalten und auch im spätmit-

118 MBKD IV, S. 830, 6 u. 21.

119 Krakau, BJ, 610 stammt aus dem Besitz von Stanislaus de Zgierz, der 1464 an der Universität Krakau nachweisbar ist. Krakau, BJ, 793 ist von einem anonymen Schreiber 1458/59 in Krakau geschrieben worden. Rom, Vat., Pal. lat 1354 stammt von der Hand eines ungenannten Schreibers aus der Umgebung des Frater Friedrich von St. Emmeran in Regensburg.

120 Vgl. Kurt Vogel: Art. Fridericus. In: NDB 5 (1961), S. 439.

121 Ludwig Schuba: Die Quadriviums-Handschriften der Codices Palatini in der Vatikanischen Bibliothek (Kataloge der Universitätsbibliothek Heidelberg 2). Wiesbaden 1992, S. 27, vermutet hinter dem Besitzer der Handschrift den Mönch Friedrich Gerhart von St. Emmeran. Da es aber zur gleichen Zeit zwei fratres fridericus in St. Emmeran gab, ist es vielleicht wahrscheinlicher, dass es sich um Fridericus Amman handelt, der ein besonderes Interesse an Naturwissenschaft und Astronomie hatte. Vgl. Elisabeth Wunderle: Die Handschriften aus St. Emmeran in Regensburg. Bd. 1. Clm 14000-14130 (Katalog der lateinischen Handschriften der Bayerischen Staatsbibliothek München T. 4). Wiesbaden 1995, S. XIVf. („Die naturwissenschaftlichen Codices von der Hand des Fridericus Amann“). 
telalterlichen Katalog von St. Emmeran verzeichnet. Umso mehr verwundert es, dass diese Handschrift mit dem Exzerpt des Picatrix nicht im Klosterkatalog aufgeführt ist und, wie die Besitzgeschichte zeigt, auch nicht im St. Emmeraner Kloster verblieben ist. Die Vermutung könnte sein - wobei ich zugeben muss, dass dies reine Spekulation ist - dass der Grund genau diese Textzusammenstellung der Handschrift war: Zusammen mit dem Picatrix finden sich De iudiciis des Arnaldus de Villanova und De astrorum scientia des Leopold de Austria, Werke also, die von Hartlieb auf die schwarze Liste gesetzt worden waren und die deshalb vielleicht nicht im Kloster verbleiben durften. Dass das Exzerpt aus dem Picatrix mit einem Liebeszauber endet, setzt dem Ganzen vielleicht die Krone auf und erklärt, wie überhaupt der ganze dämonisch-magische Chrakter des Picatrix, wieso dieses Zauberbuch in keinem Katalog verzeichnet worden ist. Der Inhalt des Giftschranks wird, nicht anders als heute, ${ }^{122}$ nicht in den offiziellen Katalog aufgenommen, nur ein Kaiser kann es sich leisten, den Besitz offiziell zu verzeichnen. Immerhin hat man dieses Zauberbuch, ebenso wie die im folgenden Anhang aufgeführten Werke, nicht verbrannt; dieses Schicksal haben nicht wenige Exemplare mittelalterlicher nigromantischer Bücher ${ }^{123}$ - in drei Fällen zusammen mit ihrem Besitzer ${ }^{124}$ - erleiden müssen. ${ }^{125}$ Soweit in den Quel-

122 Vgl. dazu den instruktiven Ausstellungskatalog: Der ,Giftschrank'. Erotik, Sexualwissenschaft, Politik und Literatur-,REMOTA': Die weggesperrten Bücher der Bayerischen Staatsbibliothek. Hrsg. von Stephan Kellner. München 2002.

123 Vgl. dazu die Nachweise bei Thomas Werner: Den Irrtum liquidieren. Bücherverbrennungen im Mittelalter. Göttingen 2007, S. 545-652 (Anhang A: Schriftenvernichtung im Mittelalter. Eine chronologische Darstellung).

124 1398, Johannes de Barro, Paris, vgl. Werner: Den Irrtum liquidieren (Anm. 123), S. 576, und oben Anm. 44; 1441, Roger Bolingbroke, Kleriker, London, vgl. Werner, S. 586; 1450, Giovanni Cani, Arzt, Florenz, vgl. Werner, S. 586.

125 Werner: Den Irrtum liquidieren (Anm. 123), S. 560 (1232, libri malefitiorum in Bologna), S. 569 (1326/27, Schriften aus dem Bereich der dämonenbeschwörenden Magie, Erlass Papst Johannes' XXII.), S. 571 (1332, ein nigromantisches Buch aus dem Besitz des Magisters Robert de la Marche, Canterbury), S. 572 (ca. 1357/58, ein Liber Salomonis, Barcelona), S. 573 (1368, verschiedene libri nigromancie aus dem Besitz eines weltlichen Beamten, Girona), S. 573 (ca. 1368/69, verschiedene libri nigromancie aus dem Besitz des Priors des Klosters Sant Miquel de Cruilles), S. 573 (ca. 1370, ein liber nigromancie aus dem Besitz von Berenguer ça Costa, Girona), S. 574 (1371, ein magisches Buch aus dem Besitz von John Crok, Westminster), S. 574 (1372/73 verschiedene Bücher de daemonum invocatione aus dem Besitz von Raymund von Tárrega OP, Tarragona), S. 575 (1384, libros nigromantie aus dem Besitz von Niccolò Consigli, Florenz), S. 575 (1393, livres et invocations de l'enemy aus dem Besitz von Bertrand Bonfils, Paris), S. 576 (1398, magische Bücher aus dem Besitz von Jean de Bar [vgl. oben Anm. 44], Paris), S. 576 (1404, libros dicte malefice et mathematice artis aus dem Besitz von Jacopo di Francesco von Sant Miniato, Florenz), S. 577 und S.631, Anm. 286 (1412, ein Buch mit, diabolischen Zeichen und Imagines' aus dem Besitz von Giovannino di Giovanni von Turin, Florenz), S. 585 (1434/35, ca. 50 volumes de libros de malas artes aus dem Besitz des Enrique de Villena, Onkel König Johanns' II. von Kastilien, Madrid), S. 585 (1440, Sammlung von magischen Schriften aus dem Besitz von Pedro March, Barcelona), S. 586 (1441, nigromantische Bücher aus dem Besitz von Roger Boling- 
len die verbrannten Zauberbücher näher beschrieben werden, sind es genau die im Speculum astronomiae, im Buch aller verbotenen Künste oder in den spätmittelalterlichen Bibliotheken zu findenden Werke: der Liber Salomonis, ${ }^{126}$ die Clavicula Salomonis, ${ }^{127}$ Semaforas ${ }^{128}$ und der Liber Razielis. ${ }^{129}$ Auch dies ist ein nicht unwesentlicher Teil der Überlieferungsgeschichte mittelalterlicher Magie.

broke, Kleriker, London), S. 586 (1450, libri di nigromatia, di ciromantia et d'incantatione di dimoni aus dem Besitz von Giovanni Cani, Arzt, Florenz), S. 588 und S. 641, Anm. 387 (1463, ein magisches Buch mit figures et karacteres detestables und mehreren Kapiteln de nigromance et de ciromancie aus dem Besitz von Thomas de Dampmartin, Dijon), S. 589 (1466, magische Schriften und Instrumente aus dem Besitz von Robert Barker, Cambridge), S. 592 (1480, mehr als 6000 Bände [?] jüdischer Bücher mit Magie und Zauberei, Salamanca).

126 Werner: Den Irrtum liquidieren (Anm. 123), S. 572.

127 Werner: Den Irrtum liquidieren (Anm. 123), S. 585 u. S. 637, Anm. 358. Aus dem Besitz von Pedro March, der eine große Zahl von magischen Büchern besaß, darunter ein Llibre del semiforas, ein Clau del semifora und die Clavicula Salomonis.

128 Werner: Den Irrtum liquidieren (Anm. 123), S. 628 (geschrieben von Jean de Bar [Johannes von Barro vgl. oben Anm. 44]; ein Exemplar wurde aber nicht verbrannt, sondern in der königlichen Bibliothek aufbewahrt), und S.637, Anm. 358 (aus dem Besitz von Pedro March).

129 Aus dem Besitz des Enrique de Villena, Onkel König Johanns' II. von Kastilien, Madrid. Werner: Den Irrtum liquidieren (Anm. 123), S. 585. 


\section{Anhang: Verzeichnis der nigromantischen und mantischen Werke des Mittelalters}

Die Verweise beziehen sich auf Thorndike, History (Anm. 23) [Th], auf Thorndike/Kibre (Anm. 22) [TK] und auf Carmody (Anm. 24) [Car]. Wenn die Texte nicht bei Th identifiziert werden konnten, werden sie mit den Spaltenzahlen bei TK aufgeführt.

\section{Unter Autornamen oder Titel überlieferte Texte}

Abdala ben Zeleman, Spatula (TK 1235)

Abdala (ibn Ali Masuphi), Geomantia (Th II, 119)

Abel, De Imaginibus (TK 376)

Abraham (ibn Ezra?), Iudicia (TK 467, 1125)

Adelard of Bath, Chiromantie (Th $\mathrm{V}, 675$ )

Albedatus, Geomantie (Th II, 119)

Albert, Chiromantie (TK 350, 1260)

Albert, De lapidibus

Albert of Basel, De Arte Pyromantia (Th III, 16)

Albertus Magnus, Chiromantie (Th $\mathrm{V}, 674$ )

Alchandiandus, Geomantie (Th I, 716 u. II, 115)

Alcherius, Geomantie (Th II, 119)

Alfarinus Abizarch, Geomantie, übers. v. Plato von Tivoli (TK 690)

Alkindi, Geomantie (Th II, 119)

Almadel, Auguria (TK 164)

Almadel, Auruspicia (TK 168)

Almadel, Geomantia (TK 583)

Almadel, Hydromantia (TK 646)

Amalricus, De Divinatio (Th II, 115f.)

Andrea Corvo, Chiromantia (Th V, 55f.)

Anselmi, Giorgio, Magica disciplina (Th IV, 243f.)
Antiochus Tibertus, Chiromantie (Th V, 54f; 673f.)

Antonius de Monte Ulmi, Comm. Hermes, De Imaginibus (Th III, 609) Apollonius, Ars notaria (Th II, 281f.)

Ps.-Aristoteles, Chiromantie, übers. v. Johannes von Sevilla (Th II, 226)

Ps.-Aristoteles, De Imaginibus (Th II, 257f.)

Arnald von Villanova, De improbatione maleficiorum (Th II, 847-851)

Aurelius, Chiromantie (übers. v. John Metham) (TK 1555)

Bacon, Roger, Nigromantia (TK 396) Bartholomus de Parma, Geomantie (Th III, 16)

Belenus, De Imaginibus (TK 429, $450,662,1566$ )

Cato, Astrologische Geomantie (Th III, 35)

Christoforo Bucii, Geomantie (TK 958)

Costa ben Lucca, Liber de ligaturis physicis (übersetzt v. Arnald von Villanova) (Th I, 652)

Dialogus inter Hilardum necromanticum et quendam spiritum (TK 1663) 
Galeotto Marcio da Narni, Chiromantia (Th IV, 399-405, ohne diesen Text; TK 443)

Gerard of Cremona, Geomantie (Th II, 119)

Hermes Trismegistos, De caracteribus et sigillis (Th II, 223ff.; Car $58,9)$

Hugo von Santalla, Geomantie (Th II, 119; Car 41)

ders., Spatulamantie (TK 691, 1343)

Humbert de Cosa, Genechiarum et sortilegiam (TK 1222)

Nicolaus Jaquerius, De calcatione demoni (TK 473, 1278)

Johannes von Barro, Semmaforas (Th IV, 120, Anm. 11)

Johannes von Chartres, Ars notoria (Th IV, 279)

John Montroy, Chiromantia (TK 1404)

Johannes von Muris, Geomantie (Th III, 323)

Kyranides (Th II, 229-235; Car 56, 7 [Hermes])

Lull, Raimundus, Ars magica (Th II, 872f.)

Mandelkern, Laurentius, Chiromantie (Th IV, 440)

Marianus Sozibus, De Sortibus (TK $346,1027)$

Michael Scotus, Geomantie (II, 331) ders., Chiromantie (II, 331)

ders., nigromantisches Experiment (TK 1477)

Nicola Monvel, Geomantie (TK 1080)
Petrus de Abano, Elucidarius magicae (Th II, 911f.) ders., Geomantie (Th II, 912)

Picatrix (Th II, 331)

Ps.-Ptolemaeus, Geomantie (TK 727, 1032, 1295, 1478; Car 24, 25)

ders., De imaginibus (TK 111, 354, 447, 483, 987, 1015, 1016, 1017, 1026, 1446; Car 28, 29)

ders., De lapidibus et sigillis eorum (Car 37)

ders., Preparatio speculi (Car 47)

Ps.-Pythagoras, prenostica (Th II, 119)

Roderus de Majoricis, Chiromantia (TK 225)

Rolandus Scriptoris, Geomantie (Th IV, 142f.)

Salomon, Clavicula (Th II, 280)

ders., Cephar (Sepher) Raziel (Th II, 281)

ders., Liber sacratus (Th II, 283-289)

Thabit ibn Qurra, De imaginibus (übers. Adelard von Bath und von Johannes v. Sevilla (Th I, 664-666; Car 18, 7)

Thomas of Toledo, Ars notaria (TK 1550, 1704)

Torella, Geronimo, De Imaginibus astrologicis (Tk 705, 1469)

Venatius de Moerbeke, De presagiis futurorum (TK 292, 626)

Ps.-Vergil, De imaginibus (TK 787)

Wilhelm von Moerbeke, Geomantie (Th II, 119)

Wilhelm von Saliceto, Geomantie (Th II, 119) 
Zahel (Ethel, Thetel), De imaginibus (Th II, 389f., 399f.)

\section{Anonym überlieferte Texte}

Aerimantia (TK 534)

Ars magica (TK 1209)

Ars notoria (TK 48, 91, 169, 485, 487, 488, 618, 713, 729, 733, 1371, 1550, 1704)

Augurium (TK 294, 835, 1173, 1463)

Caracteres (TK 655, 783)

Chiromantie (TK 42, 125, 153, 157, 281, 286, 291, 294, 296, 303, 335, 531, 596, 710, 777, 778, 781, 825, 848, 1045, 1101, 1299, 1416, 1434, 1453, $1531,1585,1502)$

De daemonibus (TK 461, 464, 473, 655, 674, 771, 822, 900, 1067, 1201, $1278,1603,1628,1643,1661,1667)$

Divinatio (TK 32, 185, 249, 339, 37, 372, 602, 616, 653, 710, 733, 806, 880, 926, 938, 1054, 1056, 1197, 1226, $1238,1243,1257,1281,1446,1449$, $1451,1454,1455,1456,1459,1470$, 1475, 1536)

--, aus dem Donner (TK 315, 652, 653, 830, 867, 936, 946, 1451, 1466, 1504, 1712)

Gem, consecration (TK 78, 996)

Gem, engraved (TK 487, 715, 1169, $1254,1344,1436,1452)$

Geomantie (TK 28, 51, 62, 109, 112, 176, 188, 189, 248, 254, 336, 392, 399, ders., Liber magnus sigillorum (Car $45,14)$

$403,452,462,548,557,558,569,583$, $599,600,656,683,687,690,695,703$, 727, 733, 782, 801, 888, 889, 923, 936, 949, 958, 993, 1032, 1085, 1091, 1092, 1098, 1099, 1121, 1136, 1142, 1152, 1236, 1239, 1244, 1286, 1295, 1300, $1352,1402,1416,1419,1425,1441$, $1446,1450,1459,1460,1467,1578$, $1593,1594,1618,1623,1627,1633$, 1692)

De imaginibus (TK 489, 1237)

De incantationibus (TK 1081, 1373)

Magie (TK 21, 26, 43, 52, 244, 259, $358,378,421,489,602,809,1073$, 1209)

Magische Kerze (TK 574)

Magisches Quadrat (TK 731)

Magische Invokation (TK 169)

Necromantie/Nigromantie (TK 733)

Pyromantia parva (TK 684)

Sigillum (TK 23, 26, 330, 384, 428, $448,492,604,617,695,725,729$, 1013, 1088, 1344, 1452, 1506, 1603, 1317, 485)

Sors, Sortes (TK 1226)

Superstition (TK 970) 


\title{
Satirische, dämonologische und wissensvermittelnde Schreibweisen über die Alchemie im Werk Johann Fischarts
}

\author{
Tobias Bulang, Heidelberg
}

\section{Fischarts Schreibweisen über Alchemie - Pluralisierung in der Offizin}

Die in den Jahren 1581/82 bei Bernhard Jobin in Straßburg erschienenen Übersetzungen und Editionen Johann Fischarts thematisieren die Alchemie auf unterschiedliche Art und Weise. 1581 erscheint unter dem Titel Daemonomania magorum Fischarts 806 Druckseiten umfassende, mit eigenen Zusätzen versehene Übersetzung von Jean Bodins nur ein Jahr zuvor in Paris gedruckter Démonomanie des sorciers. ${ }^{1}$ In diesem Text wird die Alchemie unter dämonologischem Vorbehalt abgehandelt, wobei es zu satirischen Invektiven gegen sie kommet. Im gleichen Jahr erscheinen bei Jobin unter dem Titel Correctorium Alchymiae deutsche Übersetzungen vorparacelsischer Texte, welche von den zu diesem Zeitpunkt bereits verstorbenen Paracelsisten Wolf und Toxites gesammelt und für den Druck vorbereitet worden waren. Die Textsammlung enthält eine Einleitung Fischarts mit dem Titel: Vorwarnung An den Gönstig Gutherzigen Kunstliebenden Leser von Achtung der Alchimei. Dieses Vorwort weist ebenfalls satirische Elemente auf, betreibt dabei aber auch die Apologie einer korrigierten Alchemie. ${ }^{2} 1582$

1 Jean Bodin: De la démonomanie des sorciers. Paris 1580 [Nachdruck: Hildesheim, Zürich, New York 1988]; Jean Bodin, Johann Fischart: De Daemonomania magorum. Vom außgelaßnen wütigen Teuffelsheer der besessenen unsinnigen Hexen vnd Hexenmeyster [...]. Straßburg: Bernhard Jobin 1581. Eine zweite, mit weiteren Zusätzen Fischarts versehene Auflage der Übersetzung erschien 1586. Die dritte Auflage von 1591 ist mit hoher Wahrscheinlichkeit posthum und enthält auch keine Bearbeitungen Fischarts mehr. Moderne Textausgaben von Fischarts Daemonomania liegen nicht vor. Die zweite Auflage von 1586 sowie die dritte Auflage von 1591 sind als Reprint verfügbar: Bodin/Fischart: De Magorum Daemonomania [...] Unveränderter Faksimilereprint der Ausgabe Straßburg 1586. Erweitert um ein Nachwort von Ralf Georg Bogner und Christian Böhm. Saarbrücken 2008; Bodin/ Fischart: Vom aussgelasnen wütigen Teuffelsheer [...]. Um ein neues Vorwort von Hans Biedermann vermehrter Nachdruck der Ausgabe Straßburg 1591. Graz 1973. Am Germanistischen Seminar der Universität Heidelberg entsteht zur Zeit eine historisch-kritische Ausgabe des Textes mit umfassendem Kommentar.

2 [Johann Fischart (Hrsg.):] Correctorium Alchymiae Richardi Anglici. Das ist Reformierte Alchimy/ oder Alchimeibesserung/vnd Straffung der Alchimistischen Mißpråuch: vom Alten vnd långstberümten Medico/ Richardo aus Engelland beschriben. II. Rainmvndi Lvlli Apertorium \& Accuratio Vegetabilium. Von erơffnung vn̄ entdeckung wachsender Sachen / $v \bar{n}$ des Philosophischen steyns/ des Wolbekannten Philosophi vnd Eremiten Rainmundi Lul- 
wird Fischarts zweite Auflage seiner Übersetzung von Rabelais' Gargantua unter dem Titel Affentheurliche und Naupengeheurliche Geschichtklitterung gedruckt. Diese Auflage ist gegenüber der 1575 erschienenen Erstauflage von Fischart vielfach ergänzt worden, ${ }^{3}$ unter anderem mit satirischem Spott die Alchemie betreffend und mit Parodien der alchemischen Sprache. Im Werk Johann Fischarts ist somit eine Auseinandersetzung mit der Alchemie auszumachen, welche durch eine eigentümliche Unabgegoltenheit wissensvermittelnder, dämonisierender und satirisch-parodistischer Schreibweisen gekennzeichnet ist. Eine solche auf frühneuzeitliche Pluralisierungsphänomene verweisende, gewissermaßen multiple auktoriale Position zum Thema findet eine erste Erklärung darin, dass der Ort von Fischarts Schreiben eine frühneuzeitliche Offizin ist, mithin ein Ort, an dem Pluralisierungsvorgänge in besonderer Weise relevant und manifest werden. Der Überlagerung verschiedener Schreibweisen soll in diesem Beitrag besonders mit Blick auf die skizzierte, zu Beginn der 1580er Jahre entstandene Werkgruppe nachgegangen werden. Im Zentrum steht dabei die Edition alchemischer Schriften, das 1581 erschienene Correctorium Alchymiae.

\section{Alchemistenspott und Wissensvermittlung-Positionen der Fischartforschung}

In der Daemonomania Magorum findet sich folgende Anekdote über Alchimisten:

Aber ich hab von dem fürnemen Laborierer Conftantino gehơrt/ welcher für den gefchicktften inn der Pyrotechny vnnd Metallifcher Kunft inn Franckreich angefehen/ vn deshalben bei vns wol bekant ift/ daß er Gefellen gehabt/ welche wann fie lang ohn anfcheinung einiger fruchtbarkeit gefchürtt vnd geplafen gehabt/ zu letzft den Teuffel rhats gefragt haben/ ob fie mit der fachen recht vmgehen/ vnd ob fie einmal zu dem Rechten Zweck werden gelangen? Den hab er mit dem einigen Wort/ Arbeitet/ jhren befcheyd geben/ Deffen dife Kolenverderber vnd Blaßbålg wol zu

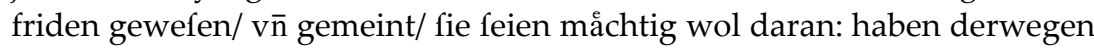
noch mehr åfchen gemacht vnd gefchürt/ vnd fo lang fuffliert/ biß fie alles zu Nichts haben Multipliciert: Wirden auch noch an dem Lapide Ploßauffico auffzublafen haben/ wann fie gedachter Conftantinus nit darvon abgemanet het/ vnd fie erinnert/ daß der Sathan pflegt zweiffelhafften be-

li Tractat. III. Des Königs Gebers auß Hispanien Secretū, dessen sich die Venetianer hoch austhun. Alles nun erstmals zu dienst vnd nutz allen Reyner vnd Geheymnußreicher Artznei vbenden vn̄ beliebenden inn Truck gefărtigt. Straßburg: Jobin 1581, Vorrede. Im Jahr 1596 erschien bei Jobins Erben eine seitenidentische Ausgabe.

3 Johann Fischart: Geschichtklitterung (Gargantua). Synoptischer Abdruck der Fassungen von 1575, 1582 und 1590. Mit 3 Titelblättern und den Originalholzschnitten der Ausgabe von 1590 von Tobias Stimmer. Neu hrsg. von Hildegard Schnabel. 2 Bde. Halle a.S. 1969 (Neudruck deutscher Literaturwerke 65/69; 70/71). Die erste Auflage erschien noch unter dem Titel Affentheurliche Naupengeheurliche Geschichtschrift. Die beiden Folgeauflagen, die noch zu Lebzeiten Fischarts erschienen, enthalten jeweils Zusätze Fischarts. 
fcheid zugeben/ vnd diß Wort/ Arbeitet/ nichts anderft auff fich trage/ dann daß fie der Alchimei müffig ftehn/ vnd auff fonft ehrliche Arbeit vnd kunft jhr müh vn fleiß wenden follen/ darmit fie fich ernehren vnd außpringen mo̊gen. Seiteinmal es eitel Affenwerck ift/ in fo kurtzer zeit vermeinen Golt nachzumachen/ fo doch die Natur wol taufent Jar darzu bedarf: deßgleichen aus betrachtung/ weil nicht jeder darzu genaturt ift/ noch inn eym gantzen Land kaum eynem die Gab befcheret. ${ }^{4}$

Diese äußerst skeptischen Bemerkungen zur Alchemie werden an gegebenem Ort nicht überraschen, sind doch die bösen Umtriebe und der Schadenszauber von Hexen und Zauberern, ihr Umgang mit Dämonen und die Notwendigkeit ihrer unnachgiebigen juristischen Verfolgung Gegenstand dieses Buches. Satirischer Zusatz Fischarts über Bodins Vorlage hinaus ist die Rede vom Lapide Ploßauffico. Im Neologismus steckt das Aufgeblasene (,auff ploßen') - womit die alchemistische Rede von Stein gemeint sein könnte - sowie der Hinweis auf das Trinken (,bloß sauffen') und damit eine Diskreditierung der Adepten. Spott über Alchemisten und Parodien alchemistischer Sprache finden sich bei Fischart auch an anderer Stelle, wie etwa im Catalogus catalogorum, ${ }^{5}$ Fischarts Parodie der Gesnerschen Weltbibliographie Bibliotheca universalis. Ich nenne nur zwei Beispiele aus den vielen Verballhornungen in Fischarts imaginärem Bibliothekskatalog: Die Morgenròt der auffgehenden Künst / mit Gegenschein derselbigen Abendröt: durch Woluffgang Ehrenbrot und Cacatorium Medicorum: per Blasium Bechofen. ${ }^{6}$ Im ersten Beispiel wird dem in Titeln alchemistischer Publikationen mitunter vorkommenden Morgenrot das Abendrot - und damit der Untergang der Kunst - entgegengesetzt, wodurch das Pathos des Beginns in parodistischer Inversion unterlaufen wird. In der Verballhornung des Namens Wolfgang zu Woluffgang

4 Bodin/Fischart: De Daemonomania Magorum 1581 (Anm. 1), S. 463.

5 Johann Fischart: Catalogus Catalogorum perpetuo durabilis (1590). Mit Einleitung und Erläuterungen hrsg. von Michael Schilling. Tübingen 1993. Vgl. zu diesem Text die Einleitung von Michael Schilling in Fischart: Catalogus. Weiterhin: Adolf Hauffen: Catalogus Catalogorum. In: Neue Fischart-Studien. Leipzig, Wien 1908, S. 1-41; ders.: Johann Fischart. Ein Literaturbild aus der Zeit der Gegenreformation. 2 Bde. Berlin, Leipzig 1921/22; Erich Kleinschmidt: Die konstruierte Bibliothek. Zu Johann Fischarts Catalogus catalogorum (1590). In: Etudes Germaniques 50 (1990), S. 541-555; Jan-Dirk Müller: Universalbibliothek und Gedächtnis. Aporien frühneuzeitlicher Wissenskodifikation bei Konrad Gesner (mit einem Ausblick auf Antonio Possivino, Theodor Zwinger und Johann Fischart). In: Erkennen und Erinnern in Kunst und Literatur. Kolloquium Reisensburg 4.-7. Januar 1996. Hrsg. von Dietmar Peil, Michael Schilling und Peter Strohschneider. Tübingen 1998, S. 285-309; Ulrich Seelbach: Ludus lectoris. Studium zum idealen Leser Johann Fischarts. Heidelberg 2000; Dirk Werle: Copia librorum. Problemgeschichte imaginierter Bibliotheken 1580-1630. Tübingen 2007, S. 58, 170-203. Demnächst: Tobias Bulang: Mögliche Diskurse und Entfaltung des Impliziten. Literaturtheoretische Überlegungen zu Johann Fischarts Catalogus Catalogorum von 1590. In: Satirical Catalogues - Fictitious Libraries (16th-18th centuries). Hrsg. von Anne-Pascale Pouey-Mounou und Paul Smith. Erscheint in Leiden u.a. 2015.

6 Fischart: Catalogus Catalogorum (Anm. 5), Nr. 207, 279, S. 17, 20, $22 \mathrm{f}$. 
wird aus dem Wolf ein schöner Sonnenaufgang (,wol uffgang'), was man als betrügerisches Beschönigen des, wölfischen' Namens und mithin als Verbergen von Betrugsabsichten deuten mag. Der zweite Titel kontaminiert in der Tradition Rabelais' und der Dunkelmännerbriefe Wissensliteratur mit fäkalischen Ausdrücken.

Die ältere Fischartforschung, aber auch die jüngere Alchemieforschung haben angesichts solcher Späße skeptisch über die von Fischart besorgte Herausgabe alchemistischer Schriften in deutscher Sprache geurteilt. Betrachteten die Fischartforscher des 19. und frühen 20. Jahrhunderts prinzipiell die Alchemie als entbehrliche und bedauerliche Verwirrung des Geistes, so suchten sie Fischart davon zu entlasten, indem sie unterstellten, er habe das Correctorium Alchymiae nur seinem Schwager und Drucker Bernhard Jobin zu Gefallen ediert, und überhaupt sei das Ganze nur auf den geschäftlichen Erfolg ausgerichtet gewesen. ${ }^{7}$ Noch Wilhelm Kühlmann und Joachim Telle, denen man ein mangelndes Interesse an der Alchemie nicht unterstellen kann, schreiben nach Berücksichtigung aller Umstände, die Vorwarnung mache:

[...] in Fischart keinen von paracelsistischen Lehren durchdrungenen Publizisten kenntlich, wohl aber einen Apologeten der von Paracelsisten aktualisierten Transmutationsalchemie. Mit ziemlicher Sicherheit beteiligte sich Fischart an der Drucklegung der von Toxites hinterlassenen und zum Druck vorbereiteten Alchemicaabschriften H. Wolffs nur „zu gefallen" seines aus kommerziellen Gründen an einem Druck interessierten Schwagers B. Jobin. ${ }^{8}$

Gemeinsam ist diesen Einschätzungen die Frage nach der Einstellung: Entweder ist Fischart überzeugter Alchemiker oder das Projekt ist nur auf kommerziellen Erfolg berechnet. Ich möchte im Folgenden fragen, ob es vielleicht noch andere Gründe für die Herausgabe alchemischer Schriften gab, und gehe dazu in einem ersten Schritt auf Fischarts Sprachprogrammatik in der Vorrede zu diesem Kompendium ein (III.), ${ }^{9}$ sodann auf die Umsetzung des Programms in den

7 Camillus Wendeler: Fischart als Herausgeber alchymistischer Schriften. In: Archiv für Litteratur-Geschichte 6 (1877), S. 487-509, hier S. 501, 509; Hauffen: Johann Fischart (Anm. 5), S. 189-196.

8 Wilhelm Kühlmann, Joachim Telle: Corpus Paracelsisticum. Dokumente frühneuzeitlicher Naturphilosophie in Deutschland. Der Frühparacelsismus. Bd. 3. Tübingen 2013, Nr. 116, S. 419.

9 Ich knüpfe hier ergänzend an bereits publizierte Überlegungen zur Alchemie bei Fischart an, vgl. Tobias Bulang: Konzepte der literarischen Produktivität - Probleme ihrer Begründung am Beispiel Johann Fischarts. In: Konzepte von Produktivität im Wandel vom Mittelalter in die Frühe Neuzeit. Hrsg. von Corinna Laude und Gilbert Heß. Berlin 2008, S. 89-118; ders.: Zur poetischen Funktionalisierung hermetischen Wissens in Fischarts Geschichtklitterung. In: Erzählen und Episteme. Literatur im 16. Jahrhundert. Hrsg. von Beate Kellner, JanDirk Müller, Peter Strohschneider unter Mitarbeit von Tobias Bulang und Michael Walten- 
edierten Texten (IV.) und die von Fischart ergänzten Paratexte (V.), um zuletzt alternative Funktionsbestimmungen zu erwägen (VI.).

\section{Fischarts sprachkritisches Programm in der Vorrede zum Correctorium Alchymiae}

Die Vorwarnung An den Gönstig Guthertzigen Kunstliebenden Leser von Achtung der Alchimei ${ }^{10}$ nimmt alchemische Schriften und Praktiken gegen ihre Gegner ebenso in Schutz wie gegen bestimmte Befürworter. Die gängige Apologetik alchemistischer Schriften ist bei Fischart aufgelockert durch beigegebene Spottverse und Exempel. Jenes von Kaiser Tiberius eröffnet die Vorrede, der, als das Glas erfunden worden sei, die neue Erfindung verboten und die Tötung der Erfinder veranlasst habe, um eine Entwertung des Goldes und der daraus gefertigten Gefäße zu verhindern. Alternativ zur ökonomischen Begründung der harten Strafe bietet Fischart eine diätetische für das Verhalten des Kaisers: Tiberius sei ein Biberius gewesen und hätte jm zu lieb/ ond seinem Hirn zu leyd / jhm selbs eyn Aberwitz getruncken gehabt (S. 415), weil der Wein ihn aus dem neuen Glase so schön angelacht habe. Die Folgen des Abusus habe der Kaiser dem Glas und den Glasmachern angelastet und sie deshalb umgebracht.

Die Vorrede rechtfertigt die Goldmacherkunst einerseits, die auf Basis alchemistischer Praktiken entwickelten neuen Arzneimittel andererseits. Jene, die Goldmacherei und neue Arzneikunst ablehnen, werden mit dem törichten Tiberius bzw. Biberius verglichen. Aber auch die Geheymnus erfarenen stellten ihrerseits fürwitzige Tiberios dar. Weil sie fürchten,

es möchte dises Mystery zu gemeyn vnd jederman bekantlich werden/ vnd also männiglich zu vberflüssiger Reichtumb gedeien/ so verführet sie jhr Fürwitz auch inn eyn vergonst/ daß sie sich befleissen/ dise Kunst auffs aller verborgenest/ vnverständlichst/ vndeitlichst/ vnd wie eyn verdeckts Essen den Leuten fürzutragen/ vnd gleichsam Sphyngis oder Rähtersweiß auffzugeben. (S. 417)

berger. Berlin, New York 2011, S. 41-68; ders.: Enzyklopädische Dichtungen. Fallstudien zu Wissen und Literatur in Spätmittelalter und früher Neuzeit. Berlin 2011, S. 448-466.

10 Zum Correctorium Alchymiae sind nach wie vor die Ausführungen Wendelers informativ, auch wenn diese nicht ihre Ablehnung der Alchemie verhehlen und Fischart entsprechend in Schutz zu nehmen suchen: Wendeler: Fischart als Herausgeber (Anm. 7). Bei ihm auch ein Abdruck der Vorrede (S. 496-501); vgl. auch Bulang: Enzyklopädische Dichtungen (Anm. 9), S. 459-460. Die Vorrede zitiere ich nach ihrer kommentierten Edition von Kühlmann/Telle (Anm. 8), S. 415-418. Die Traktate des Bandes werden im Folgenden nach der Ausgabe von 1581 zitiert. Ich verwende das Exemplar der Bayerischen Staatsbibliothek München (Signatur: Alch. 236), welches auch als Digitalisat verfügbar ist: https://download.digitalesammlungen.de/pdf/1404729432bsb00015164.pdf (29.7.2014). 
Hier kritisiert Fischart die dunkle Rede des alchemistischen Schrifttums, ein Reizthema des alchemistischen Diskurses, ${ }^{11}$ fordert von den Autoren Verständlichkeit und occiniert den Rähterschreibern folgendes Lied:

Entweder schreib/ daß man versteh/

Oder des Schreibens müssig geh:

Willt schreiben/ daß man nicht soll wissen/

So last das Papir wol vnbschissen. (S. 417)

Im Folgenden entkräftet Fischart die Standardapologien der Alchemiker ihre dunkle Rede betreffend. ${ }^{12}$ Er fordert schließlich eine Klarheit der Diktion als Form des naturgemäßen Schreibens:

Wiltu ein Nachömer vnd Folger der Natur sein vnd heyssen/ so folge auch im schreiben der Natur/ vnd schreib verstäntlich: Es wirts dannoch nur fassen/ der da mag. Sonst wo du die fremdesten vnd weitgesuchtesten Wörter vnd Gleichnussen fürgrübelst vnd brauchst/ bringstu bei den Guthertzigen die Natürgeschickte kunst vil mehr inn bösen verdacht/ dan inn ein Großachtung: vnd bei den Neidern vil mehr zu spott/ dan zu eyner verwunderung. (S. 417-418)

Die Polemik gegen die fremdesten ond weitgesuchtesten Wörter ond Gleichnussen zeigt, wie der alchemistische Diskurs einerseits bedient, andererseits stilkritisch und sprachdidaktisch auch distanziert wird. Die in diesem Buch zusammengetragenen Autoren Richardus Anglicus, Rainmundus Lullus und Geber werden als besonders zu ehrende Männer gepriesen, die das von Gott Offenbarte deitlich/ verständlich/ treulich vnd guthertziglich männiglichen/ so zu diser Kunst lust trägt/ haben zum vnterricht inn Schrifften mitgetheylt (S. 418). Gelobt werden auch jene, die sich um solche, von Neidern zurückgehaltene Bücher bemühen und sie zum Druck befördern und dem gemeinem Nutzen zur Verfügung stellen. Der Nürnberger Arzt Heinrich Wolff habe dem Toxites seine Collectaneis übergeben, um deren Druck zu befördern, was aber aufgrund des Todes von Toxites unterblieben sei und nun nachgeholt würde. Fischarts Vorwort würdigt die in der Edition versammelten Texte nicht allein aufgrund ihrer deutschen Sprachgestalt, sondern unterstellt ihnen auch die Umsetzung eines Stilideals der Klarheit und Verständlichkeit. Diese Behauptung sei im Folgenden geprüft: Zeichnen sich die von Fischart edierten Texte tatsächlich durch die Abwesenheit der Decknamen und Allegorien aus, die in weiten Bereichen des alchemistischen Diskurses obligatorisch sind?

11 Vgl. mit weiterer Literatur Bulang: Enzyklopädische Dichtungen (Anm. 9), S. 448-452.

12 Vgl. hierzu: Corpus Paracelsisticum. Bd. II: Dokumente frühneuzeitlicher Naturphilosophie in Deutschland. Der Frühparacelsismus. Zweiter Teil. Hrsg. und erläutert von Wilhelm Kühlmann und Joachim Telle. Tübingen 2004, S. 18-27. 


\section{Arkansprachliche Elemente in den edierten Texten des Correctorium Alchymiae}

Betrachtet man die Zusammenstellung der Texte, so fällt zunächst eine gewisse Nachlässigkeit auf. Auf dem Frontispiz sind drei Werke angekündigt und römisch nummeriert: Richardus Anglicus, Raimundus Lullus und Geber. In das Buch selbst aber sind weitere Texte aufgenommen, und die Nummerierung stimmt nicht mit jener auf dem Frontispiz überein. Unter I. findet sich darin das pseudoepigraphische, Richardus Anglicus zugeschriebene, Correctorium Alchymiae (Bl. 1 $\left.{ }^{\mathrm{r}}-30^{\mathrm{r}}\right){ }^{13}$ unter II. der Text eines unbekannten Verfassers unter dem Titel Eyn kurtze betrachtung von dem ,Lapide Philofophorum', die in der Kopfzeile weiterhin als Reformirte Alchimei bezeichnet wird (Bl. 31 $-80^{\mathrm{r}}$ ). Unter III. wird Des Sinnerleuchten Berümten Philofophi Rainmundi Lulli/ des Eremiten/ auß der Inful ,Maiorica', Geheymnußreich Büchlein geboten (Bl. 81-129r), unter IV. ein weiterer Raimundus Lullus zugeschriebener Traktat Raimundi Lulli vor nie erfehener Tractat / vom Philofophischen Steyn (Bl. 129v-137r) und unter V. schließlich Des Koniges Gebers auß Hifpanien Buch der Heyligkeyt/ fo er feinem Sohn zu lieb ond Nutz gefchriben (Bl. 137v-151r). ${ }^{14}$

Das von Fischart in der Vorrede immer wieder betonte naturgemäße Vorgehen findet sich auch als Forderung an den Adepten in den Traktaten. Allenthalben wird verlangt, man solle in allem der Natur folgen. Das Verhältnis von Natur und Kunst ist in besonders ausführlicher Weise Gegenstand des ersten Traktats:

Dann wiewol die kunft/ die Natur nicht verfteigt/ noch eyn Neue natur machen kónte/ durch fchlechte arbeyt/ jedoch vberfteigt fie die natur fo ferrn/ daß fie diefelbige eygentlich kan fubtil machen: Darum fagt man/ Ars imitatur naturam, die Kunft folgt nach der Natur. Nicht daß fie eyn Natur machete/ fondern daß fie diefelbige Natur fubtiliert [...]. (Bl. $1^{\mathrm{v}}$ )

Auch der anonyme zweite Traktat enthält ein Kapitel Von der Natur vnd Menfchlicher Kunft/ welche die Naturam nachfolget (Corr. Alch., Bl. 31v). Dass vnfer werck vnd vnfer Medicin [...] alleyn auß der natur zufā̄en gefetzt v̄̄ componirt feie behauptet auch der vierte, Raimundus Lullus zugeschriebene Text (B1. 86v). Dabei freilich ist vom opus magnum die Rede, nicht von seiner sprachlichen Darstellung. Fischart nimmt also in der Vorrede eine zentrale Forderung aus den Texten selbst auf und modifiziert sie zu einem Gebot sprachlicher Deutlichkeit (Schreiben nach der Natur). Aber dass die edierten Texte besonders vorbildlich oder auch nur auffällig seien, was die Umsetzung der von Fischart geforderten ver-

13 Vgl. Joachim Telle: Ricardus Anglicus. In: Die deutschsprachige Literatur des Mittelalters. Verfasserlexikon. Zweite, völlig neu bearbeitete Auflage hrsg. von Kurt Ruh u.a. Bd. 8. Berlin, New York 1992, Sp. 38-41.

14 Vgl. Joachim Telle: Geber. In: Die deutsche Literatur des Mittelalters (Anm. 13) Bd. 2. 1980, Sp. 1105-1109. 
ständlichen, weil natürlichen Diktion angeht, trifft keineswegs zu. ${ }^{15}$ Typische alchemistische Apologien der dunklen Rede, über die sich Fischart in seiner Einleitung kritisch äußert, finden sich in fast jedem der Texte affirmativ umgesetzt. Auch die für das alchemistische Schrifttum typischen Reihungen von Decknamen zu Synonymketten sind zu beobachten:

Dife weiffe/ fo erfcheinet nach der fchwartzen/ nennen wir den weiffen Steyn/ das weiß Golt/ eyn vollē Mon/ eyn weiß fruchtbar Erdrich/ geweiffet/ gereyniget/ vnd gecalciniert/ eyn weiffen Kalch/ eyn Saltz der Metalle// eyn calcinirt corpus: vnd mit andern vil Namen nennen wir folhe obgemelte weiffe farb. (Bl. 61 ${ }^{\mathrm{r}}$ )

Insbesondere der zweite, anonym überlieferte Traktat strotzt von Geheimnamen und verrätselten alchemistischen Allegorien, wie zum Beispiel dem folgenden Gleichnis vom Mercurio:

Der Himlisch lufft ift allen Menfchen verfchloffen worden/ vnd haben alle Menfchen müffen herab fteigen/ vnd hieniden bleiben/ auff daß fie ewiglich auff dem Erdrich auffgehalten werden: Aber die gantz nidertrăchtig Jungfrau Maria des himlifchē luffts/ der auff dem Berge Olimpia gewefen/ hat die Thür auffgethan/ vnd hat dem Plutoni dem Hellifchen Gott fein Reich oder Hell eróffnet/ auff daß er folchs zerstơret. Da aber Maria auß vnaußfprechlicher güte/ vnd auß des Heyligen Geysts würckung inn jren Jungfraulichē leib/ durch fonderliche Geheymnuß vnd verborgenheyt empfangen hat/ daß da im Himel/ das aller furtrefflichft/ vnd auch auff Erden was/ da hat fie vns entlich geboren der gantzen Welt Heyland/ darmit durch feine vnaußfprechliche Güte/ alle die da fleiffig ftudiren die Philofophiam/ felig vnd reich zumachen/ fo fie fich offt zu jm bekehrten. Die Jungfrau ift aber vnbefleckt bliben: derhalben wůrt nicht vnbillich der Mercurius der allerherrlichften jungfraue Mariæ verglichen. (Bl. 37r-37v).

In den weiteren Ausführungen ist schließlich noch von der Jungfrau Mercuria oder Minerua on alle Mackel die Rede (Bl. 37v). Diese Unabgegoltenheit der stilistischen Forderung der Vorwarnung mit dem Inhalt der präsentierten Texte ist der älteren Forschung ins Auge gefallen und auch dies hat zur Annahme geführt, Fischart sei es mit dem Projekt so besonders ernst nicht gewesen. ${ }^{16}$

\section{Sprachpatriotismus im Paratext}

Fischarts Anteil am Correctorium Alchymiae jedoch beschränkt sich nicht allein auf die Vorrede, von seiner Hand sind auch Paratexte wie Kapitelüberschriften und Marginalien sowie Kolumnentitel. Hier findet sich vereinzelt absichtlich

15 So bereits Hauffen: Johann Fischart (Anm. 7), Bd. 2, S. 196.

16 Vgl. Wendeler: Fischart als Herausgeber (Anm. 7), S. 501, 509; Hauffen: Johann Fischart (Anm. 7), S. 196. 
oder unfreiwillig Komisches, wenn es beispielsweise in einer Marginalie heißt: Dem fteyn muß man die Nafen butzen. (Bl. 68r). An einer anderen Stelle macht Fischart seine Leser auf rezente alchemische Druckerzeugnisse aufmerksam: Turba Philofophorum nunmals auch getruckt. (B1. $\left.35^{\mathrm{r}}\right) \cdot{ }^{17}$ Prinzipiell jedoch zeigt sich das Interesse daran, den Text nachvollziehbar zu gliedern und Zitate von Autoritäten zu markieren. Auffällig ist darüber hinaus, dass die Stellen, an denen die Verfasser polemisch, teils auch satirisch über falsche Alchemisten schelten, konsequent markiert sind: z.B. mit Notandum den Alchimiften (Bl. 9r) bzw. Wider die Betrigerifche Alchimiften zumercken (B1. 11 $)$. Hier berühren sich Fischarts satirische Einwürfe mit der in entsprechenden Traktaten obligatorischen alchemistischen Polemik gegen Betrüger in den eigenen Reihen. Erkennbar sind freilich auch sprachliche Eingriffe in den Text und der Versuch, einem genaueren Verständnis zuzuarbeiten. Diese Mühe lässt sich nicht gleichermaßen überall im Buch ausmachen, sie fällt insbesondere zu Beginn des Bandes ins Auge; die im Folgenden angeführten Verfahren kommen also keineswegs konsequent zur Anwendung, dennoch scheinen sie mir aufschlussreich für die Konzeption der Edition zu sein.

In den Kapitelüberschriften des ersten Traktats fällt sogleich Fischarts eigentümliche Diktion auf, insbesondere, wenn man diese Kapitelüberschriften mit jenen vergleicht, die sich in einer alternativen, 1613 herausgegebenen Übersetzung derselben dem Richardus Anglicus zugeschriebenen Texte finden. ${ }^{18}$ Lautet dort die Überschrift zu den Ausführungen über das die alchemische Praxis begleitende Studium der Philosophischen Bücher schlicht: Vom Nutz des Studierens, ${ }^{19}$ so findet sich bei Fischart die Überschrift: Daß das ftudium oder die Lehrnuß der Philofophy nothwendig fei zu difer Kunst. (Bl. $2^{\mathrm{v}}$ ). Die Doppelformel das ftudium oder die Lehrnuß ist ebenso charakteristisch für Fischarts Schreiben wie der Einsatz von Neologismen: ,Lehrnis' findet sich im Deutschen Wörterbuch durchaus, aber nur mit zwei Belegen aus dem Ehzuchtbüchlein von Johann Fischart, wir hätten es hier also mit einem dritten Beleg beim gleichen Autor zu tun und können festhalten, dass sich, anders als bei anderen Wörtern, Fischarts Versuch, eine neue deutsche Entsprechung zu einem lateinischen Wort (studium) zu etablieren, nicht langfristig hat durchsetzen können. Die Fischartforschung hat solche Zwillings-, mitunter auch Drillingsformeln im Zeichen einer poetischen Artistik dem Manierismus dieses Autors zugeschrieben. ${ }^{20}$ Bei genauerem Hinsehen zeigt sich

17 Gemeint ist folgender Druck: Avriferae artis, quam chemiam vocant antiquissimi avthores, fiue Tvrba philosophorvm, Basel: Peter Perna 1572.

18 Tvrba philosophorvm. Das ift/ das Buch von der gůldenen Kunft/ neben anderen Authoribus, welche miteinander 3.6 Bůcher in fich haben. Darinn die beften vråltesten Philosophi zufammen ge tragen/ welche tractiren alle einhellig von der Univerfal-Medizin [...] durch Philippum Morgenstern Islebiensem, Basel: Ludwig Kơnig 1613.

19 Tvrba philosophorvm (Anm. 18), S. 477.

20 Vgl. zur Manierismusdiskussion Rüdiger Zymner: Manierismus. Zur poetischen Artistik bei Johann Fischart, Jean Paul und Arno Schmidt. Paderborn u.a. 1995; Tobias Bulang: Manie- 
jedoch, dass Fischart hier auch Übersetzungsarbeit betreibt und deutsche Entsprechungen für Fachsprachliches vorstellt: Von den Natürlichen principijs oder anfägen $\left(\mathrm{Bl} .3^{\mathrm{v}}\right)$, Von den Metallen/ die jren vrfprung haben auß Mercurio inn gemeyn wnd genere $\left(\mathrm{Bl} .4^{\mathrm{v}}\right)$ bzw. Wie die Metallen auß Mercurio gemacht werden/ innsonderheyt inn specie (Bl. 5r), Wie der weiffe ond rote Sulphur oder Schwebel in Luna ond Sole, oder Son und Mon feien $\left(\mathrm{Bl} .15^{\mathrm{v}}\right)$, Wie der Lapis preparirt oder zubereitet werde (B1. 52v).

Dieses Verfahren ist auch in anderen Texten Fischarts anzutreffen, wie zum Beispiel in seiner Bodin-Übersetzung, der Daemonomania magorum, dort etwa in Fischarts Übersetzungsvorschlägen zum Begriff der Antipathia bei Bodin: Seiteynmal zwifchen dem Zucker vnd Butter eyne Natürliche widerige Neygung ond gegenart oder Antipathia ift. ${ }^{21}$ Einer umfassenden Abhandlung zu den verschiedenen Formen der Prophetie ist folgende Überschrift vorangestellt: Von dem Propheceien/ oder GotsWarsagungen vnd anderen Göttichen Mittelen/ verborgene fachen vorzuwiffen und Weißzufagen.22 In der Vorlage Jean Bodins werden in diesem Zusammenhang Sprachreflexionen ausgeführt, welche Fischart übersetzt und auf die deutsche Sprache hin erweitert:

Die Griechē nennen eynen Vor oder Worfager Manten/ vom Wơrtlein Manteia, welches eyne Vorfagung oder Vormanung heyffet: (Darmit beinach das Teutsch Wort Manen ubereyn stimt/als ob die Mante weren / die eyns Manten eh es gefchicht. $)^{23}$

Auch im satirischen Schrifttum Fischarts lässt sich dieses Verfahren ausmachen, so etwa allenthalben in seiner Rabelais-Übersetzung, der Geschichtklitterung. Wo bei Rabelais im 23. Kapitel des Gargantua das neue humanistische Studium des Riesenprinzen unter der Überschrift Comment Gargantua feut institué par Ponocrates en telle discipline qu'il ne perdoit heure du jour erzählt wird, ${ }^{24}$ heißt es bei Fischart in der Ausgabe von 1582: Wie Gargantual mit dermaffen feiner zuchtlehrung v $\bar{n}$ lehrzucht durch Lobkundum von Ehrnsteig ward vnterricht/ daß er kein stündlin vergebens hinricht. ${ }^{25}$ Fischart hat das Riesenhafte seines Helden durch phonetische Assoziation an einen Wal (Gargantual) gegenüber Rabelais eigens betont und mit Zuchtlehrung vnnd Lehrzucht semantische Alternativen angeboten, auch den Na-

rismus? Johann Fischarts Geschichtklitterung. In: Alterität als Leitkonzept für historisches Interpretieren. Hrsg. von Anja Becker und Jan Mohr. Berlin 2012, S. 285-300.

21 Bodin/Fischart: Daemonomania magorum 1581 (Anm. 1), S. 217; vgl. Deutsches Fremdwörterbuch. Begonnen von Hans Schulz, fortgeführt von Otto Basler. Zweite Auflage, völlig neu bearbeitet am Institut für deutsche Sprache. Bd. 2: Antinomie-Azur. Bearbeitet von Gerhard Strauß u.a. Berlin, New York 1996, S. 4-7, hier S. 4f.

22 Bodin/Fischart: Daemonomania magorum 1581 (Anm. 1), S. 104.

23 Bodin/Fischart: Daemonomania magorum 1581 (Anm. 1), S. 104.

24 François Rabelais: CEuvres complètes. Édition établie, annotée et préfacée par Guy Demerson. Paris 1973, S. 106.

25 Geschichtklitterung 1582 (Anm. 3), cap. XXVII. 
men Ponokrates einer zweiteiligen deutschen Übersetzung und Verfremdung unterzogen, die bereits auf die Namenspiele des Catalogus Catalogorum vorausweist. In der Folgeauflage von 1590 ist an derselben Stelle aus dem Gargantual ein Gurgellantua geworden, ${ }^{26}$ die Ausgabe verfügt, anders als die Vorgängerauflagen, über Kolumnentitel, in denen die Sprachvervielfältigung im Deutschen durch weitere Benennungen fortgeführt wird: D. lobkundi Paedagogei und Hoffmeisterei. ${ }^{27}$

Solche Arbeit an der deutschen Sprache zeigt sich mitunter auch in den Marginalien des Correctorium Alchymiae. Die Übersetzung des Richardus Anglicus spart oft die deutschen Namen der Substanzen aus. So findet sich für Quecksilber immer Argentum vivum. Fischart, der in die Texte selbst nicht eingegriffen hat, ergänzt hier in den Marginalien oft die deutschen Bezeichnungen, gelegentlich durch eine Doppelformel (Argentom viuū oder Queckfilber - Bl. 5v, 6r) oder nur durch Beigabe des im Text fehlenden deutschen Wortes. Die Marginalien leisten also neben der parataktisch gliedernden Funktion auch Spracharbeit.

Hier wird eine Arbeit an der deutschen Sprache manifest, die für Fischarts Schreiben, aber auch für die Projekte seines Schwagers, des Druckers Bernhard Jobin, charakteristisch ist. Die Sprachreflexionen in Fischarts verschiedenen Publikationen, auch die mit dem Oberrheinischen Paracelsisten Toxites zusammengestellte Onomastica ${ }^{28}$ weisen auf eine programmatisch vorangetriebene und patriotisch motivierte Pflege der deutschen Sprache hin. Die vielen Übersetzungsprojekte aus der Jobinschen Offizin zeigen dies ebenso. Erkennbar ist eine mitunter idiosynkratisch motivierte Mühe, die Benennungspotentiale und die Superiorität des Deutschen auch gegen das Lateinische, Italienische und Französische zu erweisen und vorzuführen.

\section{Bestandsaufnahme und Ästhetisierung}

Fischarts Geschichtklitterung ist nicht nur Rabelais-Übersetzung und Wissensparodie, das Buch präsentiert auch eine Fülle von deutschen Worten aus allen Bereichen, besonders die deutschen Fachbegriffe der artes. Hier ein die Alchemie betreffendes Beispiel aus dem 27. Kapitel, in dem der junge Gargantua die Regenzeit nutzt, um die verschiedenen Werkstätten und die dort zum Einsatz kommenden Tätigkeiten und Geräte kennenzulernen:

26 Solche Namensspiele durchziehen die Geschichtklitterung, sie variieren mitunter zwischen den Auflagen. Eine Aufstellung bietet der Anhang der Ausgabe von Hildegart Schnabel: Fischart: Geschichtklitterung (Anm. 3), S. 545f.

27 Fischart: Geschichtklitterung (Anm. 3), S. 258-277. Die Kolumnentitel in dieser Ausgabe finden sich in den ersten beiden Auflagen nicht, nur in der Ausgabe letzter Hand von 1590: Johann Fischart: Geschichtklitterung (Anm. 3) [...], Straßburg: Bernhard Jobin 1590, S. 332337.

28 [Fischart, Johann, Michael Toxites], Onomastica II. I: Philosophicum, Medicum, Synonymum ex variis vulgaribusque linguis. II: Theophrasti Paracelsi: hoc est earum vocum, quarum in scriptis eius solet usus esse, explicatio [...]. Straßburg: Bernhard Jobin 1574. 
Oder sie giengen auß, oder fuhren herumb etliche künstliche Werck vnd fund zubeschawen, wie man die Metall extrahirt vnd soluirt, scheidet vnd auß ziehet: die Alchemisten, wie sie calcinieren, reuerberiren, cimentiren, sublimiren, fixiren, putreficirn, circulirn, ascrudirn, lauiren, imbibiren, cohobiren, coaguliren, tingiren, transmutiren, laminiren, stratificiren, den Ko̊nig suchen, den Geist, den ,lapidem philosophorum', den Mann beim Weib, den entloffenen Mercurium, vnd , per omnes species' gradiren [...]: Jtem wie man falsche Perlein, Edelgestein vnd Corallen mach: dann auß dem mißbrauch lehrt man den rechten brauch: der mißbrauch ist aller guten bråuch rost, der sich stets an hångt: also $\mathrm{dz}$ auch einer schreibet, ,Superstitiones' seien ,Religionis Rubigines'. ${ }^{29}$

Der Alchemistenspott dieser Passsage steht im Anschluss an die umfassend ausgebreitete Fachsprachenterminologie. Das entsprechende Kapitel des Romans bietet viele weitere solcher Wortlisten, welche die Fachterminologie der Münzpräger, der Fechter, der Bergleute etc. versammeln und alle mit Invektiven gegen die speziellen Betrugsmöglichkeiten enden. Der Spott ergießt sich also über alle Gewerke und Verrichtungen. Die deutschen Fachausdrücke, welche Fischarts 27. Kapitel bietet, wurden von den Brüdern Grimm aus der Geschichtklitterung in das Deutsche Wörterbuch aufgenommen. Die fachsprachlichen alchemischen Ausdrücke sind noch nicht Bestandteil der ersten, 1575 erschienenen Auflage der Geschichtklitterung, sie wurden in der zweiten Auflage ergänzt, die 1582, also ein Jahr nach dem Correctorium Alchymiae, erschien. Das Beispiel zeigt mithin auch den Austausch zwischen den satirischen Schriften Fischarts und seinen Fachschriften.

Vor diesem Hintergrund nun wären die für das Correctorium Alchymiae in der bisherigen Forschung formulierten Alternativen (Ausdruck eines überzeugten Alchemisten oder nur kommerziell orientiert) noch einmal zu hinterfragen. Die Handreichung für an deutschsprachigen Texten interessierte Freunde und Liebhaber der Alchemie passt auch in die verschiedenen patriotischen Bemühungen der Offizin Jobin, zur Aufwertung des Deutschen und zu einer Vorführung der Differenziertheit und Genauigkeit deutscher Fachbegriffe beizutragen. Über die patriotischen Bestrebungen Jobins und Fischarts, deutsche Fach- und Literatursprache durch den Druck verschiedener literarischer und fachsprachlicher Texte voranzubringen, wird demnächst die Zusammenschau über die Bücher der Offi-

29 Fischart: Geschichtklitterung 1969 (Anm. 3), S. 280f. - Die kursivierten Passagen in der Ausgabe von Hildegart Schnabel weisen auf den 1582 gegenüber der Erstauflage hinzugekommenen Text Fischarts. Die in einfache Anführungszeichen gesetzten lateinischen Begriffe sind im Original durch Antiqua ausgezeichnet, die deutschsprachigen Passagen sind in Schwabacher gesetzt. 
zin Jobins in der Dissertation von Silvia Brockstieger informieren. ${ }^{30}$ Ich meine, dass trotz aller Mängel in der konsequenten Durchführung so ein Bestreben auch in den von Fischart herausgegebenen alchemischen Schriften erkennbar bleibt. Fischarts Zusammenarbeit mit Toxites an den Onomastica due zeigt, dass hier von einer Schnittmenge zwischen einem Interesse an der Verbreitung paracelsistischer und alchemischer Schriften und der patriotischen Sprachpolitik Fischarts und Jobins ausgegangen werden kann. Fischart wird dadurch nicht zum glühenden Paracelsisten oder Alchemiker, eine kommerzielle Orientierung allein greift als Erklärungsmodell allerdings zu kurz.

Und Fischart belässt es nicht bei der Sprachpräsentation. In der Geschichtklitterung werden die Fachsprachen Gegenstand sprachlicher Manipulation und poetischer Modifizierung. Ein letztes Beispiel aus dem Bereich der Alchemie, das durch Sprachspiele mit anderen Fachterminologien ergänzt werden kann: Fischart entwirft eine aberwitzige Aitiologie des Krieges aus einem Streit um Eier und kommt von da aus auf die Alchemisten zu sprechen. Auch dieser Passus findet sich in der Erstauflage von 1575 nicht, Fischarts Ergänzung lässt sich mithin im Umfeld der Auseinandersetzung mit alchemischer Sprache im Correctorium Alchymiae situieren:

Vnd die Alchymisten, wie viel verderben sie Eyer mit jrem Calcinieren? Aber es sind bo̊ß Bruthennen, sie lauffen gemeynlich bald von der Brut? [...] Daruon der Londisch Johan vom Ey groß Monadisch heimlichkeit den Keyser lehrt, als er beweißt, die Welt geh wie ein Ey umb: [...] Nun so viel hat dannoch der vom Ey, auß den Grabakarabis ,Pillularijs' ergarakrabelet, daß wir all auß eim Ey herkommen, weil die Welt ein Ey ist: das hat gelegt ein Adler, das ist die hoch, weit und schnellfliegend Hand des Jupiters, das ist das ,Chaos', das ,Cauum', das ,Chaouum', der offen Ofen, hauffen, Hafen, welches des Adlers Hitz Chaouirt, Fouirt, Feurofirt, Chaoquirt vnnd Coquirt: Ja Jupiters krafft war distillirer inn dem ,Vacuo Cauo Ouo', inn dem Ofen Hafen Ey: Der schoß war der Himmel: O jhr Alchymisten frewet euch, hie geht euer geheimnuß an. Diß scho̊n Ey, hat zersto̊rt die Sủndflutisch Mistkäferey, da ein Mistkasten vber die Wolcken inn den andern Elementen ist vmbgefahren, der Dotter im Eyerklar. ${ }^{31}$

Wenn es in der Alchemie nicht gelingen kann, die Metalle auf eine materia prima $\mathrm{zu}$ reduzieren und durch Neuformierung zu etwas Anderem und Neuem zu machen - in der Sprache ist dergleichen durchaus möglich. Wortbildungsspiele, die nach der alchemistischen Devise solve et coagula die Morpheme durch Kom-

30 Der Arbeitstitel der 2014 verteidigten Dissertation lautet: Arbeit am Deutschen. Johann Fischart im Kontext der Offizin Bernhard Jobin. Die Arbeit wird voraussichtlich 2015 in der Reihe Frühe Neuzeit erscheinen.

31 Fischart: Geschichtklitterung (Anm. 3), S. 294-95-zur typographischen Einrichtung vgl. oben Anm. 29. 
position und Derivation zu Neologismen erhitzen, finden sich in der Geschichtklitterung allenthalben. Von hier aus gesehen lassen sich Fischarts wissensvermittelnde Partizipation am alchemischen Diskurs einerseits sowie seine dämonisierende Kritik und satirische Verspottung der Alchemie andererseits als Phänomen neuzeitlicher Pluralisierung fassen, welche verschiedene und auf den ersten Blick gegensätzliche Schreibweisen auf eine Person zu vereinen erlaubt, zumal, wenn diese Person als studierter Jurist in einer Offizin arbeitet, von der aus ganz verschiedene Rezipientenbedürfnisse bedient werden. Zugleich zeichnet sich bereits bei Fischart eine Ausbeutung alchemischer Sprache, Bilder und Verfahren zu sprachästhetischen Zwecken ab. Dies geschieht im engen Zusammenspiel mit Aufwänden, welche der Etablierung und Begründung einer deutschen Fachsprache gelten. Alchemische und magische Praktiken und Vorstellungen der frühen Neuzeit sind nicht lediglich als Vorstufe moderner Naturwissenschaften zu betrachten, von ihnen aus führt auch ein Weg in moderne Sprach- und Literaturästhetik. ${ }^{32}$

32 Vgl. dazu die Beiträge von Volkhard Wels und Jan-Dirk Müller in diesem Band. 


\title{
Epistemische Figurationen
}

\section{Überlegungen zum Status von Magiern und Alchemisten in der Wissensordnung der Frühen Neuzeit}

\author{
Marina Münkler, Dresden
}

In der Forschung zur mittelalterlichen und frühneuzeitlichen Alchemie ist heftig umstritten, welchen Status sie in der Wissensordnung hatte und ob die herausragende Bedeutung der Alchemie und des alchemistischen Schrifttums im 16. und 17. Jahrhundert darauf hindeutet, dass sich hier ein epistemischer Bruch vollzog, der sich darin zeigt, dass die Alchemie in die Chemie transformiert wurde und damit den Status einer Wissenschaft erlangte. ${ }^{*}$ Ähnliches gilt für die Geschichte der Magie, die während des ganzen Mittelalters praktiziert wurde, im späten 15. und 16. Jahrhundert ein gelehrtes und teilweise sehr populäres Schrifttum entfaltete, sich gleichzeitig aber gegen den Verdacht erwehren musste, eine teuflische Kunst zu ein. Es geht in diesen Diskussionen grundsätzlich um die Frage, welcher Status Magie und Alchemie zugewiesen wurde, welche Geltungsbehauptungen mit ihnen verbunden waren und welche Anerkennung sie erlangten. Umstritten ist in diesem Kontext auch, ob, und wenn ja, welchen $\mathrm{Zu}$ sammenhang es zwischen Alchemie und Magie gibt. Einerseits finden sich zeitgenössisch wechselseitige Distanzierungen von Magiern und Alchemisten, andererseits gibt es zahlreiche Überschneidungen und Übereinstimmungen beider Gruppen. Zu klären ist von daher, ob Magier und Alchemisten im 16. Jahrhundert epistemische Figurationen bildeten, die zu Kristallisationspunkten eines Kampfes um die Ordnung des Wissens wurden.

Um dieser Frage nachzugehen, werde ich zunächst einige Aspekte der Wissensgeschichte erläutern und meine Verwendung der beiden Leitbegriffe Episteme und Figuration in Anlehnung an Michel Foucault sowie Norbert Elias und Niklas Luhmann zu klären versuchen, anschließend den Status und die Geltungsbehauptungen magischen und alchemischen Wissens im Kontext der Wissensordnungen und anhand bildlicher Darstellungen betrachten, um am Schluss meine Thesen zur Ausgangsfrage darzulegen. Der Beitrag nimmt nicht für sich in Anspruch, Geltung und Status alchemischen und magischen Wissens in der

* Dieser Beitrag ist im Rahmen eines Projekts entstanden, das vom support-the-bestProgramm aus Mitteln der Exzellenzinitiative an der Technischen Universität Dresden gefördert wird. 
Frühen Neuzeit klären zu können. Er versteht sich vielmehr als Beitrag zur Diskussion über die Frage epistemologischer Schwellen.

\section{Wissenschaftsgeschichte und Episteme}

In seiner Archäologie des Wissens hat Michel Foucault drei Modelle der Wissensgeschichte unterschieden: 1. die rekurrentielle Analyse, 2. die historische Analyse oder epistemologische Geschichte und 3. die archäologische Geschichte. Unter rekurrentieller Analyse versteht er die retrospektive Geschichte einer Wissenschaft seit der Überschreitung ihrer Formalisierungsschwelle, d.h. eine Wissenschaftsgeschichte, die innerhalb der von ihr beschriebenen Wissenschaft angesiedelt ist und der es darum geht, den Weg ihrer zunehmenden Perfektionierung darzustellen. ${ }^{1}$ Dagegen erläutert die historische Analyse oder epistemologische Geschichte, wie sich eine Wissenschaft gegen und über ein vorwissenschaftliches Niveau hinweg entwickelt hat, welche Hindernisse und Grenzen sie überwinden musste. Die konstituierte Wissenschaft, so Foucault, wird dadurch zur Norm, die Geschichte wird erzählt unter dem Aspekt der binären Codierung von Wahrheit und Irrtum, Rationalität und Irrationalität, Wissenschaftlichkeit und Unwissenschaftlichkeit. ${ }^{2}$ Die archäologische Geschichte dagegen untersucht die Schwellen der Epistemologisierung, d.h. der diskursiven Praktiken, „insoweit sie einem Wissen Raum geben und dieses Wissen das Statut und die Rolle von Wissenschaft annimmt ". ${ }^{3}$ Das impliziert, auch all jene diskursiven Formationen zu untersuchen, denen es nicht gelingt, die Schwelle der Anerkennung als Wissenschaft zu überschreiten, ohne selbst die Wissenschaft zur herrschenden Norm $\mathrm{zu}$ machen. ${ }^{4}$

Foucault unterscheidet vier Schwellen einer diskursiven Formation: 1. die Schwelle der Positivität, 2. die Schwelle der Epistemologisierung, 3. die Schwelle der Wissenschaftlichkeit und 4. die Schwelle der Formalisierung. ${ }^{5}$

Die Abfolge dieser vier Schwellen ist jedoch nicht als quasi-natürlicher $\mathrm{Ab}$ lauf oder als Regel zu verstehen; nicht jede diskursive Formation überschreitet jede dieser Schwellen und auch deren Reihenfolge ist nicht eindeutig festgelegt. Ihre Anordnung ist vielmehr ein besonderes Merkmal der jeweiligen diskursiven Formation. Das bedeutet, dass Diskurse auch Aussagen umfassen, die nicht einer institutionalisierten Wissenschaft zugerechnet oder in diese überführt werden können, weil die Schwelle der Wissenschaftlichkeit nur eine bestimmte

1 Vgl. Michel Foucault: Die Archäologie des Wissens. Frankfurt a.M. 1973, S. 270 (frz. Original: L'archéologie du savoir. Paris 1969).

2 Vgl. Foucault: Archäologie des Wissens (Anm. 1), S. 270f. Ein imposantes Beispiel für diese Art der Wissenschaftsgeschichtsschreibung, wie sie insbesondere im 19., aber auch noch bis weit in das 20. Jahrhundert dominant war, ist Lynn Thorndike: History of Magic and Experimental Science. 8 Bde. London, New York 1923-1958.

3 Foucault: Archäologie des Wissens (Anm. 1), S. 271.

4 Vgl. Foucault: Archäologie des Wissens (Anm. 1), S. $271 \mathrm{f}$.

5 Vgl. Foucault: Archäologie des Wissens (Anm. 1), S. $265 \mathrm{f}$. 
Schwelle in der Geschichte des Wissens markiert. ${ }^{6}$ Die Geschichte der epistemischen Ordnungen ist daher nicht mit der Geschichte der Wissenschaften gleich zu setzen.

Unter Episteme versteht Foucault

die Gesamtheit der Beziehungen, die in einer gegebenen Zeit die diskursiven Praktiken vereinigen können, durch die die epistemologischen Figuren, Wissenschaften und vielleicht formalisierten Systeme ermöglicht werden; den Modus, nach dem in jeder dieser diskursiven Formationen die Übergänge zur Epistemologisierung, zur Wissenschaftlichkeit und zur Formalisierung stattfinden und sich vollziehen; [...] die lateralen Verhältnisse, die zwischen epistemologischen Figuren oder Wissenschaft bestehen, insoweit sie zu benachbarten, aber distinkten diskursiven Praktiken gehören. ${ }^{7}$

In Bezug auf den Zusammenhang von Magie, Alchemie und Chemie sind die zuletzt genannten "lateralen Verhältnisse“ von besonderem Interesse, denn sie weisen darauf hin, dass weder alle epistemologischen Figuren in einer Wissenschaft aufgehen noch von ihr unmöglich gemacht werden. Obgleich diese lateralen Verhältnisse darauf schließen lassen, dass es sich um übergreifende Wissensformen handelt, versteht Foucault sie keineswegs als synonym zu Begriffen wie Weltbild oder Mentalität. Wenn er schreibt, dass die Episteme nicht das sei, was man in einem Zeitalter „unter Berücksichtigung der technischen Unzulänglichkeiten, der geistigen Gewohnheiten oder der durch die Tradition gesetzten Grenzen" ${ }^{\prime 8}$ wissen könne, sondern das, was in einer diskursiven Praxis die Existenz der epistemologischen Figuren und Wissenschaften möglich mache, wird deutlich, dass er damit nicht universale, epochale Merkmale oder Denkmuster meint, sondern eine bestimmte diskursive Anordnung dessen, was ausgesagt werden kann.

Episteme lässt sich demnach am ehesten mit Wissensordnung übersetzen, deren besondere Gestalten die epistemologischen Figuren bilden, also je spezifische Anordnungen des Wissens, die einerseits unterhalb der Schwelle der Wissenschaftlichkeit liegen, andererseits das Feld bilden, in dem diese erscheinen kann. ${ }^{9}$ Wissenschaftlichkeit ist hier nicht im Sinne eines eingelösten Anspruchs

6 Vgl. Barbara Birkhan: Foucaults ethnologischer Blick. Kulturwissenschaft als Kritik der Moderne. Bielefeld 2012, S. 132f.

7 Foucault: Archäologie des Wissens (Anm. 1), S. 272f.

8 Foucault: Archäologie des Wissens (Anm. 1), S. 274.

9 Die epistemologischen Figuren sind daher nicht mit Vorläufern von Wissenschaften zu verwechseln. Siehe dazu die instruktiven Ausführungen Hans-Jörg Rheinbergers (Historische Epistemologie zur Einführung. Hamburg 2007, S. 104) zu George Canguilhems Modellierung der Wissenschaftsgeschichte sowie zu Michel Foucaults Archäologie. Vgl. Georges Canguilhem: Der Gegenstand der Wissenschaftsgeschichte. In ders.: Wissenschaftsgeschichte und Epistemologie. Gesammelte Aufsätze. Hrsg. von Wolf Lepenies, übers. von M. Bi- 
auf Wahrheit zu denken, sondern im Sinne eines leitenden Paradigmas mit institutionalisierten Räumen, Statusverteilungen und Positionen, dem Wahrheit als Geltungsanspruch zugeschrieben wird.

\section{Epistemologische Figurationen}

In der Archäologie des Wissens wie schon in der Ordnung der Dinge werden solche epistemologischen Figuren jenseits ihrer Protagonisten gedacht. ${ }^{10}$ Weder Autoren noch Werke von Vertretern einer jeweiligen Wissensordnung spielen für Foucault eine Rolle, vielmehr schreibt er die "stumme Geschichte" eines Denkens. ${ }^{11}$ In seiner Antrittsvorlesung am Collège de France (1970) ändert er diese Auffassung aber insofern, als er nunmehr den Autor „als Prinzip der Gruppierung von Diskursen, als Einheit und Ursprung ihrer Bedeutungen, als Mittelpunkt ihres Zusammenhalts " begreift. ${ }^{12}$ Während er ein Subjekt, das Bedeutung generiert, ablehnt, fasst er den Autor als eine Funktion der Regulierungsmechanismen von Diskursen. Der Diskurs bestimmt demnach die Regeln, nach denen Aussagen gemacht werden können, und definiert, wie und in welcher Weise Autoren darin erscheinen. Dazu gehören in erster Linie die Regeln der Disziplin, die nach dem Prinzip der Ausschließung, der Verknappung und der Beschränkung organisiert sind. ${ }^{13}$ Über diese beiden Funktionen wird der Zugang zu Diskursen reglementiert. An Diskursen kann nicht jeder teilhaben, sondern nur diejenigen, die durch das Ritual, die Diskursgesellschaften, die Doktrinen und die gesellschaftlichen Aussagen zugelassen werden. Das Ritual besteht aus den vorgeschriebenen Qualifikationen, Gesten und Verhaltensweisen, die die sprechenden Individuen besitzen bzw. beherrschen müssen, um eine bestimmte Position einnehmen und eine bestimmte Aussage tätigen zu können. ${ }^{14}$

Obwohl es naheliegend wäre, erwähnt Foucault in diesem Kontext bestimmte Typisierungen von Diskursfunktionen nicht. Die Funktion des Autors und des Rituals sind jedoch auch insofern miteinander verschränkt, als beide in bestimmten Typisierungen miteinander korreliert werden. Diskurse bringen nicht nur die Funktion des Autors hervor, der sich bestimmten Ritualen unterwerfen

schoff und W. Seitter. Frankfurt a.M. 1979 (frz. Original: L'objet de l'histoire des sciences. Paris 1968). Vgl. auch Hans-Jörg Rheinberger: Historialität, Spur, Dekonstruktion. In ders.: Experiment, Differenz, Schrift. Zur Geschichte epistemischer Dinge. Marburg 1992, S. 47-66, sowie Ulrich Johannes Schneider: Wissensgeschichte, nicht Wissenschaftsgeschichte. In: Michel Foucault. Zwischenbilanz einer Rezeption. Frankfurter Foucault-Konferenz 2001. Hrsg. von Axel Honneth und Martin Saar. Frankfurt a.M. 2003, S. 220-229.

10 Michel Foucault: Die Ordnung der Dinge. Eine Archäologie der Humanwissenschaften. Frankfurt a.M. 1971, S. 46-56 (frz. Original: Les mots et les choses. Paris 1966).

11 Philipp Sarasin hat dies unter anderem auf Foucaults Cassirer-Lektüre zurückgeführt. Vgl. ders.: Michel Foucault zur Einführung. Hamburg 2005, S. $102 f$.

12 Michel Foucault: Die Ordnung des Diskurses. Mit einem Essay von Ralf Konersmann. Erw. Auflage. Frankfurt a.M. 1991, S. 20 (frz. Original: L'ordre du discours. Paris 1971).

13 Vgl. Foucault: Ordnung des Diskurses (Anm. 12), S. 20-22.

14 Vgl. Foucault: Ordnung des Diskurses (Anm. 12), S. 27. 
muss, um als Autor anerkannt zu werden, sondern auch Typisierungen solcher Autoren. So produziert der medizinische Diskurs den Mediziner, der biologische Diskurs den Biologen etc. Solche Typisierungen bezeichne ich als epistemische Figurationen. Epistemische Figurationen fungieren als Leitbilder und Kulminationspunkte epistemischer Ordnungen. Unter epistemischen Figurationen verstehe ich somit die verkörperten Typisierungen, in denen Diskurse zusammenlaufen. In diesem Sinne ist der Magier die epistemische Figuration des Magiediskurses, der Alchemist die Figuration des alchemischen Diskurses, die beide innerhalb des Diskurses der Naturkunde angesiedelt sind. Epistemische Figurationen sind daher mehr als bloße Personifikationen eines bestimmten Typus, wie etwa Sebastian Brants Haintz Narr oder Doktor Gryiff, oder bestimmter Gegenstände und Begriffe, wie etwa sol und luna oder Hobbes' Leviathan. Anders als Personifikationen verkörpern Figurationen zugleich Interdependenzen und Machtgeflechte, Wahrheitsansprüche und Diskurspositionen. Wer einen Alchemisten oder Magier beschreibt oder bildlich darstellt, muss keine bestimmte Person zeigen, sondern eine Figur, die an ihren Positionierungen und Handlungen als Magier oder Alchemist identifizierbar ist, weil an ihr bestimmte Interdependenzgeflechte und epistemische Relationen sichtbar werden. Beide sind Figurationen eines Wissens, das epistemologisch relevant, mit hohen Geltungsansprüchen ausgestattet, andererseits aber auch prekär ist, weil es die Schwelle der Wissenschaftlichkeit nicht überschritten hat.

Für Magier und Alchemisten ist kennzeichnend, dass sie als Figurationen der Naturerkenntnis und Naturbeherrschung gedeutet werden können - oder als solche, die an dieser Aufgabe scheitern. Damit sind sie, und das ist eines ihrer Spezifika, zugleich Figurationen von Risiko. Sie verkörpern das Risiko von Praktiken und Identitäten, die einen je bestimmten epistemologisch relevanten Anspruch personifizieren, der sich auf besondere Fähigkeiten und Fertigkeiten stützt und sich häufig über die Abgrenzung vom herrschenden Diskurs definiert, aber nur in Teilen oder gar nicht über eine institutionell gesicherte Position verfügt. Von zentraler Bedeutung sind dabei die Positionierung innerhalb gesellschaftlicher Machtgeflechte und die Geltungsmacht, die sich etwa über Beziehungen zu den jeweiligen Herrschern und Höfen aufbauen lässt oder verschlossen bleibt.

Im Hinblick auf die Aspekte von Machtgeflechten und Geltungsmacht kann ein solcher Figurationsbegriff an Überlegungen von Norbert Elias, Pierre Bourdieu und Niklas Luhmann anschließen. Norbert Elias versteht unter einer Figuration ein dynamisches soziales Netzwerk von untereinander abhängigen Individuen. Die Beziehungen zwischen den Akteuren sind innerhalb seiner Theorie sozialer Beziehungen zunächst nicht mehr als das Grundcharakteristikum jeder sozialen Gemeinschaft.

Das Geflecht der Angewiesenheiten von Menschen aufeinander, ihre Interdependenzen, sind das, was sie aneinander bindet. Sie sind das Kern- 
stück dessen, was hier als Figuration bezeichnet wird, als Figuration aufeinander ausgerichteter, voneinander abhängiger Menschen. [...] Der Begriff der Figuration ist gerade darum eingeführt worden, weil er klarer und unzweideutiger als die vorhandenen begrifflichen Werkzeuge der Soziologie zum Ausdruck bringt, daß das, was wir ,Gesellschaft' nennen, weder eine Abstraktion von Eigentümlichkeiten gesellschaftslos existierender Individuen, noch ein ,System' oder eine ,Ganzheit' jenseits der Individuen ist, sondern vielmehr das von Individuen gebildete Interdependenzgeflecht selbst. ${ }^{15}$

Insofern haben Figurationen bei Elias einen hohen Allgemeinheitsgrad. Sie sind aber mit Machtbalancen verknüpft, die ein integrales Element personaler Beziehungen bilden:

Aber ob die Machtdifferenziale groß oder klein sind, Machtbalancen sind überall da vorhanden, wo eine funktionale Interdependenz zwischen Menschen besteht. Der Gebrauch des Wortes Macht führt uns in dieser Hinsicht in die Irre. [...] Macht ist nicht ein Amulett, das der eine besitzt, der andere nicht; sie ist eine Struktureigentümlichkeit menschlicher Beziehungen $[\ldots] .^{16}$

Dass solche Machtdifferenziale immer auch ein Bestandteil diskursiver Ordnungen sind, hat Foucault in der Ordnung des Diskurses formuliert und damit gegenüber der Archäologie des Wissens seiner Diskursanalyse einen neuen und zentralen Aspekt eingefügt. Die Ausschlussmechanismen von Diskursen sind grundsätzlich vom Willen zur Macht bestimmt. ${ }^{17}$ Auf Machtbalancen beruhende Interdependenzgeflechte lassen sich auch als Netzwerke mit je spezifischen Knotenbildungen beschreiben, in denen Aspekte kulminieren, die bestimmte Identitäten ausprägen. Der Einzelne wird darin nicht mehr als konkrete Person, sondern als Verkörperung bestimmter Vorstellungen, Haltungen und Handlungen innerhalb eines Netzwerkes begriffen. Figurationen entstehen somit innerhalb von Netzwerken und bilden bestimmte Identitäten aus. ${ }^{18}$ Pierre Bourdieu be-

15 Norbert Elias: Über den Prozeß der Zivilisation. Frankfurt a.M. 1976 (zuerst 1939), Bd. 1, S. LXVIIf. Vgl. auch ders.: Die Gesellschaft der Individuen. Frankfurt a.M. 1967, S. 31-34.

16 Norbert Elias: Was ist Soziologie? Weinheim ${ }^{10} 2004$, S. 85. Zur Figurationssoziologie vgl. Herbert Willems: Theatralität als (figurations-)soziologisches Konzept: Von Fischer-Lichte über Goffman zu Elias und Bourdieu. In: ders.: Theatralisierung der Gesellschaft. Hrsg. von dems. Bd. 1: Soziologische Theorie und Zeitdiagnose. Wiesbaden 2009, S. 75-110, zu Elias S. 100-107.

17 Vgl. Michel Foucault: Ordnung des Diskurses (Anm. 12), S. 11

18 Eine sehr instruktive Analyse von Figurationen, allerdings mit einem anderen Fokus, hat Jan A. Fuhse vorgelegt. Vgl. ders.: Systeme, Netzwerke, Identitäten. Die Konstitution sozialer Grenzziehungen am Beispiel amerikanischer Straßengangs. (Schriftenreihe des Instituts für Sozialwissenschaften der Universität Stuttgart: No. 1/2003) Stuttgart 2003. Fuhse verweist darin auf die Untersuchung von Eiko Ikegami über den japanischen Samurai, dessen 
greift solche Interdependenzgeflechte als die Verfügung über soziales und kulturelles Kapital innerhalb eines sozialen Feldes, das einen bestimmten Habitus ausprägt. ${ }^{19}$

Niklas Luhmann schließlich versteht derart generierte Identitäten als Ordnungsaspekte, die Erwartungen hervorrufen und bestätigen:

Es werden Identitäten projektiert, an denen man Erwartungen festmachen kann, und durch solche Zuweisung an identisch Bleibendes werden Erwartungen sachlich geordnet. So richtet man Zusammenhänge und Unterscheidungen ein. [...] Die Identität ist mithin [...] ein punktualisierter, hochselektiver Ordnungsaspekt von Welt. ${ }^{20}$

Solche Identitäten begreife ich als Figurationen, die bestimmbare Positionen, d.h. Knotenpunkte innerhalb von Netzwerken, Machtkonstellationen und Wissensordnungen ausmachen.

\section{Magisches Wissen}

Die Geschichte der Magie wird zumeist als Geschichte magischer Praktiken und Rituale beschrieben. ${ }^{21}$ Häufig wird sie unter dem Rubrum ,Geschichte des Aberglaubens' zusammengefasst und mit der Volkskultur in Verbindung gebracht. ${ }^{22}$ Magie war im Mittelalter aber keineswegs nur ein Element der Volkskultur, sondern sowohl von ihrer theoretischen Konzeption als auch von ihren Praktiken her ein Elitenphänomen. Mittelalterliche Gelehrte, Theologen, Philosophen und Mediziner beschäftigten sich mit Magie, und an den mittelalterlichen Höfen

Konstruktion ähnlichen Netzwerkregeln folgt, wie ich sie hier für den Magier und den Alchemisten annehme. Vgl. dies.: The Taming of the Samurai. Honorific Individualism and the Making of Modern Japan. Cambridge, Mass. 1995.

19 Zum Habitusbegriff vgl. Pierre Bourdieu: Zur Soziologie der symbolischen Formen. Frankfurt a.M. 1970, bes. S. 132-145; siehe dazu auch Pierre Bourdieu, Loï J.D. Wacquant: Reflexive Anthropologie. Frankfurt a.M. 1996, S. 155. Zu den Kapitalsorten vgl. ders.: Ökonomisches Kapital, kulturelles Kapital, soziales Kapital. In: Soziale Ungleichheiten. Hrsg. von Reinhard Kreckel. Göttingen 1983, S. 183-198.

20 Niklas Luhmann: Soziale Systeme. Frankfurt a.M. 1996, S. $426 f$.

21 Zur Geschichte der Magie im Mittelalter vgl. nach wie vor Richard Kieckhefer: Magie im Mittelalter. München 1992 (engl. Original: Magic in the Middle Ages, Cambridge 1992); ders.: Magic. In: Medieval Latin. An Introduction and Bibliographical Guide. Hrsg. von Frank A.C. Mantello, Arthur G. Rigg. Washington 1996, S. 422-426; Helmut Birkhan: Magie im Mittelalter. München 2010; Christoph Daxelmüller: Zauberpraktiken. Eine Ideengeschichte der Magie. Düsseldorf ${ }^{4} 2001$.

22 Vgl. dazu den instruktiven Tagungsbericht von Thomas Wünsch: Religion und Magie in Ostmitteleuropa: Spätmittelalter und frühe Neuzeit. Ein Tagungsresümee. In: zeitenblicke 5 (2006), Nr. 1, URL: http://www.zeitenblicke.de/2006/1/Wuensch/index_html, URN: urn:nbn: de:0009-9-2833 (02.01.2015). Beide Ansätze der Geschichte der Magie als Volks- und als Elitenphänomen verbindet Kieckhefer: Magie im Mittelalter (Anm. 21). 
standen insbesondere Astrologen und Wahrsager als Ratgeber in politischen und militärischen Entscheidungen hoch im Kurs. ${ }^{23}$

Umstritten in der Geschichte der Magie war seit dem frühen Christentum die Einteilung in weiße und schwarze, d.h. in natürliche und dämonische Magie. Das lag nicht zuletzt daran, dass das Christentum seit seinen Anfängen selbst beschuldigt wurde, dämonischer Magie zu huldigen und eine von einem Magier begründete Sekte zu sein. Das Grundproblem bestand darin, dass die Wunder, die Christus, die Apostel und die Heiligen nach christlicher Auffassung gewirkt hatten, von außen betrachtet von Zauberei nicht zu unterscheiden waren. Nicht zuletzt das Zeichen des Kreuzes und die Reliquienverehrung konnten als Magie und Zauber angesehen werden. ${ }^{24}$ Umgekehrt beschuldigten frühchristliche Autoren die Anhänger heidnischer Religionen, gar keine Religion zu haben, sondern Götzen anzubeten und von Dämonen angeleitete Magie und Zauberei zu betreiben.

Aufgrund dieser Gemengelage gab es für die gelehrte Magie ein doppeltes Abgrenzungsproblem: einerseits von den volkskulturellen Praktiken, andererseits vom Vorwurf, schwarze Magie zu betreiben. Die Abgrenzung von natürlicher und dämonischer, weißer und schwarzer Magie blieb deshalb während des ganzen Mittelalters virulent. Sie begleitete die Geschichte der gelehrten Magie bis in die Frühe Neuzeit und findet sich häufig auch in den gelehrten Abhandlungen derjenigen, die eine natürliche Magie propagierten und unter dem Zwang standen, sich von der dämonischen Magie abzugrenzen. Das war freilich alles andere als einfach, denn die Grundlage für ihre Verwechselbarkeit bildete die Wissensordnung selbst, welche die Schöpfung als von geistigen Kräften durchwirkt sah, in denen die Zeichen Gottes in der Welt niedergelegt waren. Die Natur trug das Wort und die Schrift Gottes ebenso in sich wie ihre Nachahmung und Verfälschung durch das Wirken des Teufels. Ob es also darum ging, die Zeichen der Schrift oder die Zeichen der Natur zu lesen und die ihnen innewohnenden geistigen Kräfte anzurufen oder die dämonischen Kräfte zu bannen, war im Prinzip nicht unterscheidbar; es konnte nur durch die Ausschlussmechanismen der diskursiven Ordnung hergestellt werden, indem festgelegt wurde, wer sprechen durfte, von welcher Position aus, mit welchem Wahrheitsanspruch etc. Die Grundlage der gelehrten Magie aber bildete die Episteme der Ähnlichkeit.

Die Vorstellung einer natürlichen Magie hatte es im ganzen Mittelalter gegeben, in der Renaissance jedoch erlangte sie mit den Vertretern des Florentiner

23 Vgl. Frank Fürbeth: Die Stellung der artes magicae in den hochmittelalterlichen ,Divisiones philosophiae'. In: Artes im Mittelalter. Hrsg. von Ursula Schäfer. Berlin 1999, S. 249-262; für einen Überblick über die in der Forschungsgeschichte zugrunde gelegten Magievorstellungen und den mittelalterlichen Wortgebrauch von ars magica und magia siehe auch ders.: Zum Begriff und Gegenstand von Magie im Spätmittelalter. Ein Forschungsproblem oder ein Problem der Forschung? In: Jahrbuch der Oswald von Wolkenstein Gesellschaft 12 (2000), S. 411-422.

24 Vgl. Kieckhefer: Magie im Mittelalter (Anm. 21), S. 45-51. 
Humanismus einen entscheidend verbesserten Zugang zur Macht. Dieser ermöglichte es den Florentiner Intellektuellen, an der von Cosimo de' Medici gegründeten Akademie ihren Interessen nachzugehen, ohne auf deren Integrationsfähigkeit in die Ordnung der mittelalterlichen Universität achten zu müssen. Die Universität, die die Funktion eines Diskurswächters inne hatte, konnte damit umgangen werden.

Der Florentiner Neuplatonismus beschrieb die natürliche Magie als eine Wissenschaft, der es darum ging, die okkulten Kräfte der Natur zu ergründen und nutzbar zu machen. In seinem 1489 erschienen Werk De vita libri tres, einer Diätetik, die insbesondere für die unter dem Einfluss des Saturn stehenden Gelehrten gedacht war, begründete Marsilio Ficino aus der Verbindung von Neuplatonismus und Astrologie eine verborgene Macht der Gestirne, bei der die proprietates occultae der Materie von den Sternen herrührten. ${ }^{25}$ Die Magie verfolgte daher das Ziel, sich den spiritus mundi zu Nutze zu machen, der im gestirnten Himmel verborgen war. ${ }^{26}$ Insbesondere der dritte Teil von De vita libri tres beschäftigte sich mit der Frage, wie man den Einfluss der Gestirne neutralisieren oder positiv nutzen könne. Für den Melancholiker empfahl Ficino insbesondere all die Dinge, die von solarer Natur waren, wie etwa Honig, Safran, Bernstein und Gold, um dem dunklen Einfluss des Saturn entgegen zu wirken. Für Ficino war die gesamte Natur von okkulten Einflüssen beseelt, weil sie von der Weltseele durchwirkt war. Da dies auch für den Menschen galt, die Schnittstelle von Makrokosmos und Mikrokosmos, waren insbesondere diejenigen, die sich darauf verstanden, die Natur zu erkennen, nämlich die Magier, dazu prädestiniert, den universalen Geist des Kosmos nutzbar zu machen. ${ }^{27}$

Anders als Marsilio Ficino richtete Giovanni Pico della Mirandola seinen Blick nicht gen Himmel, um die proprietates occultae der Natur zu erkennen und nutzbar zu machen, sondern auf die Kabbala. Stärker noch als Ficino war Giovanni Pico, der astralmagischen Einflüssen durchaus skeptisch gegenüber stand, von der Wirksamkeit magischer Worte überzeugt.

25 Zu Marsilio Ficino vgl.: Marsilio Ficino: His Theology, his Philosophy, his Legacy. Hrsg. von Michael J.B. Allen und Valery Rees. Leiden 2002. Siehe daneben nach wie vor: Paul Oskar Kristeller: Die Philosophie des Marsilio Ficino. Frankfurt a.M. 1972. Zur Konzeption der natürlichen Magie bei Marsilio Ficino vgl. Wolf-Dieter Müller-Jahncke: Astrologisch-magische Theorie und Praxis in der Heilkunde der frühen Neuzeit. Stuttgart 1985, S. 41-56; ders.: Zum Magie-Begriff in der Renaissance-Medizin und Pharmazie. In: Humanismus und Medizin. Hrsg. von Rudolf Schmitz und Gundolf Keil. Weinheim 1984, S. 99-116, hier S. 100-104. Siehe daneben auch Wayne Shumaker: The Occult Sciences in the Renaissance. Los Angeles, London 1972, S. 120-133.

26 Vgl. Marsilio Ficino: Liber de vita triplici. Three Books on Life. A Critical Edition and Translation with Introduction and Notes. Hrsg. von Carol V. Kaske und John R. Clark, Binghamton, N.Y. 1989, III, S. 248 u. 258.

27 Vgl. Kieckhefer: Magie im Mittelalter (Anm. 21), S. 168-171. 
Wie Ficino betonte er aber den Wert der natürlichen Magie, die Kräfte der Natur zu erkennen und zu nutzen. In seiner Schrift De hominis dignitate (1496) schrieb er dem Magier nahezu schöpferische Macht zu:

[...] sie [die Magie, MM] holt die in den Tiefen der Welt, im Schoß der Natur, in den geheimen Speichern Gottes verborgenen Wunder ans Licht hervor, als wäre sie selber ihr Schöpfer, und wie der Bauer die Ulmen mit den Weinreben, so vermählt der Magier die Erde mit dem Himmel, das heißt das Untere mit den Gaben und Kräften des Höheren. ${ }^{28}$

Für Giovanni Pico war die Magie jedoch weniger ein Instrument der Manipulation als vielmehr der Erkenntnis der Natur. Insofern stand sie auch nicht im Widerspruch zur Erkenntnis Gottes, sondern war vielmehr ihr Medium:

Denn nichts fördert die Frömmigkeit und die Verehrung Gottes mehr als die ständige Betrachtung der Wunder Gottes. Wenn wir diese durch die natürliche Magie, die wir hier behandeln, gut erforscht haben, werden wir uns für die Verehrung und Liebe des Schöpfers glühender begeistern und nicht anders können als zu singen: ,Voll sind die Himmel, voll ist die ganze Erde von der Majestät deiner Herrlichkeit.' ${ }^{29}$

Mit Giovanni Pico rückte das Studium der jüdischen Kabbala ins Zentrum magischen Wissens. Die magischen Worte der Kabbala waren für ihn die Grundlage magischer Macht. ${ }^{30}$

Das gilt auch für Johannes Reuchlin, der seit seinen beiden Florentiner Aufenthalten in den Jahren 1482 und 1490 mit Ficino und Pico in Kontakt stand und das Studium des Hebräischen und der Kabbala mit großer Inbrunst betrieb. In seinem im Abstand von mehr als zwanzig Jahren entstandenen Werken De verbo mirifico (1494) und De arte Cabalistica (1517) beschreibt er die machtvollen Worte der Kabbala als Grundlage der wunderbaren Werke, die der Magier mit der Hilfe Gottes zu bewirken vermag. ${ }^{31}$ Das wunderwirkende Wort (verbum mirificum) wirkte aber nicht nur auf der Grundlage einer mystischen Vereinigung von

28 [...] [magia] in mundi recessibus, in naturae gremio, in promptuariis arcanisque Dei latitantia miracula, quasi ipsa sit artifex, promit in publicum, et sicut agricola ulmos vitibus, ita Magus terram caelo, idest inferiora superiorum dotibus virtutibusque maritat. Giovanni Pico della Mirandola: De hominis dignitate / Über die Würde des Menschen. Lateinisch-deutsch. Übers. von Norbert Baumgarten, hrsg. und eingeleitet von August Buck. Hamburg 1990, S. 57.

29 Pico della Mirandola: De hominis dignitate (Anm. 28), S. 57.

30 Vgl. Kieckhefer: Magie im Mittelalter (Anm. 21), S. 170-174. Zur Rezeption der Kabbala im 15. und 16. Jahrhundert vgl. Wilhelm Schmidt-Biggemann: Geschichte der christlichen Kabbala: 15. und 16. Jahrhundert. Stuttgart-Bad Cannstatt 2012.

31 Vgl. Charles Zika: Johannes Reuchlin und die okkulte Tradition der Renaissance. Sigmaringen 1998; ders.: Exorcising Our Demons: Magic, Witchcraft, and Visual Culture in Early Modern Europe. Leiden 2003, S. 21-68. 
Mensch und Gott, sondern trug diese Macht in sich selbst und konnte so die Wundermacht des Menschen begründen. ${ }^{32}$

Heinrich Cornelius Agrippa, der die naturmagischen und kabbalistischen Schriften Marsilio Ficinos, Giovanni Picos della Mirandola und Johannes Reuchlins rezipiert hatte, stellte sich in diese Tradition und führte unterschiedliche Aspekte im Prinzip des Okkulten zusammen. In seinem 1510 zunächst handschriftlich verbreiteten und 1533 in einer erweiterten Ausgabe gedruckten Werk De occulta philosophia unterschied er die elementarische, die himmlische und die geistige Welt, woraus sich drei verschiedene Arten von Magie ergaben: Die natürliche Magie beschäftigte sich mit der elementarischen Welt und untersuchte deren okkulte Sympathien; die Magie der himmlischen Welt behandelte die Einflüsse und Kräfte der Planeten und deren Nutzbarmachung; die zeremonielle Magie richtete sich an die Engel, die der Magier sich durch mystische Gebete und andächtiges Flehen geneigt machen könne. ${ }^{33}$ Die Möglichkeit einer magia caeremonialis beruhte auf der Kenntnis der seelischen virtutes des Menschen, die der anima mundi ähnelten, weil beide die vom Archetypus ausgehenden Ideen in sich trugen. ${ }^{34}$ Wirksam werden konnte sie allerdings nur, wenn es dem magus gelang, seine Seele vom Körper zu lösen und so Mikrokosmos und Makrokosmos zu beherrschen. Nach Agrippa bot die magische Wissenschaft den besten Weg, die Natur zu erkennen, die in ihr wirkenden virtutes elementales und virtutes occultae zu verstehen und wirksam zu machen. ${ }^{35}$

Die magische Wissenschaft, der so viele Kräfte zu Gebot stehen, und die eine Fülle der erhabensten Mysterien besitzt, umfasst die tiefste Betrachtung der verborgensten Dinge, das Wesen, die Macht, die Beschaffenheit, den Stoff, die Kraft und die Kenntnis der ganzen Natur. Sie lehrt uns die Verschiedenheit und die Übereinstimmung der Dinge kennen. Daraus

32 Vgl. Zika: Exorcising our Demons (Anm. 31), S. 24f.

$33 \mathrm{Zu}$ dieser Einteilung bei Agrippa von Nettesheim vgl. Wolf-Dieter Müller-Jahncke: Agrippa von Nettesheim: De occulta philosophia. Ein „Magisches System“. In: Magia naturalis und die Entstehung der modernen Naturwissenschaften. Hrsg. von Alfred Heinekamp und Dieter Mettler. Wiesbaden 1978, S. 19-26, hier S. 22; ders.: Magie als Wissenschaft im frühen 16. Jahrhundert. Die Beziehung zwischen Magie, Medizin und Pharmazie im Werk des Agrippa von Nettesheim. Marburg, Lahn 1973; ders.: The Attitude of Agrippa von Nettesheim (1486-1535) torwards Alchemy. In: Ambix 22 (1975), S. 134-150; Paola Zambelli: Cornelius Agrippa, ein kritischer Magus. In: Die okkulten Wissenschaften in der Renaissance. Hrsg. von August Buck. Wiesbaden 1992, S. 65-90; Zika: Exorcising Our Demons (Anm. 31), S. 99154.

34 Vgl. Christopher I. Lehrich: The Language of Demons and Angels. Cornelius Agrippa's Occult Philosophy. Leiden 2003, bes. S. 185-205.

35 Zur Relation von virtutes elementales und virtutes occultae vgl. Müller-Jahncke: Agrippa von Nettesheim (Anm. 33), S. 24f. Zur Konzeption von Magie als Wissenschaft bei Agrippa siehe ders.: Magie als Wissenschaft (Anm. 33), S. 35-36. Vgl. auch ders.: Astrologisch-magische Theorie und Praxis in der Heilkunde der frühen Neuzeit. Stuttgart 1985 (Sudhoffs Archiv, Beiheft 25), S. 95-97. 
folgen ihre wunderbaren Wirkungen; indem sie die verschiedensten Kräfte miteinander vereinigt und überall das entsprechende Untere mit den Gaben und Kräften des Oberen verbindet und vermählt. Die Wissenschaft ist daher die vollkommenste und höchste, sie ist eine erhabene und heilige Philosophie, ja sie ist die absolute Vollendung der edelsten Philosophie. ${ }^{36}$

Dazu diente insbesondere die Betrachtung der Sprache, denn die Buchstaben ließen sich nach der Emanationslehre als geistige virtutes begreifen, die durch den Schöpfer selbst in die Welt gelegt worden waren. Deshalb auch mussten die Worte und insbesondere der Name des Schöpfers, wie er im hebräischen Tetragrammaton und seiner Umwandlung in das christliche Pentagrammaton niedergelegt war, ergründet werden. ${ }^{37}$

Die Behauptung der strikten Wissenschaftlichkeit von Magie ging nicht zufällig mit einer deutlichen Abgrenzung von Zauberern und Teufelsschülern einher, von denen Agrippa sich in seiner Occulta philosophia scharf distanzierte ein Vorwurf, dem er im Übrigen selbst immer wieder ausgesetzt war. Insbesondere die von ihm einbezogene zeremonielle Magie ließ sich nicht leicht von der magia daemonica (schwarzen Magie) abgrenzen, als deren Hauptcharakteristikum die Bezwingung von Dämonen galt. Die Anrufung von Dämonen, die er zu Handlungen zwingen wollte, setzten ihn dem Verdacht des Teufelspakts aus, d.h. der Unterwerfung unter die Macht des Teufels. ${ }^{38}$ Dem versuchte er durch die scharfe Abgrenzung von der schwarzen Magie zu begegnen, was freilich

36 Magica facultas, potestatis plurimae compos, altissimis plena mysteriis, profundissimam rerum secretissimarum contemplationem, naturam, potentiam, qualitatem, substantiam et virtutem totiusque naturae cognitionem complectitur et quomodo res inter se differunt et quomodo conveniunt nos instruit, hinc mirabilis effectus suos producens, uniendo virtutes rerum per applicationem earum ad invicem et ad sua passa congruentia, inferiora superiorum dotibus ac virtutibus passim copulans atque maritans: haec perfectissima sumaque scientia, haec altior sanctiorque philosophia, haec denique totius nobilissimae philosophiae absoluta consummatio. Cornelius Agrippa: De occulta philosophia libri tres. Hrsg. von Vitoria Perrone Compagni. Leiden 1992, Liber I, cap. 2, S. 86.

37 Zur Funktion der Sprache vgl. Christopher I. Lehrich: The Language of Demons (Anm. 34), bes. S. 157-159.

38 Vgl. Michael Keefer: Cornelius Agrippa's Double Presence in the Faustian Century. In: The Faustian Century. German Literature and Culture in the Age of Luther and Faustus. Hrsg. von James M. van der Laan und Andrew Weeks. Rochester, New York 2013, S. 67-92, hier S. 70-72. Zur Faust-Tradition vgl. Marina Münkler: Narrative Ambiguität. Die Faustbücher des 16. bis 18. Jahrhunderts. Göttingen 2011; zu Faust als Alchemist vgl. Helen WatanabeO'Kelly: Exploring the „Three-Fold World“: Faust as Alchemist, Astrologer, and Magician. In: The Faustian Century. German Literature and Culture in the Age of Luther and Faustus. Hrsg. von James M. van der Laan und Andrew Weeks. Rochester, New York 2013, S. 241256. 
nicht verhinderte, dass er verdächtigt wurde, mit dem Teufel im Bund zu stehen und schwarze Magie zu betreiben. ${ }^{39}$

Eine ähnlich Geste der Abgrenzung vollzog Agrippa auch gegenüber der Alchemie, deren allegorische Arkansprache er scharf von der Sprache der Magie abgrenzte. Im XC. Kapitel von De incertitudine et vanitate scientiarum spottete er über die Sprache der Alchemisten,

es wäre allzu langatmig all die törichten Mysterien und unnützen Rätsel dieser Kunst zu erzählen, von dem grünen Löwen, dem fliehenden Hirschen, dem fliegenden Adler, dem springenden Narren, dem Drachen, der seinen Schwanz verschlingt, der aufgeblähten Kröte, dem Rabenkopf, von der Schwärze, die schwärzer als schwarz ist, dem Siegel des Hermes, dem Dreck der Narrheit (ich sollte sagen Weisheit) und ähnlichem unendlichen Unsinn. ${ }^{40}$

\section{Alchemie, Chemie und die Alchemisten}

Ähnlich negativ wie Heinrich Cornelius Agrippa urteilte Sebastian Brant in seinem 1493 erschienen Narrenschiff über die Alchemie. Brant charakterisiert die alchemey im Titel des 102. Kapitels seines Narrenschiffs als falsch vnd beschiss und urteilt in dem das Bild begleitenden gnomischen Vers:

Man spüert wol in der alchemey

Vnnd in des wynes artzeny

was falsch / vnd bschiss vff erden sy. ${ }^{41}$

Brants satirische Invektive wandte sich zunächst allgemein gegen Fälscherei und Betrug:

Betrůger sint / vnd fålscher vil

Die to̊nen reht zủm narren spiel

Falsch lieb / falsch rot / falsch frünt / falsch gelt

Voll vntruw ist yetz gantz die welt[.] $]^{42}$

Anschließend wandte er sich explizit der alchemey zu, unter der er die Transmutation von Metallen verstand:

Do mit ich nit vergeß hie by

Den grossen bschiß der alchemey

39 Vgl. Keefer: Cornelius Agrippa's Double Presence (Anm. 38). Paola Zambelli: Scholastiker und Humanisten: Agrippa und Trithemius zur Hexerei. In: Archiv für Kulturgeschichte 67 (1985), S. 41-79.

40 Agrippa von Nettesheim: De incertitudine et vanitate scientiarum, Kap. XC: De alcumistica. In: Heinrich Cornelius Agrippa von Nettesheim, Opera. Hildesheim, New York 1970, S. 263.

41 Sebastian Brant: Das Narrenschiff. Studienausgabe. Mit allen 114 Holzschnitten des Drucks Basel 1494. Hrsg. von Joachim Knape. Stuttgart 2005, Kap. 102, S. 464.

42 Brant: Das Narrenschiff (Anm. 41), Kap. 102, 1-4, S. 465. 
Die macht das sylber / golt / vff gan

Das vor ist jnn das ståcklin gtan

Sie goucklen / vnd verschlagen grob

Sie lont eyn sehen vor eyn prob

So würt dann bald eyn uncken druß

Der guckuß manchen tribt von huß

Der vor gar sanfft / vnd trucken saß

Der stoßt sin gůt jns affenglaß

Biß ers zů puluer so verbrent

Das er sich selber nit me kennt

Vil hant also verderbet sich

Gar wenig sint syn worden rich

Dann Aristoteles der gycht

Die gstalt der ding wandeln sich nicht[.. ${ }^{43}$

Offenbar gingen Agrippa und Brant von unterschiedlichen Aspekten der Alchemie aus: Während Agrippa die Arkansprache der gelehrten Alchemie kritisierte, rügte Brant die nach seiner Überzeugung betrügerische Behauptung, Stoffe transformieren zu können, mit denen der Alchemist freilich nicht nur seinem Publikum, sondern auch sich selbst etwas vormache, weil er auf der vergeblichen Suche nach Reichtümern sein ganzes Hab und Gut verschleudere. Die Alchemie, auf die Brant zielte, war die Werkstattalchemie der wenig Gebildeten, die sich an alchemischen Experimenten versuchten, um zu Reichtum zu gelangen. Ähnlich wie die Magie unterteilte sich die Alchemie in gelehrtes naturkundliches und praktisches Wissen.

Die Äußerungen zeigen, dass die Alchemie im System der mittelalterlichen Wissensorganisation in anderer Weise prekär war als die Magie. ${ }^{44}$ Die Alchemie war weder in den septem artes liberales vertreten noch war sie, etwa neben der Medizin, ein eigenständiges naturkundliches Fach. Sie konnte aber auch nicht wirklich zu den artes mechanicae gerechnet werden, obwohl deren Feld für die unterschiedlichsten praktischen, auf Anwendung hin orientierten Künste offen war. Was zu den artes mechanicae gehörte, war zwar nicht genau definiert, aber in keiner der bekannten Definitionen ließ sich die Alchemie ohne weiteres integrieren. Fasste Johannes Scotus Eriugena im 9. Jahrhundert darunter vestiaria (Bekleidungshandwerk), agricultura (Landwirtschaft), architectura (Bauhand-

43 Brant: Das Narrenschiff (Anm. 41), Kap 102, 49-64, S. $466 f$.

44 Einen allgemeinen Überblick über die Geschichte der Alchemie bieten: Joachim Telle: Art. Alchemie II. In: Theologische Realenzyklopädie, Bd. 2 (1978), S. 199-227; Richard van Dülmen: Das Buch der Natur - die Alchemie. In: Macht des Wissens. Die Entstehung der modernen Wissensgesellschaft. Hrsg. von dems. Köln u.a. 2004, S. 131-154; Michael Horchler: Die Alchemie in der deutschen Literatur des Mittelalters. Ein Forschungsbericht über die deutsche alchemistische Fachliteratur des Mittelalters. Baden-Baden 2005; ders.: Art. Alchemie. In: Lexikon zur Geschichte der Hexenverfolgung, in: historicum.net, URL: http:// www.historicum.net/no_cache/persistent/artikel/5525/ (15.12.2014). 
werk), militia (Kampfkunst, Waffenkunde), venatoria (Jagdkunst), mercatura (Handel), coquinaria (Kochkunst) sowie metallaria (Schmiedehandwerk, Metallurgie), ${ }^{45}$ so rechnete Hugo von St. Viktor in seinem Didascalicon dazu lanificium (Webekunst), armatura (Waffenschmiedekunst), navigatio (Schiffahrt), agricultura (Landwirtschaft), medicina (Heilkunst), venatio (Jagdkunst) sowie theatrica (Schauspielkunst). ${ }^{46}$

Die Alchemie kam hierbei als eigenständige ars mechanica nicht vor. Sie hatte zwar Überschneidungen mit dem Färberhandwerk, der Metallurgie, der Medizin und der Kochkunst, fügte sich aber unter keine von ihnen wirklich ein. Andererseits bildete die Alchemie seit der Aristotelesrezeption des 13. Jahrhunderts und den Übersetzungen aus dem Arabischen, in denen vielfach naturkundliches Wissen im Zentrum stand, einen wichtigen Zweig der abendländischen Wissenskultur. In Theologie und Philosophie hatten naturkundliche Untersuchungen durchaus Platz. Da die gelehrte Alchemie unterschiedliche Wissensgebiete berührte und theoretisch wie theologisch durchaus anspruchsvoll war, gab es hier zunächst keinen Grund, alchemisches Wissen auszugrenzen, auch wenn die Alchemie keinen festen Platz in der mittelalterlichen Universität hatte. ${ }^{47}$ Seit dem 15. Jahrhundert häuften sich an den Universitäten aber Vorlesungen, die die Frage aufwarfen, ob die Alchemie eine wahrhaftige ars oder vom göttlichen Gesetz verboten war: Utrum alchimia sit ars vera nec lege divina prohibite. ${ }^{48}$ So gestellte Fragen lassen eher auf ein kritisches Verhältnis gegenüber der Alchemie schließen, das sich nicht in erster Linie darauf bezog, dass die Alchemie sich

45 Vgl. Iohannis Scotti annotationes in Marcianum. Hrsg. von Cora E. Lutz (Mediaeval Academy of America). Cambridge, Mass. 1939, S. 59.

46 Hugo von St. Viktor: Didascalicon de studio legendi. Hrsg. von Ch. H. Buttimer. Washington 1939, Buch II, Kap. XX, 760A (Divisio mechanicae in septem): Mechanica septem scientias continet: lanificium, armaturam, navigationem, agriculturam, venationem, medicinam, theatricam. Ex quibus tres ad extrinsecus vestimentum naturae pertinent, quo se ipsa natura ab incommodis protegit, quattuor ad intrinsecus, quo se alendo et fovendo nutrit, ad similitudinem quidem trivii et quadrivii, quia trivium de vocibus quae extrinsecus sunt et quadrivium de intellectibus qui intrinsecus concepti sunt pertractat. Dt. Übers. zitiert nach: Hugo von Sankt Victor: Studienbuch [Didascalicon de studio legendi, um 1128]. Übers. und eingeleitet von Thilo Offergeld. Freiburg 1997, S. 193f.

$47 \mathrm{Zu}$ den artes mechanicae vgl. Jutta Bacher: Artes mechanicae. In: Erkenntnis, Erfindung, Konstruktion. Hrsg. von Hans Holländer. Berlin 2000, S. 35-49; zum Verhältnis von artes mechanicae und artes liberales vgl. ,Scientia' und ,ars' im Hoch- und Spätmittelalter. Hrsg. von Ingrid Craemer-Ruegenberg und Andreas Speer. 2 Bde. Berlin, New York 1994. Zum Status der Alchemie im Mittelalter vgl.: Barbara Obrist: Die Alchemie in der mittelalterlichen Gesellschaft. In: Die Alchemie in der europäischen Kultur- und Wissenschaftsgeschichte. Vorträge des 16. Wolfenbütteler Symposiums vom 2.-5. April 1985 in der Herzog August Bibliothek. Hrsg. von Christoph Meinel. Wiesbaden 1986, S. 33-60; George-Florin Călian: Alkimia operativa und alcimia speculativa. Some modern controversies on the Historiography of Alchemy. In: Annual of Medieval Studies at CEU, Bd. 16 (2010), S. 166-190.

48 Vgl. Joachim Telle: Alchemie und Poesie. Deutsche Alchemikerdichtungen des 15. bis 17. Jahrhunderts. Untersuchungen und Texte, Bd. 1. Berlin, Boston 2013, S. 380. 
nirgendwo wirklich zuordnen ließ, sondern darauf, dass sie den Anspruch erhob, unterschiedliche Arten von Stoffen durch Rückführung auf eine prima materia wandeln zu können.

Seit Beginn der Frühen Neuzeit beanspruchte die Alchemie überdies für sich den Rang einer selbstständigen Wissenschaft. Dieser Anspruch ist in erster Linie mit dem Namen Paracelsus und dem sich auf ihn beziehenden Paracelsismus verbunden, der durch seine Verehrung als Begründer einer neuen Wissenschaft, die nicht in der galenischen medizinischen Tradition, sondern ganz in Gott wurzelte, als Konkurrenz zur akademischen Medizin auftrat. ${ }^{49}$

Die gelehrte Alchemie stand der Magie durchaus nah, denn wie die gelehrte Magie versuchte sie, die Geheimnisse der Natur zu ergründen und ihre verborgenen Kräfte zu beherrschen. Die Annahme von qualitates und virtutes occultae, der okkulten causae und rationes der stofflich-materiellen Geschehnisse stellte eine systematische Verbindung zwischen der Astrologie, der Magie und der Alchemie her. ${ }^{50}$ Alle drei gingen davon aus, dass es der unmittelbaren Wahrnehmung verborgene Eigenschaften und Wirkungen der Substanzen gab, die man dem Verstehen zugänglich machen und nutzen konnte.

Die substanzspezifische Wirkung von Medikamenten und Giften, die Identität chemischer Verbindungen, die Einflüsse von Sonne und Mond, elektrostatische und magnetische Anziehung, all dies war durch bloße Mischung der Primärqualitäten warm/kalt, feucht/trocken und der davon abgeleiteten Tastqualitäten nicht zu erklären. Daß aber derartige virtutes oder facultates existierten, war nicht zu bestreiten. Folglich mußte auf die Frage nach der causa efficiens eine sinnlich nicht wahrnehmbare, ,verborgene' Qualität als Ursache angegeben werden. ${ }^{51}$

49 Zum Paracelsismus vgl. Wilhelm Kühlmann: Paracelsismus und Hermetismus. Doxographische und soziale Positionen alternativer Wissenschaft im postreformatorischen Deutschland. In: Antike Weisheit und kulturelle Praxis. Hermetismus in der Frühen Neuzeit. Hrsg. von Anne-Charlott Trepp und Hartmann Lehmann. Göttingen 2001, S. 17-39; ders.: Das häretische Potential des Paracelsismus - gesehen im Licht der Gegner. In: Heterodoxie in der Frühen Neuzeit. Hrsg. von Hartmut Laufhütte und Michael Titzmann. Tübingen 2006, S. 217-242; Hanns-Peter Neumann: Wissenspolitik in der frühen Neuzeit am Beispiel des Paracelsismus. In: Diskurse der Gelehrtenkultur in der Frühen Neuzeit. Ein Handbuch. Hrsg. von Herbert Jaumann. Berlin, New York 2011, S. 255-304. Zum Verhältnis von Magie und Paracelsismus siehe Maximilian Bergengruen: Nachfolge Christi-Nachahmung der Natur. Himmlische und natürliche Magie bei Paracelsus, im Paracelsismus und in der Barockliteratur (Scheffler, Zesen, Grimmelshausen). Hamburg 2007.

50 Vgl. Christoph Meinel: Okkulte und exakte Wissenschaften. In: Die okkulten Wissenschaften in der Renaissance. Hrsg. von August Buck. Wiesbaden 1992, S. 21-44. Zu den virtutes oder qualitates occultae in der Alchemie vgl. William R. Newman: The Occult and the Manifest among the Alchemists. In: Tradition, Transmission, Transformation: Proceedings of Two Conferences on Pre-modern Science held at the University of Oklahoma. Hrsg. von F. Jamil Ragep, Sally P. Ragep und Steven John Livesey. Leiden, New York, Köln 1996, S. 173-198.

51 Meinel: Okkulte und exakte Wissenschaften (Anm. 50), S. 22. 
Daran änderte auch die Verkürzung von Alchemie in Chemie nichts. ${ }^{52}$ Aus der Perspektive der Wissenschaftsgeschichte der Chemie scheint es eine klare Trennung zwischen der Alchemie und der Chemie zu geben. Die Alchemie gehört demnach zur nicht-wissenschaftlichen Vorgeschichte der Chemie. Freilich entspricht dies, wie William R. Newman und Lawrence M. Principe gezeigt haben, keineswegs dem frühneuzeitlichen Sprachgebrauch. ${ }^{53}$ Sowohl im 16. als auch im 17. Jahrhundert finden sich zahlreiche Quellen, in denen die Begriffe Alchemie/Alchymie und Chemie/Chymie synonym verwendet werden und die Differenz lediglich sprachlich auf die Nutzung des arabischen bestimmten Artikels al oder sein Fehlen zurückgeführt wird. So schreibt Werner Rolfinck (1599-1673), der erste Professor für Chemie an der Universität Jena, in seiner 1661 erschienenen Chimia in Artis Formam Redacta:

Tatsächlich gibt es zwischen der Chemie und der Alchemie keinen Unterschied. Mit beiden Worten wird dieselbe Kunst [ars] bezeichnet. Auch sind diejenigen nicht auf dem richtigen Weg, welche die Alchemie und die Chemie daran unterscheiden, dass diese sich nur mit der kunstvollen Herstellung von Medikamenten, jene mit der Transmutation von Metallen beschäftige. Beide bezeichnen die gleiche Sache, mit dem einzigen Unterschied, dass die erstere einen Arabischen Praefix hat, der dem griechischen Artikel ho, hē, to entspricht. ${ }^{54}$

Zwar lehnte Rolfinck die Suche nach dem Stein der Weisen entschieden ab, aber er nutzte dies nicht, um darüber eine grundsätzliche Entgegensetzung von Alchemie und Chemie vorzunehmen. Die Differenz zwischen Alchemie und Chemie beruhte nach seiner Auffassung eher auf der Trennung von Alchemisten und Chemikern. Rolfinck trennte Alchemie und Chemie nicht über eine begriffliche, sondern eine sozio-moralische Differenzierung. Das wird etwa an einer Äußerung über die Motive, Fähigkeiten und insbesondere die prekären Lebensumstände der Alchemisten deutlich, über die Rolfinck unter Bezug auf eine englische Publikation anmerkt:

52 Vgl. Kaspar von Greyerz: Alchemie, Hermetismus und Magie. Zur Frage der Kontinuitäten in der wissenschaftlichen Revolution. In: Im Zeichen der Krise. Religiosität im Europa des 17. Jahrhunderts. Hrsg. von Hartmut Lehmann und Anne-Charlott Trepp. Göttingen 1999, S. 415-432, hier S. 425f.

53 Vgl. William R. Newman, Lawrence M. Principe: Alchemy vs. Chemistry: The Etymological Origins of a Historiographic Mistake. In: Early Science and Medicine 3 (1998), S. 32-65. Scharfe Kritik an Newman/Principe übt George-Florin Călian: Alkimia operativa und alkimia speculativa (Anm. 47), bes. S. 170-172.

54 [Werner Rolfinck] Guerneri Rolfincii Chimia In Artis Formam Redacta. Jena 1661, S. 21: Verùm inter chimiam \& alchimiam nullum discrimen. Utroque vocabulo eadem ars denotatur. Neque etiam reĉtam insistunt viam, qui alchimiam $\mathcal{E}$ chimiam sic distinguunt, ut haec solùm in artificiosa medicamentorum praeparatione, illa verò in metallorum transmutatione saltem occupata sit. Eadem est ejusdem rei appellatio, nisi qvod altera praefixum habeat Arabicum Al aequipollens Graecorum articulo ho, hē, to. (Transkr. und Übers. MM) 
,Alchimia', so schreibt knapp der Mercurius Britannicus in Mundo altero $\mathcal{E}$ eodem, ,ist eine Kunst ohne Kunst, deren Wissen darin besteht, Teile mit Teilen zu mischen, deren Mitte es ist, entschlossen zu lügen, und ihr Ende, am Bettelstab zu gehen oder den Galgen zu besteigen'. ${ }^{55}$

\section{Das Bild des Magiers und des Alchemisten}

Auch Rolfinck orientiert sich damit an der Trennung von gelehrter und praktischer Alchemie, die für den Alchemiediskurs kennzeichnend war. Insbesondere die Transmutation von unedlen Metallen in Gold bildet dabei den entscheidenden Angriffspunkt. Dagegen ist die Figuration des Alchemisten ein in der Druckgraphik und der Malerei des 16. und 17. Jahrhundert klar umrissenes Motiv. Das hängt nicht zuletzt damit zusammen, dass sich der Alchemist aufgrund der praktischen Seite der Alchemie innerhalb eines Ambiente zeigen ließ, das eine klare Zuordnung ermöglichte und Wiedererkennbarkeit garantierte. Für die Transformation von Metallen, die Herstellung von Medikamenten, die Produktion des Lebenselixiers und des Steins der Weisen bedurften die Alchemisten bestimmter Apparaturen, mit deren Hilfe sie Stoffe tingieren, schmelzen, destillieren etc. konnten. Die dafür erforderlichen Räume waren zunächst Werkstätten, die sich nur durch die vorhandenen alchemistischen Instrumente von den Werkstätten der Handwerker unterschieden. Zumeist dominierte ein Kamin mit offenem Feuer, um den herum Blasebälge zum Entfachen des Feuers, Schüsseln und Töpfe, Mörser und Stößel, aber auch spezielle alchemistische Geräte, wie Destillatoren (etwa Retorte und Serpentine) platziert waren. Als Labor, abgeleitet vom lateinischen laborare (arbeiten), wurden solche Werkstätten regelmäßig erst im 17. Jahrhundert bezeichnet. ${ }^{56}$ Ursprünglich verwendet wurde der lat. Begriff laboratorium wohl in Anlehnung an scriptorium (Schreibstube) und dormitorium (Schlafraum) um die Mitte des 15. Jahrhunderts im Kontext des

55 Rolfinck: Chimia In Artis Formam Redacta (Anm. 54), S. 26 (Transkr. und Übers. MM). ,Alchimia', breviter Mercurius Britannicus in mundo altero \& eodem, ,est ars sine arte, cujus scire est pars cum parte, medium strenuè mentiri, finis mendicatum ire, vel in patibulo superbite'. In patibulo sapite, den Galgen besteigen, hatte Rolfinck seiner angegebenen Quelle hinzugefügt.

56 Zur Geschichte der frühneuzeitlichen Laboratorien vgl. Ursula Klein: Die technowissenschaftlichen Laboratorien der Frühen Neuzeit. In: Zeitschrift für Geschichte der Wissenschaften, Technik und Medizin (NTM), N.S. 16 (2008), S. 5-38; Pamela Smith: Laboratories. In: The Cambridge History of Science. Bd. 3: Early Modern Science. Hrsg. von Katharine Park und Lorraine Daston. Cambridge 2006, S. 290-305; dies.: The Business of Alchemy. Science and Culture in the Holy Roman Empire. Princeton 1994, S. 228-246; Rudolf Werner Soukup, Helmut Mayer: Alchemistisches Gold, Paracelsische Pharmaka. Laboratoriumstechnik im 16. Jahrhundert. Chemiegeschichtliche und archäometrische Untersuchungen am Inventar des Laboratoriums von Oberstockstall/Kirchberg am Wagen. Wien, Köln und Weimar 1997; Henning Schmidgen: Labor. In: Europäische Geschichte Online (EGO). Hrsg. vom Institut für Europäische Geschichte (IEG). Mainz 2011-01-03. URL: http://www.iegego.eu/schmidgenh-2011-de URN: urn:nbn:de:0159-20101025256 (01.02.2015). 
Klosters. Im 16. Jahrhundert bezeichnete der Begriff Labor dann zunehmend die Werkstätten von Apothekern, Alchemisten und Metallurgen.

Freilich gab es noch lange Zeit keinerlei Festlegung, wie das Labor eines Alchemisten beschaffen sein musste, um den behaupteten wissenschaftlichen Ansprüchen zu genügen. „Die Laboratorien der Frühen Neuzeit, einschließlich derjenigen des 18. Jahrhunderts, waren hybride Institutionen, in denen Naturbeobachtungen und Experiment mit handwerklich-gewerblicher Produktion und Innovation auf vielfältige Weise verwoben waren." ${ }^{57}$ Nur einige wenige Alchemisten, denen es gelungen war, die Gunst eines Landesherrn zu erringen, verfügten über saubere und wohl geordnete Räume, die allein der alchemistischen Arbeit vorbehalten und mit den besten verfügbaren Instrumenten ausgestattet waren. ${ }^{58}$

Einer davon war Tycho Brahe, für den auf der dänischen Insel Ven in einem schlossartigen Gebäude ein astronomisch-mathematisches Forschungszentrum eingerichtet worden war, das nach Urania, der antiken Muse der Astronomie, Uraniborg hieß. Im obersten Stockwerk beherbergte es eine Sternwarte, im mittleren Geschoss Räume für Karten und Berechnungstafeln und im Keller ein alchemistisches Labor mit den besten und neuesten Geräten der Zeit. ${ }^{59}$ Die alchemistische Praxis der Zeit war zumeist eine andere: Auch an den Laboratorien der Höfe war eine Mischung unterschiedlicher Tätigkeiten und Verfahren gang und gäbe. So hatte Wolfgang II. Graf von Hohenlohe im frühen 17. Jahrhundert zwar ein Labor eingerichtet, aber es war kaum von einer Werkstatt zu unterscheiden. ${ }^{60}$

Die Trennlinie innerhalb der alchemistischen Tradition zwischen gelehrter und praktischer Alchemie zeigte sich auch in den Bildern. Bis ins 17. Jahrhundert waren die bildlichen Darstellungen von Alchemisten in ihren Werkstätten oder Laboren häufig mit einer deutlich negativen Konnotation versehen. ${ }^{61}$ Die Alchemisten erschienen nicht als Gelehrte, sondern als armselige Anhänger einer Kunst, die unwirksam war oder die sie jedenfalls nicht zu beherrschen in der Lage waren.

57 Klein: Die technowissenschaftlichen Laboratorien (Anm. 56), S. 10.

58 Vgl. Jost Weyer: Graf Wolfgang II. von Hohenlohe und die Alchemie. Alchemistische Studien im Schloß Weikersheim, 1587-1610. Sigmaringen 1992.

59 Vgl. John Robert Christianson: On Tycho's Island. Tycho Brahe, Science and Culture in Sixteenth Century England. Cambridge 2000, bes. S. 58-85.

60 Vgl. Smith: Laboratories (Anm. 56), S. 292.

61 Vgl. Jane Russell Corbett: Convention and Change in seventeenth century depictions of alchemists. In: Art and Alchemy. Hrsg. von Jacob Wamberg. Kopenhagen 2006, S. 249-272. 


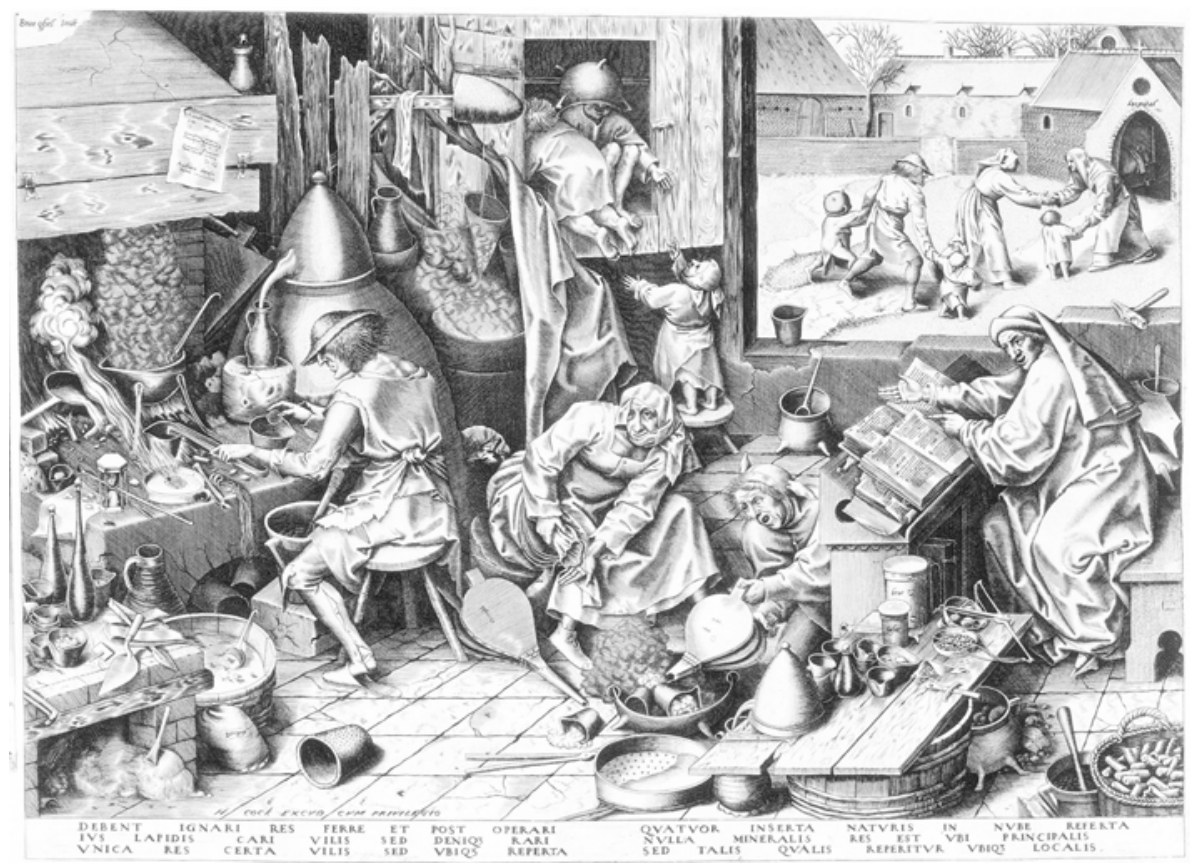

Abb. 1: Philips Galle nach Pieter Bruegel d. Ä.: Der Alchemist, um 1558.

Das wird etwa deutlich in einer nach 1558 entstandenen Federzeichnung Pieter Bruegels d. ̈.., die als Vorlage für einen Kupferstich Philips Galles diente. ${ }^{62}$

Bruegel zeigt auf seinem Bild, wie sinnlos die Bemühungen des Alchemisten sind und welche verhängnisvollen Folgen das für seine Familie hat. ${ }^{63}$ Die Darstellung hat zwei Zeitebenen: Im Vordergrund sieht man die wüste Werkstatt eines auf der linken Seite an einem offenen Kamin sitzenden, in zerrissene Lumpen gekleideten Alchemisten, der damit beschäftigt ist, Münzen zu schmelzen. Über seinem Kopf hängt an der Kaminhaube ein Zettel mit unleserlicher Schrift, auf dem vermutlich eine alchemistische Rezeptur steht. Rechts vor ihm steht eine gewaltige Destillierhaube, aus der eine Flüssigkeit in einen Krug fließt. In der Werkstatt stehen und liegen zahlreiche Dinge herum, von denen einige als Destillierkolben oder andere Alchemistengerätschaften zu erkennen sind. Hinter

62 Philips Galle nach Pieter Bruegel d. Ä.: Der Alchemist (um 1558), Kupferstich, 30,7 x 43,6 cm, Kupferstichkabinett Berlin. Inv.-Nr. KdZ 4399.

$63 \mathrm{Zu}$ Bruegels Alchemist vgl. Roger H. Marijnissen: Bruegel. Das vollständige Werk. Unter Mitarbeit von Peter Ruyffelaere, Peter van Calster, A.W.F.M. Meij. Köln 2003 (niederl. Original: Bruegel, Amsterdam 1988), S. 103-109; Walter S. Gibson: Pieter Bruegel and the Art of Laughter. Berkeley, Los Angeles 2006, S. 44-46; Lawrence M. Principe, Lloyd DeWitt: Transmutations. Alchemy in Art. Selected Works from the Eddleman and Fisher Collections at the Chemical Heritage Foundation. Philadelphia, Penns. 2002, S. 11f. 
dem Alchemisten liegt ein achtlos hingeworfener Blasebalg, neben dem in der Bildmitte seine auf einem Schemel hockende Frau den leeren Geldbeutel ausschüttet, hoffend, es werde noch eine Münze in ihre hingehaltene hohle Hand fallen. Links hinter ihr befindet sich an der Wand ein Vorratsschrank, in den die drei hungrigen Kinder des Alchemistenpaars, offenbar auf der Suche nach etwas Essbarem, hineinzugelangen versuchen. Eines der Kinder sitzt schon mit einem leeren Topf auf dem Kopf darin, das zweite klettert gerade hinein, während das dritte, kleinste der Kinder, schreiend auf einem Schemel steht und hilflos die Arme emporreckt. Neben der abgehärmt aussehenden Ehefrau hockt ein Narr mit einem Blasebalg in der Hand auf dem Boden und versucht damit, in einer Metallschüssel ein Feuer zu entfachen, in dem Gefäße geschmolzen werden sollen. Rechts von ihm sitzt an einem Pult ein Gelehrter, der mit seinem Habit nicht wirklich in die Werkstatt zu passen scheint. Er deutet mit der rechten offenen Hand auf ein vor ihm liegendes aufgeschlagenes Buch, das mit Alghe Mist betitelt ist. Alghe Mist ist doppeldeutig und kann Alchemist oder al he mist bedeuten, was sowohl „alles ist vergeblich" als auch „alles hier ist Mist" heißen kann. ${ }^{64}$ Der Gelehrtenkommentar wird durch die zweite Zeitebene des Bildes, oberhalb seines Pults bestätigt: Durch ein großes, einfach aus der Wand herausgebrochenes Fenster sieht man den zwei seiner Kinder mühsam an der Hand haltenden Alchemisten, dessen Frau mit dem mittleren Kind gerade eine Nonne bittet, sie ins Armenhaus aufzunehmen.

Ähnliche Motive finden sich bei Adriaen van de Venne und Adriaen van Ostade (1610-1685). ${ }^{65}$ Beide zeigen auf ihren Gemälden chaotische Werkstätten, in denen der verarmte Alchemist versucht, Gold herzustellen, während der Blick auf die ebenfalls im Bild befindliche verhärmte Ehefrau und die hungrigen Kinder diese Bemühungen als sinnlos und den Anspruch als wahnhaft erscheinen lassen.

64 Die Bedeutung des Gelehrten ist in der Forschung umstritten; in manchen Untersuchungen wird er als Kommentator des Geschehens begriffen, z.B. von Marijnissen: Bruegel (Anm. 52), S. 106, in anderen wird er als der eigentliche Alchemist gedeutet, der die Anweisungen für die Transmutationsversuche erteilt und die Familie damit ins Unglück stürzt, vgl. Jürgen Müller: Der Alchemist. In: Pieter Bruegel d. Ä. und das Theater der Welt. Hrsg. von Ingrid Mössinger und Jürgen Müller. Berlin, München 2014, S. 182f.; Gibson: Pieter Bruegel (Anm. 63), S. 45.

65 Adriaen van Ostade: Der Alchemist (1661), Öl auf Eiche, 34 x 45,2 cm, London, National Gallery (NG846); Adriaen van de Venne: Rijcke-armode (1636), Öl auf Eiche, Chemical Heritage Foundation Collections, Fisher Collection 00.01.284. Zu van de Venne vgl. Lloyd de Witt, Lawrence M. Principe: Alchemy and its Images in the Eddleman and Fisher Collections at the Chemical Heritage Foudation. In: Art and Alchemy. Hrsg. von Jacob Wamberg. Kopenhagen 2006, S. 221-247, hier S. 225f. 


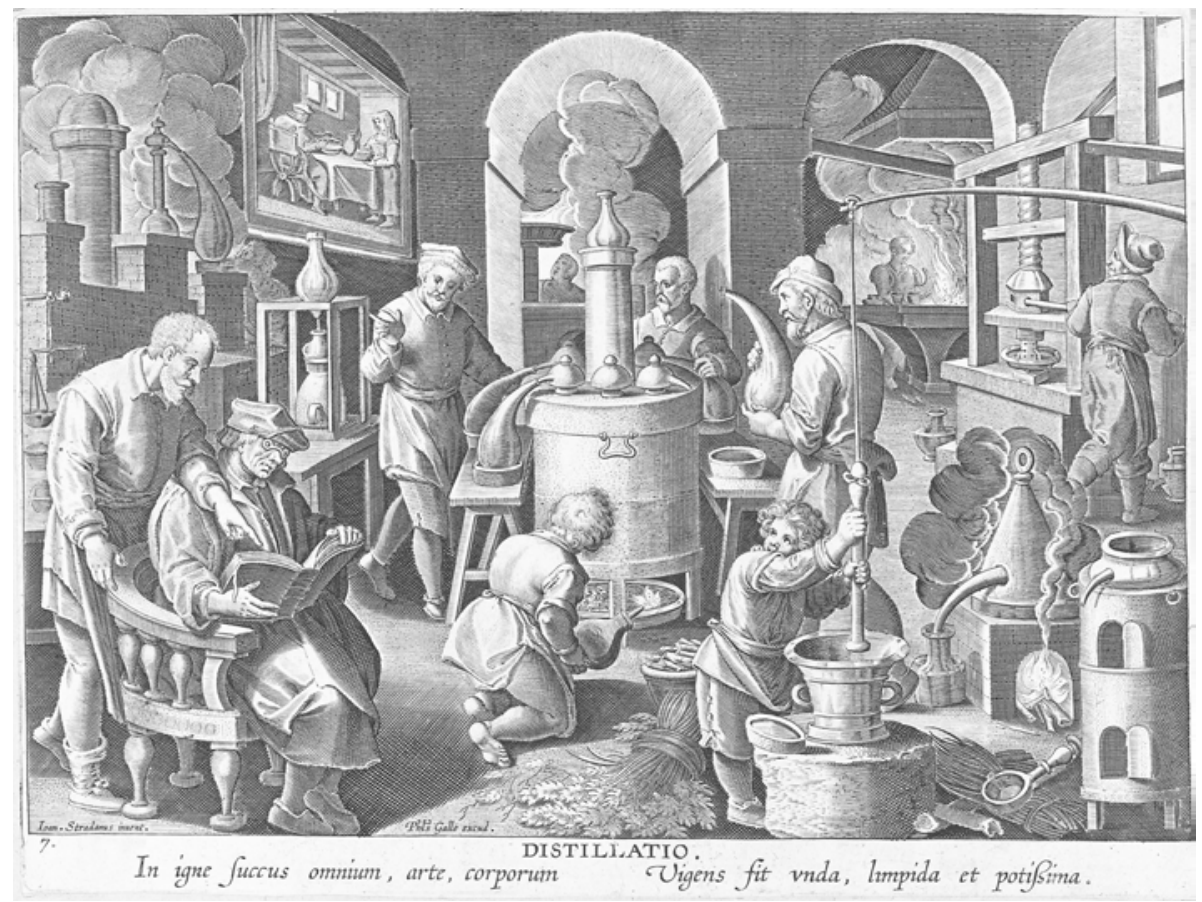

Abb. 2: Unbekannter Stecher nach Jan van der Straet: Distillatio, um 1576-1600.

Andererseits gibt es aber durchaus auch positive Bildfigurationen des Alchemisten. So zeigt ein Kupferstich in Philips Galles Nova reperta (um 1570) ${ }^{66}$ ein perfekt eingerichtetes Labor mit einem schon an seinem Humanistenhut als gelehrt erkennbaren Alchemisten. ${ }^{67}$

Der gesamt Bildaufbau vermittelt den Eindruck wohlorganisierter Ordnung. Sieht man nur auf die Labortätigkeiten, so sind sie nahezu vollständig versammelt: In der Bildmitte befindet sich ein großes Wasserbad mit Destillierhelmen, rechts eine Haubendestillation. Im Hintergrund links steht ein großer Turmofen mit Destillatorium. Von den gängigen Laborarbeiten wird das Auspressen von Pflanzensäften mit einer Schraubenpresse und das Zerkleinern einer Substanz im Mörser dargestellt. Der riesige Pistill ist zur Erleichterung an einer elastischen Wippe aufgehängt. Die Arbeiten werden freilich nicht vom Alchemisten

66 Unbekannter Stecher nach Jan van der Straet: Distillatio (um 1576-1600), Kupferstich, 244 x 370 mm, Herzog August Bibliothek, Wolfenbüttel, Signatur: Graph. A1: 784d.

67 Der flämische Maler Jan van der Straet stellte in seinen Kupferstichen die neuen Erfindungen und Entdeckungen seiner Zeit dar. Dazu gehörten der Buchdruck, die Entdeckung Amerikas, aber auch die Alchemistenlabore, die an den großen Höfen eingerichtet wurden, wie in diesem Fall am Hof des toskanischen Großherzogs Cosimo I. Jan van der Straet malte 1571 auch für das Studiolo Francescos I. im Florentiner Palazzo Vecchio ein Gemälde, das einen Alchemisten in seinem Labor zeigt. 
selbst, sondern von seinen Gehilfen ausgeführt. Der Alchemist sitzt dagegen mit Brille in humanistischer Gelehrtentracht am linken Bildrand auf einem bequemen Sessel, hinter dem interessiert in das aufgeschlagene Buch schauend ein Mann steht, bei dem es sich vermutlich um den Großherzog handelt. Macht und Wissen sind auf diese Weise eng zusammengerückt, der Alchemist ist von der unmittelbaren körperlichen Arbeit befreit, die ihm den Odor des untergeordneten Dienstes verliehen hatte, und in den Status des Wissenden aufgerückt.

Der unter dem Bild abgedruckte lateinische Wahlspruch verkündete optimistisch die Fähigkeit, das von den Alchemisten lange gesuchte Lebenselixier herzustellen: „Hast Du durch Kunst im Feuer den Saft aller Körper geschieden, wird er ein heilsames Nass, klar und so tausendfach stark."

Eine vergleichbare Bildkarriere blieb dem Magier verschlossen. Als epistemische Figuration ist der Magier eine nahezu bildlose Gestalt. Er wird jedenfalls nicht in der Weise figurativ typisiert, dass er mit bestimmten Bildmotiven verknüpft wäre, in denen eine Figur unmittelbar als Magier erkennbar wäre, wie dies für den Alchemisten gilt. Eine der wenigen Ausnahmen bildet das Titelbild zu Paulus Ricius 1516 in Augsburg erschienenen Portae Lvcis H[a]ec est porta Tetragra[m]maton iusti intrabu[n]t p[er] eam, einer Übersetzung von Joseph Gikatillas Kabbalakommentar. ${ }^{68}$

Das Bild zeigt einen auf einem Schemel sitzenden gelehrten Kabbalisten, der einen stilisierten Baum mit den in hebräischer Schrift geschriebenen zehn Sefirot, den göttlichen Namen und Wesenheiten, in der recht Hand hält und ihn sinnierend betrachtet.

Diese Darstellung des durch die Namen Gottes die Natur erkennenden Magiers ist jedoch äußerst selten. In der Regel wird er von konkreten Gestalten verkörpert: seine positive Figuration in der Gestalt des Hermes Trismegistos, die negative Seite in Simon Magus. Eine weitere Verkörperung erlebt der Magier dann noch einmal in der zentralen Gestaltung als der Teufelsbündner Johann Faust. ${ }^{69}$ Seit dem Beginn des Hexendiskurses hat jedoch die Hexe das Bild des Magiers weitgehend abgelöst. ${ }^{70}$

68 Ğîquậ̣lā, Yôsēf Ben-Avrāhām/Paulus Ricius: Portae Lvcis H[a]ec est porta Tetragra[m]maton iusti intrabu[n]t p[er] eam. Augustae Vindelicoru[m], 1516, 17,37 x 20,31 cm, Bayerische Staatsbibliothek, München, Signatur: 4 Exeg. 690, Tbl. Urn:nbn:de:bvb:12-bsb00002115-2. Zu Paulus Ricius vgl. Schmidt-Biggemann: Geschichte der christlichen Kabbala (Anm. 30), S. 209-262; zu den Portae Lucis S. 235-241.

69 Vgl. zur Rolle der curiositas und der Melancholie in diesem Kontext: Marina Münkler: allezeit den Spekulierer genennet. Curiositas als identitäres Merkmal in den Faustbüchern des 16. und 17. Jahrhunderts. In: Faust-Jahrbuch 2 (2005/2006). Hrsg. von Tim Lörke und Bernd Mahl. Tübingen 2006, S. 61-81; dies.: Melancholy and Despair: The Historia von D. Johann Fausten. In: Melancholie - zwischen Attitüde und Diskurs. Konzepte in Mittelalter und Früher Neuzeit. Hrsg. von Andrea Sieber und Antje Wittstock. Göttingen 2009, S. 75-93.

70 Vgl. Charles Zika: The Appearance of Witchcraft. Print and Visual Culture in SixteenthCentury Europe. London, New York 2007. 
Marina Münkler

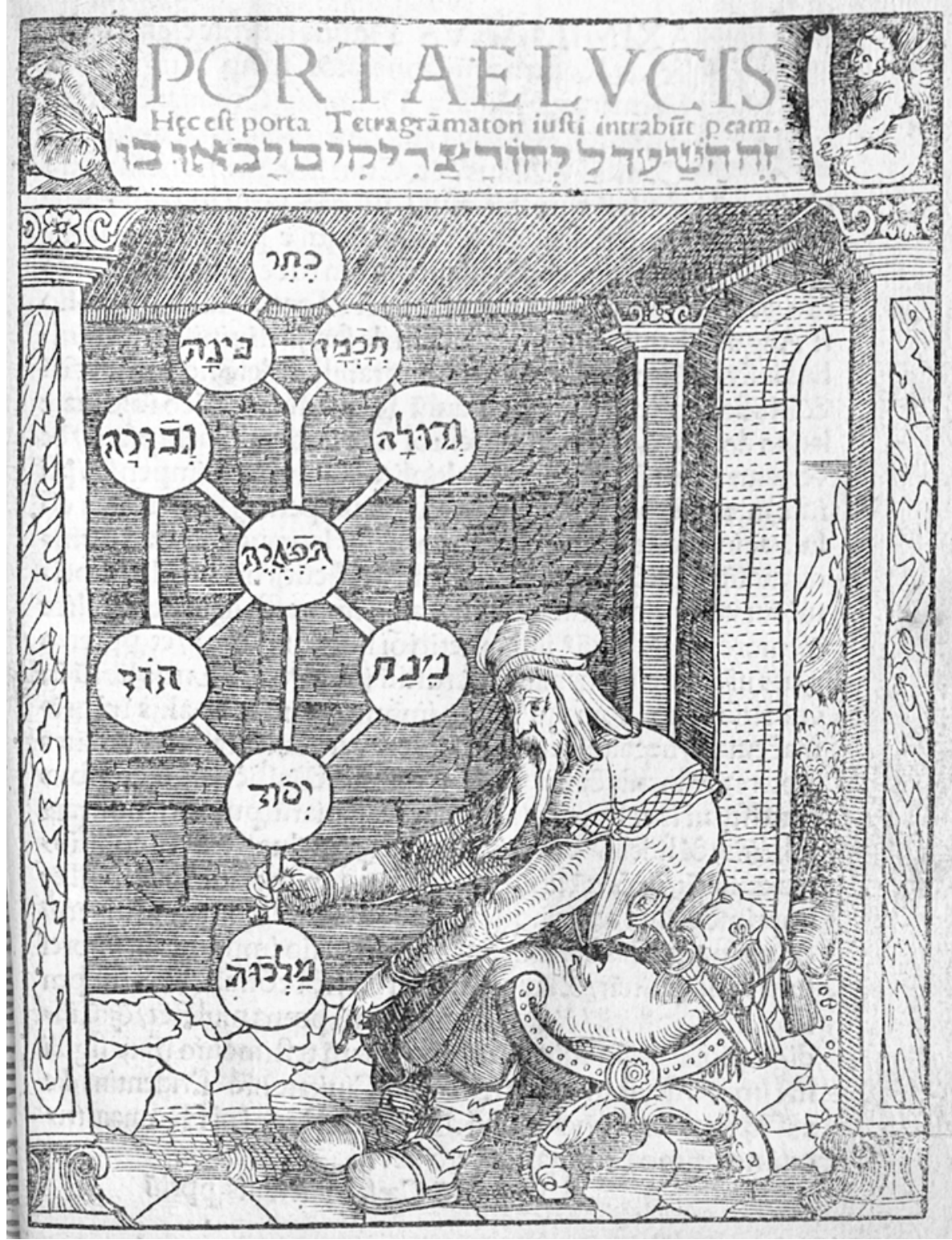

Abb. 3: Paulus Ricius: Portae Lucis, 1516. 


\section{Die Episteme der Ähnlichkeit und die Lesbarkeit der Welt}

Ungeachtet dessen, was Magier und Alchemisten trennte, waren beide Figurationen der Episteme der Ähnlichkeit. Nicht nur die Magie, sondern auch die Alchemie beruhte auf der Episteme der Ähnlichkeit, der Verbindung von Mikrokosmos und Makrokosmos, von elementarer und himmlischer Welt. ${ }^{71}$ Bis ins 16. Jahrhundert drehte sich die Welt, so Michel Foucault, in sich selbst, sie war Wiederholung, Widerspiegelung, Repräsentation. Da die Welt zuerst Raum war, wurden räumliche Beziehungen selbst zu Zeichen, deren grundlegendes das der Ähnlichkeit war. Es erlaubte, Fernes und Nahes miteinander in Beziehung zu setzen, jeden einzelnen Punkt des Raumes mit einem anderen zu verknüpfen und Beziehungen über weiteste Entfernungen hinweg herzustellen. ${ }^{72}$ Als die vier wichtigsten Figuren der Ähnlichkeit beschreibt Foucault die convenientia, die aemulatio, die analogia und das Zusammenspiel von Sympathie und Antipathie. Die convenientia ist die Bezeichnung für die Nachbarschaft von Dingen, convenientes sind die Dinge, die nebeneinander stehen. Diese Nachbarschaft ist eine räumliche Beziehung, aber sie ist zugleich mehr als das. Sie ist nämlich nicht zufällig, sondern bezeichnet eine Ähnlichkeit der Eigenschaften. Nachbarschaft ist nicht nur Zeichen einer äußerlichen Beziehung zwischen den Dingen, sondern sie ist zugleich Zeichen einer tiefen, wenn auch dunklen Verwandtschaft. Die aemulatio kennzeichnet dagegen einen Reflex oder Spiegel, in dem die Dinge aufeinander antworten. Die Dinge können sich über die größte räumliche Entfernung hin aufeinander beziehen, indem sie sich ineinander spiegeln. In der analogia überlagern sich convenientia und aemulatio. Die Ähnlichkeit besteht hier in der subtilen Ähnlichkeit der Verhältnisse der Dinge zueinander. Das Gras etwa verhält sich zur Erde wie die Sterne zum Himmel. Mit der analogia können sich alle Gestalten der Welt einander annähern, ohne dass ihre Distanz aufgehoben wird, und der Mensch selbst erscheint in der Analogisierung von Mikrokosmos und Makrokosmos als der Schnittpunkt all dieser Analogien. Das heißt nicht, dass sie auf ihn zugeschnitten sind. Vielmehr ist er selbst als Bestandteil der Welt ein Teil der göttlichen Offenbarung, wenn er auch, wie etwa bei Hildegard von Bingen, als eine gegenüber dem Makrokosmos höhere Stufe der Offenbarung erscheint. Stärkste Form der Zeichenbeziehung zwischen den Dingen ist die Sympathie, die die Grenzen von Raum und Zeit aufhebt. Die Sympathie ist insofern auch die Figur, welche die Möglichkeit einer Unterscheidung in Frage stellt. Eine solche Infragestellung aber ist problematisch, weil sie die Möglichkeiten der Grenzziehung und damit der Geschiedenheit negiert. Die Sympathie überwindet Raum wie Zeit in einer ideellen Identität der Dinge; und deshalb muss sie immer

71 Vgl. Călian: Alkimia operativa und alkimia speculativa (Anm. 47), S. 179. Grundsätzlich zur Verbindung von Religiosität, Reformation und Alchemie vgl. Urszula Szulakowska: The Sacrificial Body and the Day of Doom: Alchemy and Apocalyptic Discourse in the Protestant Reformation. Leiden 2006.

72 Vgl. Foucault: Die Ordnung der Dinge (Anm. 10), S. 46-56. 
durch ihre Zwillingsgestalt, die Antipathie, kompensiert werden, damit die Dinge sich nicht vollständig assimilieren und ununterscheidbar werden. Die Antipathie garantiert, dass Raum und Zeit ausgedehnte Größen bleiben und nicht zu Punkten zusammenschmelzen, sie zieht die Grenze, die von der Ähnlichkeit zwar immer wieder übersprungen, aber nicht vollständig verwischt wird. Über die Grenzen hinweg können die Dinge aber kommunikativ vermittelt, d.h. so verglichen werden, dass die Relation zwischen ihnen als eine Relation gewahrt bleibt. Die Ähnlichkeit war freilich nicht selbstevident und nicht auf den ersten Blick äußerlich erkennbar. Um sie erkennen zu können, bedurfte es der Signatur, des Zeichens an der Oberfläche, das die unsichtbaren Ähnlichkeiten signalisierte und erkennbar machte. Deshalb mussten die Dinge zunächst beschrieben und benannt werden, um die Signaturen auffinden und die Ähnlichkeiten aufdecken zu können. Dabei konnten die Namen der Dinge ebenso zeichenhaft sein wie ihre Gestalt und die Orte, an denen sie sich befanden, ebenso bedeutsam wie die Eigenschaften, die ihnen zugeschrieben werden. Ähnlichkeit und Signatur ermöglichten somit auch, dass man in der Beschreibung der Welt alles aufnehmen und nebeneinander stellen konnte, was aus den unterschiedlichsten Quellen überliefert war. Schon Augustinus hatte betont, Gott sei nicht der Verfasser eines, sondern zweier Bücher. ${ }^{73}$ Neben die Heilige Schrift trat das Buch der Natur, das ebenfalls gelesen, d.h. über die unmittelbare Wahrnehmung hinaus nach denselben hermeneutischen Regeln gedeutet werden konnte wie die Schrift. In dieser Weise hatte schon Alain de Lille im zwölften Jahrhundert in seinem Rosenhymnus die Lesbarkeit der Welt in den berühmten Vers gefasst: Omnis mundi creatural Quasi liber et pictural Nobis est et speculum. Nostrae vitae, nostrae mortis, I nostri status, nostrae sortis / fidele signaculum. ${ }^{74}$

Die Natur war das Buch, in dem der Mensch las, das Bild, das er betrachtete, und der Spiegel, in dem er sich sah. ${ }^{75}$ Alle Gegenstände konnten damit ebenso untereinander wie zu ihrem Schöpfer in Beziehung gesetzt werden, und indem man die Zeichen las, die Gott auf der Oberfläche der Welt niedergelegt hatte, konnte zugleich der Schöpfer selbst erkannt werden. Auf der Oberfläche der Welt ließ sich in den Dingen ihr Sinn ablesen, und dieser Sinn konnte dann wieder in Büchern niedergelegt werden, die das Buch der Natur deuteten, wie Bonaventura in seinen Collationes in Hexaemeron formulierte: Hic autem liber est Scripturae, qui ponit similitudines proprietates et metaphoras rerum in libro mundi scriptarum. ${ }^{76}$

73 Vgl. Aurelius Augustinus: De Genesi ad Litteram. In: Patrologia Latina 34. Hrsg. von Jean Paul Migne. Paris 1845, S. $219 \mathrm{ff}$.

74 Alani ab Insulis: Liber De Planctu Naturae. In: Opera Omnia. Hrsg. von Jean Paul Migne (Patrologia Latina, CCX), Paris 1855, S. 579f. Vgl. Hans Blumenberg: Die Lesbarkeit der Welt. Frankfurt a.M. ${ }^{21983, ~ S . ~} 51$.

75 Vgl. Clarence Glacken: Traces on the Rhodian Shore. Berkeley 1990, S. $73 f$.

76 Bonaventura Sanctus: Collationes in Hexaemeron. Das Sechstagewerk. Lateinisch und Deutsch. Übersetzt und eingeleitet von Wilhelm Nyssen. München 21979, S. 409. „Dies aber 
Aufgrund der prinzipiellen Zeichenhaftigkeit aller Dinge gab es, wie Michel Foucault gezeigt hat, nicht nur zwei Bücher, die Heilige Schrift und das Buch der Natur; vielmehr traten Sprache und Natur als prinzipiell einheitliches Deutungsfeld nebeneinander:

Es gibt keinen Unterschied zwischen jenen sichtbaren Zeichen, die Gott auf der Oberfläche der Erde gezeigt hat, um uns deren innere Geheimnisse erkennen zu lassen, und den lesbaren Wörtern, die die Bibel oder die Weisen der Antike, die durch ein göttliches Licht erleuchtet worden sind, in ihren Büchern, die die Überlieferung gerettet hat, niedergelegt haben. Die Beziehung zu den Texten ist von gleicher Art wie die Beziehung zu den Dingen; hier wie da nimmt man Zeichen auf. ${ }^{77}$

Durch die Homogenität von Natur und Sprache war es möglich, die Signaturen des Seins aus den Signaturen der Sprache abzulesen. ${ }^{78}$

\section{Erfahrenheit und Erfahrung}

Unter dieser Perspektive bleibt als entscheidende Frage, ob Magier und Alchemisten zwar der Episteme der Ähnlichkeit verhaftet waren, die Alchemisten aber durch die besondere Betonung der Erfahrung und die Arbeit im Labor möglicherweise $\mathrm{zu}$ deren Ablösung beitrugen. Begrifflich erscheint jedoch durchaus fragwürdig, ob der Bezug auf Erfahrung allein als Markierung einer epistemologischen Transformation angesehen werden kann. Experientia und experimentum werden in der Regel synonym verwendet, als experimenta gelten überdies auch die Beschwörungen der Magier.

Anders als im modernen Erfahrungsbegriff wurden Wahrnehmung und Erfahrung nicht in eins gesetzt. So schrieb Johannes Buridan in der Mitte des 14. Jahrhunderts in seinen Quaestiones super octo phisicorum libros Aristotelis:

Jede allgemeine Aussage der Naturphilosophie kann man zum Prinzip erheben, die man durch eine Ableitung aus der Erfahrung [per experimentalem inductionem] beweisen kann, so dass in vielen einzelnen Dingen nachweisbar ist, dass es sich so verhält, und in keinem [und] nie ein Widerspruch erscheint, wie nämlich Aristoteles richtig sagt, dass man viele

ist das Buch der Schrift, das die Gleichnisse (similitudines), Eigenschaften und den Sinn der Dinge, die im Buch der Welt geschrieben sind, darstellt." (S. 410) Similitudines wäre m.E. besser mit Ähnlichkeiten zu übersetzen. Vgl. zu Bonaventura und der Natur als Buch Carsten Colpe: Weltdeutungen im Widerstreit. Berlin, New York 1999, S. $160 f$.

77 Foucault: Die Ordnung der Dinge (Anm. 10), S. 65.

78 Foucaults Darstellung des epistemischen Bruchs zwischen der Episteme der Ähnlichkeit und der Episteme der Repräsentation ist nicht unkritisiert geblieben. Vgl. etwa - mit Bezug auf die Magie - Gary Tomlinson: Music in Renaissance Magic: Toward a Historiography of Others. Chicago 1993, S. 32-66. Dagegen hat Maximilian Bergengruen betont, dass der Magier das Buch der Natur nicht nur zu lesen, sondern auch [mit-]zu schreiben beanspruche. Vgl. Bergengruen: Nachfolge Christi (Anm. 49), S. 160-176. 
Prinzipien aufgrund der Sinne, der Erinnerung und der Erfahrung annehmen und wissen muss; $[\ldots] .{ }^{79}$

Erfahrung war vielmehr eng mit Erinnerung verknüpft, wie dies schon Aristoteles formuliert hatte, der von einer dreistufigen Relation von Wahrnehmung (gr. aisthesis, lat. perceptio), Erinnerung (gr. mneme, lat. memoria) und Erfahrung (gr. empeiria, lat. experientia) ausging.

empeiria im aristotelischen Sinne war die durch Kenntnis des Besonderen erworbene Fähigkeit, eine Unterscheidung zu treffen. Sie war nicht identisch mit der sinnlichen Wahrnehmung, vielmehr war sinnliche Wahrnehmung (aisthesis) eine ihrer Voraussetzungen:

„Aus der Erinnerung geht bei den Menschen die Empirie hervor; erst viele Erinnerungen nämlich ein und derselben Sache ergeben die Fähigkeit einer Erfahrung. " 80

Auf einem ähnlichen Erfahrungsbegriff baute die paracelsische Erfahrung auf, wie schon am Titel seiner Medicinae Paramirum deutlich wird: Volumen medicinae Paramirum Philippi Theophrasti Paracelsi des hocherfarnen Philosophi / ond beider Artzney Doctor. Wenn Paracelsus hier als „hocherfarner Philosoph“ bezeichnet wird, so ist damit Erfahrenheit im Sinne einer Kombination von Wahrnehmung, Erinnerung und daraus resultierender Urteilskraft zu verstehen.

Die Grundlage der Erkenntnis war bei Paracelsus zwar die einzelne Sinneswahrnehmung, das experimentum, die jedoch nur den Anfang der Erkenntnis bildet:

und weiter merket von der experienz, das beweisen die augen, noch ist aber der verstant nit da, dan die augen zeigen experimentum an, aber nit experientiam, dan sie sehen experientiam nicht, welche also verstanden sol werden. ${ }^{81}$

Es bedarf jedoch des „richtigen Sehens“, nämlich der Theorie der Ähnlichkeit und damit des Wissens um die Ordnung der Natur, der Verbindung von Mikround Makrokosmos und der Erinnerung an gleichartige oder unterschiedliche Sinneswahrnehmungen. Daraus resultiert dann Erfahrenheit (experientia, experi-

79 Item omnis propositio universalis in scientia naturali debet concredi tanquam principium que potest probari per experimentalem inductionem sic quod in pluris singularibus ipsius manifeste inveniaur [i.e. inveniatur] ita esse et in nullo nunquam apparet instantia, sicut enim bene dicit Aristoteles quod oportet multa principia esse accepta et scita sensu, memoria et experientia; [...]. [Johannes Buridan]: Acutissimi philosophi reuerendi Magistri Johannis buridani subtilissime questiones super octo phisicorum libros Aristotelis diligenter recognite et reuise A magistro Johanne dullaert de gandano antea nusquam impresse. Parisiis 1509 (Faksimiledruck Frankfurt a.M. 1964), fol. 73v, col 1 (Transkr. MM).

80 Aristoteles: Metaphysik, 980b.

81 Paracelsus: Sämtliche Werke, Abt. I, Bd. 1: Labyrinthus medicorum errantium. Hrsg. von Karl Sudhoff. München, Berlin 1922, S. 191f. 
enz). ${ }^{82}$ Insofern zeichnete sich hier kein epistemischer Bruch ab. Grundlage blieb die Signaturenlehre, wie Paracelsus sie in der Philosophia sagax kennzeichnete: „Nichts ist, das die natur nicht gezeichnet hab, durch welche zeichen man kann erkennen, was im selbigen, was gezeichnet ist." ${ }^{83}$

Das Labor brachte in dieser Hinsicht noch keinen fundamentalen Einschnitt. Erst durch die im Empirismus erfolgende Begründung einer universalen Mathesis $^{84}$ und die Neudefinition des Experiments ${ }^{85}$ als planmäßig wiederholbarem Ereignis, dessen Bedingungen genau definiert und nicht mehr in einer alchemischen Geheimsprache verborgen waren, änderte sich die Ordnung der Dinge.

82 Ähnlich argumentiert auch Andrew Weeks. Vgl. ders.: Paracelsus. Speculative Theory and the Crisis of the Early Reformation. Albany, NY 1997, S. 183f. Vgl. auch Matthias Vollmer: Die bildhafte Sprache des Paracelsus und ihr Verhältnis zu den alchemistischen Diagrammen. Die Zeichen und das Zeigen. In: Paracelsus im Kontext der Wissenschaften seiner Zeit. Kultur- und mentalitätsgeschichtliche Annäherungen. Hrsg. von Albrecht Classen. Berlin u.a. 2010, S. 129-150, hier S. 135-140.

83 Philippus Theophrastus Paracelsus: Astronomia Magna oder die ganze Philosophia sagax der großen und kleinen Welt. Hrsg. von Norbert Winkler. Frankfurt a.M. u.a. 1999, S. 65.

84 Zur Begründung einer universalen Mathesis mit Descartes als ihrem herausragenden Exponenten vgl. Foucault: Die Ordnung der Dinge (Anm. 10), S. 82f. Als grundlegendes Kennzeichen der Diskontinuität zwischen der schriftdominierten Kultur der Ähnlichkeit und der messbarkeitsdominierten Kultur der Identität und des Unterschieds bezeichnet Foucault die Beziehung zum Text: „Von da an hört der Text auf, zu den Zeichen und zu den Formen der Wahrheit zu gehören." (S. 89).

85 In der Scholastik und der Renaissance wird experimentum weitgehend mit experientia gleichgesetzt. Die Neudefinition des Experiments als definierten Bedingungen unterworfenem, planbarem und wiederholbarem Ereignis findet sich erst bei Francis Bacon ausformuliert. Vgl. G. Frey: Art. Experiment. In: Historisches Wörterbuch der Philosophie. Bd. 2. Hrsg. von Joachim Ritter und Karlfried Gründer. Basel 2007, S. 868f. 
(C) 2015, Otto Harrassowitz GmbH \& Co. KG, Wiesbaden ISBN Print: 9783447104951 - ISBN E-Book: 9783447194129 


\title{
Die Alchemie der Frühen Neuzeit als Gegenstand der Wissensgeschichte
}

\author{
Volkhard Wels, Berlin
}

Im Folgenden geht es mir um zweierlei, nämlich einerseits um die Wissensformen der Alchemie in der Frühen Neuzeit, andererseits um das Konzept einer Wissensgeschichte. Genauer gesagt geht es mir mit diesem zweiten Punkt um die Frage, was ein spezifisch wissensgeschichtlicher Zugriff auf die frühneuzeitliche Alchemie leisten könnte, im Gegensatz zu einem wissenschafts-, literaturoder religionsgeschichtlicher Zugriff. ${ }^{1}$ Indem die Alchemie der Frühen Neuzeit in ihrem epistemischen Status zwischen verschiedenen Wissensformen steht, die sich mit dem Beginn der sogenannten Moderne zu getrennten Kategorien entwickeln - ,Wissenschaft', ,Literatur', ,Religion' -, stellt die frühneuzeitliche Alchemie einen interessanten Untersuchungsgegenstand dar, was den Prozess der Ausdifferenzierung dieser Kategorien betrifft. Denn wie ich im Folgenden zeigen möchte, kann man bei den Wissensformen der frühneuzeitlichen Alchemie nicht klar bestimmen, ob es sich um ,Wissenschaft', ,Religion' oder ,Literatur' handelt. An der frühneuzeitlichen Alchemie lassen sich damit paradigmatisch einige der Wissensbewegungen ablesen, die bei der Ausdifferenzierung dieser Bereiche und -praktiken eine Rolle gespielt haben.

Der erste Teil des Aufsatzes beschreibt deshalb einige grundlegende Spezifika der vormodernen Chemie als Wissensform, darunter vor allem deren arkansprachlichen Charakter. Zweitens wende ich mich mit dem Paracelsismus einer spezifischen Sonderentwicklung der frühneuzeitlichen Alchemie zu, die unter wissensgeschichtlichen Aspekten besondere Aufmerksamkeit verdient. Während sich nämlich im Paracelsismus eine religiöse Aufladung des alchemischen Wissens vollzieht, entwickelt sich - drittens - gleichzeitig aus der traditionellen mittelalterlichen Alchemie im Verlauf des 17. Jahrhunderts eine Chemie als moderne ,Naturwissenschaft' im Sinne des 18. Jahrhunderts. Der vierte Teil ist dem literaturgeschichtlichen Aspekt der Alchemie gewidmet, nämlich alchemischen Texten in poetischen Formen, wobei es auch hier wieder ausschließlich um den epistemischen Status dieses poetisch vermittelten, alchemischen Wissens geht.

1 Die Literaturangaben in den Anmerkungen beschränken sich auf die Arbeiten, die für meine Argumentation von unmittelbarer Bedeutung sind und verstehen sich insofern als stellvertretende Verweise. 


\section{Wissensformen der vormodernen Chemie}

Die frühneuzeitliche Chemie ist keine marginale Erscheinung, sondern, wie Wilhelm Kühlmann und Joachim Telle es formuliert haben, die „Leitwissenschaft", in deren Zeichen sich die frühneuzeitliche Entdeckung und Erforschung der Natur vollzieht. ${ }^{2}$ Das heißt an erster Stelle, dass wir es nicht mit vereinzelten Texten zu tun haben, sondern mit einem riesigen und gegenwärtig noch schwer überschaubaren Textmassiv.

Unter dem Namen der "Chemie" oder "Alchemie" (beide Begriffe werden bis weit ins 17. Jahrhundert hinein gleichbedeutend verwendet) versammeln sich Abhandlungen zur Transmutationsalchemie, zum Bergbauwesen, zu Verhüttungs- und Schmelztechniken, zu dem, was heute organische und anorganische Chemie heißt, zu Materialwissenschaft und Werkstoffkunde, zu Biologie und Biochemie, zu Medizin und Pharmazeutik, genauso aber zu einer ,mystischen', spirituellen oder, wie man das später nennen wird, ,esoterischen' Alchemie. Der Stein der Weisen, das Elixier des Lebens und die künstliche Herstellung von Gold, wie sie heute in trivialisierenden Darstellungen allein mit der Alchemie identifiziert werden, bilden dabei nur einen eher Teilaspekt dieser Wissensformen. Der alchemische Buchmarkt vor 1550 wird von pharmazeutischen Werken und von Kunstbuchliteratur metallurgisch-technischen Inhalts beherrscht. ${ }^{3}$

Wer sich mit dieser vormodernen Chemie beschäftigt, muss sich von zwei großen Erwartungen befreien. Erstens ist diese Chemie keine quantitativ verfahrende Chemie, die es mit einzelnen chemischen Elementen zu tun hätte. ${ }^{4}$ Eine

2 Allgemein zur Alchemie vgl. den Überblick von Joachim Telle: Art. Alchemie II. In: Theologische Realenzyklopädie Bd. 2 (1978), S. 199-227. Eine unter wissensgeschichtlichem Aspekt hervorragende Darstellung der frühneuzeitlichen Alchemie, der ich viel verdanke, ist Bruce T. Moran: Distilling Knowledge. Alchemy, Chemistry, and the Scientific Revolution. Cambridge, Mass. 2005. Stellvertretend zur Geschichte der vormodernen Chemie verweise ich auf William R. Newman: Promethean Ambitions. Alchemy and the Quest to Perfect Nature. Chicago, London 2004 und Lawrence M. Principe: The Secrets of Alchemy. Chicago, London 2013. Ein Überblick zur deutschen Tradition von Bernhard Dietrich Haage findet sich in: Bernhard Dietrich Haage und Wolfgang Wegner: Deutsche Fachliteratur der Artes in Mittelalter und Früher Neuzeit. Berlin 2007, S. 106-126. Den Begriff der „Leitwissenschaft" verwenden Kühlmann und Telle in ihrer Einleitung in: Corpus Paracelsisticum. Dokumente frühneuzeitlicher Naturphilosophie in Deutschland. Hrsg. und erläutert von Wilhelm Kühlmann und Joachim Telle. Tübingen 2001-2013, hier Bd. I, S. 17.

3 Joachim Telle: Bemerkungen zum Rosarium Philosophorum. In: Rosarium Philosophorum. Ein alchemisches Florilegium des Spätmittelalters. Faksimile der illustrierten Erstausgabe Frankfurt 1550. Hrsg. und erl. von Joachim Telle, aus dem Lateinischen ins Deutsche übers. von Lutz Claren und Joachim Huber. Weinheim 1992, S. 161-201, hier S. 163f.

4 Diese Behauptung ist insofern zu relativieren, als William R. Newman: The Summa Perfectionis of the Pseudo Geber. Leiden 1991 und ders.: Experimental Corpuscular Theory in Aristotelian Alchemy. In: Late Medieval and Early Modern Corpuscular Matter Theories. Hrsg. von Christoph Lüthy, John E. Murdoch, und William R. Newman. Leiden 2001, S. 291-329 gezeigt hat, dass der mittelalterlichen Alchemie von Anfang an eine korpuskulare Theorie 
Elementenlehre im modernen Sinne gibt es nicht, stattdessen besteht einer der Grundgedanken dieser Alchemie darin, dass es eine einheitliche Materie gibt, die in verschiedenen Formen die Substanz der Welt bildet. Diese Materie ist einem Prozess der Reifung oder Vervollkommnung unterworfen, wobei Gold als ihr höchster Zustand gilt. Ziel insbesondere der Transmutationsalchemie ist es, den Reifungsprozess der Materie zu kontrollieren und zu beschleunigen. In der Konsequenz dieser Vorstellungen gibt es in den Prozessbeschreibungen der vormodernen Chemie keine genau quantifizierten Angaben $\mathrm{zu}$ bestimmten chemischen Elementen, wie wir das heute kennen, sondern nur die Annahme bestimmter, allgemeiner Prozessabläufe, wie etwa der Destillation, der Verbrennung, der Kalzinierung, der Verschmelzung oder der Faulung. Zugrunde liegt die Vorstellung, dass man die Materie, indem man sie diesen Prozessen unterzieht, verändern - oder eben genauer: transmutieren - kann.

Der vormoderne Chemiker sieht also in seiner Retorte genauso wie in der Natur nicht einzelne chemische Stoffe, die sich vereinigen und trennen, sondern er sieht die Gemeinsamkeiten einer beschränkten Zahl von Prozessen:

Folgende aber sind die Verfahren zur Herstellung jenes Steines, mit deren Hilfe die Substanz, die wir suchen, hervorgebracht und in das wirkliche Sein (esse actuale) übergeführt wird. Ein Verfahren ist das Sublimieren, ein zweites die Descension, ein drittes das Destillieren, ein viertes das Kalzinieren, ein fünftes die Lösung, ein sechstes das Verfestigen (congelatio), ein siebentes das Fixieren, ein achtes die Wiederholung und ein neuntes das Weichmachen (ceratio). Man spricht weiter von unendlich vielen, den genannten ähnlichen Verfahren; die Verfahren sind allerdings, mögen sie auch dem Begriff nach (ratione) voneinander verschieden sein, doch eins in der Sache. Irgendwann nämlich haben die Philosophen bei der Betrachtung ihres Stoffes - der, wenn er im Gefäß ist und Sonnenwärme verspürt, andauernd verdunstet bzw. verdampft in Gestalt feinsten Rauchs und ins Oberteil (caput) des Gefäßes emporsteigt - dieses Aufsteigen ,Erhebung' (sublimatio) genannt. Als sie später diesen Stoff, der aufgestiegen war, wiederum auf den Boden des Gefäßes herabsinken sahen, nannten sie das Destillation (,Abtropfen') bzw. Deszension (,Absteigen'). Als sie nun noch sahen, daß dieser Stoff sich verdichtete und schwarz wurde und dabei einen üblen Geruch von sich gab, nannten sie das Faulung (putrefactio). Als sie sahen, daß die schwarze bzw. dunkle Farbe und der üble Geruch nach langer Zeit schwand und ein gewisses

der Materie zugrunde liegt. Zum Atomismus im 17. Jahrhundert vgl. Antonio Clericuzio: Elements, Principles and Corpuscles. A Study of Atomism and Chemistry in the Seventeenth Century. Dordrecht 2000. 
Weiß in der Art der Farbe der Asche an den Tag kam, nannten sie das Incineration (,Veraschung') bzw. Dealbation (,Weißung'). ${ }^{5}$

Die vormoderne Chemie analysiert keine Prozesse, die sich zwischen einzelnen Elementen abspielen, sondern ,deduziert' aus der Vielzahl der zu beobachtenden Veränderungen der Materie eine kleine Zahl immer wiederkehrender Vorgänge.

Die gesamte vormoderne Chemie von vornherein unter den Generalverdacht der Scharlatanerie und Betrügerei zu stellen, wie es seit dem 18. Jahrhundert immer wieder geschehen ist (paradigmatisch etwa in Adelungs Geschichte der menschlichen Narrheit oder Lebensbeschreibungen berühmter Schwarzkünstler, Goldmacher, Teufelsbanner, Zeichen- und Liniendeuter, Schwärmer, Wahrsager und anderer philosophischer Unholden, 1785-89), wäre dabei völlig verfehlt. Einmal ganz abgesehen von den unzweifelhaften Erfolgen dieser Wissenstraditionen, etwa im Bergbau oder in der Pharmazeutik, konnte auch die Goldherstellung als durchaus erfolgreich wahrgenommen werden, wie die zahlreichen Berichte erfolgreicher Transmutationen zeigen. Bei der Bewertung solcher Transmutationen ist immer zu bedenken, dass ,Gold' in Zeiten vor der exakten Bestimmbarkeit des Feingehaltes eines Metalls ein relativer Begriff ist, der sich vor allem an sinnlichen Qualitäten wie Farbe und Gewicht festmacht. ${ }^{6}$

Die zweite große Erwartung, von der man sich bei der vormodernen Chemie befreien muss, betrifft die Sprache dieser Chemie. Die klassische Form eines in Fachterminologie abgefassten Lehrbuchs oder Prosatraktats, wie es sie immer schon etwa für die Logik, die Medizin oder die Rechtswissenschaft gegeben hat, findet sich nur in Teilen der vormodernen Chemie, insbesondere in der arabischen Tradition. Im lateinischen Mittelalter hat diese Tradition ihren bedeutendsten Ausdruck in der Summa perfectionis aus dem 13. Jahrhundert gefunden.

Neben dieser , prosaischen' Tradition gibt es - wohl mit zunehmender Tendenz zur Frühen Neuzeit hin - Visionsbeschreibungen, Dialoge, Spruchsammlungen, Lehrgedichte oder Rätsel, häufig in Versform. Während die Summa perfectionis in einer relativ klaren und ,technischen' Sprache verfasst ist, begegnet daneben - wohl auch mit zunehmender Tendenz, die Forschungslage lässt auch hier noch keine klaren Aussagen zu - eine metaphorische, bildliche Sprache, in der von grünen Löwen, von Sonne und Mond, von Drachen, Schlangen und Vögeln, von Hermaphroditen und Königen die Rede ist. Diese scheinbar so ,poetische' Sprache hat entscheidend zur ,spirituellen' Deutung der Alchemie beigetragen.

5 Rosarium Philosophorum (Anm. 3) Bd. 2, S. 150. Das lateinische Original Bd. 1, S. 178. Die Ergänzungen in Klammern stammen von den Übersetzern.

6 Zur Geschichte der Alchemie als experimenteller Wissenschaft vgl. William R. Newman: Atoms and Alchemy. Chymistry and the Experimental Origins of the Scientific Revolution. Chicago 2006. 
Der Psychoanalytiker Carl Gustav Jung etwa hat die Bilderserie des Rosarium philosophorum 1946 gar nicht als Symbole stofflicher Prozesse aufgefasst, sondern als „intuitive Antizipationen "7 und unbewusste Beschreibung psychischer Strukturen: „Nicht nur in allgemeinen Umrissen, sondern auch in oft verblüffenden Einzelheiten schildert die Alchemie jene psychische Phänomenologie, die der Arzt im Verlaufe der Auseinandersetzung mit dem Unbewußten beobachten kann." ${ }^{8}$ Alchemie erscheint damit nicht als technisches Wissen um natürlich Prozesse, sondern als "mystische Philosophie“9 und symbolische Darstellung eines Wegs der inneren Wandlung. ${ }^{10}$ Diese ,spirituelle‘ oder ,esoterische‘ Deutung der Alchemie geht - freilich mit signifikanten Veränderungen, und um nur einige Stationen zu nennen - über Rudolf Steiner und die "Theosophische Gesellschaft", die „Esoterik" des 19. Jahrhunderts, die "Gold- und Rosenkreuzer" des 18. Jahrhunderts und Teile der Romantik über Jakob Böhme und die Mystik des 17. Jahrhunderts zurück bis auf den Paracelsismus des 16. Jahrhunderts. Über die Legitmation einer solchen ,spirituellen' Deutung der Alchemie kann mithin kein Zweifel bestehen.

Schwierig wird diese Deutung der Alchemie, wo sie die frühneuzeitliche und mittelalterliche Alchemie insgesamt zu vereinnahmen sucht. Denn die metaphorische Sprache der Alchemie ist - zumindest ursprünglich - weder ,poetisch' noch ,spirituell' gemeint, sondern gehört zur Tradition der Arkansprachen. ${ }^{11}$ Es

7 Carl Gustav Jung: Die Psychologie der Übertragung. In ders.: Gesammelte Werke Bd. 16. Zürich u.a. 1956, S. 174-345, hier S. 180.

8 Jung: Psychologie der Übertragung (Anm. 7), S. 211.

9 Jung: Psychologie der Übertragung (Anm. 7), S. 180.

10 Modifiziert aufgegriffen haben diese Deutung der Alchemie neuerdings Hereward Tilton: The Quest for the Phoenix. Spiritual Alchemy and Rosicrucianism in the Work of Count Michael Maier. Berlin, New York 2003, bes. S. 1-34 und George-Florin Călian: Alkimia operativa and Alkimia speculativa. Some modern controversies on the Historiography of Alchemy. In: Annual of Medieval Studies at CEU 16 (2010), S. 166-190 (digital zugänglich unter www.archive.org). Beide richten sich vor allem gegen Lawrence M. Principe und William R. Newman: Some Problems with the Historiography of Alchemy. In: Secretes of Nature. Astrology and Alchemy in Early Modern Europe. Hrsg. von Anthony Grafton und William R. Newman. Cambridge 2001, S. 385-430.

11 Zur chemischen Arkansprache vgl. die präzise Zusammenfassung von Joachim Telle: Der Splendor Solis in der frühneuzeitlichen Respublica Alchemica. In: Daphnis 35 (2006), S. 421448, hier S. 421-423. Zur Transformation der Arkansprache in der Frühen Neuzeit vgl. Florian Ebeling: ,Geheimnis' und ,Geheimhaltung' in den Hermetica der Frühen Neuzeit. In: Antike Weisheit und kulturelle Praxis. Hermetismus in der Frühen Neuzeit. Hrsg. von AnneCharlott Trepp und Hartmut Lehmann. Göttingen 2001, S. 63-80. Zur Entstehung der Vorstellung von einer „wissenschaftlichen Öffentlichkeit“ und der mittelalterlichen SecretaLiteratur William Eamon: From the Secrets of Nature to Public Knowledge. The Origins of the Concept of Openness in Science. In: Minerva 23 (1985), S. 321-347. Spezifisch zur Chemie Jan V. Golinski: Chemistry in the Scientific Revolution: Problems of Language and Communication. In: Reappraisals of the Scientific Revolution. Hrsg. von David C. Lindberg und Robert S. Westman. Cambridge 1990, S. 367-396 sowie besonders Stephen Clucas: Alchemy and Certainty in the Seventeenth Century. In: Chymists and Chymistry. Studies in 
handelt sich um eine verschlüsselte Symbolik, um Decknamen, die dem Schutz eines bestimmten Wissens um chemische Prozesse dienen. Die Arkansprache der Alchemie erfüllt damit die Funktion, die heute etwa eine Gewerbeerlaubnis oder das Patentrecht hat. ${ }^{12}$ Sie dient unter den Bedingungen schriftsprachlicher Vermittlung dem Schutz eines ursprünglich mündlichen, von Lehrer zu Schüler übermittelten Wissens, wie es in handwerklich geprägten Traditionen üblich ist.

$\mathrm{Zu}$ diesen handwerklichen Traditionen gehört die Alchemie. Bis zu Beginn des 17. Jahrhunderts - 1609 wird in Marburg der erste Lehrstuhl für Chemie eingerichtet, im Grunde dauert es aber noch bis weit ins 18. Jahrhundert hinein, bis von einer erfolgreichen Institutionalisierung die Rede sein kann ${ }^{13}$ - hat das chemische Wissen keinen Platz an Schule und Universität, sondern wird vorwiegend in mündlicher Form überall dort vermittelt, wo chemische Prozesse eine Rolle spielen: im Bergbau bei Verhüttungstechniken, im Schmiedehandwerk, in der Pharmazeutik oder eben bei der Transmutationsalchemie mit dem Ziel der Goldherstellung. Den Zugang zu einem bestimmten Beruf und damit Gelderwerb, den bei Ärzten oder Juristen das Prüfungswesen der Universitäten sicherstellt, muss im Falle der vormodernen Chemie - wenn sie sich schriftlicher Formen bedient - die arkansprachliche Verschlüsselung des Wissens sicherstellen.

Wo dieses Wissen schriftlich vermittelt wird, wie im Rosarium philosophorum (Druck 1550), ${ }^{14}$ dient die bildliche Sprache deshalb einerseits dem Schutz eines unmittelbar ökonomisch relevanten Wissens, andererseits aber der mnemotechnischen Zweckmäßigkeit. Ein Hermaphrodit, der auf einer Mondsichel steht, ein Löwe, der eine Sonne verschlingt oder drastische sexuelle Darstellungen - das sind alles Beispiele aus dem Rosarium - dürften auch in der Vormoderne schon wesentlich leichter $\mathrm{zu}$ memorierende Bilder gewesen sein als die chemischen Prozesse, die damit symbolisiert werden. Dem selben Zweck dürften auch die begleitenden Verse dienen, die durch den der Versform inhärenten Zwang zur Verknappung, ihre metrische Form und den Reim leichter zu memorieren sind als Prosa.

the History of Alchemy and Early Modern Chemistry. Hrsg. von Lawrence M. Principe. Sagamore Beach 2007, S. 39-51.

12 Telle: Art. Alchemie II (Anm. 2), S. 211.

$13 \mathrm{Zu}$ Marburg vgl. Bruce T. Moran: The Alchemical World of the German Court. Occult Philosophy and Chemical Medicine in the Circle of Moritz of Hessen (1572-1632). Stuttgart 1991, zur Institutionalisierung der Alchemie vgl. Christoph Meinel: „Artibus Academicis Inserenda": Chemistry's Place in Eighteenth and Early Nineteenth Century Universities. In: History of Universities 7 (1988), S. 89-115. Zur Entwicklung in Frankreich vgl. Antonio Clericuzio: Teaching Chemistry and Chemical Textbooks in France: From Beguin to Lemery. In: Science and Education 15 (2006), S. 335-355.

14 Zur Text- und Druckgeschichte sowie zur historischen Einordnung des Rosarium vgl. Joachim Telle: Bemerkungen zum Rosarium Philosophorum (Anm. 3). 


\section{CONIVNCTIO SIVE Coitus.}

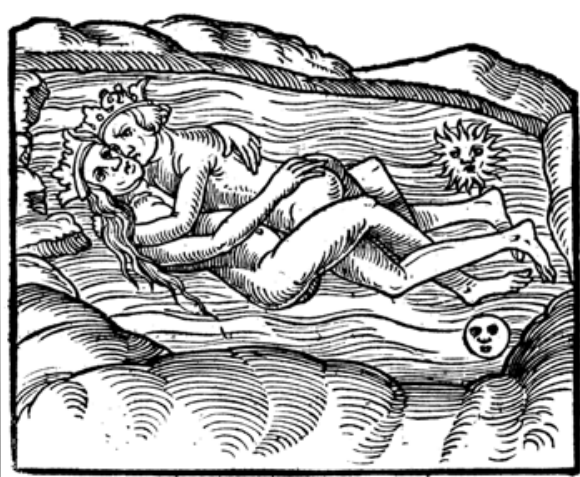

O1) Luma burdo meyn vmbgeben/vnt fuffe myntel Doirftu fhoin//Farct/vno gewaltig alsid) byn. (1) Gol/ou bift vber alle lied)t 3 u ertenmen/ Go bedarffudod mein als ber banter bennen.

\section{PHILOSOPHOR VM.}

\& ficca foluantur, calcinentur, fiue fublimentur fe cundum quod viderit, $\&$ melius iudicatur fecun dum fanum fenfum operantis.

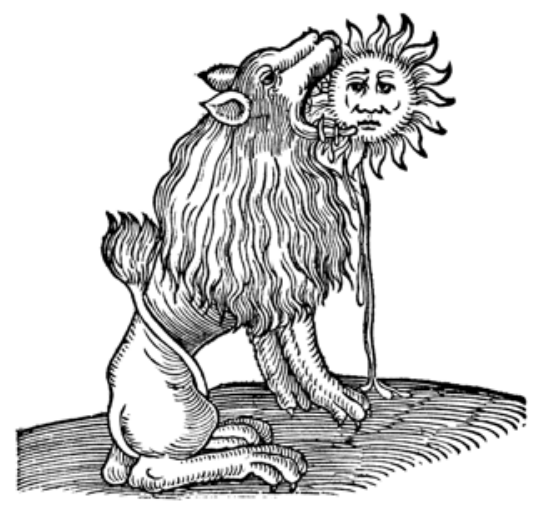

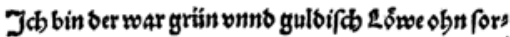
Jnn mir feeft alle beimlidbeyt ber pbilofophen verborgen.

$Y$ iij
PHILOSOPHOR VM.

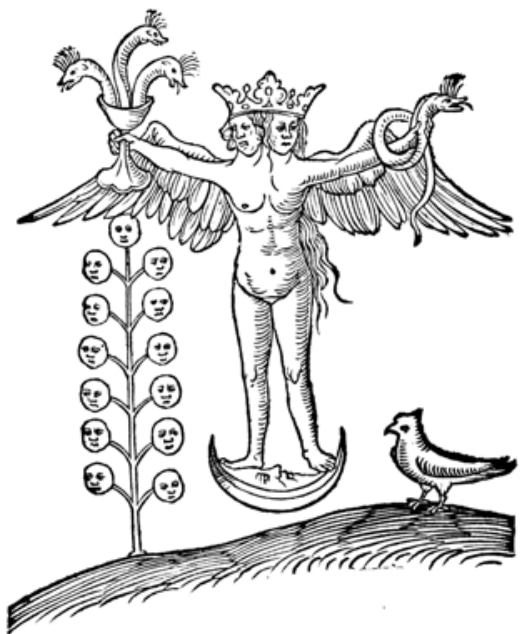

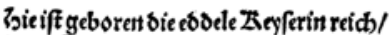
Die meifter nenmen fie ibrer bod ter gleid. Die vermeret fidb/gebiert tinder obn 3 al/ Gein vonpótlich rein/vnno obnalles mabl.

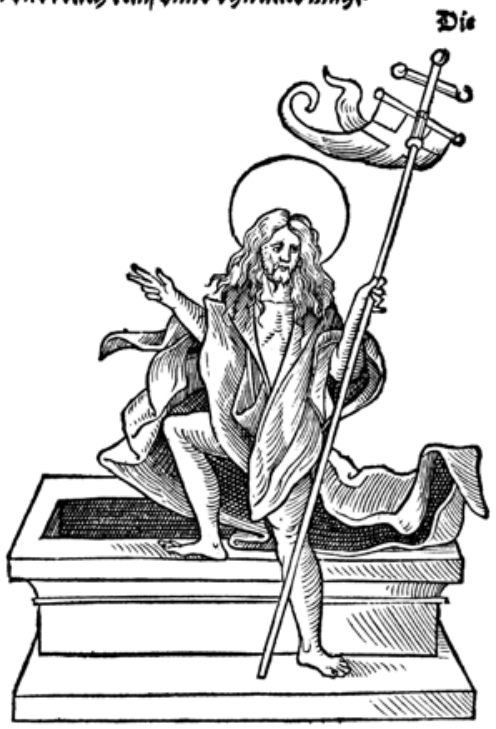

Tad meinem viel vnno mandeo leiben vnno marter (grofl

Qàlafis

Abbildungen aus dem Rosarium Philosophorum, Frankfurt a.M. 1550, f. Fiijv (Coniunctio), M $4^{r}$

(Hermaphrodit), Yiij ${ }^{r}$ (Löwe) und f. a $4^{\mathrm{r}}$ (Christus). 
Das Rosarium philosophorum ist deshalb ein gutes Beispiel für die epistemische Konfiguration der vormodernen Chemie. Bei diesem Text handelt es sich um eine florilegienhafte Kompilation alchemischer Prozessbeschreibungen aus dem 14. Jahrhundert, dessen eigentliche Wirkungsgeschichte allerdings erst mit der editio princeps 1550 beginnt. Die Holzschnitte, die sich in dieser Druckfassung finden - das Sol und Luna-Bildgedicht, wie es Joachim Telle genannt hat ${ }^{15}$-, haben dabei weder bloß illustrativen Charakter, noch sind sie Ausdruck einer ,mystischen' Alchemie. Die Verbildlichung der alchemischen Arkansprache hat didaktische und mnemotechnische Zwecke, indem sie etwa die Gliederung übersichtlich macht und gleichzeitig das alchemische Lehrgut vereinfacht und in einprägsame Bilder bringt. ${ }^{16}$

Im Rosarium wird die Summa perfectionis außerdem mit den Worten zitiert: „Wo immer wir offen gesprochen haben, dort haben wir [...] nichts gesagt. Aber wo wir etwas verschlüsselt [...] und in Bildern niedergeschrieben haben, dort haben wir die Wahrheit verhüllt." ${ }^{17}$ Diese Verschlüsselungstechnik wird an anderer Stelle ausdrücklich mit den Verfahren der Dichtung verglichen: „Die Philosophen wissen, daß ein solcher Stoff nur in verdeckter Weise (mystice) weitergegeben werden darf, (etwa) in der Art, wie die Poesie mit Fabeln und Parabeln (arbeitet). "18 Damit ist sehr deutlich gesagt, dass es sich bei der sprachlichen Form der Alchemie weder um ,Mystik' noch um Dichtung handelt, sondern um eine bewusste Verschlüsselungstechnik, die sich lediglich der Methoden der Dichtung bedient.

Sowohl mit seiner Verbildlichung wie mit seiner bewussten Verrätselung des alchemischen Wissens könnte das Rosarium Philosophorum dabei eine ähnliche wissensgeschichtliche Entwicklung unter den Bedingungen einer ,pragmatischen Schriftlichkeit' ${ }^{\prime 19}$ illustrieren, wie sie bei den Fecht- oder Büchsenmeisterlehren dieser Zeit $\mathrm{zu}$ beobachten ist. Auch bei diesen handelt es sich um ein nicht-akademisches, handwerkliches, ursprünglich im mündlichen Unterricht vermitteltes Wissen, das unmittelbare ökonomische Relevanz besaß. Bei seinem Übergang in die Schriftlichkeit wird es gezielt verschlüsselt und verrätselt, um einerseits den Zugang zu diesem Wissen zu reglementieren, gleichzeitig aber den Schülern und Eingeweihten mnemotechnische Unterstützung zu bieten. Die Fechtlehre Hans Lecküchners, wie sie Jan-Dirk Müller beschrieben hat, ${ }^{20}$ bedient

15 Vgl. Joachim Telle: Sol und Luna. Hürtgenwald 1980.

16 Telle: Bemerkungen zum Rosarium Philosophorum (Anm. 3), S. $184 \mathrm{f}$.

17 Rosarium philosophorum (Anm. 3), S. 64.

18 Rosarium philosophorum (Anm. 3), S. 69. Eine ähnliche Äußerung auch noch S. 127f. Die Ergänzungen in runden Klammern stammen von den Übersetzern des Rosarium.

19 So der Titel eines Sonderforschungsbereichs an der Universität Münster 1986-1999. Vgl. dazu den Sammelband: Pragmatische Schriftlichkeit im Mittelalter. Erscheinungsformen und Entwicklungsstufen. Hrsg. von Hagen Keller. München 1992.

20 Jan-Dirk Müller: Hans Lecküchners Messerfechtlehre und die Tradition. Schriftliche Anweisungen für eine praktische Disziplin. In: Wissen für den Hof. Der spätmittelalterliche Ver- 
sich mit einem zum Teil bewusst, für sich genommen unverständlichen Versteil, einem ,erklärenden' Prosakommentar und der bildlichen Darstellung ganz ähnlicher Formen wie das Rosarium.

Auch im Falle einer solchen Fechtlehre dürften nicht nur die Verse, sondern vor allem auch die Abbildungen mnemotechnisch motiviert gewesen sein. Sie rufen bestimmte Körperhaltungen und Bewegungsabläufe, die im mündlichen Unterricht vermittelt und auf dem Fechtboden eingeübt worden sind, wieder in Erinnerung beziehungsweise halten sie dort fest. Ähnlich könnte man sich vorstellen, dass die Verse und Abbildungen des Rosarium vor allem als Gedächtnisstütze für ein ursprünglich mündlich vermitteltes Wissen unter den Bedingungen des Übergangs in die Schriftlichkeit dienen. Sie wären dann mnemotechnische Hilfestellungen für denjenigen, der bereits weiß, was mit ihnen gemeint ist.

Wenn es sich bei der Bildlichkeit der Alchemie um eine Übernahme poetischer Verfahren zum Zweck der Verschlüsselung handelt, ist damit auch schon ein Hinweis auf den religiösen Kontext der vormodernen Alchemie gegeben. Der letzte Holzschnitt des Rosarium zeigt den auferstandenen Christus über einem geöffneten Grab. In den begleitenden Versen heißt es: Nach meinem viel und manches Leiden vnnd Marter groß/ I Bin ich erstanden/ clarificiert vnd aller mackel bloß. Damit wird die Reinigung und Läuterung der Materie, wie sie sich im chemischen Prozess vollzieht, mit der Auferstehung Christi und seiner Lösung vom irdischen Körper parallelisiert. Im begleitenden Prosatext des Rosarium wird diese Analogie allerdings gar nicht erwähnt, ${ }^{21}$ was die mnemotechnische Motivation dieser Abbildung nur umso deutlicher macht. Auch die Tatsache, dass gerade dieses Bild (und die beiden vorhergehenden) der handschriftlich tradierten Fassung des Sol und Luna-Bildgedichtes nachträglich für den Druck eingefügt wurde, ${ }^{22}$ unterstützt diese These. Wenn es sich bei den Abbildungen um mnemotechnisch motivierte Hilfestellungen handelt, spricht wenig dagegen, dass jeder Bearbeiter und Herausgeber diese Hilfestellungen bearbeitet und erweitert.

Allgemein spielen im Rosarium christliche oder überhaupt religiöse Glaubensinhalte keine nennenswerte Rolle. Auch damit ist das Rosarium nicht unty-

schriftungsprozeß am Beispiel Heidelberg im 15. Jahrhundert. Hrsg. von Jan-Dirk Müller. München 1994, S. 355-384. Zu den Büchsenmeisterbüchern vgl. Rainer Leng: Franz Helm und sein Buch von den probierten Künsten. Ein handschriftlich verbreitetes Büchsenmeisterbuch in der Zeit des frühen Buchdrucks. Wiesbaden 2001. Müller und Leng gehen allerdings nur andeutungsweise auf die mnemotechnische Bedeutung der Bilder ein. Im Falle des von Leng untersuchten Büchsenmeisterbuchs von Franz Helm haben die Abbildungen bereits eine ausschließlich illustrative Funktion angenommen, weisen jedoch auf eine ältere mnemotechnische Funktion hin. Ich danke Frank Fürbeth für seinen Hinweis auf beide Traditionen.

21 Vgl. Rosarium Philosophorum (Anm. 3), S. 160. Ich korrigiere damit eine frühere Äußerung, vgl. Volkhard Wels: Manifestationen des Geistes. Spiritualismus, Frömmigkeit und Dichtung in der Frühen Neuzeit. Göttingen 2014, S. 202f.

22 Telle: Sol und Luna (Anm. 15), S. 62. 
pisch für die alchemische Textwelt des späten Mittelalters. Zwar gibt es Texte wie die Aurora consurgens aus dem 14. oder frühen 15. Jahrhundert, die wohl den alchemischen Prozess mit dem Läuterungsprozess der Seele analogisiert, oder wie das Buch der Heiligen Dreifaltigkeit (1410-19),, ${ }^{23}$ aber auch diese Texte entfalten keine religiös aufgeladene Alchemie, sondern bringen religiöse Inhalte in ein metaphorisches Verhältnis zu chemischen Prozessen - oder anders gesagt, sie verwenden chemische Prozesse als allegorische Bildgeber. ${ }^{24}$ Das ist theologisch harmlos, und damit unterscheidet sich die allegorische Deutung chemischer Prozesse nicht von der allegorischen Deutung von Pflanzen, Himmelserscheinungen oder etwa der antiken Mythologie. Auch die Alchemie der Aurora consurgens und des Buchs der Heiligen Dreifaltigkeit ist mit diesen allegorischen Deutungen kein Phänomen der Religionsgeschichte, sondern tut nur das, was im Mittelalter und in der Frühen Neuzeit überall zu beobachten ist: Sie deutet Erscheinungen der Natur und Geschichte allegorisch auf das Heilsgeschehen hin aus. Erst mit dem Paracelsismus bekommt die Alchemie eine spirituelle, religiöse Dimension.

\section{Paracelsismus und Alchemie}

Der frühneuzeitliche Paracelsismus hebt um 1560, also etwa zwanzig Jahre nach dem Tod des Paracelsus, an und wächst sich dann sehr schnell zu einer Bewegung aus, die in ihrem Einfluss auf die weitere Geschichte der (Al-)Chemie kaum überschätzt werden kann. ${ }^{25}$ In Chemie und Medizin wird der Paracelsis-

23 Zur Aurora consurgens vgl. den Artikel von Joachim Telle in: Lexikon des Mittelalters Bd.1. München, Zürich 1980, S. 1245f., zum Buch der Heiligen Dreifaltigkeit den Artikel „Ulmannus“ von Telle in: Die deutsche Literatur des Mittelalters. Verfasserlexikon Bd. 11: Nachträge und Korrekturen. Berlin, New York 2004, Sp. 1573-1580.

24 Vgl. auch den Befund von Joachim Telle: Art. Alchemie II (Anm. 2), S. 208 („Zwischen Alchemie und Theologie kamen erst seit der frühen Neuzeit tiefergehende Konflikte auf.") sowie den Befund von Principe und Newman: Some Problems with the Historiography of Alchemy (Anm. 10), S. 399: „But in all these interactions of alchemy with spirituality, it is clear that alchemy functions as a source of tropes and imagery for rhetorical embellishment or didactic exemplification rather than as an inherently spiritual exercise which elevates the practitioner by some exoteric illumination".

25 Zum Paracelsismus vgl. die umfassende Dokumentation: Corpus Paracelsisticum. Dokumente frühneuzeitlicher Naturphilosophie in Deutschland. Hrsg. und erläutert von Wilhelm Kühlmann und Joachim Telle. Tübingen 2001-2013. Insbesondere die Einleitungen in die einzelnen Bände bieten einen hervorragenden Überblick. Grundlegend zum religionsgeschichtlichen Kontext sind außerdem Carlos Gilly: ,Theophrastica sancta'. Der Paracelsismus als Religion im Streit mit den offiziellen Kirchen. In: Analecta Paracelsica. Studien zum Nachleben Theophrast von Hohenheims im deutschen Kulturgebiet der frühen Neuzeit. Hrsg. von Joachim Telle. Stuttgart 1994, S. 425-488 und zwei Arbeiten Wilhelm Kühlmanns, vgl. ders.: Paracelsismus und Hermetismus: Doxographische und soziale Positionen alternativer Wissenschaft im postreformatorischen Deutschland. In: Antike Weisheit und kulturelle Praxis. Hermetismus in der Frühen Neuzeit. Hrsg. von Anne-Charlott Trepp und Hartmut Lehmann. Göttingen 2001, S. 17-39 und ders.: Das häretische Potential des Paracelsismus - 
mus zum wichtigsten Kontrahenten des akademischen Aristotelismus und Galenismus. Als ,alternative' Medizin unterscheidet er sich von der akademischen ,Schulmedizin' dabei von vornherein nicht nur durch seine Inhalte - darunter an erster Stelle eine chemische Pharmazeutik -, sondern auch durch seinen antiakademischen Habitus. Man will sich um jeden Preis vom ,toten Buchwissen' des akademischen Galenismus mit seiner Fixierung auf die antike Medizin unterscheiden. ${ }^{26}$ Statt auf ,totes Buchwissen' beruft sich der Paracelsismus auf die ,lebendige Erfahrung' der Natur - auf das ,Licht der Natur', wie das Schlagwort heißt.

Genau diese ,lebendige Erfahrung’ der Natur verbürgt dem Paracelsismus aber die Alchemie, die eben bis in diese Zeit niemals eine akademische Institutionalisierung erfahren hatte. Der Alchemiker, der in seinem Ofen, in seinen Destillierkolben und Reagenzgläsern die Natur selbst befragt, der sich die Hände schmutzig macht, wenn er auf der Suche nach seltenen Mineralien mit den Bergknappen in die Stollen einfährt, wird zum Gegenbild des Akademikers, des Arztes und Professors, der nur über seinen Büchern sitzt und Rezepte abschreibt. Die viel diskutierte paracelsische Signaturenlehre - also die Überzeugung, dass sich die ,inneren' Eigenschaften der Lebewesen, Pflanzen und Mineralien in ihren äußeren Erscheinungsformen ausdrücken, dass das Äußere eine Signatur des Inneren ist-diese Signaturenlehre ist nicht nur Ausdruck eines Analogiedenkens, sondern auch in ganz grundsätzlichem Sinne eine Aufforderung zum Studium der Natur selbst. Die Signaturenlehre impliziert eine Berufung auf die sinnliche Evidenz der Lebewesen, Pflanzen und Mineralien. ${ }^{27}$

Mit dieser Berufung auf die sinnliche Erfahrung wird die Alchemie zum Paradigma eines neuen Wissens von der Natur in scharfer Abgrenzung von dem Buchwissen der antiken Autoritäten und den akademischen Disziplinen. Das chemische Laboratorium wird zum Instrument einer Befragung der Natur. Dieser Antiakademismus ist kein Kollateralschaden, sondern gehört zum sozialhistorischen Kern des Paracelsismus. Schon Paracelsus selbst hatte sich gezielt zum großen Außenseiter stilisiert, allein der Natur verpflichtet, der allen Autoritäten der Antike sein „Ihr müsst mir nach, nicht ich Euch" entgegen gehalten hatte.

gesehen im Licht seiner Gegner. In: Heterodoxie in der Frühen Neuzeit. Hrsg. von Hartmut Laufhütte und Michael Titzmann. Tübingen 2006, S. 217-242.

26 Hanns-Peter Neumann: Wissenspolitik in der frühen Neuzeit am Beispiel des Paracelsismus. In: Diskurse der Gelehrtenkultur in der Frühen Neuzeit. Ein Handbuch. Hrsg. von Herbert Jaumann. Berlin, New York 2011, S. 255-304.

27 Zur paracelsistischen Signaturenlehre am Beispiel Crolls vgl. Wilhelm Kühlmann: Oswald Crollius und seine Signaturenlehre: Zum Profil hermetischer Naturphilosophie in der Ära Rudolphs II. In: Die okkulten Wissenschaften in der Renaissance. Hg. von August Buck. Wiesbaden 1992, S. 103-123. 
Auf Aristoteles und Plinius könne man "scheißen“, heißt es wörtlich im Buch Paragranum. ${ }^{28}$ Auch diese Wortwahl gehört zum antiakademischen Gestus.

Das ist allerdings nur die halbe Wahrheit über die paracelsistische Alchemie als Wissensform. Mit dem ,Licht der Natur' beruft sich der Paracelsismus nicht nur auf ein neues, empirisches Wissen, sondern - indem dieses ,Licht der Natur' mit dem ,Licht der Gnade' identifiziert wird - auch auf ein ,spirituelles', religiöses Wissen. Die Natur spricht nur deshalb zum paracelsistischen Arztalchemiker, weil Gott als spirituell in dieser Natur anwesend gedacht wird. Diese Annahme einer spirituellen Präsenz Gottes in der Materie knüpft sich meist an die Auslegung der "Genesis" und erscheint damit als „mosaische Physik" (physica mosaica), das heißt als eine aus dem Schöpfungsbericht abgeleitete Chemie. ${ }^{29}$

Weil die Schöpfung der Welt sich nach Gen.1.1-2 („,Am Anfang schuf Gott Himmel und Erde. Und die Erde war wüst und leer, und es war finster auf der Tiefe, und der Geist Gottes schwebte auf dem Wasser.") als eine ,Begeisterung' der primordialen Materie (,Wasser“) vollzog, ist der göttliche Geist das lebenserhaltende Prinzip der Natur. Heinrich Khunrath kann die Natur geradezu mit dem göttlichen Geist identifizieren:

Freylich ist die Natur ein Höchstweises/ sich selbst bewegendes/ lebendigmachendes/ vberaus sehr mechtiges vnd wunderthetiges Licht vnd Fewer/ ja ein mechtig-krefftiger Geist/ oder Geistliche krafft/ von dem Allerweisesten/ Ewigen/ lebendigen/ Allmechtigen vnd wunderbaren dreyeinigen Gott (der ein Fewer vnd Geist ist) selbst herfliessende/ in das erst Weld-anfangs erschaffene Hylealische/ das ist/ Pri-materialische wesserige Chaos eingehende/ dasselbige seeligende vnnd auch schwengerende/ vnd das gantze daraus erbawete Gebew der grossen Weld/ bis an sein von Gott demselben angesatztes ende/ erhaltende. ${ }^{30}$

28 Paracelsus: Das Buch Paragranum. In ders.: Werke. Hrsg. von Will-Erich Peuckert. Bd. 1: Medizinische Schriften. Darmstadt 1965, S. 495-584, hier S. 501f.

29 Zur physica mosaica vgl. Stephan Meier-Oeser: Das kosmogonische Modell der ,physica mosaica'. In: Die Philosophie des 17. Jahrhunderts. Bd. 4: Das Heilige Römische Reich Deutscher Nation, Nord- und Ostmitteleuropa. Hg. von Helmut Holzhey und Wilhelm SchmidtBiggemann. Basel 2001, S. 12f. und die Hinweise von Kühlmann und Telle in Corpus Paracelsisticum Bd. 2 (Anm. 25), S. 669f.

30 Heinrich Khunrath: Vom hylealischen, das ist/ pri-materialischen catholischen oder allgemeinen natürlichen Chaos, der naturgemässen Alchymiae und Alchymisten. Frankfurt a.M. 1708. Ndr. mit einer Einführung von Elmar R. Gruber, Graz 1990, S. 67. Zu Khunraths Alchemie vgl. vor allem die Arbeiten von Peter Forshaw, darunter insbesondere Peter J. Forshaw: Curious Knowledge and Wonder-Working Wisdom in the Occult Works of Heinrich Khunrath. In: Curiosity and Wonder from the Renaissance to the Enlightenment. Hrsg. von R.J.W. Evans und Alexander Marr. Ashgate 2006, S. 107-129; Peter J. Forshaw: Subliming Spirits: Physical-Chemistry and Theo-Alchemy in the Works of Heinrich Khunrath (1560-1605). In: Mystical Metal of Gold. Essays on Alchemy and Renaissance Culture. Hrsg. von Stanton J. Linden. New York 2007, S. 255-275; Peter Forshaw: Alchemy in the Amphitheatre. Some Considerations of the Alchemical Content of the Engravings in Heinrich 
Ähnliche Überzeugungen finden sich bei Alexander von Suchten, Oswald Croll, Heinrich Nolle, Abraham von Franckenberg und Johann Baptist van Helmont und dürften zum Kernbestand des Paracelsismus gehören. Entscheidend bei dieser Annahme einer spirituellen Präsenz Gottes in der Natur ist für den Paracelsismus als Wissensform dabei die religiöse Aufladung des naturphilosophischen, medizinischen Wissens. Aufgrund der spirituellen Präsenz Gottes in der Natur hat der Paracelsist es niemals nur mit den natürlichen Eigenschaften der Dinge zu tun, sondern immer auch mit übernatürlichen, eben spirituellen Eigenschaften.

Die medizinische Instrumentalisierung dieser im wörtlichen Sinne übernatürlichen Eigenschaften nennt der Paracelsismus Magie, und auch das ist in erster Linie als eine gezielte Provokation der akademischen Wissenschaften zu verstehen. Magie und Alchemie erscheinen vor allem als eines, nämlich als wirksame Beherrschung der Natur im Gegensatz zum wirkungslosen Geschwätz der akademischen Ärzte und Professoren.

So etwa heißt es bei Alexander von Suchten, die menschliche Vernunft sei immer trügerisch, das wahre Wissen dagegen sei das Wissen der Magie. ${ }^{31}$ Dieses magische Wissen bekomme niemand ohne Offenbarung deß H. Geistes/ und Eingebung Gottes, er sey Baccalaureus, Meister/ oder Doctor. ${ }^{32}$ Oswald Croll ist sich sicher, dass nicht durch die Vernunft, nicht mit Syllogismis oder Schlußreden/ sondern Reipsa oder mit der That der Betrug der Schulen widerlegt werde. Wo prächtige Titul zugegen, da sei keine Demut, kein wahrhaft christliches Leben und also auch keine Präsenz des Heiligen Geistes zu erwarten, sondern nur tieffe Finsternuß und der Zanck der vnrühigen vermeinten Gelährten. ${ }^{33}$ Der academische Geist steht als ein Geist der Zanksucht dem Heiligen Geist konträr entgegen. ${ }^{34}$

1648 beschreibt Johann Baptist van Helmont, der mit seinem ganzen Leben und Werk paradigmatisch den Antiakademismus der paracelsistischen Medizin und Alchemie illustriert, in seinem Ortus Medicinae seinen eigenen Erkenntnisprozess als eine Abkehr von der Vernunft. Wenn Salomon den Geist des Menschen eine Leuchte nenne, so meine er damit, daß die geheimen Wissenschaften der Dingel von dem Vater des Lichts/ vermittelst dieser Lampe in uns eingestrahlet werden.

Khunrath's Amphitheatre of Eternal Wisdom (1609). In: Art and Alchemy. Hrsg. von Jacob Wamberg. Kopenhagen 2006, S. 195-220.

31 Alexander von Suchten: Vom Antimonio Oder Spießglaß. In ders.: Chymische Schrifften. Hrsg. von Ulrich C. Dagitza. Frankfurt a.M. 1680, S. 229-304, hier S. 247.

32 (Pseudo-)Alexander von Suchten: Dialogus. In: Alexander von Suchten: Chymische Schriften. Hrsg. von Ulrich C. Dagitza. Frankfurt a.M. 1680, S. 305-356, hier S. 317.

33 Oswald Croll: Basilica Chymica Oder Alchymistisch Königlich Kleinod. Frankfurt a.M. 1623, S. 59 .

34 Croll: Basilica chymica (Anm. 33), S. 73. 
Die natürliche angeschaffne Erkänntnus sei deshalb viel edler und gewisser als jede akademisch-institutionell vermittelte Erkenntnis. ${ }^{35}$

Dieser paracelsistische Antiakademismus richtet sich nicht nur gegen die medizinische Fakultät, sondern auch gleichermaßen gegen die theologische. Ausdrücklich hatte Luther die Möglichkeit einer unmittelbaren Inspiration oder überhaupt einer außerbiblischen Offenbarung Gottes bestritten. Was Gott den Menschen zu sagen hatte, stand in der Bibel, und auf deren richtiges Verständnis kam deshalb alles an. Glaube, so konnte es damit scheinen, war das Ergebnis eines langen Studiums, mithin eines Wissens, das nur an den Universitäten zu erhalten war. In der Konsequenz hatte das Luthertum eine Fixierung auf die ,Schrift' und das, äußere Wort' der Bibel entwickelt, die in der zweiten Hälfte des 16. Jahrhunderts - also zeitgleich mit dem Erstarken des Paracelsismus eine akademische Theologie hervorgebracht hatte, die mit ihren philologischhermeneutischen Exzessen alles bis dahin Bekannte in den Schatten stellte.

Gegen diese Intellektualisierung und Rationalisierung des Glaubens einer als ,tote Orthodoxie‘ geschmähten akademischen Theologie richtet sich der Ruf nach einer ,lebendigen Gotteserfahrung' und einer ,gelebten Frömmigkeit' (praxis pietatis), wie das Schlagwort bis hin zur Entwicklung des Pietismus lauten wird. Diese Konvergenz von Paracelsismus und betont antiakademischer Frömmigkeit kommt in der Person Johann Arndts - des späteren Generalsuperintendenten des Fürstentums von Braunschweig-Lüneburg, der während seines Medizinstudiums mit dem Paracelsismus bekannt geworden sein dürfte - am prägnantesten zum Ausdruck. Während seine äußerst einflussreichen Vier Bücher vom wahren Christentum (1606 ff.) sich als eine Art Anleitung zur Frömmigkeit verstehen und sich nur implizit gegen die akademische Theologie richten, bietet seine nur handschriftlich überlieferte Oratio. Welcher gestalt die uhralte Philosophia, und Göttliche Weißheit der alten weysen wiederumb zu erlangen. Item Von Eytelkeit der Wissenschafften und Künsten dieser itzigen Zeit (1580) einen expliziten und in ihrer Aggressivität kaum zu überbietenden Angriff auf die akademisch institutionalisierte Theologie und Medizin. ${ }^{36}$

Auch bei Arndt äußert sich die Kritik des akademischen Wissens als eine Berufung auf das ,uralte' Wissen der Magie, in diesem Fall bereits parallelisiert mit einer weiteren, gleichermaßen ,uralten' wie antiakademischen Wissensform, nämlich der jüdischen Kabbala. Diese Parallelisierung von Alchemie, Magie und Kabbala im Zeichen des Paracelsismus findet sich programmatisch auch in

35 Zitiert nach der deutschen Übersetzung Jan Baptista von Helmont: Aufgang der ArtzneyKunst. Sulzbach 1683. Ndr. München 1971, S. 21.

$36 \mathrm{Zu}$ Arndt vgl. Hanns-Peter Neumann: Natura sagax - die geistige Natur: zum Zusammenhang von Naturphilosophie und Mystik in der frühen Neuzeit am Beispiel Johann Arndts. Tübingen 2004 und das leider schwer lesbare Buch von Hermann Geyer: Verborgene Weisheit. Johann Arndts Vier Bücher vom Wahren Christentum als Programm einer spiritualistischhermetischen Theologie. 2 Bde. Berlin, New York 2001. Hanns-Peter Neumann bereitet eine Edition der Wolfenbütteler Handschrift von Arndts Oratio vor. 
Oswald Crolls Basilica chymica (1609). Die Kabbala steht dort für den theologischen, die Magie für den astrologisch-makrokosmischen und die Alchemie für den medizinisch-mikrokosmischen Aspekt des paracelsistischen Wissens. Genau dieselbe Analogie figuriert in Heinrich Khunraths Amphitheatrum sapientiae aeternae (1595/1609) wirkmächtig schon im vollständigen Titel: Amphitheatrum sapientiae aeternae solius verae, christiano-kabalisticum, divino-magicum, nec non physico-chymicum, tertriunum, catholicon. Mit seinen Kupferstichen bietet das Amphitheatrum die eindrücklichste Darstellung der gleichermaßen alchemischen, magischen und kabbalistischen Erkenntnisform. ${ }^{37}$

Diese Verbindung von Alchemie, Magie und Kabbala ist für die ältere Alchemie keineswegs selbstverständlich. Im 16. Jahrhundert ist sie ein Spezifikum des Paracelsismus und erklärt sich vor allem aus dessen Antiakademismus. Wenn seit dem 18. Jahrhundert Magie und Alchemie ganz selbstverständlich nebeneinander gestellt werden, dürfte das auf die Zeitenwende zurückgehen, die mit dem Paracelsismus eingesetzt hat und im Laufe des 17. Jahrhunderts zunehmend Geltung erlangt. Im Mittelalter jedenfalls scheinen Magie und Alchemie noch nicht als verwandte Wissensformen wahrgenommen worden $\mathrm{zu}$ sein. Noch im Neuplatonismus der Renaissance um 1500 ist die Verbindung bestenfalls ansatzweise vorhanden. Weder Marsilio Ficino, der in seinen De vita libri tres (1489) die einflussreichste Theorie der Magie entwickelt, ${ }^{38}$ noch Agrippa von Nettesheim, der mit seiner Occulta philosophia (1510/31) die wichtigste Systematisierung der Magie liefert, stellt eine Verbindung zur Alchemie her. Agrippa bestreitet in der Occulta philosophia die Möglichkeit einer Transmutation von Metallen sogar ausdrücklich.

Interessanterweise verknüpft trotzdem Erasmus in einer kritischen Reaktion auf Agrippas Occulta philosophia bereits Alchemie, Magie und Kabbala ${ }^{39}$ und Julius Cäsar Scaliger spottet 1557 in seinen Exercitationes exotericae in einem Zug über Alchemie und Magie. Allerdings sieht Scaliger deren Gemeinsamkeit nicht in ihrem ,okkulten' Charakter, sondern in ihrer Wirkungslosigkeit. ${ }^{40}$ Damit greift er ein durchaus gängiges Argument der scholastischen Magie-Diskussion auf, das sich gut in seine Polemik gegen die qualitates occultae als asylum ignorantiae

37 Heinrich Khunrath: Amphitheatrum Sapientiae Aeternae-Schauplatz der ewigen allein wahren Weisheit. Vollständiger Reprint des Erstdrucks von [Hamburg] 1595 und des zweiten und letzten Drucks 1609. Hrsg. von Carlos Gilly, Anja Hallacker, Hanns-Peter Neumann und Wilhelm Schmidt-Biggemann. Stuttgart-Bad Cannstatt 2014. Zum Bildprogramm der Kupferstiche vgl. dort Schmidt-Biggemann: Der Text der Bilder. Das ikonologische Programm von Khunraths Amphitheatrum Sapientiae Aeternae, S. 41-83.

$38 \mathrm{Zu}$ Ficinos spärlichen Bemerkungen zur Alchemie vgl. Peter Forshaw: Marsilio Ficino and the Chemical Art. In: Laus Platonici Philosophi: Marsilio Ficino and His Influence. Hrsg. von S. Clucas, P.J. Forshaw und V. Rees. Leiden 2011, S. 249-271.

39 Alle Angaben nach Wolf Dieter Müller-Jahncke: The Attitude of Agrippa von Nettesheim (1486-1535) towards Alchemy. In: Ambix 22 (1975), S. 134-150.

40 Julius Cäsar Scaliger: Exercitationes exotericae. Paris 1557, vgl. dort die exercitatio 327, S. $444 \mathrm{f}$. 
fügt. Die Annahme ,verborgener Eigenschaften' der Dinge, deren sich die Magie bedient, ist demnach nur ein Symptom von Unwissenheit. Das richtet sich auch gegen Agrippa, der mit seinem Begriff einer occulta philosophia keinesfalls einen modernen Begriff von ,okkult' verwendet, sondern nur die gängige scholastische Unterscheidung zwischen manifesten und verborgenen, im Sinne des Wortes also ,okkulten' Ursachen aufgegriffen hatte. Gegen deren Ausweitung polemisiert Scaliger mit seinem aristotelischen Begriff von scientia als Ursachenforschung. ${ }^{41}$

Wenn im Laufe des 16. Jahrhunderts Magie und Alchemie gemeinsam zu ,okkulten' Wissenspraktiken im modernen Sinne werden - also Wissenspraktiken, bei denen es jetzt um übernatürliche Ursachen geht - impliziert das auch für den Begriff der Magie eine massive Umdeutung. Frank Fürbeth hat gezeigt, dass es im Mittelalter zwei Traditionen gibt, was die Beurteilung der Magie betrifft: eine kirchliche Tradition, „die jedes magische Verfahren als pagan-dämonisch und damit superstitiös" disqualifizierte, und eine insbesondere an den artes-Fakultäten beheimatete Tradition, in der die magischen Verfahren als Erforschung verborgener Ursachen (wie vor allem der stellaren Einflüsse) betrieben wurde. ${ }^{42}$ Während die Theologen die Magie qua impliziertem Dämonenpakt ablehnten, verteidigten die Vertreter der artes-Fakultäten die Magie als Naturphilosophie.

Wenn Magie und Alchemie also im Verlauf des 16. und 17. Jahrhunderts mit der Umdeutung der verborgenen Ursachen zu übernatürlichen Ursachen auch $\mathrm{zu}$,okkulten' Wissenspraktiken im modernen Sinne wurden, ist eine Verteidigung der Magie als naturphilosophische Ursachenforschung nicht mehr möglich. ${ }^{43}$ Dieser These ist der folgende Abschnitt gewidmet: Erst die Paracelsisten, die sich bewusst und offensiv zu einer Magie als übernatürlicher Praxis bekannten, machten eine Verteidigung der Magie als Erforschung verborgener, aber natürlicher Ursachen unmöglich. Magie und Alchemie werden zu ,okkulten Wissensformen im modernen Sinne.

41 Zum Begriff der qualitates occultae und seiner Umdeutung in der Frühen Neuzeit vgl. Paul Richard Blum: Qualitates occultae. Zur philosophischen Vorgeschichte eines Schlüsselbegriffs zwischen Okkultismus und Wissenschaft. In: Die okkulten Wissenschaften in der Renaissance. Hrsg. von August Buck. Wiesbaden 1992, S. 45-64.

42 Frank Fürbeth: Die Stellung der artes magicae in den hochmittelalterlichen ,Divisiones philosophiae'. In: Artes im Mittelalter. Hrsg. von Ursula Schaefer. Berlin 1999, S. 249-262, hier S. 260; sowie Frank Fürbeth: Zum Begriff und Gegenstand von Magie im Spätmittelalter. Ein Forschungsproblem oder ein Problem der Forschung? In: Jahrbuch der Oswald von Wolkenstein Gesellschaft 12 (2000), S. 411-422.

43 Zur Entstehung des Gegensatzes von ,okkulten' und, exakten' Wissenschaften vgl. Christoph Meinel: Okkulte und exakte Wissenschaften. In: Die okkulten Wissenschaften in der Renaissance. Hrsg. von August Buck. Wiesbaden 1992, S. 21-43, der dem Gegensatz von ,okkulten' und ,exakten' Wissenschaften jede Relevanz in historischem Kontext bestreitet. 


\section{Die traditionelle Alchemie um 1600 und ihre Entwicklung zur ,Naturwissenschaft"}

Wenn es im Mittelalter keine grundsätzlichen Konflikte zwischen Theologie und Alchemie gegeben hat, weil eben - das war mein erster Punkt - die Alchemie keine theologisch strittigen Positionen vertreten oder theologisch prätentiöse Ansprüche erhoben hatte, ändert sich das im Laufe des 16. Jahrhunderts. Der Paracelsismus okkupiert die Alchemie im Sinne einer klar gegen die akademische Medizin und Theologie gerichteten Berufung auf unmittelbare Offenbarungen Gottes in der Natur. Theologisch hat dies zu massiven Dauerkonflikten geführt, die von der Mitte des 16. Jahrhunderts bis ans Ende des 17. Jahrhunderts reichen. Aber auch von alchemischer Seite ist die theologische Instrumentalisierung der Alchemie keineswegs unwidersprochen geblieben. Insbesondere Andreas Libavius hat sich der paracelsistischen Vereinnahmung und theologisch-spirituellen Überformung der Alchemie schon sehr früh und sehr aggressiv widersetzt.

Libavius fällt ein wenig durch die Raster der Wissenschaftsgeschichte oder hat dort - jedenfalls bis zu der wegweisenden Studie von Bruce Moran ${ }^{44}$ - nicht die Aufmerksamkeit gefunden, die er verdient. Als aggressiver akademischer Gegner der Paracelsisten erscheint er nur als konservativ-reaktionäres Hemmnis auf dem Weg zu einer modernen Pharmazeutik, andererseits steht er als Aristoteliker noch vor dem epochalen Umbruch, der sich fast gleichzeitig mit Daniel Sennert ankündigt und dann Mitte des 17. Jahrhunderts im Werk von Robert Boyle ausdrücklich vollzogen wird, nämlich die Formulierung einer Korpuskulartheorie der Materie und damit einer grundsätzlich mechanistischen Auffassung chemischer Prozesse.

Die damit implizierte Existenz chemischer Elemente, die der wichtigste Schritt auf dem Weg zum modernen Atomismus war, musste sich gerade gegen den aristotelischen Hylemorphismus (also die Vorstellung, dass es nur eine Materie gibt, die verschiedene Formen annehmen kann) durchsetzen, sodass Libavius auch aus der Perspektive der Chemiegeschichte als Vertreter einer überkommenen Wissenschaft erscheint. Zwar nimmt Libavius deshalb vielleicht in der Wissenschaftsgeschichte der Chemie keinen bedeutenden Platz ein, wohl aber in der Geschichte des chemischen Wissens. 1597 erscheint die erste Ausgabe der Alchymia, die Libavius in der Folge immer stärker erweitert. In der Ausgabe von 1611 umfasst sie drei schwere Foliobände, die weit über tausend Seiten zählen.

Was Libavius in diesem Werk bietet, ist eine erste systematische Erfassung und Ordnung des chemischen Wissens. Abgehandelt werden die chemischen Substanzen, die Werkzeuge des Alchemikers, das Laboratorium mit seinen Retorten, Destillationskolben, Pressen und Öfen, die chemischen Arbeitsvorgänge

44 Bruce T. Moran: Andreas Libavius and the Transformation of Alchemy. Separating Chemical Cultures with Polemical Fire. Sagamore Beach, Ma. 2007. 
bis hin zum architektonischen Entwurf eines Laboratoriums. Nicht zu Unrecht ist die Alchymia deshalb das erste Handbuch der Chemie genannt worden. 1603 ist unter dem Titel Alchymistische Practic eine deutschsprachige Kurzfassung erschienen, die als Lehrbuch angelegt ist. Für ein solches Lehrbuch gibt es jetzt auch Bedarf, denn zu Beginn des 17. Jahrhunderts erlebt die Chemie ihre ersten Bemühungen um akademische Institutionalisierung.

In diesen Lehrbüchern von Libavius ist nicht mehr von grünen Löwen, Drachen und Hermaphroditen die Rede. Vielmehr heißt es ausdrücklich schon im Titel der Alchymistischen Practic, der Leser finde hier alles ohn figürliche und Parabolische reden/ eigentlich unnd deutlich also gelehret/ daß dergleichen zuvor wissentlich niemals im Truck gesehen worden. Der dritte Teil der Alchymia trägt im selben Sinne den programmatischen Titel Zusammenstellung ausgewählter und klar vermittelter Geheimnisse der Alchemie (Syntagma selectorum undiquaque et perspicue traditorum Alchymiae Arcanorum, 1611). Fast ein halbes Jahrhundert vor Robert Boyle der 1655 An Invitation to a free and generous Communication of Secrets and Receits in Physic schreibt ${ }^{45}$ - fordert Libavius damit schon ein Ende der Geheimnistuerei. Libavius ist sich seiner Vorreiterrolle also klar bewusst. Mit dem handbuchartigen Charakter der Alchymia und dem Verzicht auf die Arkansprache distanziert er sich von der älteren Alchemie, wie sie etwa das Rosarium philosophorum verkörpert. Die Arcana der Alchemie werden enthüllt.

Seinen eigentlichen Gegner sieht Libavius aber nicht in dieser traditionellen Alchemie, sondern im Paracelsismus. In seinen Rerum chymicarum epistolica forma (1595) macht Libavius schon in den ersten Sätzen klar, dass er mit dem Paracelsismus nichts zu schaffen hat. ${ }^{46}$ Libavius kämpft für eine Alchemie als Materialwissenschaft, die sich von den theologisch-spirituellen Ansprüchen des Paracelsismus scharf distanziert. Die Tatsache, dass die Universität Paris 1603 in ihrer Verdammung des Paracelsismus die gesamte Alchemie mit verurteilt hatte gegen dieses Urteil kämpft Libavius -, zeigt dabei, wie sehr zu diesem Zeitpunkt die Alchemie mit dem Paracelsismus identifiziert wurde. ${ }^{47}$

Im Gegensatz zu den Paracelsisten konzipiert Libavius die Alchemie nicht als Komplement von Magie und Kabbala, sondern als ein technisches Wissen um die Eigenschaften der Materie. Von einer spirituellen Präsenz Gottes in dieser Materie ist bei Libavius keine Rede, genauso wenig wie von einer göttlichen Inspiration oder vom ,Licht der Natur'. Ganz ähnlich wie Libavius bemüht sich auch Daniel Sennert um eine solche Begründung der Alchemie als Materialwis-

45 Insbesondere zum religiösen Kontext dieser Schrift vgl. Michael Hunter: The Reluctant Philanthropist: Robert Boyle and the Communication of Secrets and Receits in Physick. In ders.: Robert Boyle (1627-91). Scrupulosity and Science. Woodbridge 2000, S. 202-222.

46 Andreas Libavius: Rerum chymicarum epistolica forma. Frankfurt a.M. 1595, Liber primus, praefatio ad lectorem, f. ${ }^{*} 7 \mathrm{r}$.

47 Libavius' ausführliche Rechtfertigung der Alchemie und ihre Abgrenzung gegenüber dem Paracelsismus im Vorwort der Commentariorum Alchymiae, Frankfurt 1606, S. 1-68 ist gegen das Pariser Urteil gerichtet. 
senschaft. ${ }^{48}$ In Sennerts Abhandlung Über die Unterschiede und Gemeinsamkeiten zwischen Chymikern und Aristotelikern und Galenisten (De chymicorum cum Aristotelicis et Galenicis consensu ac dissensu, 1619) sind mit "Chymikern“ nicht die Paracelsisten gemeint, sondern die traditionellen Alchemiker. Paracelsus sind nur einige wenig schmeichelhafte und recht einseitige Kapitel gewidmet, in denen Sennert vor allem darauf hinweist, wie viel Paracelsus aus den Schriften der älteren Alchemie gelernt habe, ohne dies zu vermerken. ${ }^{49}$ Paracelsus stellt mit seinen theologischen Prätentionen, seinem unakademischen Lebenswandel und seiner provokanten Berufung auf die Magie für Sennert eine bedauernswerte Ausnahme in der Entwicklung der (Al-)Chemie als akademisch etablierter Wissensform dar.

Worum es Sennert geht, ist, die Unterschiede in der chemischen und aristotelischen Naturphilosophie darzustellen und hier - im Gegensatz zu dem Aristoteliker Libavius - für eine neue Materietheorie einzutreten. Damit steht die alchemia transmutatoria am Anfang der wissenschaftlichen Bewegung, die im 20. Jahrhundert mit der Atomtheorie und der Quantenphysik die Verwandlung der Metalle (und damit den alten Traum der Alchemie, die ,künstliche' Herstellung von Gold) tatsächlich Wirklichkeit hat werden lassen. Denn im Gegensatz zur Polemik des 18. Jahrhunderts gilt es im Auge zu behalten, dass sich der Glaube an eine Verwandelbarkeit der Materie keinesfalls als Scharlatanerie herausgestellt hat.

Auch das verdeutlicht die unterschiedlichen Traditionen, denen das chemische Wissen verpflichtet ist. Die alchemia transmutatoria ist mit ihrer Überzeugung von einer Wandelbarkeit der Materie keine spekulative oder ,okkulté Wissensform, sondern steht in einer Tradition, die auf moderne Vorstellungen von Technik als praktischem, zweckrationalen Wissen vorausweist. Der Paracelsismus dagegen - der zumindest ursprünglich die alchemia transmutatoria abgelehnt hat - steht mit seiner medizinischen Konzeption der Alchemie in einer Tradition, die auf die ,esoterischen' Bewegungen der Moderne vorausweist. Diese Perspektivierungen sind sicherlich eine grobe Vereinfachung, sollen aber auch nur eines deutlich machen: Eine lineare Entwicklung des chemischen Wissens, die vom Dunklen ins Licht, vom Aberglauben zur Vernunft, von der Träumerei zur Technik führte, gibt es nicht.

Wenn es in der Geschichte des chemischen Wissens einen Säkularisierungsprozess gegeben hat, der von einer religiös aufgeladenen Alchemie zur Chemie als einer ,modernen', säkularisierten, allein auf Naturbeobachtung und Experiment gegründeten ,Naturwissenschaft' führt, dann ist diese Geschichte kompli-

$48 \mathrm{Zu}$ Sennert vgl. Christoph Meinel: Early Seventeenth-Century Atomism: Theory, Epistemology, and the Insufficiency of Experiment. In: Isis 79 (1988), S. 68-103 sowie Antonio Clericuzio: Elements, Principles and Corpuscles. A Study of Atomism and Chemistry in the Seventeenth Century. Dordrecht 2000.

49 Daniel Sennert: De chymicorum cum Aristotelicis et Galenicis consensu ac dissensu. Wittenberg 1619, Kap. 4, S. 28-51. 
zierter verlaufen, als es manche Wissenschaftsgeschichte glauben machen möchte. Aus der Perspektive einer Wissenschaftsgeschichte, die ihren Begriff der Wissenschaft dem 18. und 19. Jahrhundert entnimmt, mag man schreiben können: "Chemistry moved from a theological to a secular interpretation of nature, as is found in modern science. " ${ }^{50}$ Eine Wissensgeschichte der Chemie dagegen könnte zeigen, dass es sich bei der ,Säkularisierung' um eine historiographische Kategorie handelt, die nur der Selbstlegitimation der sogenannten Moderne als einer angeblich säkularen Erscheinung dient.

Wenn Libavius und Sennert für eine mechanistische Konzeption der Materie eintreten, heißt das nicht, dass hinter dieser mechanistischen Konzeption keine religiöse Überzeugung stünde. In der Tradition von Melanchthons Naturphilosophie, zu deren Vertretern Libavius und Sennert gehören, erscheint die Natur selbstverständlich als Schöpfung Gottes. Der entscheidende Punkt ist, dass Gott sich für Libavius und Sennert in der Natur nicht unmittelbar als ein ,Licht der Gnade' offenbart, wie für die Paracelsisten, sondern nur mittelbar in den „natürlichen Ursachen“, den causae naturales. Erforschung der Natur heißt für Libavius und Sennert deshalb Erforschung der Gesetze, nach denen Gott die Natur eingerichtet hat. Die "natürlichen Ursachen“ können verborgene und also im wörtlichen Sinn „okkulte" Ursachen sein, wie etwa beim Magnetismus, sie bleiben aber trotzdem natürliche Ursachen. Übernatürliche Ursachen - also okkulte Ursachen im modernen Sinne - gibt es für Libavius gar nicht, ${ }^{51}$ weil Gott seine Schöpfung nach natürlichen Gesetzen eingerichtet hat.

Dieser Punkt ist für die Wissensgeschichte der frühneuzeitlichen Alchemie von größter Bedeutung. Im Gegensatz zu Libavius und seiner, naturalistischen' Konzeption der Alchemie sind die Paracelsisten gerade auf der Suche nach den übernatürlichen Ursachen chemischer Wirkungen. Weil die Paracelsisten die Natur als göttlich belebte, spirituell durchflutete wahrnehmen, operieren sie in ihren chemischen Prozessen mit übernatürlichen Kräften. Das besagt die Berufung auf Magie und Kabbala in chemischem Kontext.

Die entscheidende Frage ist damit nicht, ob die Alchemie mit ,okkulten' Kräften arbeitet oder nicht, sondern ob diese ,okkulten' Kräfte als natürliche konzipiert werden, die als ,verborgene' einfach nur unterhalb der Wahrnehmungsschwelle liegen, oder als übernatürliche, die als solche auf übernatürliche Ursachen zurückgehen. ${ }^{52}$ Im ersten Fall ist der Alchemiker eine Art Materialwissenschaftler, ein Techniker und Mechaniker, im zweiten Fall ist er ein Magier. Wenn diese Behauptung zutrifft, dann hätten wir in der Auseinandersetzung zwischen

50 Michael T. Walton: Genesis and the Chemical Philosophy. True Christian Science in the Sixteenth and Seventeenth Centuries. New York 2011, Vorwort S. XIII.

51 Nahe gelegt wird dieser Befund von Moran: Libavius (Anm. 44), er verdiente allerdings eine genauere Untersuchung. Die Möglichkeit von Wundern wird damit nicht geleugnet, denn sie gelten gerade als Aufhebung der natürlichen Ursachen.

52 Zur Transformation der qualitates occultae in der Frühen Neuzeit vgl. Blum: Qualitates occultae (Anm. 41). 
Libavius und den Paracelsisten einen Punkt erreicht, an dem sich die spätere Unterscheidung zwischen der Alchemie als einer im religiösen Sinne, spirituellen', ,okkulten' Wissensform und der modernen Chemie als einer mechanistischen Materialwissenschaft ankündigt, wie sie dann im 18. Jahrhundert zur Entfaltung kommen wird.

In maximalem Gegensatz zu Khunraths Bestimmung der Natur als ein Höchstweises/ sich selbst bewegendes/ lebendigmachendes/ vberaus sehr mechtiges vnd wunderthetiges Licht vnd Fewer/ ja ein mechtig-krefftiger Geist/ oder Geistliche krafft (vgl. Zitat oben) heißt es bei Robert Boyle in der Tradition von Libavius und Sennert, unmittelbar aber natürlich im Gefolge des cartesianischen Mechanismus, Gott hätte die Natur als eine "Maschine“ konstruiert, die „durch den bloBen Behelf der rohen Materie" (by the mere contrivance of brute matter) und bewegt nur durch certain laws of local motion, mithin durch mechanische Ursachen, am Laufen gehalten werde. Die Weisheit Gottes bezeuge sich in der Perfektion, mit der er diese Maschine konstruiert habe. ${ }^{53}$ Spätestens in der Mitte des 17. Jahrhunderts ist damit der Konflikt zwischen einem spiritualistischen und einem mechanistischen Naturbegriff, wie er sich in der Auseinandersetzung von Libavius mit den Paracelsisten ankündigte, manifest geworden. Im Falle von Boyle kommt er in der Auseinandersetzung mit dem Cambridger Platoniker Henry More zum Ausdruck. ${ }^{54}$ Mit seinem Begriff einer plastic nature vertritt dieser einen spiritualistischen Naturbegriff, der vom Paracelsismus inspiriert gewesen sein dürfte.

Wie bei Libavius und Sennert ist auch bei Boyle die mechanistische Konzeption der Natur religiös keineswegs indifferent. Boyle hat im selben Maße theologische wie chemische Schriften verfasst. In den theologischen Schriften versteht er seine experimentalphilosophischen Studien geradezu als religiöse Tätigkeit. The Usefulness of Experimental Philosophy heißt eine Schrift von 1663, wobei es dabei nur um den Nutzen der Experimentalwissenschaft für die Theologie geht. The Christian Virtuoso: shewing that by being addicted to experimental philosophy, a man is rather assisted than indisposed to be a good Christian, lautet der analoge Titel einer Schrift von 1690.

53 Robert Boyle: A Free Enquiry Into the Vulgarly Receiv'd Notion of Nature. In ders.: Works Bd. 10. Hrsg. von Michael Hunter und Edward B. Davis. London 2000, S. 437-571, hier S. 447: And as it more recommends the skill of an Engineer, to contrive an Elaborate Engine, so as that there should need nothing to reach his ends in it, but the contrivance of parts devoid of understanding; [...] so it more sets off the Wisdom of God in the Fabrick of the Universe, that he can make so vast a Machine, perform all those many things which he design'd it should, by the meer contrivance of Brute matter, managed by certain Laws of Local Motion and upheld by his ordinary and general concourse [...].

54 Zur Auseinandersetzung zwischen Boyle und More vgl. John Henry: Henry More versus Robert Boyle. The Spirit of Nature and the Spirit of Providence. In: Henry More (1614-1687). Tercentenary Studies. Hrsg. von Sarah Hutton. Dordrecht 1990, S. 55-76. 
Boyles Experimentalwissenschaft mit ihrem mechanistischen Naturbegriff impliziert im theologischen Sinne einen starken Supranaturalismus, das heißt die Überzeugung, dass Gott die Gesetze der Natur als eine Art oberster Ingenieur (engineer) geschaffen hat. ${ }^{55} \mathrm{Im}$ Laufe des 17. Jahrhunderts wird diese Überzeugung zunehmend zur Theologie der entstehenden ,Naturwissenschaften'. Die mechanischen Gesetze der Natur halten die Welt am Laufen, sei es durch den beständigen Willen Gottes im Sinne eines theologischen Voluntarismus (Gassendi, Boyle, Newton), sei es wie eine Uhr, die einmal aufgezogen wird und dann ihren Gang geht (Descartes, Leibniz). Leibniz zufolge wäre die Schöpfung der Welt selbst sogar das einzige im eigentlichen Sinne übernatürliche Ereignis, während der weitere Weltlauf dann ganz der göttlichen Providenz und den mechanischen Gesetzen folgte. Mechanizistischer Naturalismus und religiöser Supranaturalismus gehen Hand in Hand. ${ }^{56}$

Das Beispiel Boyle zeigt aber nicht nur, dass die Entstehung der Chemie als ,Naturwissenschaft' nur sehr bedingt als Säkularisierungsbewegung zu beschreiben ist, sondern auch, dass die gängige Beschreibung der Geschichte der Chemie als eine Entwicklung von der vormodernen Alchemie zur modernen Chemie korrekturbedürftig ist. Lawrence Principe hat die ,alchemischen' Interessen Boyles - also seinen Glauben an eine Möglichkeit der Transmutation von Metallen - herausgearbeitet und damit die Unterscheidung von vormoderner qua vorwissenschaftlicher ,Alchemie' und moderner qua wissenschaftlicher ,Chemie' grundsätzlich in Frage gestellt. ${ }^{57}$ Parallel dazu hat Principe zusammen mit William R. Newman die ,okkultistische' und ,esoterische' Vereinnahmung der Alchemie von der Romantik über den Spiritismus der Jahrhundertwende bis zu den esoterischen Bewegungen der Gegenwart nachgezeichnet. ${ }^{58}$ Diese ,esoterische' Vereinnahmung vollzieht sich zeitgleich mit dem Entwurf einer Wissenschaftsgeschichte der Chemie als unaufhaltbarem Fortschritt der Experimentalund ,Naturwissenschaft' im Sinne einer zunehmenden ,Aufklärung', die aus dem Dunkel ins Licht führt.

$55 \mathrm{Zu}$ Boyles theologischen Überzeugungen vgl. Margaret J. Osler: The Intellectual Sources of Robert Boyle's Philosophy of Nature: Gassendi's Voluntarism and Boyle's Physico-Theological Project. In: Philosophy, Science, and Religion in England, 1640-1700. Hrsg. von Richard Kroll, Richard Ashcraft und Perez Zagarin. Cambridge 1992, S. 178-198; Jan W. Wojcik: Robert Boyle and the Limits of Reason. Cambridge 1997 sowie die gesammelten Studien von Michael Hunter: Robert Boyle (1627-1691). Scrupulosity and Science. Woodbridge 2000.

56 Vgl. Keith Hutchison: Supernaturalism and the Mechanical Philosophy. In: History of Science 21 (1983), S. 297-333, bestätigt von Christoph Meinel: Okkulte und exakte Wissenschaften. In: Die okkulten Wissenschaften in der Renaissance. Hrsg. von August Buck. Wiesbaden 1992, S. 21-43 und von Moran: Distilling Knowledge (Anm. 2), S. 138f.

57 Lawrence M. Principe: The Aspiring Adept. Robert Boyle and his Alchemical Quest. Princeton 1998.

58 Lawrence M. Principe und William R. Newman: Some Problems with the Historiography of Alchemy. In: Secretes of Nature. Astrology and Alchemy in Early Modern Europe. Hrsg. von Anthony Grafton und William R. Newman. Cambridge 2001, S. 385-430. 
Symptomatisch in diesem Sinne verrechnet etwa Hans-Werner Schütt in seiner Geschichte der Alchemie die Alchemie mit einem „vormodernen Denken“, das zwischen theologischen und ,naturwissenschaftlichen' Behauptungen nicht unterscheiden könne, im Unterschied zur Chemie als einer „anständigen Naturwissenschaft", wie sie die Moderne hervorgebracht habe. ${ }^{59}$ Isaac Newton wird mit seinen mathematisch-naturwissenschaftlichen Schriften der Moderne zugeschlagen, mit seinen alchemischen Interessen aber der Vormoderne. ${ }^{60}$ Eine Wissenschaftsgeschichte, die sich solcherart als eine Geschichte der großen Entdeckungen, der neuen Erkenntnisse und des Fortschritts versteht, weiß mit ihrem Begriff der ,Wissenschaft' natürlich immer schon im Voraus, was zur Moderne und was zur Vormoderne gehört.

Eine solche Wissenschaftsgeschichte ist völlig legitim, wenn es darum geht, die Entwicklung der modernen Chemie als ,Naturwissenschaft' ${ }^{\prime}$ zu beschreiben. Es kann deshalb nicht darum gehen, eine solche Wissenschaftsgeschichte grundsätzlich in Frage zu stellen, sondern nur darum, die Implikationen und den Preis $\mathrm{zu}$ benennen, um den eine solche Wissenschaftsgeschichte $\mathrm{zu}$ haben ist. Für die Alchemie ist dies die Einheit des (al-)chemischen Wissens. Wer die mathematisch-physikalischen Schriften Newtons einer wissenschaftlichen Moderne und die alchemischen Schriften einem „vormodernen Denken“ zuweist, leistet vielleicht einen Beitrag zur Geschichte der Chemie als „anständiger Naturwissenschaft", sicher aber nicht zur Rekonstruktion der Einheit von Newtons Denken. Was man auf der anderen Seite gewinnen könnte, wenn man die Trennung von Alchemie und Chemie aufgibt, hat Principe mit seiner Studie zu Boyle gezeigt, indem er die enge Verknüpfung ,chemischer' und ,alchemischer' Interessen nachgewiesen hat. ${ }^{61}$

In diesem Sinne ist auch mein Plädoyer für eine Wissensgeschichte der Chemie $\mathrm{zu}$ verstehen. Im Gegensatz $\mathrm{zu}$ einer Wissenschaftsgeschichte muss eine solche Wissensgeschichte das zusammendenken, was in der Frühen Neuzeit noch zusammengehört: theologische Überzeugungen, ,spirituelle' Praktiken, philosophische Reflexionen, technisches Wissen um die Verwandlungen der Materie, institutionell-sozialhistorische Bedingungen des Wissens und poetische Formationen. Statt die Fortschritte der Chemie als ,Naturwissenschaft' im Sinne

59 Hans-Werner Schütt: Auf der Suche nach dem Stein der Weisen. Die Geschichte der Alchemie. München 2000. Auch wenn der Ausdruck „,anständige Naturwissenschaft“ dort S. 476 ironisch gebraucht wird, illustriert er das historische Konzept Schütts. Ein ganz ähnliches Konzept liegt auch Bernhard D. Haage: Alchemie im Mittelalter. Ideen und Bilder - von Zosimos bis Paracelsus. Zürich, Düsseldorf 1996 zugrunde, wenn Haage die Alchemie ausdrücklich mit „Esoterik“, „Bildlichkeit“ und „Mystik“ verrechnet, die Chemie dagegen mit einer "nüchternen Experimentalwissenschaft", die sich in der Moderne vollständig von der Alchemie getrennt habe.

60 Schütt: Geschichte der Alchemie (Anm. 59), S. 484. Ganz ähnlich auch Schütts Urteil über Helmont, den er S. 468 als „Grenzfall“ zwischen Chemie und Alchemie charakterisiert.

61 Principe: The Aspiring Adept (Anm. 57). 
einer ,Dogmengeschichte' zu rekonstruieren, wäre für eine Geschichte des (al-) chemischen Wissens gerade interessant, welche epistemischen Verschiebungen sich ereignen müssen, damit ein bestimmtes Wissen als ,Religion', ,Esoterik', ,Wissenschaft' - oder, worüber jetzt zu sprechen sein wird, ,Literatur' - gelten kann.

\section{Chemisches Wissen in poetischer Form}

Joachim Telles Arbeiten zur Rezeptionsgeschichte des Sol und Luna-Bildgedichts haben gezeigt, dass um 1600 der Reiz und die Faszinationskraft der älteren alchemischen Bildlichkeit - also dem, was bis dahin die alchemische Arkansprache gewesen war - erheblich zunimmt, während diese Bildlichkeit im gleichen Zuge ihres technischen Charakters beraubt wird. So jedenfalls wird man es verstehen müssen, wenn Telle einen "Zersetzungs- und Verdunklungsprozeß" des alchemischen Gehalts diagnostiziert, während doch im selben Zuge dieselben Gehalte zu buchgestalterischen und drucktechnischen Höchstleistungen führen. ${ }^{62}$ Zeitgleich mit dem erstarkenden Paracelsismus entstehen in der zweiten Hälfte des 16. mit einem Höhepunkt zu Beginn des 17. Jahrhunderts illuminierte Handschriften, Bilderzyklen und mit Kupferstichen illustrierte Bücher, die ihren Reiz vor allem aus den merkwürdigen Bildwelten der älteren Alchemie beziehen.

An erster Stelle ist der Splendor Solis zu nennen, ein Bilderzyklus, der seit ca. 1530 fassbar ist und sich in mehreren Handschriften erhalten hat. ${ }^{63}$ Seine Motive sind von der Aurora consurgens und allgemein der alchemischen Tradition des Mittelalters inspiriert, haben aber keinesfalls bloß illustrative Bedeutung. (vgl. die Farbabbildungen S. 444 und 445) Ganz im Gegenteil sind sie schon allein aufgrund der Herstellungskosten das eigentlich Entscheidende. Nur Vertreter des Hochadels und der hohen Geistlichkeit konnten solche illuminierten Handschriften überhaupt in Auftrag geben. Die Bilder des Splendor Solis versinnlichen chemisches und biologisches Wissen, waren aber sicherlich nicht als mnemotechnische Hilfestellungen für laborpraktische Anweisungen gedacht. Diesem Befund entsprechen die knappen Texte, von denen die Bilder begleitet werden. Als ,Erklärungen' können sie nur dem- jenigen dienen, der mit der Arkansprache der Chemie bereits vertraut ist. Für jeden anderen potenzieren sie die Rätselhaftigkeit der Bilder.

62 Telle: Sol und Luna (Anm. 15), S. 66, sowie Telle: Bemerkungen zum Rosarium Philosophorum (Anm. 3), S. 199. Allgemein zum Komplex der alchemischen Lehrdichtung in der Frühen Neuzeit vgl. die gesammelten Studien von Joachim Telle: Alchemie und Poesie. Deutsche Alchemikerdichtungen des 15. bis 17. Jahrhunderts. Untersuchungen und Texte. Berlin, New York 2013.

63 Vgl. Jörg Völlnagel: Splendor solis oder Sonnenglanz. Studien zu einer alchemistischen Bilderhandschrift. München, Berlin 2004, sowie die Beiträge in Bd. 2 von: Splendor Solis. Handschrift 78D3 des Kupferstichkabinetts der Staatlichen Museen zu Berlin, Preußischer Kulturbesitz. Gütersloh, München 2005. 
Ein zweites Beispiel wäre der sogenannte Lamspring, um 1500 entstanden, 1625 mit Radierungen von Matthias Merian erschienen. ${ }^{64}$ Auch hier gilt, dass die Ausgabe von 1625 mit ihrer Annäherung an die zeittypischen Emblembücher kaum als laborpraktisches Lehrbuch oder Handbuch gedient haben kann, vergleicht man den Lamspring mit den gleichzeitigen Lehrbüchern, sei es von Seiten einer traditionellen Alchemie (Libavius), sei es von paracelsistischer Seite (Croll). Damit ist nicht gesagt, dass der Lamspring - dem Telle „fachliche Aktualität und hohen Gebrauchswert" 65 bescheinigt hat - 1625 kein chemisches Sachwissen mehr vermitteln würde. Aber unzweifelbar übt auch die alchemische Arkansprache und ihre Rätselhaftigkeit für sich genommen eine große Faszinationskraft aus.

$\mathrm{Ob}$ die künstlerisch anspruchsvollen Radierungen, mit denen Merian 1625 den Lamspring versehen hat, noch eine mnemotechnische Funktion haben, kann man bezweifeln, sollte man aber nicht von vornherein ausschließen, wie das Beispiel von „Basilius Valentinus“ lehrt. In dem Textkorpus, das um 1600 unter diesem Namen gedruckt worden ist, finden sich etwa die Zwölf Schlüssel, die zwar ebenfalls mit scheinbar rätselhaften Abbildungen ausgestattet sind, gleichzeitig aber in den begleitenden Prosatexten chemische Rezepte und Arbeitsanweisungen entfalten, an deren technischem Charakter kein Zweifel bestehen kann. Ihr Bezug zu den Abbildungen ist auch heute noch so deutlich, dass ihre mnemotechnische Funktion höchst wahrscheinlich ist. Claus Priesner und Lawrence Principe haben zudem für Schriften des „Basilius Valentinus“-Korpus die chemische Umsetzbarkeit der Anweisungen demonstriert. ${ }^{66}$

Chemie und Poesie, Dichtung und Wissenschaft sind keine Gegensätze, sondern können durchaus komplementär wahrgenommen werden. Ein weiteres Beispiel dafür ist die Atalanta fugiens Michael Maiers, 1618 erschienen. ${ }^{67}$ Sie potenziert die bildliche Verrätselung der alchemische Motive, indem sie sie durch Fugen und Epigramme ergänzt. Alchemiker aber, die bei der Arbeit komplizierte dreistimmige Fugen singen können, dürften auch im 17. Jahrhundert schon äußert selten gewesen sein. Die Atalanta ist damit ein Buch, das sicherlich niemals in einem chemischen Labor gelegen hat. Im Vorwort der Atalanta heißt es

64 Die Ausgabe 1625 ist unter dem Titel Ein Tractat vom Philosophischen Stein erschienen in: Dyas chymica tripartita. Hrsg. von Hermann Condeesyanus [Johannes Rhenanus]. Frankfurt a.M. 1625, S. 83-117. Die Zentralbibliothek Zürich besitzt ein illuminiertes Manuskript aus dem Jahr 1556, vgl. http://dx.doi.org/10.7891/e-manuscripta-6275. (26. 8. 2014)

65 Joachim Telle: Art. Lamspring. In: Killy Literaturlexikon. 2. Auflage. Hrsg. von Wilhelm Kühlmann u.a. Berlin, New York 2010, Bd. 7, S. 184-18, hier S. 185.

66 Claus Priesner: Basilius Valentinus und die Labortechnik um 1600. In: Berichte zur Wissenschaftsgeschichte 20 (1997), S. 159-172; Lawrence Principe: „Chemical Translation“ and the Role of Impurities in Alchemy: Examples from Basil Valentine's Triumph-Wagen. In: Ambix 34 (1987), S. 21-30.

67 Grundlegend zu Maier ist Erik Leibenguth: Hermetische Poesie des Frühbarock. Die Cantilenae intellectuales Michael Maiers. Tübingen 2002. 


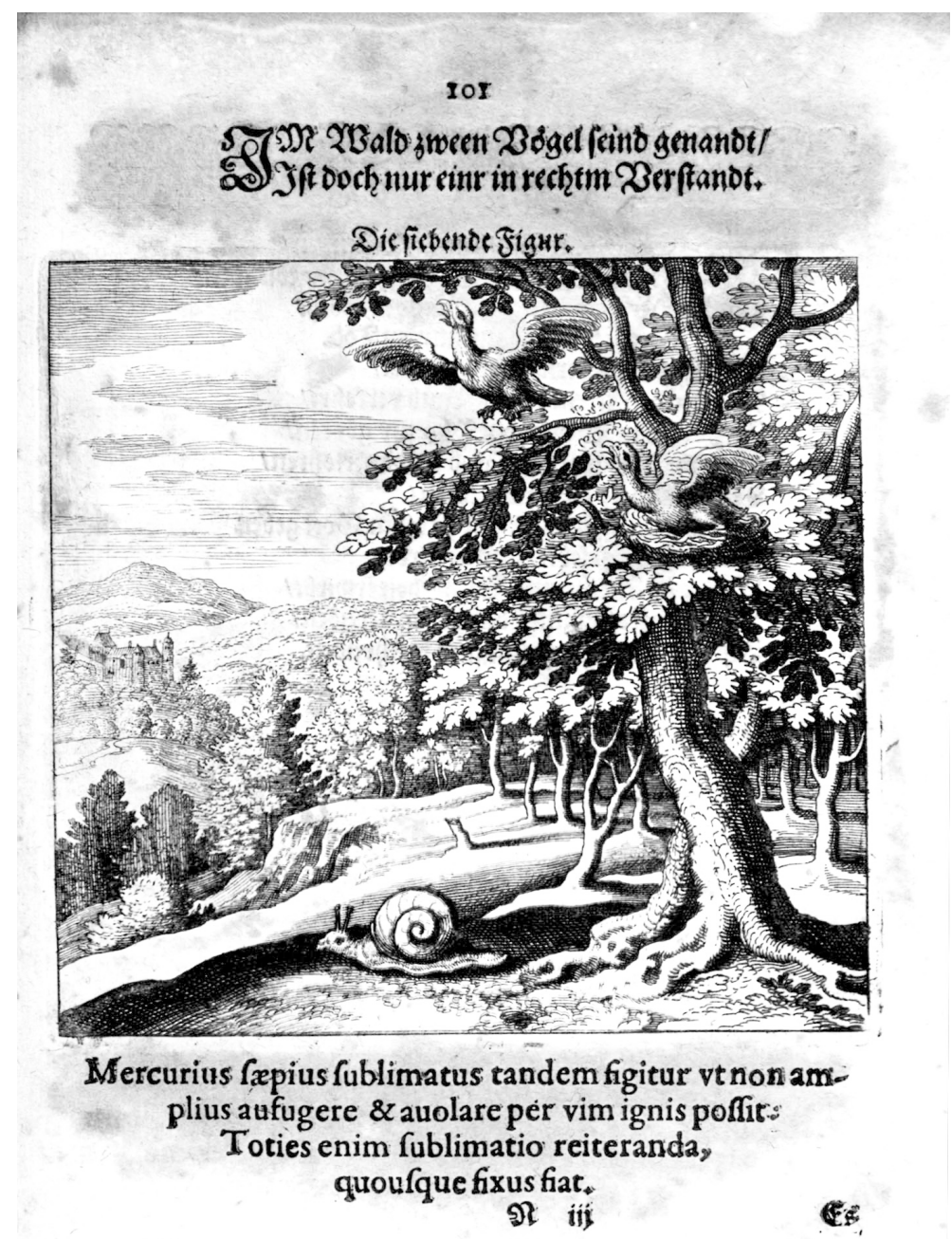

Abbildung aus dem Lamspring, erschienen als: Ein Tractat vom Philosophischen Stein. In: Dyas chymica tripartita. Hrsg. von Hermann Condeesyanus [Johannes Rhenanus]. Frankfurt a.M. 1625, S. 83-117, hier S. 101: „Die siebende Figur“. Abdruck mit freundlicher Genehmigung der Herzog August Bibliothek Wolfenbüttel. Auf der hier nicht mit abgebildeten, gegenüberliegenden Seite stehen die dazugehörigen Verse: Es wird ein Nest im Wald gefunden I Hermetis Vogel drinn hat sein Jungen/ I Der eine stets auffliegen will/ I Der ander im Nest lieget still/ I Der ein den andern nicht will verlassen/ I Sondern behelt ihn bester massen/ I Das müssens im Nest zusammenbleiben I Als ein Mann im Haus mit seim Weibel I In der Eheschafft aufs best verbunden I Das wir vns frewn zu allen stunden | Daß wir sie sampt haben behalten I Vnd lassens Gott den Vatter walten. 


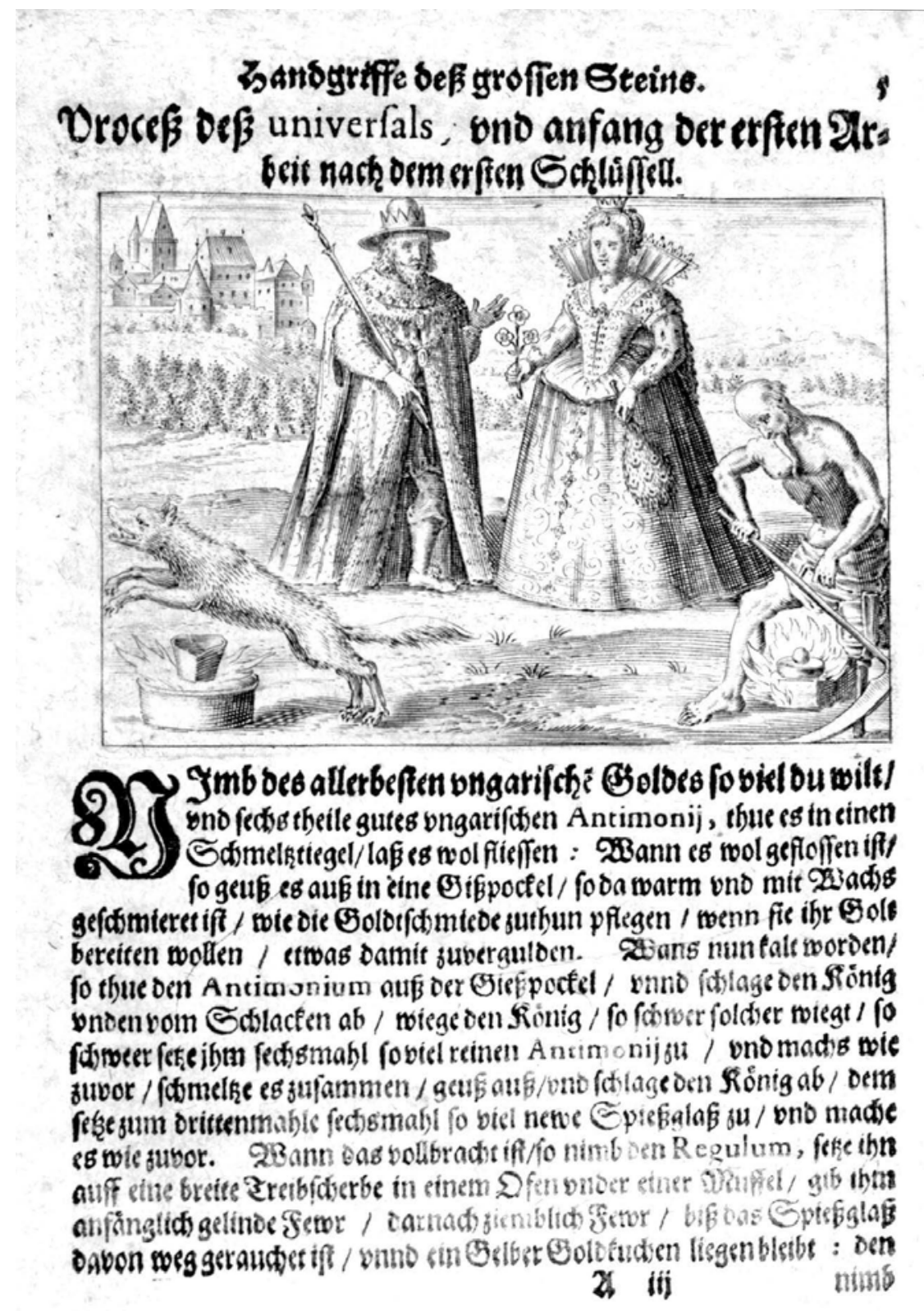

Basilius Valentinus: Vier Tractätlein. In: Dyas chymica tripartita. Hrsg. von Hermann Condeesyanus [Johannes Rhenanus]. Frankfurt a.M. 1625, S. 5: „Erster Schlüssel“. Abdruck mit freundlicher Genehmigung der Herzog August Bibliothek Wolfenbüttel. 

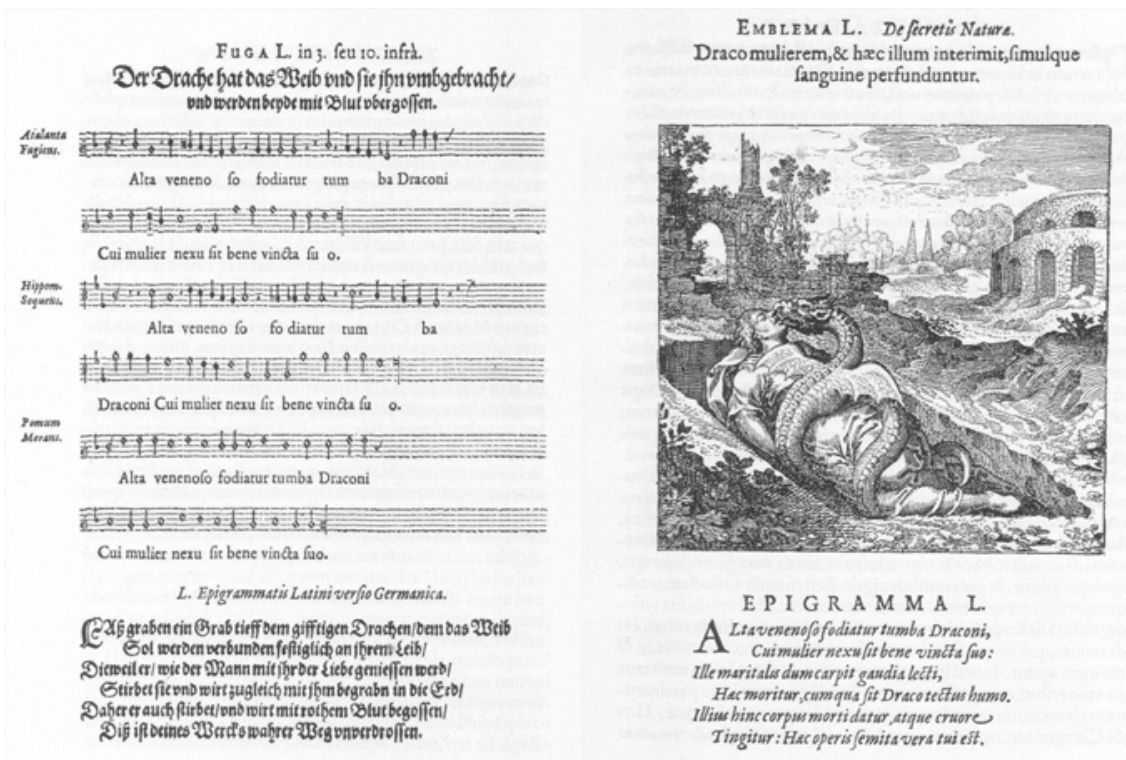

Michael Maier: Atalanta fugiens. Oppenheim 1618, Emblem 50.

auch schon sehr deutlich, es handle sich bei dieser um poëtische Gedichte, verblümte Redens-Arten, Bilder und Emblemata (ficta, poëtica et allegorica, picta, emblematica). ${ }^{68}$ Maier hat die Atalanta damit klar als poetischen Text ausgewiesen.

Das besagt auch, dass es sich bei dem in der Atalanta vermittelten Wissen nicht um Magie im Sinne des Paracelsismus oder um irgendwelche anderen Formen von ,Mystik' oder ,Okkultismus' handelt. ${ }^{69}$ Genauso wenig findet man in der Atalanta konkrete chemische Anweisungen. Die Texte der Atalanta verrätseln und verschlüsseln ein allgemein naturphilosophisches, im heutigen Sinne biologisches und chemisches Wissen. Die musikalische und bildliche Rahmung macht dieses Sachwissen "sinnfällig", indem sie ihm eine sinnliche, visionelle und akustische Form gibt. Das ist auf jeden Fall eine Form der Veranschaulichung, wenn auch nicht unbedingt eine Form der Erklärung.

Gerade mit dieser eher abseitigen Form der Wissensvermittlung macht die Atalanta fugiens deutlich, dass es einen Gegensatz zwischen ,Literatur' und ,Wissenschaft', wie er für die Moderne zumindest in bestimmten Facetten konstitutiv ist, in der Frühen Neuzeit nicht gegeben hat. Martin Opitz hat 1624 in seinem Buch von der deutschen Poeterey - also zeitgleich mit der Atalanta fugiens und dem

68 Michael Maier: Atalanta fugiens. Oppenheim 1618, S. 8. Ich zitiere die Übersetzung von 1708, vgl. Michael Maier: Chymisches Cabinet. Atalanta fugiens deutsch nach der Ausgabe von 1708. Hrsg. von Thomas Hofmeier. Berlin, Basel 2007, Vorrede S. 77.

69 Vgl. allerdings dagegen Tilton: Quest for the Phoenix (Anm. 10), der die Atalanta weiterhin in der Tradition von Carl Gustav Jung als Ausdruck einer "spirituellen Alchemie" liest. 
von Merian illustrierten Lamspring - die Dichtung als eine sinnreiche faßung aller sachen mit dem Zweck der vberredung vnd vnterricht auch ergetzung der Leute definiert. ${ }^{70}$ Das ist keine Leerformel, sondern wörtlich $\mathrm{zu}$ nehmen. Um genau eine solche sinnreiche, das heißt sinnlich ansprechende faßung oder "Veranschaulichung" von chemischem und biologischem Sachwissen handelt es sich bei der Atalanta fugiens. Genauso, wie sich Maier in seiner Septimana philosophica (1620) einem Lehrgespräch zwischen Salomon und der Königin von Saba - der dialogischen Form bedient, um das vermittelte Wissen interessant zu machen, bedient er sich in der Atalanta der Bilder und der Musik.

Solche ,Veranschaulichungen' von naturphilosophischem Wissen sind um 1600 ein kommerzieller Erfolg. 1624 veranstaltet der Verleger Lucas Jennis unter dem Titel Viridarium Chymicum (Chymisches Lustgärtlein) eine Sammelausgabe der alchemischen Kupferstiche aus den Werken von Daniel Mylius und Michael Maier, wobei es in erster Linie darauf ankam, die wertvollen Kupferplatten ein zweites Mal zu verwenden. Daniel Stoltzius, den Jennis damit beauftragt, die Kupferstiche mit begleitenden Versen zu versehen, gesteht im Vorwort mit dankenswerter Offenheit ein, im Verlauf der Arbeit gemerkt zu haben, dass die Beschreibungen mit den Figuren nicht vberein stimmeten/ ich auch jhre Außlegungen niergend finden kunde, was ihn in grosse angst versetzt und in ein vnaufflößliche[s] Labyrinth geführt hätte. ${ }^{71}$

Die Bemerkung zeigt, dass schon 1624 die chemische Entschlüsselung der Bilder als zweitrangig gegenüber ihrem enigmatischen Charakter empfunden wurde. Man konnte anfangen, die Kupferstiche mit Versen zu versehen, ohne genau zu wissen, was sie bedeuten. Erst waren die Kupferstiche da, dann wurde jemand beauftragt, die ,erklärenden' Verse zu schreiben. Der ,poetische', rätselhafte Charakter, nicht der alchemische Sinngehalt, ist das Argument für den Abdruck der Kupferstiche - von den kommerziellen Interessen des Verlegers einmal abgesehen. Paradigmatisch belegt diese Anekdote die Faszinationskraft der alchemischen Bildlichkeit.

Was für die bildlichen Darstellungen gilt, dürfte auch für die literarischen Bearbeitungen gelten, die sich der alchemischen Bildlichkeit bedienen. Genauso, wie die Atalanta fugiens kein ,mystisches' und ,esoterisches' Werk ist, sind auch die Chryseidos Libri IIII (1631) des Johann Nicolaus Furichius, ${ }^{72}$ die Jäger-Lust (1635) von Thomas Rappolt, ${ }^{73}$ der Philosophische Phönix des Johann Rist, ${ }^{74}$ die

70 Martin Opitz: Buch von der deutschen Poeterey. In ders.: Gesammelte Werke. Hrsg. von George Schulz-Behrend, Bd. II.1. Stuttgart 1978, S. 331-416, die Zitate hier S. 360 und S. 351.

71 Daniel Stoltzius von Stolzenberg, unpag. Vorrede. In: Chymisches Lustgärtlein. Frankfurt a.M. 1624. Ndr. Darmstadt 1987. Zu Kontext und Entstehungsgeschichte vgl. Telle: Sol und Luna (Anm. 15), S. 65f.

72 Vgl. dazu Thomas Reiser: Mythologie und Alchemie in der Lehrepik des frühen 17. Jahrhunderts: die Chryseidos Libri IIII des Straßburger Dichterarztes Johannes Nicolaus Furichius (1602-1633). Berlin, New York 2011.

73 Vgl. Rosmarie Zeller: Hermetisches Sprechen in alchemischen Texten. Die Jäger-Lust von 
Metamorphosis Planetarum (1663) Monte-Snyders oder das Conjugium Phoebi et Palladis (1677) Christian Knorr von Rosenroths keine ,mystischen' oder ,okkulten' Werke, sondern das, was sie schon durch ihre Form zu sein behaupten: nämlich Dichtung.

Vor allem aber gilt dies für das ,esoterische' Werk schlechthin, die Chymische Hochzeit Christiani Rosenkreutz (1616) von Johann Valentin Andreae, mithin also für das Werk, das am Anfang der Rosenkreuzer-Bewegung steht und bis in die Gegenwart zu zahllosen esoterischen Interpretationen und Spekulationen Anlass gegeben hat. Nicht zuletzt ist dieses Werk dafür verantwortlich, dass die Alchemie für den Orden der Rosenkreuzer überhaupt eine so wichtige Rolle gespielt hat. In den beiden Rosenkreuzer-Manifesten selbst, der Fama Fraternitatis (Druck 1614) und der Confessio Fraternitatis (Druck 1615), spielt die Alchemie nur eine höchst untergeordnete Rolle.

Schon 1617 geht Ratichs Brotoffer (Anagramm für Christoffer Rodtbart) in seinem Elucidarius maior davon aus, dass die Chymische Hochzeit eine verschlüsselte Darstellung des Prozesses ist, der zum Stein der Weisen führt. Damit liest er die Chymische Hochzeit nicht als einen poetischen Text, der mit der alchemischen Arkansprache spielt, sondern als einen tatsächlich im Sinne dieser Arkansprache bewusst verschlüsselten Text. Andreae selbst hat einen solchen Versuch aber ausdrücklich zurückgewiesen. In der Mythologia christiana (1619) bezeichnet er die Rosenkreuzer-Schriften als "Spiel“ (lusus) und in De curiositatis pernicie (1621) als „Scherz" (ludibrium) und „Märchen“ (fabula). ${ }^{75}$ In Christianopolis (1619) versichert er, sich selbst nie in chemischer Laborarbeit versucht, sondern sich nur theoretisch mit der Alchemie beschäftigt zu haben. ${ }^{76}$ Damit erscheint die Chymische Hochzeit als ein poetisches Spiel mit der enigmatischen Bildlichkeit der Alchemie.

Im Gegensatz zur spielerisch-literarischen Rezeption der alchemischen Arkansprache in der Chymischen Hochzeit steht die Bedeutung, die Andreae der Alchemie in Christianopolis zuspricht. Alchemie wird dort als genau das praktiziert, als was sie zeitgleich bei Libavius und später bei Boyle entwickelt wird: als eine Experimentalwissenschaft, die für die Verbesserung der menschlichen Lebensbedingungen von enormer Bedeutung ist. Sie ist auf das Wohl des Nächsten ausgerichtet und jeder theologischen Spekulation abhold, genauso wie dem praxisfernen Bücherwissen etwa aristotelischer Provenienz. Als eine praktische

Thomas Rappolt. In: Konzepte des Hermetismus in der Literatur der Frühen Neuzeit. Hrsg. von Peter-André Alt und Volkhard Wels. Göttingen 2010, S. 195-212.

74 Vgl. dazu den Beitrag von Stefanie Stockhorst in diesem Band.

75 Johann Valentin Andreae: Mythologia christiana. Straßburg 1619, S. 329; Johann Valentin Andreae: De curiositatis pernicie syntagma ad singularitatis studiosos. Straßburg 1621. Ndr. Schwäbisch Gmünd 1963, S. 35.

76 Johann Valentin Andreae: Christianopolis 1619. Originaltext und Übertragung nach D.S. Georgi 1741. Eingel. und hrsg. von Richard van Dülmen. Stuttgart 1972, 44, S. 114: non exercuisse hanc artem, sed inspexisse. 
Naturforschung ist sie vollständig der lutherischen Religion untergeordnet, die den Lebenskern von Christianopolis bildet. Von paracelsistischem Spiritualismus, ,Mystik' oder ,Esoterik' kann keine Rede sein.

Wer die poetische Alchemie der Chymischen Hochzeit oder der Atalanta fugiens mit dem Paracelsismus verrechnen möchte, wird diese Gegensätze erklären müssen. Die scheinbar so ,esoterischen' Bildwelten Andreaes und Maiers rekrutieren ihr Bildmaterial aus der traditionellen Alchemie, nicht aus der spiritualistischen Alchemie des Paracelsismus. Gegen alle ,esoterischen' Deutungsversuche, aber auch gegen manche Wissenschaftshistoriker ${ }^{77}$ - die Extreme berühren sich -, wird man davon ausgehen müssen, dass die poetische Alchemie Andreaes und Maiers und die spiritualistische Deutung der Alchemie im Paracelsismus als Gegensätze anzusehen sind, nicht aber die poetische Alchemie und deren Deutung als praktisches, lebensnahes Wissen, als Technik im Sinne der späteren ,Naturwissenschaften'.

Unter all den esoterischen Interpreten der Chymischen Hochzeit war Rudolf Steiner vielleicht noch der scharfsichtigste. Steiner nämlich war wenigstens ehrlich genug, anzuerkennen, dass der "schmalzige ", "philiströse Pastor", der Andreae für Steiner war, mit seinen "salbungsvollen“, „fettig-öligen“ Schriften, unmöglich derselbe Mensch gewesen sein könne, der die Chymische Hochzeit geschrieben hat. ${ }^{78}$ Steiner folgert daraus allerdings nicht, dass die Chymische Hochzeit vielleicht bloß eine poetische „Spielerei“ gewesen sein könnte, sondern dass im Gegenteil die Chymische Hochzeit gar nicht von Andreae als "physischer Persönlichkeit" stamme, sondern von einer "geistigen Wesenheit", die sich nur der Hand Andreaes bedient habe. Deswegen sei es auch kein Wunder, dass der "schmalzige Pastor" von dem, was er da geschrieben hat - nach Steiner handelt es sich um "kosmische Geheimnisse", "hybernische Mysterien“, „spirituelle Offenbarungen", "gewaltige Erlebnisse zwischen dem Menschen und dem Makrokosmos" -, gar nichts verstanden habe.

Damit ist zwar die Differenz zwischen der Chymischen Hochzeit und den anderen Schriften Andreaes anerkannt, allerdings nur um den Preis eines etwas unkonventionellen Begriffs von Autorschaft. Wer dagegen weiterhin von einer psychisch-physischen Einheit des Autors Andreae ausgehen möchte, wird gut daran tun, die Chymische Hochzeit als das zu behandeln, was sie auf den ersten Blick zu sein scheint: eine Dichtung. Was wir deshalb dringend brauchen, ist eine genuin wissensgeschichtliche Studie zur Chymischen Hochzeit, die sich aller esoterischen, psychoanalytischen, anthroposophischen und rosenkreuzerischen

77 Schütt: Geschichte der Alchemie (Anm. 60), S. 401 deutet das Vordringen von Bildern in die Alchemie als Anzeichen für das "Überhandnehmen von hermetischen oder neo-hermetischen Vorstellungen" und bringt es damit per se in einen Gegensatz zur Chemie als ,Naturwissenschaft'.

78 Rudolf Steiner: Mysteriengestaltungen. Vierzehn Vorträge. Hrsg. von Marie Steiner. Dornach 1931. Neunter Vortrag vom 9. 12. 1923, S. 98-113, hier S. 110f. Dort auch alle folgenden Zitate. 
Spekulationen enthält und stattdessen die genaue Herkunft des Bildmaterials klärt, das Andreae in diesem Werk verarbeitet hat. ${ }^{79}$

Genauso wie bei der Atalanta fugiens geht es darum, den Literaturbegriff nicht bloß so zu erweitern, dass er diese Werke erfasst, sondern Literaturgeschichte als Wissensgeschichte zu betreiben. Paradoxerweise wird man vielleicht erst dann die Chymische Hochzeit als das wahrnehmen können, was sie ist: nämlich eine der bildgewaltigsten Dichtungen der Frühen Neuzeit. Als solche verdient die Chymische Hochzeit weit mehr Aufmerksamkeit, als ihr bisher von Seiten der Literaturwissenschaft zugestanden wurde. Symptomatisch dafür ist die halbe Seite, auf der die Chymische Hochzeit in der neuesten Literaturgeschichte besprochen wird, und das in einem Kapitel zu „Pansophischen und mystischen Strömungen". 80

\section{Schlussfolgerungen}

Die vormoderne Chemie repräsentiert ein Wissen, dass die modernen Kategorien der ,Wissenschaft', ,Religion' und ,Literatur' transzendiert. Eine Wissensgeschichte dieser Chemie ist also nicht bloß interdisziplinär, sondern muss die historische Bedingtheit der modernen Disziplinen und Kategorien selbst herausarbeiten. Eine Wissenschaftsgeschichte, die ihren Wissenschaftsbegriff dagegen aus dem bezieht, was sich im Laufe des 18. und 19. Jahrhunderts als ,Wissenschaft' konfiguriert hat, wird die vormoderne Chemie immer als bloße Vorgeschichte wahrnehmen, als "Alchemie“ im Gegensatz zur „Chemie“.

Wenn Principe und Newman aus einer ähnlichen Diagnose heraus für die frühneuzeitliche Chemie den Begriff der "Chymistry“ vorgeschlagen haben, als ein Kunstwort für eine Epoche, die zwischen der mittelalterlichen "Alchemy“ und der modernen "Chemistry" vermittelt, ${ }^{81}$ geht dieser Vorschlag noch nicht weit genug, denn damit wird nur ein zweistufiges durch ein dreistufiges historiographisches Modell ersetzt. Wichtig aber wäre, die Kontinuitäten und Diskontinuitäten des chemischen Wissens jenseits aller vorher schon getroffenen Klassifikationen, jenseits der ,scientific revolution' als angeblicher Schwelle von "Moderne' und ,Vormoderne' herauszuarbeiten. Indem diese ,wissenschaftliche Revolution' den Begriff der ,Wissenschaft' überhaupt erst hervorbringt, eignet sich dieser Begriff nicht, ein Wissen zu beschreiben, das noch vor der ,Wissenschaft' liegt.

79 Einen Anfang bildet Regine Frey-Jaun: Die Berufung des Türhüters. Zur Chymischen Hochzeit Christiani Rosenkreutz von Johann Valentin Andreae (1586-1654). Bern u.a. 1989.

80 Volker Meid: Die deutsche Literatur im Zeitalter des Barock. Vom Späthumanismus zur Frühaufklärung 1570-1740. München 2009, S. 820. Michael Maier erfährt kaum eine namentliche Nennung. Das ist kein Vorwurf, denn der Band repräsentiert damit nur den Stand der Forschung.

81 William R. Newman und Lawrence M. Principe: Alchemy vs. Chemistry: The Etymological Origins of a Historiographical Mistake. In: Early Science and Medicine 3 (1998), S. 32-65. 
Ähnliches gilt für den religionshistorischen Aspekt. Auch hier sind die Weichenstellungen des 17. Jahrhunderts von einschneidender Bedeutung, insofern der Begriff der Religion in dieser Zeit eine zunehmend schärfere Trennung zwischen einem supranaturalistischen Gott und einem rein mechanisch ablaufenden Weltgeschehen impliziert. Der Graben zwischen der mechanischen und der moralischen Welt, zwischen ,Religion' und ,Naturwissenschaft' wird größer. Die religiöse Dimension insbesondere der paracelsistischen Alchemie wird dagegen im selben Zuge zu einer frühen Form der ,Esoterik' oder des ,Okkultismus' erklärt und in einen Topf geworfen mit der poetischen Alchemie der Chymischen Hochzeit oder der Atalanta fugiens.

Dem gegenüber ist festzuhalten, dass die Kategorien der ,Esoterik' und des ,Okkulten' moderne Konstrukte sind, denen in der Vormoderne nichts entspricht. Für die religiöse Konfiguration der frühneuzeitlichen Chemie entscheidend ist dagegen, dass mit dem mechanistischen Supranaturalismus einerseits und dem paracelsistischen Spiritualismus andererseits zwei eigenständige religiöse Aufladungen des chemischen Wissens zu beobachten sind, in denen sich jeweils ganz unterschiedliche Konzeptionen von Religion spiegeln. Ausgehend von ihren Vorläufern im Paracelsismus wird die ,Esoterik' im Laufe des 18. und 19. Jahrhunderts genau in den Leerraum treten, den die "Supranaturalisierung' Gottes und die Mechanisierung der Natur hinterlassen haben. Der merkwürdige, zwischen den modernen Kategorien von ,Wissenschaft' und ,Religion' changierende Status der ,Esoterik' dürfte sich aus dieser Herkunft erklären.

Eine Wissensgeschichte könnte schließlich auch drittens die disziplinäre Eingrenzung einer Literaturgeschichte aufheben. Weil man in der Frühen Neuzeit nicht ohne weiteres zwischen sogenannten ,Sachtexten' und ,poetischen' Texten unterscheiden kann, und der Begriff der ,Literatur' schon ganz und gar ein Konstrukt des 18. Jahrhunderts ist, kann man alchemische Texte in poetischen Formen nicht als Gegenstand einer ,Literaturgeschichte' isolieren. Die Chymische Hochzeit Andreaes oder die Atalanta fugiens Maiers sind im Sinne der Zeit poetische Texte, und das heißt: Sie vermitteln auf anschauliche Art ein sachliches Wissen. Oder etwas präziser: Sie spielen mit dem Anspruch, ein solches Wissen $\mathrm{zu}$ vermitteln. Eine Wissensgeschichte der frühneuzeitlichen Chemie könnte dabei helfen, den poetischen Status von Texten wie der Chymischen Hochzeit überhaupt erst zu erkennen und sie damit aus der ,Mystik-' und ,Esoterik'-Ecke zu befreien. 
(C) 2015, Otto Harrassowitz GmbH \& Co. KG, Wiesbaden ISBN Print: 9783447104951 - ISBN E-Book: 9783447194129 


\title{
Satirische Erbauungsalchemie
}

\author{
Zum Verhältnis von Humanistenschalk, Laborpraxis und \\ Gotteserkenntnis in Johann Rists Philosophischem Phoenix (1638)
}

\author{
Stefanie Stockhorst, Potsdam
}

\section{Rist - ein lutherischer Alchemiker}

Seine größte literarische Bedeutung erlangte Johann Rist sicherlich als Lyriker, insbesondere als protestantischer Kirchenlieddichter. ${ }^{1}$ Zumindest in literaturwissenschaftlichen Kreisen kennt man Rist auch als Dramatiker ${ }^{2}$ sowie als Sprachund Dichtungstheoretiker, der streitlustig die "Statthalterschaft des Opitzianismus im nördlichen Deutschland“" ${ }^{3}$ übernimmt. ${ }^{4}$ Als Naturwissenschaftler und

1 Vgl. u.a.: „Ewigkeit, Zeit ohne Zeit“. Gedenkschrift zum 400. Geburtstag des Dichters und Theologen Johann Rist. Hrsg. von Johann Anselm Steiger. Neuendettelsau 2007; siehe auch Hans-Henrik Krummacher: Lehr- und trostreiche Lieder. Johann Rists geistliche Dichtung und die Predigt- und Erbauungsliteratur des 16. und 17. Jahrhunderts. In: Vox Sermo Res. Beiträge zur Sprachreflexion, Literatur- und Sprachgeschichte vom Mittelalter bis zur Neuzeit. FS Uwe Ruberg. Hrsg. von Wolfgang Haubrichs, Wolfgang Kleiber und Rudolf Voß. Stuttgart 2001, S. 143-168; W. Gordon Marigold: Aspekte des geistlichen Liedes im 17. Jahrhundert. Johann Rist, Hinrich Elmenhorst, Christian Knorr von Rosenroth. In: MorgenGlantz 6 (1996), S. 81-98; Donald Lee Madill: Johann Rist as Hymnwriter. A Study of his Life and Works with Particular Emphasis on his Himmlische Lieder und Sonderbahres Buch. Kansas 1985; Irmgard Scheitler: Das geistliche Lied im deutschen Barock. Berlin 1982, S. 230-271; Leif Ludwig Albertsen: Strophische Gedichte, die von einem Kollektiv gesungen werden. Das Zersingen, analysiert am Schicksal einiger Lieder von Johann Rist. In: Deutsche Vierteljahrsschrift für Literaturwissenschaft und Geistesgeschichte 50 (1976), S. 84-102.

2 Vgl. u.a. Thomas Rahn: Krieg als Störfall der Rhetorik. Die Friedensspiele von Johann Rist und Justus Georg Schottelius. In: Krieg und Rhetorik. Hrsg. von dems. Tübingen 2003, S. 4357; Klaus Garber: Pétrarquisme pastoral et bourgeoisie protestante: La Poésie pastorale de Johann Rist et Jakob Schwieger. Übers. von Danielle Laforge. In: Le genre pastoral en Europe du XVe au XVIIe siècle. Hrsg. von Claude Longeon. Saint-Etienne 1980, S. 269-297, bes. S. 273-290; Eberhard Mannack: Johann Rists Perseus und das Drama des Barock. In: Daphnis 1 (1972), S. 141-149.

3 Günter Dammann: Johann Rist als Statthalter des Opitzianismus in Holstein. Aspekte seiner literaturpolitischen Strategie anhand der Widmungsbriefe und Vorreden. In: Literaten in der Provinz - provinzielle Literatur? Schriftsteller einer norddeutschen Region. Hrsg. von Alexander Ritter. Heide, Holstein 1991, S. 47-66; vgl. auch Klaus Garber: Literarischer und kulturpolitischer Statthalter im Norden Deutschlands. Ein Portrait Johann Rists. In: „Ewigkeit, Zeit ohne Zeit" (Anm. 1), S. 9-36; Eberhard Mannack: Opitz und seine kritischen Verehrer. In: Martin Opitz (1597-1639). Nachahmungspoetik und Lebenswelt. Hrsg. von Thomas Borgstedt, Walter Schmitz. Tübingen 2002, S. 272-279; sowie Ulrich Moerke: Die 
Naturphilosoph hingegen ist Rist bislang sehr viel weniger erforscht, und das, obwohl er auf diesem Gebiet keineswegs nur dilettierte, sondern vielmehr die beiden Schwerpunkte seiner akademischen Ausbildung, die Theologie und die Pharmazie, miteinander verknüpfte. ${ }^{5}$ Die vergleichsweise geringe wissenschaftliche Aufmerksamkeit, die diesem Bereich bisher zuteilwurde, hängt vermutlich mit der Wertungsproblematik zusammen, die sich mit den Monatsgesprächen (1663-68) als naturwissenschaftlichem Hauptwerk Rists traditionell verband. In Verkennung seiner anspruchsvollen kosmologischen Architektur wurde diesem Text lange ein "seltsame[r] Mischcharakter" ${ }^{\prime \prime}$ unterstellt. Dieses Missverständnis wurde nicht nur durch eine grundsätzliche Barock-Aversion der älteren Forschung begünstigt, sondern auch dadurch, dass Rist vor der Fertigstellung des Werkes verstarb. Daher wurden die fehlenden sechs von zwölf Gesprächen durch den Buntschriftsteller Erasmus Francisci (1627-1694) ergänzt, der jedoch nur die äußere Form, nicht aber die kosmologischen Finessen der zyklischen Komposition fortführte - vielleicht absichtlich mit Blick auf anders gelagerte Publikumsinteressen, vielleicht, weil er sie selbst nicht bemerkte oder beherrschte. Neuerdings werden zumindest Rists Anteile an den Monatsgesprächen nicht nur als mögliche Vorläufer von Literaturkritik und Zeitschrift diskutiert, ${ }^{7}$ sondern rücken auch als naturwissenschaftliche bzw. naturphilosophische ${ }^{8}$ sowie als kosmologische ${ }^{9}$ Schriften in den Blick.

In diesen Monatsgesprächen bekennt die Figur des ,Rüstigen', wie Rists Gesellschaftsname bei den Fruchtbringern lautete, an mehreren Stellen eine langjährige Begeisterung für die Alchemie. ${ }^{10}$ Außerdem widmet Rist sogar das ganze März-Gespräch (1664) diesem Gegenstand. Er beschreibt darin außerordentlich

Anfänge der weltlichen Barocklyrik in Schleswig-Holstein. Hudemann, Rist, Lund. Neumünster 1972, S. 88-94.

4 Vgl. Garber: Literarischer und kulturpolitischer Statthalter (Anm. 3), S. 9-36.

5 Vgl. Klaus Conermann: Die Mitglieder der Fruchtbringenden Gesellschaft 1617-1650. 527 Biographien. Transkriptionen aller handschriftlichen Eintragungen und Kommentare zu den Abbildungen und Texten im Köthener Gesellschaftsbuch. Weinheim, Deerfield Beach 1985, S. 567; sowie Dieter Lohmeier, Klaus Reichelt: Johann Rist. In: Deutsche Dichter des 17. Jahrhunderts. Das Leben und Werk. Hrsg. von Harald Steinhagen und Benno von Wiese. Berlin 1984, S. 347-364, bes. S. 348.

6 Alfred Jericke: Johann Rists Monatsgespräche. Berlin, Leipzig 1928, S. 192.

7 Vgl. Sylvia Heudecker: Modelle literaturkritischen Schreibens. Dialog, Apologie, Satire vom späten 17. bis zur Mitte des 18. Jahrhunderts. Tübingen 2005, S. 53-67.

8 Vgl. Ferdinand van Ingen: Johann Rist und die Naturwissenschaften seiner Zeit. Anmerkungen zu seiner intellektuellen Biographie anlässlich des 400. Geburtstags am 8. 3. 2007. In: Daphnis 36 (2007), H. 3, 4, S. 487-510.

9 Vgl. Stefanie Stockhorst: Wissensvermittlung im Dialog. Literarische Pflanzenkunde und christliche Weltdeutung in den Rahmenstücken von Johann Rists Monatsgesprächen und ihrer Fortsetzung durch Erasmus Francisci. In: Polyhistorismus und Buntschriftstellerei. Populäre Wissensformen und Wissenskultur in der Frühen Neuzeit. Hrsg. von Flemming Schock. Berlin 2012, S. 67-90.

10 Vgl. van Ingen: Johann Rist und die Naturwissenschaften seiner Zeit (Anm. 8), S. 503-510. 
spektakuläre Experimente, denen der Rüstige zwar nicht selbst beigewohnt habe, sondern - nota bene - nur vom Hörensagen kenne, ${ }^{11}$ die er jedoch für wahr halte, dann ob ich schon eben dises / selber nicht angeschauet / so habe ich doch etwas, das disem nicht ungleich / mehr als hundert mahl gesehen. ${ }^{12}$ Rists literarisches alter ego führt seine gelehrten Gäste freimütig durch alle seine Arbeitsräume, darunter neben der Apotheke und der Bibliothek auch eine eigene Kammer / wo der Rüstige seine Distillieröfen [!] hat. ${ }^{13}$ Ferner teilt er über seine Vernetzung im Feld der Alchemie und zugleich über seine praktischen Erfahrungen auf diesem Gebiet mit,

es hielten sich die allerfürtrefflichste Chymici offt etliche viel Wochen bei mir auff / da wir dan nicht nur gemeine / sondern auch zu Zeiten / die aller verwunderlichste Dinge im Feuer versüchten / und das fanden / was wir zu finden niemals vermeinet hatten ${ }^{14}$

- worum es sich bei diesen Funden genau handelte, verrät er wohlweislich nicht. Verwundert registrierte bereits Alfred Jericke Rists unverblümt eingestandene Begeisterung für "seltsame, kaum glaubwürdige Erscheinungen“,15 obgleich doch bereits der Titel des März-Gespräches, die Die AllerEdelste Tohrheit Der gantzen Welt, nahelegt, dass es dem Wedeler Pastor kaum ernstlich darum zu tun sein konnte, naiven Wunderglauben, und sei er als Torheit noch so edel, zu verbreiten. Und noch Hans-Georg Kemper wollte "geradezu von einer dualen Identität sprechen", da ihm Pfarramt und Alchemie zutiefst widersprüchlich vorkamen: „Auf der Kanzel predigte er das orthodoxe Christentum, in seinem Garten und Laboratorium suchte der Anhänger des Kopernikus nach dem ,Stein der Weisen'. Beide Arten von Gottesdienst stehen unverbunden nebeneinander." 16

11 Vgl. Johann Rist: Die AllerEdelste Tohrheit Der gantzen Welt, Vermittelst eines anmuhtigen und erbaulichen Gespräches, Welches ist diser Ahrt Die Dritte, und zwahr Eine MärtzensUnterredung, Beschrieben und fürgestellet [1664]. In ders.: Sämtliche Werke. Hrsg. von Eberhard Mannack. Bd. 5: Epische Dichtungen (Die alleredelste Torheit, Die alleredelste Belustigung). Berlin, New York 1974, S. 1-181, hier insbes. S. 163-166; van Ingen nimmt hier irrtümlich Augenzeugenschaft an, vgl. van Ingen: Johann Rist und die Naturwissenschaften seiner Zeit (Anm. 8), S. 505.

12 Rist: Die AllerEdelste Tohrheit (Anm. 11), S. 167f.

13 Johann Rist: Die alleredelste Zeit-Verkürtzung Der Gantzen Welt, Vermittelst eines anmuthigen und erbaulichen Gespräches, Welches ist dieser Art die Sechste, Und zwahr eine Brachmonats Unterredungen, Beschrieben und fürgestellet [1668]. In ders.: Sämtliche Werke. Unter Mitwirkung von Helga Mannack hrsg. von Eberhard Mannack. Bd. 6: Epische Dichtungen (Die Alleredelste Erfindung, Die Alleredelste Zeitverkürzung). Berlin, New York 1976, S. 241-448, hier S. 288.

14 Johann Rist: Die alleredelste Erfindung Der Gantzen Welt, Vermittelst eines anmutigen und erbaulichen Gespräches, welches ist dieser Art, die Fünffte, Und zwar eine Mäyens-Vnterredungen, Beschrieben und fürgestellet [1667]. In ders.: Sämtliche Werke (Anm. 13), S. 1240, S. 29; vgl. auch ders.: Die AllerEdelste Tohrheit (Anm. 11), S. 152.

15 Jericke: Johann Rists Monatsgespräche (Anm. 6), S. 57.

16 Hans-Georg Kemper: „Eins in All! Und all in Eins!“. Christliche Hermetik als trojanisches Pferd der Aufklärung. In: Aufklärung und Esoterik. Rezeption-Integration- 
Bei einem dogmatisch untadeligen Lutheraner wie Rist können dahingehende Aktivitäten freilich nur dann stutzig machen, wenn man die Alchemie stark vereinseitigt als obskures Betätigungsfeld für Goldköche und Geldschneider versteht. Denkgeschichtlich gehört sie jedoch vielmehr zum Kernbestand der frühneuzeitlichen Naturphilosophie, mit dem sich honorige Intellektuelle von Marsilio Ficino über Isaac Newton bis hin zu Luther selbst völlig problemlos befassten. ${ }^{17} \mathrm{Im}$ Dienste des Strebens nach Einsicht in die höheren Zusammenhänge der Kosmologie besitzen daher auch für Rist seine Chymische Verrichtunge keinen anderen Stellenwert als den einer experimentellen Naturphilosophie auf christlichem Fundament, ${ }^{18}$ mit der er, wie er schreibt, manche liebe Stunde zubringe / und die grosse Wercke GOttes mit höchster Belustigung [s]einer Seelen / in dieser edlen Wissenschafft betrachte. ${ }^{19}$ So hat Ferdinand van Ingen denn auch völlig Recht mit seiner Feststellung, dass lediglich die ausgiebige praktische Tätigkeit im Laboratorium ein wenig aus dem Rahmen falle:

Es ist nicht erstaunlich, daß Rist sich für diese Wissenschaft interessierte [...]. Daß er sie in den höchsten Tönen lobt und seine Aussagen mit Zitaten von Hermes (,aller Philosophorum Vatter'), Geber, Basilius Valentinus, Raimundus Lullus, Samuel Trismosinus und (selbstverständlich) Paracelsus erhärtet, war schließlich wissenschaftlicher Usus. Aber überraschend ist die freimütige Art, wie er die Abenteuer am Ofen, an Kolben und Retorten beschreibt [...]. ${ }^{20}$

Desgleichen bestanden offenbar im zeitgenössischen Kontext keinerlei Vereinbarungsschwierigkeiten, wenn Rist mit dem Lutheraner Anton Buscher (15731638), der wie er selbst zur Theologie Johann Arndts tendierte, ${ }^{21}$ zeitweilig nicht

Konfrontation. Hrsg. von Monika Neugebauer-Wölk. Tübingen 2008, S. 28-52, hier S. 38, Anm. 34.

17 Vgl. zur Allianz von Christentum und Alchemie Johann Anselm Steiger: Medizinische Theologie. Christus medicus und theologia medicinalis bei Martin Luther und im Luthertum der Barockzeit. Mit Edition dreier Quellentexte [...]. Leiden, Boston 2005; sowie AnneCharlott Trepp: Zur Differenzierung der Religiositätsformen im Luthertum des 17. Jahrhunderts und ihrer Bedeutung für die Deutung von ,Natur'. In: Pietismus und Neuzeit 32 (2006), S. 37-56.

18 Vgl. Volkhard Wels: Zwischen Spiritualismus, Hermetik und lutherischer ,Orthodoxie'. Zu Hans-Georg Kempers Vorgeschichte der Naturlyrik. In: Zeitsprünge 16 (2012), H. 3, S. 243284, darin speziell zu Rist S. 262f.

19 Johann Rist: Die alleredelste Erfindung Der Gantzen Welt, Vermittelst eines anmutigen und erbaulichen Gespräches, welches ist dieser Art, die Fünffte, Und zwar eine Mäyens-Vnterredungen, Beschrieben und fürgestellet [1667]. In ders.: Sämtliche Werke. Unter Mitwirkung von Helga Mannack hrsg. von Eberhard Mannack. Bd. 6: Epische Dichtungen (Die Alleredelste Erfindung, Die Alleredelste Zeitverkürzung). Berlin, New York 1976, S. 1-240, hier S. 79.

20 van Ingen: Johann Rist und die Naturwissenschaften seiner Zeit (Anm. 8), S. 505.

21 Vgl. Martin Brecht: Die Aufnahme von Arndts Vier Bücher von wahrem Christentum im deutschen Luthertum. In: Frömmigkeit oder Theologie. Johann Arndt und die Vier Bücher von 
nur Vnterredungen [...] / so wol von der Vbunge der wahren Gottseligkeit / als auch vielen in der Natur verborgenen Geheimnissen ${ }^{22}$ führte, sondern ihm in Reminiszenz an diese Gespräche später auch sein Alchemietraktat widmete, um dessen Wirkungsstrategien es im vorliegenden Beitrag gehen soll.

Nach eigenem Bekunden nahm Rist einiges in Kauf, um seinen alchemischen Interessen nachgehen zu können. Zum einen hat er sich offenbar körperlich nachhaltig verausgabt -

ich pflag etliche Tage und Nächte / nach ein ander bei meinem [!] unterschiedlichen öfen zu sitzen und zu schwitzen / und ie mehr ich fand in disen Geheimnissen / ie unverdrossener ward ich zur Arbeit / kan aber nun mit der Zeit spühren/ daß ich dadurch meine Gesundheit nicht wenig verletzt / ia mein Leben habe verkürtzet. ${ }^{23}$

Zum anderen blieben die zu erwartenden Anfeindungen nicht aus, gegen die er sich jedoch vehement verwahrt:

Einer der der wahren / ungeänderten Augsburgischen Bekenntnisse [sc. der lutherischen Confessio Augustana, 1530] ist zugethan / hat mit etlichen hocherfahrnen Philosophis, die man für Rosenkreützer / neüe Propheten und Weigelianer [sc. für einen Anhänger des Paracelsisten Valentin Weigel (1553-1588)] gehalten / guhte Kundschafft gepfleget / und nebenst ihnen / (als welche er eintzig und allein deßwegen in seinem Hause zur Herberge hat auffgenommen) in den allerschönsten Chymischen Wissenschafften sich geübet / darüm muß er auch nohtwendig ein Weigelianer / Rosenkräutzer / neuer Prophet und Phantast sein / ist mir dieses nicht ein schöner Schluß? ${ }^{24}$

\section{Der Philosophische Phoenix im alchemischen Kontext}

Sein eigenes Alchemietraktat, der Philosophische Phoenix, erschienen im Jahr 1638, gliedert sich in einen theoretischen Teil mit grundsätzlichen Überlegungen zur Alchemie und einem abschließenden Gebet sowie einen praktischen Teil, dessen zunächst äußerst detailgenaue Anweisungen in einige arkanmetaphorisch angereicherte Pirouetten münden. Die Publikation des Philosophischen Phoenix war dicht gefolgt von einer geharnischten Anklageschrift mit dem Titel Phoenicis

wahrem Christentum. Hrsg. von Hans Otte und Hans Schneider. Göttingen 2007, S. 231-262, hier S. 235f.; sowie Krummacher: Lehr- und trostreiche Lieder (Anm. 1), S. 37-76.

22 Johann Rist: Philosophischer Phoenix. Das ist: Kurtze, jedoch Gründliche vnnd Sonnenklare Entdeckunge der waren vnd eigentlichen Matery des AllerEdelsten Steines der Weisen [...]. In ders.: Sämtliche Werke. Bd. 7: Prosaabhandlungen (Philosophischer Phoenix, Rettung des Phoenix, Teutsche Hauptsprache, Adelicher Hausvatter). Unter Mitwirkung von Helga Mannack und Klaus Reichelt hrsg. von Eberhard Mannack. Berlin, New York 1982, S. 1-29, hier S. 5.

23 Rist: Die AllerEdelste Tohrheit (Anm. 11), S. 152.

24 Rist: Die AllerEdelste Tohrheit (Anm. 11), S. 153. 
subreptitij in libertatem vindicatio, in der ein Anonymus unter dem Namenskürzel „A. V. S." und sine loco einen Neudruck des Textes veranstaltet. Zugleich gibt er sich als wirklicher Verfasser des Philosophischen Phoenix aus, den Rist sich unrechtmäßig $\mathrm{zu}$ eigen gemacht und durch seine Überarbeitung entstellt habe. Allerdings wurden seltsamerweise alle angeblich unpassenden Änderungen Rists im Neudruck beibehalten, eine programmatische Einleitung sowie ein Gebet wurden als Fremdzutaten nicht nur in herausgehobener Stellung als Additiones erneut mit abgedruckt, sondern sogar für "gut" ${ }^{\prime 25}$ befunden, und zudem enthält der Text auf Durchschaubarkeit hin angelegte Sinnentstellungen. Das von dem A. V.S. begonnene Verwirrspiel um die Ortsangaben setzt Rist in seiner ebenfalls noch 1638 veröffentlichten, nicht minder polemischen Gegendarstellung, der Nothwendigen Rettung, fort. Vieles spricht dafür, dass die hier nur skizzierten Ereignisse als publizistisches Schelmenstück eines fingierten Plagiatsskandals in allen drei Teilen auf Rist selbst zurückgehen, der auf diese Weise seine Ansichten zur Alchemie nicht weniger als drei Male spektakulär in Szene setzten konnte. ${ }^{26}$ Die von Rist vollzogene Kombination aus Verstellung (dissimulatio) und - gespielter - Empörung (indignatio) gehört zu den elementaren Winkelzügen der humanistischen Satiretradition. Als prominentestes Beispiel für solche perfiden Schreibweisen dürfen die Epistulae obscurorum virorum (1514-17) gelten, deren satirisches Spiel mit den Schwächen der Gegner bekanntlich mehr als einen seiner zeitgenössischen Leser erfolgreich aufs Glatteis zu führen vermochte. ${ }^{27}$

Spätestens mit Rists Einlassungen zur Urheberproblematik des Philosophischen Phoenix tritt das parodistische Kalkül durch die übertriebene Bestätigung einer Autorität, die schwerlich als intellektueller Verbündeter Rists denkbar ist, vollends zutage. Denn Rist gibt nicht nur rundheraus zu, dass er seinem Traktat ein fremdes Manuskript zugrunde gelegt, dieses jedoch nicht unterschlagen,

25 A. V. S.: Vindicatio: Phoenicis subreptitij in libertatem vindicatio. Daß ist: Ein kurtzes Philosophisch Tractätlein vom Stein der Weysen: So kurtzverwiechener Zeit ein guter Geselle fälschlich vor sein außgegeben, und zu Hamburg in offentlichen Druck verfertigen lassen, unter dem Nahmen und Titul. J. R. H. Philosophischer Phoenix; Anjetzo aber von dem warhafften Authore erkant [...]. [sine loco] 1638, S. [18]-Zit. nach dem Digitalisat der SLUB Dresden: http://digital.slub-dresden.de/werkansicht/dlf/12911/1/cache.off (17.06.2014).

26 Vgl. dazu ausführlich, insbes. auch zur Problematik des Verfasserkürzels A. V. S., Stefanie Stockhorst: Johann Rists Alchemietraktat Philosophischer Phoenix - Plagiat oder Parodie? In: Johann Rist (1607-1667). Profil und Netzwerke eines Pastors, Dichters und Komponisten in der Barockzeit. Hrsg. von Johann Anselm Steiger und Bernhard Jahn. Berlin, Boston 2015, S. 673-696. - Überlegungen, die dort bereits angelegt sind, werden hier teilweise aufgegriffen und weitergeführt.

27 Vgl. nur Theodor Verweyen: Die Dunkelmännerbriefe (,Epistolae obscurorum virorum'): Ein Beispiel humanistischer Satire und Parodie [1997]. In: Einfache Formen der Intertextualität. Theoretische Überlegungen und historische Untersuchungen. Hrsg. von Theodor Verweyen und Gunther Witting. Paderborn 2010, S. 83-99; sowie Karl Riha: Zur ,Sache' der ,Dunkelmänner'. Ein satirischer Humanistenbriefwechsel. In ders.: Kritik, Satire, Parodie. Gesammelte Aufsätze [...]. Opladen 1992, S. 7-16. 
sondern mit guter vnd vntadlicher Manier an [s]ich gebracht ${ }^{28}$ habe. Zudem versichert er in der Nothwendigen Rettung bezüglich des Verfassers der fraglichen Handschrift wiederholt und mit Nachdruck, dass

dieses Conceptlein keines andern als eben deß Edlen vnd weitberühmten Chymici Alexandri Von Süchten währe / dessen hinterlassen Scripta also distrahiret vnd von etlichen ignoranten vmbher getragen würden / die denn solche vnd derogleichen Sachen offt vor die jhrige außruffeten. ${ }^{29}$

Der Aufruf gerade des polnischen Alchemikers Alexander von Suchten (ca. 1520-1575) ${ }^{30}$ als Gewährsmann, unter dessen Namen postum eine ganze Flut von mehr oder weniger dubioser, paracelsistisch-spiritualistisch orientierter Alchemieliteratur kolportiert wurde, ${ }^{31}$ erscheint in ideengeschichtlicher Hinsicht für einen ansonsten linientreuen Lutheraner mehr als unwahrscheinlich ${ }^{32}$ und in philologischer Hinsicht nichtssagend, zumal Rist die fragwürdige Überlieferungslage gleich mit in Erinnerung ruft für den Fall, dass sie dem Leser nicht präsent ist.

Während es in gelehrten Abhandlungen der Frühen Neuzeit allgemein üblich war, möglichst viele einschlägige Koryphäen zur Betonung der eigenen Gelehrsamkeit und Überzeugungskraft zu nennen, bleibt Rist in seinem Philosophischen Phoenix vorzugsweise unspezifisch - ein grosser hauffe Philosophorum, alle vernünftige vnd hocherfarne Philosophi oder viel fleissige vnd ohnverdroßne Philosophi vnd Naturkündiger ${ }^{33}$ verbürgen seinen Standpunkt anonym. Das mag teilweise der traditionell heterodoxen Verfasstheit alchemischen Wissens geschuldet sein, bewirkt aber zugleich eine unspezifische Selbstverortung im alchemischen Diskurs. Ohne eine markierte Traditionslinie fortzuschreiben, vergegenwärtigt Rist in seinen Ausführungen beiläufig einige Archegeten der Alchemie. Er lässt jedoch nur völlig unstreitige, aufgrund ihres Verbreitungsgrades beinahe etwas

28 Johann Rist: Nothwendige Rettung vnd rechtmässige Vertheidigung des Philosophischen PHOENIX [...]. In ders.: Sämtliche Werke. Bd. 7: Prosaabhandlungen (Philosophischer Phoenix, Rettung des Phoenix, Teutsche Hauptsprache, Adelicher Hausvatter). Unter Mitwirkung von Helga Mannack und Klaus Reichelt hrsg. von Eberhard Mannack. Berlin, New York 1982, S. 31-65, hier S. 41.

29 Rist: Nothwendige Rettung (Anm. 28), S. 44.

30 Vgl. Wilhelm Kühlmann: Art. ,Suchten, Alexander von' [erscheint in: Frühe Neuzeit in Deutschland 1480-1520. Hrsg. von dems., Jan-Dirk Müller, Michael Schilling, Johann Anselm Steiger und Friedrich Vollhardt. Berlin, Boston 2011ff.]. Für die Möglichkeit zur Einsichtnahme in das unveröffentlichte Manuskript danke ich Wilhelm Kühlmann.

31 Vgl. Corpus Paracelsisticum. Hrsg. und erl. von Wilhelm Kühlmann und Joachim Telle. Bd. 1: Dokumente frühneuzeitlicher Naturphilosophie in Deutschland. Tübingen 2001, bes. S. $548 f$.

32 Vgl. Wels: Zwischen Spiritualismus, Hermetik und lutherischer ,Orthodoxie' (Anm. 18), bes. S. 262f.; sowie van Ingen: Johann Rist und die Naturwissenschaften seiner Zeit (Anm. 8), S. 503-507, hier S. 262f.

33 Rist: Philosophischer Phoenix (Anm. 22), S. 10, S. 12 und S. 15. 
abgedroschen anmutende Versatzstücke einfließen, etwa, indem er hin und wieder Verse aus Vergils Georgica anführt oder eine für die Naturphilosophie der Frühen Neuzeit wichtige Stelle wie diese aus Aristoteles' De Physica ${ }^{34}$ zitiert: Sol et homo hominem generant, die Sonne vnd der Mensche erzeugen einen Menschen. ${ }^{35}$ Gleiches gilt für die gelegentlichen Bezugnahmen auf die mythische Gründungsfigur des Hermes Trismegistos, so etwa im nachstehenden Passus, der auf ein Bild aus der Tabula Smaragdina (portavit illud ventus in ventre suo) ${ }^{36}$ anspielt, aus einer Schrift, deren Entlarvung als unauthentisch indes kaum Auswirkungen auf ihre Stellung als Referenztext der späten, insbesondere der paracelsistischen Alchemie hatte. ${ }^{37}$ Sie erlangte u.a. als Eingangsemblem der kunstvoll illustrierten Atalanta fugiens (1617/18) des norddeutschen Alchemikers Michael Maier (15691622) große Berühmtheit (Abb. 1). Rist paraphrasiert die betreffende Stelle folgendermaßen:

Ein solcher Künstler / hat sich nemlich mit dem Æolo in eine sonderbahre Freundschafft vnd Verbündnisse eingelassen / der jhn denn getrewlichst hat vnterrichtet / wie er einen bequehmen Gürtel oder Strick soll bereiten vnnd zurichten / in welchem er den Schwangeren Wind / der (wie Hermes saget) vnsere Philosophische Frucht in seinem Bauche angebohren herumme träget / möge feßlen vnnd einschliessen. ${ }^{38}$

Nicht zuletzt gehört in diesen alchemischen Traditionszusammenhang das Analogiedenken, das sich damals freilich nicht auf Alchemikerkreise beschränkte, sondern überhaupt eine elementare Denkfigur des christlichen Weltbildes darstellte. Rist formuliert diese Vorstellung als gewaltige Harmonei, gleichförmig keit vnd übereinstimmunge der oberen Geschöpffe mit den vnteren, ${ }^{39}$ was sinngemäß unter anderem nachzulesen ist in der Tabula Smaragdina: Quod est inferius, est sicut (id)

34 Vgl. Sylvain Matton: Marsile Ficin et l'alchimie. Sa position, son influence, appendice: La Critique de Ficin alchimiste par Nicholas Guibert (texte latin). In: Alchimie et philosophie à la Renaissance. Actes du Colloque international de Tours, 4-6 décembre 1991. Hrsg. von dems. und Jean-Claude Margolin. Paris 1993, S. 123-192.

35 Rist: Philosophischer Phoenix (Anm. 22), S. 13.

36 Julius Ruska: Tabula Smaragdina. Ein Beitrag zur Geschichte der hermetischen Literatur. Heidelberg 1926, S. 2.

37 Thomas Erastus hatte die Tabula Smaragdina schon 1572 für „offensichtlich falsch und erfunden" erklärt, vgl. Thomas Erastus: Explicatio quaestionis famosae illius, utrum ex metallis ignobilioribus aurum verum et naturale arte conflari possit. Basel 1572, S. 101ff., zit. nach Carlos Gilly: Vom ägyptischen Hermes zum Trismegistus Germanus. Wandlungen des Hermetismus in der paracelsistischen und rosenkreuzerischen Literatur. In: Konzepte des Hermetismus in der Frühen Neuzeit. Hrsg. von Peter-André Alt, Volkhard Wels. Göttingen 2010, S. 71-131, hier S. 105, Anm. 114; siehe auch Wilhelm Kühlmann: Der ,Hermetismus' als literarische Formation. Grundzüge seiner Rezeption in Deutschland. In: Scientia Poetica 3 (1999), S. 145-157, bes. S. 150f.

38 Rist: Philosophischer Phoenix (Anm. 22), S. 16.

39 Rist: Philosophischer Phoenix (Anm. 22), S. 14. 


\section{E м в L m a I. De fecretis Nature. Portavit eum ventus in ventre fuo.}

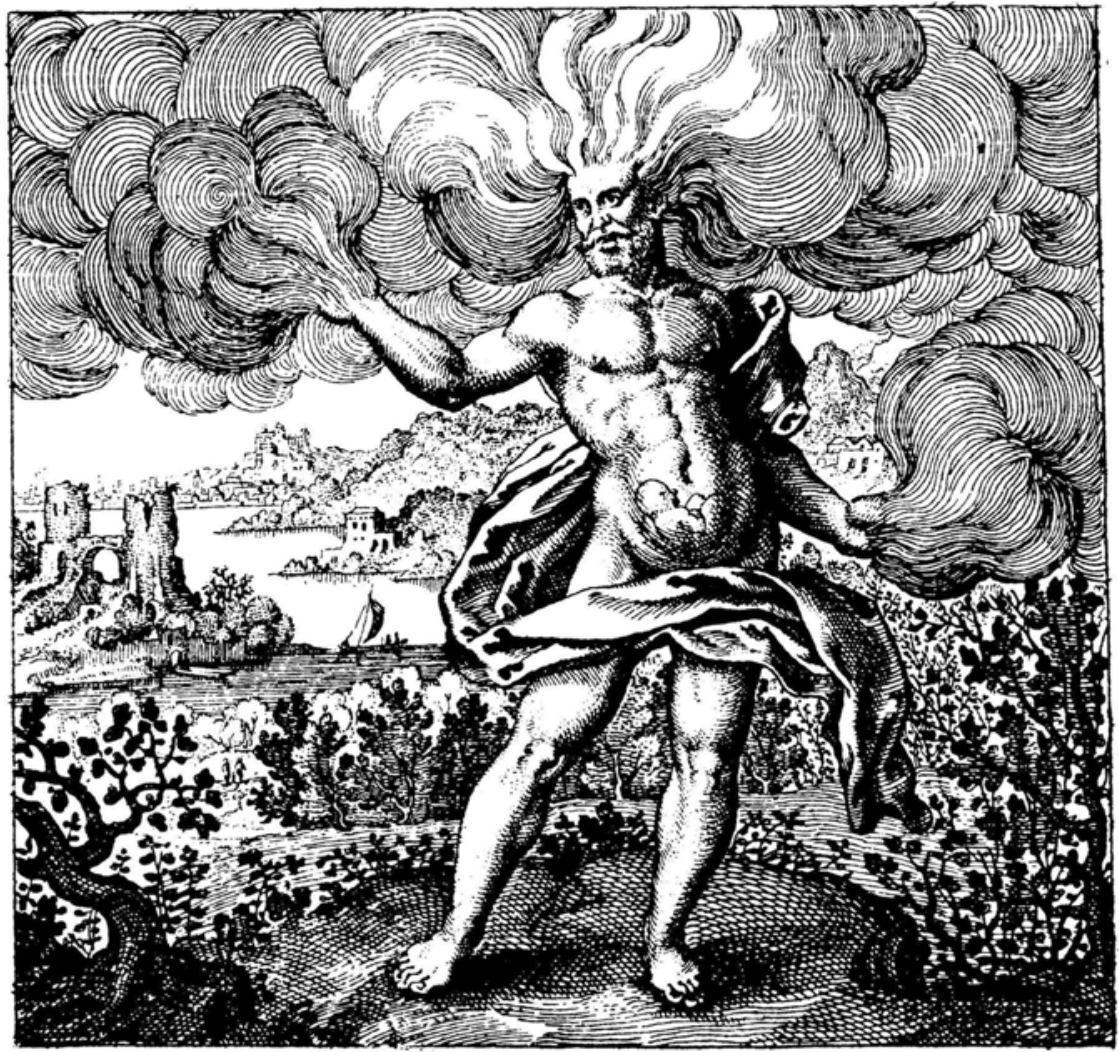

Abb. 1: Michael Maier: Emblema I: Portavit eum ventus in ventre suo. In: ders.: Atalanta Fugiens, hoc est, Emblemata Nova De Secretis Naturae Chymica [...]. Oppenheim 1618, S. 13. Wiedergegeben mit freundlicher Genehmigung nach dem Digitalisat der HAB Wolfenbüttel: http://digilib.hab.de/drucke/196-quod-1s/start.htm, S. [15] [28.03.2014].

quod est superius, et quod est superius, est sicut (id) quod est inferius [...]. ${ }^{40}$ Nachdem Rist seine Vertrautheit mit den überlieferten Hauptquellen demonstriert hat,

40 Ruska: Tabula Smaragdina (Anm. 36), S. 2. 
aber fast schon ostentativ darauf verzichtet, eine profilierte, womöglich originelle Position einzunehmen, beklagt er für seine Gegenwart eine Trivialisierung der Alchemie ob der schändlichen Kremerey / die heut zu tage mit herrlichsten Scriptis der hocherleuchteten Männer / als des Theophrasti, Bernhardi, Comitis Trevisani, Crollij vnd anderer wird getrieben. ${ }^{41}$ Diese Diagnose von der schändlichen Krämerey, zu der die hohe Kunst der Alchemie verkommen sei, gilt es für eine Deutung des Philosophischen Phoenix sehr ernst zu nehmen.

Wenn Rist in den theoretischen Vorüberlegungen seines Traktats darlegt, dass der Stein der Weisen nichtes anders seyn solle / als eben daßjenige / was wir sonsten Lufft heissen / zu Latein AER, AURA ond SPIRITUS genand, ${ }^{42}$ stützt er sich zum einzigen Mal in seinem Text auf eine neuzeitliche Quelle der Alchemie, und zwar ausgerechnet auf den in aller Welt hochberühmte[n] Sendivogius, der von diesem lufftigen Geist in seinen güldenen Schrifften sehr herlich vnd vortreflich berichte. ${ }^{43}$ Das Hauptwerk Novum Lumen Chymicum (1604) des nicht minder populären als obskuren Alchemikers Michael Sendivogius (1566-1636) erschien bis 1787 in 47 Ausgaben und neun Nachdrucken. ${ }^{44}$ Die Nennung solcher Vorbilder musste das kundige zeitgenössische Publikum hellhörig machen, zumal Rist sich ja ausdrücklich gegen die zeitgenössische Populäralchemie stellte. In freier Übersetzung referiert Rist indes aus der Gedankenwelt des Sendivogius einen Passus, der den Ansatzpunkt für seinen eigenen praktischen Anweisungsteil bildet:

Der Mensche auß der Erden erschaffen / lebet von der Lufft / denn in der Luft ist eine verborgene Speise deß Lebens / welches wir des Nachtes Thaw / deß Tages aber Aquam rarefactam oder ein dünn gemachtes Wasser nennen / dessen vnsichtbarer / congelirter, dick- oder festgemachter Geist seinem Wesende / Tugenden vnnd Wirckungen nach viel edler vnd besser auch höher ist zu schätzen / als der gantze Kloß der Erden. ${ }^{45}$

41 Rist: Nothwendige Rettung (Anm. 28), S. 44.

42 Rist: Philosophischer Phoenix (Anm. 22), S. 12.

43 Rist: Philosophischer Phoenix (Anm. 22), S. 13.

44 Diese Angaben nach Karin Figala: Art. ,Sendivogius, Michael‘. In: Alchemie. Lexikon einer hermetischen Wissenschaft. Hrsg. von ders. und Claus Priesner. München 1998, S. 332-334 hier S. 333. - Rist behauptete zudem, wenngleich nicht im Philosophischen Phoenix, sondern erst knapp dreißig Jahre später in den Monatsgesprächen, dass Suchten substantielle Anleihen bei Sendivogius gemacht habe. So nennt er eine Schrift Alexandri von Süchten, von dem rechten Philosophischen Stein in zwölff Tractätlein, welche man vermeinet, das sie von dem hocherfahrnen Sendivogio, herkommen, Rist, Die AllerEdelste Tohrheit (Anm. 11), S. 179f.

45 Rist: Philosophischer Phoenix (Anm. 22), S. 13f. - Die Formulierung bei Sendivogius im Epilog zum zwölften Traktat: Creatus homo de terra, ex aêre viuit est enim in aêre occultus vite [!] cibus, quem nos rorem de nocte, de die aquam vocamus, rarefactam, cuius spiritus inuisibilis congelatus melior est quam, terra vniuersa. (hier nach dem Exemplar der BSB München: [Michael Sendivogius:] Novum Lvmen Chimicvm, e naturæ fonte et manuali experientia depromptum, \& in duodecim Tractatus diuisum [...]. Köln 1610). 
Mit dieser freilich dekontextualisierten Anleihe bei Sendivogius öffnet Rist bereits vorab zumindest die Denkmöglichkeit, dass der Stein der Weisen gleichsam aus der Luft gegriffen sei, auch wenn der spiritus mundi als Materie des Steins alchemisch tatsächlich in der Luft vermutet wurde. Eine ganz deutlich ridikülisierte Wendung gibt er der Suche in der Luft später im März-Gespräch, wenn er die Anekdote von einem Bekannten mitteilt, der glaubte, die wahre Materia des Steins der Weisen" sei in der Luft zu finden, weshalb er allmorgendlich nach seinem Gebet ehrfürchtig in ein Behältnis zu hauchen pflegte - Rist gab ihm darauf "deütlich zuverstehen / daß es nichtes / als nur ein Glaß / voll nüchtern Speichel wäre / die man nirgends nützen könte. ${ }^{46}$ Nicht minder sachlich nennt er bereits im Philosophischen Phoenix als Bedingungen für eine erfolgversprechende alchemische Tätigkeit, dass man für allen dingen Gott ond dessen heilige Gebot fürchtet vnd liebet" und dazu mit "nohttürfftigen vnd geschickten Instrumenten, Gefessen / Herden / Oefen vnd allen anderen dazu gehörigen Dingen genugsam versehen ist. ${ }^{47}$ Auf ein gebetsförmiges Gnadengesuch für sich und alle nach göttlicher Weisheit strebenden Mitmenschen folgt ein praktischer Teil, in dem auffälliger Weise die ohnehin simplen Dinge genau beschrieben werden, die experimentell anspruchsvolleren hingegen knapp oder gar nicht, sodass die vordergründige Anleitung in Wirklichkeit als solche gar nicht taugt.

\section{Anweisungen zur praktischen Alchemie}

In Rists laboralchemischen Anweisungen, die weitaus stärker an die karnevalesken Momente der Mesalliance (von Diskursen) und der Profanation (von Geheimwissen) gemahnen denn an genuin alchemische Schreibweisen, ${ }^{48}$ fällt als erstes ins Auge, dass sie über weite Teile hinweg überaus konkret, kleinschrittig und ohne jegliche Codierungen durch Arkanmetaphern verfasst sind, obwohl typischerweise gerade nicht die Machbarkeit für Jedermann, sondern gerade die womöglich nicht nur vordergründige Unverständlichkeit den eigentümlichen Reiz alchemischer praecepta konstituiert. ${ }^{49}$ In der Kombination von alchemischen Termini für Arbeitsschritte und Gerätschaften mit traditionswidrig konkreten Mengen- und Zubereitungsangaben erzeugt Rist eine Persiflage der Laboralchemie. Man erfährt, die beste Zeit, den Stein der Weisen zu erzeugen, sei Morgens, und der beste Ort dafür liege hoch / bergicht / vnnd von allen nassen Pfützen / auch einem feuchten / zähen / schleimichten / ond schweflichten Erdreich ziemlich fern. Man benötige dafür ein aus einem Walknochen hergestelltes Instrument oder

46 Rist: Die AllerEdelste Tohrheit (Anm. 11), S. 156.

47 Rist: Philosophischer Phoenix (Anm. 22), S. 15.

48 Vgl. Michail M. Bachtin: Literatur und Karneval. Zur Romantheorie und Lachkultur. Übers. von Alexander Kaempfe. Frankfurt a.M. 1990 [dt. EA 1969], S. 49.

49 Vgl. zur Tradition des alchemischen Schweigegebots gegenüber Uneingeweihten Volkhard Wels: Manifestationen des Geistes. Frömmigkeit, Spiritualismus und Dichtung in der Frühen Neuzeit. Göttingen 2014, bes. S. 213-216, dort auch Hinweise auf weiterführende Literatur. 
Gefäß, welches die Gestalt vnnd das ansehen einer Glocken oder Cucurbiten haben und ohnegefehr an seiner dicke die helffte des allerkleinesten Fingers an eines Mannes Hand behalten ${ }^{50}$ solle. Als Ingredienzen nennt Rist [e]rstlich die Feilspäne vom Staal oder Eisen / hernacher der Weißliechten durchscheinenden Kiesel-Steine, also die gängigen alchemischen Grundstoffe Erz und Stein, welche man in pulverisierter Form zu gleichen Teilen in ein großes Behältnis geben müsse, um darüber den als alchemische Zutat ansonsten nicht verbürgten außgepresseten Saft von den Bachkrebsen zu gießen, dessen prominenteste Eigenschaft sein strenger Geruch sein dürfte, vnd zwar desselben Safftes so viel / daß es nicht allein dies vermischte Pulver oben bedecke / besonderen noch dazu vier querFinger [!] breit darüber her stehe. ${ }^{51}$ Diesen Sud müsse man acht Tage mit einander stille stehen vnnd digeriren ${ }^{52}$ lassen und sodann zur Destillation in eine Retorte umfüllen. In dem gewonnenen Destillat solle das Walknochengefäß ohngefehr 24. Stunde in einer feinen / sanfften vnd gelinden Wärme einweichen und dann schleunigst über einem grossen vnnd starcken Kohlfewr trocknen, ein Mazerationsvorgang, den es nach Rist siebenmal zu wiederholen gilt. ${ }^{53}$ Das solchermaßen vorbereitete Behältnis müsse man nun

auff einem hohen vnnd bergichten Orte / entweder an einen Zweig eines Baums oder auch an eine lange Stangen auffhengen / so wird alßdenn selbiges Gefäß in einer einzigen Stunde so viel unsers Lufftes an sich ziehen / als seine weite vnd grösse immer kann fassen ${ }^{54}$.

Die Fähigkeit eines offenen Gefäßes, gerade so viel Luft in sich aufzunehmen, wie es seinem Fassungsvermögen entspricht, vermag zwar physikalisch nicht eben zu verblüffen, aber immerhin ließe sich das beschriebene Procedere soweit mit etwas Geschick vermutlich bewerkstelligen. Im Gegensatz zur übertriebenen Simplizität der vorbereitenden Schritte erscheint die Vollendung des Ristschen opus magnum technisch allenfalls in den Laboratorien von Laleburg denkbar:

So bald du nun vermerckest / daß das Gefässe voll ist / so lange es herunter / thu die gesamlete Lufft herauß vnd mache es ledig / darauff henge oder setze es wieder an seinem vorigen Ort/ vnnd wann es sich wiedrumb voll gezogen / alßdenn entledige es wieder / vnnd treibe solche Arbeit so lange / biß daß du endlich einen guten grossen Vorrath sollicher Lufft hast zu hauffe gebracht vnd versamlet. ${ }^{55}$

Nach diesem Umschlag von der Banalität in die Unmöglichkeit solle man fernerhin die auffgefangene Lufft in eine Phiole einfüllen, diese auff Hermetische Weise versiegelen, den Inhalt zwei Wochen lauwarm digeriren vnd circuliren lassen, durch

50 Rist: Philosophischer Phoenix (Anm. 22), S. $20 \mathrm{f}$.

51 Rist: Philosophischer Phoenix (Anm. 22), S. 21.

52 Rist: Philosophischer Phoenix (Anm. 22), S. 21.

53 Rist: Philosophischer Phoenix (Anm. 22), S. 22.

54 Rist: Philosophischer Phoenix (Anm. 22), S. $22 \mathrm{f}$.

55 Rist: Philosophischer Phoenix (Anm. 22), S. 23. 
einen alembic abziehen, ihn anschließend wieder in eine Phiol giessen, und das so lange, bis das Wasser heller vnd klarer ist als ein Christall. An diesem Punkt liege das rechte gebenedeyte Wasser vor, das Hermes Trismegistos totius Fortitudinis fortitudinem fortissimam die allerkräfftigste Krafft aller Kräfte nenne, wie Rist einmal mehr aus der Tabula Smaragdina zitiert. ${ }^{56}$

Zum Abschluss des Philosophischen Phoenix brennt Rist ein regelrechtes Feuerwerk der alchemischen Bildlichkeit ab, das er mit Anspielungen aus der klassischen Mythologie untermengt. Freilich gilt es diese Überspitzung der Arkanästhetik nicht laborpraktisch zu entschlüsseln, sondern aus einer poetisch vermittelten Distanz, was Rist zu Beginn des letzten Teils mit zwei Absätzen über Pegasus nahelegt, dem ein Platz als Symboltier weniger in der Alchemie als in der Poesie zukommt. Rist berichtet, mit seinem Hufschlag habe das geflügelte Pferd auf dem Parnass das Chrystalline Bächlein der Musen ( Om potabile) ${ }^{57}$ freigesetzt, wobei der erläuternde Klammerzusatz das zu den höchsten Arkana der Alchemie gehörige Trinkgold als Produkt derselben Quelle demaskiert, aus der für gewöhnlich die poetische Inspiration entspringt, wie - der Analogieschluss scheint nicht nur erlaubt, sondern gewünscht - auch manche Spielarten der Alchemie nicht mehr als erfindungsreiche Chimären seien.

Auf ein genuin poetisches Verfahren, nämlich das der aemulatio, greift Rist auch selbst zurück, wenn er im rasanten Endspurt seines Philosophischen Phoenix nicht nur einmal, sondern gleich dreimal eine chymische Hochzeit, also gewissermaßen die Kernfusion der Alchemie, stattfinden lässt. Das erste Mal heißt es: Dieses ist vnsere wunderschöne Diana, welche jhrem allerliebsten Bräutigamb dem Apollini, bald / bald auff eine geistliche Weise soll zugefüret vnd vermählet werden. ${ }^{58}$ Beim zweiten Mal geht es um die Vermehrung von Gold, indem das zuvor hergestellte Wasser in gleichem Gewichte mit Gold gemischt werden solle, welcher Bräutigamb alß denn diesen Geist / als seine liebste Braut vnnd Eheweib / auff das allerfreundlichste wird vmbfangen. ${ }^{59}$ Auch beim dritten Mal macht Rist deutliche terminologische Anleihen aus der Alchemieliteratur, die er mit fortgesetztem Anweisungsduktus so ausspielt, als müssten sie gar nicht metaphorisch, sondern wörtlich verstanden werden:

So nimb derowegen des Männlichen güldenen Saamens ein theil; des Weiblichen Sylberen Samens neun theil: Diese beyderley Saamen füge fein zusammen in einem Philosophischen Ey / vnd nach dem du solches auf recht Hermetische Art vnd weise hast versiegelt / so setze es alßdenn

56 Rist: Philosophischer Phoenix (Anm. 22), S. 24; in der Tabula Smaragdina: totius fortitudinis fortitudo fortis, Ruska: Tabula Smaragdina (Anm. 36), S. 2.

57 Rist: Philosophischer Phoenix (Anm. 22), S. 24.

58 Rist: Philosophischer Phoenix (Anm. 22), S. 25.

59 Rist: Philosophischer Phoenix (Anm. 22), S. 26. 
ins Fewr / damit dasselbe diese junge Eheleute mit einem vnauflößlichem Bande verknüpffe vnd zusammen heffte. ${ }^{60}$

Spielerisch unternimmt Rist den Ansatz, seine Anweisung kosmologisch in den Jahreslauf einzuordnen, was in der alchemischen Tradition durchaus üblich ist (vgl. z.B. Abb. 2). Während diese und weitere Einlassungen, die dem Winter zugeordnet werden, mehrere Druckseiten einnehmen, folgt nur ein kurzer Absatz über den Frühling, der mit mancherley schönen Blumen vnd wolschmeckenden Früchten ${ }^{61}$ Einzug halte, wobei jeglicher alchemische Bezug fehlt.

Völlig unvermittelt geht es in den beiden anschließend eingeschobenen Absätzen zum ersten und einzigen Mal im ganzen Text um den Vogel Phönix, der in der Alchemie die höchste, rote Stufe (rubedo) im opus magnum d. h. in der Erlangung des lapis philosophorum, symbolisiert (Abb.2), gefolgt von der weißen Stufe des Schwans (albedo) und der untersten, schwarzen Stufe des Raben (nigredo):

Wann nun ferner auch die Schwärtze ist hinweg gethan vnnd vergangen / so wird alßdenn ein bunter vnnd sehr gläntzender Pfaw erscheinen / vnd wenn hierauff das Fewr gebührlich wird gestärcket / so wird sich alßdenn bald sehen lassen ein schneeweisser Schwan / auff welchen zu guter letzte folget ein schöner / Braunrohter / oder Rubinfarber PHOENIX. Vnd also kan man augenscheinlich mercken / wie der allerschönste Sylbern Vogel / der mit seinen Lilien weissen Federen auch die hell gläntzende Tauben beschemet / in einen gantz Kohlschwartzen Raben auff eine sehr wunderbare weise wird transformiret vnd verkehret. ${ }^{62}$

Am Beispiel von Michael Maiers Symbola aureae mensae duodecim nationum (1617) machte Wilhelm Kühlmann deutlich, wie darin gerade der Phönix eine „irritierende Mehrdeutigkeit" anzeigt, fungiere er doch „als übergeordneter mythischer Bildcode jener philosophisch-alchemischen Arkanmetaphern [...], die ihrerseits der Entschlüsselung durch den Wissenden bedurften". ${ }^{63}$ Nichts anderes ist bei Rist der Fall, denn der Phönix bildet offensichtlich nicht ansatzweise den Gegenstand des Textes, sondern vielmehr einen bildlichen Fingerzeig auf seinen Rätselcharakter. Zugleich lässt sich in der Resurrektionssymbolik des stets werdenden und wieder vergehenden Vogels auch ein Hinweis auf die zutiefst christliche Auflösung sehen. Anne-Charlott Trepp vereindeutigte daher ihre Interpreta-

60 Rist: Philosophischer Phoenix (Anm. 22), S. 27.

61 Rist: Philosophischer Phoenix (Anm. 22), S. 28.

62 Rist: Philosophischer Phoenix (Anm. 22), S. 28.

63 Wilhelm Kühlmann: Sinnbilder der Transmutationskunst. Einblicke in die mytho-alchemische Ovidrezeption von Petrus Bonus bis Michael Maier. In: Metamorphosen. Wandlungen und Verwandlungen in Literatur, Sprache und Kunst von der Antike bis zur Gegenwart. FS Bodo Guthmüller. Wiesbaden 2002, S. 163-176, hier S. 172f. 


\section{MITTEL: CONIVNCTION:}

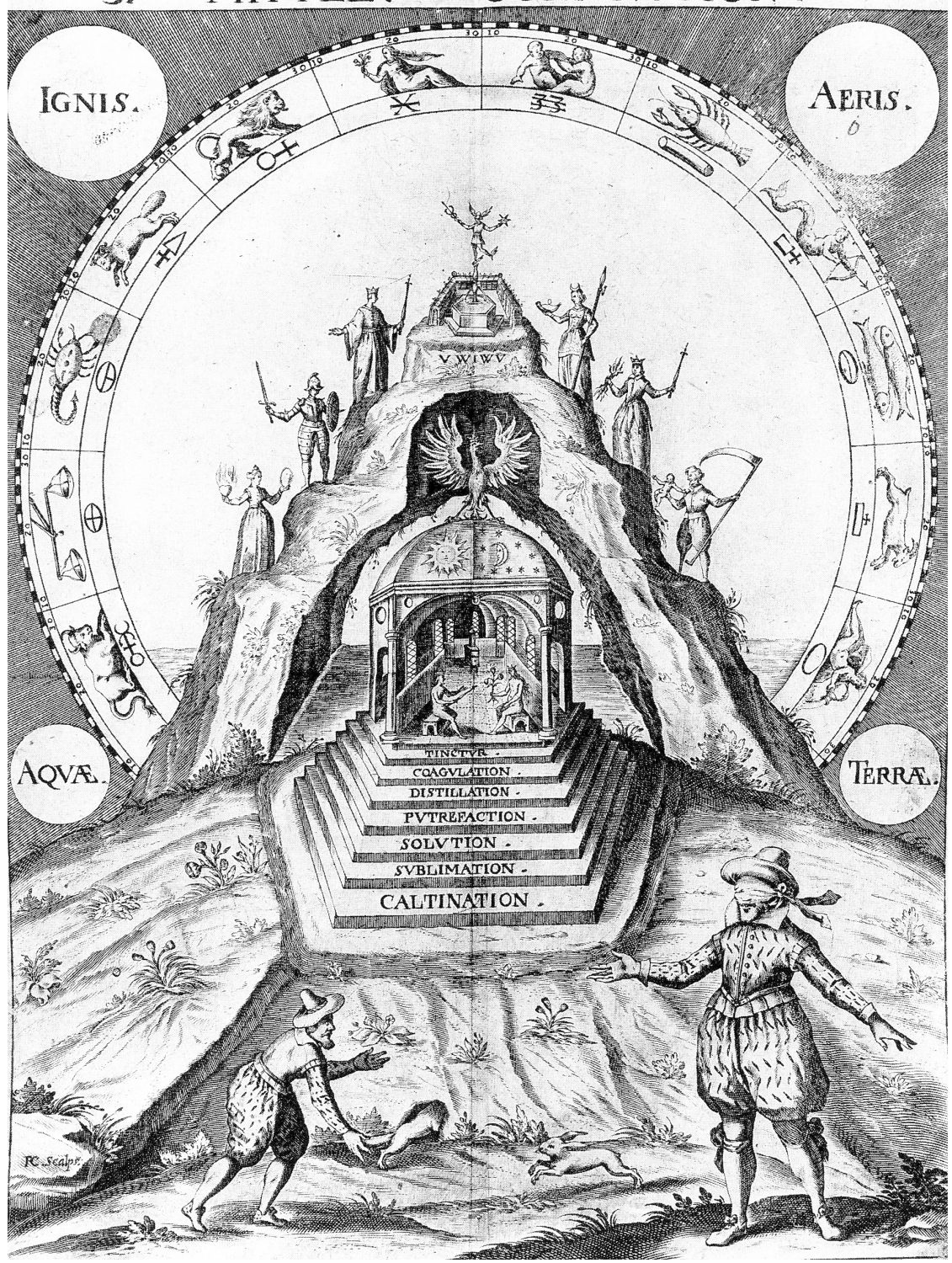

Abb. 2: Stephan Michelspacher: Cabala, Specvlvm artis et naturæ, in Alchymia [...]. Augsburg 1616 [EA 1615], unpaginierter Bildanhang. Wiedergegeben mit freundlicher Genehmigung nach dem Digitalisat der HAB Wolfenbüttel: http://digilib.hab.de/drucke/46phys-2s/start.htm, S. [21] [17.06.2014]. - Stellvertretend für viele ähnliche illustriert diese Abbildung zugleich die Stellung des Phönix im opus magnum und dessen kosmologische Einbettung in den Jahreslauf. 
tion dahingehend, dass Rists Botschaft lautet: "Aus dem alchemischen Wandlungsgeschehen können ,Beweise' für die Auferstehung erbracht werden. [...] Mehr noch: Er versucht die Offenbarungen durch das Experiment regelrecht zu ,verifizieren'."64

Nach der ebenso effektvollen wie kurzen Erscheinung des titelgebenden Fabelwesens lässt Rist das begonnene kosmologische Schema des Jahreszeitenzyklus ins Leere laufen, indem er den Sommer gänzlich überspringt und zum Herbst ausgesprochen lapidar feststellt, er endiget sich nun auch zuletzt. ${ }^{65}$ Das abrupte Finale lässt im praktischen Teil des Philosophischen Phoenix für die Praxis zwar manche Frage offen. Jedoch gibt Rist am Ende die ganz entscheidende Verstehenshilfe, dass trotz der vordergründigen Verworrenheit seiner Ausführungen darin doch alles Nötige gesagt sei:

Mehr vnd weitleuftiger von diesem hohen Geheimnisse zu schreiben / wil so wenig die kürtze der Zeit / als auch sonsten andere Vngelegenheit vor dieses mahl nicht leyden noch zugeben / wiewol ein jedweder rechtverständiger Liebhaber vnserer geheimen Philosophey / benebenst mir auffrichtig wird bekennen müssen / daß den wahren Philosophis vnd Kinderen dieser heiligen Kunst / dasselbe / was jhnen zu wissen hochnöhtig / mit nichten verheelet / besonderen zu genüge / auch schier mehr als sich gebühren wollen davon kund gethan vnd offenbaret worden. ${ }^{66}$

\section{Das opus magnum bei Rist - eine Allegorie der Offenbarung}

Wenn Rist es seinem Publikum am Ende des Philosophischen Phoenix zur Aufgabe macht, den eigentlichen Sinn seines Textes zu ergründen, entspricht er vollauf den zeitgenössischen Genrekonventionen der Alchemieliteratur. „Die Vermutung, daß hinter einer Mitteilung immer noch eine zweite - eigentliche - Botschaft stehen könne, ist", so Claus Priesner, „in der alchemischen Literatur des 17. und 18. Jahrhunderts durchweg gegenwärtig und auch realisiert." 67 Der Zugang zu einem weitergehenden Verständnis von Rists Philosophischem Phoenix als Erbauungsschrift erschließt sich aus dem merkwürdig ungleichgewichtigen Zusammenspiel der theoretischen und praktischen Ausführungen. Während sich erstere durch äußerst klare, logisch präzise Gedankenarbeit auszeichnen, beginnen letztere als scheinbar simple, überaus konkrete Anleitung, die jedoch im Fortgang zunehmend lückenhaft erscheint, um schließlich in überbordenden

64 Anne-Charlott Trepp: Im ,Buch der Natur' lesen: Natur und Religion im Zeitalter der Konfessionalisierung und des Dreißigjährigen Krieges. In: Antike Weisheit und kulturelle Praxis. Hermetismus in der Frühen Neuzeit. Hrsg. von ders. und Hartmut Lehmann. Göttingen 2001, S. 103-143, hier S. 138 und 140 (fortlaufend, S. 139 ganzseitige Abb.).

65 Rist: Philosophischer Phoenix (Anm. 22), S. 29.

66 Rist: Philosophischer Phoenix (Anm. 22), S. 29.

67 Claus Priesner: Über die Wirklichkeit des Okkulten. Naturmagie und Alchemie in der Frühen Neuzeit. In: Diskurse der Gelehrtenkultur in der Frühen Neuzeit. Ein Handbuch. Hrsg. von Herbert Jaumann. Berlin [u.a.] 2011, S. 305-345, hier S. 333. 
Bilderkompilationen ad absurdum geführt zu werden. Sie ergeben selbst nach den auf alles andere als Klarheit oder Allgemeinverständlichkeit bedachten Darstellungsstandards der Alchemie ${ }^{68}$ schwerlich einen sinnvollen Zusammenhang, sondern münden in ein freies Spiel traditioneller Arkanformeln. Mit diesem Kunstgriff, der an das damals in der Malerei beliebte chiaroscuro erinnert, wirft Rist ein helles Licht auf seine im Text angelegten theologischen Maximen sowie auf einige im christlichen Diskursgeschehen konsensfähige Denkfiguren aus der Alchemie, lässt aber zugleich deren allzu materielle Seiten in tiefem Dunkel verschwinden. In der Vindicatio, die alle maßgeblichen Gesichtspunkte des Philosophischen Phoenix noch einmal schlaglichtartig hervorhebt, heißt es sogar wörtlich, daß wo es am hellesten scheinete / doch der Verstand am dunckelsten were / ond hinkegen [!] / wo es am dunckelsten scheinete / man die warheit alsda am leichtesten begreiffen konte. ${ }^{69}$

Stellt man eine solche Lichtregie mitsamt ihren Ausleuchtungs- und Verdunkelungseffekten in Rechnung, so erscheint nicht mehr befremdlich, sondern nachgerade konsequent, wenn Rist die Autorschaft des Philosophischen Phoenix letzten Endes ganz für sich allein reklamiert. Denn obgleich er Material Suchtens mit aufgenommen hat oder zu haben behauptet, verfolgt er offenbar eine eigene, völlig anders ausgerichtete Zielsetzung:

Vnd gesetztet / ich hätte an diesem gantzen Büchlein mehr nichts gethan / als daß ich des Alexandri von Süchten schweres vnd tunckeles Tractätlein auß der lateinischen Sprache in die Teutsche hätte vbergesetzet (da doch das gantze Werck viel anders / vnd ich zehnmal mehr daran gearbeitet / wird bezeugen) so ist vnd bleibet es dennoch mein Werck oder Scriptum, wie mir solche Meinung alle gelahrte vnd auffrichtige Leute zweiffels ohn bekräfftigen $[\ldots] .{ }^{70}$

Seine Absicht habe, wie er in der Nothwendigen Rettung erklärt, darin bestanden, den Philosophischen Phoenix seinem

Neben-Christen zur nötigen Warnung vnd Abhaltung von vnnützen vnd schweren Kosten (darinn gemeiniglich die jenige / welche in der practicâ dieses Geheimnüsses des rechten Weges verfehlen / geführet werden) auß gutem Hertzen getrewlich zuzutheilen, ${ }^{71}$

damit man

auß Verlesung meines Philosophischen Phœnix verstehen lernet / was für grosse Wunder die Allmacht GOTTES in die Natur gepflantzet/ als in

68 Vgl. z.B. Florian Ebeling: „Geheimnis" und „Geheimhaltung“ in den Hermetica der Frühen Neuzeit. In: Antike Weisheit und kulturelle Praxis (Anm. 64), S. 63-80.

69 A. V. S.: Vindicatio (Anm. 25), S. [16]f.

70 Rist: Nothwendige Rettung (Anm. 28), S. 62.

71 Rist: Nothwendige Rettung (Anm. 28), S. 42. 
welcher der allgemeine Geist (welchen wir nochmahlen auram vnd Spiritum nennen) sein tägliche ja stündliche Wirckung hat. ${ }^{72}$

Aufgrund dieser klaren Gewichtung von Idee und Umsetzung sei der praktische Teil seines Traktats zwar auch etlicher massen / jedoch nur kurtz vielleicht auch etwas dunckel auffgesetzet worden / weil es mir fürnemlich vmb die Erkentnüsse der wahren materix zu thuende gewesen. ${ }^{73}$

Nicht zufällig klingt in dieser programmatischen Erklärung Rists der homiletische Dreischritt von doctrina, consolatio und adhortatio an, der hier unter alchemischen Vorzeichen durch die naturphilosophische Belehrung, die Tröstung in der Allmacht Gottes und die Aufforderung zur Einhaltung des rechten Weges zur Gotteserkenntnis umgesetzt wird. Eine derartige, theologisch grundierte Wirkungsästhetik stellt eine wesentliche Qualität von Rists gesamtem Euvre dar. Sie zeigt sich nicht nur in den naturwissenschaftlichen Schriften, sondern auch in der Lyrik. So wies Hans-Henrik Krummacher nach, dass die wiederkehrenden Tröstungsmotive in den Titeln der geistlichen Liedersammlungen Rists „keine bloßen Formeln sind, sondern programmatischen Charakter haben“, dass Rist oft ,ausführlich und eindringlich seine Lieder mit den homiletischen usus Lehre, Trost, Vermahnung und Warnung begründend verknüpft", und schließlich auch, dass diese Lieder nicht nur rhetorisch, sondern auch inhaltlich ", nahe verwandt [sind] mit der umfangreichen Erbauungsliteratur in Prosa, die eine der kennzeichnendsten Erscheinungen geistlicher Literatur im 17. Jahrhundert ist" ${ }^{74}$

Die Verschränkung homiletischer und alchemischer Schreibweisen, wie Rist sie im Philosophischen Phoenix unter dem Deckmantel der Satire anlegt, erscheint in einer Zeit, in der Teile des ehemals streng gehüteten alchemischen Arkanwissens zunehmend der Popularisierung unterlagen, ${ }^{75}$ durchaus naheliegend. Zum einen verbanden sich mit der volkssprachlich für weite Kreise in Umlauf gebrachten Populäralchemie einige Risiken, die ohne weiteres in die Zuständigkeit eines lutherischen Seelenhirten fielen, sei es die kommerziell betriebene Übervorteilung derer, die nach Reichtum, Macht oder Weisheit streben, sei es der Missbrauch chemischer Erzeugnisse ${ }^{76}$ oder auch das Problem der superbia, der eine allzu spirituell ausgerichtete Alchemie gefährlich nahestehen konnte. Zum anderen erfolgte im 17. Jahrhundert nach und nach eine Aufspaltung des alchemischen Schrifttums in zwei Strömungen, über die Claus Priesner zutreffend festhielt:

72 Rist: Nothwendige Rettung (Anm. 28), S. 58.

73 Rist: Nothwendige Rettung (Anm. 28), S. 60.

74 Krummacher: Lehr- und trostreiche Lieder (Anm. 1), S. 39, S. 50 und S. 55f.

75 Vgl. Martin Mulsow: Epilog: Das schnelle und das langsame Ende des Hermetismus. In: Das Ende des Hermetismus. Historische Kritik und neue Naturphilosophie in der Spätrenaissance. Dokumentation und Analyse der Debatte um die Datierung der hermetischen Schriften von Genebrard bis Casaubon (1567-1614). Hrsg. von dems. Tübingen 2002, S. 305-310, hier S. 307.

76 Vgl. Priesner: Über die Wirklichkeit des Okkulten (Anm. 67), S. 334f. 
Eine führt zu einer religiös-spirituellen Auffassung des Opus Magnum als Allegorie eines Heilswegs der Selbstvervollkommnung, der der Stein als Metapher des Seelenheils erscheint. Die andere beschreitet den Weg der rationalen Naturforschung [...]. ${ }^{77}$

Obwohl Rist als Student in Rostock nicht nur Theologie, sondern auch Mathematik, Medizin und Pharmazie hörte, ${ }^{78}$ schlägt er in seinem Philosophischen Phoenix den ersten, den allegorischen Weg ein. Für ihn besitzt es, wie er später in den Monatsgesprächen mitteilt, denselben Stellenwert wie das Gebot der Nächstenliebe, dass ein Christ seinen GOtt und Schöpfer /nach deme ihme von demselben verliehenen Verstande / so wol aus der Natur / als der heiligen Schrift recht lerne erkennen. ${ }^{79}$ Zur Gotteserkenntnis aus dem liber naturae finden sich noch weitere sehr deutliche Hinweise in den Monatsgesprächen, darunter etwa dieser mit einer biblisch verankerten Legitimation:

Jn Summa / wir können wol recht sagen auß dem 19. Psalm. [!] daß die Himmel die Ehre Gottes erzehlen / und die Feste / seiner Hände Wercke verkündigen / und gewißlich einem Christlichen Hertzen kommen dise grosse Geschöpffe nicht anders vor / als wenn sich das eine über das andere verwunderte. ${ }^{80}$

Vor diesem Hintergrund wird das Gebet als Schlüsselstelle des Philosophischen Phoenix sinnfällig, das Rist seinem vermeintlichen praktischen Anweisungsteil unmittelbar voranstellt. Er bittet, Gott möge

ja alle ohnvernünfftige vnnd leichtfertige Spötter dieser Himlischen Wissenschafft / wie auch alle andere ohnwürdige / vnd sonderlich diejenigen / welche nur diese Jrrdische Welt mit jhrer vergänglichen Wollust lieb haben / vnnd nichtes anders als als zeitliche Ehr vnd flüchtiges Gut vnnd Schätze hiedurch zu erwerben suchen / mit einer solchen Blindheit schla-

77 Priesner: Über die Wirklichkeit des Okkulten (Anm. 67), S. 341.

78 Vgl. Conermann: Die Mitglieder der Fruchtbringenden Gesellschaft (Anm. 5), S. 567; sowie Lohmeier, Reichelt: Johann Rist (Anm. 5), bes. S. 348.

79 Johann Rist: Das AllerEdelste Nass der gantzen Welt, Vermittelst eines anmuhtigen und erbaulichen Gespräches, Welches ist diser Ahrt die Erste, und zwahr Eine Jänners-Unterredung, Beschriben und fürgestellet [1663]. In ders.: Sämtliche Werke. Unter Mitwirkung von Helga Mannack hrsg. von Eberhard Mannack. Bd. 4: Epische Dichtungen (Das alleredelste Naß, Das alleredelste Leben). Berlin, New York 1972, S. 1-120, hier S. 46.

80 Johann Rist: Die alleredelste Erfindung Der Gantzen Welt, Vermittelst eines anmutigen und erbaulichen Gespräches, welches ist dieser Art, die Fünffte, Und zwar eine Mäyens-Vnterredungen, Beschrieben und fürgestellet [1667]. In ders.: Sämtliche Werke. Unter Mitwirkung von Helga Mannack hrsg. von Eberhard Mannack. Bd. 6: Epische Dichtungen (Die Alleredelste Erfindung, Die Alleredelste Zeitverkürzung). Berlin, New York 1976, S. 1-240, hier S. 62, vgl. auch S. 31 . 
gen / daß sie auch am hellen vnd liechten Mittage in diesem hohen Geheimnisse mit offenen Augen nichtes sehen noch erkennen mügen. ${ }^{81}$

Mit dieser Stoßrichtung darf Rists Alchemietraktat füglich wie die Atalanta fugiens als "alchemisches Andachtsbuch“ aufgefasst werden, in dem, so Volkhard Wels über Maiers Text, „,weder Goldmacherkunst noch überhaupt Laborpraxis“ vermittelt wird, sondern die „Erkenntnis der Natur als einer Schöpfung Gottes" ${ }^{\prime 2}$ Auch bei Rist geht es keineswegs darum, alchemische Geheimnisse womöglich anleitungsförmig zu lüften; vielmehr ruft er wie Maier mit Nachdruck in Erinnerung, dass die Alchemie über die secreta naturae zur Erkenntnis höchster Wahrheit aus den Werken der Schöpfung führen könne. Im Unterschied zu Maier arbeitet Rist jedoch nicht mit den Mitteln der Ästhetisierung, sondern bietet eine polemisch flankierte Satire auf die seit Vergil sprichwörtlich gewordene auri sacra fames (Vergil, Aeneis 3,57). Diese Alchemie bedarf weder besonderer Kosten und Mühen noch ausgeklügelter Destillations- und Coagulationsverfahren, sondern sie erweist sich als Frage der Gedankenarbeit, die aus der Tugend eines gläubigen Christen erwächst. In dieser Ermahnung zum rechten Gebrauch der Alchemie besteht Rists zentrale theologische Botschaft, sodass er guten Gewissens noch drei Jahrzehnte nach der Publikation des Philosophischen Phoenix die folgende Bilanz aus seinem alchemischen März-Gespräch ziehen kann:

Auß disem Allem erscheinet nun Sonnenklahr / das das Suchen und forschen nach disem hohen Geheimnisse des Steins der Weisen mitnichten / wie viele unverständige Knadasten [sc. grobe Menschen] urtheilen / für die AllerEdelste Tohrheit / sondern vielmehre für die Aller-Edelste Klugheit der gantzen Welt sei zu schätzen [...]. ${ }^{83}$

81 Rist: Philosophischer Phoenix (Anm. 22), S. 17.

82 Volkhard Wels: Poetischer Hermetismus. Michael Maiers Atalanta fugiens (1617/ 18). In: Konzepte des Hermetismus in der Frühen Neuzeit. Hrsg. von dems., Peter-André Alt. Göttingen 2010, S. 149-194, hier S. 164.

83 Rist: Die AllerEdelste Tohrheit (Anm. 11), S. 179. 


\title{
Hexenflug und Hagelzauber. Zum poetischen Umgang mit Magie in neulateinischen Gedichten aus Humanismus und Barock
}

\author{
(Pharmaceutria-Eklogen, Conrad Celtis, Paul Schede Melissus, \\ Johannes Bisselius SJ.)
}

Jost Eickmeyer, Berlin

Joachim Telle zum Gedenken

\section{Hexerei als Gegenstand frühneuzeitlicher Diskurse}

Das Wissen um die bedrohliche Präsenz von Schadenszauber und Hexerei war im 17. Jahrhundert allgemein verbreitet und sowohl in Gelehrtenkreisen als auch im Volksglauben fest verankert. Ersichtlich wird dies neben den zahlreichen Protokollen zu Hexenprozessen, von denen ein guter Teil mittlerweile ediert ist, vor allem aus der einschlägigen Kompendien-, Predigt- und Traktatliteratur, etwa dem notorischen Malleus maleficarum (Speyer 1487), der freilich von kirchlicher Seite nur kurze Zeit unbestritten blieb, ${ }^{1}$ Jean Bodins De la démonomanie des sorcières (1580) und der für den deutschsprachigen Raum wichtigen, nur ein Jahr später erschienenen Übersetzung Vom Außgelaßnen Wütigen Teuffelsheer, deren Autor Johann Fischart nicht nur an einer Neuedition des Malleus maleficarum (ab 1582 bei Basse in Frankfurt) beteiligt war, sondern als Amtmann im lothringischen Forbach mit einiger Sicherheit in den dortigen Hexenprozessen durchaus praktisch engagiert gewesen sein dürfte. ${ }^{2}$ Für den lutherischen Bereich dürfen

1 Siehe dazu André Schnyder: Der Malleus Maleficarum. Fragen und Beobachtungen zu seiner Druckgeschichte sowie zur Rezeption bei Binsfeld, Bodin und Delrio. In: Archiv für Kulturgeschichte 74 (1992), S. 323-364; zur allgemeinen Orientierung verweise ich auf die Beiträge in: Der Hexenhammer. Entstehung und Umfeld des Malleus Maleficarum von 1487. Hrsg. von Peter Segl. Köln 1987.

2 Zu Fischarts Übersetzung siehe Gerhild Scholz-Williams: Die Wissenschaft von den Hexen: Jean Bodin und sein Übersetzer Johann Fischart als Dämonologen. In: Knowledge, Science, and Literature in Early Modern Germany. Hrsg. von ders. und Stephan K. Schindler. Chapel Hill 1996, S. 191-218; zur praktischen Anwendung des Teufelsheers bei Verfahren gegen vermeintliche Hexen siehe Wolfgang Behringer: Hexenverfolgung in Bayern. Volksmagie, Glaubenseifer und Staatsräson in der Frühen Neuzeit. München 1987, S. 132. - Das verdienstvolle Unternehmen einer kritischen und kommentierten Edition von Fischarts Dämo- 
die im 16. Jahrhundert hoch populären volkssprachlichen Teufelsbücher nicht vergessen werden. Vor allem der Zauber Teuffel (1563, 64 und 66) des hessischen Pfarrers Ludwig Milich(ius) bietet eine konzise Darstellung des Verständnisses von Zauberei innerhalb der lutherischen Orthodoxie. ${ }^{3}$ Milich klammert nämlich (anders als nahezu alle altgläubigen Autoren, die sich diesem Thema widmen) die Magia naturalis ausdrücklich aus seiner Darstellung aus ${ }^{4}$ und erkennt bündig formuliert Zauberei dann, wenn die menschen ein Creatur unnd geschöpff Gottes anders brauchen unnd ein ander wirckung darinn suchen denn Gott verordnet hat/ man thuo solches zu helffen oder zu schaden, ${ }^{5}$ mithin wenn falsche chrêsis vorliegt. Unter diesem Lemma einer ,magischen Zauberei' führt der Autor selbstverständlich auch Teufelsbündler, Zauberer und Hexen an. Schließlich ist gerade für die res publica litteraria noch der flämische Jesuit Martinus Antonius Delrio zu nennen, dessen Disquisitiones Magicae zwischen 1599 und 1600 erschienen, mit ihren sechs umfangreichen Büchern das bis dato umfassendste und systematischste Werk zur Dämonologie bildeten und bis ins 18. Jahrhundert über zwanzig Auflagen erfuhren. Dass Delrio und seine Disquisitiones nicht nur im katholischen Europa geschätzt wurden, zeigt ein lobendes Gedicht in Hendekasyllaben, das kein geringerer als Justus Lipsius, ein Studienfreund Delrios, ihnen widmet und dabei den Leser adressiert:

In R.V. Martini Delrii Disquisitiones Magicas.

Cuius doctum opus hoc? Quod ima, summa

Pennâ permeat et sagace mente

Sagas et stygias striges reuelat?

Quod tu Thessala terra vosque Colchi

Infames malè cantibus patrastis;

Quod Panes, Satyrique, Dusijque

Peccastis, genus improbum saláxque,

Totum hoc eruit erutis medetur:

Sed quis? Delrius eruditione

Idem relligione clarus. ergo

nologie hat jüngst eine Heidelberger Forschergruppe um Prof. Tobias Bulang in Angriff genommen.

3 Ludwig Milichius: Der Zauber Teuffel. Das ist/ Von Zauberei Warsagung/ Beschwehren/ Segen/ Aberglauben/ Hexerey/ vnd mancherley Wercken des Teufels/ wolgegründter [...] Bericht $[\ldots . .$. . Frankfurt a.M.: Sigmund Feyerabend und Simon Hüter 1563. In: Teufelbücher in Auswahl. Hrsg. von Ria Stambaugh. Bd. I: Ludwig Milichius. Zauberteufel. Schrapteufel. Berlin 1970, S. 1-185.

4 Siehe Milichius: Der Zauber Teuffel (Anm. 3), S. 22,9f.

5 Milichius: Der Zauber Teuffel (Anm. 3), S. 15,3-6. Zur im Einzelfall prekären Unterscheidung zwischen ,natürlicher' und illiziter Magie vgl. Wilhelm Kühlmann: Grimmelshausen und Prätorius. Alltagsmagie zwischen Verlockung und Verbot. Anmerkungen zu Simplicissimi Galgen-Männlin (1673). In: Simpliciana 26 (2004), S. 61-75, hier S. 62-64. 
Hîc pura et liquida omnia; hîc venena

Nulla quae timeas opinionum:

Huic libro faueas, faue tibi ipse,

Atque istum lege, vt ima summa noris. ${ }^{6}$

\section{Auf des hochverehrten Herrn Martin Delrios Disquisitiones Magicae}

Wer schrieb dieses gelehrte Werk? Das mit seiner Feder das Tiefste und Höchste durchdringt und mit Weisheit und Geist die Zauberinnen und höllische Hexen entlarvt? Was du, thessalisches Land und ihr, verruchte Kolcher mit euren bösartigen Zaubergesängen vollbracht habt; was ihr, Pane, Satyrn und Nachtmahre gesündigt habt, ihr schamloses und geiles Volk, all das hat er zu Tage gefördert und ihm Abhilfe geschaffen: Aber wer? - Delrio, der von Gelehrsamkeit ebenso wie vor Frömmigkeit glänzt. Also ist hier alles rein und klar; hier gibt es kein Gift der [widerstreitenden] Meinungen, die du fürchten müsstest. Schätze dieses Buch hoch, gönne es dir selbst und lese es, auf dass du das Tiefste und Höchste kennest.

Kaum noch nötig zu erwähnen, dass alle hier genannten Werke, wenngleich in unterschiedlicher Deutlichkeit, eine Verbindung von Magie, Teufelsbund (auf den auch Lipsius in V. 6f. anzuspielen scheint) und Häresie vornehmen und somit weltliche wie geistliche Institutionen zu höchster Wachsamkeit und tatkräftigem Durchgreifen auffordern.

Dies alles ist bekannt und soll hier nur den Hintergrund für eine bemerkenswerte literarhistorische Leerstelle bilden. Gemessen an der Brisanz des Themas und seinen praktischen gesellschaftlichen Auswirkungen ab der zweiten Hälfte des 16. Jahrhunderts werden Hexerei oder Hexenverfolgung in der frühneuzeitlichen Lyrik des Alten Reiches - soweit diese bisher zu überblicken ist erstaunlich wenig thematisiert. Und dies obwohl die antike Tradition humanistischen Dichtern ja mit Horazens Hexe Canidia, Lucans Nekromantin Erictho und Ovids diversen Zauberinnen, unter anderem Dipsas (am. 1,8), Medea und Circe hinreichend literarischen Stoff zur Verfügung gestellt hat. Zwar werden die genannten Figuren und entsprechende Szenen in verschiedenen, meist misogynen Kontexten oft katalogartig genannt, doch schlägt kaum ein Poet die Brücke zum zeitgenössischen Hexenwesen. Selbst im Zusammenhang der Konfessionspolemik bleiben Zauberei und Teufelsbündlertum marginal, abzulesen etwa bei dem Niederländer Andreas Alenus, der in einem allegorisch-kirchengeschichtlichen Gedicht lediglich in zwei Distichen vermerkt, Luthers Abneigung

6 Zitiert nach Martin Delrio: Disquisitionum Magicarum libri sex [...]. Mainz: Peter Henning 1624, S. (:)2r. 
gegen die (altgläubige) Messe sei aus seinem regelmäßigen Umgang mit dem Teufel zu erklären. ${ }^{7}$

Im Folgenden seien nun die wenigen lyrischen Zeugnisse, in denen Zauberei und Hexerei in einem zeitgenössischen Rahmen zur Darstellung kommen, durchgemustert und die Art und Absicht dieser Darstellung untersucht. Zunächst aber ist eine frühneuzeitlichen Mode-Gattung zu betrachten, in der schon von ihren antiken Vorläufern her Magie eine Rolle spielen konnte und die in gewisser Weise eine Zwischenstellung zwischen der gelehrt-antikisierenden Einzelanspielung und Gedichten zum frühneuzeitlichen Hexenwesen einnimmt: die Ekloge.

\section{Magie im fiktiven ländlichen Raum: frühneuzeitliche Pharmaceutria- Eklogen}

In der an Theokrits Idyllen und insbesondere an Vergils bukolische Dichtung anknüpfenden Tradition findet sich eine nicht direkt auf die berühmtberüchtigten Hexenfiguren der Antike zurückweisende Darstellung magischer Praktiken. Im ländlichen Milieu der Hirten oder (seit der Renaissance) Fischer wird meist ein Liebeszauber gewirkt, der einen treulosen Geliebten zur verlassenen Frau zurückbringen oder aber vernichten soll. Hatte in Theokrits zweitem Idyllion Simaithas zauberische Beschwörung noch quantitativ deutlich hinter ihrer Liebesgeschichte zurückgestanden, so hatte Vergil dagegen das Gewicht deutlich auf die magische Handlung bzw. die verbale Verfluchung des untreuen Mannes verschoben - zumal in komplizierterer Perspektivierung: In der zweiten Hälfte der achten Ekloge lässt er den Hirten Alphesiboeus ein Lied in der Maske eines Mädchens singen, das den treulosen Daphnis mit magischen Mitteln an sich binden will. ${ }^{8}$ Als charakteristisch für solche Pharmaceutria (d.h. Giftmischerin)-Szenen können die recht detaillierte Schilderung der magischen Handlungen, Ingredienzien und Sprüche sowie ein das Gedicht selbst strukturierender Refrain-Vers gelten, der oftmals mit der Beschwörung des Geliebten zusammenfällt und dem Hirtengesang seinen Liedcharakter eigentlich erst verleiht; im Fall der achten Ekloge: ducite ab urbe domum, mea carmina, ducite Daphnin. ${ }^{9}$

In dieser Tradition steht in der Frühen Neuzeit eine ganze Reihe von Dichtungen, die mit der Gattung auch das bukolische Sujet der Hirtendichtung, mehr oder minder modifiziert, übernehmen. Der neapolitanische Dichter Jacopo San-

7 Siehe Andreas Alenus: Sacrarum Heroidum libri tres. Louvain: Velpius 1574, S. $142^{\mathrm{v}}-145^{\mathrm{r}}$ (epist. III,28: Ecclesia Militans Ecclesiae Triumphanti), hier S. 144r, V. 65-68.

8 Theokrit: Gedichte. Griechisch-deutsch. Hrsg. von F.P. Fritz. Stuttgart 1970, S. 16-27 (Pharmakeutría); Vergil: Opera. Hrsg. von R.A.B. Mynors. Oxford 1969, S. 22f.: ecl. 8,64-109.

9 „Bringt aus der Stadt ihn nach Haus, meine Zaubersprüche, bringt meinen Daphnis.“ Vergil: Opera (Anm. 8), ecl. 8, V. 68, 72, 76, 79, 84, 90, 94, 100, 104 und 109 (dort variiert: parcite, ab urbe uenit, iam parcite carmina, Daphnis. - „Lasst ab, schon kommt aus der Stadt - lasst ab, ihr Zaubersprüche - mein Daphnis."). Übersetzungen aus dem Lateinischen hier und im Folgenden, sofern nicht anders angegeben, von mir. 
nazaro (1458-1530), ansonsten für sein Epyllion auf die Jungfrauengeburt (De partu virginis) berühmt, publizierte 1526 ein sehr einflussreiches Buch mit fünf Eklogen, in denen er den ländlichen Raum der vergilischen Hirten durch den der Fischer am Golf von Neapel ersetzte. ${ }^{10}$ Auch er bietet, in der Ecloga piscatoria 5, eine Pharmaceutria-Episode, hier im Gesang des Fischers Dorylas. Dessen Beginn sei zitiert:

Sebethi ad liquidas descenderat Herpylis undas, Herpylis Euboidum non ultima, quam pater Alcon Erudiit, Musis et Phoebo cognitus Alcon. Venerat et socii partem subitura laboris Unanimis soror et calathum de more ferebat.

Ipsa comas effusa pedemque exuta sinistrum Cum philtris longum submurmurat atque ita fatur: „Pone aram et vivos hauri de flumine rores

Canaque vicino decerpe absinthia campo;

Illum illum magicis conabor adurere sacris Qui miseram tota spoliatam mente reliquit. Volvite praecipitem iam nunc, mea licia, rhombum. ${ }^{11}$

Herpylis stieg hinab zu den klaren Fluten des Sebethos; Herpylis, nicht die letzte unter den Frauen Neapels, sie, die der Vater Alcon unterrichtet hatte, Alcon, bekannt bei den Musen und Phoebus. Es kam auch, ihren Teil an den Mühen der Gefährtin zu tragen, ihre Schwester, gleichen Muts, und trug, wie es Sitte war, einen Korb. Sie selbst trug das Haar offen und den linken Fuß unbedeckt, murmelte lange über ihren Liebestränken und sprach so: „Richte den Altar auf, schöpfe frisches Wasser aus dem Fluss und pflücke weißen Wermut vom Feld dort drüben. Ihn, ihn will ich mit zauberischem Werk zu verbrennen suchen, der mich Elende mit ganz zerrüttetem Geist zurückließ. Dreht den Kreisel, der sich schon neigt, meine Fäden.

Der letzte zitierte Vers bildet zugleich den Refrain, der im Weiteren - ganz ana$\log$ zu Vergil - das Gedicht gliedern wird. ${ }^{12}$ Der Zauber-Kreisel, der bereits bei antiken Elegikern auftauchte, ${ }^{13}$ soll hier dazu beitragen, einen gewissen Maeon

10 Jacopo Sannazaro: Latin Poetry. Ed. and transl. by Michael C. J. Putnam. Cambridge 2009, S. 102-141; siehe dazu Carmelo Salemme: Il canto del Golfo. Le Eclogae piscatoriae di Iacopo Sannazaro. Napoli 2007.

11 Die Ekloge findet sich in Sannazaro: Poetry (Anm. 10), S. 132-141, siehe hier die V. 20-75, zitiert V. 21-32.

12 Siehe Sannazaro: Poetry (Anm. 10), S. 132-141, V. 36, 40, 43, 48, 64, 59, 63 sowie 69 und 73 variiert: Sistite praecipitem, iam sistite, licia, rhombum. - „Bremst den sich neigenden, bremst schon, meine Fäden, den Kreisel." Die aemulatio Vergils wird so schon strukturell deutlich.

13 Vgl. etwa Properz 2,28,35: Deficiunt magico torti sub carmina rhombi („Es versagen die Kreisel, 
zu behexen, der Herpylis verlassen hat. Das doppelte illum (V. 32) verdeutlicht mit seinem zweifachen Bezug - einerseits auf das absinthium (V. 29), andererseits als Korrelativ zum Relativpronomen "Qui“ (V. 31) - die magische Praxis im Grammatischen: Wie die Pflanze brennt, so soll auch der untreue Liebhaber brennen. Als weitere magischen Ingredienzien dienen verbrannte Algen (V. 37), das Gift eines Zitterrochens, aus dem die Zauberin Maeon einen giftigen Trank kredenzen will (V. 60-62), sowie ein zerschnittener Seehase, mit dessen Überresten die Schwelle des Verhassten bestrichen werden soll (V. 64-68). Carmelo Salemme hat nachgewiesen, dass diese steigernd geschilderten magischen Inhaltsstoffe nicht nur die bukolisch-ländlichen Materialien aus Vergils Alphesiboeus-Lied durch fischerlich-marine ersetzen, sondern dass Sannazaro neben Vergil auch das zweite Idyllion Theokrits mit einbezieht, auf dessen Zauber etwa das Bestreichen der Schwelle und vermutlich auch der Zitterrochen (als marine Entsprechung zum Salamander) anspielen. ${ }^{14}$

Nun stellten Sannazaros Fischer-Eklogen nicht nur in sich ein raffiniertes Spiel mit literarischen Traditionen dar, ${ }^{15}$ sondern sollten ihrerseits die weitere Renaissance-Bukolik maßgeblich beeinflussen, ${ }^{16}$ wohl auch deshalb, weil Europas einflussreichster Poetiker, Julius Caesar Scaliger, Sannazaros zweite Piscatoria im Rang unmittelbar nach den Eklogen Vergils positionierte. ${ }^{17}$ Just sein Pharmaceutria-Gedicht scheint dabei das am meisten imitierte gewesen zu sein. ${ }^{18}$ So unterschiedliche Dichter wie Petrus Lotichius Secundus, Simon Lemnius oder Melchior Barlaeus legten Bucolica nach Vergil und Sannazaro vor, ebenso der

die unter zauberischen Gesängen gedreht wurden“; z.B.: Popertius: Elegiarum libri sex. Hrsg. von Paulo Fedeli. Stuttgart 21994, S. 117); Ovid: Liebesgedichte. Lateinisch/Deutsch. Übers. und hrsg. von Michael von Albrecht. 2. Auflage. Stuttgart 2010, S. 30f. (am. 1,8,7f., von der Hexe Dipsas): scit bene quid gramen, quid torto concita rhombo / licia, quid valeat [...]. „Sie weiß wohl um die Kraft der Kräuter, der bewegten Fäden an gedrehter Scheibe [...]." Als Bezugstext für beide kommt wohl Theokrit, Id. 2,17 in Frage.

14 Salemme: Canto (Anm. 10), S. 89-91.

15 Salemme: Canto (Anm. 10), S. 91: [U]n gioco finissimo di riprese, di variazioni, di combinazioni.

16 Einen sehr guten Überblick gibt Eckart Schäfer: Zur Sannazarius-Rezeption in der Renaissance-Bukolik. In: Sannazaro und die Augusteische Dichtung. Hrsg. von dems. Tübingen 2006, S. 249-275; beizuziehen ist ferner Nicholas Smith: The Genre and Critical Reception of Jacopo Sannazaro's Eclogae Piscatoriae (Naples, 1526). In: Humanistica Lovaniensia 50 (2001), S. 199-219.

17 Scaligers Text ist bequem greifbar bei Ilse Reineke: Julius Caesar Scaligers Kritik der Neulateinischen Dichter. Text, Übersetzung und Kommentar des 4. Kapitels von Buch VI seiner Poetik. München 1988, S. 240-255, hier V. a. 252f.: „Auch im Hirtengedicht ist von allen, die nach Vergil geschrieben haben, er allein lesenswert." Siehe dort ferner Reinekes Kommentar zu Scaligers Auffassung von Sannazaro, S. 494-496.

18 Schäfer: Sannazarius-Rezeption (Anm. 16), S. 253; eine weitere frühneuzeitliche Pharmaceutria-Ekloge präsentiert Alexander Cyron: Melchior Barlaeus, 5. Ekloge Pharmaceutria. TextÜbersetzung - antike Vorbilder. In: Vestigia Vergiliana. Vergil-Rezeption in der Neuzeit. Hrsg. von Thorsten Burkard, Markus Schauer und Claudia Wiener. Berlin, Boston 2010, S. $147-168$. 
aus dem Umkreis von Minden gebürtige spätere Rostocker Professor Johannes Bocer (1526-1565), der wie Sannazaro in seiner Schluss-Ekloge eine Hexe auftreten lässt. ${ }^{19}$

Bei ihm fällt allerdings der singende Hirte perspektivisch mit dem lyrischen Ich zusammen, das in bewusster Nachfolge von Vergils Tityrus und seiner „Mu$\mathrm{se}{ }^{20}$ von der betrogenen Liebe einer gewissen Crocale zum Jüngling Thrasyllus erzählt und dabei, ganz der bukolischen Tradition entsprechend, die Rede der verlassenen Frau wiedergibt. Nachdem diese über gut vierzig Verse ihre Liebe zu Thrasyllus und dessen Treulosigkeit beschrieben hat, entschließt sie sich, den Liebeszauber zu unternehmen.

I, soror, et geminas arcanis ritibus aras

Erige, quo manes circum volitare sepulchra

Nigra solent. Locus hic magicis es artibus aptus.

Hic nigrum mactato canem, fusumque cruorem

Lacte novo mistum positas ter funde per aras,

Fronte sed aversa, nec te lux pura morantem

Conspiciat Magicas nox conscia diligit artes.

Vertite vos subito, celeres, vos vertite, pelves! ${ }^{21}$

Geh, Schwester, und errichte zwei Altäre für geheime Riten dort, wo Totengeister für gewöhnlich düstere Gräber umfliegen. Dieser Ort ist für magische Künste geeignet. Hier schlachte einen schwarzen Hahn und gieße sein mit frischer Milch vermischtes Blut dreimal auf die aufgestellten Altäre, doch mit abgewandtem Gesicht. Und nicht erblicke dich der helle Tag, während du dort verweilst. Die Nacht liebt, als Komplizin, die magischen Künste. Dreht euch sogleich, dreht euch geschwind, ihr Schüsseln!

Vers 55 fungiert im Folgenden als Refrainvers, der dreimal wiederkehrt und dann noch zweimal in negativer Abwandlung, wie es von Theokrit bis Sannaza-

$19 \mathrm{Zu}$ Leben und Werk Bocers jetzt umfassend Lothar Mundt: ,Bocer(us) (Bodeker, Bokerus), Johannes'. In: Frühe Neuzeit in Deutschland 1520-1620. Literaturwissenschaftliches Verfasserlexikon. Hrsg. von Wilhelm Kühlmann, Jan-Dirk Müller, Michael Schilling, Johann Anselm Steiger und Friedrich Vollhardt. Bd. 1. Berlin, Boston 2011, Sp. 296-307; die mustergültige Edition von Bocers Eklogen stammt ebenfalls von Mundt, vgl. Johannes Bocer: Sämtliche Eklogen. Mit einer Einführung in Leben und Gesamtwerk des Verfassers hrsg., übers. und komm. von Lothar Mundt. Tübingen 1999.

20 Das fragliche Gedicht findet sich bei Bocer: Eklogen (Anm. 19), S. 72-79 (Pharmaceutria. Aegloga VII), siehe hier V. 1: Dum pastorali sequimur te, Tityre, Musa, in Mundts Übersetzung: „Da wir im Hirtengesang dir nachfolgen, Tityrus".

21 Zitiert nach Bocer: Eklogen (Anm. 19), S. 74, V. 48-55; die Übersetzung Bocer: Eklogen (Anm. 19), S. 75. 
ro üblich war. ${ }^{22}$ Doch damit nicht genug. Bocer weiß sich im Wettstreit mit seinen Vorgängern, zumal Sannazaro, dessen Zauberin Herpylis ja auch Hilfe von ihrer Schwester bekam. ${ }^{23}$ Ebenso hier Crocale, die aber nach dem magischen Tun der Gehilfin auch selbst aktiv wird:

Hoc nigrum laevo sic dirige pollice filum.

Hoc omnes vinctos stringam captosque ligabo

Currite iam magica vertigine, currite fila!

Hac virga coryli, gelido qua nuper in antro

Mordentem ranam lubricum placavimus anguem

Et qua servavi muscam, quam laesit Arachne,

Hac ego Thrasylli leviter si tempora tangam,

Ferreus ille licet fuerit, miserebitur ultro

Et supplex iterum nostro se subdet amori.

Currite iam magica vertigine, currite fila! ${ }^{24}$

Führe diesen schwarzen Faden so mit dem linken Daumen. Damit werde ich alle [sc. soeben beschworenen Geister] gefesselt im Zaume halten und als Gefangene binden. Lauft jetzt durch magische Drehung, lauft, ihr Fäden! Wenn ich mit dieser Haselrute, mit der ich kürzlich in kühler Grotte eine Schlange besänftigte, die einen Frosch biß, und mit der ich eine von einer Spinne verletzte Fliege rettete: wenn ich mit dieser Rute leicht des Thrasyllus Schläfen berühre, wird er, mag er auch aus Eisen gewesen sein, von sich aus Mitleid empfinden und sich demütig wieder meiner Liebe unterwerfen. Lauf jetzt durch magische Drehung, lauft, ihr Fäden!

Bocers Gesang fügt der ersten Refrain-Serie eine zweite hinzu, die dann bis zum Ende der Ekloge reicht, wodurch er nicht nur die magischen Handlungen weiter ausschmückt, sondern auch seine antiken und rinascimentalen Vorgänger überbietet. ${ }^{25}$ Betrachtet man die magischen Handlungen selbst, so zeigt sich auch hier eine Technik von Ausschmückung und Kumulation: Zwei Altäre werden errichtet statt eines bei Sannazaro, Tiere werden geschlachtet und Flüssigkeiten wie

22 Vgl. Bocer: Eklogen (Anm. 19), V. 60, 66, 73 und in den V. 80 und 86 die Variationen State, nec ulterius celeres procedite, pelves! In Mundts Übersetzung: „Haltet an und bewegt euch nicht geschwind weiter, ihr Schüsseln!" - Welche rituelle Funktion diese sich drehenden Schüsseln genau haben, bleibt - auch dem Kommentator - unklar.

23 Lothar Mundt weist in seinem Kommentar zur Ekloge ferner plausibel auf eine Pharmaceutria-Ekloge des Pfälzer Neulateiners Petrus Lotichius Secundus sowie auf die Dido-Episode in Vergils Aeneis als Vorläufer hin, vgl. Bocer: Eklogen (Anm. 19), S. 163 und 166.

24 Zitiert nach Bocer: Eklogen (Anm. 19), S. 76, V. 91-100; Mundts Übersetzung Bocer: Eklogen (Anm. 19), S. 77.

25 Siehe Bocer: Eklogen (Anm. 19), S. 76-78, V. 107, 114, 120, 126, 132 und die dreimalige (!) Variation in V. 139, 147 und 158: Sistite, fila, citos, iam tandem sistite cursos! In Mundts Übersetzung: „Haltet ein, Fäden, es ist genug, haltet jetzt ein in eurem schnellen Lauf!“ 
bei Sannazaro vergossen. Die „Komplizin Nacht“ (V. 54) markiert im Lateinischen einen gängigen Bezug zur römischen Epik und Liebeselegie. ${ }^{26}$ Zugleich scheint das Schwesternpaar Geister zu beschwören (Spiritibus, V. 88), die der Crocale, welche buchstäblich die Fäden in der Hand hält, dann dienstbar sein sollen. Doch der Einsatz dieser Geister wird im Folgenden nicht thematisiert, vielmehr setzen die vom Refrainvers gerahmten Segmente immer wieder mit neuen magischen Praktiken und Werkzeugen ein, die Thrasyllus Schaden zufügen sollen, etwa der Haselrute im obigen Zitat. ${ }^{27} \mathrm{Zu}$ ihr gesellen sich Tierhaare (V. 101-104), magische Kräuter (V. 108-113), behauene Pfähle (V. 115-119), Muscheln (V. 121-125), Pfeil und Bogen (V. 126-131), und sogar Sannazaros Seehase wird zerteilt, obwohl die Szene sich keineswegs in Meeresnähe abspielt (V. 140146). Offenkundig geht es Bocer in diesen Passagen nicht um die Präsentation magischen Wissens in Form eines einheitlichen, zweckhaften magischen Rituals, sondern um die Anreicherung mit möglichst vielen verschiedenen Motiven aus der Tradition antiker Darstellungen des Liebeszaubers.

Dennoch würden vor dem Hintergrund zeitgenössischer Dämonologie hier zweifelsfrei Nekromantie und Hexenwerk dargestellt, indem Crocale und ihre Schwester sich Geister, womöglich der Toten auf dem Friedhof, dienstbar machen und mit allerhand magischem Gerät hantieren. Dass Thrasyllus schließlich auf einem Bock durch die Lüfte fliegt, spielt einerseits deutlich auf die DaphnisEkloge des Lotichius an, kann aber im Horizont frühneuzeitlicher Imaginationen von Hexentanz und Hexenflug auch einen ganz anderen, teuflischeren Reiter meinen. Drei Faktoren, die sich mutatis mutandis auf alle frühneuzeitlichen Pharmaceutria-Eklogen übertragen lassen, stellen sich freilich einer solchen Interpretation entgegen: Gattungstopoi, Fiktionssignale und eine für die Frühneuzeit typische imitatio veterum. Letztere lässt sich etwa für das letzte Segment der Ekloge in Anschlag bringen, wenn Crocale die Wirkmacht ihrer Zaubersprüche (Carmina) herausstellt, die den Lauf der Natur ändern, Wetter machen und auf alles, was lebt, einwirken könnten. ${ }^{28}$ Die Verse ließen sich als Beleg zeitgenössischen Wetter- und Schadenszaubers lesen, doch Lothar Mundt weist im Kommentar zur Stelle die zahlreichen Similien zu Vergils achter Ekloge auf. ${ }^{29}$ Bocer geht es somit nicht um eine wie auch immer authentische Präsentation von Hexenwesen und Schadenszauber, sondern darum, sich wie Sannazaro, Lotichius und andere vor ihm als innovativen Dichter in der Imitation und Aemulation einer traditionellen Gattung zu erweisen.

$\mathrm{Zu}$ den Topoi dieser Gattung gehört es auch, die Handlung in einem teils fiktiven, teils (etwa in Vergils ecl. 1 und 4) historisch situierbaren ländlichen Raum

26 Vgl. Ovid: epist. 18,105, oder im eher sakralen Zusammenhang Ovid, Met. 6,587; Met. 13,15.

27 Zur frühneuzeitlichen Diskussion um die magische Wirkung von Hasel- und Wünschelruten vgl. den Beitrag von Bernd Roling im vorliegenden Band.

28 Siehe Bocer: Eklogen (Anm. 19), S. 78f., V. 147-157.

29 Siehe Bocer: Eklogen (Anm. 19), S. 166. 
anzusiedeln, dessen Agenten mit ihren antikisierenden Hirtennamen zwar individuell gezeichnet, doch keineswegs authentisch identifizierbar sind. Eine magische Handlung in dieser Welt des bukolischen Hirtenwesens ist somit prinzipiell von einer solchen $\mathrm{zu}$ unterscheiden, die das lyrische Ich selbst auszuüben oder zu bezeugen angibt oder als Geschehen in seinem historischen Umfeld präsentiert.

Um auf dieser Ebene Verwechslungen vorzubeugen, fügt Bocer direkt am Anfang seiner Ekloge wichtige Fiktionssignale ein. Gleich nachdem er sich auf die „Muse des Tityrus" berufen hat, fährt er fort: Perque vices veris miscemus ficta, canemus / Iam quoque difficiles, quibus urebatur, amores, / Infelix Crocale. ${ }^{30}$ Nicht nur die im Versbau suggerierte Anspielung auf die infelix Dido ${ }^{31}$ weist Crocale als primär literarischen Charakter aus; vor allem Bocers Hinweis auf eine ,abwechselnde' Struktur von faktualen und fiktionalen Gegenständen ist hier von Bedeutung: Die vorangegangene sechste Ekloge pries nämlich unverkennbar die Schönheiten des Schweriner Schlosses und zumal seiner Kirche und muss demnach zur ,realitätshaltigen' Eklogendichtung gezählt werden. ${ }^{32}$ Demnach weist der Dichter selbst das siebte Hirtengedicht samt seinem Hexenpaar als klar fiktionales Poem aus, das im Folgenden dann literarisch mit den Vorgängern Ovid, Sannazaro und Lotichius wetteifert.

Obgleich solche poetischen und deutlich als fiktional gekennzeichneten Passagen von frühneuzeitlichen Dämonologen ganz selbstverständlich als Belege für ihre Wissenschaft vom Hexenwesen herangezogen wurden, ${ }^{33}$ sind sie dennoch klar von Dichtungen zu unterscheiden, welche die Authentizität der in ihnen beschriebenen magischen Handlungen suggerieren oder auf diese sogar pochen. Sie sind in Humanismus und Barock höchst selten.

30 Bocer: Eklogen (Anm. 19), S. 72, V. 2f., deutsch S. 73: „,[...] und im Wechsel Wahres mit Erfundenem mischen, werden wir jetzt auch von der unseligen Liebe reden, in der Crocale glücklos entbrannte."

31 Vgl. Vergil: Opera (Anm. 8), S. 241 (Aeneis 6,456).

32 Vgl. Bocer: Eklogen (Anm. 19), S. 58-71 sowie den Kommentar auf S. 156-162.

33 So verweist etwa der erwähnte Ludwig Milichius in seinem Zauber Teuffel bei der Erörterung magischer Mittel und Zeremonien ganz selbstverständlich auf antike Dichtungen von Horaz, Ovid oder Juvenal und bringt als Beispiel für Zauberformeln eine deutsche Versübersetzung just aus Vergils achter Ekloge, (Milichius: Zauber Teuffel [Anm. 3], S. 47,1-6; 47,25-48,9; siehe etwa auch S. 82,20-83,2, wo als Belege für Giftmischerei Vergils drittes Georgicon sowie Plinius zitiert werden). - Auf der anderen Seite der konfessionellen Trennlinie sah es nicht anders aus. Martin Delrio etwa führt in seinem Kompendium über Magie als Teufelsbündlertum reichhaltige Stellenkataloge aus antiker und teils zeitgenössischer Dichtung an, ohne sich an der Frage der Fiktionalität zu stören; über die Wirkungen von Magie und Hexerei etwa zitiert er ausführlich die ,klassischen Stellen' über das Wettermachen, Herabholen des Mondes, über Circe, Medea, Erictho u.a. aus Vergil, Ovid, Tibull, Properz, Lucan, Seneca, Silius, Claudian, Ausonius u.a.: Delrio: Disquisitiones (Anm. 6), S. 125,2C129,2E; 139,1D; 141,2D, 152,1B-152,2B, 154,2D-155,1C, 187,1A-187,2C, 198,1C-198,2A, 204, 2A; speziell zu Liebeszauber und ihren Gegenmitteln werden Pharmaceutria-Eklogen einschlägig genannt: S. 364,2E-365,1D und 368,1B-374,1D. 


\section{Hexenwesen in der Lyrik des deutschen Humanismus}

Eine solche Authentizität suggerierende und obendrein frühe Ausnahme stellt Conrad Celtis (1459-1508) dar, der in verschiedenen Gedichten und Epigrammen Magie und auch konkrete magische Praktiken thematisiert, mitunter sogar genauer schildert. So zeigt er in der vierzehnten Elegie des ersten Buches seiner 1502 publizierten Amores sein elegisches Ich als eifrigen Schüler eines „,auf der ganzen Welt gelehrteste[n] und allmächtige[n] Nekromanten “ ${ }^{34}$ und beschreibt ein magisches Ritual zum Zweck der Geisterbeschwörung detailliert über vierzig Verse hin: ${ }^{35}$

Mox ego stringo comas vittis: Maestamque tiaram

Induo praecingens furiali corpora lino

Et citus obliquam telluri inscribo figuram

Ense secans stricto: vivisque adolescere flammis

Verbenam iubeo: terque ante altaria circum

Intrepidus mucrone cano: dein quatuor oras

Terrarum caelique noto: qua Phoebus ab ortu

Surgit: et hesperias cubitum qua fertur in undas

Et septem gelidi lucent ubi nocte triones

Et qua devexus calidum polus excipit austrum

Deinde locum facibus stygiis et ture vaporo

Consecro: velato capite inclinatus ad aras

Iam magicis lustratus aquis: tum carmina diro

Tristia ab ore ruunt: mox magno impulsa tumultu

(Horresco referens) tellus per inane voracem

Immenso subducta sinu patefecit hiatum

Unde sepulcrales gemitus [...].

Alsbald umwinde ich meine Haare mit einer Binde, setze eine dunkle Priestermütze auf, hülle den Körper in gräßliches Leinen und zeichne schnell mit gezücktem Schwert eine schräge Figur auf den Boden. Ich lasse eine Rute in lebendigen Flammen aufgehen und singe dreimal rings um den Altar, furchtlos im Schutze des Schwertes; darauf bezeichne ich die vier Richtungen des Himmels und der Erde, wo sich Phoebus im Aufgang erhebt und wo er zur Ruhe niedersinkt in hesperische Wasser, wo in der Nacht das kalte Siebengestirn leuchtet und wo der sich neigende Himmel den warmen Südwind aufnimmt. Dann weihe ich den Ort mit

34 Das Gedicht samt deutscher Übersetzung und reichhaltigem Kommentar findet sich in: Humanistische Lyrik des 16. Jahrhunderts. Lateinisch-deutsch. Ausgewählt, übers., erl. und hrsg. von Wilhelm Kühlmann, Robert Seidel und Hermann Wiegand. Frankfurt a.M. 1997, S. 86-97, hier zitiert S. 91, lat. S. 88, V. 63f.

35 Humanistische Lyrik des 16. Jahrhunderts (Anm. 34), S. 90-92, V. 98-132, hier zitiert V. 98114. 
höllischen Fackeln und mit Schwaden von Weihrauch, zum Altar geneigt mit verhülltem Haupt, schon geweiht mit magischem Nass; sodann erschallen unheilvolle Gesänge aus meinem grausigen Mund. Bald aber (mich schaudert bei dem Bericht) eröffnete die Erde tief in ihrem ungeheuren Schoß unter lautem Getöse einen ins Leere klaffenden Schlund. Von dort ertönten Grabesstimmen [...].

Die Genauigkeit der Darstellung reicht bis in die Requisiten: Von einer dunklen Priestermütze und einem entsprechenden Gewand ${ }^{36}$ ist die Rede, von Schwert und Dolch, von verbranntem Holz, Weihrauch und genau abgemessenen Bewegungen und Gesten, von zauberkräftigen Flüssigkeiten und grausigen Zauberformeln (V. 110f.: carmina Tristia ${ }^{37}$ ). Die magischen Handlungen sind teils in sehr gedrängten Formulierungen zum Ausdruck gebracht: Die Wendung terque ante altaria circum / Intrepidus mucrone cano (V. 102f.) drückt zugleich aus, dass der Beschwörende dreimal seine Formel spricht, wobei ihm die zuvor mit dem Schwert gezogene magische Figur um ihn herum (circum) als Schutz dient (Intrepidus). Neben solchen sehr knappen Fügungen finden sich aber auch deutlich antikisierende, ausführlichere Passagen, wie etwa die Antonomasie der vier Himmelsrichtungen. Diese Tempowechsel erzeugen Spannung, ebenso der retardierende Kommentar zum Erfolg dieser Beschwörung (V. 111-114): Das Geschehen lässt das lyrische Ich noch beim Bericht darüber erschauern!

Sachlich ist dieser Zauberritus dabei nicht weit von den ähnlichen Vorgängen in den oben genannten Eklogen entfernt. Folgenreich scheint aber die Inserierung desselben in einen nun elegischen Kontext zu sein, in dem wir uns trotz der an sich regelwidrigen, rein hexametrischen Form - mit den Amores befinden. Hier wird eben nicht mehr der verderbliche Liebeszauber einer wie immer fiktionalen Zauberin in den fernen Welten der Schäferei (oder Fischerei) dargestellt, sondern das lyrische Ich, das in der frühen Neuzeit - zumal im Genus der Elegie ${ }^{38}$ - niemals ganz vom Autor zu trennen war, geriert sich als praktizierender Adept schwarzer Künste. Damit geht Celtis bei aller antikisierenden

36 Die Formulierung furiali lino bereitet einer deutschen Übersetzung Probleme. Einerseits wird, wie hier im Deutschen ausgedrückt, auf die Furien und ihre Schrecken angespielt, andererseits hängt furialis auch mit dem furor, dem göttlich (oder dämonisch) initiierten Wahnsinn des Priesters zusammen. Gemeint ist, dass der magische Practicus hier den Boden der Vernunft verlässt.

37 Die Majuskel in „Tristia“ könnte eine Anspielung auf Ovids gleichnamigen autobiographischen Trauer-Brief aus dem Exil nach Rom darstellen. Immerhin entwickelte der Augusteer mit den Tristia die elegische Form weiter, die Celtis in den Amores ja seinerseits fortschreibt.

38 Autobiographische Deutungen sowohl antiker als auch zeitgenössischer Elegik stellten die Regel dar, was Folgen für Produktion wie Rezeption hatte. Vgl. dazu etwa Achim Aurnhammer: Tristia ex Transilvania. Martin Opitz' Ovid-Imitatio und poetische Selbstfindung in Siebenbürgen (1622/23). In: Deutschland und Ungarn in ihren Bildungs- und Wissenschaftsbeziehungen während der Renaissance. Hrsg. von Wilhelm Kühlmann und Anton Schindling. Wiesbaden 2004, S. 253-272. 
Lexik einen wichtigen Schritt zur Darstellung zeitgenössischen Hexenwesens im Gedicht. Wie aber werden die hier poetisch präsentierten Zauberpraktiken bewertet?

Hermann Wiegand hat in seiner Interpretation des Celtis-Gedichtes die antiken Prätexte der Schilderung ausmachen können. Die Elegie verweist nicht nur auf Vorläufer desselben Genres, etwa Zauberszenen bei Ovid oder Tibull, sondern prominent auf Horazens Satire 1,8. ${ }^{39}$ Folgt man den Hinweisen Wiegands genauer, so stellt sich Celtis' Gedicht geradezu als Parodie dieser Satire dar: Wie bei Horaz eine Priapstatue spricht und sich, weil sie auf einem Friedhof aufgestellt ist, als inutile lignum bezeichnet, ${ }^{40}$ so ist auch Celtis' Liebhaber vor der Tür seiner geliebten Hasilinna am falschen Ort und in rebus eroticis eher nutzlos. Doch während der Priap sich über die grausigen Rituale der Hexen auf dem Friedhof beklagt, ${ }^{41}$ initiiert Celtis' elegisches Ich die nekromantischen Praktiken selbst; wenn schließlich der Priapus Canidia und ihre Gesellinnen durch einen obszönen Laut vertreibt und herzlich auslacht,42 so schlägt der Liebhaber bei Celtis vielmehr seinen Nebenbuhler in die Flucht, als der sich der vermeintlich beschworene Schatten entpuppt:

Haec ego. At vmbra leuem festinans prendere portam

Conticuit: crepitu sonuit mox ianua rauco

Cardine corpoream nobis testata figuram

Ast ego: cur viuo fuerant mea territa vultu

Pectora? non alio me ludes tempore dixi

Vmbra leuis nostrae. Te miscens nocte puellae. ${ }^{43}$

Dies sprach ich; der Schatten aber ergriff eilends die leichtbewegliche Tür und schwieg; das Tor aber gab gleich darauf ein rauhes Geräusch aus den Angeln von sich und zeugte mir damit von einer wirklich existierenden Gestalt. Ich aber sagte: „Wieso konnte eine lebendige Gestalt mein Herz erschrecken? Nicht noch einmal wirst du Spott mit mir treiben, flüchtiger Schatten, und es nächtens mit meinem Mädchen treiben.“

39 Hermann Wiegand: Konrad Celtis, die Magie und Horaz. Zu Elegie 1,14 der Amores, ihren Traditionslinien und ihrer Zeitgenossenschaft. In: Horaz und Celtis. Hrsg. von Ulrike Auhagen, Eckard Lefèvre und Eckart Schäfer. Tübingen 2000, S. 307-319, hier S. 315. - Der antike Text ist bequem greifbar in Horaz: Sämtliche Werke. Lateinisch/deutsch. [...] Mit einem Nachwort hrsg. von Bernhard Kytzler. Stuttgart 22006, S. 382-387.

40 Horaz: Sämtliche Werke (Anm. 39), V. 1.

41 Horaz: Sämtliche Werke (Anm. 39), V. 17-45. - Diese Nekromantie-Szene wurde in dämonologischen Traktaten der Frühen Neuzeit häufig als Beleg zitiert; vgl. etwa Delrio: Disquisitiones (Anm. 6), S. 537,1C-537,2A.

42 Horaz: Sämtliche Werke (Anm. 39), S. 386, V. 46-50.

43 Humanistische Lyrik (Anm. 34), S. 94-96, V. 157-162. 
Das Zauberritual wird in ein Missverständnis überführt. Die umbra bezeichnet nicht etwa antikisierend die Seele eines Toten, sondern tatsächlich den Schatten des umherschleichenden Konkurrenten (corporea figura). Anders als ein Geist, der - vom Zauber ,gezwungen' - Antwort geben müsste, schweigt der Mensch aus Fleisch und Blut, während das Geräusch der Türangel an seiner statt Auskunft darüber gibt, dass der Beschwörer es eben mit einem Menschen zu tun hat, der auf ein Tor angewiesen ist. Mag damit auch das Gedicht in der halb komischen, halb elegischen Szene zweier Nebenbuhler vor der Tür der Geliebten enden, so ist damit das Zauberritual doch nicht entwertet. $\mathrm{Ob}$ das lyrische Ich tatsächlich Adept eines Magiers ist und selbst Hexerei betreibt, lässt sich aus dem Gedichttext nicht entscheiden. Insofern ist Wiegand Recht zu geben, der sich dezidiert gegen die Forschungsmeinung ausspricht, Celtis habe Magie stets eindeutig komisiert oder ironisiert. ${ }^{4}$ Ich würde sogar noch weitergehen: In Elegie I,14 wird ein Zauber, indem er den Nebenbuhler vertreibt und insofern seinen Zweck erfüllt, so nahe am Gelingen gezeigt, wie es literarisch möglich war, wollte man nicht wie Celtis' Freund, der Sponheimer Abt Johannes Trithemius, in den Ruch kommen, selbst Schwarze Kunst zu betreiben. ${ }^{45}$ Zur Hexerei im engeren Sinne ist noch ein weiterer Text des Schweinfurter Dichters heranzuziehen, eines von vier Epigrammen, die sich mit Zauberei beschäftigen. ${ }^{46}$ Und in diesem Fall scheint die Deutung zunächst weniger problematisch.

\section{De hydromantica submersa}

Thessala fatidicas effudit flumine ceras,

Et variis formis docta natare iubet.

Ex illis potuit cunctis praedicere fata,

Praeterito et gestum tempore quidquid erat.

Illa tamen potuit proprium non cernere fatum,

Dum culeo tumidis clausa periret aquis. ${ }^{47}$

Von einer Hydromantin, die ertrank

Eine thessalische Hexe gab wahrsagende Tafeln ins Wasser und befahl ihnen, kundig, in verschiedenen Zeichen zu schwimmen. Aus ihnen konnte sie jedem das Schicksal vorhersagen und alles bestimmen, was in der Vergangenheit geschehen war. Aber sie konnte nicht ihr eigenes

44 Zugleich konzediert Wiegand, dass dies in anderen Gedichten durchaus der Fall sein kann; vgl. Wiegand: Konrad Celtis (Anm. 39), S. 316f. sowie die von ihm diskutierte Forschung.

45 Vgl. dazu immer noch das Standardwerk von Klaus Arnold: Johannes Trithemius (14621516). Zweite, bibliographisch und überlieferungsgeschichtlich neu bearbeitete Auflage. Würzburg 1991, hier S. 180-200; ferner Noel L. Brann: Trithemius and Magical Theology. A Chapter in the Controversy over Occult Studies in Early Modern Europe. Albany, NY 1999.

46 Vgl. Fünf Bücher Epigramme von Konrad Celtes. Hrsg. von Karl Hartfelder. Ndr. Hildesheim 1963: 1,$43 ; 2,16 ; 2,73 ; 3,37$.

47 Zitiert nach: Fünf Bücher Epigramme (Anm. 46), S. $36(2,60)$. 
Schicksal erkennen, bis sie, in einen Sack eingeschnürt, in den tobenden Fluten zugrundeging.

Die bittere Pointe des Epigramms ist deutlich: Eine aus dem Wasser wahrsagende Hexe kann ihr eigenes tödliches Schicksal nicht voraussagen, was die prägnante Wortwiederholung von potuit (V. 3 und 5) sowie der Formen von fatum (V. 3 und 5) unterstreicht. Zudem ist die Technik der Hydromantie hinreichend genau beschrieben, um nahezulegen, dass die Zauberin tatsächlich Schwarze Magie ausübt. ${ }^{48}$ Zugleich verweist der letzte Vers jedoch auf eine schon aus vorchristlicher Zeit überlieferte, in der Frühen Neuzeit gelegentlich noch bei Voruntersuchungen in Hexenprozessen angewandte Kaltwasserprobe (euphemistisch auch "Hexenbad“ genannt), ${ }^{49}$ bei der die ertrunkene Person gerade vom Verdacht der Hexerei exculpiert wurde. Insofern dürfte die submersa eben keine echte hydromantica sein. Doch die Verwendung des culeus im letzten Vers deutet wiederum eher auf das Säcken, eine Art der Todesstrafe, die vor allem bei Mörderinnen Anwendung fand. Befragt man also das Epigramm über den Wirklichkeitsstatus der dargestellten Magie, bleibt dieser letztlich ebenso unklar wie in der Elegie der Amores und bildet damit womöglich eine argumentative Unschärfe des Hexendiskurses insgesamt ab: Unklar unter den Dämonologen blieb, bzw. je nach argumentativer Erfordernis unterschiedlich bewertet wurde, ob der Teufel tatsächlich in die Gefüge von Natur, Kausalität und Substantialität verändernd eingreifen könne oder ob er (so die Behauptung seit Augustinus) bei seinen Anhängern wie Opfern nur Sinnestäuschungen erzeugen könne. ${ }^{50}$

Zumindest erwähnt sei auch der Pfälzer Rat und europaweit gefeierte Dichter Paul Schede, genannt Melissus (1539-1602). Zwei Gedichte, die eindeutig und apotropäisch gegen Hexen gerichtet sind, erschienen 1595 in seiner Sammlung Meletemata Pia. Die Forschung hat sie plausibel in die Zeit der seit Februar 1595 währenden langen Krankheit Schedes eingeordnet, ${ }^{51}$ einer Extremsituation,

48 Vgl. systematisch Delrio: Disquisitiones (Anm. 6), S. 543,2A-545,1A (lib. 4, cap. 2, quaest. 6, sect. 3).

49 Peter Dinzelbacher: Das fremde Mittelalter. Gottesurteil und Tierprozess. Essen 2006, S. 35f. - Letztlich stellt diese Kaltwasserprobe ihrerseits eine Art Hydromantie dar, wie Johann Georg Krünitz in seiner Encyklopädie lakonisch vermerkt: Oekonomische Encyklopädie, oder allgemeines System der Staats- Stadt- Haus- u. Landwirthschaft, in alphabetischer Ordnung, Bd. XXVII. Berlin: Pauli 1783, S. 479. - Selbst unter den affirmativen Dämonologen war sie übrigens umstritten, Delrio etwa lehnte die Wasserprobe als "deutsche Unsitte“ ab (Delrio: Disquisitiones [Anm. 6], S. 637,1B-641,2A).

50 Siehe dazu die primär philosophischen Überlegungen von Maximilian Bergengruen: Genius malignus. Descartes, Augustinus und die frühneuzeitliche Dämonologie. In: Unsicheres Wissen. Skeptizismus und Wahrscheinlichkeit 1550-1850. Hrsg. von Carlos Spoerhase, Dirk Werle und Markus Wild. Berlin, New York 2009, S. 87-108, hier v.a. S. 98-103.

51 Wilhelm Kühlmann: Poetische Hexenangst - Zu zwei Gedichten des pfälzischen Humanisten Paul Schede Melissus (1539-1602) und ihrem literarischen Kontext. In ders.: Vom Humanismus zur Spätaufklärung. Ästhetische und kulturgeschichtliche Dimensionen der 
in der sich die existenzielle Angst vor Schadenszauber aus dem Munde eines (vermeintlich) Betroffenen äußert. Solch' offene Aussprache des kurfürstlichen Hof- und Bibliotheksrates entbehrten nicht der Brisanz, galt doch die Pfälzer Regierung im späten 16. Jahrhundert als dem sog. ,Hexenwahn' gegenüber weitgehend resistent, was zum Einen mit bestimmten Rechtsauffassungen des Rates, zu Anderen auch mit dem Einfluss prominenter Gegner der Verfolgungen, wie Johannes Weyer oder Hermann Witekind, ${ }^{52}$ zusammenhing. Nichts davon bei Schede, dessen alkäische Ode gerade in der ,frommen' calvinistischen Kurpfalz das Wirken von Giftmischern beklagt und sich selbst samt seiner Manneskraft als Opfer von Schadenszauber und Pharmaceutria präsentiert. ${ }^{53}$ Ich möchte hier kurz das zweite Hexengedicht zitieren, an dessen Eingang sich Kontraste und Bezüge zu den bisher vorgestellten Gedichten ablesen lassen: ${ }^{54}$

In veneficarum sagarumque incantamenta. \& Christianae fidei ejerationes. Carmen VIII

Dira monstra veneficæ noxiosaque sagae

Turba, quae magicis nigri Ditis artibus usae

Nemini prope parcitis; quid lucrive bonive

Ex mala capitis technâ? Vos tenella puellûm

Membra, tum juvenum \& senum fascinare suëstis 5

Corda.

Gegen die Zaubergesänge der Giftmischerinnen und Hexen sowie das Abschwören vom Christlichen Glauben. Achtes Gedicht

Gräßliche Scheusale seid ihr Giftmischerinnen und eine verderbliche Schar ihr Hexen, die ihr euch der magischen Künste des finsteren Höllenfürsten bedient und beinahe niemanden verschont; welchen Gewinn,

frühneuzeitlichen Lyrik und Verspublizistik in Deutschland. Hrsg. von Joachim Telle, Friedrich Vollhardt und Hermann Wiegand. Tübingen 2006, S. 323-340, hier S. 330f.

52 Johannes Wierius: De praestigiis daemonum, et incantationibus, ac veneficijs libri V. Basel 1563 u.ö.; Augustin Lerchheimer [i.e. Hermann Wilken, alias Witekind]: Christlich bedencken und erinnerung von Zauberey. Heidelberg 1585 u.ö. Über Witekind siehe Otto Ulbricht: Der sozialkritische unter den Gegnern: Hermann Witekind und sein Christlich bedencken vnd erjnnerung von Zauberey von 1585. In: Vom Unfug des Hexen-Processes. Gegner der Hexenverfolgung von Johann Weyer bis Friedrich Spee. Hrsg. von Hartmut Lehmann und dems. Wiesbaden 1992, S. 99-128. - Auf der anderen Seite hatte der herzogliche Leibarzt Thomas Erastus in seiner Disputatio de Lamiis seu Strigibus (1572) scharf Position für die tödlichen Hexenprozesse bezogen, konnte sich aber letztlich nicht durchsetzen; vgl. dazu H.C. Erik Midelfort: Witch Hunting in Southwestern Germany 1562-1684. The Social and Intellectual Foundations. Stanford, CA 1972, S. 56-58.

53 Vgl. die Ode mit deutscher Übersetzung und Kommentar in Humanistische Lyrik (Anm. 34), S. 850-853.

54 Zitiert mit leichter Modifikation der Übersetzung nach Kühlmann: Poetische Hexenangst (Anm. 51), S. 340f., V. 1-6. 
welchen Nutzen zieht ihr aus eurer üblen Kunst? Ihr pflegt der Knaben zarte Glieder und überdies die Herzen junger und alter Männer zu verhexen.

Weder von der kühnen Selbstermächtigung mittels magischer Verrichtungen noch von der bitterbösen Ironie eines Conrad Celtis ist hier etwas zu finden. Ein Opfer magischer Künste flucht auf die Hexen und stellt ihnen im weiteren Verlauf des Gedichtes ewige Höllenstrafen in Aussicht. Die Membra (V. 5) dürften wiederum auf die Impotenz des Sprechers gemünzt sein, eine Wirkmacht des Schadenszaubers, die bereits im Malleus maleficarum und generell in dämonologischer Literatur ausführlich thematisiert wurde. ${ }^{55}$ Wichtiger als die Bezüge zum Sachschrifttum scheint mir aber die seltene metrische Form des Poems zu sein, der allenfalls aus Catull geläufige Priapeus, zu dem sich die hier und in den folgenden 38 Versen beachtliche Anzahl von Flüchen und Beschimpfungen gegen die Hexen fügt. Inhaltliche Beziehungen zu Catull oder der Appendix Vergiliana scheinen weniger ergiebig als die Vermutung, dass Priapus gleichsam als Gegenmittel gegen die versehrte Manneskraft gelten soll, freilich um des decorums willen lediglich metrisch greifbar wird. ${ }^{56}$ Doch gerade bei dem HorazKenner und -Aemulator Schede scheint mir ein Bezug zur oben erwähnten achten Satire des Venusiners wahrscheinlich. Wie dort soll auch hier der potente Gartengott schließlich die Hexen vertreiben. So erst geraten die incantamenta (Titel) zu Trägern eines Gegenzaubers, dem freilich jedes Spottgelächter des horazischen sermo fern liegt.

Überdies wandelt sich das Gedicht von den Klagen eines persönlich Betroffenen über die Aufzählung diverser Schadenszauber (V. 7-20) zu einer bitteren Anklage an die Zauberinnen als Teufelsbündler:

\section{Pacta turpia inistis}

Cum manu Cacodaemonum sonte, foedifragaeque

Desciistis ab optimo maximoque JEHOVA,

Lubricâ instabiles fide, pravitate rebelles.

Abnegastis item sacri jura sancta lavácri,

Infideliter a DEI filio, duce nostro,

Castra in hostica transfugae; nequiter quibus ipsam

55 Johannes Trithemius etwa widmete das gesamte vierte Buch seines gegen Hexerei gerichteten Traktats Antipalus maleficiorum (1508) ausschließlich der Frage nach einer durch Schadenszauber induzierten Impotenz und ihren Heilmöglichkeiten; vgl. Arnold: Johannes Trithemius (Anm. 45), S. 196f. mit der dort genannten Literatur. - Delrio bringt das Beispiel eines durch Schadenszauber Impotenten, der wiederum von einem Magier kuriert wird, vgl. Delrio: Disquisitiones (Anm. 6), S. 925,2B-926,1C.

56 So Kühlmann: Poetische Hexenangst (Anm. 51), S. 335. 
Vitam, \& ipsam animam rato pignori opposuistis, Perfidumque Satanico stigma ab ungue recepistis. ${ }^{57}$

Üble Pakte habt ihr geschlossen mit der grausen Schar böser Dämonen. Den [alten] Vertrag gebrochen habt ihr und euch losgesagt vom gütigsten und höchsten JEHOVA, ihr Aufrührer in eurem schwankenden Glauben und eurer Verdorbenheit! Ihr habt die unantastbaren Gesetze der heilige Taufe verleugnet, indem ihr treulos von GOTTES Sohn, unserem Herrn, ins Lager des Feindes übergelaufen seid, in nichtswürdiger Weise diesem Leben und Seele verpfändet und von der Klaue Satans ein schändliches Mal empfangen habt.

Dies stellt nun einen wichtigen Zusatz dar, den der Jurist Schede sicherlich absichtsvoll so stark betont hat: Durch den Teufelsbund, der gleich mehrfach und teils drastisch mit den „Klauen Satans“, die ein Kainsmal aufgeprägt haben, umschrieben wird (V. 20, 24, 26f.), werden die zunächst als schädliche Zauberinnen weltlich belangbaren Frauen obendrein zu Ketzerinnen (V. 23: rebelles!), die ebenso von geistlicher Gerichtsbarkeit verfolgt werden müssen. Mit dieser starken Betonung des häretischen Status' der Hexen, den auch zeitgenössische dämonologische Traktate immer wieder herausstellten, verlässt Schede sichtlich das Feld antikisierender Aemulatio, wie sie für die Pharmaceutria-Eklogen prägend war, und positioniert sich im Hexerei-Diskurs seiner Gegenwart. Bemerkenswert muss angesichts dessen jedoch erscheinen, dass Schede am Schluss des Gedichts tatsächlich eine Möglichkeit der Rettung für diese „verkommenste Schar" formuliert:

Si DEUM tamen, o manus perditissima, vestri

Vel parum miseresceret; gratiâ illius unâ

Entheam bene posse vos obtinere salutem

Dico, \& aetheriâ dehinc porró sede potiri. ${ }^{58}$

Wenn GOTT dennoch mit euch, ihr verkommenste Schar, nur ein wenig Erbarmen hat, dann könnt ihr allein durch seine Gnade auf gute Weise das Heil der Gottesnähe erlangen und künftig in die himmlische Wohnstatt einziehen. Das verkünde ich euch.

Im calvinistischen Kontext kann es nur die Gnade Gottes sein, durch welche die Hexen noch zu retten wären. Wilhelm Kühlmann hat m.E. zu Recht in der merkwürdigen Formulierung von Enthea salus (V. 47) und aetheria sedes eine hin-

57 Zitiert nach Kühlmann: Poetische Hexenangst (Anm. 51), S. 340f., V. $20-28$ unter leichter Modifikation der deutschen Übersetzung.

58 Zitiert nach Kühlmann: Poetische Hexenangst (Anm. 51), V. 45-48 unter leichter Modifikation der deutschen Übersetzung. 
tersinnige Pointe vermutet: ${ }^{59}$ Die Hexen steigen insofern in die Lüfte und nähern sich demzufolge Gott an, indem sie als Ketzer verbrannt werden. Das selbstbewusste Dico im letzten Vers führt somit die konsequente Verfluchung der Zauberinnen durch eines ihrer Opfer zu einem konsequenten Schluss- und Höhepunkt.

\section{Zwei barocke Hexengedichte des Johannes Bisselius SJ.}

In wiederum ganz anderem Ton sind dagegen jene beiden Elegien verfasst, die nun im Mittelpunkt stehen sollen. Verfasst hat sie in den 1630er Jahren der oberschwäbische Jesuit Johannes Bisselius (Bislin; 1601-1682), Gymnasiallehrer in Regensburg, nach der Besetzung der bayerischen Pfalz durch kaiserliche Truppen Ethik-Professor in Ingolstadt, wo zeitgleich Jacob Balde Poesie unterrichtete. Wie dieser bekleidete er, freilich nur ein Jahr lang, das Amt des Hofhistoriographen in München. Obwohl seine Tätigkeit durch viele Ortswechsel und längere Krankheiten beeinträchtigt war, konnte Bisselius nicht nur eine beeindruckende Zahl von umfangreichen historischen Werken veröffentlichen, sondern eben auch Dichtungen. 1638 erschienen seine Deliciae Veris („Frühlingsfreuden“) als erster Teil eines den gesamten Jahreslauf abschreitenden Zyklus', von dem der Autor allerdings nur noch den zweiten Teil (Deliciae Aestatis, 1644) vorlegte, bevor ihn die Geschichtsschreibung bis an sein Lebensende absorbieren sollte. ${ }^{60}$

Ausschließlich aus Elegien bestehend, weisen die Deliciae Veris eine selbst für einen Jesuitendichter bemerkenswerte Breite an Themen auf, von der Verarbeitung volkssprachlicher Schwankliteratur über biblische und kirchengeschichtliche Sujets bis zu expliziten Hagiographica und sinnlich ansprechenden Naturgedichten. Nur plane Jahreszeiten- und Feiertagsdichtung in der Imitation der Fasti Ovids oder Ludovico Lazzarellis vermeidet Bisselius offenbar bewusst. Die beiden hier interessierenden Gedichte folgen direkt aufeinander, finden sich jedoch an einem Ort, wo man sie nicht vermuten würde, nämlich in einem Segment, das mit Otia et Lusus (Mußestunden und Spiele) und einem Bibelzitat (Hiob 21) überschrieben ist: „Ihre Jungen gehen aus wie eine Herde, und ihre Kinder hüpfen und spielen; halten Pauken und Harfen, und freuen sich beim Klange der Pfeifen. Sie bringen ihre Tage in Wohlleben zu etc. " 61 Die folgende neunte Elegie des dritten Buches knüpft direkt daran an, wenngleich ihr Titel

59 Kühlmann: Poetische Hexenangst (Anm. 51), S. 338: ,_...] bleibt für die [...] Unholde allenfalls die Hoffnung auf Gottes Erbarmen - zu ergänzen: nach ihrem verdienten Tod durch den irdischen Henker."

60 Ausführlicher zu Bislins hier nur knapp skizziertem Leben siehe die Einleitung in Johannes Bisselius: Deliciae Veris - Frühlingsfreuden. Lat. Text, Übersetzung, Einführungen und Kommentar. Hrsg. von Lutz Claren, Jost Eickmeyer, Wilhelm Kühlmann, Hermann Wiegand u.a. Berlin, Boston 2013, S. 4-17; bibliographisch flankierend dazu: Philipp Weiß, Alexander Winkler: Der Dichter und Historiker Johannes Bisselius SJ (1601-1682) - Ein personalbibliographischer Überblick. In: Humanistica Lovaniensia 61 (2012), S. 482-510.

61 Zitiert nach Bisselius: Deliciae Veris (Anm. 60), S. 293. 
(„Ein unheilvoller Spaziergang, der in Donnerschlägen und verzaubertem Hagel endete") bereits irritiert. Zunächst beschreibt der Autor aber einen geselligen Maispaziergang, der dem Leser die jungen Jesuitenzöglinge plastisch vor Augen stellt:

Mecum aequaeva cohors, non una matre, sed una

Gente, sati comites, Nisus et Euryalus:

Tum Lupus, et Trebulus, Lepidúsque, et Marcus, et Anser;

ANSER plus centum garrulus anseribus.

10

In manibus citharae, fatuóque tonantia bombo

Tympana; qui pictos tantùm animaret equos.

Pascua contigimus. Pastorem turba sequuntur

Omnis: et in modulos LVDICRA Musa coit.

Ludebam Mopsum; comites lusêre Menalcam:

Vox pastoris erat; Iô! Meliboee, DEVS! ${ }^{62}$

Mit mir ging ein Grüppchen von Männern meines Alters: Die Gefährten Nisus und Euryalus, nicht von einer Mutter geboren, doch aus einer Familie, dann Lupus, Trebulus, Lepidus, Marcus und Anser (ANSER, der geschwätziger ist als hundert Gänse). In Händen hielten wir Lauten und Tamburine, die mit ihrem drögen Dröhnen sogar gemalte Pferde hätten antreiben können. Wir kamen zum Weideland. Die ganze Herde folgte dem Hirten, und die LEICHTE Muse vereinte uns in fröhlichen Liedchen. Ich spielte den Mopsus, meine Gefährten den Menalcas. Der Hirtenruf schallte: „Oh Meliboeus, ein GOTT!“

Die teils bukolischen Musikinstrumente sowie die Nennung der wie auch immer verschlüsselten Namen erzeugen den Eindruck ungezwungener Privatheit und verweisen womöglich im autobiographischen Rückgriff auf eine gesellige Praxis jesuitischer Bildungseinrichtungen. Wenn gegen Ende des Zitates auch Hirtennamen aus der Tradition der Schäferdichtung - namentlich Vergils fünfter Ekloge - fallen, wähnt man sich gänzlich in der idyllischen Sphäre augusteischer Bukolik. Bezeichnend für Bisselius' souveränen Umgang mit der Tradition der Hirtendichtung, der sich die Elegie somit zunächst annähert, wirkt das Ludebam (V. 15), das nicht nur ein durchaus plausibles Hirtenspiel der jungen Jesuitenzöglinge evoziert, sondern eben auch Bisselius' Fähigkeit betont, hier bukolische Szenerien spielerisch zu entwerfen.

Dann jedoch schlagen Stimmung und Wetter um, ein ungeheures Hagelwetter bricht los, dem die jungen Leute kaum unverletzt entkommen und das jedenfalls die umliegenden Fluren und Felder verwüstet (V. 16-31). Die Ursache solch' unverhoffter Zerstörung ist am folgenden Tag ausgemacht und ordnet das Gedicht urplötzlich der Hexendichtung zu:

62 Zitiert nach Bisselius: Deliciae Veris (Anm. 60), S. 292f. 
Vix bene reddiderat totum lux postera Solem:

Accusatur Anus; Brullia nomen erat.

Brullia convicta est, primi sub lumina Phoebi,

Sollicitè varias circumijsse fores:

Brullia, lac quaesîsse recens, lactísque reperti

Sinum, in vicini rura tulisse Senis.

Vidêre et testes (quos non Maga viderat ipsa)

Confusum albenti rore natare solum:

Et (dictu infaustum, at strigibus notum atque Megaeris)

Fumum, post vetulae carmen, in astra rapi. ${ }^{63}$

Kaum hatte uns der nächste Tag die Sonne ganz und wohlbehalten zurückgebracht, klagt man eine Alte an; Brullia hieß sie. Brullia wurde überführt, im ersten Morgengrauen angelegentlich um verschiedene Türen herumgeschlichen zu sein; ferner, sich frische Milch beschafft und von dieser Milch einen Kübel auf das Land eines alten Nachbarn gebracht zu haben. Zeugen hatten, von der Hexe selbst unbemerkt, gesehen, wie die Erde, die sie damit begossen hatte, in weißem Tau schwamm: und sie sahen auch - es bringt schon Unglück, es nur auszusprechen, aber die Hexen und bösen Weiber wissen davon -, wie auf einen Zauberspruch der Alten Rauch zu den Sternen emporgezogen wurde.

Milchdiebstahl sowie der daran geknüpfte Schadenszauber des „Hagelsiedens“ gehören zu gängigen Vorwürfen dämonologischer Kompendien oder Wetterpredigten ${ }^{64}$ wie auch $\mathrm{zu}$ den Geständnissen in dokumentierten Hexenprozessen; ${ }^{65}$ gerade das diebische Abmelken hatte auch Paul Schede in seinem Priapeen-Gedicht den Zauberinnen zum Vorwurf gemacht. ${ }^{66}$ Das Abziehen des Rauches markiert - wie auch die antikisierende Bezeichnung Megaeris (V. 41) - intertextuelle Bezüge zu antiken Vorläufern. Der bukolische Anfang der Elegie wird nun durch eine ganz andere Wendung als bei Theokrit, Sannazaro oder Bocer mit dem Motiv der Zauberei verknüpft. Kein bloß im Lied vergegenwärtigter Liebeszauber begegnet hier, sondern ein mit aller Gewalt wirkender ländlicher Schadenszauber. So vorbereitet, wird der Leser in den abschließenden beiden

63 Zitiert nach Bisselius: Deliciae Veris (Anm. 60), V. 34-42.

64 Delrio führt eine solche Handlung, allerdings mittels einer Schale Wassers, unter Berufung auf Sprengers und Institoris' Malleus an, vgl. Delrio: Disquisitiones (Anm. 6), S. 747,1B-E. Zum frühneuzeitlichen Verhältnis von Magie, praktischer Moral und Gewitter siehe den luziden Essay von Heinz-Dieter Kittsteiner: Das Gewissen im Gewitter. In ders.: Gewissen und Geschichte. Studien zur Entstehung des moralischen Bewußtseins. Heidelberg 1990, S. 25-65, hier zur Kontroverse ums „Hagelsieden“ S. 38f.

65 Entsprechende „Urgichten“ aus unterdessen gut erschlossenen Prozessakten führt Kühlmann in seinem Kommentar zu Bisselius' Elegie an: Bisselius: Deliciae Veris (Anm. 60), S. $646 f$.

66 Vgl. Kühlmann: Poetische Hexenangst (Anm. 51), S. 340f., V. 10-13. 
Distichen geschickt zum Mitwisser gemacht, der das notwendig folgende Todesurteil über die Hexe nur bestätigen kann:

An dubitemus adhuc, quin juncta volaverit ipsa, Fumosae vires distulerítque trahae?

Certè, Anus est confessa scelus. Tam noxia fassam

Medeam, in nubes Furca (sed Vsta) tulit. ${ }^{67}$

Sollen wir da noch bezweifeln, dass sie zugleich auch selbst mitgeflogen ist und die Kräfte der rauchigen Dreschgabel verbreitet hat? Es ist gewiss, die Alte gestand ihr Verbrechen. Diese Medea, die so große Schuld bekannt hatte, hob dann eine Gabel (aber eine verbrannte) zu den Wolken.

Gerade die suggestive erste Person Plural soll auch beim Leser jede Zweifel an der Wirklichkeit dieser Hexerei vertreiben. Prozess, Vernehmung, eventuell Folterung und Urteil werden von Bisselius in einem Distichon maximal verdichtet. ${ }^{68}$ Als geradezu bösartige Lakonik, die Paul Schedes oben zitierten Gedichtschluss mühelos überbietet, kann die sinnreiche Verknüpfung gelten, in der ein angeblicher Hexenflug auf der fumosa traha (V. 44) mit dem letztlichen ,Aufflug' der verurteilten Hexe, nun aber an einer „verbrannten Gabel“ (V. 46), nämlich dem Stamm, an dem sie auf dem Scheiterhaufen gefesselt ist, steht. Von den Einwänden, die zeitgleich in Bayern, wo sich auch diese Jugenderinnerung des Bisselius zumindest fiktional abgespielt haben dürfte, Adam Tanner als Ordensgenosse des Autors vehement gegen die Hexenprozesse erhob, ${ }^{69}$ ist in diesem Gedicht nichts zu spüren. Womöglich ist es sogar als ausdrückliche Einrede gegen Tanners Position zu lesen.

Die folgende ungleich längere Elegie lässt unter dem unverdächtigen Titel „Ein Bäcker im Mehl“ nichts weniger als ein Hexengedicht erwarten, obendrein eines, das, wenn nicht in der generellen Aussage, so doch in Stil und Tonlage ganz anders geartet ist. Bisselius versieht es, wie viele seiner Gedichte in der Sammlung, mit einem Prosa-Vorspann, der für die Authentizität des Geschilderten wichtig ist. Es fasst zunächst die Handlung kurz zusammen: Ein Bäckerge-

67 Zitiert nach Bisselius: Deliciae Veris (Anm. 60), S. 292f., V. 43-46.

68 Zum Ablauf eines solchen, bekanntlich oftmals sehr gewaltsamen Verfahrens verweise ich nur auf die materialreiche und gut lesbare Darstellung bei Lyndal Roper: Witch Craze. Terror and Fantasy in Baroque Germany. New Haven, London 2004, S. 44-66.

$69 \mathrm{Zu}$ Adam Tanners Leben und Werk, soweit es die Diskurse um Magie und Hexerei betrifft, siehe Johannes Dillinger: Friedrich Spee und Adam Tanner. Zwei Gegner der Hexenverfolgung aus dem Jesuitenorden. In: Spee Jahrbuch 7 (2000), S. 31-58, mit weiterer Literatur; zu Tanners Eintreten für den ebenfalls als Schwarzmagier inkriminierten Trithemius siehe immer noch Anton Dürrwächer: Adam Tanner und die Steganographie des Trithemius. In: Hermann Grauert zur Vollendung des 60. Lebensjahres, gewidmet von seinen Schülern. Festgabe zum 7. September 1910. Hrsg. von Max Jansen. Freiburg 1910, S. 354-376. 
selle beobachtet nächstens seine Dienstherrin Pulta (gleich eingangs als Canidia bezeichnet) dabei, wie sie sich mit Hexensalbe einreibt und mit Hilfe einer Zauberformel zum Hexenflug ausfährt. Neugierig geworden, versucht er auch von der Salbe, kann aber die Zauberformel nicht mehr reproduzieren und behilft sich mit einem anderen Vers. Doch die Salbe, doppelt aufgetragen, wirkt immerhin, und so erhebt er sich halb in die Lüfte, wobei er in den mehlbestäubten Backtrog stürzt. Nach abermaligem Murmeln der falschen Formel erhebt sich der auch ein wenig gesalbte Trog samt dem unglücklichen Gesellen in die Lüfte und fliegt über Land. Nur die im Affekt gestammelte Anrufung Christi entkräftet den Zauber, sodass der verhinderte Zauberer samt Trog in ein Sumpfgebiet stürzt. Nach längerem Rückmarsch zeigt er die Hexe an. Wichtig ist nun der Nachsatz, mit dem Bisselius diese halb komische Hexengeschichte abschließt:

sui similibus Exemplum non fabulosum futurus; Ne LVSVM tentent, quem sine scelere nemo didicit, sine Numinis ira nemo exercuit, sine flamma (vel mortali vel immortali) nemo expiavit. ${ }^{70}$

ein nicht erdichtetes Beispiel für Seinesgleichen. damit sie sich nicht an einem ,SPIEL'versuchen, das noch niemand ohne ein Verbrechen erlernte, niemand ohne Gottes Zorn ausübte, niemand ohne das Feuer (ob irdisch oder ewig) sühnte.

Die Formulierung non fabulosum deutet auf einen zumindest für den Dichter empirischen Grund der Erzählung, der im Sinne der gattungstheoretischen Dyade von fabula und historia (wichtig u.a. für die Roman-Diskussion der Frühen Neuzeit ${ }^{71}$ ) das Geschehen als authentisch bekräftigt. Zugleich schlägt die hier formulierte Warnung vor einem nur scheinbar unernsten „Spiel“ die Brücke zur Thematik des Titels über dem gesamten Kapitel.

Unabhängig von dieser Beglaubigungsstrategie ist anzumerken, dass die Ausgangssituation für den versuchten Hexenflug, nämlich die nicht ohne erotischen Beiklang geschilderte Beobachtung der Zauberin durch einen Türspalt, einen unmarkierten intertextuellen Bezug zu den Metamorphosen des Apuleius darstellt, wo die ohnehin verdächtige Pamphile ebenfalls von Bediensteten bei ihrem zauberischen Treiben beobachtet wird (zitiert nach der Übersetzung von Rudolf Helm):

[...] und heißt mich durch eine Türritze beobachten, was dort in folgender Weise vor sich ging: Zunächst entkleidet sich Pamphile aller Gewänder, schließt eine kleine Truhe auf und entnimmt daraus mehrere Büchsen;

70 Zitiert nach Bisselius: Deliciae Veris (Anm. 60), S. 294f.

71 Siehe dazu Stefan Trappen: Fiktionsvorstellungen in der Frühen Neuzeit. Über den Gegensatz von „fabula“ und „historia“ und seine Bedeutung für die Poetik. Mit einem Exkurs zur Verbreitung und zur Deutung von Laktanz: Divinae institutiones I 11, 23-25. In: Simpliciana 20 (1998), S. 137-163; Rosmarie Zeller: Fabula und Historia im Kontext der Gattungspoetik. In: Simpliciana 20 (1998), S. 49-62. 
von einer von ihnen entfernt sie den Deckel und holt daraus eine Salbe, die sie lange in ihren Händen reibt; dann bestreicht sie sich ganz und gar von den Zehenspitzen bis zu den Haaren, spricht im Geheimen viel mit der Lampe und schüttelt in zitternder Bewegung ihre Glieder. Und während sie in sanfter Schwingung sich wiegen, sprießt zarter Flaum hervor [...]. Pamphile wird zum Uhu [...], dann hebt sie sich in die Höhe und fliegt mit mächtigen Flügelschlag hinaus. ${ }^{72}$

Bei Bisselius wird freilich die Verwandlung in einen Vogel durch die Gabel als Fluggerät ersetzt, welche in einschlägigen Berichten der Frühen Neuzeit ebenso anzutreffen ist wie auf unzähligen bildkünstlerischen Darstellungen, etwa den Hexen-Zyklen eines Hans Baldung Grien.

Zum Abschluss soll noch die Repräsentation magischen Wissens in dieser Elegie genauer betrachtet werden. Sie unterscheidet sich wesentlich von den akkumulierten ,literarischen' magischen Praktiken in frühneuzeitlichen Pharmaceutria-Eklogen, deren Motivarsenal mehr oder minder aus antiken und zeitgenössischen Prätexten geschöpft war. Wie verhält es sich nun bei Bisselius mit den Passagen, die sich mit der Zauberformel befassen? Anders als die meisten Dämonologen und Autoren von Teufelsbüchern scheut sich Bisselius nämlich nicht, die magischen Worte der Hexe anzuführen. Er muss ja den komischen Effekt vorbereiten, der entsteht, wenn der Bäckergeselle die Formel zu ersetzen sucht:

Oblita, carminibus lenit: furcáque prehensâ; Furca, per has, per eas, (inquit) abito vias!

Ecce tibi! erupit; celeríque volumine vecta, Iam non visa fuit, quae modò visa fuit. ${ }^{73}$

Die Glieder, die beschmiert waren, lullt sie mit Gesängen ein und ergreift die Gabel: "Gabel“ (sprach sie), „trag mich dahin auf diesen, auf jenen Wegen!“ Sieh nur, sie steigt auf, und im schnellen Bogen empor getragen, ward sie, die eben noch sichtbar war, schon nicht mehr gesehen.

Durch Wortwiederholung und vor allem den mehrfachen Binnenreim auf ",-as" imitiert Vers 20 mehr eine Zauberformel, als dass der Leser sie für eine tatsächliche halten dürfte. Der vom Alkohol benebelte Verstand des Bäckergesellen hat freilich nur den optischen, nicht den akustischen Eindruck der magischen Praktik aufnehmen können:

Sola recordatur nondum bene Thessala verba:

Haeret, et haerentem linguáque vóxque fugit.

72 So auch im Kommentar Bisselius: Deliciae Veris (Anm. 60), S. 649.

73 Zitiert mit leichter Modifikation nach Bisselius: Deliciae Veris (Anm. 60), S. 296f., V. 19-22; Kursivierung im Original. 
Mox recipit vocem; Non sunt Alemannica (fatur)

Quae modò praefata est verba volucris hera.

Quidquid id est, utcunque fuit; sint verba Latina!

Qualiacunque loquar grammata docta, juvat.

Ergò linens iterum, priùs oblitus unguine, membra, 35

Stipite sese armat: jámque vehendus, ait;

Pinsitus, ac Pistus, Pinsúsque a Pinsuit, Exi!

(Has docuit voces Emmanuelis Opus,

Has olim puer, has juvenis, tradente magistro,

Cognôrat: factus Pistor, in ore tulit. $)^{74}$

Allein an die ,thessalischen' Worte erinnerte er sich noch nicht recht. Er stockt und, während er stockt, schwinden Laut und Stimme. Bald kann er wieder sprechen: „Es sind keine deutschen Worte“ (sagte er), „die eben die fliegende Herrin aussprach. Was auch immer es ist und wie auch immer es war, es sind wohl lateinische Worte. Es hilft alles, was ich an gelehrten Buchstaben ausspreche." Also ergreift er, indem er die Glieder wiederum salbte, obwohl er sie schon vorher gesalbt hatte, einen Stab und spricht, schon bei der Abfahrt: „Zerstoßen, zerstampft und gemahlen von ,er hat gemahlen', komm heraus!" (Diese Formen hatte ihn das Werk des Emmanuel gelehrt, Bezeichnungen, die er teils als Knabe, teils als junger Mann aus dem Munde seines Lehrers kennengelernt hatte; als er Bäcker wurde, führte er sie ständig im Munde.)

Die Passage bezieht ihre komische Wirkung nicht nur aus dem eher schlichten Versuch des Gesellen, sich zu behelfen, und seinen Folgen, sondern auch aus der Parenthese. Denn der junge Mann ersetzt die magische Formel durch einen Merkvers aus der weit verbreiteten Grammatik des portugiesischen Jesuiten Manuel Álvarez, ${ }^{75}$ erweitert nur um den vermeintlich der Situation angemessen Imperativ Exi. Dass Bisselius nicht nur den Vers einsetzt, sondern auch die Quelle ausdrücklich benennt und im nächsten Vers fortfährt: „Doch die Worte vermochten nichts" (V. 41: Verba quidem valuêre nihil), mag man als ironische Spitze gegen den Kollegen und Schulmann lesen. Zugleich insinuiert der Autor jedoch, dass der Bäckergeselle einst Jesuitenzögling gewesen, der Schule aber ins Bäckerhandwerk entlaufen sein mag. Vor diesem Hintergrund bekommt die Warnung des Prosa-Vorspanns, die ja an "Seinesgleichen“ (s.o.) gerichtet ist, den Nebensinn, dass ehemalige oder gar derzeitige Jesuitenschüler vor der Versuchung der Zauberei nicht unbedingt gefeit sind.

74 Zitiert nach Bisselius: Deliciae Veris (Anm. 60), S. 296f., V. 29-40; Kursivierung im Original.

75 Manuel Álvarez: De institutione grammatica libri tres. Köln: Birckmann 1596, S. 250; zu diesem sehr verbreiteten Lehrbuch siehe das Lemma im Kommentar Bisselius: Deliciae Veris (Anm. 60), S. 653. 
In der Logik der Handlung mag ein skeptischer moderner Leser vermuten, dass der völlig betrunkene Bäckerlehrling zunächst die Backstube samt Trog verwüstet und dann im schweren Schlaf die Hexenausfahrt geträumt haben oder gar zur Rechtfertigung des Schadens erfunden haben könnte. Der Schluss des Gedichtes unterstützt zum Einen diese Skepsis, will sie aber sogleich in einer drastisch-lakonischen Wendung, die an die vorangegangene Elegie erinnert, ausräumen: In dubio mala caussa diu fuit: acta negabant. / Iudicium clarum postmodo Flamma dedit. - „Im Zweifel stand lange die böse Sache: Sie [i.e. Pulta und ihre Gefährtinnen] leugneten das Geschehene. Ein klares Urteil gab bald darauf das Feuer." ${ }^{\prime 76}$

Bisselius' so ganz eindeutige, beinahe grausame Position in der Hexenfrage, die weit von den Bemühungen seiner Zeit- und Ordensgenossen Adam Tanner, Friedrich Spee oder auch eines Johann Matthäus Meyfart entfernt ist, ${ }^{77}$ mag autobiographische Gründe haben. Im Nekrolog von 1682 findet sich die wohl auf eigene Angaben des Autors zurückgehende Nachricht, dass der kleine Johannes Nachstellungen einer Hexe ausgesetzt gewesen sei, vor denen ihn lediglich die Fürbitte seiner Mutter gerettet habe. ${ }^{78}$ Wie es sich damit auch verhalten mag, in den beiden zitierten Gedichten tritt uns eine deutlich andere (heutige Leser mindestens befremdende) Haltung entgegen als bei dem mit Magie und Hexerei mal spöttisch, mal poetisch ingeniös umgehenden Celtis oder bei dem aus der Perspektive des Opfers die Zauberei verwünschenden Schede Melissus. Als souverän auch mit den Traditionen der Pharmaceutria-Ekloge vertrauter Autor verurteilt Bisselius die Hexen, sinnt dieses Urteil auch seinen Lesern an oder nutzt die Schilderung einer Hexenausfahrt trotz komisierendem Ton zur Warnung vor zauberischem Unwesen.

76 Bisselius: Deliciae Veris (Anm. 60), S. 300f., V. 113f.

77 Umfassend und höchst instruktiv zu Meyfart und der zeitgenössischen kritischen Literatur zum Hexenprozesswesen Erich Trunz: Johann Matthäus Meyfart. Theologe und Schriftsteller in der Zeit des dreißigjährigen Krieges. München 1987, S. 211-244. - Speziell zu den Verhältnissen im katholischen Südwestdeutschland siehe ferner Midelfort: Witch Hunting (Anm. 52), S. 57-64.

78 HSA München, Jesuitica 1126: Historia Collegii Ambergensis S.J., hier S. 77r; abgedruckt in Bisselius: Deliciae Veris (Anm. 60), S. 738, zu Deutsch: „In seiner Kindheit entging er den Nachstellung von Hexen, da seine Mutter ein Gebet an die Heiligen richtete." 


\title{
Paradoxe Perspektiven \\ Zur Poetik des Wunderbaren in Grimmelshausens \\ Wunderbarlichem Vogel-Nest (1672/75)
}

\author{
Simon Zeisberg, Berlin
}

\section{1}

In ihrem Aufsatz zur Beziehung von „Wunder und Beweis“ zwischen Mittelalter und Früher Neuzeit rekonstruiert Lorraine Daston einen historischen Wandlungsprozess in der Auffassung des Wunderbaren, der von der Reformation bis in die frühe Aufklärung reicht. Der Bereich, in dem die außernatürlichen weltlichen Wunder angesiedelt sind - und der bis ins 18. Jahrhundert hinein in einer Flut von Wunderbüchern und magiologischen Schriften aller Art publizistisch präsent ist -, wird spätestens seit dem 16. Jahrhundert von zwei tiefgreifenden Prozessen der Ausdifferenzierung von Wissen erfasst: Auf der einen Seite führen Reformation und Konfessionalisierung dazu, dass das übernatürliche Wunder im christlichen Sinne vom außernatürlichen Wunder schärfer abgegrenzt wird - mit der Folge, dass das Außernatürliche „immer enger mit Magie und Wahrsagerei, also mit obskuren, möglicherweise dämonischen Praktiken in Verbindung gebracht" wird. ${ }^{1}$ Auf der anderen Seite mündet die in Scholastik und frühneuzeitlicher Naturphilosophie getroffene Unterscheidung von Natur und Außernatürlich-Wunderbarem in die Auslagerung fremder, unerklärlicher Phänomene aus dem Bereich der Natur. ${ }^{2}$ Das Außernatürlich-Wunderbare vor der Aufklärung lässt sich damit als doppelt liminale Kategorie beschreiben: Auf der einen Seite begrenzt vom Bereich des naturphilosophisch Zugänglichen - dem (Natur-)Wissen -, auf der anderen vom Bereich des Übernatürlichen - der Offenbarung - eignet ihm eine erkenntnistheoretische „Labilität“3, die Ausdruck seiner (tendenziellen) Uneinholbarkeit im Sinne epistemischer und religiöser Ordnungskonzepte ist. Bevor die unerklärlichen außernatürlichen Dinge im späten 17. und 18. Jahrhundert zum Gegenstand aufklärerischer Wissenschaft werden, bleiben sie Objekte des Staunens, oder - und dies ist im deutschsprachigen 17. Jahrhundert insgesamt wohl häufiger noch der Fall - es muss vor

1 Lorraine Daston: Wunder und Beweis im frühneuzeitlichen Europa. In dies.: Wunder, Beweise und Tatsachen. Zur Geschichte der Rationalität. Aus dem Englischen von Gerhard Herrgott, Christa Krüger und Susanne Scharnowski. Frankfurt a.M. 2001, S. 29-76, hier 36.

2 Daston: Wunder und Beweis (Anm. 1), S. 36.

3 Daston: Wunder und Beweis (Anm. 1), S. 38. 
ihnen als Medien dämonischer Täuschung und Natur-Manipulation gewarnt werden.

Betrachtet man das Außernatürlich-Wunderbare der Frühen Neuzeit unter diesen Voraussetzungen als stabil-instabile Grenzkategorie historischer Formationen des Wissens und Glaubens, so ergeben sich Fragen, die nicht nur die von Daston untersuchte ,Geschichte der Rationalität' betreffen, sondern auch als Fragen an die Geschichte der Literatur ${ }^{4} \mathrm{zu}$ stellen sind. Die erste und wichtigste unter ihnen betrifft den funktionalen Konnex von epistemisch-religiöser Liminalität und poetischer Funktion des Außernatürlich-Wunderbaren: Wie und mit welcher Begründung bzw. Absicht wird in literarischen Texten von den Grenzen und Grenzüberschreitungen erzählt, die das Außernatürlich-Wunderbare kategorial impliziert? Wie Christel Meier festgestellt hat, handelt es sich beim Wunderbaren der Literatur zwischen Mittelalter und Aufklärung um ein „,überaus komplexes Phänomen in historisch differenzierten Antworten hinsichtlich seiner poetologischen Bewältigungsstrategien und Begründung “. ${ }^{5}$ Komplexität entsteht dabei auf zwei Ebenen: Zum einen ist beim Blick auf literarische Texte von einer „Multifunktionalität des Wunderbaren“ auszugehen - Liminalität und Labilität der Kategorie schlagen sich in je unterschiedlichen textuellen Sinngebungen bis hin zu auf Dauer gestellten "Ambivalenzen der Deutung“ nieder. ${ }^{6}$ Zum anderen wird Komplexität erzeugt durch die Vielfalt frühneuzeitlicher Modi literarischer Weltbeobachtung: Eine Schreibweise des Wunderbaren der Frühen Neuzeit isolieren zu wollen, macht angesichts der Fülle vorhandener Formen wenig Sinn. ${ }^{7}$ Vielmehr ist von einer Vielzahl von Schreibweisen des

4 Die Rede von einer Geschichte der Literatur impliziert im Fall der Frühen Neuzeit ein Bewusstsein für die z.T. tiefgreifende Alterität des Literaturbegriffes vor 1750: Weder kann Literatur in der Frühen Neuzeit mit Fiktionalität gleichgesetzt werden, noch darf übersehen werden, dass die poetisch-rhetorischen Verfahren, die die (aus moderner Sicht), literarischen' Texte der Zeit prägen, auch in anderen Bereichen des Schrifttums Anwendung finden. Von entscheidender Bedeutung schließlich ist die Tatsache, dass die Funktion literarischer Texte der Frühen Neuzeit im Anschluss an Konzepte der (römischen) Antike und des Mittelalters an einem moralisch-theologischen Geltungsrahmen gemessen wird, der erst im 18. Jahrhundert an Verbindlichkeit verliert. Dazu allgemein Ingo Stöckmann: Vor der Literatur. Eine Evolutionstheorie der Poetik Alteuropas. Tübingen 2001.

5 Christel Meier: ,Ut rebus apta sint verba'. Überlegungen zu einer Poetik des Wunderbaren im Mittelalter. In: Das Wunderbare in der mittelalterlichen Literatur. Hrsg. von Dietrich Schmidtke. Göppingen 1994, S. 37-83, hier 71f. Es sei darauf hingewiesen, dass Meier sich insbesondere auf das Hochmittelalter und die frühe Aufklärung konzentriert. Die sich ab dem 16. Jahrhundert in der Literatur manifestierende dämonologische Deutung des Außernatürlich-Wunderbaren entgeht ihr dadurch ebenso wie die frühneuzeitlichen Konkurrenzen zwischen Naturwissen und Wunderglaube, die sich - mit Daston gesprochen - an den Grenzen zwischen dem Natürlichen und dem Außernatürlich-Wunderbaren abspielen.

6 Meier: Ut rebus (Anm. 5), S. 81.

7 So kann man zwar, wie Karl-Heinz Stahl dies getan hat, die Regelpoetiken der Frühen Neuzeit auf ihre Beobachtung des Wunderbaren hin untersuchen - das Ergebnis bildet dann aber nur den Bereich einer Poetik des Wunderbaren ab, der regelpoetischer Beobachtung 
Wunderbaren vor 1700 auszugehen, deren jeweilige Fundierung im System der Gattungen und rhetorisch-poetischen Verfahren philologisch zu prüfen ist. ${ }^{8}$ In diesem Sinne gilt: $\mathrm{Ob}$ und inwiefern das Wunderbare in Texten der Frühen Neuzeit zum "poetologischen Schlüsselkonzept" ${ }^{\text {"9 }}$ wird, hängt nicht nur vom wissens- und religionshistorischen Ort der Texte ab, sondern auch von ihrer generisch programmierten Faktur. Ein Beispiel mag dies illustrieren: Dem Monster auf dem Titelkupfer von Grimmelshausens Simplicissimus Teutsch (1668) dieselbe Funktion der „Bezeichnung des Göttlich-Wunderbaren“ zuzuschreiben, die das Monströse in den Expositiones in ierarchiam coelestem des Johannes Scotus Eriugena hat, ${ }^{10}$ macht nicht nur deshalb keinen Sinn, weil die epistemischen und religiösen Bedingungen des (Nicht-)Wissens vom Außernatürlich-Wunderbaren im 17. Jahrhundert weitgehend andere sind als im 9. Jahrhundert. Auch zielt die von den Autoren jeweils implizierte "Gegenpoetik"11 auf völlig verschiedene literarische Schreibweisen ab: Der theologisch begründeten Aufwertung von Vision und Allegorie bei Eriugena steht die profane „Devianzrhetorik“12 des simplicianischen Romans gegenüber, dem spekulativen Konzept der Expositiones das inversive der Satire.

Nicht um Monster, sehr wohl aber um die spezifische Konstellation von Satire und Außernatürlich-Wunderbarem im letzten Drittel des 17. Jahrhunderts soll es im Folgenden gehen. Anvisiert ist damit eine Zeit, in der, wie Daston festgestellt hat, die Spannungen an den Grenzen von Wissen und Nicht-Wissen - dem third space des Außernatürlich-Wunderbaren - erheblich zunehmen. Kurz bevor die Aufklärung die "Zone des Halbschattens"13 mit allen Mitteln naturwissenschaftlicher Rationalität ausleuchten wird, kommt es zu einer Konjunktur des Außernatürlich-Wunderbaren in gelehrten und populären Diskursen, die sich durch Verschiebungen im liminalen Bereich der Kategorie erklären lassen: Im sich verschärfenden Spannungsfeld zwischen Dämonologie und naturphilosophischer bzw. naturwissenschaftlicher Beobachtung gerät das AußernatürlichWunderbare (abermals) in Bewegung und eröffnet einen Raum diskursiver Auseinandersetzung, der von unzähligen Schriften der Zeit ventiliert wird. Eine unter ihnen ist Grimmelshausens Wunderbarliches Vogel-Nest (1672/75), das im

zugänglich ist. Wesentliche Diskurse, die (tendenziell) außersystemische Gattungen wie den Roman und die Satire betreffen, bleiben dabei auf der Strecke. Vgl. Karl-Heinz Stahl: Das Wunderbare als Problem und Gegenstand der deutschen Poetik des 17. und 18. Jahrhunderts. Frankfurt a.M. 1975.

8 In diesem Sinne spricht auch schon Meier: Ut rebus (Anm. 5), S. 81, von einer „notwendigen Differenzierung der literarischen Genera und Aussagemitteln".

9 Torsten Hoffmann und Claudius Sittig: Art. ,Das Wunderbare'. In: Historisches Wörterbuch der Rhetorik. Bd. 9. Hrsg. von Gert Ueding. Tübingen 2009, Sp. 1444-1459, hier: Sp. 1447.

10 Ich greife hier ein Beispiel von Christel Meier auf. Vgl. Meier: Ut rebus (Anm. 5), S. 51.

11 Meier: Ut rebus (Anm. 5), S. 51. Auf Grimmelshausen geht Meier ebd., S. 78, kurz ein.

12 Meier: Ut rebus (Anm. 5), S. 75.

13 Lorraine Daston, Katharine Park: Wunder und die Ordnung der Natur 1150-1750. Aus dem Englischen von Sebastian Wohlfeil sowie Christa Krüger. Berlin 1998, S. 18. 
Zentrum der Überlegungen dieses Aufsatzes stehen soll. Bei dem Roman handelt es sich um ein hervorstechendes Beispiel für die Relevanz generischer Aspekte bei der Erkundung des poetischen bzw. metapoetischen Funktionsspektrums des Außernatürlich-Wunderbaren in der Literatur des späten 17. Jahrhunderts. Im Modus satirischer Weltschau erzählt das Vogel-Nest in zwei Teilen von den Erlebnissen und Erfahrungen zweier Figuren, die nacheinander in den Besitz eines unsichtbar machenden Vogelnestes kommen. Der erste unter ihnen, ein einfacher Stadtsoldat namens Michael Rechulin von Sehmsdorff, nutzt das Wunderding, um seine leiblichen Bedürfnisse zu befriedigen, behält dabei jedoch eine moralisierende Weltsicht bei, die seine Abkehr vom Nest am Ende des ersten Romanteils begünstigt. Im zweiten Teil meldet sich ein Kaufmann, der mit dem Nest teilweise schwerste Verbrechen begeht. Dass auch er am Ende seines Erfahrungsberichtes vom Nest Abstand nimmt und in dessen Vernichtung einwilligt, scheint auf den ersten Blick ein klarer Beleg für die auf Erbauung und moralisch-religiöse Einsicht zielende satirische Erzählstrategie des Romans. ${ }^{14}$ Auf den zweiten Blick erweist sich dieses Urteil jedoch als anfechtbar: Trotz der schematischen Struktur der autodiegetischen Erfahrungsberichte, die jeweils mit der Auffindung des Nestes beginnen und mit der Bekehrung der Erzählerfiguren enden, bleibt die Funktion des Außernatürlich-Wunderbaren in Grimmelshausens Roman ambivalent. Dies zumindest hat die jüngere Forschung festgestellt und dabei auf die besonderen poetischen und metapoetischen Potenziale des Nestes hingewiesen: Der satirische Einsatz des „Instruments des Wunderbaren“, so schreibt etwa Zeller, laufe bei Grimmelshausen auf einen Prozess metapoetischer Selbstverständigung des Erzählens hinaus, der es erlaube, „die beiden Romane auch als Romane über die Wirkung der Imagination bzw. fiktiver Literatur [zu] lesen“. ${ }^{15}$ Ganz ähnlich lautet die Diagnose bei Wesche, der vom wunderbaren Nest als einem „Fiktionsindikator" spricht, aus dessen "Möglichkeitsspielraum" dem satirischen Diskurs, historisch gesehen, neue „poetische Lizenzen“ zuwüchsen. ${ }^{16}$ Interessant ist, dass in beiden Lektüren eine Verbindung hergestellt wird zwischen der Dynamik metapoetischer Selbstverständigung des Textes und der Destabilisierung eben jener moralischreligiösen Geltungen, die die Bekehrung der Hauptfiguren begründen. Zeller

14 Als erbaulich wurde der Schluss der Romane in der älteren Forschung denn auch aufgefasst. In der Dialektik von Weltbeobachtung und Selbsterkenntnis der Vogelnestträger, so heißt es etwa bei Stefan Trappen, verbinde sich „die satirische Kritik mit der erbaulichen Bestärkung der Frömmigkeit" und verdichte sich das Ziel des Textes, den Leser in die Lage zu versetzen, „daß Sünden gemieden werden und Anfechtungen widerstanden wird." Vgl. Stefan Trappen: Grimmelshausen und die menippeische Satire. Eine Studie zu den historischen Voraussetzungen der Prosasatire im Barock. Tübingen 1994, S. 318.

15 Rosmarie Zeller: Magia naturalis, Zauberkunst und Kritik des Wunderbaren im Wunderbarlichen Vogelnest. In: Simpliciana 28 (2006), S. 151-167, hier S. 163.

16 Jörg Wesche: Unsichtbares Lesen. Narrative Selbstreflexion in Grimmelshausens Vogel-Nest. In: Simpliciana 28 (2006), S. 69-82, hier S. 76f. 
spricht in diesem Sinne von einer Negation der "moralische[n] Absicht" durch die Eigenlogik des simplicianischen Diskurses. ${ }^{17}$ Und Wesche betont den Unterschied zwischen dem Roman und dem Modell traditioneller Moralsatire: Der „Möglichkeitsspielraum“ des Erzählens „und nicht die Vermittlung strenger Verhaltensnormen" seien das eigentliche Thema des Vogel-Nestes, weshalb der Text ein Beispiel für die Entfaltung „poetischer Freiheit“ in der Literatur der Spätfrühneuzeit gebe. ${ }^{18}$

So anregend die Überlegungen Zellers und Wesches sind, bleiben sie in ihrer Begründung des Zusammenhangs von Außernatürlich-Wunderbarem und poetischer Fiktionalität im Vogel-Nest (zu) vage. Vor allem Wesches Begriff der ,poetischen Freiheit' dürften sich eines gegen ihn erhobenen Anachronismusverdachtes kaum erwehren können. Wenn bei Grimmelshausen Fiktionalität zum Thema wird - und diese Grundeinschätzung teile ich vollauf -, dann sicher nicht unter den Auspizien eines modernen Freiheitsbegriffes von Kunst, der im 17. Jahrhundert so schlechterdings nicht zu finden ist. In den Blick zu nehmen sind vielmehr die wissens- wie literarhistorisch spezifischen Bedingungen, unter denen sich das Erzählen im Vogel-Nest ausbildet. Dies betrifft zum einen das Nest und seine Funktion als, wunderbarliches' Medium des Erzählens. Zum anderen betrifft es die Einbettung dieser Funktion in den übergeordneten Diskurs satirischer Weltbeobachtung, der im Vogel-Nest (wie auch anderswo bei Grimmelshausen) in „auffallend paradoxe[ ] Selbstthematisierungen des Erzählens" ${ }^{19}$ mündet. Um Fiktionalität geht es dabei auf beiden Ebenen: Erregt das Nest als wunderbares Ding, wie Vollhardt schreibt, „Zweifel an der Objektreferenz und der Zuverlässigkeit der Zeichenvermittlung“ 20 - leistet also einer Fiktionalisierung des Diskurses Vorschub -, so lässt sich die poetologische und epistemologische Relevanz dieses Vorgangs erst unter Einbezug der im Roman metareflexiv beobachteten Programmierungen eines Erzählens begreifen, das gemäß der Tradition menippeischer Satire Fiktionalität, Wunderbares und Skepsis zu einem hochdynamischen poetisch-epistemologischen Komplex verknüpft. Im Zeichen einer paradoxen Selbstaufhebung der normativen Ansprüche satirischen Erzählens operiert das Vogel-Nest an den Grenzen und Schwellen jenes Komplexes von (Nicht-)Wissen und Glauben, als der sich der Bereich des Außernatürlich-Wunderbaren im späten 17. Jahrhundert darstellt.

17 Zeller: Magia naturalis (Anm. 15), S. 163.

18 Wesche: Unsichtbares lesen (Anm. 16), S. 74.

19 Gerhard Lauer: Grimmelshausen oder die Kunst des Erzählens vor Gott. In: Hans Jacob Christoffel von Grimmelshausen. Hrsg. von Heinz Ludwig Arnold. München 2008, S. 22-31, hier S. 23.

20 Friedrich Vollhardt: Die interpretatorische Relevanz nichtfiktionaler Elemente in literarischen Texten der Frühen Neuzeit (Grimmelshausen). In: Fiktion und Fiktionalität in den Literaturen des Mittelalters. Jan-Dirk Müller zum 65. Geburtstag. Hrsg. von Ursula Peters und Rainer Warning. München 2009, S. 243-266, hier S. 266. 
2

Weil das Vogelnest, anders als der spiritus familiaris in Grimmelshausens Courasche (1670) oder die Alraune aus Grimmelshausens Galgen-Männlin (1673), in den einschlägigen deutschsprachigen magiologischen Kompendien des 17. Jahrhunderts nicht auftaucht, hat die Forschung bisher dazu geneigt, dasselbe als Erfindung des Autors aufzufassen. ${ }^{21}$ Dies kann verwundern, ist doch in einem seit dem Spätmittelalter weit verbreiteten Wunderbuch eben von einem solchen Nest die Rede. So heißt es im Liber de mirabilibus mundi des Pseudo-Albertus Magnus einem Text wohl des späten 13. Jahrhunderts -, dass ein Mensch sich unsichtbar machen könne, wenn er jenen wunderbaren Stein bei sich trage, der im Nest des Wiedehopfes zu finden sei: In nido upupæ est quidam lapis, qui est diversorum colorum, defer tecum ipsum, E eris invisibilis. ${ }^{22}$ Mehr erfährt man über Stein und Nest bei Pseudo-Albertus nicht. Knappheit von Information und gesichertem Wissen bedeutet im Fall des Wunderbaren allerdings nicht unbedingt einen Mangel. Vielmehr, so scheint es, eröffnet der Text mit seiner schlichten Folge von Proposition und Instruktion genau jene Zone des (Nicht-)Wissens, in der in Mittelalter und Früher Neuzeit das Wunderbare dies- und jenseits der ausgeleuchteten Bereiche epistemischen Wissens, aber auch religiöser Wunder-Diskurse blüht. Ins Auge fällt zumal der Verzicht auf eine die Ursachen für die außernatürliche Wirkung des Nestes erforschende Beobachtung: Über das Nest darf der Leser staunen oder muss sich fürchten - denn wo genau dessen Ort in der "elektrisch geladen[en]“ Liminalordnung des Außernatürlich-Wunderbaren ${ }^{23}$ ist, lässt sich auf Grundlage der Informationen des (Pseudo-)Albertus Magnus nicht sagen. Ausgeschlossen werden kann mithin auch nicht, dass das Nest dämonischen Ursprungs ist. Wenn sich in einer Hexenprozessakte des 16. Jahrhunderts Hinweise auf die schwarzmagische Verwendung von Vogelnestern finden lassen, ${ }^{24}$

21 So konnte Rosmarie Zeller noch 2006 schreiben, es sei „kein Zufall, dass die Grimmelshausen-Forschung noch keine Quelle ausmachen konnte für das Phänomen des unsichtbar machenden Vogelnestes." Vgl. Zeller: Magia naturalis (Anm. 15), S. 166, hier Anm. 30.

22 Hier zitiert nach einer Ausgabe aus Grimmelshausens Lebenszeit: [Pseudo-]Albertus Magnus: De mirabilibus mundi. In ders.: De Secretis Mulierum Item De Virtutibus Herbarum Lapidum et Animalium. Amstelodami. Apud Ioannem Ianßonium A ${ }^{\circ} 1662$, S. 170-218, hier S. 204f. Soweit ich sehe, liegt bis 1672/75, den Jahren der Veröffentlichung des Vogel-NestRomans, keine vollständige deutsche Übersetzung von De mirabilibus mundi vor. Eine solche wird, auf Grundlage der hier zitierten lateinischen Ausgabe, erst 1678 bei Johann Hoffmann in Nürnberg vorgelegt. In einer späteren Auflage dieser Übersetzung wird die Stelle folgendermaßen übersetzt: In einem Widhopffen=Nest ist ein Stein / von unterschiedlichen Farben; den trage bey dir / so wirst du unsichtbar seyn. Vgl. [Pseudo-]Albertus Magnus: Von den Geheimnussen derer Weiber; Wie auch Von den Tugenden derer Kräuter / Steine und Thiere: Und den Wunderwercken der Welt. Samt Michael Scoti Büchlein / Von den Geheimnussen der Natur. [...] Nürnberg / Jn Verlegung Johann Hoffmanns / seel. Wittib [...] / 1704, S. 333.

23 Daston, Park: Wunder und die Ordnung der Natur (Anm. 13), S. 22.

24 Vgl. Maximilian Bergengruen: Nachfolge Christi-Nachahmung der Natur. Himmlische und Natürliche Magie bei Paracelsus, im Paracelsismus und in der Barockliteratur (Scheffler, Zesen, Grimmelshausen). Hamburg 2007, S. 259. 
so spiegelt dies die epistemisch unsichere Struktur des spätmittelalterlichen mirabilia-Diskurses wider: Aus dem, was nicht gewusst und deshalb bestaunt wird, kann - unter den Bedingungen einer sich wandelnden Ordnung des Wissens und Glaubens - das Zünglein an der Waage zwischen Leben und Tod eines der Zauberei verdächtigten Menschen werden.

Blickt man von hieraus auf Grimmelshausens Vogel-Nest-Roman, so fällt auf, dass dieser das Nicht-Wissen vom Ursprung des Nestes thematisiert, indem er das Nest als niemals versiegende Quelle von Vermutungen, Projektionen, Befürchtungen und Diskussionen darstellt. ${ }^{25}$ Michael Rechulin von Sehmsdorff, zweiter Vogelnestträger und Protagonist des ersten Teils des Wunderbarlichen Vogel-Nestes, identifiziert im Nicht-Wissen die eigentliche Voraussetzung des Wunderbaren. ${ }^{26}$ Das Staunen (die Verwunderung) der anderen Stadtsoldaten (Hellebardierer) beobachtend, die sich nicht erklären können, wie ihr Kamerad so plötzlich verschwinden konnte, erkennt er zum einen, daß die Verwunderungen auß der Unwissenheit enstehe [sic!], zum anderen wird ihm klar, dass dort, wo das Unerklärliche geschieht, alsbald unterschiedlich Red und Meynungen zirkulieren. ${ }^{27}$ Diese Mobilisierung von epistemisch nicht gedeckten Diskursen führt der Simplicianische Zyklus vom Springinsfeld (1670), an dessen Ende das Nest entdeckt wird, bis zu den beiden Teilen des Vogel-Nestes ein ums andere Mal vor. Je nach Seelensituation der Figuren dominiert dabei entweder das Moment des Begehrens oder das der Furcht, welche letztere sich auf irdische und überirdische Bestrafungsinstanzen, die Obrigkeit und Gott, beziehen kann. Beide Affekte werden von Beginn an mit dem Nest verbunden: Die Leyrerin, die das Nest in Begleitung Springinsfelds findet, teilt mit, ihre Eltern hetten vilmahl von einem Kerl gesagt; der ein solches Nest gehabt: und sich durch dessen Krafft und Würckung gantz reich gemacht hette; entsprechend dieser "Red“ - ein Beispiel für die intradiegetische Relevanz zirkulierender Erzählungen vom Wunderbaren im Roman will sie das seltene Kleinod[ ] für Diebeszüge einsetzen. ${ }^{28}$ Dagegen äußert Springinsfeld die Furcht, die Wirkung des Nestes, die er - ganz ähnlich dem PseudoAlbertus - auf einen im Nest verborgenen Stein, ein Kraut oder eine Wurzel zurückführt, könnte unzuverlässig sein, möge es sich doch leicht schicken / daß sich irgends einer fände / der mehr als andere Leuth sehen köndte / durch welchen alsdann

25 Dies stellt schon Zeller: Magia naturalis (Anm. 15), S. 161, fest.

26 Damit reproduziert die Figur den bereits antiken Diskurs über das Wunderbare, der sich in zahlreichen Filiationen bis ins 17. und 18. Jahrhundert fortsetzt. Vgl. dazu auch Stefan Matuschek: Über das Staunen. Eine ideengeschichtliche Analyse. Tübingen 1991.

27 Hans Jacob Christoffel von Grimmelshausen: Das Wunderbarliche Vogel-Nest. Erster Teil. In ders.: Werke. Hrsg. von Dieter Breuer. Bd. I/2. Frankfurt a.M. 1997, S. 297-447, hier S. 303. Nach dieser Ausgabe wird im Folgenden aus den Werken Grimmelshausens zitiert. Die beiden Teile der Vogel-Nest-Dilogie werden im Kurztitel als Vogel-Nest I und Vogel-Nest II angegeben.

28 Grimmelshausen: Springinsfeld. In ders.: Werke I/2 (Anm. 27), S. 153-295, hier S. 276. 
einer erdapt und endlich an seinen allerbesten Hals auffehenckt werden möchte. ${ }^{29}$ Wie berechtigt Springinsfelds Furcht ist, zeigt der Fortgang der Handlung. Am Ende des Romans erfährt der Leser, dass die Leyrerin von ihrem nächsten Geliebten einem Bäckersknecht, der es ob der wundersamen Fähigkeiten seiner Gespielin mit der Angst zu tun bekommen hatte - in eine Falle gelockt und mit einem Straich erschlagen worden ist, daß man nit allein die viel gedachte Melusina selbst dort todt ligen; Sonder ihr auch Lung und Leber sambt dem Ingeweid in ihrem Leib: Und das Hertz noch zapplen sehen konte. Die Kleinodien, köstliche[n] Ring und Gold und Perlen, die man bei der Leiche findet, bringen die Taten der Erschlagenen ans Licht: Sie hat ihre Unsichtbarkeit genutzt, um Reichtümer anzuhäufen. ${ }^{30}$

So klar das Erzählmuster damit zunächst auch scheint - auf die Verlockung durch das Nest und die Missetaten folgt die (Todes-)Strafe -, so unklar bleibt, ob das gegen die Leyrerin postum vollstreckte Urteil der Hexerei ${ }^{31}$ durch das (textimmanente) Wissen vom Nest gedeckt ist. Eine dämonische Herkunft des Nestes wird zwar im direkten Anschluss an die Passage, nämlich zu Beginn des VogelNestes I vom nächsten Träger des Nestes, Michael Rechulin von Sehmsdorff, ins Spiel gebracht. Allerdings kann von sicherer Erkenntnis dabei nicht die Rede sein. ${ }^{32}$ Rechulins Argumentation ist nicht geeignet, dem Nest einen festen Platz in der kosmologischen Ordnung der Dinge zuzuweisen (und sei es der des Teufels). Vielmehr zieht er sich auf eine moralisch-praktische Argumentation zurück, für die er Vorbilder in der Roman-Literatur des 16. Jahrhunderts findet: Seiner Meinung nach sei schon dem Fortunatus zu entnehmen, dass dergleichen verwunderliche Stück [...] endlich sonst nichts als alles Unglück auf dem Rucken mit sich bringen, weshalb letzthin nichts daran gelegen sei, solche seltene ungewöhnliche extraordinari Glücks Stücke (wie man sie nennen möchte) hätten gleich ihrem [sic!] Ursprung und ihre Würckungen auß dem überreichen: aber gleichwol annoch vielen verborgenen Schätzen und Geheimnussen der Natur / oder seyen vom Schaden froh / dem Verderber und Ertzfeind deß menschlichen Geschlechts selbst an die Hand gegeben worden $[\ldots] .{ }^{33}$ Als symptomatisch für die besondere Stellung des Wunderbaren bei Grimmelshausen darf die auffällige affektive Widerläufigkeit in Rechulins Rede betrachtet werden. Auf der einen Seite wird in paränetischer Absicht der Teufel als Schaden froh, Verderber und Ertzfeind deß menschlichen Geschlechts an die Wand gemalt - und damit einer dämonologischen Zuspitzung zugearbeitet, die am Ende des zweiten Teils in der Mahnrede des den zweiten Erzähler zur Be-

29 Grimmelshausen: Springinsfeld. In ders.: Werke I/2 (Anm. 27), S. 153-295, hier S. 276.

30 Grimmelshausen: Springinsfeld. In ders.: Werke I/2 (Anm. 27), S. 153-295, hier S. 291.

31 Springinsfeld berichtet davon: Sie ist ohngefähr aus ihrem Angesicht vor 20. Jahr alt geschätzt: Und ihr Cörper als einer Zauberin verbrand [...]. Vgl. Grimmelshausen: Springinsfeld. In ders.: Werke I/2 (Anm. 27), S. 153-295, hier S. 292.

32 In diesem Sinne ist Bergengruen zu widersprechen, der die dämonische Herkunft des Nestes im Roman als gesichert ansieht. Vgl. Bergengruen: Nachfolge Christi (Anm. 24), S. 259.

33 Grimmelshausen: Vogel-Nest I. In ders.: Werke I/2 (Anm. 27), S. 297-447, hier S. 302. 
kehrung bringenden Paters mit theologischen Argumenten untermauert wird. ${ }^{34}$ Auf der anderen Seite bleibt hier eine sich mit dem wunderbaren Ding verbindende Faszination greifbar, die theologisch niemals völlig steuerbar erscheint (wie Rechulins Roman-Lektüre an sich schon nahe legt). Mit Formulierungen wie der von den seltene[ $n]$ ungewöhnliche[n] extraordinari Glücks Stücke[n] unterwandert Rechulin die paränetische Rhetorik und regt die Neugier des Lesers gerade dort an, wo sie - aus christlich-religiöser Sicht - besonders schädlich ist (oder sein könnte). Dass er damit letzthin auch auf das Paradox des Erzählens vom Nest im Spannungsfeld von Begehren und Angst, Frömmigkeit und Neugier hinweist, liegt auf der Hand. In der Reflexion über den wunderbaren Gegenstand, der sich allem irdischen Wissen entzieht, wendet sich der Diskurs des Ich-Erzählers bei Grimmelshausen nicht nur an dieser Stelle ins Poetologische. Die Frage ist, wie sich diese reflexive Bewegung vor dem Hintergrund der eingangs angesprochenen satirischen Erkenntnisproblematik des Erzählens in den Vogel-Nest-Romanen erklären lässt. Wenn Breuer darin zuzustimmen ist, dass im „Zentrum“ der Erzählungen „der Perspektivismus menschlicher Urteile, schließlich auch der Urteile des Satirikers selbst und die Frage nach einem Ausweg aus dem Dilemma relativer Wahrheit" steht ${ }^{35}$ - welche Rolle spielt das Nicht-Wissen, das mit dem Nest (und dem Wunderbaren) verbunden ist, in diesem Zusammenhang?

\section{3}

Um das Andere zu beschreiben, das sich im Außernatürlich-Wunderbaren des Nestes manifestiert, braucht es eine Einsicht in die Formationen des Eigenen, von denen aus Aspekte der Liminalität und Transgressivität erst beobachtet werden können. In den Blick kommen im Vogel-Nest-Roman dabei zwei Dimensionen von Macht und Erkenntnis, die über die Grenzverläufe im Diskursgefüge der integrierten Erzählungen bestimmen. Auf die erste dieser Dimensionen, die Religion, hat die Forschung bereits vielfach hingewiesen. ${ }^{36}$ Laut dem Springins-

34 Der Pater hat eine wichtige Rolle inne, denn er ist es, der am Ende des zweiten Teils den Kaufmann von der Vernichtung des Nestes überzeugt. Dies gelingt ihm, indem er den Einfluss des Teufels auf Denken und Handeln des Menschen totalisiert. Ähnlich wie Rechulin argumentiert er, dass es nicht wichtig sei, ob das Nest als solches teuflischen Ursprungs sei oder nicht. Der Teufel sei imstande, natürliche Dinge zum Instrument der Verführung zu machen, wobei er streng ökonomisch vorgehe: Was hat der leidige Teuffel weiters vor Mühe an dich zu wenden bedörfft / dich zu sich in sein Reich der Verdampten zu ziehen / da er dich mit der Unsichtbarkeit schon dermassen angeseylet hatte / daß du von dir selbst gegen der Höllen zurennest? Vgl. Grimmelshausen: Vogel-Nest II. In ders.: Werke I/2 (Anm. 27), S. 449-650, hier S. 635.

35 Dieter Breuer: Grimmelshausen-Handbuch. München 1999, S. 106.

36 Vgl. dazu u.a. Friedrich Gaede: Substanzverlust. Grimmelshausens Kritik der Moderne. Tübingen 1989, S. 56-58; ders.: Das plicarische Prinzip - Die Astgabel als poetischer Initialpunkt. In: Simpliciana 28 (2006), S. 57-67; Peter Heßelmann: Gaukelpredigt. Simplicianische Poetologie und Didaxe. Zu allegorischen und emblematischen Strukturen in Grimmelshausens Zehn-Bücher-Zyklus. Frankfurt a.M. 1988, S. 323. 
feld-Roman fällt das Nest der Leyrerin auff der Zwickgabel ${ }^{37}$ eines Baumes in die Hände, wodurch der Leser auf eine religiöse Deutungsfolie für die Vogel-NestDilogie eingeschworen wird. Das „Motiv des Baumes (Erkenntnis)“, so hält Vollhardt fest, weise, verbunden mit dem in der Astgabel diagrammatisch präsenten „Y-Signum (Wegewahl)“, auf die Dialektik von Sünde und Bekehrung, Laster und Tugend als eigentlichem Thema der Vogel-Nest-Romane:

Wie die Wirkung des Instrumentes [i.e. des Vogelnestes] den Widerspruch von Verhüllung und Aufrichtigkeit, Schein und Wesen, Täuschung und Wissen verstärkt und damit ins Verderben, aber auch zur Einsicht in die eigene Sündhaftigkeit, zu Bekehrung und Tugend führen kann, zeigen die beiden Vogelnest-Romane - es geht um die Suche nach Erkenntnis. ${ }^{38}$

Aus der von Vollhardt aufgewiesenen religiösen Perspektive bedeutet Erkenntnis (die nicht fromme Selbsterkenntnis ist) freilich in erster Linie superbia. Entsprechend furchtsam registriert Michael Rechulin - der skrupulöseste der Vogelnestträger - die Erlangung des Vogelnestes als Wiederholung des Sündenfalls. Das Versprechen des Eritis sicut Deus scientes bonum et malum (1 Mose 3,5), das der Teufel den Stammeltern des Menschengeschlechts gibt, erzeugt aus christlicher Sicht die Ur-Paradoxie irdischer Erkenntnis, stellt es doch eine Übertragung des „absoluten Blick[es]“ ${ }^{39}$ Gottes auf den Menschen in Aussicht, die die Hierarchie innerhalb des göttlichen ordo infrage stellt. Wenn sich Rechulin im frischen Besitz des Nestes vor [s]einer Macht entsetzt [ ] ${ }^{40}$, so in (unbewusster) Vorwegnahme der frommen Einsichten, die ihn am Ende seines Parcours zur Aufgabe des Nestes bewegen. Das theologische Modell hinter dem Erzählen bleibt damit durchaus überschaubar: Nachdem insbesondere im ersten Teil des Romans das Spiel der Verwechslung menschlicher und göttlicher „Kontroll- und Strafblicke ${ }^{\prime 41}$ ausgiebig gespielt worden ist, führt aus christlicher Perspektive kein Weg an der Vernichtung des Nestes vorbei, dessen außernatürliche Kräfte die Grenzen theologischer Normen sprengen.

Dass es damit im Vogel-Nest-Roman nicht getan ist, liegt an der Verflechtung der religiösen mit der satirischen Dimension des Erzählens, welche bei Grimmelshausen auf einem eigenen, von religiösen Geltungen abweichenden Erkenntnisprogramm basiert. Paradigmatisch gefasst wird dieses auf dem Titel-

37 Grimmelshausen: Springinsfeld. In ders.: Werke I/2 (Anm. 27), S. 153-295, hier S. 275.

38 Vollhardt: Die interpretatorische Relevanz nichtfiktionaler Elemente (Anm. 20), S. 257.

39 Vgl. Paul Ricœur: Symbolik des Bösen. Phänomenologie der Schuld II. Freiburg, München 1971, S. 100.

40 Grimmelshausen: Vogel-Nest I. In ders.: Werke I/2 (Anm. 27), S. 297-447, hier S. 302.

$41 \mathrm{Vgl}$. Wilhelm Kühlmann: Machtspiel und Begehren. Zum epischen Tagtraum in Grimmelshausens Vogelnest-Romanen. In: Simpliciana 28 (2006), S. 11-23, hier: S. 16. 
kupfer zum Vogel-Nest I. ${ }^{42}$ Die eindrückliche Darstellung zeigt einen Satyr Personifikation der Satire als transgressiver Schreibweise -, der die erratisch in den Bildhintergrund flüchtende Welt durch das in seiner rechten Hand befindliche Vogelnest ins Visier nimmt. Dies unterscheidet ihn vom Putto an seiner Seite, der zur Einschärfung der Welt ein Perspektiv bemüht, mit diesem jedoch nur auf einen Haufen Masken blickt. Breuer hat in dieser Konstellation eine vom simplicianischen Text reklamierte Überlegenheit satirischer Schreibweise gegenüber der des ,hohen' Romans gesehen, als dessen Personifikation der ,höfische' Putto ins Bild gesetzt sei. ${ }^{43}$ Dies lässt sich schon deshalb bezweifeln, weil es im Vogel-Nest-Roman, anders als im Simplicissimus Teutsch, keine weiteren Anzeichen für eine Auseinandersetzung des Erzählens mit Strukturen und Motiven ,hoher' Romanpoetik gibt. Näher kommt man der Funktion des Putto, betrachtet man ihn als Kontrahenten des Satyrs auf epistemologischer Ebene. ${ }^{44}$ Als solcher nämlich vertritt er ein Dispositiv naturwissenschaftlicher Erkenntnis (Perspektiv), das um 1670 längst stabil genug ist, um sich selbst als überlegene Erkenntnismethode zu beschreiben. Grimmelshausen konnte das in der von ihm mehrfach konsultierten Acerra Philologica (erstmals 1633) des Peter Lauremberg nachlesen. ${ }^{45}$ Unter dem Lemma Was man zu vnser Zeit für Dinge im Himmel erfunden heißt es dort, die Italiener (Galileo wird nicht namentlich genannt) hätten Dinge im Himmel gefunden, die die Alten nicht gekannt hätten. Möglich habe dies der tubus opticus gemacht, ein newerdachte[s] Instrument [ ], durch das man die Gestalt I Farben vnd dergleichen natürliche qualiteten eines dinges / wie sie an sich selber seyn erkennen könne, aber die grösse vnnd die nahe etzliche zwantzig / ja hundertmal vermehret vnnd vergrössert wird. ${ }^{46}$ Erwähnenswert ist mit Blick auf Grimmelshausens Titelkupfer, dass Lauremberg als Vertreter der Alten nicht etwa die griechischen

42 Vgl. die Abbildung in: Grimmelshausen: Vogel-Nest I. In ders.: Werke I/2 (Anm. 27), S. 297447, hier S. 298.

43 Vgl. Breuer: Grimmelshausen-Handbuch (Anm. 35), S. 100f.; außerdem ders.: Stellenkommentar. In: Grimmelshausen: Werke I/2 (Anm. 27), S. 889-944, hier S. 889.

44 Diesen Vorschlag unterbreitet bereits Wesche: Unsichtbares lesen (Anm. 16), S. 76f., ohne allerdings auf Konsequenzen desselben einzugehen.

45 Nachweise für die Lauremberg-Lektüre Grimmelshausens liefert der reichhaltige Stellenkommentar Breuers in Grimmelshausen: Werke I/2 (Anm. 27), S. 770-1062. Auf die hier besprochene Konstellation geht Breuer allerdings nicht ein.

46 [Peter Lauremberg:] Acerra Philologica Das ist: Zweyhundert außerlesene / nützliche / lustige vnd denckwürdige Historien vnd Discursen, zusammen gebracht auß den berühmsten Griechischen vnd Lateinischen Scribenten. [...]. Rostock / Jn Verlegung Johann Hallervords / Buch=Händlers doselbst / 1637, S. 166f. Laurembergs Text gibt ein schönes Beispiel, wie neugewonnene naturwissenschaftliche Erkenntnisse im 17. Jahrhundert per Buntschreiberei literarisch popularisiert werden. In dem kurzen Abschnitt der Acerra erfährt der Leser, dass man sich die Mondflecken inzwischen als Licht/Schatten-Verhältnisse auf der Mondlandschaft erkläre; außerdem seien vier Trabanten des Jupiter (die Sydera Medicea) entdeckt worden, die Lauremberg als vier neue Planeten bezeichnet (weshalb es jetzt elf Planeten gebe); die Sonne sei elliptisch und habe Flecken; die Milchstrasse sei keine Wolke, sondern eine Menge von Fixsternen, von denen man inzwischen 1022 identifiziert habe usw. 
Naturphilosophen anführt, sondern den grosse[ $n]$ Spottvogel ${ }^{47}$ Lukian von Samosata, der allerlei Fabelhaftes über den Mond geschrieben habe - etwa, dass es dort einen Staat von Mondleuten gebe, auch allerlei seltsame Tiere und einen Brunnen, über welchem stehe ein Spiegel / darin man alles sehen (ja auch hören) kan / was hierunter auff Erden geschehet. ${ }^{48}$ Dem Polyhistor Lauremberg ist natürlich bewusst, dass Lukians Fabeln keineswegs antiker Lehrmeinung entsprechen. Um diese geht es ihm aber auch nicht, sondern darum, an den Wundern des Himmels den Gegensatz von Dichtung und Wahrheit zu exemplifizieren. Der tubus opticus, das Fernglas, steht für einen Erkenntnisprozess, in dessen Verlauf durch die Gewinnung neuen Wissens eben jene Areale des Unbekannten ausgeleuchtet werden, auf die sich Lukians Dichtungen beziehen. ${ }^{49}$ Das Wunderbare bleibt dabei auf beiden Seiten im Spiel. Auch die neuen Entdeckungen bezeichnet Lauremberg als newe seltzame und Wunderdinge. ${ }^{50}$ Jedoch besteht er darauf, dass in ihrem Fall das Wunderbare nicht wie in den Geschichten Lukians auf Lüge basiert, sondern Effekt der Neuheit und Außerordentlichkeit des in Rede stehenden Wissens ist. Würde Lukian selbst von diesen Dingen erzehlen hören, so Lauremberg, so würde er sie zweiffels ohne seinen warhafftigen Lügen gleich halten [...]. Dennoch es keine erdichtete Fratzen / sondern warhafftige vnd vnfeilbare Dinge seyn..$^{51}$

Laurembergs Diskurs um Fiktion und Wahrheit liefert wichtige Anhaltspunkte für die Analyse des Verhältnisses von Satire und Wunderbarem in Grimmelshausens Vogel-Nest. Zu Lukian führen dabei gleich mehrere Spuren. Da ist zum einen das satirische Druckprivileg des zweiten Teils, das Grimmelshausen als Dokument aus der Kanzlei des Mondkönigs Nullander ausgibt. Dass für diese Invention kein anderer als Lukian Pate steht, wird bereits im ersten Satz deutlich. Das Wercklein, so heißt es hier, habe das Privileg

vom Grossen und zwar Unsichtbaren / und also auch Aller-Unüberwindlichsten Groß-König der Welt grossen und allervolckreichsten Landschafft Selenitite, (worinnen die Weiber / wie Lucianus bezeuget / gantze Körb voll Eyer legen / und Schockweise ihres gleichen Menschen darauß

47 Lauremberg: Acerra Philologica (Anm. 46), S. 165.

48 Lauremberg: Acerra Philologica (Anm. 46), S. 166.

49 Es sei an dieser Stelle betont: Bei der Auseindersetzung Laurembergs mit Lukian geht es nicht um den Erweis der Lügenhaftigkeit der lukianischen Dichtungen. Dass diese erfunden sind, gibt Lukian selbst zu. Im Mittelpunkt des Interesses steht das Wissen über die entfernten Teile der Welt (Mond, Planeten, Sonne usw.), auf die sich Lukians Imagination - aus Sicht Laurembergs - frei beziehen konnte, weil über sie zu seinen Lebzeiten wenig oder nichts bekannt war.

50 Lauremberg: Acerra Philologica (Anm. 46), S. 166.

51 Lauremberg: Acerra Philologica (Anm. 46), S. 166. 
brüten / ) daß es nemlich kauffen darff / wer Lust / Lieb und Geld darzu hat. ${ }^{52}$

Fällt das Wunderbarliche Vogel-Nest damit ins Hoheitsgebiet eines Souveräns, dessen Reich Lauremberg als Beispiel für die erdichteten Fratzen Lukians anführt, so liegt die Pointe des simplicianischen Konzeptes in der Aufwertung des fiktionalen Wunderbaren gegenüber objektiven Erkenntnisverfahren, wie Lauremberg sie beschreibt. Durch das Vogelnest, so lautet das Versprechen des ersten Titelkupfers, soll eine Wahrheit über die Welt sichtbar werden, die der optisch gerüstete Beobachter auch dann nicht erkennt, wenn er die Dinge der Welt etzliche zwantzig / ja hundertmal vermehret vnnd vergrössert (Lauremberg).

Dies lenkt den Blick auf den Kernaspekt von Grimmelshausens LukianRezeption. ${ }^{53}$ Demnach geht es im Vogel-Nest (auch) um die reflexive Begründung einer Schreibweise des Wunderbaren, die ihre Fiktionalität nicht nur offen ausstellt, sondern als notwendige Bedingung des satirischen Erkenntnisverfahrens begreift. Charakteristisch für diese Form menippeischer Fiktionalitätsaffirmation ist die Gleichzeitigkeit von Entgrenzung und Paradoxierung der satirischen Perspektive. Wie Koppenfels im Rückgriff auf Bachtin und Frye betont, gewinnt die Menippea seit der Antike ihr alteritäres epistemologisches Profil durch die Entfaltung exzentrischer Perspektiven auf die Welt. ${ }^{54}$ Diese können extraterristrischer Natur sein, etwa wenn Lukian seinen Helden auf den Mond schickt, wo er durch einen wunderbaren Brunnen alles sehen ( $j a$ auch hören) kan / was hierunter auff Erden geschehet (Lauremberg). Möglich sind aber auch "Situationen innerweltlicher Exzentrik", die - wie die Metamorphosen des Apuleius, aber eben auch Grimmelshausens Vogel-Nest zeigen - ein nicht weniger großes satirisches Transgressionspotenzial freisetzen. ${ }^{55}$ Der Mehrwert an Erkenntnis, der durch die Aufhebung natürlicher, religiöser und epistemischer Grenzen von Beobachtung im Zeichen des Wunderbaren entsteht, bleibt dabei an Formen „paradoxe[r]

52 Grimmelshausen: Vogel-Nest II. In ders.: Werke I/2 (Anm. 27), S. 449-650, hier S. 453. Den Höhepunkt der Ironie erreicht das simplicianische Privileg, wenn Nullander - bei Lukian heißt der Mondkönig Endymion - am Ende (ebd., S. 455) allen und jeden das Recht erteilt, diß Tractätlein in Teutscher Sprach aller Orten und Enden nachzutrucken / feil zu haben / zu verkauffen / zu verstechen / und zu veralieniren / und zu ihrem allerbesten Nutzen zu verwenden / wann und so offt es ihnen beliebt [...].

53 Ohne auf Lauremberg einzugehen, thematisiert die Lukian-Rezeption Grimmelshausens Trappen: Grimmelshausen und die menippeische Satire (Anm. 14), S. 312f. Warum Trappen Grimmelshausen keine direkte Lukian-Lektüre zutraut, sondern hartnäckig von Garzoni als Vermittler ausgeht, bleibt sein Geheimnis. Zumindest Lukians Wahre Geschichten waren durch die Übersetzung des Andreas Heinrich Bucholtz (1607-1671) zu Grimmelshausens Zeit auch des Lateinischen unkundigen Lesern bequem zugänglich. Weitere Lukian-Kenntnis hätte Grimmelshausen aus Gabriel Rollenhagens Vier Büchern Wunderbarlicher biß daher unerhörter / und ungleublicher Indianischer Reisen (erstmals 1603) beziehen können.

54 Werner von Koppenfels: Der andere Blick oder Das Vermächtnis des Menippos. Paradoxe Perspektiven in der europäischen Literatur. München 2007, S. 27-29.

55 Koppenfels: Der andere Blick (Anm. 54), S. 27. 
Widersprüchlichkeit der Standpunkte" ${ }^{56}$ gekoppelt, die bei Lukian und seinen frühneuzeitlichen Nachfolgern zum Ausweis skeptischer Erkenntnispositionen innerhalb markiert-fiktionaler Erzählprogramme werden. ${ }^{57}$ In diesem Sinne kann gesagt werden, dass die Paradoxierung von Perspektiven in der Menippea stets eine metareflexive Funktion erfüllt. Der Akt des Überschreitens von Grenzen der Natur, der Religion und des epistemischen Wissens dient nicht nur der Verunsicherung etablierter Modelle einer "Systematik der Welt". ${ }^{58}$ Auch und darüber hinaus geht es um eine Auseinandersetzung des literarischen Textes mit den paradoxen Grundlagen seines eigenen Erkenntnisverfahrens. Wo dies geschieht, spiegelt der „andere Blick“ (Koppenfels) der Menippea sich in sich selbst zurück und eröffnet Räume poetologischer Reflexion, in denen eine skeptische Beobachtung der Verflechtung literarischer, religiöser, politischer und epistemischer Ordnungskonzepte möglich wird.

Im ersten Teil von Grimmelshausens Vogel-Nest gewinnt das metareflexive Verfahren seine besondere Dynamik durch die Paradoxierung der satirischen Erkenntnisposition im Spannungsfeld religiöser und politischer Beobachtung des Menschen. Auf die religiösen Einwände gegen die Macht, die das Nest verleiht, wurde zu Beginn dieses Abschnitts bereits eingegangen: Das Nest gilt den Frommen und Bekehrten als eine vom Teufel inszenierte Versuchung, stellt es mit seiner wunderbaren Kraft doch die Souveränität Gottes in Frage (und muss aus christlicher Sicht daher vernichtet werden). Auf der anderen Seite geht es im Roman um das Verhältnis der Satire zu Konzepten politischer Souveränität. Ausgangspunkt des diesbezüglichen Reflexionsprozesses ist die von Rechulin ins Spiel gebrachte Vorstellung, dass das unsichtbar machende Nest als unübertreffliches Machtmittel irdischer Herrschaft dienen könnte. Frisch im Besitz des Nestes ahnt der Hellebardierer bereits, dass er etwas in Händen hält, das der König von Engelland umb alle seine Königreich und Provintzien zu erlangen gesonnen sein müsste. ${ }^{59}$ Die Angemessenheit dieser Einschätzung erhellt aus der Gyges-Erzählung, auf die an derselben Stelle verwiesen wird. Wie der Lyderkönig Kandaules seine Herrschaft nicht gegen den Schäfer Gyges behaupten kann,

56 Koppenfels: der andere Blick (Anm. 54), S. 26.

$57 \mathrm{Zu}$ Lukians Rolle als Vertreter skeptischer Positionen vgl. Jennifer Hall: Lucian's Satire. New York 1981; zur Skepsis als philosophische Basis menippeischer Schreibweisen allgemein Koppenfels: Der andere Blick (Anm. 54), S. 22-24.

58 Koppenfels: Der andere Blick (Anm. 54), S. 19.

59 Grimmelshausen: Vogel-Nest I. In ders.: Werke I/2 (Anm. 27), S. 297-447, hier S. 301. In der nach Grimmelshausens Tod erschienenen Werkausgabe C1 von 1683 wird das Gedankenspiel weiter ausgebaut. Nicht nur der König von England, auch der französische König (der seinen Louvre für das Nest hergeben würde) und der Papst werden hier als potenzielle Eigner des Nestes thematisiert. Insbesondere die Referenz auf Ludwig XIV. stellt eine interessante Erweiterung dar, wird dessen schrankenlose Machtgier im zweiten Teil doch zum zentralen Gegenstand tiefgreifender politischer Erörterungen der Figuren. Vgl. Grimmelshausen: Vogel-Nest II. Texterweiterungen. In ders.: Werke I/2 (Anm. 27), S. 880-889, hier S. 881 . 
weil dieser über die Macht der Unsichtbarkeit verfügt, so birgt laut Rechulin auch das Vogelnest die Kraft, seinen Träger auß aller Menschen Gewalt zu erlösen. ${ }^{60}$ Diese Bemerkung spitzt den metareflexiven Diskurs - die Spiegelung des ,anderen Blickes' des Textes auf sich selbst - auf das Moment der exemptio als Kerntheorem frühneuzeitlicher Souveränitätslehre zu. Dieser Spur ist im Folgenden mit Blick auf das Funktionsspektrum satirischer Poetik bei Grimmelshausen genauer nachzugehen.

Was der simplicianische Text als Souveränitätsparadox an sich selbst beobachtet, ist in der frühneuzeitlichen Satiretheorie in nuce bereits angelegt. So hat Berns auf den Umstand verwiesen, dass der Argwohn gegen die Satire im 17. Jahrhundert nicht zuletzt aus deren exemptiven Status innerhalb des literarischen Systems resultiere, und dies an einer Stelle aus Gottfried Wilhelm Sacers Literatursatire Reime dich / oder ich fresse dich (1673) belegt. ${ }^{61}$ Angeblich mit Scaliger stellt Sacer hier fest, dass das einzige Gesetz, nach dem sich die Satire richte, das Gesetz der Gesetzlosigkeit sei: Haec scribendae Satyrae lex est, scribendi sine lege. ${ }^{62}$ Sacers Argumentation läuft allerdings nicht auf eine Affirmation des Satzes hinaus. Vielmehr geht es ihm darum, diejenigen Autoren des Regelverstoßes zu überführen, die die - an sich zutreffende - Bestimmung Scaligers als Legitimationsgrundlage für das Schreiben von Schmähschriften und Pasquillen nutzten. Entsprechend rasch ist der Jurist mit einer Einschränkung des Souveränitätsbegriffes bei der Hand. Auch die Satire habe am Ende ihre Leges auff gewisse maaß [...] / wie bei Scaligero, Jacob Balde, Massenio, Alexandro Donato und andern zu lesen. ${ }^{63}$ Die Konzeptualisierung des Satirikers als unbeobachtbarem Beobachter erscheint bei Sacer in ihrer Bedrohlicheit damit deutlich abgemildert. Welcher Art die Leges sind, denen sich die Satire zu unterwerfen hat, spielt für ihn dabei keine wesentliche Rolle. ${ }^{64}$ Entscheidend ist, dass es diese Gesetze gibt. Sie ermöglichen eine (immanente) Beobachtung des satirischen Beobachters, der bei

60 Grimmelshausen: Vogel-Nest I. In ders.: Werke I/2 (Anm. 27), S. 297-447, hier S. 441.

61 Jörg Jochen Berns: Policey und Satire im 16. und 17. Jahrhundert. In: Simpliciana 13 (1991), S. 423-441, zum Folgenden hier bes. S. 432-434.

62 [Gottfried Wilhelm Sacer:] Reime dich / oder ich fresse dich / Das ist / deutlicher zu geben / ANTIPERICATAMETANAPARBEUGEDAMPHIRIBIFICATIONES POETICAE oder Schellen- und Scheltenswürdige Thorheit Boeotischer Poeten in Deutschland / [...] Zu belachen und $\mathrm{zu}$ verwerffen vorgestellet von Hartmann Reiholden [...]. Northausen / Bey Barthold Fuhrmannen. 1673, S. 56. Laut Sacer handelt es sich bei dem Satz um ein Zitat aus Scaligers De re poetica. Welchen Text er damit meint, ist unklar. In Julius Caesar Scaligers Poetices libri septem (1561) ist die Stelle nicht aufzufinden. Daher liegt der Verdacht nahe, dass Sacers Referenz falsch ist und der Satz aus einer anderen Poetik des 16. Jahrhunderts, etwa aus Georg Fabricius' De re poetica (1565), stammt. Ob dies der Fall ist, wäre zu prüfen.

63 Sacer: Reime dich / oder ich fresse dich (Anm. 62), S. 56.

$64 \mathrm{Zu}$ den Rahmenbedingungen und zum Verlauf der diesbezüglichen Debatte vgl. Christoph Deupmann: Furor satiricus. Verhandlungen über literarische Aggression im 17. und 18. Jahrhundert. Tübingen 2002. 
Sacer damit letzthin in die - wiederum paradoxe - Lage versetzt wird, souverän zu operieren, ohne auß aller Menschen Gewalt (Rechulin) erlöst zu sein.

Der Blick auf die zeitgenössische Satiretheorie macht deutlich, wie rückhaltlos sich das Vogel-Nest auf das Konzept unbeobachtbarer Beobachtung einlässt. Von einer ,Lösung' des poetologisch gewendeten Souveränitätsparadoxes im Sinne Sacers will Grimmelshausens Roman nichts wissen. Das hat seinen Grund in der skizzierten Eigenschaft menippeischer Satire, die „paradoxe Widersprüchlichkeit der Standpunkte“ (Koppenfels) nicht nur auszuhalten, sondern - als Katalysator des skeptischen Einwandes gegen das je herrschende politische (religiöse, epistemische etc.) Stabilisierungsideal - poetisch produktiv werden zu lassen. Das Vogel-Nest I tut dies, indem es mit dem städtischen Ordnungsbeamten Rechulin einen diegetischen Vertreter des Titelkupfer-Satyrs präsentiert, der sich dem ordo-Denken politischer Souveränität erkennbar verpflichtet fühlt. Wenn der Hellebardierer unsichtbar in Wohnstuben, Küchen und Keller eindringt, um das Tun und Lassen der Menschen zu beobachten (und gegebenenfalls zu intervenieren), so handelt er im Einklang mit dem „Ideal der vollkommenen Information", 65 wie es die Policey-Literatur des 17. Jahrhunderts propagiert. Als größter Tugendheld erscheint ihm jener edle Römer, der sein Haus ohne jeden Winkel der Verborgenheit hätte bauen lassen:

Wie vermeinest du wol / daß uns Christen jener edle Römer / der doch nur ein Heid war / und den wahren GOtt nicht erkannte / an jenem grossen Tag / daran alle Werck offenbahr werden sollen / beschämen wird / umb willen er nicht gewollt / daß ihm der Bau / oder Werckmeister sein Hauß bauen solte / daß niemand sehen könte / was darinn geschahe / sondern im Gegentheil begehrte / solches also zuzurichten / daß jederman schauen und wahrnehmen könte / was darinnen vorgieng. ${ }^{66}$

Entsprechend schrankenlos erstreckt sich Rechulins Erkenntnisinteresse in alle Winkel der Welt. Wohin er blickt, entdeckt er Normverstöße: Angefangen mit der Problematik des verarmten Adels, der seine Repräsentationspflichten nicht mehr erfüllen kann, ${ }^{67}$ über das Problem der falschen Bettler, ${ }^{68}$ die Armut, ${ }^{69}$ die

65 Justus Nipperdey: ,Intelligenz' und ,Staatsbrille'. Das Ideal der vollkommenen Information in ökonomischen Traktaten des 17. und frühen 18. Jahrhunderts. In: Information in der Frühen Neuzeit. Status, Bestände, Strategien. Hrsg. von Arndt Brendecke und Sabine Friedrich. Münster 2008, S. 277-299.

66 Grimmelshausen: Vogel-Nest I. In ders.: Werke I/2 (Anm. 27), S. 297-447, hier, S. 413.

67 Rechulin beobachtet die komisch-scheiternde Eheanbahnung in einem mittellosen Adelshaus. Vgl. Grimmelshausen: Vogel-Nest I. In ders.: Werke I/2 (Anm. 27), S. 297-447, hier S. 304-317.

68 Rechulin zieht ein Stück Wegs mit einer Gruppe ,starker' Bettler. Vgl. Grimmelshausen: Vogel-Nest I. In ders.: Werke I/2 (Anm. 27), S. 297-447, hier S. 317-322.

69 Rechulin im Haus einer armen Familie. Vgl. Grimmelshausen: Vogel-Nest I. In ders.: Werke I/2 (Anm. 27), S. 297-447, hier S. 368-373. 
Frage nach der Ordnung des religiösen Lebens (cura religionis), ${ }^{70}$ die Hygiene, ${ }^{71}$ die Gastwirtschaften, ${ }^{72}$ bis hin zur Beobachtung der Ordnung in den Haushalten (cura oeconomiae $)^{73}$ reihen sich die Episoden $\mathrm{zu}$ einem Generalaufriss policeylicher Erkenntnisbereiche. Mühelos überbietet Rechulins Erfahrung dabei überliefertes Buchwissen. Bei der Beobachtung eines Schäferehepaares meint er, so viel gesehen zu haben, dass man den treuherzigen Colerum wol beschuldigen" könne, er seye den Schäfern noch lang nicht hinter alle ihre Schelmstück und Diebsgriffe kommen / wiewol er deren zimlich in seiner Oeconomia erzehlet. ${ }^{74}$

Um zu verstehen, auf welcher historischen Basis die Verschränkung satirischer und policeylicher Beobachtung bei Grimmelshausen steht, lohnt ein kurzer Seitenblick auf den Policey-Diskurs der Zeit. Dieser nämlich ist von einer Tendenz geprägt, die man mit Alt als Tendenz zur "Zerstreuung von Souveränität ${ }^{\prime 75}$ bezeichnen kann. Anders als noch vor dem Dreißigjährigen Krieg gehen die Policey-Schriften im späteren 17. Jahrhundert davon aus, dass die Stabilität des Staates nicht allein vom Auge des Fürsten garantiert werden könne. Vielmehr bedürfe es der Ausbildung eines Apparates von Policey-Beamten, die ihre Augen überall dorthin wenden, wo die „unmittelbare Gouvernementalität des Souveräns als Souverän"76 nicht hinsehen kann. Welche Spannungen dies im Souveränitätsdiskurs erzeugt, lässt sich anhand eines Abschnittes aus Harsdörffers Teutschem Secretarius (1655/59) erhellen. Unter dem Titel Von dem Rugambt präsentiert der zweite Teil der Schrift zwei Briefe, deren fiktive Urheber über die Notwendigkeit der Einführung einer policeylichen Institution, des sogenannten Rugambtes (Rügeamtes), diskutieren. Während der Schreiber des ersten Briefes entschieden pro-policeylich argumentiert und anführt, ohne Rügeamt würde erst dieses und jenes Hauswesen / endlich auch das gantze Regiment / als welches in Haushaltungen bestehet / zu Grund fallen, äußert der Respondent Zweifel. ${ }^{77}$ Aus

70 Rechulin beendet die Provokationen einiger Calvinisten gegen zwei Katholiken durch eine beherzte Ohrfeige. Vgl. Grimmelshausen: Vogel-Nest I. In ders.: Werke I/2 (Anm. 27), S. 297-447, hier S. 323-330.

71 Rechulin beobachtet eine Bäuerin dabei, wie sie auf einen zum Verkauf bestimmten Käse uriniert. Vgl. Grimmelshausen: Vogel-Nest I. In ders.: Werke I/2 (Anm. 27), S. 297-447, hier S. 334f.

72 Rechulin beim Wirt, der Wein verdünnt (vgl. Grimmelshausen: Vogel-Nest I. In ders.: Werke I/2 (Anm. 27), S. 297-447, hier S. 342f.), und beim reumütigen Wirt (ebd., S. 386f.).

73 Rechulin beim geizigen Bauern (vgl. Grimmelshausen: Vogel-Nest I. In ders.: Werke I/2 (Anm. 27), S. 297-447, hier S. 330-334), im Haus des sterbenden Reichen (ebd., S. 336-341), im Haus der armen Familie (ebd., S. 368-373), bei den Schäfern (ebd., S. 385-386). Weitere Episoden könnten angeführt werden.

74 Grimmelshausen: Vogel-Nest I. In ders.: Werke I/2 (Anm. 27), S. 386.

75 Peter-André Alt: Der Tod der Königin. Frauenopfer und politische Souveränität im Trauerspiel des 17. Jahrhunderts. Berlin u.a. 2004, S. 204.

76 Michel Foucault: Sicherheit, Territorium, Bevölkerung. Geschichte der Gouvernementalität I. Vorlesung am Collège de France 1977-1978. Aus dem Französischen von Claudia BredeKonersmann und Jürgen Schröder. Frankfurt a.M. 2004, S. 488.

77 Vgl. [Georg Philipp Harsdörffer:] Deß Teutschen Secretarii Zweyter Theil. Oder: Allen 
seiner Sicht sind die Rugbedienten dort, wo [...] der Fürsten und Herren sind [...] nicht von nöthen / als welcher einen jeden / nach den Gesetzen deß Landes / zu gebührlicher Straffe / an Gelt oder am Leib zu verurtheilen wissen wird. ${ }^{78}$ Die Rollen sind klar verteilt: Des Respondenten Ablehnung des Rügeamtes wendet sich gegen die Tendenz zur ,Zerstreuung der Souveränität', während der erste Briefschreiber von einer das Staatswohl gefährdenden Begrenzung des absoluten Herrscherblicks ausgeht (massen unmüglich ist / daß die Obrigkeit aller Orten mit zusehen kön$n e)^{79}$. Sein Entwurf eines geordneten Policey-Staates, in dem "die Rugbeamten zu der Burgerlichen Gebühr antreiben, die Gleichstimmigkeit und Gleichständigkeit deß Regiments wolklingend $z$ u machen, ${ }^{80}$ wird vom Respondenten indes als Illusion entlarvt. Davon auszugehen, dass alle Rugbeamte[ $n$ ] [...] redliche Leute seyn / welche sich mit Geschenck nicht blenden / mit Freundschafft und Feindschafft die Pflicht nicht vergessen / oder in andere Wege sich von ihrer Ambtsgebühr nicht wendig machen lassen, ${ }^{81}$ sei gefährlich, da auf diese Weise die zu Laster und Sünde neigende Natur des Menschen vergessen werde. In der Praxis werde zu beobachten sein, daß die Rüger gleich seyn den Lamien / die von aussen viel und alles übersehen / inwendig aber / was ihre eigne Laster betrifft / blind sind. ${ }^{82}$ Dass sich damit schließlich auch der Respondent in Widersprüche verwickelt, liegt auf der Hand. Einerseits befürchtet er, dass die Rügebeamten aufgrund mangelnder moralischer Selbstkontrolle zu Schädlingen des Staates werden könnten. Andererseits begründet er seine Ablehnung des Rügeamtes damit, dass es für die Stabilisierung staatlicher Ordnung ausreiche, wenn jeder Untertan sein Handeln vor seinem christlichen Gewissen und vor Gott verantworte (Es ist genug / daß er Gott und seinem Gewissen Rechenschafft geben). ${ }^{83}$ Wer verhindert dann aber die Destabilisierung des Gemeinwesens dort, wo moralische Selbstkontrolle der Untertanen ausbleibt?

Cantzleyen / Studier= und Schreibstuben dienliches Titular- und Formularbuch [...]. Alles nach gebräuchlichem Hof= Cantzley und Handels=Stylo zusammen getragen $/$ auffs neu übersehen / und mit allem Fleiß corrigirt, von Etlichen Liebhabern der Teutschen Sprache. [...] Nürnberg / Jn Verlegung Christoph und Paul Endtern / Buchhändlern. Jm Jahr 1661, S. 507.

78 Harsdörffer: Deß Teutschen Secretarii Zweyter Theil (Anm. 77), S. 508.

79 Harsdörffer: Deß Teutschen Secretarii Zweyter Theil (Anm. 77), S. 506.

80 Harsdörffer: Deß Teutschen Secretarii Zweyter Theil (Anm. 77), S. 506.

81 Harsdörffer: Deß Teutschen Secretarii Zweyter Theil (Anm. 77), S. 506.

82 Harsdörffer: Deß Teutschen Secretarii Zweyter Theil (Anm. 77), S. 509. Die mythologische Allusion des Respondenten ist drastisch: Wie man in Plutarchs De Pythia oraculis (Kap. 9) nachlesen kann, gehen die Lamien der antiken Mythologie auf die libysche Königin Lamia zurück, eine Geliebte des Zeus-Jupiter, der ihr die Fähigkeit verlieh, die Augen aus dem Leib zu nehmen. Nach der Ermordung ihres Sohnes verwandelt Lamia ihr Haupt in einen Schlangenkopf und treibt als grausame Kindermörderin ihr Unwesen.

83 Harsdörffer: Deß Teutschen Secretarii Zweyter Theil (Anm. 77), S. 509. Bezüglich der Unterscheidbarkeit von Gut und Böse ist der Respondent übrigens Optimist. Es sei kein Mensch so dumm / daß er nicht das Böse von dem Guten solte unterscheiden können - eine Aussage, die zur pessimistischen Beobachtung der Rugbeamten in Spannung steht. Vgl. Harsdörffer: Deß Teutschen Secretarii Zweyter Theil (Anm. 77), S. 510. 
Hierauf gibt es bei Harsdörffer keine Antwort: Die Diskussion mündet in eine Sackgasse, an deren Ende die Bruchlinie zwischen religiöser und politischer Beobachtung des Menschen (als Kind Adams/als Untertan) sichtbar wird, um die auch die Diskurse des simplicianischen Romans kreisen.

Die Parallelen zwischen Harsdörffers und Grimmelshausens Diagnosen fallen ins Auge. Im Teutschen Secretarius wie im Vogel-Nest I verdichtet sich das Problem unbeobachtbarer Beobachtung nicht an der zentralen Sichtachse des Souveräns, sondern im peripheren Raum von Staat und Welt, den die exzentrische Perspektive der Rügebeamten/des Vogelnestträgers erschließt. Geht es hier wie dort darum, die Obrigkeit - bei Grimmelshausen: den Leser - aller Orten mit zusehen zu lassen, so gerät dieser Anspruch in beiden Texten in Konflikt mit einem Diskurs religiöser Weltabstinenz, dessen einzig gestatteter Erkenntnismodus derjenige der frommen Selbsterkenntnis des Menschen ist. In der jeweils empfohlenen bzw. vollzogenen Abkehr vom ,Ideal der vollkommenen Information' (Nipperdey) kommt es zu einer Abspaltung des Anderen vom göttlichen Eigenen des Christenmenschen, die mit einer Dämonisierung des Abgespaltenen einhergeht: Aus den Rügebeamten bei Harsdörffer werden monströse Lamien, während Rechulin sein Handeln als Vogelnestträger an der religiösen Schlüsselstelle des Textes metapoetisch unzweideutig mit dem dämonischen Treiben des Satyrs assoziiert. [W]ie ein geiler Bock und wider Natur strebender Satyrus (deren Gestalt und Annehmung den höllischen Geistern zum höchsten beliebet), sei er für seine eigene Laster blind gewesen - und dies, wie er ergänzt, ausgerechnet dort, wo Gott ihm durch Vorstellung anderer Leute / ihnen selbst verderblichen Exempeln (daran du dich billich hättest spiegeln sollen) gelernet / daß du seine Gegenwart allweg vor Augen haben und zu deinem Nutz ehren soltest. ${ }^{84}$

Die Formulierung ist zu beachten, nicht nur, weil sie die liminale Stellung des Außernatürlich-Wunderbaren in der Frühen Neuzeit in Erinnerung ruft. ${ }^{85}$ Auch wird in ihr die Widersprüchlichkeit der Perspektiven bis zu dem Punkt zugespitzt, an dem die funktionale Paradoxie simplicianischer Satire an die Textoberfläche tritt. Sie besteht darin, dass die Vorstellung von verderblichen Exempeln, die Rechulin nun als Strategie Gottes zur Besserung des Menschen auffasst, im satirischen Verfahren des Textes an das wunderbare Erkenntnismedium des Nestes und damit an das Andere göttlicher Ordnung gebunden bleibt. Wenn Rechulin das Nest am Ende des ersten Teils zum Zeichen seiner Bekehrung vernichtet, geht er damit auch gegen das satirische Prinzip vor, dem er seine Bekehrung verdankt.

84 Vgl. Grimmelshausen: Vogel-Nest I. In ders.: Werke I/2 (Anm. 27), S. 297-447, hier S. 430.

85 Zur dämonischen Dimension von Satyr und Satire im 17. Jahrhundert vgl. Bergengruen: Nachfolge Christi (Anm. 24), S. 267-285; außerdem Walter E. Schäfer: Der Satyr und die Satire. Zu Titelkupfern Grimmelshausens und Moscheroschs. In: Literatur im Elsaß von Fischart bis Moscherosch. Gesammelte Studien. Hrsg. von Wilhelm Kühlmann und Walter E. Schäfer. Tübingen 2001, S. 245-287. Hier bes. S. 258. 
4

Mit dem Verfahren der Vorstellung von verderblichen Exempeln spricht Rechulin das erbauungspoetische Konzept an, das ihn zur Abfassung jener Erzählung, die in der simplicianischen Diegese als das wunderbarliche Vogel-Nest / ein so genanntes Tractätlein in offenem Druck ${ }^{86}$ zirkuliert, motiviert. Wenngleich vom Schreibakt im Roman litteraliter nicht erzählt wird, bleiben dessen subjektive Voraussetzungen keineswegs im Dunkeln - zu offensichtlich lädt die Erzählung von der Vernichtung und Ausstreuung des Nestes im Irgendwo des Schwarzwaldes zu einer allegorischen Deutung als Schreibszene ein. Welche Autoritäten Rechulins Denken als Autor bestimmen, zeigt seine Sprache. ${ }^{87}$ Vom Moment des Zerreißens des Nestes berichtet der Hellebardierer in einer Diktion, in der sich typische Elemente biblischer Offenbarungsrhetorik [a] mit Elementen juridisch-bürokratischer Sprache [b] mischen:

Sihe [a] so fällete ich das Urtheil [b] darüber / daß es [das Nest, S.Z.] unverweilet cassiret und vertilgt $[\mathrm{b}]$ werden solte / nahme es derowegen auß meinem Busen hervor / und zerrisse es wol zu sibenzehenhundert Fetzen. Gehe hin [a] / sagte ich / deinet halben soll hinfort keines Menschen Heimligkeit durch einen andern gesehen und offenbaret werden [...]. ${ }^{88}$

Die lokale Sprachanalyse zeigt: Im Moment des Zerreißens des Nestes konkurrieren in Rechulins Diskurs eben jene Codes, die auf metareflexiver Ebene des Textes als unvereinbar beobachtet werden. Dem vom Nest kurierten, in seinem Selbstbild jedoch alles andere als demütigen Hellebardierer bleibt dieser Widerspruch freilich unbewusst (soweit dieser Begriff auf frühneuzeitliche Figurenkonzepte angewendet werden kann). Anstatt die zumal aus religiöser Sicht bedrohlichen Paradoxien satirischen Schreibens zu erkennen und vom Abfassen des Wunderbarlichen Vogel-Nestes abzusehen - was in der Konsequenz bedeuten würde, dass das simplicianische Buch auch dem realen Leser nicht zur Verfügung stände -, imaginiert er eine Ordnung der Dinge, in die die Geltungen von Religion und Politik konfliktlos integrierbar erscheinen. Unter dieser Voraussetzung bringt der Bekehrte seine Erzählung als gedrucktes Buch unters Volk - ein Vorgang, den der Text allegorisch durch die Geste des Ausstreuens der sieben-

86 Dass das Buch in der simplicianischen Diegese zirkuliert, bestätigt mit diesen Worten der dritte Vogelnestträger, der, sich Rechulins Bericht zum Vorbild nehmend, am Ende des zweiten Teils seine eygene Histori verfasst. Vgl. Grimmelshausen: Vogel-Nest II. In ders.: Werke I/2 (Anm. 27), S. 449-650, hier S. 650.

87 Als Meta-Schreibweise, die von der Hybridisierung von Sprach- und Diskurstypen (Satyra als satura, Mischmasch etc.) lebt, ist die menippeische Satire ein - wenn nicht das - Beispiel für die Leistungsfähigkeit vormoderner Verfahren sprachorientierter Diskursanalyse. In der systematischen Untersuchung dieses Aspekts liegt ein bisher weitgehend unbearbeitetes Feld (nicht nur) der Grimmelshausen-Forschung.

88 Grimmelshausen: Vogel-Nest I. In ders.: Werke I/2 (Anm. 27), S. 297-447, hier S. 441 (Hervorhebung S.Z.). 
zehnhundert Nestfetzen thematisiert. ${ }^{89}$ In Rechulins Vorstellung soll das Wunderbarliche Vogel-Nest, wenn es in der Welt/im Staat zirkuliert, zur Stabilisierung des ordo beitragen. Inspiriert wird dieser Gedanke durch die Betrachtung der im Wald umher laufenden Ameisen, die, wie Rechulin staunend bemerkt, die Fetzen des Nestes in mühevoller, uneigennütziger Arbeit in ihren Haufen einbauen:

Weilen sich dann eben ein grosser Ameyssen-Hauffe neben mir fande / dessen Jnwohner überauß geschäfftig waren allerhand Materialia, und sonderlich das Genist von dem zerrissenen Vogel-Nest einzutragen; so sahe ich deren emsigen Fleisse und unverdrossene Arbeit mit Verwunderung zu / und erinnerte mich deß Spruchs Salomonis / da er sagt / gehe hin du Fauler zu den Omeysen / etc. da beobachtete ich / wie eine der andern so vernünfftig auß dem Weg wiche / wie eine der andern ihren Last tragen halffe / wie sie alle so einmüthig waren ihre Arbeit zu befördern / und so fortan; darauß nun faste ich allerhand schöne Lehren / und nahm mir einen Hauffen guts Dings hinfort zu vollbringen vor $[\ldots] .{ }^{90}$

Die alteuropäische „Faszinationsgeschichte“ der Beobachtung von Ameisenstaaten ${ }^{91}$ braucht nicht umständlich entfaltet $\mathrm{zu}$ werden, um festzustellen, welche Funktion die von Rechulin gefassten schöne[n] Lehren im allegorischen Verhandlungsraum der Passage übernehmen sollen. $\mathrm{Zu}$ evident ist die Ersetzung der Modi des Außernatürlich-Wunderbaren durch religiöse ordo-Topik, zu durch-

89 Über die Auslegung der Zahl 1700 darf spekuliert werden. Unzweifelhaft ist, dass es sich bei ihr um eine Variante der Zahl 17 handelt, die, wie Breuer gezeigt hat, als Chiffre für die Autorfunktion Grimmelshausen anzusehen ist. Vgl. Dieter Breuer: Die sinnreiche Siebzehn. Zahlenallegorese bei Grimmelshausen. In: Literatur und Kultur im deutschen Südwesten zwischen Renaissance und Aufklärung. Festschrift für Walter E. Schäfer. Hrsg. von Wilhelm Kühlmann. Amsterdam 1995, S. 267-282. Angesichts der Höhe der Zahl kommen allerdings weitere Deutungsmöglichkeiten ins Spiel. Eine davon geht in Richtung einer möglichen Auflage des Wunderbarlichen Vogel-Nestes I: Sollte diese irgendwo zwischen 1500 und 2000 gelegen haben - was immerhin nicht völlig außerhalb der heute üblichen Schätzungen liegt -, könnte der Akt des Zerreißens des Nestes als Hinweis auf die drucktechnische Vervielfältigung des Textes gelesen werden. Eine andere Möglichkeit besteht darin, die Zahl als Hinweis auf die Gesamtzahl der Seiten des Simplicianischen Zyklus' in den Erstausgaben zwischen 1668 und 1675 zu verstehen, die bei knapp über 1700 liegt. Der Einwand, dass Grimmelshausen die finale Seitenzahl des Zyklus' 1672 noch nicht kennen konnte, lässt sich relativieren, wenn man bedenkt, dass der ,Simplicianische Autor' am Ende des ersten VogelNest-Romans die in Kürze zu erwartende Veröffentlichung des zweiten Teils ankündigt. Es ist nicht zu beweisen, aber auch nicht auszuschließen, dass ein Anagrammatiker und Zahlenspieler wie Grimmelshausen den Umfang des Manuskriptes für die Fortsetzung (und damit die daraus wahrscheinlich resultierende Anzahl an Druckseiten) zu diesem Zeitpunkt bereits abschätzen konnte. Nimmt man diese Deutung ernst, so würde in der allegorischen Chiffre der Vernichtung und Ausstreuung des Nestes der metareflexive Bezugsrahmen wesentlich erweitert. Nicht nur der Doppelroman, sondern der gesamte Simplicianische Zyklus als satirisches Großunternehmen stände auf dem Spiel.

90 Grimmelshausen: Vogel-Nest I. In ders.: Werke I/2 (Anm. 27), S. 297-447, hier S. 442.

91 Niels Werber: Ameisengesellschaften. Eine Faszinationsgeschichte. Frankfurt a.M. 2013. 
sichtig die fromme Entparadoxierungsstrategie des Hellebardierers. Das Staunen über die Macht, die das Nest verleiht, weicht hier - oder soll weichen - der Verwunderung (Rechulin) über die von Gott eingerichtete Ordnung von Natur und Welt, die ihre politische Dimension in der auch bei Harsdörffer zum Ideal erhobenen Gleichstimmigkeit und Gleichständigkeit deß Regiments ${ }^{92}$ gewinnt.

Wie nun schon anhand der Ironiesignale in der Bekehrungsszene deutlich wird, ${ }^{93}$ kann die von Rechulin zwar authentisch erfahrene, poetisch-epistemologisch jedoch zweifelhafte erbauliche Wende im Diskurs des AußernatürlichWunderbaren die Paradoxien der Vogel-Nest-Poetik nicht lösen. Die Referenz auf Gottes Ordnung hebt die oben bezeichneten Widersprüche nicht auf, sie setzt sie allenfalls vorübergehend in einen Zustand der Latenz. Entsprechend beschränkt ist die reflexive Reichweite der schöne[n] Lehren, die Rechulin propagiert. Schon das aus der Einsicht in die Schädlichkeit des Nestes resultierende Urteil, es solle hinfort keines Menschen Heimligkeit durch einen andern gesehen und offenbaret ${ }^{94}$ werden, erscheint absurd, sorgt Rechulin als Autor des Vogel-Nestes I doch dafür, dass die Heimlichkeiten der von ihm beobachteten Menschen einem unabsehbar großen Publikum bekannt werden. So kann es schließlich auch nicht verwundern, wenn der simplicianische Text die Figur gewissermaßen überstimmt und ihr Urteil über das Nest aufhebt. Was im Übergang zwischen erstem und zweitem Romanteil cassiret wird, ist nicht das liminale Medium des AußernatürlichWunderbaren (und der menippeischen Satire), sondern die Erbauungspoetik Rechulins, die im blinden Vertrauen auf die ordo-Stabilität der Welt über sämtliche Widersprüche von Glauben und Erkenntnis hinwegsieht. In dieser Hinsicht fungiert das dämonische Spektakel rund um die Wiederauffindung des Nestes

92 Harsdörffer: Deß Teutschen Secretarii Zweyter Theil (Anm. 77), S. 506.

93 Diese Signale wurden von der Forschung bisher regelmäßig ignoriert. Zu nennen sind mindestens drei: Erstens die bereits erwähnte sprachliche Dimension des Bekehrungsaktes; indem Rechulin sich einerseits zum pastoralen Verkünder von Heilsbotschaften (Sihe, Gehe hin), andererseits zum weltlichen Richter (so fällete ich das Urtheil darüber / daß es unverweilet cassiret und vertilgt werden sollte) aufschwingt, überschreitet er seine Kompetenzen und konterkariert vor allem die christlichen Demutsgesten, die seine Bekehrung beglaubigen sollen. Zweitens irritiert aus theologischer Sicht die Ummünzung der Hauffen-Metapher auf die Menge der zu vollbringenden guten Taten (und nahm mir einen Hauffen guts Dings zu vollbringen vor). Die hier artikulierte Quantifizierungslogik im individuellen Heilsverständnis Rechulins ist mit dem postreformatorischen Sünden- und Gnadenverständnis, das in Grimmelshausens Romanen Stand der Dinge ist, kaum vereinbar. Drittens läuft Rechulins Bekehrung auf die bei Grimmelshausen immer wieder ausgespielte Paradoxie der innerweltlichen Außerweltlichkeit hinaus. Das geht so weit, dass der Hellebardierer sich vornimmt, alle verdächtige Oerter zu meiden, da er besorglich sündigen könte / ob er gleich einen steiffen Vorsatz hat nimmermehr zu sündigen, vgl. Grimmelshausen: Vogel-Nest I. In ders.: Werke I/2 (Anm. 27), S. 297-447, hier S. 433. Wie und wo er unter diesen Bedingungen in der simplicianischen Welt fortleben soll, bleibt sein Geheimnis. Die Tatsache, dass die Figur am Ende des ersten Teils die mit tausend Dukaten gefüllten Geldschläuche der Leyrerin in einer Astgabel (!) findet, lässt in sündentheologischer Hinsicht wenig Gutes erwarten.

94 Grimmelshausen: Vogel-Nest I. In ders.: Werke I/2 (Anm. 27), S. 297-447, hier S. 441. 
im zweiten Teil keineswegs nur als moralisch-religiöses Warnsignal an den Leser. ${ }^{95}$ Es markiert auch den Punkt des Wiedereintrittes der Paradoxie in den satirischen Diskurs des Romans. Aus dem Rauch der Beschwörungsszene, wie sie das Titelkupfer zum zweiten Teil zeigt, steigt Deß Wunderbarlichen Vogelnests Zweiter theil als Text gewordene Dementierung der frommen Verdrängung des Außernatürlich-Wunderbaren am Ende des ersten Teils herauf. ${ }^{96}$

Nimmt man die allegorische Deutung der Handlung um das Nest im Ameisenhaufen ernst (und das sollte man), kann gesagt werden, dass das Buch mit dem Titel Das Wunderbarliche Vogel-Nest im zweiten Teil zweimal gefunden und gelesen wird. Die eine Leseszene liefert der Text unverschlüsselt: Am Ende seines Parcours wird der Kaufmann, inzwischen bekehrt und über die Gefahren des Nestes aufgeklärt, zum Aufschreiben seiner Erlebnisse inspiriert, indem er, so seine Worte, das wunderbarliche Vogel-Nest / ein so genanntes Tractätlein in offenem Truck zu meiner Heimkunfft gefunden und gelesen / auch auß den Umbständen gesehen / daß solches eben die jenige Kunst und Materi gewest / die ich gehabt. ${ }^{97}$ Dass das Pronomen solches sich grammatisch hier auf das vorgefundene Buch bezieht, ist mehr als ein Versehen. Mit der Verunsicherung der Differenz zwischen der Kunst und Materi des Vogelnestes und der Kunst und Materi des Vogel-Nestes knüpfen die letzten Sätze des Romans an den allegorisch gefassten metareflexiven Diskurs an, der den Übergang zwischen den Romanteilen beherrscht. In ihr wird der Kaufmann als Figur ins menippeisch-satirische Verfahren des Romans eingeführt. Auf der Suche nach seinem verlorenen Schatz wird er von einem zauberkundigen scholasticus vagans zum Ameisenhaufen geleitet, wo er sich, vor die Wahl zwischen Schatz und Nest gestellt, für das wunderbare Kleinod entscheidet. ${ }^{98}$ Dieses freilich muss aus dem Ameisenhaufen erst geborgen werden. Um herauszufinden, wo sich das stück / welches unter der Ameysen zusammen getragenen Sachen wäre, befindet, nimmt der fahrende Schüler jeweils eine Handvoll Material aus dem Haufen heraus, bis er vor den Augen des Kaufmanns

95 Wobei es, wie Zeller gezeigt hat, wichtig ist, zwischen dem Beschwörungsszenario und dem Vogelnest magiologisch zu unterscheiden. Wenngleich der Kaufmann durch die Hilfe eines Schwarzmagiers zum Nest gelangt, bleibt das Nest selbst ein Gegenstand unklarer Herkunft. Mit anderen Worten: Das Außernatürlich-Wunderbare wird auch im zweiten Teil nicht einfach dämonisiert, sondern fungiert weiterhin als Index epistemischer und religiöser Liminalität. Vgl. Zeller: Magia naturalis (Anm. 15), bes. S. 155-160.

96 Vgl. Grimmelshausen: Vogel-Nest II. In ders.: Werke I/2 (Anm. 27), S. 449-650, hier S. $450 / 451$.

97 Vgl. Grimmelshausen: Vogel-Nest II. In ders.: Werke I/2 (Anm. 27), S. 449-650, hier S. 650.

98 Grimmelshausen: Vogel-Nest II. In ders.: Werke I/2 (Anm. 27), S. 449-650, hier S. 478. Auf die interessante Tatsache, dass die Auffindung des Nestes im Ameisenhaufen zu den simplicianischen Ereignissen gehört, die aus zwei verschiedenen Perspektiven - aus der Rechulins und aus der des Kaufmanns - erzählt werden, kann hier nicht näher eingegangen werden. Als These darf jedoch formuliert werden, dass der Fokalisierungswechsel die Entfaltung widerstreitender, nicht vereinbarer Perspektiven auf das Außernatürlich-Wunderbare im Roman unterstützt. 
unsichtbar wird. ${ }^{99}$ Die anschließende Bergung des, wie es heißt, kleinen Steinlein[s] oder Würtzlein[s], geschieht mit höchster Sorg und Auffsicht und stellt damit die genaue Kontrafaktur der Achtlosigkeit dar, die die Nestsucher beim Aussortieren der natürlichen Materialien des Nestes an den Tag legen. ${ }^{100}$ Der Vorgang lässt sich unschwer als Allegorie auf das Lesen des Wunderbarlichen Vogel-Nestes entschlüsseln. Der Akt des Auf-Lesens (collectio/ receptio) der Nestfetzen steht dabei für eine Lektüre, die alle Illusionen des frommen (Co-)Autors Rechulin zerstört. In der von dämonischen Erscheinungen umlagerten Glücks-Stund, ${ }^{101}$ in der sich der Kaufmann das Nest aneignet, kommt es zu einer Selektion, der diejenigen Elemente des Nestes zum Opfer fallen, die bloß der Stabilisierung des ordo (Ameisenhaufen) dienen. Was für den Kaufmann zählt, sind nicht die Wunder der von Gott geordneten Schöpfung, sondern ist die verlockende Kraft des Außernatürlich-Wunderbaren, das ihm einen Weltzugang jenseits der Grenzen des Bekannten und Erlaubten verspricht.

Wird der letzte Vogelnestträger damit als Leser zu seinem eigenen Gegenbild - am Beginn des Romans liest er das Vogel-Nest im Bann des AußernatürlichWunderbaren, am Ende unter dem Eindruck seiner (temporären?) Bekehrung -, so verbindet sich damit die Frage, wie sich die Doppelung von Leseszenen zum Paradox der Vogel-Nest-Poetik insgesamt verhält. Wichtig ist auch hier zu betonen, dass die unterschiedliche moralisch-religiöse Bewertung der Lektüreakte keine letzten Schlüsse über deren metareflexive Funktion im Roman zulässt. Zwar steht der Rezeptionsvorgang am Ende des zweiten Teils im Zeichen der Warnung des Kaufmanns vor solchen gefährlichen Künsten ${ }^{102}$ und wiederholt damit die erbauliche Distanzierungsgeste, wie Rechulin sie bereits vollführt hatte. Insofern der Kaufmann zur Beglaubigung dieser Abgrenzung jedoch ein weiteres Buch namens Das wunderbarliche Vogel-Nest in die Welt setzt, ist auch dem Ende des zweiten Teils die Möglichkeit einer - von keiner Autorität beherrschbaren - literarischen Wiederkehr des Außernatürlich-Wunderbaren eingeschrieben. ${ }^{103}$ Auf dieser Ebene simplicianischer Metareflexion erscheint die Linearität

99 Grimmelshausen: Vogel-Nest II. In ders.: Werke I/2 (Anm. 27), S. 449-650, hier S. 478.

100 Grimmelshausen: Vogel-Nest II. In ders.: Werke I/2 (Anm. 27), S. 449-650, hier S. 478.

101 Grimmelshausen: Vogel-Nest II. In ders.: Werke I/2 (Anm. 27), S. 449-650, hier S. 479.

102 Grimmelshausen: Vogel-Nest II. In ders.: Werke I/2 (Anm. 27), S. 449-650, hier S. 650.

103 Wie wahrscheinlich diese Rückkehr ist, zeigen die Einlassungen des Simplicianischen Autors - einer Art Meta-Erzähler des Simplicianischen Zyklus - in der dem zweiten Teil vorausgehenden Vorrede an den geneigten Leser. Hier heißt es einerseits zwar, dass dieser zweite Teil geschrieben worden sei, um die unbehutsame Menschen (auch mit Exempeln) unter dem Schein kurtzweiliger Geschichte / vor dem jenigen treulich zu warnen / was sie / wie gemeldt / gar leicht vom höchsten Gut absondern / hingegen in deß leidigen Teufels Gewalt [...] bringen mag. Andererseits werden jedoch ausgerechnet die unbehutsame[n] Menschen, an die sich die Paränese richtet, als prinzipiell ungeeignet angesehen, die erbauliche Botschaft des Textes $\mathrm{zu}$,finden'. Es sei unter 17. Lesern kaum einer [...] / der da findet / was er [der ,Autor', S.Z.] ihn unterrichten wolle; nur die [v]erständige Leut / denen es gedeyt, würden den Kern schon zu finden / und ihnen zu Nutz zu machen wissen. Damit relativiert die vom 
des Bekehrungsnarratives aufgehoben in einer Kreisbewegung des Lesens und Schreibens, deren Antrieb das vom Roman entfaltete Paradox der Anziehung und Abstoßung der außernatürlich-wunderbaren Kunst und Materi des Vogelnestes/Vogel-Nestes ist. Auch die Vernichtung des Nestes im Rhein, in die der Kaufmann nach eindringlichen Mahnreden des Paters einwilligt, unterbricht den Zirkel nicht. ${ }^{104}$ Im Gegenteil lässt sich das Bild des zuletzt zum Stäublein ${ }^{105}$ gewordenen, sich diegetisch verflüchtigenden Nestes als Wiederholung der Dispersionsbewegung vom Ende des ersten Teils deuten, die die fiktionale Entreferentialisierung der Zeichenkomplexe, die sich an das Nest knüpfen, auf der Ebene der erzählten Welt realisiert. Damit schließt sich der Kreis um sämtliche Dimensionen, die die Selbstthematisierung des Erzählens im Roman aufzubieten hat. Am Ende des Textes steht ein Bekenntnis zur Fiktionalität des Erzählten, das keinen Zweifel daran lässt, dass der ,andere' Raum des Wunderbaren kein Gegenstand des Wissens oder Glaubens, sondern der einer Satire ist, die sich den Grenzbestimmungen von Wissen und Religion entzieht, indem sie sie beobachtet.

Simplicianischen Autor entworfene Typologie des Publikums den von den Erzählerfiguren und auch vom Simplicianischen Autor erhobenen Erbaulichkeitsanspruch. Belehrt werden durch das Vogel-Nest nur diejenigen, die bereits belehrt (verständig) sind. Alle anderen verfallen der Faszinationskraft des „wunderbarlichen“ Erzählens und werden damit in einen Bereich des Wissens und Glaubens hineingeführt, in dem eine Orientierung kaum möglich ist. Vgl. Grimmelshausen: Vogel-Nest II. In ders.: Werke I/2 (Anm. 27), S. 449-650, hier S. 458f.

104 Dies als Einwand gegen Wesches Einschätzung, dass sich das „„überfließende ingenium“ Grimmelshausens mit der Vernichtung des Nestes „etwas Endgültiges verordnet" habe. Vgl. Wesche: Unsichtbares lesen (Anm. 16), S. 78.

105 Grimmelshausen: Vogel-Nest II. In ders.: Werke I/2 (Anm. 27), S. 449-650, hier S. 649. 
(C) 2015, Otto Harrassowitz GmbH \& Co. KG, Wiesbaden ISBN Print: 9783447104951 - ISBN E-Book: 9783447194129 


\section{Alchemia oeconomica \\ Johann Joachim Bechers (1635-1682) Sozialutopismus am Schnittpunkt von Projektemacherei, alchemischer Natur- philosophie und Staatsräson*}

Michael Lorber, Berlin

Bereits sein erster Biograph sah sich mit der Herausforderung konfrontiert, eine angemessene Berufsbezeichnung für den Tausendsassa Johann Joachim Becher zu finden. Denn da man nun nicht weiß/ ob er mehr ein Philologus oder Mathematicus, ein Chimicus oder Cameralistel ein Medicus, oder Kauffmann gewesen/ so lässt sich seine Wissenschafft in keines von diesen Fächern accurat einsperren. ${ }^{1}$ Am ehesten erschien Urban Gottfried Bucher deshalb Das Muster eines Nützlich-Gelehrten (1722) die vielseitigen Betätigungsfelder Bechers einfangen zu können. Tatsächlich war Becher als Alchemiker, Hofökonom, Reformpädagoge, Arzt und anderes mehr international bekannt und hat sich mit seinem Schaffen einen festen Platz in der Geschichte der Naturwissenschaften, der politischen Ökonomie, der Erziehungswissenschaften und auch der Agrarwissenschaft gesichert. Vor diesem Hintergrund entwerfe ich in meinen folgenden Ausführungen Becher als typischen Repräsentanten der frühneuzeitlichen Projektemacherei. Dabei erscheint er als eine interessante Wissensfigur in der epistemologischen Unschärfezone zwischen vormoderner und ,Neuer Wissenschaft' des 17. Jahrhunderts, insofern er mit seinen zahlreichen Projekten einerseits wichtige und anschlussfähige Impulse für die funktionelle Ausdifferenzierung von Wissen in moderne Einzeldisziplinen lieferte, er aber andererseits in seinen Schriften immer noch ganz klar einem universalwissenschaftlichen Reformdenken verpflichtet blieb. ${ }^{2}$ Ich fokussiere dabei vor allem sozialutopische Aspekte in Bechers Schaffen, die

* Der vorliegende Beitrag präsentiert Ergebnisse meiner Dissertationsschrift: Zwischen Erlösung und Produktivität. Zur Performanz alchemischen Wissens und den Projekten Johann Joachim Bechers (1635-1682) in der Frühen Neuzeit. Die Schrift wurde 2012 von der Freien Universität Berlin angenommen und wird derzeit für den Druck vorbereitet.

1 Urban Gottfried Bucher: Das Muster eines Nützlich-Gelehrten in der Person Herrn Doctor Johann Joachim Bechers, Kayserl. Majestät Cammer- und Commercien-Raths: nach seinen Philologischen, Mathematischen, Physicalischen, Politischen und Moralischen Schrifften beurtheilet, und nebst seinem Lebens-Lauff vorgestellet. Nürnberg und Altdorff 1722, S. 2.

2 Zur disziplinären Ausdifferenzierung von Wissen in der Moderne vgl. Rudolf Stichweh: Zur Entstehung des modernen Systems wissenschaftlicher Disziplinen. Physik in Deutschland 1740-1890. Frankfurt a.M. 1984, insbes. S. 17f. und S. 39-62. 
sich - wie ich zeigen werde - trotz aller Modernität immer noch maßgeblich aus eschatologischen Vorstellungen speisen. Die Alchemie bleibt, so meine zentrale These, für Becher in all seinen Projekten letzter und maßgeblicher Bezugspunkt: Sein ganz spezifisches Verständnis der göttlichen Kunst bildet gewissermaßen die Hintergrundfolie, auf der seine heterogenen Tätigkeiten zusammengeführt werden können. Abschließend zeichne ich nach, auf welche Weise Becher die Alchemie in die politische Hofökonomie einführt und damit gewissermaßen eine alchemia oeconomica begründet. Mein Augenmerk liegt hier auf den Reibungspunkten zwischen Bechers alchemischem Sozialutopismus und der frühneuzeitlichen Staatsräson, wobei vor allem die - scheinbare - Paradoxie im Zentrum steht, die sich zwischen Becher als Sozialutopisten und Becher als politischem Ökonom ausmachen lässt. ${ }^{3}$

\section{Johann Joachim Becher, der Projektemacher}

Johann Joachim Becher wird vermutlich 1635 in Speyer als Sohn eines protestantischen Pfarrers in bescheidenen Verhältnissen geboren. In seinen autobiographischen Angaben wird Becher nicht müde, auf die autodidaktische Herkunft seiner Fertigkeiten hinzuweisen. In seiner von Armut geprägten Jugend habe er sich in den Nachtstunden grundlegende Kenntnisse in Pädagogik, Theologie, Mathematik, Medizin, Alchemie, den Handwerkskünsten, Politik und Juristerei selbst beigebracht, während er tagsüber für den Unterhalt der Familie arbeiten musste. ${ }^{4}$ In den 1650er Jahren führt Becher ein Wanderleben an den Höfen des Heiligen Römischen Reiches Deutscher Nation. Erst ab Mitte der 1650er Jahre lassen sich seine autobiographischen Angaben um andere Quellen ergänzen. So findet Becher lobende Erwähnung in der Korrespondenz von Henry Oldenburg und Samuel Hartlib. ${ }^{5}$ Vermutlich aus politischen Gründen konvertiert er zu

3 Mit der hier aufgeworfenen Fragestellung habe ich mich bereits aus der wissensgeschichtlichen Perspektive der historia literaria des 18. Jahrhunderts beschäftigt, sodass sich inhaltliche Überschneidungen sowohl mit Blick auf die biographischen Eckdaten Bechers als auch mit Blick auf Teilaspekte der inhaltlichen Diskussion ergeben. Vgl. Michael Lorber: Der Wunsch, einen , seichten aufgeblasenen Kopf in seiner ganzen Größe darzustellen'. Historische Hintergründe zur Rezeption Johann Joachim Bechers in der historia literaria. In: Scharlatan! Eine Figur der Relegation in der frühneuzeitlichen Gelehrtenkultur (= Zeitsprünge. Forschungen zur Frühen Neuzeit/ Studies in Early Modern History, Culture and Science 17 (2013), 2/3). Hrsg. von Tina Asmussen und Hole Rößler. Frankfurt a.M. 2013, S. 183-214.

4 Vgl. Johann Joachim Becher: Methodus didactica, Das ist: Gründlicher Beweis, daß die Weg und Mittel, welche die Schulen bißhero ins gemein gebraucht/ die Jugend zu Erlernung der Sprachen/ insonderheit der Lateinischen zuführen/ nicht gewiß/ noch sicher seyen/ sondern den Reguln und Natur der rechten Lehr und Lern-Kunst schnurstracks entgegen lauffen/ derentwegen nicht allein langweilig/sondern auch gemeiniglich unfruchtbar und vergeblich ablaufen. Sambt Anleitung zu einem besseren. München 1668, S. 27.

5 We met in our passing through Maintz a rare artiste, called Becher, a young man, who hath found, he saith, the perpetual motion, the possibility whereof hath been hitherto so much disputed by Philosophers. He hath almost finished a work, wherein he doth demonstrate his invention, which we haue seen, and the dessein and way whereof the master told himself he would within a very few weeks put 
dieser Zeit zum Katholizismus. Nach einem Aufenthalt in Mainz (ca. 1657-1664) und ständigen Reisen zwischen Wien und München (1664-1670) wechselt Becher 1670 als kaiserlicher Kommerzienrat schließlich fest an den Wiener Kaiserhof. Im Rahmen einer Hofintrige, in der seine Rolle nicht ganz geklärt ist, wird Becher in Abwesenheit Bestechlichkeit vorgeworfen, weshalb er von einer 1676 angetretenen Reise nicht mehr nach Wien zurückkehrt. Es beginnt erneut ein Wanderleben von Hof zu Hof. Nachdem in Holland das aufwendige Projekt misslungen ist, aus Meeressand Gold zu gewinnen, flüchtet Becher vor seinem schlechten Ruf auf dem Kontinent und von Schulden geplagt nach London. ${ }^{6}$ Dort versucht er, Fellow der Royal Society zu werden. ${ }^{7}$ Die Königliche Gesellschaft lehnt seinen Antrag aber ab, womit sich für Becher die letzten Hoffnungen auf einen glücklichen Neuanfang in England in Luft auflösen. Im Oktober 1682 stirbt Becher in ärmlichen Verhältnissen in London. ${ }^{8}$

Becher war einer der letzten großen und zu seiner Zeit weithin anerkannten Alchemiker des 17. Jahrhunderts. Sein Lebensweg entsprach aber nicht mehr dem schon zu seiner Zeit zum Klischee gewordenen Adepten, der in seiner Alchemistenküche abgeschieden vor sich hin laboriert und ausschließlich damit beschäftigt ist, mit Athanor und Destillierkolben das alchemische opus magnum zu realisieren. Bereits er selbst entwarf von sich das Bild eines Alchemikers, der gleichsam über den traditionellen Tellerrand seiner Profession hinausblickt und der seine naturphilosophischen Kenntnisse und Fähigkeiten auf klare und nachvollziehbare Weise in den Dienst von Fürsten/ und dem Vatterland stellt. ${ }^{9}$ Im Laufe

in print here at Frankford which being, I shall buy severall copies of it to communicate to [my?] friends. [Henry Oldenburg an Samuel Hartlib, 18. Juli 1658]. The Hartlib Papers. Second Edition. A Complete Text and Image Database of the Papers of SAMUEL HARTLIB (c. 16001662). Held in Sheffield University Library. 2 CD-Roms. Sheffield, England, 2002, Bun. 39/3/16A.

6 Vgl. H. A. M. Snelders: Becher und sein Gold-aus-Sand-Projekt. In: Johann Joachim Becher (1635-1682). Hrsg. von Gotthardt Frühsorge und Gerhard F. Strasser. Wiesbaden 1993, S. 103-114.

7 Vgl. Thomas Birch: The History of the Royal Society of London for Improving of Natural Knowledge from its First Rise. 4 Bde. Eingel. und bibliogr. Anmerkungen von A. Rupert Hall und Maria Boas Hall. New York, London 1968 [Nachdruck d. Ausg. London 1757], Bd. 4, S. 17.

8 Zur Biographie Bechers siehe Herbert Hassinger: Johann Joachim Becher (1635-1682). Ein Beitrag zur Geschichte des Merkantilismus. Wien 1951, sowie Pamela H. Smith: The Business of Alchemy. Science and Culture in the Holy Roman Empire. Princeton (NJ) 1997.

9 Johann Joachim Becher: Chymisches Laboratorium, Oder Unter-erdische Naturkündigung: Darinnen enthalten wird I. Die tieffe Zeugung derer unter-erdischen Dinge: Wie auch der wunderbare Bau der ober- und unter-erdischen Erd-Wasser und Lufft-Kugel: Und dann die absonderliche Natur der unter-erdischen Dinge Aufflöß und Zerlegung in ihre Theile/ und derselben Eigenschafft. II. Neue Chymische Proben/ einiger künstlichen gleich darstelligen Verwandelung derer Metallen/ nach Anleitung der in vorigen Jahren in Druck gegebenen Physicae subterraneae. III. Ein nochmalicher Zusatz und Philosophischer Beweißthumb/ derer Chymischen/ die Wahr- und Möglichkeit derer Metallen Verwandelung in Gold/ bestreitenden Lehr-Sätze. IV. Ein Chymischer Rätseldeuter/ derer verdunckelten Wort-Sätze Urhe- 
seines Lebens hat Becher zahlreiche Projekte entworfen und $\mathrm{zu}$ realisieren versucht, die allesamt entweder unmittelbar oder zumindest mittelbar darauf abzielten, die fürstliche oder kaiserliche Ökonomie zu stabilisieren und zu fördern: Neben vielfältigen technischen Erfindungen zählt zu diesen Projekten u.a. der Plan für eine Seidenraupenzucht in München. Des Weiteren hat Becher in Wien mit dem Kunst- und Werckhaus einer Art internationales Handwerks- und Forschungszentrum für Materialien gegründet. Mit der sogenannten BesoldungsCassa, eine Art Rentenversicherung, versprach Becher, die Hofbeamten für Notfälle absichern und den Fürsten gegen Korruption schützen zu können. Zwar wurde auch das Projekt einer Besoldungs-Cassa nie realisiert, es beeinflusste aber Leibniz maßgeblich bei seinem Entwurf von Öffentliche Assekuranzen (1680). ${ }^{10} \mathrm{Zu}$ Bechers Projekten zählt auch die Einrichtung einer Sprachschule zur Erlernung des Lateinischen samt angeschlossenem Theatrum Naturae $\mathcal{E}$ Artis (eine Art enzyklopädischer Kunstkammer): Eine gute Ausbildung könne die Bevölkerung ökonomisch und damit auch moralisch festigen, und die Kunstkammer würde zugleich die teure, beschwerliche und oft auch enttäuschende peregrinatio bei Weitem übertreffen. ${ }^{11}$

Blickt man auf seine zahlreichen Unternehmungen, erscheint Becher als typischer Vertreter der barocken Projektemacherei, insofern es sein - mal mehr, mal weniger - einträglicher Beruf war, von Hof zu Hof zu ziehen und den Herrschenden mit seinen sozialen, technischen oder naturphilosophischen Projekten eine sowohl ökonomisch als auch machtpolitisch verheißungsvolle Zukunft in

bung und Geheimnisse offenbahrend und aufflösend. Wie solches alles durch fleissige Untersuchung außgefertiget Joh. Joachimus Becherus, von Speyer/ der Artzney Doctor, Nunmehr aber auff Begehren der Artzney- und Chymiae-Liebhabern in Druck übergeben hat. Franckfurt 1680 [lat. Physica subterranea [...], Frankfurt 1669], S. 26 (Paginierung in: III. Ein nochmalicher Zusatz).

10 Vgl. Michael Lorber: Vom Kauf der Gefahr. Projektemacherei und Versicherung im 17. Jahrhundert. In: Drohung und Verheißung. Mikroprozesse in Verhältnissen von Macht und Subjekt. Hrsg. von Elke Koch, Evamaria Heisler und Thomas Scheffer. Freiburg im Breisgau 2007, S. 287-314.

$11 \mathrm{Zu}$ Bechers Theatrum Naturae \& Artis vgl. Michael Lorber: ,... wie wäre ein solches Ding ein herrliches Werck'. Das Theatrum Naturae \& Artis (1668) des Alchemikers Johann Joachim Becher. In: Spuren der Avantgarde: Theatrum alchemicum. Frühe Neuzeit und Moderne im Kulturvergleich. Hrsg. von Helmar Schramm, Jan Lazardzig und dems. Berlin, New York [in Vorbereitung]. Die Bezeichnung Theatrum Naturae \& Artis im Sinne eines Ortes universalen Wissens greifen im Anschluss an Becher sowohl Athanasius Kircher als auch Gottfried Wilhelm Leibniz auf. Vgl. Horst Bredekamp: Die Fenster der Monade. Gottfried Wilhelm Leibniz' Theater der Natur und Kunst. Berlin 2004, insbes. S. 42f. sowie Angela MayerDeutsch: Athanasius Kirchers, theatrum naturae artisque' als idealer, synoptischer Blick auf ein Wissenstheater. In: Dimensionen der Theatrum-Metapher in der Frühen Neuzeit. Ordnung und Repräsentation von Wissen/ Dimensions of the Early Modern Theatrum-Metaphor. Order and Representation of Knowledge. Hrsg. von Flemming Schock, Oswald Bauer und Ariane Koller. Hannover 2008, S. 281-301, hier S. 288. 
Aussicht zu stellen. ${ }^{12}$ Am Schnittpunkt von Mechanik, alchemischem Laboratorium und Naturphilosophie kann der institutionell nicht gebundene Projektemacher Becher also einerseits im Kontext der experimentellen Naturforschung der Frühen Neuzeit verortet werden, die schließlich in die Gründung der großen Akademien mündet. Andererseits ist er auch im Bereich der Sozial- und Wirtschaftspolitik an den fürstlichen Höfen bzw. am Kaiserhof des Reiches zu situieren. Hinsichtlich all der Probleme, die mit der persönlichen Verschuldung und dem schlechten Ruf, die mit dem möglichen Scheitern der Projekte einhergehen, kann die soziale Stellung des auf sich allein gestellten Becher als durchaus prekär angesehen werden. Ein Großteil seiner vielfältigen Projekte ist entweder in der Planung steckengeblieben oder in der Ausführung misslungen. Mit Blick auf sein unstetes Leben kann Becher mit Martin Mulsow zum frühneuzeitlichen Typus der „unanständigen Gelehrten“ gezählt werden. Getrieben von einer „undisziplinierten" wissenschaftlichen Aufmerksamkeit, fügt sich sein Leben in das „oft genug beobachtet[e] Muster von mißglückter Karriere, Ausgestoßensein, ruhelosem Wanderleben, schließlich frühem Tod unter elenden Umständen und Verfolgungswahn". ${ }^{13}$ Im Falle Bechers äußert sich dieser Wahn vor allem durch den in seinen Schriften omnipräsenten Vorwurf, seine Projekte würden von seinen Feinden ausspioniert oder sabotiert werden.

Die Becherforschung hat sein Werk in der Regel unter jenen Disziplinen aufgeteilt, die im Rahmen der funktionellen Ausdifferenzierung der Wissenschaften des 18. Jahrhunderts in einem modernen Sinne erst entstehen wie Chemie, Pädagogik oder später Ökonomie. Dabei tritt sein alchemisches Schaffen im Zeichen eines universalwissenschaftlichen Anspruchs in den Hintergrund. Aus dem Werk werden gewissermaßen nur die für die jeweilige Disziplin brauchbaren Anteile herausdestilliert. Erst gegen Ende des 20. Jahrhunderts findet Bechers universalwissenschaftliches Reformdenken wieder verstärkt Berücksichtigung. Hervorzuheben ist hier vor allem die Becher-Biographie von Pamela $\mathrm{H}$. Smith. In The Business of Alchemy (1997) gelingt es ihr, Leben und Werk Bechers

12 Zur frühneuzeitlichen Projektemacherei vgl. Fritz Redlich: Die Rolle der Neuerung in einer quasi-statischen Welt. Francis Bacon und seine Nachfolger. In: Der Unternehmer. Wirtschafts- und Sozialgeschichtliche Studien. Nachwort von Edgar Salin. Göttingen 1964, S. 233-247; Alex[ander] Keller: The Age of the Projectors. In: History Today 16 (1966), 7, S. 467-474; Norbert [Herbert] Breger: Närrische Weisheit und weise Narrheit in Erfindungen des Barock. In: Ästhetik und Kommunikation. Beiträge zur politischen Erziehung 45/46 (1981), S. 114-122; Ulrich Troitzsch: Erfinder, Forscher und Projektemacher. Der Aufstieg der praktischen Wissenschaften. In: Macht des Wissens. Die Entstehung der modernen Wissensgesellschaft. Hrsg. von Richard van Dülmen und Sina Rauschenbach. Köln, Weimar, Wien 2004, S. 439-464 (dort zu Becher S. 462f.) sowie Marcus Krajewski (Hrsg.): Projektemacher. Zur Produktion von Wissen in der Vorform des Scheiterns. Berlin 2004.

13 Martin Mulsow: Die unanständige Gelehrtenrepublik. Wissen, Libertinage und Kommunikation in der Frühen Neuzeit. Stuttgart, Weimar 2007, S. VIII und S. 13. Im Gegensatz zu den meisten unanständigen Gelehrten trifft es auf Becher jedoch nicht zu, dass er aus reichem Hause stammt. 
im geistigen Umbruchsklima des 17. Jahrhunderts $\mathrm{zu}$ verorten. ${ }^{14}$ Ihren Fokus legt Smith dabei als erste seiner modernen Biograph*innen dezidiert auf Bechers Alchemie und deren Bedeutung für seine ökonomischen Projekte. Die zentrale These von Smith lautet, dass Becher die Begeisterung für Alchemie an den frühneuzeitlichen Höfen genutzt habe, um seine Ideen für ökonomische Reformen durchzusetzen. Smiths Ausführungen, die in ihrer wissenssoziologischen Stringenz sehr überzeugend sind und auf neu erschlossenem Archivmaterial aufbauen, verfolgen das Ziel, eine gewisse Modernität von Bechers ökonomischem Denken herauszuarbeiten, wonach dieser im für den höfischen Diskurs akzeptablen Gewand der Alchemie neue Wege im Bereich der Finanzpolitik beschreiten konnte. In Abgrenzung hierzu lässt sich aber auch eine gewissermaßen umgekehrte Fragestellung entwickeln, nämlich danach, welches neue Verständnis von Alchemie es Becher überhaupt erlaubt, diese für die Hofökonomie relevant werden zu lassen. Diese umgekehrte Fragestellung erweist sich dann als berechtigt, wenn man Bechers eigene Aussagen zur ökonomischen Bedeutung der Alchemie nicht nur als Zugeständnis an den höfischen Zeitgeist interpretiert, sondern als seine tatsächlich ernsthaft vertretene Überzeugung annimmt. Hierfür gibt es gute Gründe. Denn in seinen Schriften betont er immer wieder ausdrücklich, dass die Alchemie das Zentrum seiner höchst unterschiedlichen Projekte darstellt. So vergleicht er in seiner Physica Subterranea die geringen Erfolge der Alchemie rhetorisch geschickt mit dem ungewissen Eingang der Menschen in das Himmelreich, um die göttliche Kunst auf diese Weise gegen ihre Widersacher zu verteidigen. Hier erläutert er auch, auf welche Weise er den Zusammenhang zwischen christlicher Erlösung, politischer Ökonomie und Alchemie als gegeben sieht. Denn die Alchemie, so seine Argumentation, liefert dem irdischen Sehnen nach dem Himmelreich Gottes die Instrumente, die Übel schon im Diesseits zu beseitigen:

Darauf antworte ich; Es sey/ aus unsers Heylandes selbst-Worten gewiß/ daß ihrer [der Menschen] wenig in das Reich Gottes werde eingehen: folget dann drum/ es seye ein Frevel/ sich nach dem Reich Gottes sehnen: in welches doch einzugehen/ so Wenigen gedeye? Endlich wirstu sagen/ das Wort Alchymie lautet übel: ich aber halte dargegen die Worte/ Contribuieren/ Auflagen/ Acciß-Gelder/ Zinse/ Zölle/ Wucher/ Steuer/ und dergleichen/ lauten noch übler/ als durch welche die Unterthanen von ihrem Vermögen erschöpfft und beschweret werden: [...] so wolte ich kecklich sagen/ es sey keine Wissenschafft/ kein Vorsatz/ kein Grund oder Boden/ einem Fürsten ehrlicher/ nutzlicher/ den Unterthanen aber einträglicher/ als die Alchymia[.] ${ }^{15}$

14 Vgl. Anm. 8.

15 Becher: Unter-erdische Naturkündigung [...] III. Nochmalicher Zusatz (Anm. 9), S. 16. Diesem dritten Zusatz seiner Unter-Erdischen Naturkündigung stellt Becher ein Zitat des zeit- 
In seinem Chymischen Glückshafen (1682) schreibt Becher in gleicher Absicht, die Intention des wahren Alchemikers sei es, beizutragen zur

Erhaltung der Catholischen Kirch, Erweiterung der Christenheit, Unterdruckung des Erbfeinds, Erlösung der Christlichen Gefangenen, Erleichterung seiner Unterthanen von der schweren Contribution, Haußsteuer, Armen, Witwen, Waysen und Jungfrauen, Beschützung Land und Leute, auch zu Erhaltung gemeines Friedens und Ruhe. ${ }^{16}$

Vor diesem Hintergrund Bechers Bekenntnis zur Alchemie als seinem geistigen Zentrum ernst zu nehmen bedeutet nicht nur, sich der Aufgabe zu stellen, die Genese seines transformierten Alchemieverständnisses näher zu untersuchen, sondern auch der Versuchung zu widerstehen, aus einer modernen Perspektive seine Werke und Projekte - gleichsam posthum - in einzelne Wissensdisziplinen aufzufächern. Stattdessen erscheint es vielversprechend, die innere Kohärenz der heterogenen Projekte Bechers zu fokussieren. Denn aus der Spannung von innerer Kohärenz und sachbezogener Heterogenität, so meine zentrale These, resultiert der spezifische Alchemiebegriff Bechers.

Ich begreife Becher somit als eine Wissensfigur in der frühneuzeitlichen Schwellensituation entscheidender epistemologischer Umbrüche, in der sich jener Wandel in der Wahrnehmung von Welt vollzieht, der sich in neuen Wissenskonfigurationen am Übergang zur Moderne niederschlägt. Aus dieser Perspektive korrespondiert Bechers prekärer sozialer Status als Projektemacher mit dem prekären Status seines neuartigen alchemisch-ökonomischen Wissens: Materiell ist Bechers Wissen maßgeblich bestimmt durch die über halb Europa verstreuten Manuskripte zu seinen einzelnen, häufig nicht sonderlich gut doku-

genössichen niederländischen Alchemikers Augustinus Petraeus mit ähnlichem Inhalt voran: Die hochedle Chymie-Kunst verwahret den gesunden Menschen vor Kranckheiten; heylet den Krancken; hilfft dem Armen un Dürfftigen aus der Noth; enthebt die Natur; bringt heraus/ was verborgen; beträncket das Gemüth mit einer völligen Wissenschafft; thut keinem Unrecht: dienet allen Leuten; und bringt endlich zu selbst der Erkäntnüß Gottes. In diesem Zusammenhang setzt sich Becher dann auch von den Betrügern in der Alchemie ab und betont deren praktische Nützlichkeit über das Goldmachen hinaus: Also seyn/ durch Begebenheit der Alchymie/ das Büchsenoder Schieß-Pulver/ die Glasmacher-Kunst/ das Dinten machen/ Seiffen sieden/ Farb und andere Kunststück mehr erfunden worden: geschweige den Artzneyen/ der Erdgewächse Zielungen/ und viel andere nachdenckliche Geheimnissen. Kan/ solchem nach/ der Alchymist/ wann er den erwünschten Zweck erreichet/ dem Nechsten mit der Gesundheit/ Geld und Gut behülfflich seyn: erreichet er ihn nicht/ so thut er keinem andern/ als ihm selbst/ Schaden[.] Becher: Unter-erdische Naturkündigung [...] III. Nochmalicher Zusatz (Anm. 9), Titelblatt und S. 14f. (vgl. hierzu mit ähnlicher Argumentation auch ebd., S. 2, Zueignung).

16 Johann Joachim Becher: Chymischer Glücks-Hafen, oder Grosse Chymische Concordantz und Collection, Von funffzehn hundert Chymischen Processen, Durch viele Mühe und Kosten aus den besten Manuscriptis und Laboratoriis in diese Ordnung zusammen getragen, wie folgendes Verzeichniß ausweiset, Nebst einer neuen Vorrede, oder Bedencken Von der Gold-Macherey, Herrn Georg Ernst Stahls [...] Neue und viel verbesserte Edition [1682]. Halle a.S. 1726, S. 26. 
mentierten Projekten, die - wie etwa das erwähnte Kunst- und Werckhaus - selbst zum größten Teil nicht mehr erhalten sind, und sozial durch die von ihm beabsichtigte Überblendung traditioneller Alchemie mit neuartigen ökonomischem Ansätzen, weswegen er auch sein Leben lang darüber klagt, sich mit seinen revolutionären Ideen nicht gegen die Interessen der alteingesessenen und intriganten Hofbeamten durchsetzen zu können. ${ }^{17}$

Vor diesem Hintergrund lehne ich ausdrücklich eine Sichtweise ab, die einerseits Bechers großartigen ökonomischen Sachverstand lobt, aber andererseits dessen Schriften mit "alchimistischen Erörterungen ,belastet “ sieht. ${ }^{18}$ In eben diesen vermeintlichen ,Lasten' können vielmehr wesentliche Anhaltspunkte für die Verschränkung von verheißungsvoller Sozialutopie alchemischer Provenienz und politischer Ökonomie ausgemacht werden. Im Folgenden geht es mir somit auch nicht darum, ,vormodernes‘ und ,modernes‘ Wissen gegeneinander auszuspielen bzw. radikal voneinander abzugrenzen, um Becher als gleichsam zerrissene Figur irgendwo dazwischen zu skizzieren. Stattdessen gilt es zu zeigen, wie sich im spezifischen Wissensgefüge des universalwissenschaftlichen Reformdenkens Bechers neue Möglichkeiten der Welterkenntnis und -erfahrung entfalten, die für ihn eben noch nicht - wie aus einer modernen Perspektive - im offenen Widerspruch zur Alchemie stehen, sondern diese vielmehr von innen nachhaltig transformieren und sie für neue Gegenstandsbereiche öffnen.

Wie bereits dargelegt, kann Bechers Schaffen aus sozialgeschichtlicher Perspektive im Bereich der frühneuzeitlichen Projektemacherei verortet werden. Für das Verständnis der sozialutopischen Implikationen dieses Schaffens ist ein Blick zurück in das Jahrhundert vor Becher aufschlussreich und notwendig. Einige Spuren, die ich im folgenden Kapitel aufgreife, verdanken sich den wichtigen Arbeiten Herbert Bregers zu Becher, ${ }^{19}$ allerdings komme ich in wesentlichen Punkten zu ganz anderen Schlussfolgerungen.

17 Mulsow benennt-neben einem entsprechenden Inhalt-drei weitere Merkmale prekären Wissens in der Frühen Neuzeit, die im Falle Bechers alle zutreffen: 1. „Prekärer Status des Wissensträgers" (bezogen auf die Materialität des Wissensträgers, „wenn dieser Träger leicht verlorengehen oder vernichtet werden kann“); 2. „Prekärer gesellschaftlicher Status“ (Personen sind gezwungen, „ihre Überzeugungen im geheimen zu kommunizieren, sei es durch Verbergen ihrer Identität oder zumindest durch Verbergen ihrer Absichten und Meinungen“); 3. "Prekärer Status der Sprecherrolle“ (Personen haben „raffinierte Formen gefunden, um ihre Überzeugungen - wenn sie sie nicht clandestin publiziert haben - zumindest indirekt einem größeren Publikum zugänglich zu machen [...]: Maskierung, die Konstruktion einer doppelten Persona und Pseudonymisierung“). Martin Mulsow: Prekäres Wissen. Eine andere Ideengeschichte der Frühen Neuzeit. Berlin 2012, S. 15f., Hervorhebungen im Original.

18 Anton Tautscher: Wirtschaftsgeschichte Österreichs auf der Grundlage abendländischer Kulturgeschichte. Berlin 1974, S. 287.

19 Vgl. insbes. Herbert Breger: Sozialutopische Tendenzen und (Al)chemie des 17. Jahrhunderts. Johann Joachim Becher und Johann Rudolph Glauber. In: Aufklärung und Esoterik. Hrsg. von Monika Neugebauer-Wölk. Hamburg 1999, S. 108-116. 


\section{Die paracelsi(sti)schen Wurzeln des alchemischen Sozialutopismus' Bechers}

Die sicherlich einflussreichste programmatische Setzung einer Verbindung von Alchemie und Sozialutopie stammt von Paracelsus. Die Notwendigkeit, Alchemie zu betreiben, begründet Paracelsus aus iatrochemischer Sicht damit, ${ }^{20}$ dass die Natur ohne ihre Bearbeitung durch den Menschen für dessen Zwecke kaum zu gebrauchen sei: Wie ein Bäcker Brot backt, könne der Alchemiker die Natur dort für seine Zwecke zur Reifung und Vollendung bringen, wo diese von sich aus nicht weiterkomme. ${ }^{21}$ In diesem Sinne definiert Paracelsus Alchemie auch wie folgt: Die generation aller natürlichen dingen ist zweierlei, als eine die von natur geschicht on alle kunst, die ander geschicht durch kunst nemlich durch alchimiam. ${ }^{22}$

Die heilsgeschichtliche Relevanz dieses Denkens offenbart sich, wenn Paracelsus die Figur des Elias artista entwirft. Denn nicht nur die Religion verfüge über ihren biblischen Elias, sondern es gebe auch den Elias der Künste - mit Kunst ist hier Alchemie gemeint. ${ }^{23}$ Die Bedeutung des Elias artista entfaltet sich somit im biblischen Kontext: Im Judentum ist Elias der Retter in der Not, offenbart den wahren Schriftsinn der heiligen Texte und bereitet „als Hohenpriester der Endzeit" schließlich die Ankunft des Messias vor. ${ }^{24}$ Auch im Neuen Testa-

20 Joachim Telle hat darauf hingewiesen, dass sich Paracelsus - trotz gewisser Interferenzen zwischen alchemia medica und alchemia transmutatoria zu seiner Zeit und entgegen der schon unmittelbar nach seinem Tode einsetzenden Legendenbildung - nicht mit der Transmutationsalchemie beschäftigt hat. Hinsichtlich des Ziels dieser beiden Alchemieformen, nämlich "Erkundung der Stoffeswelt" und „Heilung von Mensch und Metall" können aber dennoch Gemeinsamkeiten festgehalten werden, die auch die Inanspruchnahme der oben angeführten Definition von Alchemie über die alchemia medica hinaus rechtfertigen. Das noch zu Lebzeiten des Paracelsus erschienene und deshalb mit hoher Wahrscheinlichkeit authentische Werk beschränkt sich auf iatrochemische und prognostische Texte. Joachim Telle: Paracelsus als Alchemiker. In: Paracelsus und Salzburg. Vorträge bei den Internationalen Kongressen in Salzburg und Badgastein anläßlich des Paracelsus-Jahres 1993. Hrsg. von Heinz Dopsch und Peter F. Kramml. Salzburg 1994, S. 157-172, hier S. 162.

21 Paracelsus: Das Buch Paragranum. Letzte Bearbeitung in vier Abschnitten. In: Sämtliche Werke. Hrsg. von Karl Sudhoff u.a. München, Berlin 1923ff., 1. Abteilung: Medizinische, naturwissenschaftliche und philosophische Schriften, Bd. 8: Schriften aus dem Jahre 1530, geschrieben in der Oberpfalz, Regensburg, Bayern und Schwaben (1924), S. 133-221, hier S. 181. Dass der Gedanke der Vollendung der Natur durch Menschenhand ein wesentliches Kernelement des alchemischen Denkens seit der Antike ist, weist Newman en détail nach. Vgl. William R. Newman: Promethean Ambitions. Alchemy and the Quest to Perfect Nature. Chicago 2004.

22 Paracelsus: Die 9 Bücher de Natura rerum an Johansen Winkelsteiner zu Freiburg im Üchtland, angeblich Villach 1537. In: Sämtliche Werke (Anm. 21), 1. Abt., Bd. 11: Schriftwerk aus den Jahren 1537-1541 (1928), S. 307-403, hier S. 312.

23 Vgl. Will-Erich Peuckert: Die Rosenkreutzer. Zur Geschichte einer Reformation. Jena 1928, S. 48 .

24 Joachim Jeremias: ' $H \lambda(\varepsilon)$ í $\alpha$ s. In: Theologisches Wörterbuch zum Neuen Testament. Hrsg. von Gerhard Kittel. 10 Bde. Stuttgart 1933-1970, Bd. 2 (1935), S. 930-943, hier S. 934. Strittige Fälle hinsichtlich des Sinns der Heiligen Schriften können im Rabbinertum bis heute mit 
ment ist Elias als eschatologische Figur präsent und wird mit der Offenbarung göttlichen Wissens assoziiert, das er den Menschen unmittelbar vor der Wiederkehr Jesu Christi verkünden werde. ${ }^{25}$

Paracelsus greift dieses Erlösungsversprechen im Kontext seines Elias artista auf, wenn er von einer kurz bevorstehenden und von allen Verkommenheiten gereinigten güldin welt spricht. Diese Welt werde wieder mit der ursprünglich vollkommenen Natur in Übereinstimmung gebracht sein, und die Menschen könnten ein seliges Leben führen. ${ }^{26}$ Kurt Goldammer schreibt im Kontext seiner „Paracelsischen Eschatologie“, dass für Paracelsus die „Natur nach Erlösung [schreit]“, ${ }^{27}$ und zwar die gefallene Natur, der sich der Mensch mit all seinen ihm zur Verfügung stehenden Mitteln - eben der Alchemie - anzunehmen habe. ${ }^{28}$ Der Elias artista vermittelt somit zwischen den alchemischen und den theologischen Aspekten paracelsischen Denkens im Zeichen der Heilsgeschichte. ${ }^{29}$ Der Mensch, so lässt sich resümierend festhalten, ist nach Paracelsus mit der göttlichen Kunst in der äußerst bemerkenswerten Lage, heilsgeschichtlich relevantes Wissen zu produzieren und zur materiellen Vollendung des göttlichen Schöpfungsplans aktiv beizutragen. ${ }^{30}$ Dies wird möglich, indem Paracelsus die

dem Ausspruch „bis zur Rückkehr Elias'“ vertagt werden, da sich dann alle Unklarheiten auflösen. Vgl. Markus Öhler: Elia im Neuen Testament. Untersuchungen zur Bedeutung des alttestamentlichen Propheten im frühen Christentum. Berlin, New York 1997, S. 136.

25 Vgl. Öhler: Elia im Neuen Testament (Anm. 24), S. 299f. Vgl. im Neuen Testament z.B. Matthäus 16,14 bzw. 17,11 und Johannes 1,21 sowie weiterführend Johann E. Stadler (Hrsg.): Elias. In: Vollständiges Heiligen-Lexikon oder Lebensgeschichten aller Heiligen, Seligen etc. etc. aller Orte und Jahrhunderte. 5 Bde. Augsburg 1858-1882, Bd. II (1861), S. 32-33 und Jeremias: 'H $\lambda(\varepsilon)$ í $\alpha \varsigma$ (Anm. 24), S. 938f.

26 Paracelsus: Von den natürlichen Dingen. In: Sämtliche Werke (Anm. 21), 1. Abt., Bd. 2: Frühe Schriften zur Heilmittellehre (1930), S. 59-175, hier S. 164f. Zum Begriff des „,seligen Lebens" bei Paracelsus vgl. Kurt Goldammer: Paracelsische Eschatologie. Zum Verständnis der Anthropologie und Kosmologie Hohenheims. In: Nova acta Paracelsica. Jahrbuch der Schweizerischen Paracelsus-Gesellschaft 5 (1948), S. 45-85 (Teil 1) und 6 (1952), S. 68-102 (Teil 2), S. 78f. (Teil 2). Hier wird auch der Unterschied zur augustinischen Tradition deutlich gemacht: Der Gottesstaat ist bei Augustinus noch transzendent gedacht. Vgl. auch Richard Saage: Utopische Profile. 4 Bde. Münster 2001, Bd. 1: Renaissance und Reformation, S. $48 \mathrm{f}$.

27 Kurt Goldammer: Paracelsus. Natur und Offenbarung. Hannover-Kirchrode 1953, S. 81. Vgl. hierzu auch Peter Dilg: Paracelsus-Forschung gestern und heute. Grundlegende Ergebnisse, gescheiterte Versuche, neue Ansätze. In: Resultate und Desiderate der Paracelsus-Forschung. Hrsg. von dems. und Hartmut Rudolph. Stuttgart 1993, S. 9-24, hier S. $13 f$.

$28 \mathrm{Vgl}$. hierzu auch den Brief an die Römer 8,22-23: „Wir wissen ja, daß die gesamte Schöpfung bis zur Stunde seufzt und in Wehen liegt. Und nicht nur das, auch wir, die wir die Erstlingsgabe des Geistes besitzen, auch wir seufzen in uns selbst in der Erwartung der Erlösung unseres Leibes."

29 Zum christlich-teleologischen Zeitverständnis von Paracelsus, in dessen Rahmen die Vollendung gedacht werden muss, vgl. Goldammer: Paracelsische Eschatologie (Anm. 26), S. 58-63 (Teil 1).

30 Vgl. hierzu ausführlich Michael Lorber: Alchemie, Elias artista und die Machbarkeit von Wissen in der Frühen Neuzeit. In: Natur - Religion - Medien. Transformationen frühneu- 
auf künstlichem Wege, d. h. durch Menschenhand, hervorgebrachten Produkte der Alchemie mit denen der Natur hinsichtlich ihrer heilsgeschichtlichen Wertigkeit gleichstellt. ${ }^{31}$ Der entscheidende Unterschied zur bereits im Mittelalter kontrovers diskutierten intrikaten Verbindung von Naturwissen und Erlösung im Zeichen der Apokalypse ist darin zu sehen, ${ }^{32}$ dass der Mensch als schöpferische Kraft im heilsgeschichtlichen Weltenplan nun nicht mehr ausschließlich auf die Gnade Gottes angewiesen ist. Stattdessen überschreitet er die Grenzen der eigentlichen artes einerseits und jene der passiven Naturbeobachtung andererseits, indem er im Bereich der göttlichen Natur mit seinen Experimenten aktiv tätig wird, und erzeugt in seinem produktiven Handeln zugleich erlösendes Wissen über die Natur. ${ }^{33}$

Bei Paracelsus findet der Elias artista allerdings nur am Rande Erwähnung. Seine Karriere als Wissensallegorie am Schnittpunkt von Naturphilosophie und Eschatologie entwickelt sich erst im Paracelsismus ${ }^{34}$ des 16. und frühen 17. Jahrhunderts. ${ }^{35}$ Einen paradigmatischen Höhepunkt innerhalb dieser Entwicklung

zeitlichen Wissens. Hrsg. von Thorsten Burkard, Markus Hundt, Steffen Martus, Steffen Ohlendorf und Claus-Michael Ort. Berlin 2013, S. 87-113.

31 Die grundsätzliche Machbarkeit von Wissen als solche ist im 16. Jahrhundert allerdings schon kein spezifisch alchemisch-naturphilosophischer Gedanke mehr. Das produktive Zusammenwirken von Ingenieurskunst, gelehrtem Wissen und humanistischem Gedankengut im Sinne der dignitas-Diskurse prägte bereits maßgeblich dieses Zeitalter der mechanischen Erfindungen, was das zeitgenössische Ordnungssystem der artes liberales und artes mechanicae in heftige Unruhe versetzte. Vgl. Edgar Zilsel: Die sozialen Ursprünge der neuzeitlichen Wissenschaft. In: Die sozialen Ursprünge der neuzeitlichen Wissenschaft. Hrsg. von Wolfgang Krohn. Frankfurt a.M. 1976, S. 49-65. Der entscheidende Unterschied zu diesen Formen der Machbarkeit von Wissen ist allerdings in der naturphilosophisch-heilsgeschichtlichen Einbettung der Alchemie zu sehen, die nicht nur auf eine Hervorbringung von Natur mittels bloß mimetischer alchemischer Prozeduren beschränkt ist, sondern - zumindest latent und manchmal auch explizit - in deren naturschöpferischer Kraft begründet ist.

32 Vgl. Johannes Fried: Aufstieg aus dem Untergang. Apokalyptisches Denken und die Entstehung der modernen Naturwissenschaft im Mittelalter. München 2001.

33 Eine gute Übersicht zur Geschichte menschlichen Schöpfertums bietet Vinzenz Rüfner: Homo secundus Deus. Eine geistesgeschichtliche Studie zum menschlichen Schöpfertum. In: Philosophisches Jahrbuch der Görres-Gesellschaft 63 (1955), 2, S. 248-291.

34 Ein Großteil der unter dem Namen des Paracelsus erschienenen Schriften ab 1560 dürfte aus der Feder einer „,,fortschreibenden' Gesinnungs- und Publikationsgemeinschaft naturkundlicher, oft auch quer zum Konfessionalismus stehender, akademischer wie vor allem außerakademischer Dissidenten" stammen. Wilhelm Kühlmann: Paracelsismus und Hermetismus. Doxographische und soziale Positionen alternativer Wissenschaft im postreformatorischen Deutschland. In: Antike Weisheit und kulturelle Praxis. Hermetismus in der Frühen Neuzeit. Hrsg. von Anne-Charlott Trepp und Hartmut Lehmann. Göttingen 2001, S. 17-39, hier S. 18.

35 Vgl. Hermann Kopp: Die Alchemie in älterer und neuerer Zeit. Ein Beitrag zur Culturgeschichte. 2 Bde. Heidelberg 1886, Bd. I: Die Alchemie bis zum letzten Viertel des 18. Jahrhunderts, S. 250-252; Walter Pagel: The Paracelsian Elias artista and the Alchemical Tradition. In: Medizinhistorisches Journal 16 (1981), 1/2, S. 6-19; Herbert Breger: Elias Artista - A Precursor of the Messiah in Natural Science. In: Nineteen Eighty-four. Science 
markiert Oswald Croll, der in seiner Basilica Chymica (1609) göttliche Natur und menschliche Kunst im paracelsi(sti)schen Sinne auf besondere Weise gleichsetzt: Der biblische Prophet Elias als apokalyptischer Offenbarer göttlichen Wissens wird - unter Bezug auf die Drei-Status-Lehre des Joachim von Fiore ${ }^{36}$ - explizit mit dem Elias artista als fähigem Reparator omnnium überblendet. ${ }^{37}$ Auch in den Rosenkreuzermanifesten sind seine Spuren zu finden, wenn Adam Haslmayr in seiner Antwort an die lobwürdige Bruderschaft, die bereits der ersten gedruckten Ausgabe der Fama Fraternitatis (1614) beigefügt ist, die Bruderschaft des Christian Rosencreutz mit dem geprophetierten Eliae Artistae identifiziert. ${ }^{38}$ Implizite Bezüge auf den Kern des Elias artista-Gedankens lassen sich auf dieser Spur über die späteren Sozietätsentwürfe Johann Valentin Andreaes, den Hartlib-Circle im englischen Umfeld der puritanischen Revolution und seiner Verbindung zu Johann Amos Comenius bis hin zu dessen kritischer Auseinandersetzung mit der Royal Society ausmachen. ${ }^{39}$ In den 1650er und 60er Jahren greift auch der Alchemiker Johann Rudolph Glauber - Bechers erklärter Intimfeind, mit dessen vermeintlicher Unredlichkeit er sich in einer frühen Schrift unter dem Pseudonym Antiglauberum auseinandersetzt ${ }^{40}$ - die Figur des Elias artista wieder auf und erkennt in ihm das Anagramm Et artis salia für sein wundertätiges Glauber-

between Utopia and Dystopia. Hrsg. von Everett Mendelsohn und Helga Nowotny. Dordrecht u.a. 1984, S. 49-72; William R. Newman: Elias artista. In: Alchemie. Lexikon einer hermetischen Wissenschaft. Hrsg. von Claus Priesner und Karin Figala. München 1998, S. 127128; Carlos Gilly: Johann Arndt und die ,dritte Reformation' im Zeichen des Paracelsus. In: Nova Acta Paracelsica - Neue Folge 11 (1997), S. 60-77 sowie Antoine Faivre: Elie artiste, ou le messie des philosophes de la nature. In: Aries. Journal for the Study of Western Esotericism 2 (2002), 2, S. 119-152 (Teil 1) und 3 (2003), 1, S. 25-54 (Teil 2).

36 Zur Joachims Geschichtsmodell vgl. Anne Eusterschulte: Trinitarische Geschichtstheologie. Statuslehre und spirituelle Typologie bei Joachim von Fiore. In: Scientia Poetica. Jahrbuch für Geschichte der Literatur und der Wissenschaften 5 (2001), S. 1-34.

37 Oswald Croll: Basilica Chymica oder Alchymistisch Königlich Kleiynod: Ein Philosophisch/ durch sein selbst eigne erfahrung confirmirte und bestättigte Beschreibung und gebrauch der aller fürtrefflichsten Chimischen Artzneyen so auß dem Liecht der Gnaden und Natur genommen/ in sich begreiffent. Beneben angehengetem seinem newen Tractat von den innerlichen Signaturn oder zeichen der dinge. Franckfuhrt 1623, S. 5. Auch Breger weist auf diese Passage hin (vgl. Breger: Elias arista (Anm. 35), S. 57), verzichtet jedoch darauf, auf den interessanten Umstand einzugehen, dass Croll in der beistehenden Marginalie auf EliasStellen in den Heiligen Schriften verweist. Es ist eben die den Ausführungen zum Elias artista beigefügte Marginalie, über die besagte identifizierende Überblendung auch im Seitenarrangement zum Ausdruck gebracht wird.

38 Vgl. Adam Haslmayr: Antwort An die lobwürdige Brüderschafft der Theosophen von RosenCreutz [Faksimile der Erstausgabe 1612]. In: Carlos Gilly: Adam Haslmayr. Der erste Verkünder der Manifeste der Rosenkreuzer. Amsterdam 1994, S. 69-80, hier S. 74.

39 Vgl. Michael Lorber: Der Wunsch (Anm. 3), S. 201-210.

40 Antiglauberum „Hai soo muß ich ja berechnen“ [Anagramm ergibt: Johannes Ioachim Becheruß]: Glauberus Refutatus Sev Glauberianarum Sophisticationum Centuria Prima [...]. S. 1. 1661. 
salz. ${ }^{41}$ Noch Johannes Helvetius berichtet in seinem Vitulus aureus (1667) vom Besuch eines Adepten, der niemand anderes gewesen sei als der Elias artista und ihm als Auserwähltem einen Einblick in die Kraft des lapis philosophorum gewährt habe, ${ }^{42}$ und der amerikanische Alchemiker George Starkey sah sich selbst als Vorboten des paracelsistischen Elias artista. ${ }^{43}$

$\mathrm{Ob}$ nun in der Verkörperung eines Propheten, einer gelehrten Bruderschaft oder eines Salzes mit wunderbaren Eigenschaften, die Wissensallegorie des Elias artista entfaltete über ein Jahrhundert lang eine enorme Wirkkraft am Konnex von alchemischer Naturphilosophie und Heilsgeschichte und war zu Bechers Zeiten auch an der Alchemie interessierten Laien bestens bekannt. In seiner Physica subterranea erwähnt Becher den Elias artista wie folgt:

Des gegenwärtigen Lebens überdrüssig/ eröffne ich euch Lehrgefliessenen den Weg/ auf welchem ihr zu bessern und leichtern Sachen werdet kommen: und wartet ja auf keinen andern Eliam Artistam, ohne des Isaac Hollandi seine Wercke. ${ }^{44}$

41 Elias Artista, Et Sal Artis haben uns die Thüer zu allen Götlichen und Naturlichen Geheimnussen auffgethan/ und daß [von Paracelsus] Prophezeihete bessere Seculum, oder gelobte Landt gezeiget: Gott wolle den frommen vollents darein zu kommen/ und zu Gottes Ehren/ und Trost der der dürfftigen die Frächten daselbsten zu geniessen/ Gnädige hülff und beystande verleihen/ AMEN. Johann Rudolph Glauber: Miraculi mundi, Ander Theil. Oder/ Dessen Vorlängst geprophezeiten ELIAE ARTISTÆ/ TRIUMPHIRLIcher Ein Ritt. / Und auch/ Was der ELIAS ARTISTA für einer sey? Nemlich der Weisen ihr SAL ARTIS Mirificum, als aller Vegetablien, Animalien, und Mineralien höchste Medicin./ Wie beweislich/ wann es der Vegetablien Sahmen oder Wurtzel beygebracht/ dieselbe unglaublicher massen davon wachsen und sich vermehren. Und bey allen in- und eüßerlichen Kranckheiten der Menschen und Viehes/ wie sie auch Nahmen haben möchten/ vor allen andern Artzneyen Miraculosè wircket. Wie dan auch die Unvolkommene Metallen Realiter nicht allein in [Gold] und [Silber] zu verwandlen/ sondern auch das feine [Gold] uber seinen Natürlichen 24sten/ auff den 28ten feürbeständigen Grad dardurch zu bringen. Und was noch mehr ist/ aus allen Kräutern ein Naturliches [Gold] zu ziehen/ und ein fixes [Gold] in ein jedes Kraut wiederumb dardurch thun wachsen machen/ möglich ist. Also ein Herrlicher/ Glorioser, und Triumphierender Monarch ist/ Elias Artista, wenigen bekant/ Et Artis Salia, Vielen genant. Dieses alles durch die grosse Gnad und Barmhertzigkeit Gottes erfunden/ und durch desselben weitere Hülff und Beystandt den Freunden Publicè zu demonstriren, und wahr zu machen, sich erbietet und darstelt. Ambsterdam 1660, Vorrede, fol. Avv.

42 Vgl. Johann Friedrich Helvetius: Vitulus aureus quem mundus adorat et orat. Oder ein sehr Curieuses Tractätlein/ in welchem das rare und wundersame Werck der Natur in verwandelung derer Metallen Historice ausgeführet wird. Wie nemlich das gantze Wesen des Bleyes in einem Augenblick durch Hülffe eines sehr kleinen Stücklein des Steins der Weisen zu dem allerbesten Gold von obgenandten Herrn Helvetio im Haag gemacht und verwandelt worden. Aus dem Lateinischen ins Hochteutsche übersetzet [1667]. S. 1.1705 (Elias artistaAnekdote und Dialog dort ab Cap. III).

43 Vgl. William R. Newman: Gehennical Fire. The Lives of Georg Starkey. An American Alchemist in the Scientific Revolution. Cambridge (Mass.) 1994, S. 14.

44 Becher: Unter-erdische Naturkündigung [...] I. Die tieffe Zeugung derer unter-erdischen Dinge (Anm. 9), S. 145. 
Nach Breger verwirft Becher an dieser Stelle gemeinsam mit dem apokalyptisch aufgeladenen Paracelsismus auch das Konzept des erlösenden Elias artista. ${ }^{45}$ Tatsächlich finden sich im Werk Bechers immer wieder heftige Attacken gegen Paracelsus und seine Anhänger, insbesondere auch gegen Glauber, der sich intensiv mit dem Elias artista beschäftigt hat. Allerdings richten sich diese Angriffe weniger gegen paracelsi(sti)sche Lehrinhalte als solche, die in Bechers Überlegungen durchaus eine zentrale Rolle spielen. ${ }^{46}$ Vielmehr sind sie vor allem gegen die Person des Paracelsus selbst gerichtet, den Becher des ausufernden Ideendiebstahls beim Alchemiker Johann Isaac Holland (frühes 15. Jahrhundert) bezichtigt. Damit ist zwar Bregers Interpretation insoweit zuzustimmen, als dass der Elias artista als paracelsistischer Terminus - insbesondere in seiner chiliastischen Variante - bei Becher expressis verbis verworfen wird. Aber das bedeutet nicht, dass Becher dem Konzept eines intrikaten Bezugs von alchemischer Naturphilosophie und Heilsgeschichte, das unter dem Namen Elias artista über ein Jahrhundert weiter entwickelt worden ist, überhaupt nichts mehr abgewinnen kann. Denn Becher verwirft im obigen Zitat nicht den Elias artista an sich, vielmehr argumentiert er, dass dieser nicht in den paracelsi(sti)schen Schriften, sondern im Kontext jenes Schrifttums zu situieren und zu erwarten sei, bei dem sich Paracelsus unverschämterweise bedient hat.

Obwohl der Elias artista für das Verständnis der sozialutopischen bzw. gesellschaftspolitischen Bedeutung der Alchemie bei Becher wichtig ist und dessen Grundlage bildet, müssen auch die entscheidenden Unterschiede zur paracelsistischen Tradition herausgestellt werden. Denn erst in den Differenzen gewinnt Bechers eigenwilliger alchemischer Sozialutopismus deutlich an Kontur. Im Wesentlichen sind diese Differenzen in den Unterschied zwischen einem apokalyptischen und einem utopischen Denken in der christlichen Vormoderne eingeschrieben: In beiden Fällen - Apokalypse und Utopie - wird eine verkommene oder zumindest hochgradig verbesserungswürdige Gegenwart analysiert und eine zukünftige Gegenrealität entworfen, in der diese Fehler in einem als vollkommen gedachten historischen Endzustand beseitigt sind. Der entscheidende Unterschied zwischen Apokalypse und Utopie ist in der Imagination der Realisierung dieses Ziels zu sehen: Die Apokalypse zeichnet sich definitionsgemäß durch die radikale Vernichtung des Ist-Zustands durch Gott aus, die in der vormodernen Vorstellung gleichsam die Voraussetzung für die Erlösung und die Errichtung des vollkommenen Reiches in Form des Himmlischen Jerusalems gemäß der Offenbarung des Johannes darstellt. Die Utopie hingegen geht meist von der Möglichkeit einer sukzessiven Verbesserung der vorhandenen Zustände durch den Menschen aus, ohne dass eine völlige Vernichtung des Gegenwärtigen als notwendig vorausgesetzt wird. Diese Gegenüberstellung von Apokalyp-

45 Vgl. Breger: Elias arista (Anm. 35), S. 65.

46 Zum Paracelsismus Bechers vgl. Hartmut Rudolph: Kirchengeschichtliche Beobachtungen zu J. J. Becher. In: Johann Joachim Becher (Anm. 6), S. 173-196, hier insbes. S. 173-178. 
se und Utopie ist aber vor allem für heuristische Zwecke geeignet und als idealtypisch zu begreifen. Wolfgang Braungart hat diverse Erzählstrategien in literarischen Texten der Frühen Neuzeit analysiert und darlegen können, dass sich apokalyptische und utopische Motivik sehr gut gegenseitig ergänzen können. ${ }^{47}$

Bezogen auf die apokalyptische Figur des Elias artista von Paracelsus bis hin zu Becher lässt sich vor diesem Hintergrund eine Verlagerung von einer eher apokalyptisch hin zu einer stärker utopisch geprägten Denkweise beschreiben. Bei Paracelsus steht die Figur des Elias artista zwar für die qua Alchemie experimentelle Machbarkeit heilsgeschichtlich relevanten Wissens. Die Realisierung der vollkommenen güldin welt hängt aber für Paracelsus letztlich noch davon ab, dass zuvor zwei Drittel der Menschheit entweder erschlagen werden oder aufgrund von Betrügereien umkommen müssen. ${ }^{48}$ Dieser implizite Verweis auf die Offenbarung des Johannes 9,15-21 stellt die güldin welt dann doch wieder in einen stärker apokalyptischen als utopischen Kontext - und zwar im Gegensatz zur heilsgeschichtlichen Relevanz, die in der Konzeption des Elias artista der experimentellen Machbarkeit von Wissen beigemessen wird. Dies gilt auch noch für die Rosenkreuzermanifeste, wenn etwa in der Confessio fraternitatis (1615) der in den letzten Jahrzehnten beträchtlich angewachsene naturphilosophische Wissensstand der Menschheit, der nahezu adamitisch sei, mit dem kurz bevorstehenden Ende der Welt in Verbindung gebracht wird. ${ }^{49}$

Bei Becher steht in Abgrenzung zur paracelsi(sti)schen Tradition hingegen viel stärker der utopische Aspekt einer sukzessiven Verbesserung durch Menschenhand im Vordergrund. Als Begründung sind hierfür vor allem zwei Punkte anzuführen: Der erste Punkt ist in einer im Vergleich zum Paracelsismus zeitlichen Entkoppelung von Apokalypse und Naturwissen zu sehen. Francis Bacon hat jene Entkoppelung erstmals programmatisch wirklich erfolgreich, d. h. für nachfolgende Generationen verbindlich, formuliert; 50 eine Entkoppelung, die

47 Vgl. Wolfgang Braungart: Apokalypse und Utopie. In: Poesie der Apokalypse. Hrsg. von Gerhard R. Kaiser. Würzburg 1991, S. 63-102, sowie ausführlich ders.: Die Kunst der Utopie. Vom Späthumanismus zur Frühen Aufklärung. Stuttgart 1989.

48 Paracelsus: Von den natürlichen Dingen (Anm. 26), S. 164f.

49 Johann Valentin Andreae: Confessio Fraternitatis R. C. In: Rosenkreuzerschriften (= Gesammelte Schriften, hrsg. von Wilhelm Schmidt-Biggemann, Bd. 3). Bearb., übs., komm. und eingel. von Roland Edighöffer. Stuttgart-Bad Cannstatt 2010, S. 189-252, hier S. 213.

50 Im Kern verbirgt sich hinter der frühneuzeitlichen Entkoppelung von Apokalypse und Naturwissen bei Bacon die alte Problematik des Verhältnisses von Vernunft- und Offenbarungswissen, die bereits seit der mittelalterlichen Debatte um die duplex veritas für heftige Kontroversen sorgte. Vgl. hierzu grundlegend Anneliese Maier: Das Prinzip der doppelten Wahrheit. In: Studien zur Naturphilosophie der Spätscholastik. 5 Bde. Rom 1949-1958, Bd. IV: Metaphysische Hintergründe der spätscholastischen Naturphilosophie (1955), S. 344 sowie Ludwig Hödl: ,... sie reden, als ob es zwei gegensätzliche Wahrheiten gäbe'. Legende und Wirklichkeit der mittelalterlichen Theorie von der doppelten Wahrheit. In: Philosophie im Mittelalter. Entwicklungslinien und Paradigmen. Hrsg. von Jan P. Beckmann u.a. Hamburg 1996, S. 225-243. 
noch in Bechers Pragmatik wirksam ist (vgl. das dritte Kapitel dieses Beitrags): Bacon unterscheidet zwischen Gott als first cause und den in der Natur wirksamen Kräften als second causes. ${ }^{51}$ Aufgabe der experimentellen Naturphilosophie ist es nach Bacon, sich ganz auf die Zweitursachen zu konzentrieren. Zwar gibt auch Bacon das eschatologische Programm einer Verbindung von Naturwissen und Heilsgeschichte noch nicht ganz auf, wenn er schreibt, the true ends of knowledge sei a restitution and reinvesting (in a great part) of man to the sovereignty and power (for whensoever he shall be able to call the creatures by their true names he shall again command them) which he had in his first state of creation. ${ }^{52}$ Für ihn steht die Apokalypse aber nicht mehr unmittelbar bevor, sondern verschiebt sich in eine ferne Zukunft. Deswegen entwirft er ein Wissenschaftsprogramm, das ausdrücklich auf viele Generationen von Naturforschern ausgelegt ist, bevor das Ende der Zeiten zu erwarten sei. ${ }^{53}$

I take it those things are to be held possible, which may be done by some person, though not by every one; and which may be done by many, though not by any alone; and which may be done in succession of ages, though not within the hourglass of one man's life[.] ${ }^{54}$

In ähnlicher Weise entwickeln kurze Zeit später auch René Descartes, Samuel Hartlib, Johann Amos Comenius und Blaise Pascal ein auf Generationen von Forschern ausgerichtetes naturphilosophisches Wissenschaftsprogramm, ${ }^{55}$ das

51 Francis Bacon: Advancement of Learning. In: The Works of Francis Bacon. Hrsg. von James Spedding, Robert Leslie Ellis und Douglas Denon Heath. 14 Bde. Stuttgart-Bad Cannstatt 1982 [Nachdruck d. Ausgabe London 1857-1874], Bd. 3, S. 253-491, hier S. 267.

52 Francis Bacon: Valerius Terminus of The Interpretation of Nature. In: The Works of Francis Bacon (Anm. 51), Bd. 3, S. 215-252, hier S. 222. Zur Relevanz der Heilsgeschichte für Bacons Denken vgl. Klaus Reichert: In diesem Herbst der Welt. Francis Bacons Begründung der Wissenschaft aus dem Geist der apokalyptischen Verheißung. In: Wissensideale und Wissenskulturen in der frühen Neuzeit/ Ideals and Cultures of Knowledge in Early Modern Europe. Hrsg. von Wolfgang Detel und Claus Zittel. Berlin 2002, S. 239-257.

53 Ein wichtiges Argument dafür, Theologie und Naturphilosophie in dieser Weise voneinander zu entkoppeln, findet sich in Bacons vehementer Ablehnung der Alchemie: Obwohl der Alchemie viele gute Entdeckungen und nützliche Erfindungen zu verdanken seien, so Bacon, sei sie dennoch beherrscht von blindem Aberglauben und religiöser Verzückung. Stattdessen fordert Bacon eine ganz den Sinnen gehorchende und vorurteilsfreie Experimentalphilosophie, die bei der Wissensgewinnung strikten induktiven Regeln folgt. Die Fundamentalkritik, die Becher ein halbes Jahrhundert später an der Alchemie vor seiner Zeit übt, beklagt in ähnlicher Weise deren Vorgehensweise, nämlich einerseits Meinungen ungeprüft weitergetragen und-ohne Methodik und Theorie - in planlosem Laborieren nur experimentelle Zufallsentdeckungen gemacht zu haben. Vgl. Francis Bacon: The New Organon or, True Directions Concerning the Interpretation of Nature. In: The Works of Francis Bacon (Anm. 51), Bd. 4, S. 38-248, hier S. 40, S. 65, S. 81 und S. 84, sowie Becher: Unter-erdische Naturkündigung [...] I. Die tieffe Zeugung derer unter-erdischen Dinge (Anm. 9), S. 10f.

54 Bacon: Advancement of Learning (Anm. 51), S. 328f.

55 Vgl. René Descartes: Discours de la méthode pour bien conduire sa raison, et chercher la verité dans les sciences/ Von der Methode des richtigen Vernunftgebrauchs und der wissen- 
mit den Gründungen der großen naturforschenden Akademien ab Mitte des 17. Jahrhunderts schließlich institutionalisiert wird.

Die entscheidende Konsequenz dieser Entkoppelung von Apokalypse und Naturwissen zugunsten der latent utopischen Vorstellung stetiger Vervollkommnung des Wissens - und mit dessen Hilfe auch der materiellen Welt - ist in einer massiven Verstärkung des zeitlichen Aspekts in der naturphilosophischen Produktion von Wissen zu sehen: Wissen entfaltet sich nun in einer sukzessive entgrenzten Zeit. Auch wenn die "theologische Letztbegründung" des Wissens in der heilsgeschichtlichen Apokalyptik dabei explizit noch nicht aufgehoben wird, ${ }^{56}$ wird sie dennoch so weit in den Hintergrund gedrängt, dass sich neue und zeitlich entzerrte Handlungs- und Gestaltungsspielräume für die naturphilosophische Forschung auftun. Diese Spielräume sind ihrem Charakter nach deshalb eher als utopisch denn als apokalyptisch zu bezeichnen, weil sie auf dem planvollen Handeln des Menschen beruhen, der aktiv, reflektiert und zielorientiert auf die verheißungsvolle Zukunft hin arbeitet, anstatt ausschließlich die Gnade Gottes in der Apokalypse zu erhoffen. Diese neue Zukunft scheint damit immer weniger durch den Weltuntergang einerseits und die sich mit ihm anbahnende Vollständigkeit allen möglichen Wissens andererseits terminiert zu sein. Erst im Kontext dieser zeitlichen Entgrenzung menschlicher Produktivkraft kann nach und nach ein moderner Fortschrittsgedanke im Sinne einer „unumkehrbaren Vorwärtsbewegung“ Gestalt annehmen. ${ }^{57}$ Das Naturwissen erhält vor diesem Hintergrund also seine politische Relevanz für das Dies-

schaftlichen Forschung [1637]. Französisch-Deutsch. Hrsg. und übs. von Lüder Gäbe. Durchges., Register und Bibliographie von George Heffernan. Hamburg 1997, S. 103; Samuel Hartlib: A brief Discourse Concerning The Accomplishment of our Reformation: Tending to shew, That by an Office of Publike Addresse in Spirituall and Temporall Matters, the Glory of God and the Happinesse of this Nation may be highly advanced. In: Considerations Tending To the Happy Accomplishment of Englands Reformation in Church and State. Humbly presented to the Piety and Wisdome of the Highe and Honourable Court of Parliament. S. 1. [1647], S. 1-59; Johann Amos Comenius: Der Weg des Lichtes/ Via lucis [1668]. Eingel., übs. und mit Anmerkungen von Uwe Voigt. Hamburg 1997 sowie Blaise Pascal: Fragment eines Vorwortes zur Abhandlung über den leeren Raum [1651]. In: Vermächtnis eines großen Herzens. Die kleineren Schriften. Hrsg. und übs. von Wolfgang Rüttenauer. Wiesbaden 1947, S. 1-10.

56 Die Formulierung ,theologische Letztbegründung“ übernehme ich von Peter Nitschke: Der doppelte Sieg der Nützlichkeit. Zur Interdependenz von Staatsräson und Utopie in der politischen Theorie der Aufklärung. In: Die Politisierung des Utopischen im 18. Jahrhundert. Von der Frühaufklärung zum Zeitalter der Revolution. Hrsg. von Monika NeugebauerWölk und Richard Saage. Tübingen 1996, S. 27-39, hier S. 28.

57 Werner Krauss: Studien zur deutschen und französischen Aufklärung. Berlin 1963, S. 185. Zitiert nach H. R. Jauß: Ästhetische Normen und geschichtliche Reflexion in der,Querelle des anciens et des modernes'. In: Charles Perrault: Parallèle des anciens et des modernes en ce qui regarde les arts et les sciences. Mit einer einleitenden Abhandlung von H. R. Jauß und kunstgeschichtlichen Exkursen von M. Imdahl. München 1964 [Nachdruck d. Ausgabe Paris 1688-1696], S. 8-64, hier S. 11. 
seits, insofern es nun zunehmend eine Funktion in den aktiv zu gestaltenden innerweltlichen Belangen erfüllt. ${ }^{58}$ Koselleck beschreibt mit Blick auf die sukzessiv Gestalt annehmende ,Menschheitsgeschichte' diesen Übergang aus der Gnade Gottes in die Selbstverantwortung des Menschen an der Wende zur Moderne wie folgt:

Zum einen ist nicht mehr Gott der Herr der Aktion, sondern es ist der Mensch, der die Fortschritte provoziert. Es handelt sich um einen schleichenden Wechsel des Subjekts. Zum anderen ist es nicht mehr die Zeit selber, die ihrer naturalen Regelmäßigkeit beraubt und insofern verkürzt wird; vielmehr bedient sich der Mensch der immer gleichbleibenden Naturzeit, um die von ihm ausgelösten Fortschritte chronologisch zu messen. Die erhoffte oder schon bestätigte Beschleunigung der Fortschritte wird berechnet innerhalb einer gleichbleibenden Zeit - im Gegensatz zur Zeitverkürzung, über die Gott verfügt. [...] Beiden Positionen bleibt eine Gemeinsamkeit. Denn beide Male zehren die Argumentationen von Zielbestimmung, von Teleologie, von einem Telos, das immer schneller erreicht werden soll. Das Ziel der beschleunigten Fortschritte war die Beherrschung der Natur und zunehmend auch die Selbstorganisation der politisch verfaßten Gesellschaft. Das Heil wurde nicht mehr am Ende der Geschichte, sondern seitdem im Vollzug der Geschichte selbst gesucht. ${ }^{59}$

Becher steht nun genau am Übergang dieses „schleichenden Wechsel des Subjekts“. Der zweite Aspekt, der ihn mehr als alchemischen Utopisten denn als alchemischen Apokalyptiker ausweist, betrifft unmittelbar dessen spezifische Art, Naturwissen mit Blick auf die zeitgenössischen politischen Zustände pragmatisch nutzbar machen zu wollen. Die verheerenden Verwüstungen, die der 30-jährige Krieg mit sich brachte und die ca. einem Drittel der Bevölkerung des Reiches direkt oder indirekt das Leben kosteten, ${ }^{60}$ können als radikale Zäsur in diesem Kontext nicht überschätzt werden. Denn die eschatologische Hoffnung

58 Interessanterweise muss das Naturwissen von seinen heilsgeschichtlichen Implikationen zuerst gereinigt, mithin neutralisiert werden, um ganz problemlos für rein innerweltliche politische Zwecke instrumentalisiert werden zu können. Bechers Werk kann aus dieser Perspektive als problematischer Ausdruck dieses Reinigungsprozesses betrachtet werden. Zur Neutralisierung des Naturwissens im Kontext der Gründung der Royal Society (1660-1663) vgl. vor diesem Hintergrund grundlegend Wolfgang van den Daele: Die soziale Konstruktion der Wissenschaft. Institutionalisierung und Definition der positiven Wissenschaft in der zweiten Hälfte des 17. Jahrhunderts. In: Gernot Böhme, Wolfgang van den Daele und Wolfgang Krohn: Experimentelle Philosophie. Ursprünge autonomer Wissenschaftsentwicklung. Frankfurt a.M. 1977, S. 129-182.

59 Reinhart Koselleck: Zeitverkürzung und Beschleunigung. Eine Studie zur Säkularisation. In: Zeitschichten. Studien zur Historik. Mit einem Beitrag von Hans-Georg Gadamer. Frankfurt a.M. 2000, S. 177-202, hier S. 188f.

60 Vgl. Manfred Vasold: Die deutschen Bevölkerungsverluste während des Dreißigjährigen Krieges. In: Zeitschrift für Bayerische Landesgeschichte 56 (1993), S. 147-160. 
auf eine kurz bevorstehende apokalyptische Erlösung, die zu Beginn des Jahrhunderts allerorten spürbar war, hat sich mit dem Krieg vollends zerschlagen. Sie musste angesichts der Tragödie den konkreten politischen und ökonomischen Erfordernissen des kriegsgebeutelten Reiches weichen. ${ }^{61}$ Vor diesem zeithistorischen Hintergrund einer stark dezimierten und schlecht versorgten Bevölkerung sowie einer brachliegenden Wirtschaft müssen Bechers sozialutopische Ideen zum Wiederaufbau des Reiches nach dem Krieg in der zweiten Hälfte des 17. Jahrhunderts beurteilt werden.

\section{Bechers Transformation der Alchemie in Richtung einer politischen Hofökonomie und ihre Relevanz für die absolutistische Staatsräson}

Auf welche Weise Becher für sich neue Betätigungsfelder im Bereich der politischen Ökonomie an den fürstlichen Höfen akquiriert, lässt sich anhand eines Beispiels aus seiner Zeit am kurfürstlichen Hof in München gut illustrieren. In einer auf den 20. Oktober 1664 datierten Eingabe mit dem Titel Beweiß/ was einem Fürsten an seinem Land gelegen beschäftigt sich Becher mit dem idealen Verhältnis von Wohlstand zwischen absolutistischem Herrscher und Untertanen und wägt dabei die Interessen von Privatpersonen und der öffentlichen Hand hinsichtlich der Steuerpolitik gegeneinander ab. In diesem Zusammenhang gibt er auch eine Begründung, warum er sich als offizieller Hofmedicus mit solchen Themen beschäftigt.

also seynd sie [die Beobachtungen von privaten und öffentlichen Interessen] die Ursach gewesen/ mich zu erkühnen/ von einer Sache zu handlen/ die weder meiner profession, noch condition zukompt/ dann wann ich betrachte/ daß ich nicht unter die Räthe gehöre/ welche zu diesen sachen gewidmet seyn/ [...] sehe ich dann meine profession an/ so weisen meine in Truck außgelassene Schrifften/ daß ich ein Doctor der Medicin bin/ und heist es hier wider/ was ich dann mit politischen Sachen zu thun habe/ [...]? Kürtzlich/ es hat mir nicht so gefählt in der Materi/ als in der Ursach zu der Materi/ wiewol die General-Regul die Ursach oder causa movens gnug darzu ist/ nemblich salus populi suprema lex esto, welches man wohl also verteutschen kan/ nemblich Ew. Churfürstl. Durchl. und dero Landen Wohlfahrt gehet alles vor/ determinirt alles/ alles laufft in einem centro darinnen zusammen[.] ${ }^{62}$

$61 \mathrm{Vgl}$. Wilhelm Schmidt-Biggemann: Apokalyptische Universalwissenschaft. Johann Heinrich Alsteds Diatribe de mille annis apocalypticis. In: Pietismus und Neuzeit. Ein Jahrbuch zur Geschichte des neueren Protestantismus 14 (1988) (= Chiliasmus in Deutschland und England im 17. Jahrhundert), S. 50-71, hier S. 71.

62 Johann Joachim Becher: Politische Discurs von den eigentlichen Ursachen/ deß Auff- und Abnehmens der Städt/ Länder und Republicken/ In specie, Wie ein Land Volckreich und Nahrhafft zu machen/ und in eine rechte Societatem civilem zu bringen. Auch wird von dem Bauren-Handwercks und Kauffmannsstand/ derer Handel und Wandel/ Item, Von 
Smith widmet sich ausführlich dieser Passage und identifiziert das Cicero-Zitat salus populi suprema lex esto als Kernsatz, insofern Becher hier mit der Doppeldeutigkeit des lateinischen salus populi spielt: Die Gesundheit des Volkes sei das oberste Gesetz! wird von Becher mit der Bedeutung der alternativen Übersetzung Die Wohlfahrt des Volkes sei das oberste Gesetz! überblendet. ${ }^{63}$ Sein Interesse und Engagement für die Hofökonomie begründet Becher nach Smith hier mit seiner Stellung als Alchemiker und Hofmedicus also damit, dass er auf die Bedeutung der politischen Ökonomie für die sozialen Verhältnisse verweist, von denen die gesundheitliche Verfassung der Bevölkerung maßgeblich abhänge. Die Gesundheit der arbeitenden Bevölkerung sei wiederum für die wirtschaftliche Prosperität des Landes wichtig. Mithin geht es Becher hier darum, seine Zuständigkeit für jene zwei Kernthemen der politischen Ökonomie zu begründen, die für den absolutistischen Kameralismus in der Nachkriegssituation entscheidend waren: Die Bevölkerungszahlen sollten stabilisiert und die Einkünfte der Staatskasse verbessert werden, wofür eben neue Strukturen zur Organisation des Gemeinwesens entwickelt werden mussten: [...] je volckreicher also eine Stadt ist/ je mächtiger ist sie auch; derohalben leichtlich zu erachten/ daß die vornehmste Staats-Regul/ oder maxima einer Stadt oder Lands seyn soll/Volckreiche Nahrung[.] $]^{64}$

Bei der ausgereizten Doppelbedeutung von salus populi handelt es sich aber nicht, oder zumindest nicht nur, um einen von Becher rhetorisch gekonnt durchgeführten Übersetzungstrick, mit dem er seine Kompetenzen über seine eigentliche höfische Position hinaus zu erweitern gedenkt. Becher überträgt hier und auch in seinen zahlreichen anderen Projekten vielmehr den Gedanken der transformativ-veredelnden Kraft der Alchemie auf den politisch-ökonomischen Bereich sozialer Interaktion. ${ }^{65}$ Becher hat sich selbst, wie bereits erwähnt, in erster Linie als Alchemiker begriffen. Dass er sich neben seinen experimentellen Laborarbeiten auch auf so unterschiedlichen Gebieten wie politischer Hofökonomie, Reformpädagogik oder Maschinenbau hervorgetan hat, findet hier seine logische Fundierung. Denn wenn die heterogenen Projekte Bechers weit über die

dem Monopolio, Polypolio und Propolio, von allgemeinen Land-Magazinen/ Niederlagen/ Kauffhäusern/ Montibus Pietatis, Zucht- und Werckhäusern/ Wechselbäncken und dergleichen außführlich gehandelt. Zweyte Edition. Mit Vier Theilen vermehret, worinnen viel nutzliche/ wichtige und curiose Sachen begriffen [1668]. Franckfurt 1673, S. 300.

63 Pamela H. Smith: Chemistry and Commerce. Johann Joachim Becher at the Court of the Elector of Munich. In: Johann Joachim Becher (Anm. 6), S. 143-158, hier S. 150.

64 Becher: Politische Discurs (Anm. 62), S. 2. Vgl. hierzu auch Reinhold Sellien u.a. (Hrsg.): Merkantilismus. In: Gabler Wirtschaftslexikon. 4 Bde. 13. Aufl. Wiesbaden 1992, Bd. 3, S. 2256.

65 Teich vertritt die im hier verhandelten Zusammenhang überzeugende These, dass das alchemische Denken in Naturkreisläufen (im letztlich aristotelischen Sinne von Werden und Vergehen) sowohl Bechers Naturphilosophie als auch seine politische Ökonomie im Sinne eines beständigen Geld- und Warenkreislaufs maßgeblich geprägt habe und diese dadurch miteinander verbunden seien. Vgl. Mikuláš Teich: Interdisciplinarity in J. J. Bechers's Thought. In: History of European Ideas 9 (1988), 2, S. 145-160, hier 156f. 
traditionellen alchemischen Interessen wie Metalltransmutation, Herstellung von Arzneien, Bergbau o. ä. hinausweisen, wird dabei der explizite Bezug zur Alchemie - entgegen dem ersten Eindruck - nicht einfach preisgegeben und einer zeitgenössischen Hofrhetorik geopfert. Stattdessen verändert sich in Bechers Denken vielmehr die Alchemie selbst. Sie öffnet sich neuen Gegenständen und Erkenntnisbereichen, was sich wiederum in der Doppelstruktur von Bechers Schaffen widerspiegelt: Einerseits betreibt Becher sein Leben lang experimentelle Alchemie und versucht auf diese Weise, neue Techniken der Produktion und Veredelung zu entwickeln - in diesem Zusammenhang verteidigt er stets auch vehement die Möglichkeit erfolgreicher Metalltransmutation. Andererseits politisiert, ökonomisiert, sozialisiert oder kurzum: universalisiert er den alchemischen Gedanken. Er legt die utopische Machbarkeit des Vollkommenen mittels Transformation des Materiellen der Sphäre des Politischen zugrunde, um die notwendigen ökonomischen Reformen im Reich zu realisieren. Es ist zwar völlig überspitzt und historisch schlicht grundfalsch, Becher zum kommunistischen Sozialrevolutionär avant la lettre zu stilisieren, der "die Massen [...] zum Kampf gegen die Tyrannei“ aufgerufen habe. ${ }^{66}$ Dass aber die Wohlfahrt des Einzelnen und des Staates gleichermaßen von den zu optimierenden materiellen Lebens- und Produktionsverhältnissen abhängt, davon ist Becher in einem überraschend modernen Sinne überzeugt, auch wenn immer noch die Kunst der Alchemie die Hintergrundfolie seines ökonomischen Ansatzes bildet. Im Sinne dieses zwischen Motiven der alchemischen Naturphilosophie einerseits und der Modernität politischer Ökonomie andererseits changierenden und zugleich vermittelnden Denkens kann bei Becher - so meine These - von einer alchemia oeconomica am Schnittpunkt von Vormoderne und Moderne gesprochen werden. Der alchemische Kerngedanke, wonach eine Kraft die Materialität der Welt gezielt in einen besseren oder vollkommenen Zustand transformiert, wird hierbei für Becher zum übergeordneten Konnex zwischen experimenteller Naturphilo-

66 „Becher forderte hier die niedergetretenen und ausgebeuteten Bauern auf, der Obrigkeit nicht mehr Folge zu leisten [...]. Er rief die Massen auf zum Kampf gegen die Tyrannei [...]. In vielen anschaulichen Bildern verstand er es, Grausamkeiten des Adels lebendig darzustellen." Heinz Kelbert: Johann Joachim Becher. Ein Beitrag zur Erforschung des berufspädagogischen Erbes. Berlin 1954, S. 12. Inwieweit Becher als historische Projektionsfläche für den jeweiligen Zeitgeist der politischen Verhältnisse und Interessen diente, wird darin deutlich, dass er auch im Rahmen nationalsozialistischer Propaganda instrumentalisiert wurde. Konrad Ullrichs Becher gänzlich überhöhende Studie zu dessen Experimenten mit Kohlengasen ist ein Schreiben des Amts für Technik der NSDAP vorangestellt, aus dem hervorgeht, dass seine Arbeit der ,Kanzlei des Führers' vorgelegen habe. Dem Exemplar der Staatsbibliothek zu Berlin ist zudem ein Originalbrief von Karl Bunte, Professor für Gastechnik und Brennstoffverwertung und Vorstand des Gasinstitutes in Karlsruhe, beigefügt, in dem er dem „,zünftigen Forscher der Geschichte der chemischen Technik“ für seine „Opferbereitschaft" dankt. Konrad Ullrich: Dr. Johann Joachim Becher. Der Erfinder der Gasbeleuchtung, geb. zu Speyer a. Rh. 1635. München [1936], S. 1 und Anhang (Staatsbibliothek zu Berlin, Sig. 5Per1093-23,1). 
sophie und sozialer Lebenswelt. Auf diese Weise scheint es kaum einen Wissensbereich zu geben, für den sich der Alchemiker Becher nicht zuständig zu fühlen vermag. Denn aus seiner Sichtweise können alle seine heterogenen Ambitionen und Projekte unter dem Dach einer universalwissenschaftlich-reformatorisch gedachten Alchemie subsumiert werden. In Bechers Denken bildet die göttliche Kunst der Alchemie somit die ontologische Grundlage für naturphilosophische und soziopolitische Belange gleichermaßen. Letztlich weist er damit Alchemie als universalen Königsweg für den absolutistischen Souverän aus: Denn mit ihr gelingt es Becher, Herrschaftsanspruch und materielle Wissenspraxis mit Blick auf zielorientiertes politisches Handeln dergestalt aufeinander zu beziehen und miteinander $\mathrm{zu}$ verzahnen, dass eine Verbesserung bis hin zur Vervollkommnung der Lebensumstände in universeller, d. h. in sozialer, reformpädagogischer, moralischer als auch politisch-ökonomischer Hinsicht möglich erscheint. Genau aus dieser alchemisch-universalistischen Perspektive greifen denn auch die äußerst heterogenen praktischen Projekte und theoretischen Arbeiten Bechers ineinander. Mit Blick auf das utopische Ziel einer allumfassenden Wohlfahrt können so unterschiedliche Schriften Bechers wie etwa die Methodus didactica (1668), der Politische Discurs (1668), der Moral-Discurs (1669) oder auch die Närrische Weisheit Oder Weise Narrheit (1682), in der Becher am Ende seines Lebens eine kritische Bilanz eigener und fremder Projektemacherei gleichermaBen zieht, in einen gemeinsamen Kontext gestellt werden. ${ }^{67}$

Ausgehend von den dargelegten Dimensionen des paracelsistischen Elias artista lässt sich für Becher somit folgendes Resümee ziehen: Becher nutzt jene Gestaltungs- und Handlungsspielräume, die durch die zeitliche Entzerrung von Naturwissen und Apokalypse entstanden sind, um für die Alchemie neue Aufgabengebiete im Zeichen einer utopischen Vollkommenheit im Sinne einer noch zu realisierenden, Glückseligkeit' zu erschließen. ${ }^{68}$ Diese Aufgabengebiete erkennt Becher insbesondere in der Optimierung und Vervollkommnung der politisch-ökonomischen Situation des Reiches, also in der angestrebten allgemeinen Wohlfahrt. Bechers Sozialutopismus, in den seine fortschrittlichen Reformen münden sollen, zielt expressis verbis auf eine vollkommene christliche Gemeinschaft ab: In dieser kommenden Gemeinschaft stehen alle Menschen auf einer

67 Vgl. Becher: Methodus didactica (Anm. 4); ders.: Politische Discurs (Anm. 62); ders.: Moral Discurs Von den eigentlichen Ursachen deß Glücks und Unglücks/ Allwo gleichsam auff einer Wagschal Alle und jede menschliche Actiones auf der gantzen Welt/ so zum Guten/ und Bösen gericht/ ohnpartheyisch erwogen werden. Franckfurt am Mayn 1669, sowie ders.: Närrische Weißheit Und Weise Narrheit: oder Ein Hundert/ so Politische alß Physicalische/ Mechanische und Mercantilische Concepten und Propositionen/ deren etliche gut gethan/ etliche zu nichts worden/ Sampt den Ursachen/ Umbständen und Beschreibungen derselben. Ein Tractätlein vor die Liebhaber/ sehr curios und nützlich zu lesen/ als worinnen viel nachdenckliche Sachen enthalten. Franckfurt 1682.

68 Vgl. hierzu auch Ulrich Engelhardt: Zum Begriff der Glückseligkeit in der kameralistischen Staatslehre des 18. Jahrhunderts (J. H. G. V. Justi). In: Zeitschrift für Historische Forschung 8 (1981), S. 37-79. 
Augenhöhe, gibt es kein Geld mehr, keinen Neid erregenden Besitz und keine Ungerechtigkeiten, ${ }^{69}$ wobei Becher in seiner pragmatischen Art durchaus anerkennt und in der täglichen politischen Praxis auch produktiv zu nutzen weiß, dass Geld der nervus rerum gerendarum jetziger Zeiten ist. ${ }^{70}$ In den konkreten, allerdings recht überschaubaren Beschreibungen dieser Ziele spielen für Becher heilsgeschichtliche Bezüge eine wichtige Rolle, insofern der Sündenfall bis in die Alltagsprobleme diffundiert und deren konkrete Lösung wiederum auf die utopische Erlösung in einem christlichen Sinne verweist.

[D]ieser Gegentheil [die Vollkommenheit im Vergleich zur gegenwärtigen Lage] aber ist eine vollkommene Glückseeligkeit/ so weit sie sich in dieser Welt erstrecken kan/ dann es ist zuwissen/ daß die menschliche Natur sambt der Erden von Gott so weit nicht verflucht/ als sie von uns verböst und verderbt ist worden/ darumb so seynd allezeit gewisse Puncten gewesen/ darin einige Glückseligkeit der Menschen auff dieser Welt bestanden ist/ daß aber die Menschen solche nicht gebrauchet/ sondern in unglückselige Irrwege gelaufen seynd/ ist nicht so Gott/ oder der Natur/ als der Menschlichen Boßheit zuzuschreiben [...] So dann noch etwas Guts und Glückseeliges in der Natur ist/ so lasset uns besehen/ was es seye/ und in was vor einer Larven es verborgen lige/ in deme so viel es suchen/ und doch so wenige finden/ ehe ich aber solches suche/ muß ich mich deß Wegs wegen besinnen/ und kan keinen anderen finden/ als den/ welchen die Natur uns selbsten offenbahret/ und in welchem wir/ wann wir die Warheit bekennen wollen/ übereinstimmen/ nemlich dieser Mensch seye glückseelig/ welcher Erstlich Gottselig seye; welcher Zweytens seine Vernunfft und Verstand in Wissenschafften wol gebrauchen kan; welcher Drittens/ einen ehrlichen Namen; welcher Vierdtens ehrlich zu leben habe; un endlich/ welcher Fünftens gesund seye und lang lebe. [...] [D]iese fünff Puncten seynd die Gesetze der Natur/ ja die Wurzeln aller anderer Gesetze/ als in welche alle Gesetze deß ganzen Corporis Juris Civilis, $\mathcal{E}$ Canonici, Ec. könen reducirt, auch darauß gar leicht/ nemblich auß dem rechten Grund/ wie ich wol erweisen könte/ resolvirt und interpretirt wer$\operatorname{den}[.]^{71}$

Die Realisierung der vollkommenen christlichen Gemeinschaft aus dem Geiste der Alchemie ist aber nur die eine, eher theoretische Seite der politischen Hofökonomie Bechers. Betrachtet man seinen ökonomischen Ansatz auch mit Blick auf seine konkrete Umsetzung bzw. auf die damit verbundenen Konsequenzen im unmittelbaren politischen Umfeld, ergibt sich ein ganz anderes Bild als das anvisierte Ziel einer utopischen Glückseligkeit. Denn es ist auffällig, dass

69 Vgl. Becher: Moral Discurs (Anm. 67), S. 150.

70 Becher: Politische Discurs (Anm. 62), S. 983.

71 Becher: Moral Discurs (Anm. 67), S. 5-10. 
Bechers explizit sozialutopischer Anspruch in der politischen Alltagspraxis zugunsten des Machterhalts des absolutistischen Souveräns immer wieder in den Hintergrund gerät. Es ist das markante Kennzeichen der politischen Pragmatik Bechers, dass die utopischen Ziele nur mit einer harten, aber gerechten Machtpolitik seitens der absolutistischen Herrschaft in der Gegenwart erreicht werden können; eine Herrschaft, die sich aber nicht jederzeit an einem übergeordneten Ideal orientieren soll, sondern die durchaus auch geschickt, listig und innovativ auf die alltäglichen politischen Herausforderungen reagiert. ${ }^{72}$ Modern gesprochen setzt sich bei Becher in der Praxis politischen Handelns auf gewisse Weise der Verantwortungsethiker gegenüber dem Gesinnungsethiker durch. ${ }^{73}$ Die Erwähnung christlicher Werte wie Moral, Nächstenliebe und letztlich auch Wohlfahrt erweckt in den idealisierend-sozialutopischen Ausführungen Bechers noch den Eindruck, über die eigentlichen Interessen des Staates in Richtung einer imaginierten vollkommenen Gemeinschaft hinauszuweisen. Aber in den konkreten Projekten wird die ganz auf die immanenten Interessen souveräner Herrschaft gerichtete Kehrseite dieser christlichen Werte ersichtlich. Denn Becher erklärt die Förderung christlicher Lebensweise nicht zuletzt auch deshalb zur Aufgabe des absolutistischen Souveräns, weil dieser damit die Stabilität seiner eigenen Macht sichern könne, insofern Gläubige gehorsamer sind als Ungläubige. Dieser wichtige Punkt muss eingehender betrachtet werden.

Becher erklärt also aus pragmatischer Sicht den christlichen Glauben zum unerlässlichen Bestandteil eines Ensembles von gezielt einsetzbaren Regierungstechniken im sich formierenden Verwaltungsstaat am Beginn der Moderne. Foucault hat diese Entwicklung, die sich nicht nur bei Becher beobachten lässt, sondern als politische Strategie insgesamt den Beginn der politischen Moderne

72 Becher spart in seinem Moral Discurs (1669) aber auch nicht mit einer Kritik am mächtigen Adel: Aber vergebt es mir ihr Herrn/ ists nicht wahr/ daß wir alle Menschen und Bürger der Welt seyn? Ja. Wo rühret dann die Leibeygenschafft und euer vorgewandte servitut her? Sicher von nichts anders/ als von einer Tyranney. Ich bin der Obrigkeit unterthan/ wann sie mich zum Guten anführet/ ihr zu folgen/ aber im übrigen mit Gut und Blut unterhan seyn/ und ihme die Haut über die Ohren ziehen lassen/ das hat unter dem Praetext nichts mit dieser Unterthänigkeit zu thun. Ja ich thue sünd/ so ich solches leide/ und mich mit Fleiß einer Tyranney unterwerffel wie solches klärlich stehet [...] Es sey fern von mirl daß ich der Obrigkeit ihr Gebühr disputierel wann Sie eine Obrigkeit ist/ aber warlich solche Obrigkeit ist vor keine zuachten/durch welche alles Elend in die Welt kombt. Um dem Machtmissbrauch seitens der Herrscher vorzubeugen und sie zu befähigen, die Bevölkerung in die richtigen Bahnen zu lenken, bedarf es schon in den frühesten Kindertagen der guten Erziehung der Fürsten und der guten Beratung während ihrer Amtszeit. Für beide Bereiche sah sich Becher als politischer Berater zuständig, um die Glückseligkeit der Menschen herbeizuführen. Mithin skizziert er bei näherer Betrachtung in diesem Zitat viel eher die Gefahren des zivilen Ungehorsams, als dass er dazu aufruft, und empfiehlt seine Beratertätigkeit dem Fürsten zugleich als geeignetes Remedium. Becher: Moral Discurs (Anm. 67), S. 42f.

73 Vgl. Max Weber: Politik als Beruf [1919]. In: Gesammelte politische Schriften. Hrsg. von Johannes Winckelmann. Tübingen 1980, S. 505-560. 
markiert, unter dem Stichwort Gouvernementalität eingehend untersucht. ${ }^{74}$ In einer ähnlichen Weise, wie Becher im obigen Beispiel die Bedeutung von Ciceros salus populi bei der Übersetzung ins Deutsche im Sinne seiner eigenen Interessen ausreizt, sieht Foucault den Begriff des Heils in der Frühen Neuzeit einer nachhaltigen Veränderung ausgesetzt, und zwar in dem Maße, in dem die Macht der Kirche über die Gläubigen nach und nach profaniert, d. h. in genuin staatliche Interessensbereiche übertragen wird. Nicht zufällig kommt Foucault in diesem Zusammenhang auch auf genau jene Themengebiete zu sprechen, die Becher als Arzt und Alchemiker über seinen eigentlichen Zuständigkeitsbereich hinaus am Hofe für sich requirieren möchte.

Ich glaube nicht, dass der „moderne Staat“ als eine Entität gelten muss, die sich unter Missachtung des Individuums und seiner existenziellen Eigenheit entwickelt hat, sondern als eine hoch elaborierte Struktur, in die sich die Individuen integrieren lassen, sofern man dieser Individualität eine neue Form verleiht und sie einer Reihe spezifischer Mechanismen unterwirft. In gewissem Sinne kann man im Staat eine Matrix der Individualisierung oder eine neue Form von Pastoralmacht erblicken. Ich möchte noch ein paar Worte zu dieser neuen Pastoralmacht sagen. 1. Sie erfuhr in ihrer Entwicklung einen Wechsel der Zielsetzung. Aus der Sorge um das Heil der Menschen im Jenseits wurde die Sorge um ihr Heil im Diesseits. In diesem Kontext erhält das Wort „Heil“ mehrere Bedeutungen; es meint nun Gesundheit, Wohlergehen (im Sinne eines angemessenen Lebensstandards und ausreichender Ressourcen), Sicherheit und Schutz vor Unfällen aller Art. Die religiöse Zielsetzung des traditionellen Hirtenamtes wurde durch eine Reihe „irdischer" Ziele ersetzt [...] 2. Daneben verstärkte man auch die Verwaltung der Pastoralmacht. Manchmal wurde diese Machtform vom Staatsapparat oder zumindest von einer öffentlichen Institution wie der Polizei ausgeübt. (Vergessen wir nicht, dass die Polizei im 18. Jahrhundert nicht nur zur Aufrechterhaltung von Gesetz und Ordnung und zum Schutz der Regierenden vor ihren Feinden erfunden wurde, sondern auch zur Sicherung der Versorgung in den Städten, zum Schutz der Hygiene, der Gesundheit und all der Bedingungen, die als notwendig für die Entwicklung des Handwerks und Handels galten) [...] 3. Dank der Vermehrung der Zielsetzungen und Träger der Pastoralmacht konnte die Entwicklung des Wissens über den Menschen sich auf zwei Pole konzentrieren, einen globalisierenden und quantitativen, der die Bevölkerung betraf, und einen analytischen, der dem Individuum galt. In der Folge breitete sich die Pastoralmacht, die über die Jahrhunderte, ja über mehr als ein Jahrtausend mit einer ganz bestimmten religiösen

74 Vgl. Michel Foucault: Geschichte der Gouvernementalität. I. Sicherheit, Territorium, Bevölkerung. II. Die Geburt der Biopolitik. Hrsg. von Michel Sennelart und übs. von Claudia Brede-Konersmann und Jürgen Schröder. 2 Bde. Frankfurt a.M. 2004. 
Institution verbunden gewesen war, auf die gesamte Gesellschaft aus und stützte eine Reihe von Institutionen. ${ }^{75}$

Mit der Absicht, die Regierbarkeit der Bevölkerung sicherzustellen, zielen Bechers Bemühungen ganz im gouvernementalen Sinne Foucaults in zwei Hauptrichtungen, die im 18. Jahrhundert schließlich zur gesellschaftlichen Polizierung im modernen Verwaltungsstaat führen: nämlich auf die ,Individualisierung' der einzelnen Untertanen im Sinne ihrer umfassenden Bildung und ökonomischen Produktivmachung sowie auf die ,Totalisierung' aller Untertanen im Sinne einer mit entsprechenden institutionellen Techniken regierbaren Bevölkerungsmasse. Effekt dieser Verschaltung von Individualisierung und Totalisierung im Zeichen der profanierten Pastoralmacht ist jene ,Führung zur Selbstführung ${ }^{\prime},{ }^{76}$ die den Grundstein der modernen Staatsräson bildet.

Der Ausdruck „Führung“ (conduite) vermag es in seiner Mehrdeutigkeit das Spezifische an den Machtbeziehungen vielleicht noch am besten zu erfassen. „Führung“ heißt einerseits, andere (durch mehr oder weniger strengen Zwang) zu lenken, und andererseits, sich (gut oder schlecht) aufzuführen, also sich in einem mehr oder weniger offenen Handlungsfeld zu verhalten. Machtausübung besteht darin, „Führung zu lenken“, also Einfluss auf die Wahrscheinlichkeit von Verhalten zu nehmen. Macht gehört letztlich weniger in den Bereich der Auseinandersetzung zwischen Gegnern oder der Vereinnahmung des einen durch den anderen, sondern in den Bereich der "Regierung" in dem weiten Sinne, den das Wort im 16. Jahrhundert besaß. Damals bezog es sich nicht nur auf politische Strukturen und die Staatsverwaltung, sondern meinte auch die Lenkung des Verhaltens von Individuen und Gruppen: von Kindern, Seelen, Gemeinschaften, Familien, Kranken. Es umfasste nicht nur institutionalisierte und legitime Formen politischer und ökonomischer Unterordnung, sondern mehr oder weniger überlegte und berechnete Handlungsweisen, die jedoch alle darauf abzielten, die Handlungsmöglichkeiten anderer Individuen zu beeinflussen. In diesem Sinne heißt Regieren, das mögliche Handlungsfeld anderer zu strukturieren. ${ }^{77}$

Ganz deutlich kommt bei Becher dieser Aspekt einer Führung zur Selbstführung, der aus dem Bereich der vom Pastor angeleiteten christlichen Lebensführung in den Interessensbereich des Staates übertragen wird, zum Vorschein, wenn er die fürstliche Macht als gottgegeben verteidigt und feststellt, dass

75 Michel Foucault: Subjekt und Macht [1982], übs. von Michael Bischoff. In: Dits et Ecrits. Schriften. 4 Bde. Hrsg. von Daniel Defert und François Ewald. Frankfurt a.M. 20012005, Bd. IV (2005), S. 269-294, hier S. 278f.

$76 \mathrm{Zu}$ dieser Verschaltung vgl. Michel Foucault: About the Beginning of the Hermeneutics of the Self. Two Lectures at Dartmouth [1980]. In: Political Theory 21 (1993), 2, S. 198-227.

77 Foucault: Subjekt und Macht (Anm. 75), S. 286f. 
Gott nach dem Fall die Obrigkeit gesetzt [hat]/ und Gesetze gegeben/ die Menschen in den natürlichen Gesetzen zu erhalten/ [...] diese [...] Gesetze und deren Untergebene nun zu regiren, nemblich die Menschen in dem Stand der Menschheit/ und natürlichen Gesetzen zu erhalten/ hat GOtt die Obrigkeit eingesetzt/ deren man als GOtt selbsten gehorsam seyn soll[.. $]^{78}$

Die Übernahme einer Passage des Römerbriefs aus der Luther-Übersetzung ${ }^{79}$ ist mit Blick auf jene nachhaltigen Veränderungen aufschlussreich, die sich ab Mitte des 16. Jahrhunderts für die frühneuzeitliche Staatsmacht ergeben und im Sinne der Gouvernementalität interpretiert werden können. Denn im Rahmen der Reformation wurden einige der ursprünglich der Kirche vorbehaltenen Kompetenzen dem weltlichen Souverän überantwortet. Weithin bekannt ist dies im Fall der Ehe, die nach Luther ausdrücklich ein weltlich Ding ist wie kleider und speise, haus und hoff, weltlicher oberkeit unterworffen, wie das beweisen so viel keiserliche rechte daruber gestellet, und die deshalb für ihn keinen sakramentalen Status mehr besitzt. ${ }^{80}$ Weniger offensichtlich, aber um nichts weniger wichtig für die Stärkung der weltlichen Macht ist der in Luthers Katechismus festgelegte Gehorsam gegenüber der Obrigkeit, den Becher im obigen Zitat aufgreift: Gehorsam gegenüber den Eltern ist Gehorsam gegenüber der weltlichen Macht und in letzter Instanz gegenüber Gott. ${ }^{81}$ Diese sukzessive "Verweltlichung des Geistlichen“, ${ }^{82}$ die - wenn nicht als Intention - so doch zumindest als ein Effekt der reformatorischen Bewegungen beschrieben werden kann, ${ }^{83}$ ermöglicht es der weltlichen Macht, ihren Zugriff auf das gesellschaftliche Miteinander bis in die Mikrostrukturen des Familienlebens hinein zu erweitern, indem der Staat als Vaterfigur mit erzieherischem Auftrag zwischen Familie und Gott in Erscheinung tritt. Ganz in diesem Sinne identifiziert Becher die Aufgaben von Staat und Familie: Obrigkeit und Kinderzucht seynd der Zaum und die Peitsche so die Menschen in der Glückselig-

78 Becher: Politische Discurs (Anm. 62), S. 42.

79 „Jedermann sei untertan der Obrigkeit, die Gewalt über ihn hat. Denn es ist keine Obrigkeit außer von Gott; wo aber Obrigkeit ist, die ist von Gott angeordnet. Wer sich nun der Obrigkeit widersetzt, der widerstrebt der Anordnung Gottes; die ihr aber widerstreben, ziehen sich selbst das Urteil zu." Brief an die Römer 13,1-2.

80 Martin Luther: Von Ehesachen [1530]. In: D. Martin Luthers Werke. Kritische Gesamtausgabe (Weimarer Ausgabe). 127 Bde. Weimar, Graz 1883-2009, Bd. 30 (1964), S. 205-248, hier S. 205.

81 Vgl. ausführlich Barbara Beuys: Familienleben in Deutschland. Neue Bilder aus der deutschen Vergangenheit. Reinbek bei Hamburg 1985, S. 229-238.

82 Luise Schörn-Schütte: Die Reformation. Vorgeschichte - Verlauf - Wirkung. München 2006, S. 68 .

$83 \mathrm{Zu}$ dem Umstand, dass diese „Verweltlichung des Geistlichen“ mehr als Effekt zu begreifen ist und von der reformierten Theologie in dieser Ausprägung nicht intendiert war, vgl. Claus Schwambach: Rechtfertigungsgeschehen und Befreiungsprozess. Die Eschatologien von Martin Luther und Leonardo Boff im kritischen Gespräch. Göttingen 2004, S. 62f. 
keit erhält/ und vor ihren Feinde beschützet [...]. ${ }^{84}$ Diesen für die Konstituierung des modernen Staates paradigmatischen Bruch in der herrschaftlichen Form des Regierungshandelns hat Foucault pointiert als Biopolitik beschrieben: Politische Macht manifestiert sich nicht mehr dadurch, mit dem Tod drohen zu können, sondern sie erkennt das Leben der Individuen als jene entscheidende Ressource an, welche produktiv zu regieren und mit pädagogischem Anspruch anzuleiten zur wichtigsten politischen Aufgabe und Verantwortung des Staates mutiert, um sich selbst zu erhalten. ${ }^{85}$

Als direkte und aufschlussreiche Vertiefung und Fortentwicklung dieses Führungsanspruchs des Staates kann bei Becher unter anderem sein Engagement gegen die Zünfte angesehen werden, das in vielen seiner Projekte eine wichtige Rolle einnimmt. Die Zünfte standen der weltlichen Macht als ein durchaus ernstzunehmender, privat organisierter wirtschaftlicher Gegenpol gegenüber. Um das Zunfthandwerk zu umgehen - dem Becher aufgrund seiner quasi-monopolistischen Stellung maßlose Faulheit vorwarf, mit der es den Handel zu Lasten der Staatskasse behindern würde - setzte er sich intensiv für alternative Formen wie das Verlagswesen ${ }^{86}$ oder das sogenannte hofbefreite Handwerk ein. ${ }^{87}$ Insbesondere mit der Förderung der hofbefreiten Handwerker ging

84 Becher: Moral Discurs (Anm. 67), S. 73.

85 Vgl. Michel Foucault: Der Wille zum Wissen. Sexualität und Wahrheit I. Übs. von Walter Seitter. Frankfurt a.M. 1983, S.161-190. Für den Absolutismus der zweiten Hälfte des 17. Jahrhunderts lässt sich festhalten, dass dieser regierende Zugriff des Staates auf die Mikrostrukturen des Alltags keineswegs nur in reformierten Gegenden anzutreffen ist, sondern sich bereits über konfessionelle Grenzen hinweg durchgesetzt hat. Mit Blick auf diese interkonfessionellen Dimensionen ist der Umstand aufschlussreich, dass Becher Sohn eines protestantischen Pfarrers war, der zum Katholizismus konvertierte, gegen Lebensende aber vielleicht wieder zurückkonvertierte. Vgl. Emil Kauder: Johann Joachim Becher als Wirtschafts- und Sozialpolitiker. In: Schmollers Jahrbuch für Gesetzgebung, Verwaltung und Volkswirtschaft im Deutschen Reiche 48 (1924), 4, S. 59-89, hier S. 62.

86 Ursprünglich vor allem auf dem Land üblich, drang das Verlagswesen in der Frühen Neuzeit immer weiter in die Städte vor und schwächte die Zünfte zusehends. Vgl. Johann Heirich Zedler (Hrsg.): Verleger. In: Grosses vollständiges Universallexicon Aller Wissenschafften und Künste, Welche bißhero durch menschlichen Verstand und Witz erfunden und verbessert worden [....]. 64 Bde. und 4 Ergänzungsbde. Halle, Leipzig 1706-1751, Bd. 47 (1746), Sp. 1100; Werner Sombart: Der moderne Kapitalismus. Historisch-systematische Darstellung des gesamteuropäischen Wirtschaftslebens von seinen Anfängen bis zur Gegenwart. 3 Bde. München, Leipzig 1928, Bd. II.2, S. 708-724, sowie Roland Bettger: Verlagswesen, Handwerk und Heimarbeit. In: Aufbruch ins Industriezeitalter. 4 Bde. Hrsg. von Claus Grimm. München 1985, Bd. 2, S. 175-183.

87 Die hofbefreiten Handwerker kamen im Laufe der festen Residenzenbildung im 16. Jahrhundert auf, die den Wanderhof allmählich ablöste. Im Gegensatz zu den ortsansässigen Hofhandwerkern, die fest bei Hofe angestellt waren, wurden hofbefreite Handwerker aufgrund ihrer ganz speziellen Kenntnisse unabhängig von ihrer Nationalität oder Konfession beschäftigt. Obwohl sie nicht der lokalen Zunftordnung unterstanden, durften sie vor Ort auch außerhalb des Hofes Handel treiben, mehr Lehrlinge und Gesellen - d. h. mehr billige Arbeitskräfte-als die ansässigen Zunfthandwerker einstellen und waren teils von 
das konkrete Produktionswissen unmittelbar auf den Fürsten über, indem die rigiden Regelungen der Zunftordnungen zur Geheimhaltung von Produktionsprozessen schlicht unterlaufen wurden. Die Zünfte wurden damit nach und nach ihrer existentiellen Grundlage beraubt, weil sie einerseits ökonomisch mit den hofbefreiten Handwerkern langfristig nicht konkurrieren konnten und sie andererseits ihr gut gehütetes geistiges Kapital in Form von Herstellungstechniken verloren. Somit wurde sukzessive nicht nur das Produktionswissen, sondern auch der Produktionsprozess direkt in die Hände des absolutistischen Souveräns verlegt. Diese Entwicklung verschränkt sich wiederum mit von Becher angestrebten Steuerreformen, welche die einst den Landesständen vorbehaltenen Steuereinkommen aus Zunftgeschäften nun direkt dem absolutistischen Herrscher zukommen lassen sollten. ${ }^{88}$

Paradoxerweise ist es vor dem Hintergrund der dargelegten Entwicklungen sein erweiterter Alchemiebegriff im Zeichen der Sozialutopie, der Becher einerseits in der politischen Praxis zum Vorreiter einer fortschrittsorientierten politischen Ökonomie, Pädagogik und Sozialpolitik in der absolutistischen Staatsräson werden lässt. ${ }^{89}$ Andererseits weist ihn sein theoretisches Bemühen, diese heterogenen Bereiche in einer vollkommenen christlichen Gemeinschaft letzten Endes wieder zu kontextualisieren, als Vertreter eines zu seiner Zeit obsolet werdenden universalwissenschaftlichen Reformdenkens aus, dem die moderne und zusehends auch institutionell verankerte funktionelle Ausdifferenzierung in autonome Wissens- und Wissenschaftsdisziplinen gegenübersteht. Aus diesem Blickwinkel erklären sich auch die Widersprüche, die sich aus heutiger Perspektive zwischen Becher als machtpolitischem Berater nahezu macchiavellistischer Härte und Becher als sozialutopischem Philosophen einstellen. Über sein beson-

Steuern befreit. Deshalb waren hofbefreite Handwerker gegenüber den lokalen Zünften im Vorteil, was regelmäßig deren Zorn erregte. Mit der festen Residenzenbildung geht auch die politisch wichtige Entwicklung der Zeremoniallehre einher, denn erst mit den festen Höfen fand die pompöse Inszenierung des Souveräns ihren ureigenen Ort, an dem für die repräsentativen Festlichkeiten eben das Spezialwissen der besten Handwerker, die man bekommen konnte, benötigt wurde. Vgl. ausführlich Herbert Haupt: Das Hof- und hofbefreite Handwerk im barocken Wien 1620-1770. Ein Handbuch. Innsbruck, Wien, Bozen 2007, insbes. S. 17-49, sowie Jörg Jochen Berns: Der nackte Monarch und die nackte Wahrheit. Auskünfte der deutschen Zeitungs- und Zeremoniellschriften des späten 17. und frühen 18. Jahrhunderts zum Verhältnis von Hof und Öffentlichkeit. In: Daphnis. Zeitschrift für Mittlere Deutsche Literatur 11 (1982), 1/2, S. 315-349, hier insbes. S. 335f. Zu den Zünften als finanzpolitischem Ärgernis für Regierende seit dem 16. Jahrhundert vgl. Hans J. Hatschek: Das Manufakturhaus auf dem Tabor in Wien. Ein Beitrag zur österreichischen Wirtschaftsgeschichte des 17. Jahrhunderts. Leipzig 1886, S. 9f., sowie Ulrich Troitzsch: Johann Joachim Becher als Techniker und Erfinder. In: Johann Joachim Becher (Anm. 6), S. 85-101, hier S. $91 \mathrm{f}$.

88 Vgl. Smith: Business of Alchemy (Anm. 8), S. 27f. und S. 94f.

$89 \mathrm{Zu}$ Bechers daraus abgeleiteten Regeln für eine erfolgreiche absolutistische Herrschaft vgl. Becher: Politische Discurs (Anm. 62), S. 20-60. 
deres Verständnis von Alchemie lassen sich diese Widersprüche aber zumindest näher analysieren.

Für Becher fungiert Alchemie als eine Art übergeordnetes Naturrecht, deren wesentlich naturphilosophische Konturierung in seinem Denken aber eine neue, erweiterte Gestalt annimmt. Denn mittels Alchemie kann sich Becher nun auch das soziopolitische Funktionieren der Welt erschließen, jedoch nicht ohne dabei in besagte Widersprüche zu geraten. Deutlich werden diese Widersprüche, sobald man Bechers Denken im größeren Kontext dessen verortet, was als neuzeitliche „Enttheologisierung des Naturrechts“ bezeichnet wurde, wonach - zumindest theoretisch - zusehends ein Naturrecht denkbar erschien, dessen Begründung aus der mathematischen Vernunft auch ohne Gott auskam. ${ }^{90}$ Becher steht dieser Enttheologisierung des Naturrechts einerseits völlig entgegen, wenn man unter Enttheologisierung die neutralisierende Profanierung von göttlichen Attributen versteht, in deren Rahmen die säkular-autonome Herrschaft des Menschen über seine Welt sichergestellt wird. Denn ein Wissen, das in seiner ontologischen Bestimmung und seiner praktischen Anwendung wesentlich nur noch dem Diesseits verpflichtet ist und Gott als oberste Instanz gar nicht mehr unbedingt benötigt, liegt Becher in letzter Konsequenz gänzlich fern. Andererseits kann Bechers Schaffen aber auch genau im Zentrum des erstarkenden enttheologisierten Naturrechts situiert werden: Sein Denken fügt sich nämlich dann in diese Entwicklungen, wenn es ihm darum geht, seine ganz konkreten Projekte angesichts der soziopolitischen Herausforderungen seiner Zeit unmittelbar zu legitimieren. Dabei verzichtet er meist auf eine tiefer gehende Reflexion seiner

90 „Die Enttheologisierung des N. war [...] in der These angelegt, daß die natürliche, durch menschliche Vernunft einsehbare Ordnung Teil der göttlichen Ordnung sei. [...] Der Unterschied zwischen christlichem und weltlichem N. macht sich [nach Luther] einzig darin bemerkbar, daß der weltliche Mensch infolge des Sündenfalls das göttliche Gesetz leiblich statt geistlich [...] versteht und daß sein Herz so sehr verfinstert ist, daß er durch das natürliche Recht allein nicht mehr regiert werden kann. Er bedarf daher des ,gesatzten' (kaiserlichen) Rechtes, des Stadt- und Landrechtes und einer starken Obrigkeit, die als Abbild und Statthalter des göttlichen Regiments, als Vollstrecker des göttlichen Zornes und Werkzeug seiner erhaltenden Liebe mit dem Schwert für die Durchsetzung der göttlichen Ordnung sorgt. [...] N. als Ordnung der menschlichen Beziehungen verpflichtet uns, das menschliche Leben und die menschliche Gesellschaft mit ihren Institutionen wie Ehe, Familie und Staat zu erhalten und im zwischenstaatlichen Bereich das ,jus gentium' zu befolgen. [...] Verbindliches N. sei daher, was den Geboten der Vernunft nicht widerstreite und der vernünftigen Natur entspreche. Die naturrechtlichen Bestimmungen der Vernunft wären, wie Grotius [...] sagt, auch dann gültig, wenn es keinen Gott gäbe; denn sie seien ebenso unwandelbar wie die mathematischen Sätze, sie zu leugnen, hieße, sich selbst zu widersprechen. Nur weil die vernünftigen Handlungen in sich selbst moralisch schlecht oder moralisch notwendig sind, sind sie von Gott verboten oder geboten, und nicht umgekehrt.“ A. Hügli u.a.: Naturrecht. In: Historisches Wörterbuch der Philosophie. Hrsg. von Joachim Ritter u.a. 13 Bde. Basel, Stuttgart 1971-2007, Bd. 6 (1984), Sp. 560-623, hier Sp. 582-584. Vgl. auch Michael Stolleis: Geschichte des öffentlichen Rechts in Deutschland. 3 Bde. München 1988-1999, Bd.1: Reichspublizistik und Policeywissenschaft (1988), S. 271f. 
christlich-utopischen Ziele, die er andernorts, nämlich in seinen eher programmatischen Schriften, entwirft.

Die schwierige Verortung Bechers lässt sich somit wie folgt reformulieren: Einerseits ist der ,Politiker' Becher ganz der auf das Diesseits bezogenen Rationalität menschlichen Handelns und dem politischen Machterhalt verpflichtet, andererseits bleibt aber die Erlösung im Zeichen der christlichen Heilsgeschichte für den ,Utopisten' Becher der letzte und entscheidende Bezugspunkt. Dieser Widerspruch lässt sich quer durch seine Arbeiten verfolgen und hat Breger zur These veranlasst, der utopische Sozialphilosoph Becher habe mit dem naturwissenschaftlichen Alchemiker Becher eigentlich gar nichts zu tun.

Die sozialutopischen Ausführungen, die Becher im Moral Discurs Von den eigentlichen Ursachen deß Glücks und Unglücks macht, stammen jedoch nicht von Becher, dem Naturwissenschaftler, sondern vom Privatmann oder jedenfalls dem Philosophen Becher. Nach Becher bringt zwar die Befolgung der Gesetze der Natur dem Menschen Glückseligkeit, aber das Naturrecht wird natürlich nicht vom Untersuchungsbereich des Chemikers erfaßt. ${ }^{91}$

Gegenüber Bregers These kann nun eingewendet werden, dass es genau das Verständnis Bechers von christlicher Glückseligkeit ist, das über moralphilosophische Aspekte hinaus direkt den Kern seiner politischen Ökonomie und seiner experimentellen Naturforschung gleichermaßen trifft. ${ }^{92}$ Denn politische Hofökonomie, Moral- und Naturphilosophie stellen für Becher eben noch keine voneinander unabhängigen Wissens- bzw. Lebensbereiche in einem modernen Sinne dar, sondern im Kontext der christlichen Heilsgeschichte bedingen sie einander vielmehr. Erst ihre universalwissenschaftliche Harmonisierung wird nach Becher schließlich zur vollkommenen Gemeinschaft führen, und Alchemie als göttliche Kunst der Transformation stellt hierfür den omnivalenten Schlüssel bereit.

Der Widerspruch, den Breger aus moderner Perspektive in Bechers Denken korrekt identifiziert, löst sich also auf, wenn man Bechers subjektive Sicht der Dinge einnimmt. Allerdings kann das Auseinanderdriften von Alltagspraxis im Zeichen absolutistischer Politik und Sozialutopie im Zeichen christlicher Heilsgeschichte damit noch nicht hinreichend erklärt werden. Becher ist aber eben wie bereits erwähnt - eher als Verantwortungs- denn als Gesinnungsethiker zu charakterisieren. Bezogen auf seine sozialutopischen Vorstellungen erscheint es mir deshalb sinnvoll, statt von einem normativen von einem - wie ich es nennen möchte - ,pragmatischen Utopismus' Bechers zu sprechen, der sich - zumindest nach außen hin - nahezu nahtlos in die absolutistische Staatsräson fügt. Eine Konsequenz dieser Pragmatik Bechers ist eine gewisse Inkonsistenz, die sich nicht nur zwischen Sozialutopie, Naturphilosophie und politischer Ökonomie,

91 Breger: Sozialutopische Tendenzen (Anm. 19), S. $112 \mathrm{f}$.

92 Vgl. die Zitate Bechers zu Anm. 15 und Anm. 71. 
sondern auch zwischen Theorie und Praxis einstellt. Brauneder hat diese pragmatische, d. h. „nichtjuristische“ Denkweise, die sich an den aktuellen Bedürfnissen des Staates orientiert und die in der Verwaltung die entscheidende Aufgabe der politischen Hofökonomie erkennt, lakonisch und zugleich konzise auf den Punkt gebracht.

Staatstheorie zu treiben und diese umfassend für die Staatspraxis nutzbar zu machen, war kaum das Anliegen Bechers. Lavieren, in bestimmter Weise tätig sein: $\mathrm{Zu}$ Recht sind diese Rezepte nicht so sehr als eine Staatslehre, sondern als ein Aspekt davon, nämlich eine Verwaltungslehre, verstanden worden. ${ }^{93}$

Statt die Unvereinbarkeit des Sozialutopisten mit dem Naturphilosophen zu konstatieren und beide deshalb in moderner Manier getrennt zu behandeln, eröffnet ein gemeinsamer Horizont auf den Spuren von Bechers eigenen Aussagen die Möglichkeit, sein Kernproblem in den Blick zu bekommen, das er gegen Ende seines Lebens selbst identifiziert hat: nämlich das politische Scheitern seiner Sozialutopie im Zeichen der Alchemie. In der Psychosophia Oder SeelenWeißheit (1678) greift er in einem zutiefst melancholischem Ton genau eben diese für ihn wichtige Verbindung von alchemischer Naturphilosophie, Politik und Utopie auf, wenn er enttäuscht schreibt, er könne leichter den lapis philosophorum als den lapis politicum herstellen.

Der Philosophische Stein ist zwar rar und künstlich zu machen/ trauete mir ihn aber eher zu verfertigen als den Lapidem politicum, dann die Materi des Ersten bestehet in einer Sach ganz des Meister Disposition. [...] Dann was bringt die Länder eher in Abgang/ als Regiersucht/ und wo man die erhalten/ übernommene Macht/ so man Tyranney nennt und Krieg/ Hoffart und Geiz/ woraus Geld Erpressung erfolget/ und der Unterthanen Armuth/ Wollust und Faulheit/ wordurch das Regiment/ Vorsorg/ Gerechtigkeit/ an Nagel gehenckt/ alle gute Rathschläge verachtet/ Pfaffen/Ministris und Weibern das Regiment übergeben wird/ daß es nach dem alten Sprichwort kein gut Ende nimt. ${ }^{94}$

Becher wollte auf Basis seiner alchemischen Naturphilosophie die utopische Vervollkommnung des christlichen Gemeinwesens vorantreiben und erkannte hierfür in der politischen Ökonomie der absolutistischen Staatsräson das geeignete Mittel, ohne dabei zu merken, dass Utopie und Staatsräson in einem unauflöslichen Konflikt zueinander stehen. Denn wie es die mittlerweile klassische

93 Wilhelm Brauneder: Bechers Lehre vom Staat. In: Johann Joachim Becher (Anm. 6), S. 41-67, hier S. 67.

94 Johann Joachim Becher: Psychosophia Oder Seelen-Weißheit/ Wie nemlich ein jeder Mensch auß Betrachtung seiner Seelen selbst allein alle Wissenschaft und Weißheit gründlich und beständig erlangen könne. Zweyte Edition. Von dem Authore selbsten übersehen/ corrigirt und in vielem verbessert. Franckfurt 1683, S. 165f. 
Definition der Staatsräson von Friedrich Meinecke besagt, gibt es vor allem eine "Grundaufgabe der Staatsräson", nämlich „das Streben nach Sicherheit und Selbstbehauptung um jeden Preis, mit allen Mitteln“ im nur sich selbst gegenüber verpflichteten Staat. ${ }^{95}$ Mit Blick auf die sich zu Bechers Zeiten konstituierende moderne Staatsräson trifft auch Koselleck implizit den wunden Punkt von Bechers Sozialutopismus, wenn er schreibt:

Die Genese des absoluten Staates ist begleitet von einem anhaltenden Kampf gegen religiöse und politische Weissagungen aller Art. Der Staat erzwingt sich ein Monopol der Zukunftsbeherrschung, indem er die apokalyptischen und astrologischen Zukunftsdeutungen unterdrückt. [...] Insgesamt kann man sagen, daß eine harte Politik erreicht hatte, die handfesten religiösen Zukunftshoffnungen, die nach dem Zerfall der Kirche wucherten, aus dem Bereich der politischen Willensbildung und -entscheidungen zu eliminieren. [...] Statt der erwarteten Endzeit hatte sich tatsächlich eine andere, eine neue Zeit eröffnet. ${ }^{96}$

Das Verhältnis von Utopie und Staatsräson gestaltet sich also schwierig, wie der Lebensweg Bechers beweist, aber die beiden schließen sich in der Praxis einer "Politisierung des Utopischen“ auch nicht gegenseitig aus. ${ }^{97}$ Die Utopie kann weiterhin eine Funktion haben - aber eben nur im vorrangigen Interesse der Staatsräson. Denn für die Staatsräson erweist sich eine politische Ökonomie mit utopischer Grundierung à la Becher dann als wichtiger Faktor, wenn sie mit den umzusetzenden Projekten bis in die Mikrostrukturen gesellschaftlicher Organisation vordringen kann, um sie in einem gouvernementalen Sinne produktiv zu gestalten.

Dort, wo die Staatsräson im operationellen Raum von Gesellschaft eingreift, versucht die Utopie mittels des Harmonie-Prinzips zumindest theoretisch die ideelle Gemeinsamkeit von Herrschaft und Gesellschaft zu retten. Insofern könnte man die Staatsräson auch als angewandte Utopiekomponente sehen: Während die Utopie die Zieloption verheißt, sucht die Staatsräson die Zweck-Mittel-Relation zu bewältigen. [...] Insofern bedarf es immer auch der sozialdisziplinierenden Funktion von Staatlichkeit, damit überhaupt die Gesellschaftlichkeit der Individuen nicht nur erreicht, sondern auch stabilisiert werden kann. Dieser Prozeß der Vergesellschaftung, der die Polizierung aller Vertragsteilnehmer beinhaltet, ist auf dem Gesetzeswege deshalb so schwierig, weil die „Einfach-

95 Friedrich Meinecke: Die Idee der Staatsräson in der neueren Geschichte. München 1963, S. 251.

96 Reinhart Koselleck: Vergangene Zukunft der frühen Neuzeit. In: Vergangene Zukunft. Zur Semantik geschichtlicher Zeiten. Frankfurt a.M. 1989, S. 17-37, hier S. $26 f$.

97 So lautet auch der Haupttitel eines von Monika Neugebauer-Wölk und Richard Saage herausgegebenen Sammelbandes (vgl. Anm. 56). 
heit der Natur mit den Bedürfnissen der Gesellschaft" [Rousseau] so selten in harmonischen Einklang zu bringen ist. [...] Die utopische Komponente ist hierbei offenkundig. Das gesamte System funktioniert eigentlich nur, wenn sich alle beteiligten Akteure von ihrem jeweiligen Status her in der richtigen Relation zum Gesamt einbringen, d. h. hierbei von ihren jeweiligen Positionen abstrahieren zugunsten des gemeinsamen Zielmoments - und das wiederum heißt zivile Staatlichkeit. ${ }^{98}$

Bechers naturphilosophisch imprägnierte Form politischer Hofökonomie - verstanden als Regierungstechnik, die gezielt mit utopischen Verheißungen operiert - setzt die Interessen der absolutistischen Staatsräson mittels der christlichen Hoffnung auf erlösende Vervollkommnung dort durch, wo die definitorische Gesetzesmacht des souveränen Rechts nicht hingelangen kann. In diesem Sinne verfügt die regierende Staatsräson also nicht nur über die Macht, die direkt über das Gesetz ausgeübt wird, sondern auch über jene Macht, die „,indirekt, über das Handeln der Subjekte, operiert und sie mittels einer Wahrheit führt, d. h. die Regierung vermag es, etwas als Wahrheit zu etablieren, an dem die Subjekte ihr Handeln ausrichten". ${ }^{99}$ Dass sich Becher solcher gouvernementaler Wirkkräfte grundsätzlich bewusst war, beweisen seine Ausführungen zur Bedeutung des christlichen Glaubens als stabilisierender Kraft für die Macht des absolutistischen Souveräns, eben weil Glauben nicht nur zum Gehorsam gegenüber Gott, sondern auch zum Gehorsam gegenüber der weltlichen Obrigkeit verpflichte.

Vor dem skizzierten Hintergrund erscheint Becher als ausgezeichneter Ökonom und zugleich als integrativer Bestandteil einer absolutistischen Verwaltungsapparatur, und zwar im Kontext einer Politisierung des Utopischen: Im Sinne der Staatsräson wird mittels der politischen Ökonomie eine disziplinierte und zugleich produktive Bevölkerung hervorgebracht. Entscheidend ist hierbei, dass sich die Staatsräson in jene Begehrensstrukturen nach utopischer Vollkommenheit (die Becher als historischer Telos seines eigenen Denkens und Handelns vor Augen stehen mag) nicht nur bloß einschreibt. Vielmehr generiert, verfestigt und lenkt die Staatsräson diese Begehrensstrukturen im Akt der Einschreibung gemäß ihren eigenen Interessen. Davon zeugt etwa die oben diskutierte "Verweltlichung des Geistlichen", in der kollektive Ziele wie Wohlfahrt und Heil in neue gesellschaftliche Bedeutungskontexte überführt werden. Die Policeywissenschaft, die einerseits die Bevölkerung als zu verwaltende Masse konstituiert und deren spezifisches Wissen andererseits bis in die individuellen Mikrostrukturen vordringt, tritt hierbei - komplementär zum Gesetz - als eine das Begehren verwaltende Macht mit panoptischen Grundzügen in Erscheinung. Denn die Policeywissenschaft markiert den Beginn eben jener zum Pro-

98 Nitschke: Der doppelte Sieg der Nützlichkeit (Anm. 56), S. 31-33.

99 Ludger Schwarte: Von der Möglichkeit, die Wahrheit zu sagen. Intellektuelle, Experimentalwissenschaft und Öffentlichkeit um 1700. In: Kritik in der Frühen Neuzeit. Intellektuelle , avant la lettre'. Hrsg. von Rainer Bayreuther u.a. Wiesbaden 2011, S. 245-257, hier S. 248. 
gramm gewordenen Experimentalisierung des Lebens, die bei Becher aus dem alchemischen Labor in den sozialen Raum der Gesellschaft übertritt und die Foucault als gouvernementale Biopolitik klassifiziert hat: mithin die Produktion des Subjekts durch die Staatsräson in der Moderne.

Daß das allgemeine Funktionsmodell dieser Produktion von Subjekten das Panopticon ist, nicht nur als konkrete Form von Anstalten, die dem Ideal des geordneten Raumes und der regulierten Bewegungen in ihm entsprechen [...], sondern auch als grundlegende Erkenntnisdisposition, ist freilich auch kein Zufall. Das Panopticon ist ein [sc. soziales] Laboratorium, in dem experimentelle Naturforschung, an den Menschen' betrieben wird, um ein möglichst lückenloses Wissen vom Menschen und seinen Möglichkeiten zu erstellen. ${ }^{100}$

Becher war einerseits ein sozialutopischer Reformer, der im Zeichen eines alchemischen Universalismus und unter Bezug auf die christliche Heilsgeschichte die vollkommene Gemeinschaft realisieren wollte. Zugleich war er andererseits einer der maßgeblichen Ökonomen der absolutistischen Staatsräson, in dessen Denken sich im Kern bereits die volkswirtschaftlichen Staats- und Verwaltungslehren des 18. Jahrhunderts abzeichnen. In diesem Sinne steht seine alchemia oeconomica genau am Scheidepunkt der umbrechenden Wissenssysteme der Frühen Neuzeit zur Moderne. Ich denke aber nicht, dass man sich für einen der beiden Bechers entscheiden muss. Stattdessen muss man bei ihm vielleicht noch viel stärker als bei Anderen zwischen den Zielen unterscheiden, die er persönlich verfolgt hat, und dem, was er letztlich langfristig bewirkt hat. Becher war sich seines Scheiterns gegen Ende seines Lebens durchaus bewusst. Aber dennoch scheint er einen wichtigen Punkt bis zuletzt nicht erkannt zu haben: Nicht er hat geschickt die absolutistische Staatsräson benutzt, um mit ihrer Hilfe zumindest langfristig der kommenden Gemeinschaft zum Durchbruch zu verhelfen; vielmehr hat ihn die Staatsräson benutzt, um in der zu verwaltenden Bevölkerung ein - ökonomisch höchst produktives - Begehren nach dem historischen Telos einer utopischen Gemeinschaft zu implementieren: ein Begehren, durch das sich die Staatsräson legitimiert - und zugleich ein Begehren, durch das die Staatsräson kontrolliert.

Das Scheitern von Bechers Sozialutopismus am Schnittpunkt von Alchemie und politischer Ökonomie kommt in der bereits erwähnten Psychosophia nochmals an anderer Stelle aufschlussreich zum Ausdruck, und zwar im ganz im Stil der rosenkreuzerischen Manifeste gehaltenen Appendix Entwurff Oder Einladung Einer Ruh-Liebenden und ihrem Nechsten zu dienen suchenden Philosophischen Gesell-

100 Michael Makropoulos: Möglichkeitsbändigungen. Disziplin und Versicherung als Konzepte zur Steuerung von Kontingenz. In: Soziale Welt. Zeitschrift für sozialwissenschaftliche Forschung und Praxis 4 (1990), S. 405-423, hier S. 413. 
schaft: ${ }^{101}$ Man habe sich mit der Verkündigung dieser Gesellschaft Zeit gelassen, bis alle ihr vorausgegangenen erwartungsgemäß gescheitert seien. Denn diese hätten sich nur auf religiöse Streitereien, phantastische Ideen und Zeremonien, Machterhalt und -vergrößerung kapriziert, anstatt dem Nächsten zu dienen. In dieser Gesellschaft aber herrsche Religionsfreiheit, es gebe keine Kleider- oder Zeremonialvorschriften und keine weitreichenden finanziellen Abhängigkeiten. Es müssten nur wenige Regeln eingehalten werden: Diese Regeln untersagen den religiösen und weltlichen Zwist, fördern den moralisch-bescheidenen Lebensstil, Fleiß, Gehorsam und Verschwiegenheit. Die Ziele der Gesellschaft seien ein ruhiges Leben abseits der turbulenten Weltgeschehnisse, ein von den täglichen Sorgen um Wohnen, Essen und Kleidung enthobenes Leben zu führen, die Unterrichtung der Jugend in Moral und Wissenschaft sowie die Versorgung der Alten und Kranken mit Hilfe der Iatrochemie. Um die Gesellschaft in dieser Form zu realisieren, solle ein Stück Land gekauft werden, auf dem alle notwendigen Lebensmittel in Eigenproduktion angebaut werden, ohne dabei aber die Gesellschaft gänzlich von der Welt abzuscheiden. Denn für die Gesellschaft notwendige Güter könnten auch außerhalb gekauft werden, die Gesellschaft ist also nicht gänzlich autark.

Bei Bechers Entwurf einer Philosophischen Gesellschaft handelt es sich im Kern vielleicht um jene soziale Formation, die ihm als Konsequenz einer Harmonisierung von alchemischer Naturphilosophie und politischer Ökonomie ursprünglich vor Augen gestanden haben mag. Gleichermaßen aufschlussreich wie irritierend ist jedoch der Umstand, dass Becher diese Philosophische Gesellschaft eben nicht in klassischer Manier als eine zukünftige entwirft, deren Mitglieder in religiöser Einigkeit miteinander verbunden sein werden, sondern als eine Art offene Parallelgesellschaft, die nach ganz eigenen, stark an einer weltlichen Ethik ausgerichteten Regeln funktioniert: Die Gemeinschaft ist auch nicht auf einer Insel völlig abgeschottet, sondern liegt "an einer Revier“, 102 einem Wasserlauf, der Zu- und Abfahrt für Mitglieder und Gäste ermöglichen soll. Vom Rechtsstatus her entwirft Becher die Philosophische Gesellschaft als zivile Einrichtung, die von der Obrigkeit, d. h. dem jeweiligen Landesherrn, genehmigt werden muss. Angesichts des Lebenswegs Bechers als politischer Ökonom erscheint dieses Festhalten an den ganz konkret gegebenen zeitgenössischen politischen Bedingungen im Entwurf der Philosophischen Gesellschaft konsequent. Und dennoch zeugt dieser Entwurf zugleich auch von dem ihm ganz bewussten Scheitern seiner sozialutopischen Hoffnungen: Eine künftige Gemeinschaft, in der ideale Bedingungen für alle Menschen herrschen und die auf einem gemeinsamen Glauben fußt, scheint angesichts der zeitgenössischen $\mathrm{Zu}$ -

101 Johann Joachim Becher: Entwurff Oder Einladung einer Ruh-Liebenden und ihrem Nechsten zu dienen suchenden Philosophischen Gesellschaft. In: Psychosophia (Anm. 94), Appendix (o. S.).

102 Ebd., o. S. (p iiiir). 
stände, in denen Habsucht, Gier und Neid den politischen Alltag bestimmen, für den vom Leben enttäuschten Becher wenige Jahre vor seinem Tod nicht mehr realisierbar zu sein. Was als Möglichkeit noch bleibt, ist der kollektive Weg von Gleichgesinnten in die gesellschaftliche Emigration. Aber auch in der Imagination eines kollektiven Lebens in der Emigration bleibt die Freiheit durchwoben von Regierungstechniken, die in Bechers Philosophischer Gesellschaft in Form ihrer notwendigen Genehmigung durch die Obrigkeit eben explizit mitbedacht werden müssen. Es gibt kein Außerhalb der Macht. Bis zum Schluss bleibt Becher als politischer Pragmatiker den realen Lebensbedingungen verpflichtet, was der nahezu grenzenlosen Phantasie des Sozialutopisten jedoch nicht zuwiderläuft. 
(C) 2015, Otto Harrassowitz GmbH \& Co. KG, Wiesbaden ISBN Print: 9783447104951 - ISBN E-Book: 9783447194129 


\title{
Über die Schwierigkeit der Beschreibung alchemischer Techniken.
}

\author{
Johannes Kunckels Übersetzung der Arte vetraria \\ von Antonio Neri
}

Sven Dupré, Berlin

\begin{abstract}
Die große Zahl der Übersetzungen griechischer Texte ins Lateinische und lateinischer Texte in die Volkssprachen während des Mittelalters und der Renaissance, die oft durch Vermittlung über das Arabische und Hebräische verlief, hat schon immer die Aufmerksamkeit von Wissenschafts- und Medizinhistorikern auf sich gezogen. ${ }^{1}$ Mein Beitrag teilt die Faszination für diesen umfassenden Prozess der Migration von Wissen, möchte aber den Fokus speziell darauf richten, wie die aus der Antike übernommene Gelehrsamkeit mit Wissensbeständen, die an bestimmte Orte gebunden waren, konfrontiert und verknüpft wurde. Mit Blick auf lokales Wissen ergab sich das Problem, dass Informationen zu versprachlichen waren, für die es in der gelehrten Welt noch kein BegriffsÄquivalent gab. Ein prominentes Beispiel dafür ist in der frühen Neuzeit die Begegnung mit indigenen Pflanzen und ihren Bezeichnungen, insbesondere außerhalb Europas. Die Reisenden waren mit einer Fülle ihnen unbekannter Namen, Begriffe und Konzepte konfrontiert. Die Definition und Benennung der Naturgegebenheiten und der Kategorien, denen sie zugeordnet waren, konnte sich selbst in ein und derselben Sprache als konfliktträchtige Angelegenheit erweisen. Eines der Hauptprobleme lag im Mangel an Vollständigkeit: Das Buch der Natur wuchs stetig an, und in der Konsequenz musste auch das Vokabular kontinuierlich erweitert werden. Von der Struktur den Prozessen der Benennung von indigenen außereuropäischen Pflanzen vergleichbar ist die Einführung neuer Bezeichnungen im Rahmen des Kunsthandwerks und die Verwendung dieser Terminologie in Übersetzungen und Publikationen, wenn es dafür im Lateinischen oder in den Volkssprachen keine Entsprechung gab. Um eine solche Übersetzung von kunsthandwerklichem Wissen soll es hier in einem ganz spezifischen Zusammenhang gehen, nämlich in dem der Alchemie.
\end{abstract}

1 Scott L. Montgomery: Science in Translation. Movements of Knowledge Through Cultures and Time. Chicago 2000; Science Translated. Latin and Vernacular Translations of Scientific Treatises in Medieval Europe. Hrsg. von Michèle Goyens, Pieter De Leemans und An Smets. Leuven 2008. 
Das englische Wort, translation' stammt vom lateinischen translatio und meint das Übertragen oder Transportieren von einem Ort zum anderen oder von einem Zustand in den nächsten. Auch der deutsche Begriff des, Übersetzens' bedeutet ursprünglich ein solches, Übertragen'. In Hinblick auf die Praxis des Schreibens kann translatio nicht nur die Übersetzung im Sinne der Bedeutungsübertragung eines linguistischen Ausdrucks in einen anderen meinen, sondern auch die unveränderte Übernahme und sogar die unübliche Verwendung eines Wortes, um einen übertragenen Sinn oder eine metaphorische Bedeutung zu vermitteln. Mit anderen Worten: Probleme, die sich daraus ergeben, dass (und auf welche Weise) ein ortsgebundenes Wissen an einen anderen Orte gebracht wird, haben immer mit Fragen der Übersetzung zu tun. Der Begriff Übersetzung bedeutet in anderen Sprachen (z.B. im Niederländischen) nicht nur,Wiedergabe', sondern er schließt zudem die Semantik von ,Veränderung', ,Transformation' und ,Übergabe' mit ein.

Übersetzen ist ein Prozess, in dem Informationen und Wissen von einem Ort zum anderen übertragen und währenddessen oft auch verändert werden. Veränderung ist kein Nebenprodukt von Übersetzungen, sondern macht ihr Wesen aus, auch dort, wo sie gar nicht beabsichtigt ist. Überall dort, wo Menschen unterschiedlicher Herkunftssprachen interagieren, und selbst dann, wenn Menschen derselben Herkunftssprache an unterschiedlichen Orten auf der Welt miteinander reden, kommt es zu Veränderungen. Diese verdienen es, von Wissenschafts- und Ideenhistorikern zur Kenntnis genommen zu werden. Wissenschaftliche Kommunikation impliziert weder, dass Wörter eine universelle Bedeutung besitzen, noch, dass sie nicht miteinander kompatibel wären. Übersetzung ist ein Prozess, der menschliche Kommunikation wesentlich ausmacht. Allerdings lohnt es sich, über diese grundlegende philosophische Einsicht hinaus zu gehen und die Geschichte von Übersetzungspraktiken genauer zu untersuchen. Denn Übersetzungsmethoden unterliegen dem historischen Wandel. Daher will ich hier zeigen, wie sich die Praxis der Übersetzung - im Sinne von ,Wiedergeben' oder ,Verbalisieren' - von kunsthandwerklichem Wissen in der frühen Neuzeit verändert hat.

Meine Beobachtungen führen zu einem zentralen Thema der Wissenschaftsgeschichte der Frühen Neuzeit, das seit den Arbeiten von Leonardo Olschki und Edgar Zilsel immer wieder erörtert wurde. Eine Untersuchung der Übersetzung von Künstlerwissen bedeutet einen neuen Zugang zu Ursprüngen der frühneuzeitlichen Wissenschaft in den Kulturen des Handwerks. Pamela Long zeigt in ihrem jüngsten Buch, dass im 15. und 16. Jahrhundert ,trading zones' entstehen (ein Begriff, den sie aus Peter Galisons Analyse der modernen Physik übernimmt), welche die Voraussetzungen für den Austausch von Wissen und empirischen Daten zwischen Handwerkern und Gelehrten schufen. ${ }^{2}$ Die ,trading

2 Pamela O. Long: Artisan/Practitioners and the Rise of the New Sciences, 1400-1600. Corvallis 2011, S. 94-126. 
zones' der frühen Neuzeit bestanden aus "arenas in which the learned taught the skilled, and the skilled taught the learned, and in which the knowledge involved in each arena was valued by both kinds of ,traders'." ${ }^{3}$ Mit dem Konzept der ,trading zone' lässt sich der Aspekt der Sprache hervorheben. Galison beschreibt es als „characterized by the development of pidgin languages and, at times, full-scale Creole languages as a means of communication between people from two different cultures." ${ }^{4}$ Sprache ist für Long ein zentrales Anliegen. Sehr folgerichtig zeigt sie, dass die Erfindung des Feuers ein ganzes Spektrum von handwerklichen Fertigkeiten ermöglichte, vor allem aber, nach Vitruv, „,[prompted] early humans to gather around fires, and this new proximity led them to begin to communicate and acquire language". ${ }^{5}$ Während Long sich in erster Linie darauf konzentriert, Interaktionen zwischen heimischen Kunsthandwerkern und belesenen Humanisten aufzuspüren, welche Lateinisch sprachen und eine Universitätsausbildung besaßen, geht es mir um die Übersetzung von Künstlerwissen, das heißt um den Prozess des Umstrukturierens von praktischem Wissen in Schriften über die Künste.

Dazu gehört an zentraler Stelle die Begegnung des Übersetzers mit lokalen Objekten und Wissensbeständen. Richtet man darauf den Fokus, ergibt sich als eine erste wichtige Einsicht, dass Mehrsprachigkeit ein Schlüsselproblem darstellt. So weist Florike Egmond darauf hin, dass Latein und Volkssprachen und die entsprechenden Bezeichnungen in der Praxis und in Veröffentlichungen zur Pflanzenkunde im 16. Jahrhundert nebeneinander existierten. ${ }^{6}$ Obwohl lateinische Namen dazu verwendet wurden, die internationale Kommunikation zu vereinfachen, besaß das Lateinische keinen besonderen konzeptionellen Status (bei der Entwicklung einer Klassifizierung) und hatte auch keinen höheren Status als die sogenannten Volkssprachen oder als lokale Bezeichnungen für indigene Pflanzen. Dies bedeutet eine wichtige Korrektur gegenüber der dominanten Tradition der Geschichtsschreibung, die sich fast ausschließlich auf die Übersetzungsbewegung vom Lateinischen in die Volkssprachen und auf das sogenannte Aufkommen der Volkssprache konzentriert hat. ${ }^{7}$ Stattdessen zeigt Egmond, dass Mehrsprachigkeit die Regel war. Mehrsprachigkeit ist typisch für

3 Long: Artisan/Practitioners (Anm. 2), S. 95.

4 Long: Artisan/Practitioners (Anm. 2), S. 125.

5 Long: Artisan/Practitioners (Anm. 2), S. 64.

6 Florike Egmond: Names of Naturalia in the Early Modern Period: Between the Vernacular and Latin, Identification and Classification. In: Translating Knowledge in the Early Modern Low Countries. Hrsg. von Harold John Cook und Sven Dupré. Zürich, Berlin 2013, S. 131162.

7 Cultural Translation in Early Modern Europe. Hrsg. von Peter Burke und Ronnie Po-chia Hsia. Cambridge 2007; Bernd Weitemeier: Translation and the Role of Vernacular Languages in Medieval Europe. In: Übersetzung: Ein Internationales Handbuch zur Übersetzungsforschung = Translation: An International Encyclopedia of Translation Studies = Traduction: Encyclopédie Internationale De La Recherche Sur La Traduction. Bd. 2. Hrsg. von Harald Kittel u.a. Berlin 2007, S. 1280-1295. 
eine ,trading zone', in der es zum Wissensaustausch zwischen zwei Kulturen kommt.

Schriftlich festzuhalten, wie etwas richtig ausgeführt wird, ist vermutlich so alt wie die Fähigkeit des Menschen zu schreiben. Es gibt eine lange Geschichte des Schreibens über Techniken in Form von Rezepten, welche bis in die Antike zurückreicht. Wir besitzen Tontafeln mit babylonischen Glasrezepturen. Die sogenannten Leidener und Stockholmer Papyri enthalten Anleitungen für mehrere Künste und Handwerke, deren Nachwirkung bis weit in die frühe Neuzeit andauert. Tatsächlich ist das ,Rezept' eines der gängigsten Formate, um handwerkliche Erfahrung zu reproduzieren. ${ }^{8}$ In der frühen Neuzeit waren Rezepte allgegenwärtig. Die Umsetzung einer Anleitung in die Praxis ist allerdings oft problematisch. Typischerweise schaffen es Wörter und Begriffe nicht, Materialien und Vorgehensweisen so unzweideutig zu beschreiben, dass sie zum gewünschten Resultat führen. Technikhistoriker messen den Anleitungen eine bestenfalls geringe Bedeutung für das Erlernen eines Handwerks im Rahmen einer Meister-Schüler-Beziehung in der Werkstatt bei. ${ }^{9}$ Der Standard war ,learning by doing'. Anleitungen sind Über-Setzungen: Sie haben das handwerkliche Wissen über die Werkstatt hinaus getragen.

Ein wichtiger Aspekt der Strukturierung praktischen Wissens, auf den es mir im Folgenden ankommt, ist die schriftliche Fixierung von Irrtümern. Anstatt niederzuschreiben, wie bei etwas vorzugehen ist, halten die Autoren fest, was man nicht tun sollte. Meinem Eindruck nach kommt das Schreiben darüber, inwiefern man etwas falsch gemacht hat, zuerst in der frühen Neuzeit auf. Noch vor dem 17. Jahrhundert vollzieht sich in der Rezeptliteratur damit offensichtlich ein stiller Wandel. Während des Übertragungsprozesses änderten die Autoren zunächst die Anleitungen, ohne dies ausdrücklich mitzuteilen. Offenbar wurden sie den lokalen und materiellen Bedingungen angepasst, wenn sie in neuen Kontexten nicht ohne weiteres funktionierten oder nicht zu zufriedenstellenden Ergebnissen führten. Dies heißt nicht, dass die Leser solcher Beschreibungen nicht gelegentlich am Rande einer Seite den Misserfolg einer Vorgehensweise notierten. Im Gegenteil. Dazu nur ein Beispiel: Wolfgang Seidel, sowohl Prior als auch Kopist im Kloster Tegernsee, schrieb zwischen 1540 und 1550 zwei Kunstbücher, die heute in der Bayerischen Staatsbibliothek aufbewahrt werden. ${ }^{10}$ Während seines Aufenthalts in Sankt Ulrich und in der Abtei Sankt

8 Mark Clarke, Bert de Munck und Sven Dupré: Transmission of Artists' Knowledge. Brüssel 2012; Secrets and Knowledge in Medicine and Science 1500-1800. Hrsg. von Elaine Leong und Alisha Rankin. Farnham, Burlington 2011; Pamela H. Smith: Why Write a Book? From Lived Experience to the Written Word in Early Modern Europe. In: Bulletin of the German Historical Institute 47 (2010), S. 25-50.

9 Arie Wallert: Standard and Procedures for Art Technology and Mediaeval Encyclopedias. In: Mark Clarke, Bert de Munck und Sven Dupré: Artists' Knowledge (Anm. 8), S. 69-74.

10 Sylvie Neven: Transmission of Alchemical and Artistic Knowledge in German Mediaeval and Premodern Recipe Books. In: Laboratories of Art: Alchemy and Art Technology from 
Afra in Augsburg sammelte Seidel Rezepte in den Bibliotheken in Tegernsee und in benachbarten Klöstern. Seidel stützte sich auch auf den Austausch mit Kunsthandwerkern und Gelehrten, die er in seinen Kunstbüchern als Quellen angibt. Der entscheidende Punkt ist jedoch, dass Seidels Randbemerkungen zu Cgm 4117 eigene Kommentare zu den Anleitungen darstellen. So notiert er zum Beispiel auf Blatt 53r am Rand einer Beschreibung des Schmelzens von Kristall, dass diese ihm nichts genützt habe, und dass sich auf Blatt 29 derselben Handschrift ein besseres Verfahren finde.

Mein Interesse gilt nun dem historischen Prozess, in welchem derart wertende Notizen vom Rand der Manuskriptseite ins Zentrum des Textes selbst wandern. Ich vertrete die These, dass es dabei - vielleicht zum ersten Mal im 17. Jahrhundert - zur Abfolge einer Anleitung, die in älteren bekannten oder anonymen Quellen vorgefunden worden war, mit Notaten darüber kommt, dass sie nicht funktioniert, und mit Vorschlägen zu ihrer Verbesserung. Dies ist, was ich eine ,Formalisierung von Irrtümern' nenne. Angesichts einer Flut von praktischem Wissen in der frühen Neuzeit war dies ein wirksames Mittel zu seiner Neuordnung. Eine solche ,Fixierung von Irrtümern' möchte ich an Johannes Kunckels Übersetzung von Antonio Neris L'arte vetraria von 1679 untersuchen. Neris' im Jahre 1612 publizierte Abhandlung war das erste gedruckte Buch über die Glasherstellung. Es stützte sich jedoch stark auf die handschriftlichen Anleitungen, die in den vorangegangenen Jahrhunderten zirkulierten.

Sowohl Neri als auch Kunckel waren Alchemiker, und ihr Werk über die Glasherstellung erschließt sich am besten im Kontext ihrer anderen alchemischen Bestrebungen. Alchemie war in der frühen Neuzeit ein weites Feld. ${ }^{11}$ Eine Metalltransmutation von unedlen in edlere Metalle, insbesondere die Herstellung von Gold, verbindet man vermutlich als erstes mit der Alchemie. Doch bestanden nicht nur erhebliche Meinungsverschiedenheiten darüber, wie mit dem Stein der Weisen eine Metalltransmutation durchzuführen war, Chrysopoeia (wie dieser Bereich genannt wurde) war vor allem nur ein Aspekt der frühneuzeitlichen Alchemie. Ein zweiter Bereich war die medizinische Alchemie (auch als Chemiatrie oder Iatrochemie bekannt). Nachdem Johannes de Rupescissa dieses Gebiet im 14. Jahrhundert zu einem Schlüsselbereich der Alchemie erhoben hatte, stieg in Folge der Schriften von Paracelsus im 16. Jahrhundert die Bedeutung von chemisch gewonnenen oder chemisch verbesserten Medikamenten in einem immensen Maße an. Der dritte Bereich der frühneuzeitlichen Alchemie, um den es mir hier geht, war die chemische Industrie. In Fortführung einer Rezeptliteratur, die bis in die Antike zurückreicht und zu deren bekanntesten Vertretern die Stockholmer und Leidener Papyri gehören, bedienten sich die Werkstätten der frühen Neuzeit immer häufiger chemischer Methoden, um al-

Antiquity to the 18th Century. Hrsg. von Sven Dupré. Heidelberg, New York, Dordrecht und London 2014, S. 23-52, 30-36.

11 Lawrence M. Principe: The Secrets of Alchemy. Chicago, London 2013. 
lerlei Arten von Produkten und Materialien herzustellen: Pigmente, Farben, Legierungen, Parfums, etc. Die gesamte Bandbreite an Ideen und Verfahren für die Produktion und Verarbeitung von Stoffen wurde in der frühen Neuzeit als Alchemie bezeichnet - ob Gold- oder Silbererzeugung oder die Herstellung von Medikamenten, Farben, Pigmenten, Säuren, Glas, Salzen und ähnlichem mehr. Die Alchemie war, mit anderen Worten, weit davon entfernt, auf Goldherstellung beschränkt zu sein, sondern war Theorie und Praxis stofflicher Umwandlung. ${ }^{12}$

Ein Alchemiker der frühen Neuzeit konnte in einem oder zweien dieser Bereiche tätig sein; dass jemand jedoch mit allen dreien $\mathrm{zu}$ tun hatte, kam selten vor. So gab Paracelsus zum Beispiel dem Gebiet der medizinischen Alchemie einen bedeutenden Auftrieb, auf dem Gebiet der Chrysopoeia versuchte er sich aber nicht. Weil die drei Bereiche separate Domänen der Alchemie darstellten, sei am Rande auf den interessanten Umstand hingewiesen, dass Begriffe aus dem Bereich der Metalltransmutation mitunter für Prozesse der Glasherstellung verwendet wurden, als ob die Glasherstellung dem Stein des Weisen entsprechen würde. Der Glasherstellung kam unter den alchemischen Techniken also ein besonderer Status zu. ${ }^{13}$

\section{Johannes Kunckel und das Goldrubinglas}

Nach diesen Vorbemerkungen nun zu meiner Fallstudie: Kunckel, der in eine Glasmacherfamilie geboren und als Apotheker ausgebildet worden war, trat 1667 in die Dienste des Kurfürsten von Sachsen, Johann Georgs II. ${ }^{14}$ Seine Aufgabe bestand darin, die alchemischen Schriften durchzuarbeiten, die sich im Besitz des Dresdner Hofes befanden. Anscheinend eignete Kunckel sich im Zuge dieser Tätigkeit ein großes Wissen über die Geheimnisse der Alchemie an. Fest steht, dass Kunckel sich zu dieser Zeit mit einem Chrysopoeia-Projekt beschäftigte. Nach seinem Umzug nach Brandenburg (wo seine eigentliche Tätigkeit darin bestand, Glas herzustellen), führte er seine Transmutationsexperimente auf der heute als Pfaueninsel bekannten Insel in der Havel zwischen Berlin und Potsdam fort, die er vom Brandenburger Kurfürsten Friedrich Wilhelm geschenkt bekommen hatte. ${ }^{15}$ Nach Brandenburg kam Kunckel im Jahre 1678 auf Vermittlung von Christian Mentzel, dem Leibarzt des Kurfürsten, der auch für dessen

12 Sven Dupré, Dedo von Kerssenbrock-Krosigk und Beat Wismer: Kunst und Alchemie. Das Geheimnis der Verwandlung. München 2014.

13 Sven Dupré: The Value of Glass and the Translation of Artisanal Knowledge in Early Modern Antwerp. In: Netherlands Yearbook for History of Art 64 (2014), S. 139-161; Marco Beretta: The Alchemy of Glass. Counterfeit, Imitation and Transmutation in Ancient GlassMaking. Sagamore Beach 2009.

14 Lothar Kuhnert: Johann Kunckel, Ritter von Löwenstern: Die Erfindung der Nanotechnologie in Berlin: Ein Bericht. Berlin 2008.

15 H. Günter Rau: Das Glaslaboratorium Johann Kunckels auf der Pfaueninsel. In: Ausgrabungen in Berlin 3 (1972), S. 148-171. 
Sammlung chinesischer Bücher zuständig war. Kurz nach seiner Ankunft in Brandenburg wurde Kunckel zum Leiter der Glashütte in Potsdam ernannt. Zur Herstellung von Kristallglas richtete er sich 1686 auf der Pfaueninsel ein Labor ein. Kunckel wurden zwei Privilegien eingeräumt - eines für Glasperlen, das andere für Goldrubinglas. Die Herstellung von Goldrubinglas machte Kunckel berühmt. ${ }^{16}$ Dieses tief rubinrote und dennoch durchsichtige Glas war um 1700 sehr in Mode und wurde genauso hochgeschätzt wie wenige Jahrzehnte später das Hartporzellan.

Dieser kurze biographische Ausflug sollte genügen, um zu zeigen, dass Kunckel sich zwischen den kunsthandwerklichen und gelehrten Kulturen seiner Zeit bewegte, zwischen Labor und Bibliothek, Lektüre und Praxis. Seine 1679 veröffentlichte Ars vitraria experimentalis oder Vollkommene Glasmacher-Kunst erschien zu einem Zeitpunkt, als er sich als Experte in der Glasherstellung und in der ,Chymie' am Brandenburgischen Fürstenhof etablierte. Insbesondere die Beschäftigung mit der Alchemie am Dresdner Fürstenhof brachte ihn zu der Überzeugung, dass solche Lektüre seiner Praxis der Glasfabrikation dienlich sein konnte. Typisch für den zwitterhaften Spezialisten, der sich zwischen der kunsthandwerklichen und der gelehrten Welt bewegt, präsentiert seine Ars vitraria experimentalis kunsthandwerkliches Wissen in gelehrtem Format. ${ }^{17}$

In seinem Buch behielt Kunckel das Geheimnis des Goldrubinglases ausdrücklich für sich. Er kommentierte Neris Rezept zur Verwendung von Gold als rotem Färbemittel wie folgt:

Ich habe hierinnen überaus grosse Müh angewandt und kann auch Gott Lob nebenst dem schönsten Rubin das feinste Roth machen; weil es mir aber gar viel Zeit Müh und Arbeit gekostet und eine sehr rare Sache ist als wird mich niemand verdencken daß ichs vor dißmahl nicht gemein mache. ${ }^{18}$

Ohne dass er Genaueres preisgab, benutzte Kunckel sein Buch also, um für sich und seine Kenntnisse zu werben. ${ }^{19}$ Wenn Kunckel sein größtes Geheimnis nicht veröffentlichte, was ist dann in dem Buch zu finden? Der erste Teil besteht aus einer deutschen Übersetzung von Neris L'arte vetraria, die erstmals 1612 in Ita-

16 Dedo von Kerssenbrock-Krosigk: Rubinglas des ausgehenden 17. und des 18. Jahrhunderts. Mainz 2001.

17 Ursula Klein: Introduction: Artisanal-scientific Experts in Eighteenth-Century France and Germany. In: Annals of Science 69 (2012), S. 303-306; Ursula Klein: Chemical Experts at the Royal Prussian Porcelain Manufactory. In: Ambix 60 (2013), S. 122-138.

18 Johannes Kunckel: Ars vitraria experimentalis oder Vollkommene Glasmacher-Kunst. Frankfurt a.M., Leipzig 1689, S. 89.

19 Kunckel bedient sich der Rhetorik der secreta-Literatur. Vgl. dazu William Eamon: Science and the Secrets of Nature: Books of Secrets in Medieval and Early Modern Culture. Princeton 1994; Secrets and Knowledge in Medicine and Science, 1500-1800. Hrsg. von Elaine Leong und Alisha Rankin. Farnham, Burlington 2011; Jo Wheeler: Renaissance Secrets: Recipes and Formulas. London 2009. 
lien erschienen war. Neri war ein Alchemiker aus Florenz. ${ }^{20}$ Die Glasrezepte, die er in L'arte vetraria sammelte, sind auf Erfahrungen und Studien gegründet, die er in der Glaswerkstatt im Casino San Marco in Florenz und im Haus des portugiesischen Handelsbankiers Emmanuel Ximenez sowie in der Glaswerkstatt von Filippo Gridolfi in Antwerpen gemacht hatte. ${ }^{21}$

Worum ging es also in Neris Buch? Neris Arte vetraria besteht aus sieben Büchern, von denen nur das erste der Herstellung von cristallo, also farblosem Glas, gewidmet ist. Die anderen sechs Bücher enthalten mehrere Rezepte für farbiges Glas, an denen die Medici, Neri und Ximenez ein Interesse hatten, besonders an denjenigen, die Edelsteine imitierten. ${ }^{22}$ Neris Buch über Glas beruht teilweise auf handschriftlich kursierenden Rezeptsammlungen, wie zum Beispiel dem Manuskript Ricette per far vetri colorati e smalti d'ogni sorte havute in Murano (1536) aus Montpellier, und zahlreichen anderen anonymen Sammlungen, die in Florenz im Umlauf waren. ${ }^{23}$ Darüber hinaus war Isaac Hollandus eine sehr wichtige Quelle, besonders für Buch 5 über das Imitieren von Edelsteinen. Der Antwerpener Maler Otto van Veen hob Hollandus als die wichtigste Autorität in der Alchemie hervor. ${ }^{24}$ Hollandus war ein paracelsischer Chemiker - eine vermutlich fiktive Gestalt -, dem zahlreiche Manuskripte auf Niederländisch und in anderen Sprachen zugeschrieben wurden. Er erlangte zu dieser Zeit einen mythischen Status, teilweise auch als vermeintlicher Vorgänger von und als Quelle für Paracelsus. ${ }^{25}$ Neri las Hollandus' Buch in der Bibliothek von Ximenez. ${ }^{26}$ Über einzelne Rezepte für die Herstellung künstlicher Edelsteine hinaus wurden Neri bei der Lektüre der Opera Mineralia von Isaac Hollandus die Ähnlichkeiten zwischen Glas und Mineralien stärker bewusst, und sie machten ihn mit naturphilosophischen Überlegungen zur Glasherstellung bekannt. Auch wenn Neris Buch zum Teil aus reiner Lektüre hervorging, spielte auch die Erfahrung eine wichtige Rolle. In Buch 2 der Arte vetraria zur Produktion von Chalzedongläsern finden

20 Maria Grazia Grazzini: Discorso sopra la Chimica. The Paracelsian Philosophy of Antonio Neri. In: Nuncius 27 (2010), S. 411-467; Paolo Galluzzi: Motivi paracelsiani nella Toscana di Cosimo II e di Don Antonio dei Medici: Alchimia, medicina ,chimica' e riforma del sapere. In: Scienze, credenze occulte, livelli di cultura. Hrsg. von Leo S. Olschki. Florenz 1982, S. 3162.

21 Sven Dupré: Trading Luxury Glass, Picturing Collections and Consuming Objects of Knowledge in Early Seventeenth-Century Antwerp. In: Intellectual History Review 20 (2010), S. 53-78.

22 Sven Dupré: The Value of Glass (Anm. 13), S. 146-147.

23 Cesare Moretti und Tullio Toninato: Ricettario vetrario del Rinascimento. Trascrizione da un manoscritto anonimo veneziano. Venedig 2001.

24 Sven Dupré: The Value of Glass and the Translation of Artisanal Knowledge in Early Modern Antwerp: In: Trading Values in Early Modern Antwerp. Hrsg. von Bart Ramakers, Christine Göttler und Joanna Woodall. Leiden, Boston 2014, S. 138-161, hier S. 155.

25 Annelies van Gijsen: Isaac Hollandus revisited. In: Chymia. Science and nature in medieval and early modern Europe. Hrsg. von Miguel López Pérez, Didier Kahn und Mar Rey Bueno. Newcastle 2010, S. 310-330.

26 Sven Dupré: The Value of Glass (Anm. 13), S. 155-156. 
sich interessante Variationen älterer schriftlicher Quellen der beschriebenen Experimente.

Im Anschluss an Kunckels Übersetzung von Neris L'arte vetraria und Kunckels Kommentaren zu dieser Schrift folgen in der Ars vitraria experimentalis zunächst Kunckels deutsche Übersetzung von Christopher Merretts Aufzeichnungen zu Neris L'arte vetraria, daran schließen wiederum Kunckels Observationen und curieusen Erinnerungen zu Merretts Aufzeichnungen an. Merrett war Mitglied der Royal Society in London (was Kunckel auch auf der Titelseite erwähnt). ${ }^{27}$ Im Rahmen des History of Trades-Programms der Royal Society übersetzte er 1662 Neris L'arte vetraria als The Art of Glass ins Englische. Es handelt sich dabei nicht nur um eine Wiedergabe in englischer Sprache, sondern um eine beträchtlich erweiterte Übersetzung, der Merrett seine Observations anfügt. In diesem separaten Abschnitt des Buches erörtert Merrett Fragen der Beschaffenheit, des Alters und des Nutzens von Glas. Es folgen Anmerkungen zu Neris verschiedenen Rezepten, wie etwa zu neuen experimentellen Erkenntnissen, gesammelt aus den Anekdoten von Arbeitern, aus praktischer Erfahrung und Materialien aus eigener Herstellung. Den Hauptteil dieser Anmerkungen bildeten jedoch Verweise auf die Schriften von Boyle, Glauber und vor allem von della Porta. Merretts Übersetzung von Neri geht außerdem eine kleine Liste von allgemeinen Regeln und Beobachtungen zu Verfahrensweisen voraus, die - so Merrett selbst - die monotone Wiederholung dieser Regeln in Neris Rezepten vermeiden sollen. ${ }^{28}$ Insgesamt verwendet Merrett in seiner Übersetzung eine Form gelehrter Eingriffe, die teilweise auf Kunckel vorausdeuten, teilweise jedoch auch in eine andere Richtung weisen. Kunckel stellt keine Liste allgemeiner Begriffe zusammen, um Neris Wiederholungen zu vermeiden.

Kunckels Titelseite signalisiert in vielerlei Hinsicht den Rückgriff auf gelehrte Genres für die Organisation handwerklichen Wissens. Obwohl das Buch auf Deutsch verfasst ist, wählt Kunckel mit Ars vitraria experimentalis einen lateinischen Titel aus eigener Feder, der zugleich klar als Echo von Bacons Konzept einer ,experimental history' kenntlich ist, das sowohl dem History of TradesProgramm der Royal Society als auch Merretts The Art of Glass zugrunde liegt. ${ }^{29}$ Auf der Titelseite preist er sein Buch außerdem als einen ,commentario' an, womit er sich auf die Kommentar-Tradition in der Naturphilosophie und in anderen theoriedominierten Wissensgebieten bezieht. Kunckel betont jedoch schon auf der Titelseite und dann auch im Buch selbst immer wieder, dass er ,Anmerckungen' und ,Observationen' liefert. Damit verwendet er die Termi-

27 D.E. Allen: Merret, Christopher (1614-1695). In: Oxford Dictionary of National Biography (2004), URL: http://www.oxforddnb.com/view/article/18599?docPos=1 (16.04.2015)

28 Christopher Merrett: The Art of Glass. London 1662.

29 Ursula Klein: Experimental History and Herman Boerhaave's Chemistry of Plants. In: Studies in History and Philosophy of Biological and Biomedical Sciences 34 (2003), S. 533-567; Cesare Pastorino. Weighing Experience: Experimental Histories and Francis Bacon's Quantitative Program. In: Early Science and Medicine 16 (2011), S. 542-570. 
nologie, mit der schon Merrett seine Kommentare zu Neri bezeichnet hat. Merrett und Kunckel mögen hier an das epistemische Genre der medizinischen ,Observationes' gedacht haben. ${ }^{30}$ Dieses Genre bestand aus Sammlungen von Fallgeschichten und entstand im 16. Jahrhundert aus einem anderen typisch humanistischen Genre, den ,Curationes'. Diese epistemischen Genres waren keine Blaupausen für Kunckels Fixierung von Irrtümern. Beide Genres thematisierten medizinisches Versagen - die ,Observationes‘ allerdings nicht so häufig wie die Curationes, denn dort richteten die Autoren den Fokus nicht auf die Effizienz von Heilmethoden, wie es für die Curationes typisch war. Schon in der Philologie des 15. Jahrhunderts markierte der Titel ,Observationes' ein Werk, das sich auf einzelne Teile eines Textes konzentrierte; das passt gut zu Kunckels Verwendung des Begriffs. ${ }^{31}$ Kunckel benutzte also offensichtlich gelehrte Formate ohne eine explizite Vorliebe - zur Organisation von handwerklichem Wissen.

\section{Kunckels Übersetzung von Neris L'arte vetraria}

Kunckels Übersetzung des ersten Abschnitts des Buches von Neris L'arte vetraria beginnt wie folgt:

Wie das Salz aus dem Pülverlein Rochetta und aus der Soda Hispanica auszuziehen vermittelst welches die Fritta Cristalli von den Italiänern Bollito genannt zubereitet wird als darinnen des fundament der ganzen Glassmacher-Kunst bestehet mit einer ganz neuen und geheimen Manier. ${ }^{32}$

Hier geht es um die Herstellung von Bleikristall (der italienische Begriff cristallo leitet sich vom Bergkristall ab, weil es den venezianischen Glasmachern von Murano gelungen war, Glas herzustellen, das so klar und durchsichtig wie natürlicher Bergkristall war), der Neri zufolge das Ausgangsmaterial zur Herstellung aller anderen Arten von Buntglas war. Interessanter Weise hat Kunckel mehrere von Neri verwendete italienische Begriffe nicht übersetzt, darunter am auffälligsten der Begriff fritta cristalli. Warum hat Kunckel diese Termini in italienischer Sprache belassen?

Es liegt nahe anzunehmen, dass Kunckel bestimmten verbreiteten Mustern des Übersetzens folgte. Begriffe der Ursprungssprache $\mathrm{zu}$ übernehmen, um dadurch den Eindruck der Fremdheit entstehen zu lassen, ist ein solches Muster, auf das Übersetzer zurückgreifen konnten. So entschied sich Merrett dafür, die

30 Gianna Pomata. Sharing Cases: the Observationes in Early Modern Medicine. In: Early Science and Medicine 15 (2010), S. 193-236; Gianna Pomata: Observation Rising: Birth of an Epistemic Genre, 1500-1650. In: Histories of Scientifc Observation. Hrsg. von Lorraine Daston und Elizabeth Lunbeck. Chicago, London 2011, S. 45-80.

31 Pomata: Sharing Cases (Anm. 30), S. 193-236, hier S. 200.

32 Kunckel: Ars vitraria experimentalis (Anm. 18) S. 2. 
exotischen Begriffe beizubehalten und ein Glossar zu erstellen. ${ }^{33}$ Man könnte vermuten, dass Kunckel einzelne Begriffe unübersetzt ließ, weil er mangels geeigneter deutscher Begriffe dazu gezwungen war. Paul Taylor zufolge ließ etwa Karel van Mander italienische Termini nur dann unübersetzt, wenn er keinen niederländischen Begriff verwenden konnte, der im zeitgenössischen Maleratelier in den Niederlanden bekannt war. ${ }^{34}$ Dies ist jedoch bei fritta, wie uns Kunckel in seinen Anmerckungen zu diesem Abschnitt von Neris Buch mitteilt, nicht der Fall. Im Deutschen gab es mit dem Begriff ,Gemenge' durchaus eine Übersetzung. Kunckel schreibt:

Auch habe ich zum öfftern von euch Glaßmachern gehöret daß ihr gern wissen möchtet was doch mit dem Wort Fritta angedeutet werde welches $\mathrm{zu}$ vielen malen in diesem Buch erwehnet ist. So vermelde ich euch hiermit daß es allemal so viel bedeutet als nach eurer Art zu reden wenn ihr sprecht: Gemenge; als das Gemenge ist gemacht von so viel Asche und Sand und so viel Salz und das andere Gemenge von so viel: Allso das was ihr Gemenge heisset, wird hier Fritta genennet aus daß ihr dieses Wort auch verstehet. ${ }^{35}$

Während ,Gemenge', das deutsche Äquivalent zu fritta, in deutschen Glashütten Verwendung fand, fragten sich Kunckel zufolge Glasmacher, die den Begriff fritta hörten oder lasen, was er bedeuten könnte. Kunckel erstellt für die deutschen Glasmacher also keine einsprachige Übersetzung, die sie darin unterrichten soll, wie etwas zu tun ist (hier: das Geheimnis der Herstellung von Bleikristall), sondern bietet ihnen einen fremdsprachigen Begriff, um zu benennen, was sie tun.

Wissenschaftshistoriker haben sich vorrangig auf zwei Übersetzungsprozesse konzentriert: auf die Latinisierung volkssprachlichen Wissens und auf die Übertragung lateinischen Gelehrtenwissens in die Volkssprache. Wie bereits erwähnt, fassen auch jüngere, theoretisch avancierte Bücher über die Ursprünge der neuen Wissenschaften in den Handwerkskulturen, wie das von Pamela Long, diese als Austausch und Kommunikation zwischen lateinischer Gelehrtenkultur und vernakularem Handwerkswissen auf. ${ }^{36}$ Im Gegensatz dazu hat Kunckel bewusst ein vielsprachiges Umfeld geschaffen, indem er in einer Übersetzung ins Deutsche bestimmte Termini in der Ursprungssprache beließ.

Bereits die Ausgangssituation, in der Kunckel seine Ars Vitraria verfasst hat, war durch Mehrsprachigkeit geprägt: Neris Buch war damals in mehr als einer

33 Theo Hermans: Concepts and Theories of Translation in the European Renaissance. In: Kittel: Übersetzung (Anm. 7), S. 1420-1428.

34 Paul Taylor: Italian Artistic Terms in Karel van Mander's Schilder-Boeck. In: Translating Knowledge in the Early Modern Low Countries. Hrsg. von Harold John Cook und Sven Dupré. Zürich, Berlin 2012, S. 197-216.

35 Kunckel: Ars vitraria experimentalis (Anm. 18), S. 35.

36 Long: Artisan/Practitioners (Anm. 2), S. 95. 
Sprache verfügbar. Der ersten Ausgabe von Neris L'arte vetraria im Jahr 1612 folgten nicht nur weitere italienische Auflagen in den Jahren 1661, 1663 und 1678 sowie die englische Übersetzung von Merrett, sondern auch eine lateinische Übersetzung von Neri, die zum ersten Mal 1668 gedruckt wurde. Kunckel erwähnte auf der Titelseite ausdrücklich, dass dies eine Übersetzung von Neris Veröffentlichung aus dem Italienischen und Lateinischen war. In einem Kommentar zu Neris Rezept für goldgefärbtes Glas im dritten Buch schreibt Kunckel:

Es hat mir dieser hierinn beschriebene Proceß die allergröste Müh und Verdruß über alle andere so in diesem Buch enthalten verursacht: Indeme die von dem Autor beschriebene Dosis ganz unrecht und falsch ist. Ich habe immer zu vermeint es sein in der Lateinischen Version ein Fehler gewesen; nachdem mir aber das Italiänische (als worinnen es der Autor selbst beschrieben) zu händen kommen habe ich befunden daß die Version mit demselben hierinnen ganz zutrifft: $\mathrm{Ob}$ es nun in dem Italiänischen Druck oder von dem Autor selbst versehen kann ich nicht wissen: $[\ldots]^{37}$

Hier erfahren wir gleich mehrere Dinge: Kunckel wurde mit Neris Buch über die später erschienene lateinische Ausgabe bekannt, betrachtete aber die italienische Ausgabe als die maßgebliche („als worinnen es der Autor selbst beschrieben“); seine Übersetzung war also ein Ergebnis des Vergleichens und Auswertens von Ausgaben in mehr als einer Sprache. Mehrsprachigkeit stand sowohl am Anfang der Übersetzung als auch an ihrem Ende.

Das mehrsprachige Ergebnis von Kunckels Übersetzungsbemühungen beschränkt sich nicht auf die Verwendung von italienischen Begriffen, selbst dort, wo eigentlich eine deutsche Entsprechung vorhanden wäre. Das Vorwort zu seinem Buch ist von Begriffen wie observiret, demonstrationen, operiret, experimentiret, determinirte dosin durchzogen - die hier und überall im Buch stets durch die Verwendung einer anderen Schriftart hervorgehoben werden. Die meisten dieser Begriffe haben eine epistemische Bedeutung. Hier ein Beispiel:

Es wird auch der fleissige Künstler in diesen und allen andern Dingen was ich hier tractire, befinden daß ich auch die jenige Warheit welche ich nicht von einem andern entlehnet oder erlanget sondern mit diesen meinen händen operiret, experimentiret und gelernet allhier aufgeschrieben und bewiesen habe. ${ }^{38}$

Ein weiteres Beispiel, das sich direkt auf Kunckels Behauptung bezieht, er habe jedes einzelne von Neris Rezepten selbst ausprobiert, ist das folgende: „Letzlich füge ich noch dieses hinzu [...] daß [...] ich nichts allhier mittheile welches ich

37 Kunckel: Ars vitraria experimentalis (Anm. 18), S. 85-86.

38 Kunckel: Ars vitraria experimentalis (Anm. 18), Vorrede. 
nicht selbst untersuchet und geapprobiret habe“. ${ }^{39}$ Wieder ist die epistemische Kategorie durch eine andere Schriftart hervorgehoben. Kunckel rühmt sich nicht nur der Durchführung eigener Versuche, sondern warnt seine Leser auch davor, dass die in dem Buch zu findenden Rezepte beim ersten Versuch misslingen könnten. Dies bedeute nicht, dass die Rezepte falsch seien; wahrscheinlicher sei, dass der Leser einen Fehler gemacht habe. Wenn der Leser in diese Situation geraten sei, rät Kunckel, möge er es wieder und wieder versuchen. In diesem Zusammenhang erinnert er daran, dass Übung den Meister macht. ${ }^{40}$

Pamela Smith vertritt die These, dass es bei Anleitungen und ,How-To'Büchern nicht immer, oder nicht ausschließlich, darum geht, dem Leser mitzuteilen, wie etwas zu bewerkstelligen ist, sondern wie es richtig $\mathrm{zu}$ machen ist. ${ }^{41}$ Sie sind nicht - oder nicht nur - dazu da, Wissen zu kommunizieren, sondern dienen auch der Vermittlung von epistemischen Werten, die in der Werkstatt von großer Wichtigkeit waren. Ein Beispiel dafür ist stete Aufmerksamkeit, ein weiteres Wiederholung, die Kunckel für sehr wichtig hielt. Die Vermittlung von solchen epistemischen Werten ist eines der Hauptziele von Kunckels NeriÜbersetzung. Die Verwendung fremdsprachiger Terminologie bietet dem Leser mit dem Aufgreifen von epistemischen Kategorien (Beobachtung und Experiment) ein umfangreicheres Vokabular, um darüber zu sprechen, wie man etwas richtig macht.

Das Experimentieren brachte Kunckel dazu, Neris Rezepte zu bewerten. Manchmal war seine Einschätzung voll und ganz positiv. Häufig brachten ihn seine Versuche aber auch dazu, die Rezepte den lokalen Gegebenheiten, Methoden und Ausgangsstoffen anzupassen. Eine bestimmte von Neri verwendete Materialzutat konnte sehr teuer gewesen sein oder vielleicht in Brandenburg schlichtweg nicht erhältlich. Eine der häufigsten Veränderungen nahm Kunckel aufgrund der unterschiedlichen Bedingungen bei Schmelzöfen vor. So schreibt er beispielsweise in seinen Kommentaren zu einer Lattimo-Farbe in Buch 3, Kapitel 55: „Lehret der Autor daß die Composition, 18. Tage und Nacht im Ofen stehen soll welches ganz unnötig sonderlich in unsern Deutschen Glaß-Oefen da es nicht 3. Tag und Nacht stehen darff". ${ }^{42}$

Um das Handwerk des Glasmachens zu lehren, reichte es jedoch nicht aus, nach der experimentellen Erprobung Änderungen vorzunehmen und die Rezepte dem vorhandenen Material und Wissen anzupassen. Kunckel war sich der Grenzen, die das Schreiben und Lesen mit sich brachte, sehr bewusst. Alles war eine Sache der Übung. So musste der Glasmacher etwa ein gutes Auge haben Kunckel spricht von ,Augenmaß’. ${ }^{43}$ Vielleicht waren die Grenzen der Vermitt-

39 Kunckel: Ars vitraria experimentalis (Anm. 18), Vorrede.

40 Kunckel: Ars vitraria experimentalis (Anm. 18), Vorrede.

41 Pamela H. Smith: Craft techniques and How-To Books. In: Mark Clarke, Bert de Munck und Sven Dupré: Artists' knowledge (Anm. 8), S. 75-84.

42 Kunckel: Ars vitraria experimentalis, (Anm. 18), S. 88.

43 Kunckel: Ars vitraria experimentalis, (Anm. 18), Vorrede. 
lung guter Handwerkskunst bei der stark visuell ausgerichteten Glasfabrikation stärker spürbar als bei jedem anderen Handwerk. Augenmaß war gefragt bei der Beurteilung der richtigen Menge einer Zutat für eine bestimmte Farbe: Schon kleine Unterschiede konnten hier zu großen Farbveränderungen führen. „Dieses alles aber kann wie gedacht auf dem Papier allhier nicht gelernet werden", folgerte Kunckel und hielt damit fest, wie begrenzt die Möglichkeiten der Vermittlung durch Sprache waren. ${ }^{44}$

Als Antwort auf diese Grenzen sprachlicher Darstellung führte Kunckel die schriftliche Fixierung von Irrtümern ein. Er benutzte seine Übersetzung von Neri als Vehikel, um Veränderungen an den Rezepten vorzunehmen, Anpassungen an lokale Gegebenheiten und Methoden durchzuführen, wenn diese sich von den bei Neri gefundenen unterschieden, jedoch auch, um festzuhalten, an welchen Punkten Neri sich geirrt hatte. Nachdem dieses Thema in der Wissenschaftsgeschichte lange stiefmütterlich behandelt worden war, sprachen sich in jüngster Zeit Giora Hon, Jutta Schickore und Friedrich Steinle dafür aus, die Bedeutung, die das Lernen aus Irrtümern in der experimentellen Forschung hatte, stärker zu beachten. ${ }^{45}$ So hat Schickore etwa gezeigt, dass sich die Mikroskopie im 18. Jahrhundert vorrangig auf das Aufspüren und Dokumentieren der Quellen von Beobachtungsfehlern konzentrierte. ${ }^{46}$ Vor diesem Hintergrund wäre Kunckels Identifizierung von Irrtümern sogar wichtiger als seine gelegentlichen Vorschläge von Alternativen zu Neris Rezepten und Verfahrensweisen. Für Kunckel war die Ars vitraria nicht nur ein Buch darüber, was zu tun war, sondern auch darüber, was man besser unterlassen sollte. Er selbst schrieb im Vorwort der Ausgabe von 1679: „Was sich thun und nicht thun lasset". ${ }^{47}$

Das volle Ausmaß von Kunckels Fixierung von Irrtümern wird nur dann deutlich, wenn man diese mit älteren Rezeptsammlungen vergleicht. Die Rezepte veränderten sich, ohne dass dies vermerkt wurde. Solche stillschweigenden Veränderungen gehörten zum Standard. Die Autoren korrigierten ein Rezept mitunter, weil dies die Erfahrung in der Werkstatt erforderlich machte, jedoch vermerkten sie nicht, wenn sie in ihr Ursprungsrezept eingegriffen hatten oder wenn dieses nicht mehr vorhanden war. Darüber hinaus scheinen die Autoren von Rezepten mehr daran interessiert gewesen $\mathrm{zu}$ sein, verschiedene Wege zu finden, um zu demselben oder einem ähnlichen Ergebnis zu gelangen, als daran, die richtigen von den falschen Wegen zu unterscheiden. Eine der handschriftlichen Quellen von Neris L'arte vetraria listete ganze 17 unterschiedliche Wege zur Herstellung von Chalzedonglas auf - einen nach dem anderen, ohne Unter-

44 Kunckel: Ars vitraria experimentalis, (Anm. 18), Vorrede.

45 Going Amiss in Experimental Research. Hrsg. von Giora Hon, Jutta Schickore und Friedrich Steinle. Dordrecht 2009.

46 Jutta Schickore: The Microscope and the Eye. A History of Reflections, 1740-1870. Chicago 2007.

47 Johannes Kunckel: Ars vitraria experimentalis oder Vollkommene Glasmacher-Kunst. Frankfurt a.M., Leipzig 1679, Vorrede. 
schiede $\mathrm{zu}$ machen. ${ }^{48}$ Neri selbst listet noch drei weitere auf. Sein Nachdruck liegt auf der Herkunft der Experimente und dem Netzwerk von persönlichen Verbindungen, mit denen man an die Rezepte gelangt war. So erwähnt er, dass er das erste Rezept 1601 im Florentiner Casino di San Marco unter der Leitung von Niccolo Landi ausprobiert habe; das zweite Rezept habe ihm zur Herstellung von Chalzedonglas in Flandern gedient und sei vom Großherzog Ferdinand de Medici bewundert worden. Beim dritten Rezept heißt es, es sei das Ergebnis von Experimenten in der Glaswerkstatt von Gridolfi in Antwerpen im Januar 1609 gewesen, wobei Neri hinzufügt, dass er zwei Stücke des Chalzedonglases, das nach dieser Technik hergestellt worden war, dem Fürsten von Oranien präsentiert habe. ${ }^{49}$ Man sieht also, dass Neri zwar die Rezepte zur Glasherstellung gelesen und gelegentlich auch seine Quellen angegeben hat. Er hat jedoch nicht die Irrtümer aufgezeichnet, die er in den Ursprungsrezepten fand. Kunckel aber tat das.

Manchmal lehnt Kunckel in seinen Anmerckungen eines von Neris Rezepten sogar rundweg ab. So schreibt er zum Beispiel zu einem Rezept zur Imitation von Lapis Lazuli: „Der Autor lehret bin ich ganz gewiß versichert daß er es nicht gemacht er würde es sonst anders befunden und nicht also hier gefaßet haben denn es gehet im geringsten nicht an. “50

Ein Rezept konnte in vielerlei Hinsicht falsch sein. Wie schon bemerkt, lag eine der häufigsten Fehlerquellen in der Menge der Zutaten. Manchmal war auch Neris Vorgehensweise falsch - entweder führte sie zum falschen Resultat oder sie enthielt überflüssige Verfahren, die zum Erreichen des Ziels zu umständlich oder gar nicht notwendig waren. So notierte Kunckel zu einem von Neris Rezepten für Chalzedonglas: „Der Autor macht diese Composition nur sehr schwer und kostbar da sie doch mit viel geringer Mühe und Kosten könnte gemacht werden". ${ }^{11}$ Es gab mehr als eine Möglichkeit, Dinge falsch zu machen.

\section{Fazit}

Abschließend möchte ich meine Ergebnisse noch einmal zusammenfassen. Es ging mir um zwei Arten von Übersetzung: eine zwischen der Praxis in der Werkstatt und deren sprachlicher Darstellung, die andere zwischen zwei Sprachen. Kunckel war sich der Grenzen, die Sprache dem Bemühen setzt, Werkstattpraxis darzustellen, sehr bewusst. Bei Übersetzungen von Rezepten aus einer Sprache in eine andere treten diese Grenzen noch deutlicher hervor, ja, das problematische Verhältnis von Text und Praxis wird bei der Übersetzung von Rezepten und technischem Wissen in eine andere Sprache unmittelbar deutlich.

48 Cesare Moretti und Tullio Toninato: Ricettario vetrario del Rinascimento. Trascrizione da un manoscritto anonimo veneziano. Venedig 2001, S. 43.

49 Antonio L. Neri: L'arte vertraria. Florenz 1612, S. 39-48.

50 Kunckel: Ars vitraria experimentalis (Anm. 18), S. 100.

51 Kunckel: Ars vitraria experimentalis (Anm. 18), S. 75. 
Man fragt sich, ob eine Übersetzung ohne den Rückgriff auf die Praxis - das heißt, ohne ein bestimmtes Rezept zu erproben - überhaupt möglich ist. Denn der Übersetzer ist an ortsspezifische Namen und Begriffe gebunden. Kunckel hat daraus die Konsequenz gezogen, Neris Rezepte zu erproben. Das lässt ihn in der langen Geschichte der kunsthandwerklichen Anleitungen als einen außergewöhnlichen Leser erscheinen, denn diese Anleitungen stellen in der Regel nur die Beschreibung einer Werkstattpraxis mit der Funktion dar, handwerkliches Wissen über die physischen Grenzen der Werkstatt hinaus zu vermitteln. Kunckels Übersetzung von Glasrezepten zeigt nicht nur, wie sich Künstlerwissen geografisch und gesellschaftlich von einem Ort zum anderen bewegt hat. Noch wichtiger ist, dass sich im Prozess des Übersetzens das Verständnis von handwerklichem Wissen als solchem verändert. Der auffälligste Unterschied zwischen Neris L'arte vetraria und vorangegangenen Rezeptsammlungen ist der, dass Neris Buch Menschen und Orte benennt. Er gibt nicht nur die Namen von Patronen und Städten an, sondern auch die von neueren Autoritäten - selbst dann, wenn sie so ephemer sind wie der nicht existierende Isaac Hollandus. Im Fall von Neri ging kunsthandwerkliches Wissen aus Experiment und Lektüre hervor. Indem Kunckel auf seine Erfahrungen mit Grenzen des sprachlich Möglichen mit der schriftlichen Fixierung von Irrtümern reagierte, führte er Neris Konzeption noch einen Schritt weiter.

Wie kommt es zu diesem Wandel bei der Niederschrift von kunsthandwerklichem Wissen? Hier sind mehrere Faktoren zu berücksichtigen. Einer davon ist die Welt des gedruckten Wortes. Es ist schwer vorstellbar, dass Kunckel ein solches Netz von Irrtümern hätte dokumentieren können, ohne Zugang zu den gedruckten Texten von Neri und Merrett gehabt zu haben. Die schriftliche Fixierung von Irrtümern ist damit ein Effekt der durch den Buchdruck garantierten Beständigkeit. ${ }^{52}$ Ein zweiter Faktor ist das Erscheinen von Experten an den Fürstenhöfen, die in der Alchemie bewandert waren und Luxusprodukte herstellen konnten. ${ }^{53}$ Diese Experten verbanden gelehrte und kunsthandwerkliche Kultur. Kunckel führte unterschiedliche wissenschaftliche Formate zusammen die ,experimental history ' von Bacon, medizinische ,Observationes' und die Tradition der naturphilosophischen Kommentare -, um handwerkliches Wissen zu ordnen. In seinem Übersetzungsprozess begann das Schreiben über alchemische Techniken die Lektüre zu reflektieren.

52 Im Sinne von Elizabeth L. Eisenstein: An Unacknowledged Revolution Revisited. In: The American Historical Review 107 (2002), S. 87-105, als Antwort auf die Kritik von Adrian Johns und anderen. Siehe Adrian Johns: The Nature of the Book. Print and Knowledge in the Making. Chicago 1998.

53 Sven Dupré: Introduction. In: Dupré: Laboratories of Art (Anm. 10), S. VII-XIX. 


\title{
Eine kurze Theoriegeschichte der alchemistischen multiplicatio und der Vorbothe der am philosophischen Himmel hervorbrechenden Morgenröthe des Johannes de Monte Raphaim (Amsterdam 1703)
}

\author{
Harald Haferland, Osnabrück
}

\section{Vorbemerkung zur Methode}

Ich vertrete folgende grundsätzliche Positionen: 1. Das von der Alchemie gemeinte Gold ist Gold, wie wir es heute kennen, das Silber Silber usw. 2. Bei der Rekonstruktion wissenschaftsgeschichtlicher Vorgänge ist die Kategorie des Irrtums zuzulassen; entsprechend darf sie auch eine Rolle bei der Interpretation alchemistischer Texte spielen. 3. Da man Wissen in Relation zu einem je erreichten Stand des Wissens bestimmen wird, zählt heute etwas als Wissen, was einen früheren Stand des Wissens ggf. als irrtümlich ausweisen lässt. Für wissenschafts- und wissensgeschichtliche Rekonstruktionen heißt das nicht, es abzutun, sondern als ggf. bedingten Irrtum zu erklären. Anders als im Fall der unverändert bestehen bleibenden Bezugnahme auf Gold können historische Wissenszustände im Übrigen durch einen anderen Wissensbegriff organisiert werden.

$\mathrm{Zu}$ 1. Ich setze eine Bedeutungstheorie Kripke-Putnamscher Art voraus: Eine natürliche Art wie Gold (aber auch Wasser, Tiger, elektrische Ladung usw.) wird durch den geläufigen Begriff für diese Art (,Gold' usw.) dergestalt bezeichnet, dass es einen Einführungsvorgang für die Begriffsverwendung gibt, an den eine Sprechergemeinschaft anknüpft. ${ }^{1}$ Die Sprechergemeinschaft ist in Hinsicht auf die Wissensverteilung geschichtet, d.h. es gibt Experten, die mit einer bestimmten natürlichen Art größere Erfahrung und entsprechend mehr Kenntnisse über sie haben als die Nichtexperten. Außerdem ist die Sprechergemeinschaft historisch ausgedehnt, ${ }^{2}$ d.h. sie kann auch nach tausend Jahren über Sprachgrenzen hinweg und angesichts eines immensen Zuwachses an Expertenwissen noch fortbestehen. Dabei kann sie selbstverständlich über dieselbe natürliche Art zu sprechen beanspruchen. Sie kann einem Irrtum aufsitzen, wenn sich etwa herausstellt, dass sie tatsächlich über zwei natürliche Arten spricht. ${ }^{3}$ Für eine hypo-

1 Vgl. Hilary Putnam: The Meaning of ,Meaning'. In ders.: Mind, Language and Reality. Philosophical Papers, Volume 2. Cambridge 1975, S. 215-271, hier S. $227 f$.

2 Vgl. Hilary Putnam: Explanation and Reference. In ders.: Mind, Language and Reality (Anm. 1), S. 196-214, hier S. 198-207, sowie ders.: The Meaning of ,Meaning' (Anm. 1), S. 223-227.

3 Putnam zeigt dies am Beispiel von ,Jade', worunter man in China einst zwei chemisch voll- 
thetische natürliche Art (wie z.B. Phlogiston) kann sich herausstellen, dass sie gar nicht existiert. Zudem kann ein Experte - oder mehrere - eine besondere Begriffsverwendung einführen, ohne dass dies aber Folgen für den geläufigen Begriff hat. Schließlich führt auch der Zuwachs an Wissen - auch an irrtümlichem Wissen - zu keiner Bedeutungsänderung. Es hat deshalb keinen Sinn zu sagen oder anzunehmen, jemand könne entdecken, dass Gold kein Gold sei. Sehr wohl kann er aber entdecken, dass etwas Scheingold - oder etwas anderes als Gold ist. Ich schließe daraus, dass die Alchemisten seit der Spätantike, auch wenn sie noch nicht über den modernen Elementbegriff verfügen, von demselben Gold sprechen, von dem wir immer noch sprechen. Wenn sie für einen hypothetischen gold- oder andersartigen Stoff einen begrifflichen Vorbehalt geltend machen (s.u.), so bezeugt das ihre terminologische und theoretische Umsicht.

$\mathrm{Zu}$ 2. Es gibt (mindestens) zwei Arten von Irrtümern: sozial oder durch die Begegnung mit der Natur induzierte. Man kann durch andere getäuscht werden, die dies beabsichtigen oder auch nur verursachen bzw. bewirken. Oder man kann sich etwa hinsichtlich der näheren Beschreibung natürlicher Arten irren. Die Geschichte der Wissenschaften führt nicht nur zu einem Wissenszuwachs, sondern auch zur Korrektur von Irrtümern, in die man immer wieder verfällt. In der Praxis will man im Übrigen nicht betrogen werden (z.B. durch Scheingold, d.h. eine dem Gold ähnliche Legierung). Irrtümer bilden keine moralische Kategorie, Betrug schon.

Die Erzeugung von Scheinwissen besitzt eine wichtige Funktion für die Generierung von Wissen. Wenn die Geschichte der Alchemie einerseits einen gewaltigen Wissenszuwachs produziert, so ist sie andererseits durch alle Arten von Irrtümern gekennzeichnet: solche, die die natürliche Beschaffenheit von Metallen und anderen Stoffen betreffen; solche, die auf absichtsvollem Betrug beruhen; schließlich aber auch solche, die sozial verursacht sind, ohne beabsichtigt worden zu sein. Dies sind die interessanteren Irrtümer, da sie Wissenschaft als komplexes soziales Unternehmen erkennen lassen. Die unfreiwillige Kumulation von Irrtümern mitsamt den darauf aufliegenden Umdeutungsprozessen dürfte gerade für die Geschichte der Alchemie noch nicht zureichend analysiert worden sein. Diese Geschichte ist zu einem erheblichen Anteil Religions- und Literaturgeschichte, in der die Kategorie des Irrtums keinen Platz hat; insofern sie allerdings Wissensgeschichte ist, darf die weitgehende Auffächerung unfreiwilliger Irrtümer einen zentralen Gegenstand der Untersuchung und Analyse bilden.

Zu 3. Wissens- und Wissenschaftsgeschichte kann nur aus zwei Perspektiven betrieben werden: einer Perspektive, die von einem jeweils aktuellen Wissensstand aus eingenommen wird, und einer Perspektive, die sich in einen je zeitgenössischen Wissensstand zurückbegibt. In diesem Sinne trifft sie - ggf. nur im-

kommen verschiedene Substanzen mit freilich sehr ähnlichen Eigenschaften verstand. Vgl. Putnam: The Meaning of ,Meaning' (Anm. 1), S. 241. 
plizit - Aussagen darüber, was ein historischer Experte nicht wusste und fälschlich zu wissen glaubte, aber insbesondere darüber, was er aufgrund welcher Voraussetzungen für Wissen hielt. Während Gold Gold bleibt bzw. der Begriff seinen Bezug unverändert behält, unterliegen doch das Wissen vom Gold wie auch der Begriff eines solchen Wissens einem historischen Wandel.

Die Literatur der Alchemie ist eine Literatur, die eine Phantasmagorie umkreist. Angesichts der Unzahl an Texten, die sie von der Spätantike an bis weit in die Frühe Neuzeit hervorgebracht hat, ${ }^{4}$ fragt man sich, wie es angehen konnte, dass über anderthalb Jahrtausende ein Text nach dem anderen oft nur aus der Menge vorhandener Texte abgeleitet wurde, ohne dass jemand einmal klar und wirksam ausgesprochen hätte: Der Kaiser hat keine neuen Kleider, der Kaiser ist nackt - es gibt keine Möglichkeit, Edelmetalle aus nicht edlen Metallen zu gewinnen. Derartiges vermuten und sagen zwar die schon immer vorhandenen Kritiker der Alchemie, aber sie beziehen sich auf deren technologisches Versagen und machen sich nicht erst die Mühe, sich in die umlaufenden Texte mit ihren Theorieanstrengungen einzulesen. Dies wäre allemal nach dem Ende des Mittelalters zu einer Mammutaufgabe geworden, die man sich vielleicht hätte ersparen können und sollen. Es gehört ein eigenes Interesse dazu, sich auf die vielen alchemistischen Texte einzulassen, die ihren Referenzpunkt immer wieder weitgehend und fast ohne Ende nur in anderen Texten finden. Dies scheint denn auch ein spezifischer Reiz der alchemistischen Textproduktion zu sein: die Streckung der Sprache nahezu bis ins Unendliche.

Ich werde hiervon anhand eines Kernbegriffs der Alchemie, der in der Regel am Ende alchemistischer Texte zum Zuge kommt, nur einen kleinen Ausschnitt näher beleuchten. Es geht darum, dass - wenn man das Elixier, d.h. das Mittel zur erfolgreichen Behandlung oder Umwandlung unedler Metalle, bereit machen will - man seine Wirksamkeit um ein Vielfaches verstärken kann. Es soll zu einer Vermehrung einerseits der Kräfte des Elixiers, andererseits aber auch der Menge des behandelten Stoffs kommen; theoretisch bis ins Unendliche - so die Annahme. Dieser Vorgang wird multiplicatio genannt. Der Begriff wird von ei-

4 Einen Eindruck vermittelt die von John Ferguson vorbildlich katalogisierte, höchst umfangreiche, aber immer noch nicht ganz vollständige Sammlung von James Young of Kelly and Durris, vgl. John Ferguson: Bibliotheca Chemica. A Catalogue of the alchemical, chemical and pharmaceutical books in the collection of the late James Young of Kelly and Durris. 2 Bde. Glasgow 1906 (der Katalog umfasst über tausend Seiten). Mein Urteil bezieht sich auf den großen Anteil im eigentlichen Sinn alchemistischer Texte in dieser Sammlung (unter Ausschluss etwa der chemisch-pharmazeutischen Texte). Volkhard Wels, dem ich für eine Reihe von Hinweisen danke, macht mich darauf aufmerksam, dass sich aus dieser Alchemie, die man Transmutationsalchemie nennen kann (in diesem Band, S. 233-265), viele Folgedisziplinen herleiten, die eine Unzahl medizinischer, pharmazeutischer, metallurgischer, kriegstechnischer, kunsthandwerklicher und anderer Kenntnisse zutage gefördert haben. Insofern hat man es mit einem wissenschaftsgeschichtlich in diesem Ausmaß wohl einzigartigen Phänomen nicht-intendierten Wissenszuwachses zu tun. 
nem Text zum nächsten weitergereicht. Ich werde seine Verwendung und sein theoretisches Umfeld von der Spätantike bis in die Frühe Neuzeit erläutern.

In den griechischen chemischen Papyri aus dem 3. Jahrhundert nach Christus, dem Papyrus von Leiden und dem aus Stockholm, gibt es Rezepte, die die Streckung von Silber durch Kupfer und Zinn beschreiben. Hergestellt werden Legierungen, die so aussehen wie Silber, die aber nur zu einem Teil aus Silber bestehen. Es ist die Rede von einer Verdopplung (dem $\delta \iota \pi \lambda \alpha \sigma \iota \alpha \sigma \mu o ́ s)$ oder sogar Verdreifachung (der $\tau \rho i \tau \lambda \omega \sigma \iota \varsigma$ ) des Silbers. Die Betrugsabsicht liegt offen zutage, aber es gibt Formulierungen, die einen stutzen machen. Es heißt etwa zum Ergebnis eines Verfahrens, in dem Kupfer und Zinn (wohl mit Silber) zusammengeschmolzen werden: „es wird zu erstklassigem Silber (ä $\rho \gamma v \rho o \varsigma$ ó $\pi \rho \tilde{\omega} \tau o \varsigma)$, ohne dass die Handwerker daran etwas merken können. ${ }^{5}$ In einem Satz wird hier verpackt, dass man so eine Mogelpackung herstellen kann, die sich selbst dem Sachverstand der Handwerker entzieht; sie wird aber zugleich als erstklassiges Silber bezeichnet. ${ }^{6}$ Normalisiert man diesen Sprachgebrauch, dann ist es nicht weit zu der missverständlichen Behauptung "das Kupferkalk

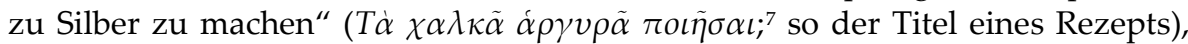
die in den Rezepten der Papyri üblich ist. Zu Silber wird hier etwas erklärt, das aussieht wie Silber und bei der Verarbeitung ungefähr dieselben Eigenschaften aufweist, indem es sich auch nicht leicht in die ursprünglichen Bestandteile auftrennen lässt; erst stärkeres und längeres Erhitzen würde die Legierung zerstören. Gewöhnt man sich an eine solche Redeweise, dann kann man (vorgebliches) Silber und Gold durch Zusatz unedler Metalle einfach vermehren. ${ }^{8}$ Sofern die Handwerker etwas merken, werden sie diese Redeweise tunlichst indizieren. In den späteren alchemistischen Rezepten wird sie für die Herstellung von "Silber' und ,Gold' aber in der Tat selbstverständlich. Man kann es verdoppeln und vermehren, wie es heißt, ${ }^{9}$ und es ist nicht leicht $\mathrm{zu}$ entscheiden, ob dabei ein

5 Otto Lagercrantz: Papyrus Graecus Holmiensis. Recepte für Silber, Steine und Purpur. Uppsala 1913, S. 3f. (eine Übers. auf S. 150f.). Vgl. auch: Les alchimistes grecs. Tome I. Papyrus de Leiden. Papyrus de Stockholm. Fragments de recettes. Hrsg. und übersetzt (franz.) von Robert Halleux. Paris 1981, Rezept Nr. 3, S. 111.

6 Fast identische Formulierungen fallen im Leidener Papyrus (Anm. 5) etwa zur Herstellung von Asem (Nr. 8, S. 86; Nr. 39, S. 95).

7 Papyrus von Leiden (Anm. 5), Nr. 26, S. 91. Vgl. auch den Papyrus von Stockholm (Anm. 2), Nr. 9, S. 112.

8 Entsprechend ist von Vermehrung $(\pi \lambda \varepsilon \sigma v \alpha \sigma \mu o ́ \varsigma)$, Verdoppelung $(\delta i \pi \lambda \omega \sigma \iota \varsigma)$ und Verdreifachung die Rede ( $\tau$ pi $\lambda \lambda \omega \sigma \iota \zeta)$. Vgl. etwa im Leidener Papyrus (Anm. 2), Nr. 15 und 16 (S. 88), im Stockholmer Papyrus (Anm. 5), Nr. 7, S. 112 u.ö.

9 Collection des alchimistes grecs. Hrsg. von Marcellin Berthelot, unter Mitarbeit von CharlesEmile Ruelle. 3 Bde. Paris 1887/1888, Nachdruck London 1963, Bd. 2, Texte grec, S. 38f., 309 u.ö. Es finden sich noch weitere seltsame Rezepte schon in den Papyri: So wird gesagt, man besäße in einem aus acht Teilen Silber mit je zwei Teilen Kupfer und Zinn zusammenge-

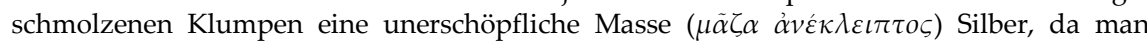
hiervon Teile (als Silber) hinweg nehmen und das Hinweggenommene durch Zusatz weiterer Teile Kupfer und Zinn ersetzen könne (vgl. Lagercrantz: Papyrus Graecus Holmiensis 
hinzugedachter Index mitspielt (,Silber in dem Sinne, dass [... $\left.]^{\prime}\right)$. Wo nicht, dort werden Silber und vorgebliches Silber irrtümlich unter einen Begriff gebracht. Allerdings ist noch eine weitere Möglichkeit in Betracht zu ziehen: die Redeweise wird unter einen Theorievorbehalt gestellt - für den Fall, dass sich nämlich tatsächlich bestätigen lassen sollte, dass Silber (und Gold) sich verdoppeln und vermehren lassen.

Mit derartigen Vorbehalten arbeitet die Alchemie von Beginn an. Durch ihre gesamte Geschichte läuft - schon von den Texten des 1. Jahrhunderts an bis weit in die Frühe Neuzeit - ein terminologischer Vorbehalt, der ausweist, dass von den genannten Stoffen nicht in dem Sinne die Rede ist, in dem die Stoffnamen üblicherweise gebraucht werden. Man signalisiert, dass nicht vom gewöhnlichen Gold die Rede ist, sondern von ,unserem Gold' oder vom ,philosophischen Gold”. „Unser Gold kann, sofern es die erforderliche Eigenschaft besitzt, [Gold]

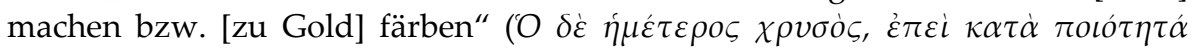
$\dot{\varepsilon} \sigma \tau \iota v, \pi \circ \varepsilon \tilde{\imath} v \kappa \alpha i \beta \alpha \dot{\tau} \tau \tau \varepsilon \iota v \delta \dot{v} v \alpha \tau \alpha \iota),{ }^{10}$ heißt es bei dem in Alexandria arbeitenden griechischen Alchemisten Zosimos von Panopolis (Ende des 3., frühes 4. Jahrhundert nach Chr.). Hier wird der terminologische Vorbehalt zu einem theoretischen, denn es wird mit dem eingeschobenen Satz eine Beschaffenheit zur Bedingung gemacht, von der einstweilen offen bleibt, wodurch sie erreicht wird. Dabei suggeriert der Nebensatz unwillkürlich, es gebe diese Beschaffenheit. Dass Gold oder Goldartiges - ,unser Gold' - seinerseits Gold herstellen soll, kann auf das in der Antike weitverbreitete hippokratische Prinzip similia similibus curantur vertrauen. ${ }^{11}$ Dennoch liegt nicht mehr als ein Theorieversprechen vor, das erst noch einzulösen ist.

Die vielversprechende Redeweise gilt ebenso für Silber, später besonders für den Mercurius (Quecksilber) und Schwefel und was der Stoffnamen mehr sind, die unter den Vorbehalt fallen sollen. Er wird allerdings weniger als Vorbehalt aufgefasst, sondern als Bestandteil einer Eingeweihtensprache sowie als Schutzklausel vor unbequemen Nachfragen. Wenn es heißt , unser $X Y^{\prime}$, dann ist ein Text immer auch gegen Festlegungsversuche aus der Praxis immunisiert. Es soll so scheinen, als könne man den Text unter Eingeweihten lesen. Pseudisten kön-

[Anm. 5], S. 154-156; vgl. zur unerschöpflichen Masse auch Halleux: Les alchimistes grecs [Anm. 5], S. 39f.). Berthelot hat angesichts des Ausdrucks $\mu \tilde{\alpha} \zeta \alpha$ an einen Gärungsprozess in dieser $\mu \tilde{\alpha} \zeta \alpha$ gedacht (Berthelot: Collection des alchimistes grecs, Bd. 1, S. 270), der durch ein Gärungsmittel bewirkt wird. In den Rezepten ist aber von einem derartigen weiteren Mittel nicht die Rede, und der Silberanteil müsste stattdessen tatsächlich immer geringer werden. Allerdings scheint hierbei die Vorstellung mitzulaufen, dass sich der überwiegende Silbergehalt ungeachtet seiner Verringerung dem zugesetzten Kupfer und Zinn weiterhin mitteile.

10 Berthelot: Collection des alchimistes grecs (Anm. 9), Bd. 2, S. 127. Weitere Stellenbelege führt Edmund O. von Lippmann: Entstehung und Ausbreitung der Alchemie. Mit einem Anhange: Zur älteren Geschichte der Metalle. Berlin 1919, S. 46 u.ö.

11 Vgl. zur Konzeption des Prinzips bei Zosimos Lippmann: Entstehung und Ausbreitung der Alchemie (Anm. 10), S. 80. 
nen darauf vertrauen, dass dies im Zweifelsfall niemand kann, da der Eingeweihtenstatus grundsätzlich nicht dafür sorgt, die Sprache auf Kommunizierbarkeit einzurichten. Eine auf Reproduzierbarkeit der Verfahren gerichtete und auf allerorten nachvollziehbare Grundbegriffe gestützte Forschung stellt ein erst modernes naturwissenschaftliches Ideal dar.

,Unser XY' bleibt durch die Geschichte der Alchemie hindurch ein hypothetisches Konstrukt, das allerdings unwillkürlich einen großen spekulativen Spielraum eröffnet. Die fehlende Bestimmtheit und Bestimmbarkeit des Begriffs schließt nicht aus, dass alchemistische Verfahren und Versuche über viele Jahrhunderte ausprobiert werden: Eine reproduzierbare Grundlage einer erfolgreich weiter $\mathrm{zu}$ gebenden Experimentierkunst liefern die alchemistischen Texte aber nur selten. So bleiben ihre Verfasser gern anonym oder verbergen sich hinter Pseudonymen, insbesondere im Mittelalter. Oft schreiben sie ihre Texte auch prominenten Autoren zu, um den Texten die Lektüre und eine Fortwirkung zu sichern, ohne doch ansprechbereit dafür einzustehen und mit dem eigenen Namen dafür zu ,haften'. Gleichwohl zeitigt dieser Zustand unabsehbare Folgen, indem er empirische Bemühungen in verschiedenste Richtungen lenkt und ungewollt dennoch zur Identifizierung von Stoffen nötigt. In diesem Sinne bringt er gewissermaßen sein Gegenteil hervor.

Warum sollte aus einer unbefangenen Perspektive nicht in der Tat eine erreichte Legierung bzw. Mischung besseres Silber darstellen, sodass die Anführungsstriche doch vielleicht hinweg zu nehmen und der Vorbehalt unnötig wäre(n)? Was heißt überhaupt ,Legierung' oder ,Krasis' und was dergleichen Begriffe für chemische Verbindungen mehr sind, und was geschieht dabei: Warum sollten sich die gemischten Bestandteile gleichbleiben und nicht zu einem neuen und besseren Ganzen verschmelzen, das ist ja tatsächlich das Ergebnis einer chemischen Reaktion? Wer weiß, ob im Innern der Natur - sei es im Erdinnern oder in den Stoffen selbst - nicht bis ins Kleinste gehende Mischungsverhältnisse einen neuen Stoff hervorzubringen erlauben oder doch neue Eigenschaften? Genau das ist die Erfahrung im Umgang mit den Stoffen über dem Feuer oder bei der Destillation. Man beginnt dabei, chemische Vorgänge zu beobachten und begnügt sich nicht mehr damit, in der Natur begegnende Stoffe nur in Augenschein zu nehmen.

Wenn man aber (noch) nicht weiß, dass bestimmte Metalle Elemente darstellen, weil man noch nicht über den chemischen Elementbegriff verfügt; wenn man zudem nicht weiß, was genau beim Zusammenschmelzen verschiedener Metalle und weiterer zugesetzter Stoffe wie Schwefel, Salzen u.a.m. vor sich geht und keine sorgfältigen Gewichtsproben vornehmen kann, die das spezifische Gewicht oder die Dichte eines Stoffes zu bestimmen und zu beachten erlauben, dann ist das Feld offen für Spekulationen verschiedenster Art. Damit beginnt die Alchemie. Edelmetalle wie Silber und Gold könnten z.B. ihrerseits Mischungen darstellen, bei denen nur ein Bestandteil den anderen so dominiert, dass er ihm 
seine Qualität mitteilt ${ }^{12}$ oder eine neue Qualität herstellt. Oder eine in die Tiefe gehende Färbung verwandelt ein unedles Metall in ein edles - in der Färbung zeigt sich nur eine tiefreichende Umwandlung der Eigenschaften des behandelten Metalls. Auch andere Möglichkeiten wären denkbar.

Ungefähr zur Zeit der zitierten Papyri beginnt die Alchemie im 3. Jahrhundert anhand derartiger Theorien zu experimentieren. Die Theorien besitzen einen technischen Anhalt, greifen aber auch spekulativ aus und laufen schnell in eine frei flottierende, schon in der Antike extrem anspielungsgeladene, metaphorisierte und allegorisierte Sprache aus, die den Anschluss an Philosophie und Religion sucht. Die auf Miniaturvorgänge zugeschnittenen Experimente scheinen geeignet, übergreifende Gesichtspunkte, ja makrokosmische Dimensionen zusammenzudenken.

Der Wunsch, eine Vermehrung von Gold und Silber herbeizuführen, hat Alchemisten früh auf den Gedanken gebracht, dass es eine chemische Wirkung geben könnte, die der Gärung/Fermentation vergleichbar sei. Es heißt u.a. bei Zosimos, dass man eine kleine Menge Gold oder Silber auf einen präparierten Stoff werfen bzw. projizieren müsse, um wie beim Aufgehen von Brotteig nach

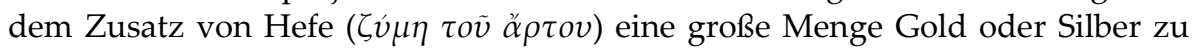
erhalten. ${ }^{13}$ Das Ferment soll also einen Stoff deutlich vermehren, indem es ihm zugleich neue Eigenschaften mitteilt. Die spätantike Alchemie ist entsprechend durch die Suche nach Konzepten gekennzeichnet, die nach dem Vorgang solcher Vermehrung und Verwandlung die Herstellung edler Metalle erklären könnten. Dann, so die implizite Annahme, müsste sich die Herstellung auch praktisch bewältigen lassen.

Solche Konzepte werden u.a. aus der Medizin übernommen, indem statt der

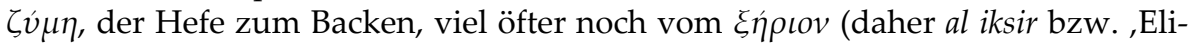
xier $\left.^{\prime}\right)$, d.h. einem Wundpulver, oder vom $\phi \dot{\alpha} \rho \mu \alpha \kappa o v$, einem heilenden Gift, die Rede ist. ${ }^{14}$ Solche Mittel sollen auf eine vorbereitete Masse, eine Metallpaste o.ä., einwirken und sie verwandeln, wie sie ja schon als Behandlungsmittel im menschlichen Körper ihre Wirkung entfalten und dabei in einem bemerkenswerten Missverhältnis ihrer Menge zu ihrer großen Wirkung zu stehen scheinen.

12 Das auf Pseudo-Demokrits Physika kai Mystika (wohl noch vor Chr.) zurückgehende Diktum natura naturam vincit (Berthelot: Collection des alchimistes grecs [Anm. 9], Bd. 2, S. 41-53, hier S. 43 u.ö.) bringt dies zum Ausdruck.

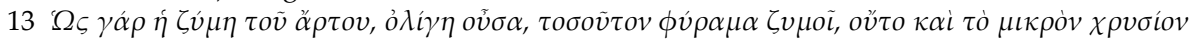

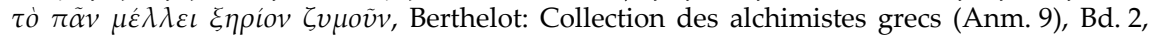
S. 145 (,Wie etwas Hefe den Teig aufgehen lässt, so lässt etwas Goldhefe die Trockenmasse aufgehen"), vgl. ähnlich auch S. 175 und 248 (vgl. auch die Übersetzung Berthelots, Bd. 3, S. 147, 174, 238). S. auch F. Sherwood Taylor: The Alchemists. Founders of Modern Chemistry. New York 1949, S. 36f.; Arthur J. Hopkins: Alchemy. Child of Greek Philosophy. New York 1967, S. 75f.

14 Vgl. einige Stellennachweise bei Lippmann: Entstehung und Ausbreitung der Alchemie (Anm. 10), S. 79f. Vgl. auch S. 68f. u.ö. Außerdem zur Fermentation Jack Lindsay: The Origins of Alchemy in Graeco-Roman Egypt. London 1970, s. Reg. zu ,fermentation'. 
Dem Mittelalter werden die zentralen Konzepte der spätantiken Alchemie über ihre arabische Rezeption zugestellt; die griechischen alchemistischen Handschriften werden erst in der Frühen Neuzeit außerhalb von Byzanz bekannt, dagegen gelangen im Rahmen der Kreuzzüge sowie über Sizilien und auch Spanien nach und nach arabische Handschriften nach Europa und werden übersetzt. So wird etwa der Liber de septuaginta, das Buch der siebzig Bücher, des arabischen Alchemisten Dschabir ibn Hayyan (zweite Hälfte des 8. Jhs.) ${ }^{15}$ in der zweiten Hälfte des 12. Jahrhunderts in Toledo von Gerhard von Cremona übersetzt. ${ }^{16}$ Der bekannteste mittelalterliche Alchemist, der sich in Anlehnung an den Namen Dschabirs hinter dem Pseudonym ,Geber` verborgen hat, kannte diesen Text und konnte sich auf ihn stützen.

Hinter Geber steckt wahrscheinlich ein süditalienischer Franziskanermönch aus der Mitte des 13. Jahrhunderts. ${ }^{17}$ Er spricht im Anschluss an den Liber de septuaginta von den medicinae, mit denen sich die infirmitates der Metalle heilen und diese perfektionieren ließen. ${ }^{18}$ Summa perfectionis magisterii heißt wiederum sein äußerst erfolgreicher Text, an den sich weitere anschließen, deren Zuschreibung zum selben Autor allerdings mit Schwierigkeiten behaftet ist. ${ }^{19}$ Wohl nicht ganz zufällig koinzidiert das Konzept der perfectio unvollkommener Metalle mit den Zielen seines Ordens, das in der perfectio der Gläubigen besteht - frühe Legenden zu Franz von Assisi sind etwa unter dem Titel Speculum perfectionis versammelt worden. ${ }^{20}$ Die alchemistischen Bemühungen des jungen Ordens, inau-

15 Paul Kraus: Jābir ibn Hayyān. Contribution à l'histoire des idées scientifiques dans l'Islam. Jābir et la science grecque. Kairo 1942, Nachdruck Paris 1986. Dazu die Textausgabe von dems.: Jābir ibn Hayyān. Contribution à l'histoire des idées scientifiques dans l'Islam. Volume I. Le corpus des écrits jabiriens. Kairo 1943, Nachdruck Hildesheim u.a. 1989. Hinter vielen dem historischen Dschabir zugeschriebenen Texten scheint sich über Dschabir hinaus ein Kollektiv zu verbergen, das unter seinem Namen ein Schriftenkorpus zusammen geschrieben hat. Das literarische Verfahren, die Texte daraufhin über Querverweise zusammenzubinden und einem Autor zuzuweisen, spiegelt sich im mittelalterlichen Pseudo-Geber-Korpus. Es folgt einem aus der Antike stammenden Usus, zusammen gehörende Wissensbestandteile auf verschiedenen Schriftrollen zu verteilen, um ihre Aneignung zu erschweren und bevorzugt Eingeweihten vorzubehalten.

$16 \mathrm{Zu}$ Gerhard vgl. Richard Lemay: Art. ,Gerhard of Cremona'. In: Complete Dictionary of Scientific Biography. Detroit 2008, Bd. 15, S. 173-192. Der Liber de septuaginta wird hier als Nr. 65 (nach der Zählung Wüstenfelds; Nr. 84 nach der Zählung Sartons) der Übersetzungen Gerhards aufgeführt.

17 So William Newman: New Light on the Identity of Geber. In: Sudhoffs Archiv 69 (1985), S. 76-90.

18 Siehe eine Ausgabe des Liber de septuaginta in Marcellin Berthelot: Archéologie et Histoire des Sciences. Paris 1906, S. 308-363. Vgl. die entsprechende Beschreibungssprache hier auf S. $320 f ., 323$ u.ö.

19 Vgl. Newman in seiner Untersuchung: The Summa perfectionis of Pseudo-Geber. A Critical Edition, Translation and Study by William Newman. Leiden u.a. 1991, Kap. 2.

20 Sie sind aus einem Ordenskonflikt von zelanti gegen solche Brüder hervorgegangen, die sich eher weltlich orientieren (mitigati). Vgl. den Text bei Paul Sabatier: Speculum perfectionis seu S. Francisci Assisiensis legenda antiquissima, auctore fratre Leone. Hrsg. von Paul Saba- 
guriert möglicherweise von dem Ordensgeneral Elias von Cortona, ${ }^{21}$ sind damit offenbar auch auf eine andere Art von perfectio gerichtet, die Naturwirkungen betrifft, und nicht nur auf Ordensmitglieder. Sie will auch natürliche Stoffe zur perfectio führen.

Geber hält sich ziemlich weitgehend an das, was er in einer bemerkenswert gut ausgestatteten Werkstatt selbst ausprobiert haben muss, und er beschreibt Arbeitsverfahren in einer durchsichtigen und nachvollziehbaren Sprache. Bei der Herstellung von tief eindringenden Medizinen, die unedle Metalle und Quecksilber in eine Art Silber und Gold verwandeln, verfährt er allerdings schematisch. Man kann durch Wiederholung der Präparation auch die Güte oder Kraft (und Menge?) der Medizinen, zumal der Medizin zur Goldherstellung erhöhen:

Je öfter die Behandlung wiederholt wird, desto stärker wird das Übermaß [an Wirkung oder Menge?] der Medizin vervielfältigt, und ihre Kraft wird erheblich vermehrt und die Zunahme an Vollkommenheit in höchstem Maße erhöht. (Et quanto huius complementi ordo reiteratur pluries, tanto et huius exuberantia medicine multiplicatur magis, et illius magis augetur bonitas, et multiplicatur illius augmentum perfectionis maxime)..$^{22}$

Geber suggeriert, es gäbe eine bestimmte besonders intensiv präparierte Medizin, in der Schwefel bis in kleine Teile (per minima) mit einer Ausgangssubstanz, die er im Anschluss an die Tradition lapis nennt, feuerbeständig verbunden werden kann.

Die vorsichtige Wiederholung der Behandlung kann die Kraft der Medizin bei der Bereitung des Steins schließlich so weit bringen, dass sie/er [die Medizin/der Stein] schließlich Quecksilber in durch und durch [oder: unendlich viel?] gold- oder silberähnliches Metall umwandelt, wobei dies auf ihrer Multiplikation beruht [gemeint ist die Zahl der Behandlungen]. (Et huic quidem medicine reiteratio bonitatis administrationis cum talis cautele industria potest in praeparatione lapidis evenire, quousque [medicina/lapis, H.H.] argentum mutet vivum [in?] infinitum solificum et verum lunificum, et non dependet nisi in multiplicatione illius). ${ }^{23}$

tier. Paris 1989. Hier wird die perfectio der Minderbrüder in ihrer Armutsnachfolge (S. 40), ihrer heiligen Demut (S. 70, 116) und anderen Ordensidealen propagiert. Sie scheint auch eine Art Kampfbegriff zu werden.

21 Salimbene von Parma berichtet, dass man Elias nachgesagt habe, sich mit Alchemie zu beschäftigen ([...] quod intromitteret se de alchimia; Salimbene von Parma: Cronica. Hrsg. von Oswald Holder-Egger. [MGH SS 32]. Hannover 1913, S. 160) und Kontakt zu allen zu halten, von deren Beschäftigung mit der Alchemie er wusste.

22 Newman: The Summa perfectionis (Anm. 19), S. 586f.

23 Newman: The Summa perfectionis (Anm. 19), S. 588. Ich übersetze: medicinae bonitas. Newman versteht argentum vivum im zitierten Nebensatz als Subjekt des Satzes, vgl. Newman: The 
Das soll wohl heißen, dass die Medizin, je mehr sie durch fortgesetzte Präparation (Lösung und Sublimation) nach innen bzw. bis in immer kleinere Teile perfektioniert wird, so viel perfectio gewinnt, dass sie diese perfectio wieder an das mit ihr behandelte Quecksilber abgeben kann, und zwar bis ins Unendliche.

Die verschiedenen antiken Annahmen über die Grundsubstanz des Goldes sind mittlerweile durch eine Theorie ersetzt worden, nach der Quecksilber diese Grundsubstanz darstellt, da es etwa die Malleabilität (Hämmerbarkeit) des Goldes in besonders hervorstechender Weise besitzt und nur durch eine Reihe von Arbeitsschritten eine neue, festere Konsistenz und Farbe erreichen müsste. Das soll durch die Zugabe von Schwefel geschehen. Das behandelte Quecksilber wird nach Geber aber nicht gleich in sol und luna, also Gold und Silber, sondern in solificum und lunificum verwandelt, es wird gewissermaßen ,solifiziert' und ,lunifiziert', d.h. gold- und silbermäßig gemacht. Hier schwingt wieder der oben angesprochene Vorbehalt mit, von einer besonderen Art Gold und Silber - einer perfekteren womöglich - zu sprechen. Dabei gibt Geber aber die Ausrichtung chemischer Arbeitsvorgänge auf die Gold- und Silberherstellung nicht preis.

In dem zitierten Satz Gebers ist von der Verwandlung des Quecksilbers zur perfectio die Rede, die von einer multiplicatio abhängig sein soll: multiplicatio meint dabei wohl die Vervielfachung der beteiligten, aber immer kleiner werdenden Teile. Geber scheint eine Theorie zu vertreten, nach der Stoffe oder Metalle bis ins Unendliche teilbar sind. Die Natur hat im Erdinnern nur eine besonders weit oder in die Tiefe gehende Vermischung von Teilen erreicht. Im Gold ist die Verbindung von Quecksilber mit Schwefel so fein und subtil und im Bauch der Erde so lange mit der richtigen Wärme durchgekocht, dass sie jede Feuerprobe erfolgreich besteht. Gold wäre also kein irreduzibles Element, sondern ein Misch- oder Verbindungsprodukt, auf das Kräfte nur lange genug und in der richtigen Proportion eingewirkt hätten. Die Skala der perfectio scheint bei Geber entsprechend ins Unendliche zu reichen, je kleiner die Teilchen werden, die sich in der Mischung verbinden. ${ }^{24}$

Summa perfectionis (Anm. 19), S. 768. In Analogie zu einer parallelen Aussage im vorhergehenden Kapitel, nach der Quecksilber in ein corpus lunare transformiert werden kann (Newman: The Summa perfectionis (Anm. 19), S. 585), verstehe ich auch hier das Quecksilber als den Bestandteil, auf den die Medizin angewendet werden soll; als Subjekt wären deshalb medicina oder lapis aus dem übergeordneten Satz zu ergänzen. Diese zentrale Stelle bleibt aber in mehrfacher Hinsicht schwierig und unklar.

24 Eine verwandte, auf die profunditas der Mischung gerichtete Theorie vertritt der pseudoaristotelische und sich in ein Rhazes-Korpus einfügende, möglicherweise (nach der Zuschreibung von Teilen des Textes in einigen Handschriften) aber von Elias von Cortona stammende und Geber bekannte Text De perfecto magisterio. S. den Text u.a. in: Guglielmus Gratarolus: Veræ alchemiæ artisque metallicæ [...] doctrina, [...]. Basel 1561, Bd. 2, S. 188225. Weitere Drucke bei Ferguson: Bibliotheca Chemica (Anm. 4), Bd. 1, S. 42. Nach der eigenartigen Theorie des Textes sind alle Metalle ineinander enthalten, indem sie an dimensionierten Eigenschaften teilhaben, die hervorgekehrt werden können. 
Es wird aus der zitierten Stelle allerdings nicht unmissverständlich klar, ob die ,Solifizierung', wenn sie [in] infinitum erfolgen soll, nur eine immer größere perfectio erreicht oder ob sie eine immer größere Menge hervorbringt. Allemal wird der Begriff der Menge, sobald er auf Stoffe bezogen wird, problematisch, und eine Reflexion auf das Gewicht täte not. Bei einer gleichbleibenden Menge (Volumen) mit einem gleichbleibenden Gewicht kann eine Teilung in immer kleinere Teile sehr wohl ins Unendliche gehen (solange der Gedanke eines Atoms nicht vorhanden ist), und eine fortschreitende Teilung mag dazu führen, dass die ,Kraft' des erreichten Mischungszustandes aus einer immer größeren ,Tiefe' kommt. Dieser Gedanke scheint im Hintergrund der Darstellung Gebers zu stehen. Geber stellt sich die Medizin dann als einen Stoff vor, der zutiefst in Teile geteilt ist und diesen extremen Teilungszustand an andere Metalle weitervermitteln kann. Die Vermehrung der Teile bedeutet dann sehr wohl eine Vermehrung ihrer Zahl, aber keine Vermehrung der Menge (bzw. des Volumens) des Ausgangsstoffs.

In der Geschichte der Alchemie hat diese Unklarheit Spuren hinterlassen, und immer wieder trifft man auf Texte und Stellen, in/an denen anlässlich der multiplicatio von einer Mengenvermehrung die Rede ist (oft heißt es auch augmentatio); selten wird im Übrigen eine Gewichtserhöhung dabei mit thematisiert, obwohl Geber sie schon mit im Auge hat. In oberflächlicher Analogie zur Fermentation lässt sich dies denn durchaus auch so verstehen, dass die Menge des Ausgangsstoffs zunimmt. Eine Beachtung des Gewichtsproblems hätte die Überlegungen indes in eine andere Richtung gelenkt. ${ }^{25}$

Schaut man sich die aus dem Arabischen übersetzten lateinischen Texte an, auf die Geber zurückgegriffen hat, dann wird der Begriff der multiplicatio hier oft in oder durch die Angabe von Zahlenverhältnissen entfaltet, ${ }^{26}$ derart, dass jede weitere Präparation der Medizin eine erhöhte Zahl an Teilen des Metalls verwandelt, auf das sie projiziert wird; sodass ein Teil von ihr 200 Teile eines Metalls färbt, nach einer weiteren Präparation 400 Teile, dann 600 usw.; so nach den Secreta secretorum des arabischen Autors Rhazes (gest. 825). ${ }^{27}$ Danach scheint eine bestimmte - in den Rezepten der Secreta aber unbestimmt bleibende - Menge

25 Gewichtsanalysen mit Bestimmung des spezifischen Gewichts von Metallen als Elementen setzen sich erst Ende des 18. Jahrhunderts durch.

26 Vgl. so im Liber de septuaginta (Anm. 18), S. 362f. Vgl. außerdem Julius Ruska: Al-Razis Buch Geheimnisse der Geheimnisse. Mit Einleitung und Erläuterungen in deutscher Übersetzung von Julius Ruska (Quellen und Studien zur Geschichte der Naturwissenschaften und Medizin, Band 6). Berlin 1937, S. 111, 116, 122, 124 u.ö.

27 Ruska: Al-Razis Buch Geheimnisse der Geheimnisse (Anm. 26), S. 132. Vgl. entsprechende Stellen auch in einer bearbeiteten lateinischen Übersetzung des Secretum secretorum: Julius Ruska: Übersetzung und Bearbeitungen von al-Razis Buch Geheimnis der Geheimnisse. Berlin 1935, S. 31. Nach Ruska (ebd., S. 85-87) ist der Bearbeiter identisch mit dem Verfasser der Summa perfectionis magisterii, also mit dem lateinischen Geber (vgl. auch Newman: The Summa perfectionis [Anm. 19], S. 62f.). Zahlenverhältnisse werden in der Summa sowenig wie in den bearbeiteten Partien des Secretum secretorum beachtet und berücksichtigt. 
des zu projizierenden Pulvers nach weiterer Behandlung eine jeweils immer größere, regelmäßig zunehmende Menge des mit dem Pulver behandelten Metalls oder Materials zu färben. Auch hier schon wird nicht klar, ob das Pulver dabei immer weiter in die Tiefe wirken soll, d.h. ob es sich bei der zunehmenden Menge von gefärbten Teilen um immer kleinere Teile handeln soll. ${ }^{28}$ Vielmehr scheint es, als ob die Menge des zu behandelnden und durch den Veränderungsprozess tangier- und/oder tingierbaren Metalls zunehmen darf/soll.

In einem anderen mittelalterlichen Text, der sich unter die Texte Gebers durch Querverweise einreiht - dem Liber fornacum -, ist anstelle des Begriffs der Medizin denn auch konsequenterweise der des Ferments benutzt. ${ }^{29}$ Das Ferment wirft man auf eine aus den Metallen bereitete Metallpaste, die es daraufhin fermentieren oder gären lässt. ${ }^{30}$ Das ist ein anderes Konzept, und auch die angegebenen stofflichen Bestandteile passen nicht zu den sonstigen Ansichten Gebers. Hier käme die multiplicatio als Gärung oder Fermentation dann dezidiert einer Mengenvermehrung, d.h. eigentlich nur einer räumlichen Vergrößerung mit einer Veränderung der stofflichen Eigenschaften, gleich. ${ }^{31}$ Wo sich dieses Konzept einmischt, gerät eine andere Leitvorstellung ins Spiel, und der Begriff der multiplicatio verliert seine Konturen. Das Konzept der Fermentation konnte man im Mittelalter aber Texten entnehmen, die gleichfalls aus dem Arabischen ins Latein übersetzt worden waren. ${ }^{32}$ Was immer aber jeweils konzeptuell zugrunde liegt, die multiplicatio wird $\mathrm{zu}$ einem oft den Abschluss alchemistischer Texte bildenden Topos und Textelement, und zwar insbesondere dann, wenn diese

28 Eine Reihe von Formulierungen in der Bearbeitung des Secretum secretorum (Anm. 27) weist in diese Richtung, wie auch schon viele Arbeitsschritte darin bestehen, immer kleinere Teile herzustellen. So ist von einem penetrare per minima oder einem introducere tincturas per minimas corporis partes die Rede; es soll eine unio bona et intima herbeigeführt werden, die in die Tiefe (profunditas) geht usw. Von hier dürfte auch De perfecto magisterio (s. Anm. 24) den Begriff der profunditas beziehen.

29 Si vero utrumque opus album et rubeum perficere conaris, utrumque fermentum per se modo iam dictum dissolve et serva. Et est nostrum argentum vivum de argento vivo extractum, quod volumus pro fermento. Pastam vero fermentandum extrahimus more solito ex imperfectis corporibus. [...]. Liber fornacum. In: Guglielmus Gratarolus: Verae Alchemiæ artisque metallicae [...]. Basel 1561, Bd. 1, S. 193-201, hier S. 197.

30 Vgl. dazu die Hinweise von Ernst Darmstaedter in: Die Alchemie des Geber. Übers. und erklärt von Ernst Darmstaedter. Berlin, Heidelberg und New York 1922, S. 180f. Dass der Liber fornacum einem anderen Autor als Geber zuzuschreiben ist, zeigt Newman: The Summa perfectionis (Anm. 19), S. 80f.

31 Was die multiplicatio ist, ist noch in den einschlägigen Nachschlagewerken zur Alchemie unklar. Vgl. z.B. Claus Priesner und Karin Figala: Alchemie. Lexikon einer hermetischen Wissenschaft. München 1998, S. 262, die darunter nur Mengenvermehrung verstehen bzw. angeben.

32 Gärung durch ein fermentum auri wird u.a. in der Turba erwähnt, vgl. Julius Ruska: Turba philosophorum. Ein Beitrag zur Geschichte der Alchemie (Quellen und Studien zur Geschichte der Naturwissenschaften und Medizin, Band 1). Berlin 1931, S. 140 und 169. 
Texte, wie es häufig geschieht, auf ein Rezept für die Herstellung des Elixiers zulaufen. ${ }^{33}$

Das ist etwa der Fall in einem Traktat (De multiplicatione) des Thomas von Aquin, den er auf Bitten seines Privatsekretärs, Reinald von Piperno, verfasst haben soll. ${ }^{34}$ Thomas von Aquin hätte sich allerdings gewiss nicht auf die Arkansprache eingelassen, durch die der Text in hohem Maße geprägt ist. Dieser dürfte vielmehr im 15. Jahrhundert entstanden und wohl nicht ohne eine latente Ironie Thomas zugeschrieben worden sein. $\mathrm{Zu}$ dieser Ironie gehört auch der Umstand, dass die Beziehung des Thomas zu seinem Lehrer Albertus Magnus, der in der Tat hermetische Materialien verarbeitet hat und in dessen Schriften etwa der Name des Hermes fällt, ausgespielt wird. Dem Bruder Reinald wird am Ende von Thomas geraten, sich lieber um sein Predigeramt und das christliche Heil zu bemühen. Dieser ironische Deckmantel wird aber über einen ausgeprägt alchemistischen Text geworfen.

Es werden in De multiplicatione viele Phraseologismen gebraucht, die durch die gesamte alchemistische Literatur laufen, darunter etwa der, dass „unsere ganze Arbeit in nur vier Worten auszudrücken ist, d.h. ein opus mulierum und ludus puerorum darstellt". ${ }^{35}$ Das meint Kochen - und dies mit Ausdauer und Geduld. Der alchemistische Phraseologismus lässt sich bis auf Zosimos zurückverfolgen. ${ }^{36}$ Es ist weiter vom Urin zwölfjähriger Knaben die Rede, von der Jungfrauenmilch und dem Drachenschwanz usw. und immer wieder von unserem Mercurius (Quecksilber), der allein - so die Theorie dieses Textes - zu präparieren sei. Es wird nach einer Anzahl von Verfahrensschritten letztlich ein Amalgam hergestellt; der Begriff fällt denn auch wiederholt. ${ }^{37}$ Dieses Amalgam - wechselweise auch als elixir, medicina oder fermentum bezeichnet, was die konzeptuelle Unschärfe unfreiwillig demonstriert - soll dann als Pulver auf Quecksilber projiziert werden, damit nach anschließender Kochung Gold oder feinstes Silber vorgefunden werden kann. ${ }^{38}$

Der Herstellung des Elixiers aber gilt nach einer Reihe von vorbereitenden Maßnahmen ein Verfahren in drei Schritten, um ihm Eigenschaften mitzuteilen, die es weitergeben können soll. Dieses Verfahren läuft auf eine multiplicatio hinaus. Im ersten Schritt gelangt man so weit, dass „ein Teil unseres Werks sieben

33 Ich gehe im Folgenden nicht auf die von Roger Bacon vertretene Theorie der multiplicatio specierum ein, die einer eigenen Untersuchung bedürfte.

34 Vgl. die Edition des Textes in Dietlinde Goltz, Joachim Telle und Hans J. Vermeer: Der alchemistische Traktat von der Multiplikation von Pseudo-Thomas von Aquin. Untersuchungen und Texte. Wiesbaden 1977.

35 totum opus nostrum stat in quattuor verbis, eo quod est opus mulierum et ludus puerorum; Goltz u.a.: De multiplicatione (Anm. 34), S. 106.

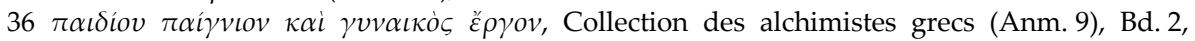
S. 251. Die Vermittlung des Diktums könnte über die Turba philosophorum (Anm. 32), S. 126 (mulierum opus et ludus puerorum) gelaufen sein.

37 Goltz u.a.: De multiplicatione (Anm. 34), S. 112-116.

38 Goltz u.a.: De multiplicatione (Anm. 34), S. 120. 
Teile gut gereinigten Mercurius" färbt (j pars nostri operis vij tingit partes mercurii bene purgati), ${ }^{39}$ d.h. man muss ein vorbereitetes, wahrscheinlich stark goldhaltiges Pulver auf gereinigtes Quecksilber im Verhältnis $1 \mathrm{zu} 7$ projizieren, wobei das Quecksilber erfolgreich (gold)gefärbt wird. Färbung, derentwegen das Elixier auch Tinktur genannt wird, wird in der Alchemie als identifizierende Eigenschaft eines Metalls verstanden.

Ein weiterer Schritt verfeinert nun das im ersten Schritt gewonnene Produkt: Das hier erhaltene Pulver ist schon subtiler, weil stärker digeriert - digestio, ,Verdauung', ist ein sehr verbreitetes mittelalterliches Konzept. Das Pulver soll nun aber noch subtiler werden. Es wird also wiederum auf sieben Teile Quecksilber projiziert und weiter behandelt. Der Verfasser lässt einige Erfahrung mit Arbeitsverfahren erkennen: So soll man es durch ein Leder passieren lassen und im geschlossenen Gefäß bei geringer Wärme lange im Ofen erwärmen usw. Danach - vermutlich ist der Quecksilberanteil dann entwichen - wird es wiederum zu einem Pulver verarbeitet, das nun noch feiner sein soll. „Deshalb tingiert ein Teil [des in diesem zweiten Schritt erhaltenen Pulvers] sieben mal sieben Teile zum Elixier" (Eo quod una pars tingit sepcies septem partes in elixir). ${ }^{40}$ Jetzt besitzt man also ein Pulver, das im Verhältnis 1:49 digeriert.

Im dritten Schritt erhält man ein sehr subtiles Pulver, „von dem eine Unze sieben mal 49 Teile färbt, das sind dreihundert und dreiundvierzig Teile" (quorum [pulveres] uncia 1 tingit partes sepcies xlix, hec sunt ccc et xliij partes). „Der Grund dafür ist folgender: Je mehr unsere Materie digeriert wird, um so feiner wird sie. Und je feiner sie ist, desto mehr vermag sie zu durchdringen und umso mehr färbt sie durch Eindringen" (Racio quia quanto materia nostra plus digeritur, tanto subtilior efficitur, et quanto subtilior tanto penetrabilior et tanto plus ingrediendo tingit). ${ }^{41}$

Nach der zugrunde liegenden Modellvorstellung schreitet die Verfeinerung im Sinne einer arithmetischen Reihe aus Siebenerpotenzen voran. Was als potenzierte Verfeinerung dargestellt wird - im Sinne einer multiplicatio der Wirkung - ist allerdings zunächst einmal einfach eine fortschreitende Verdünnung des Ausgangspulvers; die Behandlungsverfahren wiederholen sich einfach. Dass dabei eine erhöhte Wirksamkeit des Pulvers erreicht werden soll, beruht nur auf der Suggestion der arithmetischen Reihe; die Angabe des Grundes ist gewissermaßen eine Leerbehauptung, die Angabe von Potenzen ein Zahlen-Bluff. Nach dem dritten Schritt macht der Verfasser halt. Wohl weil die Drei ebenso wie die Sieben eine symbolische Zahl darstellt. Das Verfahren ist im Prinzip das selbe wie beim homöopathischen Potenzieren. ${ }^{42}$ Für eine Medizin mag das Potenzie-

39 Goltz u.a.: De multiplicatione (Anm. 34), S. 116.

40 Goltz u.a.: De multiplicatione (Anm. 34), S. 118.

41 Goltz u.a.: De multiplicatione (Anm. 34), S. 118f.

42 Man verschüttelt einen Stoff in einer Lösung und ein Quantum hiervon wiederum in einer Lösung usw. Es ist nicht ausgeschlossen, dass Samuel Hahnemanns Arzneipotenzierung von der multiplicatio abgeschaut ist. 
ren wirksam sein, nicht aber als Amalgamierungsverfahren. ${ }^{43}$ Inwieweit die Verfeinerung immer kleinere oder feinere Teile erzeugen soll, ist nicht ersichtlich. Das Konzept der digestio bedürfte hier zumindest weiterer Entfaltung, um eine Erklärung absehbar zu machen. Wie beim Ferment, bei einer Medizin und bei einem Elixier wird mit diesem erst mittelalterlichen Konzept ein tiefgreifender Wandlungsvorgang verbunden, ohne indes weiter präzisiert zu werden.

Dagegen erweckt die multiplicatio, insbesondere wenn sie über Rechentechniken expliziert wird, leicht den Eindruck zahlenmäßiger Präzision. So wird sie in der Alchemie der Frühen Neuzeit gern und oft herangezogen; eine charakteristische Darstellung findet sich in der Erklärung des prominenten Adepten Nikolas Flamel zu sog. hieroglyphischen Figuren, die sich u.a. am Giebel zum Toreingang eines Pariser Friedhofs befunden haben sollen. ${ }^{44}$ Der Livre des figures hiéroglyphiques stellt den höchst originellen Versuch dar, in ein christliches Bildprogramm einen verborgenen, angeblich alchemistischen, Sinn hineinzudeuten und einen alchemistischen Text daraus herauszuspinnen. ${ }^{45}$ Im vorletzten Kapitel, vor der endgültigen Gewinnung des Elixiers, stellt (Pseudo-)Flamel nach dem Vorgang vieler anderer Texte die multiplicatio dar.

[...] so ofte du solviren [Lösen] und figiren [Fest-Machen] wirst, so oft wirst du diese Naturen [d.h. hier eigentlich die Eigenschaften oder Aggregatzustände des den Behandlungen unterworfenen Materials; auch wohl: Teile] in der Menge oder Grósse, Gestalt und Tugend Multipliciren, nemlich nach der zehenden Zahl zur multiplication oder Vermehrung, und von dieser Zahl zu hundert, von hundert zu tausend, von tausend $\mathrm{zu}$ zehen tausend, von zehen tausend auf hundert tausend, von hundert tau-

43 Vgl. Goltz u.a.: De multiplicatione (Anm. 34), S. 51, mit einer Rekonstruktion des Verfahrens.

44 Der historische Nikolas Flamel (1330-1418) könnte die Darstellungen auf dem Giebelfeld des Toreingangs zum Cimetière des Innocents gestiftet haben. Sie sind nicht erhalten, aber auf einem Kupferstich im Livre des figures hiéroglyphiques wiedergegeben. Der Livre, in dem Flamel diese Darstellungen (angeblich) kommentiert, dürfte indes wohl erst Ende des 16./Anfang des 17. Jahrhunderts entstanden und dem historischen Nikolas Flamel fiktiv zugeschrieben worden sein. Zu den Drucken (ab 1612) s. Ferguson: Bibliotheca Chemica (Anm. 4), Bd. 1, S. 249f. Zu (Pseudo-)Flamel vgl. Jacques van Lennep: Alchimie. Contribution à l'histoire de l'art alchimique. Brüssel 1985, S. 256-262; außerdem insbesondere JeanMichel Varenne: Nicolas Flamel. Son histoire, sa personalité, ses influences. Paris 2001. Man hat schon im 18. Jahrhundert Zweifel an der Verfasserschaft des historischen Flamel, s. Johannes Franz Buddeus: Historisch- und politische Untersuchung von der Alchemie und was davon zu halten sey? In: Friedrich Roth-Scholtz: Deutsches Theatrum chemicum. Nürnberg 1728, Nachdruck Hildesheim, New York 1976, Bd. 1, S. 1-146, hier §34.-Nach dem Kupferstich im Livre des figures hiéroglyphiques (vgl. unten Anm. 47) stellte das Giebelfeld über dem Stifterbild den Kindermord in Bethlehem durch Herodes (Mt 2,16-18) dar und darüber Paulus und Petrus, die eine Darstellung Gottes flankieren. Eine erkennbare alchemistische Bedeutung besitzt das Bildprogramm nicht.

45 Während z.B. die sog. Christus-Lapis-Parallele nur die konnotative Gleichung ,Kochen (des materiellen Substrats) = Quälen (Christi)` ausspielt, wird bei (Pseudo-)Flamel das christliche Bildprogramm des Torbogens als alchemistische Allegorie ausgelegt. 
send zur Million oder tausend mahl tausend; und von dannen durch ebenmåssige Operation biß auf unendliche Zahl, wie ich dann selbsten zu dreyen mahlen, Gott sey Lob, solches versucht und gethan habe. Und wenn nun dein Elixir auf diese Weise zur Unendligkeit wird gebracht seyn, so wird ein Gran oder Gersten-Korn schwer desselben, wenn es ůber eine geflossene Metallische Quantităt [geworfen wird], ob sie auch gleich so groß und tief wăre, wie der Ocean, oder grosse Meer, ${ }^{46}$ solche in das aller vollkommenste Metall, das ist, in Silber oder Gold, nachdem es imbibiret oder fermentiret worden, tingiren und verwandeln, auch alle Unsauberkeit, und fremde Materie so sich demselben in der ersten coagulation gesellet, von sich vertreiben und zurücke lassen. ${ }^{47}$

Das Zitat lässt neben der Zahlenspielerei Präzision vermissen - ob die Teilung ins Unendliche geht oder eine Mengenvermehrung statthat, wird kaum deutlich -, es lässt dagegen Hyperbolik anklingen und es demonstriert eine gewisse Bereitschaft zum Fabulieren: Die Fremd- oder Selbstbezeugung der Durchführung einer oder mehrerer Transmutationen gehört zu der in der Frühen Neuzeit weit verbreiteten Gattung der Transmutationserzählungen. ${ }^{48}$ (Pseudo-)Flamel schickt eine solche Erzählung seiner Erklärung der hieroglyphischen Figuren voraus. Die dargestellte multiplicatio schreitet bei ihm dann in Zehnerpotenzen voran. Wenn aber davon die Rede ist, die Naturen in der Menge oder Grosse, Gestalt und Tugend zu multiplizieren, so werden diese unterschiedlichen Faktoren der multiplicatio allesamt zusammengeworfen.

46 Die Formulierung scheint auf eine Stelle aus der Turba (Anm. 32), S. 119 (s. dazu auch die Anm. Ruskas auf S. 189), zurückzugehen.

47 Ich zitiere: Des berühmten Nicolai Flamelli Chymische Werke [...]. Wien 1751, S. 41-88 (der Kupferstich nach S. 40), hier S. 84f. Der Erstdruck (P. Arnauld: Trois Traictez de la Philosophie naturelle [...]. Paris 1612, S. 45-88; Nachdruck in: Claude Gagnon: Description du Livre des Figures Hiéroglyphiques attribué à Nicolas Flamel, suivie d'une réimpression de l'édition originale et d'une reproduction des sept talismans du Livre d'Abraham authentique dudit Flamel. Montréal 1977) hat auf S. 85 folgenden Wortlaut: Car tout autant de fois que tu dissoudras \& fixeras, autant de fois ces natures multiplieront en quantité, qualité \& vertu selon la multiplication de dix, de ce nombre venant à cent, de cette à mille, de mille à dix mille, de dix mille, à cent mille, de cent mille à un million, $\mathcal{E}$ de là par mesme operation iusque à l'infini, ainsi que i'ay faict trois fois, Loüé soit Dieu. Et quand ton Elixir est ainsi conduit à l'infini, vn grain d'iceluy tombant sur une quantité metallique fondue, aussi profonde \& vaste que l'Ocean, il le teindra et conuertira en tres parfaict metal, c'est à dire, en argent ou en or, selon qu'il esté imbibé \& fermenté, chassant $\mathcal{E}$ laissant loin de soy la matiere impure $\mathcal{E}$ estrangere qui s'estoit iointe en sa premiere coagulation.

48 Vgl. Siegmund Heinrich Güldenfalk: Sammlung von mehr als hundert wahrhaften Transmutationsgeschichten. Frankfurt a.M., Leipzig 1784. Vgl. weitere Beispiele auch bei Joachim Telle: Alchemie und Poesie. Deutsche Alchemikerdichtungen des 15. bis 17. Jahrhunderts. Untersuchungen und Texte. 2 Bde. Berlin, Boston 2013, Bd. 2, S. 867. 
Dies ist nicht immer der Fall, und gelegentlich wird die multiplicatio der Kraft und der Menge sehr wohl auseinandergehalten, so etwa in der Philosophia reformata des Johannes Daniel Mylius:

Auf zwei Weisen kann die Medizin multipliziert werden: Erstens durch die Lösung und wiederholte Koagulation, und dies ist ihre multiplicatio hinsichtlich ihrer Kraft und Güte. Zweitens durch Gärung, und dies ist ihre multiplicatio hinsichtlich der Menge (Quantität). Schneller wirst du aber die Vermehrung durch Gärung vollenden, denn mit der Lösung lässt sich nicht gut arbeiten, wenn sie nicht zuerst in ihrem Ferment gärt. Vollkommener dagegen wird unsere Medizin durch Lösen und Hochtreiben vervielfacht. Auf diese Weise wird sie verfeinert (spiritualisch), und nach der ersten Lösung, Hochtreibung und Koagulation fällt ein Teil in der ersten Projektion (erfolgreich) auf hundert Teile, in der zweiten auf tausend Teile und so lässt sich weiter verzehnfachen, je durch weiteres Hochtreiben bis ins Unendliche - was die allerwertvollste Gabe Gottes ist. (Duobus autem modis multiplicari poterit medicina. Primo per solutionem et reiteratam coagulationem, et haec est eius multiplicatio virtualis in bonitate. Secundo per fermentationem, et haec est eius multiplicatio in quantitate. Citius autem augmentationem per fermentationem perficies, eo quod soluta non bene operatur, nisi prius figentat [fermentat? H.H.] in suo fermento. Perfectius ergo per solutionem et exaltationem nostra medicina multiplicatur, et hoc modo spiritualia, et post primum solutionem, exaltationem, et coagulationem pars vna in prima proiectione cadit super 100 . secunda super 1000. et sic vlterius decuplare, semper exaltando vsque in infinitum, quod preciosissimum est Dei donum). ${ }^{49}$

Bei Mylius wird klar, dass die multiplicatio virtualis in bonitate eine in Zehnerpotenzen voranschreitende Verfeinerung darstellen soll, die bis ins Unendliche fortgesetzt werden kann, und keine Vermehrung der mengenmäßigen Quantität. Deutlich wird auch, dass der dem Quecksilber zuzusetzende Schwefel nicht wieder flüchtig werden darf und deshalb die Verbindung zu einer solchen Verfeinerung getrieben werden soll, dass sie unauflöslich erscheint. Unabhängig davon kann es auch eine Mengenvermehrung im Sinne der Gärung geben.

Entfesselte Schreibweisen lassen in der Frühen Neuzeit überlieferte Darstellungsformen aufbrechen und zu eigenen textuellen Formen herauswachsen. Sie kippen oftmals zur Verspoesie, wie denn alchemistische Lehrdichtungen schon

49 Johannes Daniel Mylius: Philosophia reformata. Frankfurt a.M. 1622, S. 132f. Die viel abgebildeten Kupferstiche der Philosophia reformata kehren wieder im Chymischen Lustgärtlein von Stoltzius von Stoltzenberg, Frankfurt a.M. 1624, Nachdruck Darmstadt 1975, hier als vierter zusammenhängender Zyklus mit den Nrn. 33-60. Der der multiplicatio gewidmete Stich, auf den ich hier nicht eingehe, ist die Nr. 38. Die Stiche der Philosophia reformata werden bei John Read: Prelude to Chemistry. An Outline of Alchemy, its Literature and Relationsships. New York 1937, S. 260-273, diskutiert. 
in der Antike in Verse gegossen werden, in ein Fabulieren übergehen und die kunstvoll geprägten Decknamen und Phantasiebegriffe zu Chiffren gewendet erscheinen. ${ }^{50}$ Vom alchemistischen Prozess her wird in der Frühen Neuzeit indes auch auf den Menschen, den Kosmos und die Heilsgeschichte übergesprungen, ${ }^{51}$ und der Prozess bedeutet auf einmal viel mehr als nur ein handwerkliches Verfahren. Dieses verliert sich ggf. zugunsten einer theosophischen Umdeutung. Die Alchemie des Mittelalters wird entsprechend überformt und verallgemeinert, sodass eine breit ausladende Naturphilosophie daraus hervorgeht, die mit jüdischer und christlicher Theosophie zusammenläuft. ${ }^{52}$

Der Text, der im Folgenden im Zentrum stehen soll, ist weitgehend allein aus der multiplicatio herausgesponnen und versucht ihr in jenem aufgesprengten naturphilosophischen Feld einen neuen Sinn zu geben. Es handelt sich um den Vorbothen der am philosophischen Himmel hervorbrechenden Morgenröthe (Amsterdam 1703) des Johannes de Monte Raphaim. ${ }^{53}$,De Monte Raphaim' heißt ,vom Berg der Raphaim' - die Raphaim oder Rephaim sind Einwohner aus einer bestimmten Region Israels aus vorhistorischer Zeit. Zum Autor, der zu den sich in Amsterdam aufhaltenden Juden gehören dürfte, gibt es keinerlei Nachrichten, und es gibt sonst nur wenige Hinweise zur Druckgeschichte seines Textes. ${ }^{54}$

50 In Byzanz gibt es erstmals alchemistische Lehrdichtungen: Heliodori carmina quattuor ad fidem codicis Casselani. Hrsg. von Günther Goldschmidt. In: Religionsgeschichtliche Versuche und Vorarbeiten. Gießen 1923, Band 19, Heft 2, S. 1-59. Vgl. auch Herbert Hunger: Die hochsprachliche profane Literatur der Byzantiner. Zweiter Band. Philologie - Profandichtung - Musik - Mathematik und Astronomie - Naturwissenschaften - Medizin - Kriegswissenschaft - Rechtsliteratur. München 1978, S. 280. Den Bestand frühneuzeitlicher Lehrdichtungen hat Joachim Telle (Anm. 48) in einem Lebenswerk umrissen.

51 Das wird deutlich etwa im Wasserstein der Weisen (zuerst 1619), wenn es z.B. heißt: Wie nun dieses im Chymischen Werck / sage ich / geschicht [sc. die Bereitung der Tinktur] / vnd geschehen muß: Also auch allhier in vnserm Theologischen Werck der geistlichen Ernewerung vnd himmlischen Wiedergeburt deß Menschens / wohl in acht muß genommen werden. Johannes Ambrosius Siebmacher: Wasserstein der Weisen. Frankfurt a.M. 1661, Nachdruck Freiburg 1977, S. 95. Vgl. eine noch weiter gehende Umdeutung der Alchemie z.B. bei John Pordage: Philosophisches Sendschreiben vom wahren Stein der Weisheit. In: Roth-Scholtz: Deutsches Theatrum chemicum (Anm. 44), Bd. 1, S. 569-589. S. weitere Hinweise in Anm. 80.

52 Eine adäquate Überblicksdarstellung ist ein Desiderat. Materialien dazu etwa bei Will-Erich Peuckert: Pansophie. Ein Versuch zur Geschichte der weißen und schwarzen Magie. Berlin 31976; Antoine Faivre: Accès de l'ésotérisme occidental. Paris 1986; Gershom Scholem: Die jüdische Mystik in ihren Hauptströmungen. Frankfurt a.M. 1980. Vgl. viele Hinweise auch bei Wilhelm Schmidt-Biggemann: Geschichte der christlichen Kabbala. Bd. 1. 15. und 16. Jahrhundert. Stuttgart, Bad Cannstatt 2012; Bd.2. 1600-1660. Stuttgart, Bad Cannstadt 2013; Bd. 3. 1660-1850. Stuttgart, Bad Cannstadt 2013.

53 Johannes de Monte Raphaim: Vorbothe der am philosophischen Himmel hervorbrechenden Morgenröthe. Amsterdam 1703. Vgl. ein Digitalisat der Erstausgabe aus der Universitätsund Landesbibliothek Sachsen-Anhalt unter der URL: http://digital.bibliothek.uni-halle.de/ hd/content/titleinfo/26112 (28.11.2014).

54 Ferguson: Bibliotheca Chemica (Anm. 4), Bd. 2, S. 103f. 
Wahrscheinlich bedient Johannes sich eines Pseudonyms. ${ }^{55}$ Auffällig ist der Titel seines Textes (besonders in Bezug auf die Morgenröthe). Ein alchemistischer Cento wohl aus dem 13. Jahrhundert führt den Titel Aurora sive aurea hora oder Aurora consurgens (nach Hohelied 6,9), eine Reihe von Paracelsica führt gleichfalls ,Aurora' im Titel, ${ }^{56}$ und natürlich ist dann auch an Jacob Böhmes Aurora oder Morgenröthe im Aufgang aus dem Jahr 1612 zu denken. Im alchemistischen Kontext ist die Morgenröte auf die letzte Station der Herstellung des Elixiers zu beziehen, als Vorbote wird bei Johannes also wohl die diesem Verfahrensschritt in der Regel vorausgehende Durchführung der multiplicatio verstanden. Da er allerdings einen philosophisch gewendeten Text verfasst, bricht die Morgenröte am philosophischen Himmel hervor.

$\mathrm{Ab}$ der zweiten Hälfte des 17. Jahrhunderts versammeln sich viele BöhmeAdepten, aber auch andere paracelsistisch und theosophisch inspirierte Intellektuelle in Amsterdam, ${ }^{57}$ wo der Vorbothe der am philosophischen Himmel hervorbrechenden Morgenröthe 1703 zum ersten Mal gedruckt wird.58 Johannes de Monte Raphaim dürfte einem vergleichbaren Kreis angehört haben. Nach dem Erstdruck wird der Text im 18. Jahrhundert noch wiederholt nachgedruckt, ${ }^{59}$ so von Friedrich Roth-Scholtz 1728 in seinem Deutschen Theatrum Chemicum, aber auch später noch. ${ }^{60}$ Die Rezeption reicht noch bis in die Zeit der Aufklärung.

Johannes seinerseits führt eher beiläufig Nikolaus Flamel als alchemistischen Adepten an, von dem er sich aber distanziert. ${ }^{61}$ Daneben zitiert er aus dem Gul-

55 Emil Weller: Lexicon pseudonymorum. Nachdruck der zweiten Auflage Regensburg 1886. Nachdruck Hildesheim 1963, S. 369, führt den Namen unter den Pseudonymen auf.

56 S. schon Hermann Kopp: Die Alchemie in älterer und neuerer Zeit. Ein Beitrag zur Kulturgeschichte. Zweiter Theil: Die Alchemie vom letzten Viertel des 18. Jahrhunderts an. Heidelberg 1886, S. 389. Zu der von Gerhard Dorn - wohl fiktiv - dem Paracelsus zugeschriebenen Aurora s. Dorns Brief an Samuel Siderocrates, in: Der Frühparacelsismus. Zweiter Teil. Hrsg. und erläutert von Wilhelm Kühlmann und Joachim Telle (Corpus Paracelsisticum, Band II). Tübingen 2004, S. 906-910, mit der Erläuterung auf S. 911.

57 Ferdinand van Ingen: Böhme und Böhmisten in den Niederlanden. Bad Honnef 1984; Theodor Harmsen: Jacob Böhmes Weg in die Welt. Zur Geschichte der Handschriftensammlung, Hrsg. von Theodor Harmsen. Übersetzungen und Editionen von Abraham Willemsz van Beyerland. Amsterdam 2007, S. 457-483.

58 In den einschlägigen Arbeiten und Namenlisten ist der Name nicht dingfest zu machen, was - wenn es sich um ein Pseudonym handelt - nicht verwundert. Das gute Deutsch des Vorbothen lässt auf einen Deutschen als Verfasser, die Nennung von Saltz / Scheffel und Mercur (Johannes de Monte Raphaim: Vorbothe [Anm. 53], S. 46) auf einen Paracelsisten schlieBen.

59 Zwei Drucke werden nachgewiesen bei Ferguson: Bibliotheca Chemica (Anm. 4), Band II, S. 103f.; Kopp: Die Alchemie (Anm. 56), S. 389, nennt einen weiteren Druck.

60 Roth-Scholtz: Deutsches Theatrum chemicum (Anm. 44), Band 1, S. 597-637; später u.a. im Hermetischen Museum. Reval, Leipzig 1782, S. 65-110.

61 Flamel setze sich von allen, die unedle Metalle als Ausgangsmaterial verwendeten, ab und empfehle nur Gold selbst als Stoff, mit dem man arbeiten müsse (vgl. Johannes de Monte Raphaim: Vorbothe [Anm. 53], S. 24). Dagegen favorisiert Johannes die Suche nach einem Tinctur-Wesen ex Centro Macrocosmico (Johannes de Monte Raphaim: Vorbothe [Anm. 53]), 
denen Kalb (Vitulus aureus) des Johannes Friedrich Helvetius (zuerst 1667), einer besonders prominenten Transmutationserzählung. ${ }^{62}$ Helvetius indes verstehe selbst nicht, was er geschrieben habe. ${ }^{63}$ Gewichtiger ist der Bezug auf Aegidius Gutmanns Offenbarung göttlicher Majestat (1619, verfasst vielleicht um 1575). ${ }^{64}$ Dies ist eine in zwei dicken Bänden weit ausgreifende physiko-theologische Auslegung des Schöpfungsberichts aus dem ersten Buch Mose, die die Bestimmung der im Schöpfungsbericht genannten Größen mit der Elementenlehre sowie mit ausgebreiteten Kenntnissen alchemistischer Verfahrensweisen und chemischer Stoffe verschränkt. Auf charakteristische Weise werden dabei etwa die Rolle von Wasser und Licht metaphorisch überdehnt. Wasser ist alles, was flüssig ist, Licht wirkt als verborgenes Licht noch bis in Geist und Materie hinein. ${ }^{65}$

Johannes beruft sich auf Gutmanns Ansicht, daß das gemeine Gold voll Lichts und Finsternüs sey und man nur die Finsternis vom Licht scheiden müsse, d.h. die unreinen Teile der Metalle aussondern müsse, damit das gantze Gold zu einem rothen / Krystallischen geistlichen Corper werde. ${ }^{66}$ Hiermit habe man dann Gold

d.h. er betreibt eine makroskosmische Verallgemeinerung.

62 Helvetius, bzw. sein Gesprächspartner, nenne im Guldenen Kalb (Johannes Friedrich Helvetius: Guldenes Kalb [...]. Nürnberg 1668) das Salz als Ausgangsmaterie der Tinktur. (vgl. Vorbothe [Anm. 53], S. 25). Tatsächlich führt ein Adept Helvetius die Verwandlung von Blei in Gold mittels eines Elixiers vor Augen - es handelt sich um eine Transmutationserzählung - und verschwindet dann für immer. Auf die Frage nach der Ausgangsmaterie antwortet der Adept: Das Menstruum ist ein himmlisches Sal oder von himmlischer Tugend/ mit welchem die Philosophi das irrdene Corpus metallicum allein solviren/ und in der solution wird das kostliche Philosophische Elixir herausgezogen. Ich zitiere den späteren Druck: Johannes Friedrich Helvetius: Vitulus aureus [...]. Frankfurt 1726, S. 32.

63 Johannes de Monte Raphaim: Vorbothe (Anm. 53), S. 25.

64 Aegidius Gutmann: Offenbarung göttlicher Majestat [...]. Hanau 1619. Der Text ist anonym erschienen, zu Beginn der Praefatio ad lectorem nennt der Herausgeber allerdings Aegidius Gutmann als Verfasser und bezieht diese Kenntnis nach eigenem Eingeständnis aus Julius Sperber: Echo der von Gott hocherleuchteten Fraternität des löblichen Ordens R. C. Dantzig 1616, S. 12f. (in der Ausgabe von 1615 findet sich der Gutmann betreffende Passus auf S. 27f.). Als Datum der Niederschrift versteht der Herausgeber das in Bd. 1 auf S. 18 genannte Jahr 1575. - Zu der aus der Tradition der Genesiskommentare hervorgehenden breit ausladenden Literatur zur Physica Mosaica in der Frühen Neuzeit vgl. die Hinweise von Wilhelm Kühlmann in: Der Frühparacelsismus (Anm. 56), S. 944f.

65 Wasser wird bei Gutmann: Offenbarung göttlicher Majestat (Anm. 64) im ersten Buch, Licht im 15. und 16. Buch behandelt. Entsprechende Überdehnungen sind auch schon für Paracelsus charakteristisch.

66 Johannes de Monte Raphaim: Vorbothe (Anm. 53), S. 31. Im 31. Kapitel des 19. Buchs behandelt Gutmann z.B. die Frage Wie man die Finsternusse von einem jeglichen Baum / Holtz / Kraut / Erdgewåchs vnd Thier Scheiden möge / dass man das liechte wesen so Gott der HERR darein gelegt hat / herauß bringen / sehen / behalten / vnd brauchen mo̊chte? (Bd. 2, S. 381). Berührungen mit dem Paracelsismus liegen bei Gutmann auf der Hand. Besonders ist an Gerhard Dorn zu denken, der zur selben Zeit und durch Marsilio Ficino beeinflusst eine Art von Lichtmetaphysik entwickelt. Vgl. die Hinweise von Wilhelm Kühlmann in: Der Frühparacelsismus (Anm. 56), S. 904f. An derartige Positionen kann Johannes de Monte Raphaim anknüpfen. 
aus seiner Art gebracht und $\mathrm{zu}$ einer Tinktur bereitet, die als Universaltinktur alles, worauf sie angewendet werde, verwandele. ${ }^{67}$ Gold erscheint dabei als ein hypothetischer Stoff, der bis ins Unendliche verfeinerbar ist - es gibt úbervollkommnes Gold ${ }^{68}$-, das dann ungeahnte physikalische, aber auch medizinische Wirkungen entfalten kann. Dazu muss aber eine Multiplikation eingetreten sein, deren rechnerische Gestalt anzugeben Johannes sich bemüht. ${ }^{69}$ Der durch den Text laufende Grundgedanke einer ins Unendliche reichenden Perfektionierung ist schon bei Geber angelegt, auch die Annahme einer im Innern der Erde vorfindlichen Substanz, die den gewünschten Zustand schon erreicht hat. Will man sie künstlich erzeugen, so muss man den Herstellungsprozess der Natur nachahmen. Als Elementarprozess kann das Hervorgehen der Elemente auseinander gelten. Dabei soll die Tinktur entstehen:

GOtt aber hat ein Ding geschaffen / welches auch in dem Golde ist / das geringer geachtet wird als Gold / nemlich rothe Erde / und das ist die Tinctur! Aber wie kommt man zu dieser tincturalischen Krafft-Erde? Antwort: das Gold muß zu nicht Gold / das Leben geto̊dtet / das Feur zu Wasser / aus Wasser die Erde durchs Feur zur Lufft werden. ${ }^{70}$

Johannes bedient hier die Sprache der Alchemie, die die Veränderbarkeit/Übergänglichkeit des über dem Feuer im Destillierkolben eingeschlossenen stofflichen Substrats konventionell über die Bildung von Negationen und Oppositionen wiedergibt sowie als durch die Zirkulation der Elemente - als Wechsel von Aggregatzuständen desselben Substrats - zustandegekommen versteht.

Die Universaltinktur bildet den Kernprozess des Kosmos wie aber auch des Geistes. Die Projektion auf den Geist kündigt schon die voranstehende Reimversansprache an die wahren Weißheits-Kinder an, die eine umfangreiche Sammlung von alchemistischen Topoi zum mit dem Mercurius identifizierten Stein reiht, ihn aber auch als selbstreferentiellen Prozess des Geistes fasst:

Merckt / und verstehet recht / was hier wird angedeutet

Und daß man nur allein durch Gleichnůß euch anleitet /

GOtt aber gibt den Geist zur Weisheit und Verstand

Dahin geht eur Gemùth / dahin streckt eure Hand

Die Nahmen dieses Dings die sind nicht zu erzehlen

Habt ihr es dann erkannt so mo̊gt ihr selbst erwehlen

Wie ihr es heissen wollt [...]. ${ }^{71}$

67 Johannes de Monte Raphaim: Vorbothe (Anm. 53), S. 30.

68 Johannes de Monte Raphaim: Vorbothe (Anm. 53), S. 18.

69 Johannes de Monte Raphaim: Vorbothe (Anm. 53), S. 14, bezieht er sich auf verschiedene vorliegende Berechnungen der Multiplikationswirkung.

70 Johannes de Monte Raphaim: Vorbothe (Anm. 53), S. 30, siehe auch unten.

71 Johannes de Monte Raphaim: Vorbothe (Anm. 53), S. 7. In Telles (Anm. 47) umfangreicher Zusammenstellung und Behandlung alchemistischer Lehrdichtungen ist die Versansprache 
Johannes skizziert in seinem Vorbothen eine Reihe von übergreifenden Konzepten: ${ }^{72}$ eine Vier-Reiche-Lehre mit dem astralischen, animalischen, vegetabilischen und mineralischen Reich - Paracelsus hatte der traditionellen Drei-Reiche-Lehre bereits einen astralischen Gegenpart hinzugefügt -, in denen ursprünglich eine Universaltinktur wirksam gewesen sei, die sich aber in den am weitesten verfeinerten Vertretern dieser Reiche spezialisiert und ausgesondert habe: nämlich in der Sonne, dem Menschen, dem Wein und dem Gold. Daneben setzt er eine siebentausendjährige Geschichte an, die nach sechstausend Jahren auf einen großen Sabbat zuläuft, in dem alles sieben Mal herrlicher, kräftiger und schöner erscheinen wird. Hat sich bis dahin alles in die Peripherie verlagert, so wird dann alles wieder im Centrum Divinum versammelt. Bezogen aufs Gold heißt das, dass es in sieben Rotationen verfeinert wird. Hat schon die Natur das Gold mithilfe einer im Bauch der Erde liegenden sehr subtilen Tinktur tingiert, so muss man nur wissen, wie sie das angestellt hat, um es mithilfe der Kunst wiederholen zu können, ggf. auch schon vor dem großen Sabbat.

Nach Johannes kann man das Gold nicht nur perfect, sondern plusquamperfect machen und die Perfektion und Multiplikation bis ins Unendliche treiben - sowohl nach seinem Gewicht als Qualităt. ${ }^{73}$ Man zieht dazu nur die Tinktur aus dem gemeinen Gold aus (impliziert ist dabei: ,unser' noch herzustellendes Gold ist besser als das gemeine). Von irgendwelchen Arbeitsverfahren ist hier allerdings nicht die Rede: Johannes legt keinerlei Wert auf praktische Kenntnisse und rezeptartige Ausführungen. Hat man die Tinktur aus dem gemeinen Gold ausgezogen, dann wendet man einen Teil auf 24 Teile (einer Unze) Goldes an. Gelingt es einem,

diese Tinctur in dem Leibe des Goldes nur einmahl zu vermehren / so wird unfehlbahr dieses erhơhete oder tingierte Gold noch vier und zwantzig Theil Silbers Zusatz bey den [richtig: leiden?] und zum besten Golde machen; und wo du dieses siebenmahl wiederholest / und durch die erste grosse Rotation fủhren kanst / so wirst du befinden- / daß bei Beschluß der ersten grossen Rotation ein Theil 1536. in der andern / 196608. und bey der dritten 25185824 . Theile tingiren werde. ${ }^{74}$

des Johannes unberücksichtigt geblieben.

72 Dem Text steht ein Titelkupfer voran, das zentrale alchemistische Konzepte in einem Ternar, Quaternar und Kreis anordnet, darüber die geflügelte Weisheit mit einem Schlüssel zum Verschließen und einem zum Öffnen sowie einem Stab mit Doppelschlange. - Der Beschluss des Textes wird durch einen Anhang etlicher Lehr-Sätze vor die Schuler der Weißheit gebildet.

73 Johannes de Monte Raphaim: Vorbothe (Anm. 53), S. 15. Die oben aufgezeigte Unschärfe im Begriff der Multiplikation tritt hier wieder hervor.

74 Johannes de Monte Raphaim: Vorbothe (Anm. 53), S. 20. Die Angabe zur dritten Rotation ist fehlerhaft, auch im folgenden Text; es muss lauten: 25.165.824. Der Fehler wird im Nachdruck von Friedrich Roth-Scholtz: Deutsches Theatrum chemicum (Anm. 44), Bd. 1, S. 612, korrigiert. 
Dies wiederholt sich sieben Mal. Die Reihen und Rotationen des Johannes schreiten nicht in Siebenerpotenzen voran, sondern in Summanden, die jeweils mit sich selbst addiert werden. Jede Siebenerreihe nennt er eine Rotation, die er in eine geschweifte Klammer fasst:

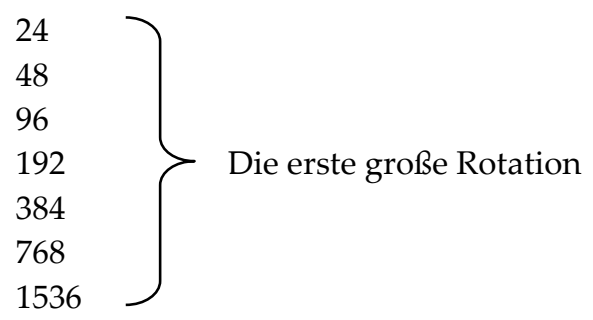

Es ist eine Seitenbeobachtung wert, wenn auch in Quirinus Kuhlmanns wenige Jahre zuvor gleichfalls in Amsterdam (1684) erschienenem Kühlpsalter geschweifte Klammern verwendet werden, als Kuhlmann sein im Sinne seiner Privatmythologie bedeutsames virmahlsibnes Jahr beschwört (V. 5760f.): ${ }^{75}$

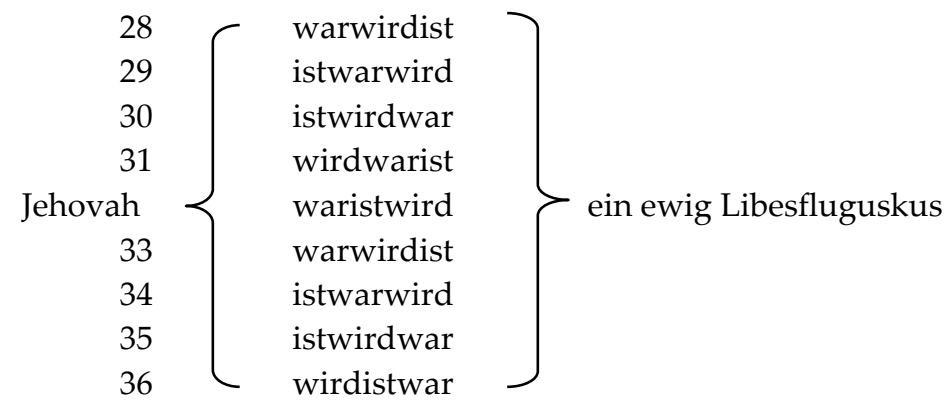

Bei Kuhlmann geht es dabei um eine Vergangenheit, Gegenwart und Zukunft überbrückende heilsgeschichtliche Konstruktion, die er seinem Kühlpsalter einschreibt. Es ist auffällig, wie hier numerologische Spekulation, sprachliche Kombinatorik und graphische Repräsentation ähnlich wie bei Johannes de Monte Raphaim zusammenlaufen. ${ }^{76}$ Es gibt einen gemeinsam geteilten intellektuellen

75 Quirinus Kuhlmann: Der Kühlpsalter. Hrsg. von Robert L. Beare. 2 Bde. Tübingen 1971, Bd. 1, S. 198. Vgl. dazu Harald Haferland: Heilsbedeutung und spekulative Alchemie. Böhme-Rezeption bei Quirinus Kuhlmann. In: Offenbarung und Episteme. Zur europäischen Wirkung Jakob Böhmes im 17. und 18. Jahrhundert. Hrsg. von Wilhelm Kühlmann und Friedrich Vollhardt. Berlin, Boston 2012, S. 143-164.

76 Geschweifte Klammern dienen grundsätzlich als graphisches Mittel der Gruppierung. Kuhlmann könnte durch ihren Gebrauch bei Lullus (vgl. dazu die Hinweise bei Erhard Wolfram Platzeck: Raimund Lull. Sein Leben - Seine Werke - Die Grundlagen seines Denkens. 2 Bde. Düsseldorf 1962, Bd. 1, S. 128 u.ö.) angeregt worden sein. Vgl. auch Thomas Leinkauf: Der Lullismus. In: Grundriss der Geschichte der Philosophie. Die Philosophie des 17. Jahrhunderts. Band 4. Das Heilige Römische Reich Deutscher Nation. Nord- und Ostmit- 
Hintergrund, aber auch erschlossene mediale Möglichkeiten des Buchdrucks, die derartige Darstellungen möglich machen.

Johannes schaltet indes anders als Kuhlmann zunächst drei Rotationsdarstellungen hintereinander, für die er die Rotationssummen (z.T. falsch) zusammenrechnet. ${ }^{77}$ Sie bedeuten für sich noch keine Heilsperspektive, kennzeichnen aber die ins Heil eingebaute Multiplikation jener universellen Tinktur. Die verbleibenden vier Rotationen erspart er sich, kann aber darauf spekulieren, dass sich bereits jetzt schon eine monströse Summe abzeichnet. Für alle sieben Rotationen lässt sich nämlich folgende Zahl errechnen: 6.755.399.441.055.744 (sechs Billiarden, 755 Billionen, 399 Milliarden, 441 Millionen, 55 Tausend, 744). Hielte der am Prozess arbeitende Meister sich diese Zahl der Multiplikation (eigentlich Summation, aber hier ist einfach Vermehrung gemeint) vor Augen - so Johannes -, so würde er die Krafft der Tinctur nicht begreiffen können / sondern dem Sabbatismo alles überlassen müssen..$^{78}$ Gleichwohl aber gebuehret uns zu suchen und zu forschen / wo das Fundamentum multiplicationis steckel und wie die Metallen wachsen und transmutiret werden. ${ }^{79}$

Und nun macht Johannes einen Vorschlag, wie dieses fundamentum verstanden werden könne. Er schreibt eine überraschende Partie, die im Kontext der zeitgenössischen Naturphilosophie auf Hegels Identitätsthese und sein Diktum ,Das Subjekt ist die Substanz' vorauszuweisen scheint und die eingehend ausgelegt zu werden verdiente: Er reinterpretiert nämlich die multiplicatio und die Universaltinktur im Anschluss an die vielen Bemühungen der Frühen Neuzeit, das Elixier und die Transmutation gar nicht im Wortsinne, sondern als Metapher für eine Veränderung des und im Menschen aufzufassen. ${ }^{80}$ Die multiplicatio durch die Tinktur wird als ein Prozess aufgefasst, der nicht beim Arbeiten im Laboratorium, sondern der im Menschen stattfindet, wenn dieser das Wesen der gesuchten Substanz sprachlich zu fassen sucht. Dann vervielfältigen sich ihm die Bedeutungen, und die Sprache lässt sich bis ins Unendliche strecken. Wie man denn auch unendlich viele Sätze bilden kann. Ist das Subjekt der Sätze keine klar umrissene, sondern eine übergängliche Größe, die sich beim Bilden der Sätze ändert, und liegt auch die Bedeutung der verwendeten Begriffe nicht fest, so geht die Produktion von Differenzierungen ins Unendliche.

teleuropa. Hrsg. von Helmut Holzhey und Wilhelm Schmidt-Biggemann. Basel 2001, S. 237290, hier S. 267f. (zu Kuhlmann).

77 Johannes de Monte Raphaim: Vorbothe (Anm. 53), S. $20 \mathrm{f}$.

78 Johannes de Monte Raphaim: Vorbothe (Anm. 53), S. 21.

79 Johannes de Monte Raphaim: Vorbothe (Anm. 53), S. 27f.

80 Von vielen entsprechenden Reflexen - z.B. bei Jakob Böhme und Valentin Weigel - abgesehen, betreiben etwa Heinrich Khunrath (Vom hylealischen, Das ist, Pri-Materialischen Catholischen, oder Algemeinem Natürlichen Chaos [...]. Magdeburg 1597) und Georg von Welling (Opus Mago-Cabbalisticum et Theosophicum [...]. Frankfurt, Leipzig ${ }^{31784}$, Nachdruck Stockholm 1971) eine großflächige Reinterpretation der Alchemie. 
Es ist die Selbstbeschreibung des Ingeniums, die sich auf diese Weise beobachten lässt; die Tinktur erscheint als der offene und ins Unendliche laufende Formulierungsprozess, der sich im Zuge ihrer Bestimmung einstellt:

36. Mercket hierbey: wann sich das Feuer nicht so mannigfaltig erwiese / so wůste man wenig oder gar nichts von der Tinctur / darum / so mancherley gradus nun des Feurs gefunden werden / also mannigfaltig ist auch die Tinctur / aber alles aus einem einigen / welches kein Mensch aussprechen oder nennen kan; und wer es kennet und weiß / der kan es niemand lehren; ja wann es gleich der Meister oft gemacht / lang bedacht und durchgesucht / so findet er doch immerzu was neues darbey / dann es fanget an ohne Ende / und endet sich ohne Anfang / darum kan niemand dem Schüler den Verstand geben / sondern selbiger [sc. der Verstand] erzeiget sich nach der Gabe und Willen GOttes mancherley.

37. Denn so wir dieses tincturische Krafft-Wesen in seinem Grunde fassen wollen / so ist es selbst das Ingenium und Fundament; iudiciren wir von ihm / so fállet es selbst das Urtheil; sinnen und dencken wir ihm nach / so wird es zu lauter Sinnen und Gedancken; disputiren wir von ihm / so ist es lauter Mund und Wort; Werden wir ungedultig / daß wir es nicht haben kónnen / wie wir es gerne wolten / so lachet es uns aus / denn es vermag das oberste zu unterst zu kehren; Achten wir seiner gar nicht / so machet es sich selbst / damit ihm der jenige keine Gewalt anthun kan / der seiner nicht werth ist; die Proceß-Laboranten wollen es wieder allen Danck regiren und in Proceß zwingen / und meinen sie seyn Herr darüber / aber sie sind wahrhafftig die mủhseligsten Tropfen unter dem gantzen Himmel. ${ }^{81}$

Der Gedanke an das Elixier ist das Elixier und es vervielfältigt sich ins Unendliche. Tritt aber der große Sabbat ein, so ist die Verfeinerung in immer kleinere Teile/Bedeutungsdifferenzierungen über sieben Rotationen bis zu einer unvorstellbaren Zahl vorangeschritten. Freilich liegt ein Weltprozess darin, der von den handwerklich arbeitenden Chemikern nur unvollkommen kontrolliert werden kann.

Die multiplicatio wird von Johannes ad absurdum geführt. Der alchemistische Prozess wird nicht nur auf den Menschen, ${ }^{82}$ sondern auf den geistigen Prozess überblendet, der mit diesem alchemistischen Prozess beschäftigt ist. Unfreiwillig offenbart der Prozess dabei seine Selbstreferentialität. Er zerlegt sich bis ins Unendliche. ${ }^{83}$

81 Johannes de Monte Raphaim: Vorbothe (Anm. 53), S. 29f.

82 Vgl. entsprechend auch den Wasserstein der Weisen, s. Anm. 51.

83 Es erscheint unentscheidbar, ob und inwieweit der Text des Johannes als Satire gelesen werden will. 
(C) 2015, Otto Harrassowitz GmbH \& Co. KG, Wiesbaden ISBN Print: 9783447104951 - ISBN E-Book: 9783447194129 


\title{
Virgula divinatrix
}

\section{Frühneuzeitliche Debatten über die Wünschelrute zwischen Magie und Magnetismus}

\author{
Bernd Roling, Berlin
}

\begin{abstract}
Als Philipp Nicolai im Jahre 1781 auf seiner Reise durch Deutschland und die Schweiz auch ins weimarische Dornburg, ein Dorf an der Saale, gelangt, erfährt er von einem großen Unternehmen, das von den Einwohnern vor Ort erst vor zwölf Jahren in Angriff genommen worden war. Unter dem Nachbarberg, den Geologen eindeutig als eine Ansammlung von Kalk und Lehmschichten identifiziert hatten, war von einem bestellten Wünschelrutengänger eine Goldader ausfindig gemacht worden. ${ }^{1}$ Im Vertrauen auf die, so Nicolai, unbekannte Kraft der Natur hatte man den Berg unter erheblichen Kosten und Mühen abtragen lassen. Gefunden hatte man unter den Erdschichten: nichts. Warum gab es in der heutigen Zeit, so Nicolai, noch immer Menschen, die lieber auf die sogenannten Geheimen Wissenschaften vertrauten und die Erkenntnisse der ausgebildeten Naturwissenschaftler in den Wind schlugen? Warum war die Wünschelrute so viel leichter und bequemer als die Auseinandersetzung mit den Gesetzen der Geologie? Der aufgeklärte Leser sollte es besser wissen, über die Einwohner Dornburgs lachen und die Geheimwissenschaften fortan ignorieren. ${ }^{2}$

Ein Blick in die Internetversion des Berliner Branchenbuchs offenbart uns, dass die von Nicolai beschworene Aufklärung noch immer nicht so erfolgreich war, wie es sich Nicolai vor 230 Jahren gewünscht hatte. Die dort angebotenen Rutendienste der, wie es heute heißt, ,Baubiologischen Gesundheitsberatung' erfreuen sich, wenn man der Kommentarfunktion glauben kann, sogar reger Nachfrage. Eine nicht repräsentative Internetrecherche klärt außerdem darüber auf, dass Wünschelruten seit jüngerer Zeit auch erfolgreich genutzt werden, um den schädlichen Einfluss von Supermarkt-Barcodes auf die menschliche Aura
\end{abstract}

1 Ich danke den Alten Abteilungen der Universitätsbibliothek in Göttingen und in Greifswald für ihre Hilfe bei der Erstellung dieser Studie, außerdem Marco Heiles (Hamburg) und Nikolaus Staubach (Münster).

2 Philipp Nicolai: Beschreibung einer Reise durch Deutschland und die Schweiz im Jahre 1781, nebst Bemerkungen über Industrie, Religion und Sitten (2 Bde.). Berlin 1788, Bd. 1, Erstes Buch, II. Abschnitt, S. 47f. 
abzumildern. ${ }^{3}$ Neue Marktsegmente haben der langen Geschichte der Wünschelrute also weitere Episoden hinzufügen können.

Hier soll der Anfang dieser Erfolgsgeschichte im Vordergrund stehen. Als die ersten Versuche zur Erklärung der Wünschelrute unternommen wurden, hatte die dämonische Magie als autonomes System ihre Halbwertzeit schon lange überschritten. Die Wünschelrute konstituierte, wie wir sehen werden, ein Objekt, das fast paradigmatisch zur argumentativen Schnittstelle magischokkulter und rein naturwissenschaftlicher Weltbetrachtung wurde, ja einen Gegenstand, in dem beide Erklärungsansätze miteinander kollidieren konnten. Die Wünschelrute war ein natürlicher Gegenstand, dessen Wirksamkeit die Praxis wiederholt unter Beweis gestellt hatte, doch für das es keine stichhaltige Erklärung gab. Das Schlagholz, wie man es auch nannte, wurde daher in einen akademischen Verwissenschaftlichungsprozess eingebunden, in dem die Dämonologie eine Option blieb, doch in Gestalt einer Verlegenheitslösung, die sich nicht in den Vordergrund drängte. Die funktionsfähige Wünschelrute thematisierte die Variante einer dämonologischen Magie - von magia naturalis ist nie die Rede -, die sich im akademischen Milieu bereits in der Defensive befand und die man dem Verfolgungsapparat in der Mitte des 17. Jahrhunderts bereits entzogen hatte. Kein Wünschelrutengänger lief mehr Gefahr, ausschließlich wegen der Benutzung der virgula mercurialis, wie sie auf Latein hieß, einem Hexenprozess unterzogen zu werden. Im Folgenden soll gezeigt werden, wie die Debatte über die Wünschelrute im Ablauf von etwa 60 Jahren trotzdem die Option der Dämonologie wachhalten musste: nicht weil die Rute als Teil eines weitreichenden gesellschaftlichen Bedrohungsszenarios kriminalisiert wurde, wie es vielleicht noch im 16. Jahrhundert der Fall gewesen wäre, sondern aus schlichtem Mangel an anderen Erklärungen. Eine Debatte begann, die mit jedem neuen Ansatz der Plausibilisierung der Rute die Dämonologie weiter marginalisieren musste. Zum Ende wird deutlich werden, dass mit der ersten systemisch geschlossenen Erklärung der Wünschelrute die Annahme, sie ließe sich nur durch die Wirksamkeit böser Mächte erklären, endgültig obsolet werden musste. War dieser Schritt zur völligen Rationalisierung an der Schwelle zum 18. Jahrhundert einmal getan, so wird sich zeigen, war die Kontroverse um die Wirksamkeit der Rute zu einer Auseinandersetzung geworden, die allein innerhalb der Naturwissenschaften ihren Ort haben konnte.

\section{Erste akademische Einlassungen zur virgula divinatoria}

Glaubt man dem ,Handwörterbuch des deutschen Aberglaubens', so war der Gebrauch der Wünschelrute spätestens seit dem 15. Jahrhundert in Mitteleuropa

3 „Die Barcode-Verschwörung - der Strichcode-Satan“, Spiegel-TV (gesendet am 12.5.2013) (https://www.youtube.com/watch?v=YOXwTGFx_8k). 
weit verbreitet; ${ }^{4}$ schon Paracelsus erwähnt sie kurz in seiner Philosophia occulta, stand ihr aber noch skeptisch gegenüber. ${ }^{5}$ In magischen Sammelhandschriften taucht die magische Rute bereits im 15. Jahrhundert auf, wenn auch weitgehend ohne theoretische Handreichungen. ${ }^{6}$ Gewöhnlich verwendete man Haselnusshölzer, mit einem gegabelten Ende, das der Träger in der Hand hielt. Die Rute diente der Suche nach Metallen, Wasseradern, aber auch verlorenen Gegenständen. Ihre Beschaffung und Verwendung begleiteten im Regelfall lokal divergierende Gebete und Spruchformeln; auch der Zeitpunkt, an dem das Holz geschnitten wurde, und sein Alter waren oft von großer Bedeutung. Das erste systematische Lehrbuch der Wünschelrutennutzung verdankte sich dem schwer fassbaren Alchemisten Basilius Valentinus, ${ }^{7}$ der in acht Kapiteln seines im Jahre 1600 zum ersten Mal veröffentlichten Testamentes beschreibt, wie man das Instrument bei der Suche nach Metalladern zu handhaben hatte. ${ }^{8}$ Großen Wert hatte Valentinus darauf gelegt, dass bei verschiedenen Erzen unterschiedliche Hölzer zur Anwendung gelangten. Die Haselstaude war auf Silber terminiert, die Esche auf Kupfer, die Fichte auf Blei. Auch warum die Rute ausschlug, erklärt Valentin: Eine „magnetische Witterung“, eine attraktive Ausdünstung, die aus dem Metall nach oben drang, versetzte das Schlagholz in Bewegung. ${ }^{9}$

So schwammig Valentins Erklärung auch wirken mochte, so hatte der obskure Alchemist doch einen entscheidenden Schritt zur Naturalisierung und Plausibilierung der Wünschelrute getan und sie aus dem Reich des Volksglaubens scheinbar ins Reich der Naturwissenschaft überführt. Die Rute aktivierte eine vis venarum, eine Anziehungskraft, die sich als Variante der zahllosen weiteren sympathetischen Kräfte der Naturordnung begreifen ließ. Auch wenn der deutsche Alchemist vielleicht nur einen Volksglauben paracelsisch überformt und in semiakademische Chiffren gefasst hatte, konnte er viele Anhänger auf seiner Seite wissen. Selten wurde die Hypothese dabei einer weiteren kritischen Reflek-

4 Friedrich Ohrt: s.v. Wünschelrute. In: Handwörterbuch des deutschen Aberglaubens. Hrsg. von Hanns Bachthold-Stäubli (10. Bde.). Berlin 1927-42. ND Berlin 1987, Bd. 9, Sp. 823-841.

5 Paracelsus: Liber de occulta philosophia. Auß einem uhralten Tractat wegen seiner einhabenden Hochwichtigkeit von neuem hervorgebracht. s.l. 1686, c. 7, S. 49f.

6 Als Beispiel eine Rutenbeschreibung aus einer magischen Sammelhandschrift aus dem schwäbischen Raum (Wien Nationalbibliothek Cod. 5327), abgedruckt bei Gerhard Eis: Altdeutsche Zaubersprüche. Berlin 1964, S. 148, dort gemeinsam überliefert mit anderen okkulten Praktiken. Ich danke Marco Heiles für diesen Hinweis.

7 Bei Basilius Valentinus handelt es sich vermutlich um ein Pseudonym von Johann Thoelde, vgl. Claus Priesner: Johann Thoelde und die Schriften des Basilius Valentinus. In: Die Alchemie in der europäischen Kultur- und Wissenschaftsgeschichte. Hg. V. Christoph Meckel. Wiesbaden 1986, S. 107-118. Außerdem Joachim Telle: Basilius Valentinus. In: Killy Literaturlexikon. Berlin 2008, S. 348-350.

8 Basilius Valentinus: Geheime Bücher oder letztes Testament vom grossen Stein der Ur-alten Weisen und andern verborgenen Geheimnissen der Natur. Straßburg 1645, dort Erstes Buch, c. 22-28, S. 73-88.

9 Basilius Valentinus: Geheime Bücher (Anm. 7), z.B. Erstes Buch, c. 26, S. 82f. 
tion unterzogen. Caspar Peucer erklärt die Wirksamkeit der virgula mercurialis, wie man sie nannte, in seinen Libri de divinatione mit der Anziehungskraft des Metalls, ${ }^{10}$ ebenso auch Andreas Libavius in seinen Arcana. ${ }^{11}$ Eine sympathia naturae war für die Reaktion des Holzes verantwortlich, ihre genaue Natur musste dem Betrachter verschlossen bleiben. Mit Popularisatoren wie Georg Philipp Harsdörffer, der in seinen Deliciae mathematicae auf die Rute eingeht, ${ }^{12}$ wird die Annahme, eine Korrespondenz von Metall und Holz sei für die erfolgreiche Schatzsuche verantwortlich, zum Gemeinplatz. Ausdünstung, Sympathie und Magnetismus werden im Folgenden fast ununterschieden verwendet. Veit Ludwig von Senckendorff empfiehlt den Gebrauch der auf Magnetismus beruhenden Rute in seinem Fürsten-Stat ausdrücklich. ${ }^{13}$ Auch ein Gesteinskundler wie Johann Becher, der mit seiner Physica subterranea ein Standardwerk der frühneuzeitlichen Geologie geschrieben hatte, referiert die Standardthese. Die Wünschelrute war von einer gravitas der Silber- und Goldminen, einer Ausdünstung aus dem Erdinneren, einer metallischen exhalatio, angezogen worden. ${ }^{14}$

Woraus aber sollte diese Anziehungskraft, die sich so leicht behaupten ließ, bestehen? Was sollte sich hinter dem Schlagwort der Sympathie zwischen Erz und Gehölz verbergen? Wie agierten beide Stoffe miteinander? War die Relation beider so zwingend, dass die Gewalt des Teufels einfach ausgeschlossen werden konnte? Es wundert vielleicht nicht, dass es gerade die Praktiker des Bergbaus und die Mineralogen waren, die auf einer genaueren Überprüfung des Phänomens beharrten. Die Grenze zwischen den Gegenständen der Dämonologie und den natürlichen Ursachenketten ließ gerade für die Vertreter der neu entstehenden geologischen Disziplinen keine Unschärferelationen zu. Wo das Reich der natürlichen Kausalität endete, musste das Imperium der causae secundae, der Engel und Dämonen, oder die völlig kontingente Wirkdomäne des Schöpfers beginnen.

Georg Agricola listet in seiner 1556 zum ersten Mal gedruckten Schrift De re metallica, mit der das moderne Bergingenieurswesen seinen Anfang nimmt, eine ganze Reihe von Instrumenten und Naturphänomenen auf, die dem Bergmann

10 Caspar Peucer: Commentarius de praecipuis generibus divinationum. Wittenberg 1580, De reliquis physiologiae generibus, fol. 371af.

11 Andreas Libavius: Appendix necessaria Syntagmatis arcanorum chymicorum. Frankfurt a.M. 1615, Alchymiae defensio II, S. 260f. Ähnlich z.B. Marcantonio Zimara: Antrum magico-medicum (2 Bde.). Frankfurt a.M. 1625-26, Bd. 2, S. 26.

12 Georg Philipp Harsdörffer: Deliciae physico-mathematicae, oder Mathematische und philosophische Erquickstunden (3 Bde.). Nürnberg 1636-53, Bd. 3, Sechster Theil, Frage 16, S. $410 f$.

13 Veit Ludwig von Senckendorff: Teutscher Fürstenstat, oder Gründliche und kurze Beschreibung, welcher Gestalt Fürstenthümer, Graff- und Herrschafften im H. Römischen Reich Teutscher Nation welche Landes-Fürstliche und Hohe Obrigkeitliche Regalien haben. Hanau 1656, Dritter Theil, c. 9, S. 180.

14 Johann Joachim Becher: Actorum laboratorii chymici Monacensis seu Physicae subterraneae libri duo. Frankfurt a.M. 1681, Liber I, Sectio 7, S. 558f. 
auf der Suche nach Schürfgebieten hilfreich sein konnten. Am Ende des dritten Buches kommt er auf das Werkzeug zu sprechen, das in dieser Zeit schon das begehrte Hilfsmittel des Gold- und Silberfreundes, ja des Schatzhungrigen jeder Art geworden war, der aus dem Haselholz gefertigten virgula. Auch Agricola erklärt, wie die Rute zu schnitzen war und hat keinen Zweifel, dass dem Wünschelrutengänger Erfolge vergönnt waren. ${ }^{15}$ Wie aber funktionierte sie? Vielleicht hatte die Rute ihre Vorbilder im Stab des Mose, der Wasser aus dem Felsen geschlagen hatte, vielleicht war sie aber auch paganer Natur und hatte ihr Urbild im Zweig, mit dessen Hilfe Aeneas den Weg ins Totenreich fand, oder im Zauberstab der Circe, die die Gefährten des Odysseus in Schweine verwandelt hatte. Die Freunde der Wünschelrute hatten behauptet, wie Agricola weiß, metallische Ausdünstungen würden das Schlagholz aktivieren. Auch Bäume ließen ihre Zweige hängen, wenn sie auf metallischem Boden ihre Wurzeln geschlagen hatten. Zugleich funktionierte die Rute nicht in den Händen aller Menschen, wie man zu wissen meinte, weil nicht jeder Träger über das richtige temperamentum verfügte, um ihre magnetische Kraft weiterzureichen. Eine proprietas naturalis, so der Jargon der Metalloskopen, hatte in diesem Fall den Einsatz der Rute blockiert. ${ }^{16}$ Beide Argumente erscheinen Agricola nicht überzeugend. Wenn die Rute aufgrund von Magnetismus tätig wurde, einer gewöhnlichen Naturkraft, warum verweigerte sie manchen Benutzern dann ihre Wirkung? Wenn sie einer magnetischen Attraktion unterlag, warum drehte sich dann nur ihre Vorderseite, während die hintere Hälfte keine Anstalten machte, sich zu neigen? Ein gewöhnlicher Magnet müsste die Rute zur Gänze an sich heranholen. Auch die Analogie mit den Zweigen ging für Agricola nicht auf. In vergleichbaren Fällen hatte der metallische Boden die Bäume ausgetrocknet, und die waren schlicht kraftlos geworden. Für Agricola liegt die Schlussfolgerung auf der Hand. Wenn die Rute nur bei Erwählten tätig wurde, konnte sie keine natürliche Kraft bewegen. Sie war also ein Werkzeug der Magie und schlug aus, weil ihre Träger sich zuvor entsprechender Zaubersprüche und Formeln bedient hatten. ${ }^{17}$ Sie war ein Instrument des Teufels.

Der Freiberger Agricola, der die Metallurgie mitbegründet, doch zugleich noch immer an Kobolde geglaubt hatte, ${ }^{18}$ war im Ausschlussverfahren zu seiner Entscheidung gelangt. Seine wissenschaftliche Expertise war enorm und Agricolas Position sollte in der Folgezeit von zahlreichen Autoren repetiert werden. Dass sich Dämonen, mit denen man einen Pakt geschlossen hatte, für die Wünschelrute verantwortlich zeigten, proklamieren unter vielen anderen Ulysses Al-

15 Georg Agricola: De re metallica libri XII, quibus officia, instrumenta, machinae, ac omnia denique ad metallicam spectantia describuntur. Basel 1667, Liber III, S. $26 f$.

16 Georg Agricola: De re metallica libri (Anm. 14), Liber III, S. 27.

17 Georg Agricola: De re metallica libri (Anm. 14), Liber III, S. $27 \mathrm{f}$.

$18 \mathrm{Zu}$ den Kobolden vgl. z.B. Georg Agricola: De animantibus subterraneis liber (1549), in: Georg Agricola: Ausgewählte Werke (7 Bde.). Berlin 1956-63, Bd. 6, Vermischte Schriften, Liber II, c. 3, 3, S. $199 f$. 
drovandi, der sich direkt auf Agricola beruft, ${ }^{19}$ oder Anton Deusing. ${ }^{20}$ Andere deutsche Metallographen wie Caspar Schwenckfeldt oder Georg von Löhneyß schließen sich ihrem mitteldeutschen Kollegen an. ${ }^{21}$ Allein bei Satan war zum Ende die Ursache für die Wirksamkeit der Rute zu suchen.

\section{Skepsis und Empirie: die universitäre Aufarbeitung der Wünschelrute}

\section{Die Jesuiten und das Wunderholz}

Noch immer kann man die Debatte zu diesem Zeitpunkt als unterkomplex bezeichnen. Es sollten, wie so oft, die technophilen und magnetismusverliebten Jesuiten sein, die der Frage, ob Dämonen oder Naturkräfte in der Rute tätig waren, in der Mitte des 17. Jahrhunderts neue Dynamik verleihen konnten. Laurenz Forer, dessen Arbeit zum Magnetismus im Jahre 1624 erschienen war, teilt zunächst die Ansicht Agricolas. Die sympathetische Relation von Holz und Metall blieb zu vage, um sich der verifizierbaren Relation an die Seite stellen zu lassen, die zwischen Magnet und Eisen oder dem seit der Renaissance beschworenen Heliotropen und der Sonne bestand; sie war also durch die Invokation des Teufels erst zu einem wirksamen Instrument geworden. ${ }^{22}$ Forers Ordensbruder Bernardo Cesi, der anfangs wichtigste Gesteinskundler der Societas, sieht es wenig anders. Die Rute war ein Zauberstab, nicht anders als der Stab, den die Magier des Pharaos benutzt hatten, um sich von Mose in den Schatten stellen zu lassen. Seine Kraft hatte ihm ein Dämon eingeflößt. ${ }^{23}$

Athanasius Kircher sollte sich mit dieser Lösung nicht zufriedengeben. In seiner Ars magnetica zeigt sich der Großgelehrte als profunder Kenner der virgula mercurialis. Dass Dämonen und Schwarzpriestertum bei ihrer Handhabung eine Rolle spielten, erscheint ihm wenig plausibel. Was konnte es dagegen mit den metallischen Ausdünstungen auf sich haben? Der Einfluss unterirdischer Metallvorkommen auf die Vegetation ließ sich nicht leugnen, wie Kircher den Metalloskopen zugutehält. Aus Erdspalten quellende Antimon- oder Arsenikdämpfe verbrannten Pflanzen, die auf ihrer Oberfläche angesiedelt waren. Auch

19 Ulysses Aldrovandi: Musaeum metallicum in libros III distributum. Bologna 1648, Liber I, S. $20 f$.

20 Anton Deusing: Sympathetici pulveris examen: quo superstitiosa fraudibus Cacodaemonis implicita vulnerum et ulcerum curatio in distans per rationis trutinam ad ipsas naturae leges expenditur. Groningen 1662, S. 55-58.

21 Caspar Schwenckfeldt: Stirpium et fossilium Silesiae Catalogus in quo praeter etymon, natales, natura et vires cum variis experimentis assignantur. Leipzig 1601, Liber I, S. 57; Georg Engelhard von Löhneyß: Bericht vom Bergwerck: wie man dieselben bawen und in guten wolstande bringen sol, sampt allen dazu gehörigen arbeiten, ordnung und rechtlichen processen. s.l. 1618, Erster Theil, S. 14f.

22 Laurenz Forer: Viridarium philosophicum, hoc est disputationes aliquot de selectis quibusdam iocundioribus et utilioribus in philosophia materiis. Dillingen 1624, Disputationes de magnete, Nr. 29, S. 273-276.

23 Bernardo Cesi: Mineralogia sive Naturalis Philosophiae thesauri. Lyon 1636, c. 7, Sectio 4, S. $124-126$. 
farbliche Varianten, gelbe oder bläuliche Blätter oder berstende Zweige waren Indizien, die auf verborgene Metallschichten einen Hinweis gegen konnten. Es war denkbar, dass Pflanzen, die auf einer Silberader wuchsen, Eigenschaften aufwiesen, die vom Silber hervorgerufen wurden. Doch durfte man daraus bereits schließen, dass Fichte und Blei, Esche und Kupfer oder Hasel und Silber in direktem Bezug zueinander standen? ${ }^{24}$ Kircher versucht zunächst, der Denkweise der Wünschelrutengänger mit weiteren Argumenten entgegenzukommen. Vielleicht war es sinnvoll, das Modell der Ausdünstung von der Idee des Magnetismus zu trennen. Der Dampf, der aus einer Wasser- oder Metallader nach oben stieg, drang, so eine weitere mögliche Hypothese, in die Holzarten ein und richtete sie auf die unter der Erdoberfläche verborgenen Substanzen aus. Ergebnis wäre eine sympathetische Relation, die auch das zurechtgeschnittene Holz in Gestalt der Wünschelrute mit einschließen konnte. Tatsächlich waren leicht schimmernde Krokusse auf Schwefelgrundlage gesichtet worden oder Weinreben, wie Kircher bemerkt, die als Folge von Quecksilber einen silbrigen Glanz aufwiesen. Liefen nicht Alchemisten als Folge des ständigen Kontaktes Gefahr, einen Flaum desselben Stoffes auf der Zunge zu tragen? ${ }^{25}$

Kircher scheint im Jahre 1654 noch nicht recht überzeugt. Am Hofe des Kardinals Palleotti, einem seiner vielen Förderer, kommt es zu einem seltsamen Experiment, als dessen Ergebnis Kircher noch eine alternative Hypothese zur Erklärung der Rute entwickelt. Aus Langeweile werfen die Vogelfänger des Kardinals einige aus Haselholz geflochtene Nester eines Zaunkönigs ins Feuer. Zur allgemeinen Erheiterung beginnt das Holz mit den noch lebenden Küken in den Flammen zu rotieren. Im Angesicht der Tierquälerei hat Kircher eine Idee. Könnte eine vergleichbare inwendige Wärme in den Fibern des Haselholzes nicht auch die Bewegung der Wünschelrute verursachen? Drang die Wärme vielleicht aus dem Boden durch die Hand des Rutengängers ins Haselholz? ${ }^{26}$ Auch diese Erklärung erscheint für Kircher nicht ausreichend. Alle eigenen Versuche, mit einer Wünschelrute Metalle aufzufinden, waren darüber hinaus gescheitert, wie Kircher noch trocken bemerkt. ${ }^{27}$ In einem späteren Werk, dem Mundus subterraneus, geht der bayerische Jesuit noch einmal auf die Rute ein, nun jedoch sichtlich desillusioniert. Von den Dämonen Agricolas möchte Kircher noch immer nichts wissen. Jeder, der etwas von Magnetismus verstand, musste sich darüber hinaus im Klaren sein, so Kircher, dass eine magnetische Kraft, die selbst bei einem gewöhnlichen Stück Eisen mühsam ausbalanciert werden musste, kaum in der Lage war, durch dicke Erdschichten auf ein Stück Holz zu wirken. Auch Ausdünstungen waren niemals von einer solchen Intensi-

24 Athanasius Kircher: Magnes sive De arte magnetica opus tripartitum. Rom 1654, Liber III, Pars V, c. 3, Consectarium, S. 500f.

25 Kircher: Magnes sive (Anm. 23), Liber III, Pars V, c. 3, Consectarium, S. 502f.

26 Kircher: Magnes sive (Anm. 23), Liber III, Pars V, c. 3, Consectarium, S. $503 f$.

27 Kircher: Magnes sive (Anm. 23), Liber III, Pars V, c. 3, Consectarium, S. 502. 
tät, dass sie eine Rute in Bewegung versetzen konnten. ${ }^{28}$ Doch es gab noch eine weitere Option, der man bisher, wie Kircher schließt, zu wenig Beachtung geschenkt hatte: den Rutengänger selbst. Die Rute arbeitete auf der Basis von Autosuggestion. Der Träger des Holzes spekulierte auf eine Silberader, seine Imagination ließ ihn den Druck spüren und die Rute setzte sich durch seine Muskelkraft in Bewegung. Das Ausschlagen des Holzes war ein Produkt der Adern und Fingerspitzen des Halters, auch wenn dieser es sich selbst nie eingestehen würde. $^{29}$

Kircher hatte also eine ganze Galerie möglicher Erklärungen der Rute gesichtet, ohne sie am Ende zur Gänze plausibel gemacht zu haben. Sein Meisterschüler Caspar Schott nimmt den Faden in seiner Magia naturalis wieder auf, doch erkennt man schnell, dass auch der Würzburger Jesuit seinem Freund in seiner Ratlosigkeit wenig nachsteht. ${ }^{30}$ Auch Schott studiert Agricola und lässt sich von Experten mit der virgula mercurialis vertraut machen. Die Haselstaude hatte ein Jahr alt zu sein und durfte nur zu bestimmten Zeiten geschnitten werden. Beim Abtrennen hatte man das Messer vom Körper weg zu bewegen. Waren alle Bedingungen erfüllt, waren die Schätze jedoch leicht zu finden, egal ob sie in der Erde, im Garten, in Mauern oder Ställen verborgen waren. ${ }^{31}$ Auch die befragten Fachleute mussten zugeben, dass manche Rutengänger im Bund mit dem Teufel standen. Zumindest bei den Schweden, die im Dreißigjährigen Krieg auf der Suche nach Gold Deutschland durchzogen hatten, war dies sicher der Fall gewesen. Doch galt dies für alle Rutengänger? ${ }^{32}$ Bemerkenswert oft blieben die Suchen erfolglos, wie Schott feststellt. Bei einem namentlich nicht genannten Fürsten war die Rotte der Metalloskopen noch vor kurzem in Erscheinung getreten, um auf dem Hof vergrabene Reichtümer wieder zutage zu fördern, doch hatten sie auch nach Stunden nichts gefunden. Ein anderer Fürst ließ die Ruten einsegnen, um vor dem Einfluss des Teufels sicher zu sein, doch auch diesen Rutengängern war kein Erfolg vergönnt. Die Schätze, so die Replik der düpierten Schatzsucher, waren von Dämonen einfach an einen anderen Ort versetzt worden, doch war ein Irrtum ausgeschlossen. ${ }^{33}$ Ein dritter Praxistext fiel noch unglücklicher aus. Ein erfahrener Rutengänger teilt Schott mit, das von ihm herangezogene Instrument sei zur Gänze zuverlässig. Tatsächlich schlägt die Rute des

28 Athanasius Kircher: Mundus subterraneus in XII libros digestus (2 Bde.). Amsterdam 1678, Bd. 2, Liber X, c. 7, S. 200af.

29 Kircher: Mundus subterraneus (Anm. 28), Bd. 2, Liber X, c. 7, S. 200b.

30 Eine wertvolle Synopse der Magia universalis gibt Dietrich Unverzagt: Philosophia, Historia, Technica - Caspar Schotts Magia universalis. Diss. Berlin 2000, passim.

31 Caspar Schott: Magia universalis naturae et artis sive recondita naturalium et artificialium rerum scientia cuius ope per variam applicationem activorum cum passivis admirandorum effectuum spectacula, abditarumque miracula eruuntur: Opus quadripartitum (4 Bde.). Frankfurt a.M. 1658-59, Pars IV, Liber IV, Syntagma IV, c. 1, S. 420-422, zu Agricola S. 426f., zu Kircher Annotatio I, S. 428f.

32 Schott: Magia universalis naturae (Anm. 30), Pars IV, Liber IV, Syntagma IV, c. 1, S. $423 f$.

33 Schott: Magia universalis naturae (Anm. 30), Pars IV, Liber IV, Syntagma IV, c. 1, S. $424 \mathrm{f}$. 
Mannes, den Schott ausdrücklich als Prahlhans bezeichnet, bei den sichtbaren Silbermünzen aus, doch ignoriert sie den weitaus größeren Münzhaufen, den Schott zuvor in dessen Nähe versteckt hatte. Die Wärme in der Hand konnte kaum ausschlaggebend sein. Beruhte das Schlagholz, wie der letzte Fall nahelegte, auf Scharlatanerie oder Selbstbetrug? ${ }^{34}$ Wenn eine vis naturalis des Metalls für die Reaktion der Haselstaude verantwortlich war, warum musste die Rute dann gabelförmig sein? Warum konnte sie keine Kreuzgestalt besitzen oder einfach die Form eines Stabs? Schott holt sich noch ein weiteres Fachgutachten ein, diesmal von seinem Ordensbruder Balthasar Conrad, der in Prag unterrichtete. Conrad hatte selbst an seiner heimatlichen Akademie mehrere Rutengänge unternommen, doch war das Organ in seinen Händen ebenfalls stumm geblieben. Physische Erklärungen der Rute lehnt der Prager ab. Tatsächlich neigte sich kein Haselzweig in Richtung einer Silberader, solange er noch am Baume hing. Unabhängig davon, welche Menge an Metall man der Rute präsentierte, die virgula schlug immer mit der gleichen Intensität aus. Magnetismus oder Erdausdünstungen konnten für dieses Phänomen also nicht verantwortlich sein. Conrad immerhin hatte das Schlagholz im Anschluss in Böhmen verbieten wollen. War es also doch der Teufel, der den Metalloskopen die Hand führte? ${ }^{35}$

\section{Die Rute im protestantischen Universitätswesen}

Die auf Empirie ausgerichteten Jesuiten schwankten in ihrem Urteil zwischen Einbildung und Teufelswerk. Gerade weil sie an naturkundlichen Erklärungen interessiert waren, mussten letztere stichhaltig sein. Von Kircher und Schott inspiriert, machen sich auch Physiker der mitteldeutschen protestantischen Universitäten daran, das Geheimnis der Rute aufzuklären. Johann Sperling, Professor zu Wittenberg, ${ }^{36}$ stellt sich 1658 einer einzigen Frage: Konnte eine qualitas occulta, eine verborgene Qualität, die Wünschelrute veranlassen, auf Metall oder Wasser zu reagieren? Wenn die Rute über eine solche Qualität verfügte, wie Sperling ausführt, musste sie jederzeit abrufbar sein, so verborgen sie auch sein mochte, und konnte nicht von der Beschaffenheit des Rutengängers abhängig sein. ${ }^{37}$ Auch verborgene Naturkräfte durften keine Ausnahmen beanspruchen. Wenn Haselholz von Metall angezogen wurde, durfte auch der am Baum hän-

34 Schott: Magia universalis naturae (Anm. 30), Pars IV, Liber IV, Syntagma IV, c. 1, S. 425.

35 Schott: Magia universalis naturae (Anm. 30), Pars IV, Liber IV, Syntagma IV, c. 1, S. 425f., Annotatio II, S. 429f.

36 Allgemein zu Leben und Schriften Sperlings vgl. Bernd Roling: Philipp Melanchthon im Streit um den Ursprung der Seelen im 17. Jahrhundert: Die Debatte zwischen Johannes Sperling und Johannes Zeisold. In: Der Philosoph Melanchthon. Hrsg. von Günther Frank und Felix Mundt. Berlin, New York 2012, S. 173-200.

37 Johannes Sperling: Disquisitio an Virgula mercurialis agat ex occulta qualitate? Ob die Wünschel-Ruthe aus verborgener Kraft würcke? Wittenberg 1742 (zuerst Wittenberg 1658), $\S 14$, S. $14 \mathrm{f}$. 
gende Zweig nicht von seiner Anziehungskraft verschont bleiben. ${ }^{38}$ Die qualitas occulta, eine der bekanntesten Krücken der Naturwissenschaft des 17. Jahrhunderts, konnte also, wie Sperling folgert, keine Hilfe bei der Erklärung der Rute sein. Ihre Verteidiger hatten zudem beteuert, wie Sperling weiß, das temperamentum des Halters könne die Wirkung vielleicht unterbinden. Wie aber sollte der Säftehaushalt des Menschen auf die Rute, die ja zum Objekt der Erdkräfte werden musste, übertragen werden können? ${ }^{39}$ Für Sperling liegt die letzte Antwort auf der Hand. Agricola hatte recht, die Rute fiel in den Geltungsbereich der Dämonologie. ${ }^{40}$

Auch ein anderer Physiker, Theodor Kirchmaier aus der Gelehrtendynastie der Kirchmaiers zu Wittenberg, nimmt sich im Jahre 1669 der Wünschelrute an. Wie seine Kollegen liest der sächsische Gelehrte nicht nur die einschlägigen Traktate, sondern holt bei fachkundigen Bergmeistern vor Ort in Freiberg weiteren Rat ein. Man versichert ihm, dass die Ruten nicht auch verborgene Handschuhe, Kerzen oder Schreibgeräte finden konnten; zugleich erhält Kirchmaier konkrete Anweisungen, wie er die Rute zu handhaben hatte, zu welcher Nachtzeit sie zu schneiden war und welche Sätze man während dieses Vorgangs zu deklamieren hatte. ${ }^{41}$ Auch Kirchmaier beschließt, alle denkbaren Ursachen für die Schlagkraft des Haselholzes zu durchlaufen, und vor allem der postulierten vis venarum, der Anziehungskraft der Metalladern, auf den Grund zu gehen. Konnte die Rute durch eine inwendige Wärme von Seiten des Trägers und des Erdbodens aktiviert werden? Kirchers rotierende Vogelnester waren kaum aussagekräftig, wie Kirchmaier versichert. Dass Erdwärme zudem aus dem Boden in den Körper des Rutengängers und von dort ins Holz der Rute gelangen konnte, war als Hypothese kaum glaubhaft. ${ }^{42}$ War es bloßer Zufall, dass die Rute ausschlug, verstärkt vielleicht durch die Einbildung des Rutengängers, der seine Hand bei einer groben Ahnung bewegte? Für diese Option konnten, wie Kirchmaier konzediert, die Schatzsucher mit ihrem Instrument entschieden zu viele Erfolge verbuchen. ${ }^{43}$ War also die von den Adern ausgehende Anziehungskraft verantwortlich? Auch diese Antwort erscheint dem Wittenberger Gelehrten nicht tragfähig. Sollte es die gleiche magnetische Kraft sein, die auch Handschuhe oder Einrichtungsgegenstände wieder ans Licht brachte? Sollte sie durch dicke Erdschichten hindurch wirksam sein und gleichzeitig auch auf winzige

38 Sperling: Disquisitio (Anm. 36), § 15, S. 15.

39 Sperling: Disquisitio (Anm. 36), § 20, S. $18 \mathrm{f}$

40 Sperling: Disquisitio (Anm. 36), §§ 21-23, S. 19-22.

41 Theodor Kirchmaier, Johannes Heinrich Martius (resp.): De virgula divinatrice. Wittenberg 1669, Sectio 1, q. 2-9, fol. A3r-Br. Eine Quelle Kirchmaiers waren, wie er selbst betont, die Briefe des Vielschreibers und Grammatikers Samuel von Butschky. Zur Rute später Samuel von Butschky und Rutinfeld: Wohl-bebauter Rosen-Thal. Nürnberg 1679, Nr. 340, S. 728 731.

42 Kirchmaier: De virgula divinatrice (Anm. 40), Sectio 2, q. 1, fol. B2rf.

43 Kirchmaier: De virgula divinatrice (Anm. 40), Sectio 2, q. 2-3, fol. B3rf. 
Münzen noch immer reagieren können? ${ }^{44}$ Auch die okkulte Qualität kam für Kirchmaier wie schon für Sperling nicht in Frage. Artefakte wie die berühmten Handschuhe, von denen die Wünschelrutenfreunde gesprochen hatten, durften von ihr nicht betroffen sein. Eine qualitas occulta musste darüber hinaus die ganze Rute angreifen und nicht nur die Spitze, die in der Hand des Trägers ausschlug. Zu guter Letzt war das Holz der Rute tot und ihre forma konnte keinerlei Wirkung mehr entfalten. ${ }^{45}$ Auch für Kirchmaier blieb nach Ausschluss aller anderen Möglichkeiten nur eine Erklärung zurück, die Magie, die Inkantation eines Dämons und der Teufelspakt, der den Träger der Rute in die Lage versetzte, mit ihrer Hilfe die Silberader wahrzunehmen. Der Teufelsbund musste nicht explizit geschlossen worden sein, doch offenbarte er sich, wie Kirchmaier unterstreicht, in seinen Auswirkungen, dem vom Teufel vermittelten Wissen. Nur zu oft verkleidete sich der Engel des Finsternis als Engel des Lichtes und war die Straße vom einfachen Aberglauben zur Idolatrie breit gepflastert. Auch die scheinbar harmlosen Instrumente konnten dem ewigen Widersacher behilflich sein, den Menschen zu verderben. ${ }^{46}$

Es scheint, als wären die Wünschelrutengänger von der gottesfürchtigen Naturwissenschaft, die keine Grauzonen zulassen wollte, ins Reich der Finsternis verbannt worden. Tatsächlich aber hatte sich die Rute, getragen von der Euphorie zahlreicher frühkapitalistischer Glücksritter, zu sehr etabliert, um sich vom Verdikt des Schwarzpriestertums dauerhaft belasten zu lassen. Noch immer stand die offenkundige Praktikabilität der Rute daher im Raum. Es war so sicher kein Zufall, dass die Karten in den letzten Dekaden des 17. Jahrhunderts noch einmal neu gemischt wurden und die Dämonologen den Rückzug antreten mussten. Teile der akademischen Wissenschaft waren geneigt, dem Volksglauben und der mit ihr verbundenen Erfahrungswirklichkeit eine Legitimation zu liefern.

Matthes Wille, ein Paracelsist aus Sulza in Thüringen, veröffentlicht im Jahre 1671 einen der wirksamsten Traktate zur Wünschelrute, der sich im Ton ganz wie eine Werbeschrift geben kann, die Vera virgulae relatio. Ausdrücklich wendet sich Wille gegen die, wie er sagt, akademischen Disputationen seiner Zeit, die den Metalloskopen zum Nigromanten degradieren wollten. Gott selbst hatte Edelmetalle, Erze und Schätze im Erdinneren verborgen, um dem Menschen zu nutzen; er hatte ihnen auch die Instrumente in die Hand gegeben, um sie der Erde zu entreißen. ${ }^{47}$ Die Rute war ein Naturobjekt, dessen Kraft in der Schöpfung selbst angelegt war. Mehr rhetorisch distanziert sich Wille von den super-

44 Kirchmaier: De virgula divinatrice (Anm. 40), Sectio 2, q. 4, fol. B3v-Cv.

45 Kirchmaier: De virgula divinatrice (Anm. 40), Sectio 2, q. 5, fol. Cv-C2v.

46 Kirchmaier: De virgula divinatrice (Anm. 40), Sectio 2, q. 6-7, fol. C2v-C4r.

47 Matthias Wille: Vera Virgulae mercurialis relatio, das ist wahrhaftiger und gründlicher Bericht von der Wünschelruthen: wie solche zu Sultza an der Ilmen bey Ausgehung eines Saltzquells ohn all Superstition ist abgebrochen und zum öfftern gebrauchet worden. Jena 1671, Prooemium, fol. A3r-A4r. 
stitiösen Praktiken, den festen Schnittzeiten und begleitenden Gebeten, die den okkulten Charakter der Rute nahelegten. ${ }^{48}$ Der Schatzsucher bedurfte dieser Begleitumstände nicht. Das sympathetische System, auf dem die Wirkmacht des Schlagholzes beruhte, war von extremer Komplexität, und verband mehrere Ebenen, den Einfluss der Planeten und ihre Konstellationen, der richtigen Hölzer, die unter dem Influxus der betreffenden Gestirne standen, und die Metalle, die wiederum in Relation zu den Pflanzen und Planeten auszuwählen waren. ${ }^{49}$ Nur wer diese subtilen Gesetze beachtete und zudem in der Synkrasie der Elemente seines eigenen Leibes die ideale Kombination besaß, konnte mit der Rute erfolgreich sein. Es war so kein Wunder, wie Wille vermerkt, dass nicht alle Menschen als Metalloskopen in Frage kamen. ${ }^{50}$

Auch Wille hatte über das Gesetz der Sympathie hinaus keine wirkliche physikalische Erklärung für das Ausschlagen der Rute geben können. Johann Christian Frommann, ein Physiker aus Coburg, hatte seinen Traktat über die virgula gründlich studiert. Auch in seinem monumentalen Traktat über die Sympathie, De fascinatione, der auch auf die Wünschelrute eingeht, distanziert er sich im Jahre 1675 mit Nachdruck von den dämonologischen Ansätzen seiner universitären Kollegen. ${ }^{51}$ Die begleitenden Rituale konnten in keinem Bezug zur erfolgreichen Arbeit der Rute stehen. Nur weil noch kein Gelehrter das unmittelbare Ursachengeflecht im Detail freigelegt hatte, besaß die Wissenschaft nicht das Recht, die Gewalten der Unterwelt ins Spiel zu bringen. ${ }^{52}$ Dass ein Gegenstand sich in seiner Wirksamkeit der sinnlichen Erfahrung verweigerte, musste nicht gleichbedeutend sein mit seiner diabolischen Natur; die Erkenntnis schritt weiter voran und konnte neue Ursachen zutage fördern. Ort, Zeit und die konkrete Anwendung der Rute und eine Fülle von komplementären Rahmenbedingungen mussten möglichweise mit berücksichtigt werden, bis das völlige, alle Ursachen mit einschließende sympathetische Geflecht von Rute und Metall sich erkennen ließ. ${ }^{53}$ Niemand konnte derzeit wissen, ob bestimmte Eigenschaften des Schlagholzes akzidenteller Natur waren oder vielleicht doch notwendig. Auch dass die Rute von Magiern verwendet wurde, deklassierte sie nicht, eben-

48 Wille: Vera Virgulae mercurialis relatio (Anm. 46), Prooemium, fol. A4r, c. 2, fol. B2vf.

49 Wille: Vera Virgulae mercurialis relatio (Anm. 46), c. 3-6, fol. B3r-D3v. Hauptquelle der sympathetischen Symmetrie war für Wille August Etzler: Isagoge physico-magico-medica. Straßburg 1631 (zuerst 1610), dort zur Haselstaude als herba mercurialis S. 133-135.

50 Wille: Vera Virgulae mercurialis relatio (Anm. 46), c. 7, fol. D3v-E2v. Zu den Paradoxien des Willeschen Traktates gehört, dass er nicht nur mit Basilius Valentinus, sondern auch mit agronomischen und metallurgischen Autoritäten aufwarten konnte, darunter Erasmus Reinhold: Gründtlicher Bericht vom Feldmessen. Frankfurt a.M. 1615, oder Lazarus Ercker: Beschreibung der allerfurnemisten mineralischen Ertz- unnd Bergkwercksarten. Frankfurt a.M. 1580, die seinen Gegenstand gar nicht enthielten.

51 Christian Frommann: Tractatus de fascinatione novus et singularis. Nürnberg 1675, Liber III, Pars V, c. 4, §§ 1-2, S. 688-690.

52 Frommann: Tractatus (Anm. 50), Liber III, Pars V, c. 4, §§ 3-4, S. $690 f$.

53 Frommann: Tractatus (Anm. 50), Liber III, Pars V, c. 4, §§ 5-6, S. 691f. 
so wenig wie Feuer oder Wasser ihre gottgeschaffene Natur verloren, wenn sie bei einem okkulten Ritus mit herangezogen wurden. ${ }^{54}$

\section{Atomismus und Wünschelrute}

1 Pierre Lorrain de Vallemont und seine Anhänger

Auf Frommanns Aufruf, der Wissenschaft eine Chance zu geben, und seinen Erkenntnisoptimismus antwortet im Jahre 1693 jener Autor, der die ostentative Verwissenschaftlichung der Rute gewissermaßen auf die Spitze trieb, Pierre Lorrain de Vallemont. Die Grenze, die für die Mehrzahl der Gelehrten bisher zwischen Wissenschaft und Dämonologie verlaufen war, sollte fortan zwischen selbstproklamierter Wissenschaftlichkeit und dem Vorwurf der Scharlatanerie verlaufen, also je nach Perspektive zwischen Wissenschaft und PseudoWissenschaft. Es war Lorrain, der paradigmatisch zahlreiche Ergebnisse und Thesen der zeitgenössischen Naturphilosophie aufgriff und ins Feld führte, um die Rute als Sieg der Naturwissenschaft zu apostrophieren. Vallemont war vorher vor allem mit Arbeiten zum Magnetismus hervorgetreten. Die Jesuiten, aber vor allem Robert Boyle und Pierre Gassendi, werden dem Franzosen zu den entscheidenden Autoritäten. Vallemont bleibt den Leitideen der Exhalation und der Sympathie in seiner fast 500 Seiten starken Auseinandersetzung mit der Rute, der Physique occulte, treu, doch überträgt er sie in die Sprache des aktuellen Atomismus. Eine feinstoffliche, auf Elementarteilchen beruhende Kausalität, gestützt auf noch unsichtbare Reiz-Reaktionen, garantierte die Funktionsfähigkeit der Rute. Ihre mikroskopisch kleine und selektive, aber dennoch notwendige Wirksamkeit musste auch jene vermeintlichen Eigenheiten erklären, die die Rute zuvor in den Augen ihrer universitären und kirchlichen Kritiker diskreditiert hatten.

Anlass zur Abfassung seines Traktates war für Vallemont ein Fall, der an den französischen Akademien für Aufmerksamkeit, aber mehr noch für Spott gesorgt hatte und nicht zuletzt Pierre Bayle veranlassen sollte, in seinem Wörterbuch unter dem Lemma Abaris auch auf die Wünschelrute einzugehen. ${ }^{55}$ Ein Jahr vor der Publikation war es einem französischen Landmann mit Namen Jacques Aymar gelungen, die Mörder eines Lyoneser Weinhändlers mit der Wünschelrute ausfindig zu machen. ${ }^{56}$ Er hatte den Tatort mit seinem Instrument einer Autopsie unterzogen, die Rute hatte ausgeschlagen und Aymar war es gelungen, die Schuldigen, zwei Provenzalen, über 45 Meilen zu Land und 30

54 Frommann: Tractatus (Anm. 50), Liber III, Pars V, c. 4, §§ 7-8, S. 692-694.

55 Pierre Bayle: s.v. Abaris. In: Dictionnaire historique et critique, Bd. 1, Basel 1738 (3. Auflage), dort S. 5-7.

56 Pierre Lorrain de Vallemont: La physique occulte, ou Traité de la Baguette divinatoire. Amsterdam 1693, Preface (ohne Seitenzählung), und c. 2, S. 26-48. Lorrain de Vallemonts Traktat erschien deutsch als Pierre Lorrain de Vallemont: Der heimliche und unerforschliche Natur-Kündiger, oder: Accurate Beschreibung von der Wünschel-Ruthe. Nürnberg 1694, dort die Vorrede (ohne Seitenzählung), und c. 2, S. 27-48. 
Meilen zu Wasser, wie es hieß, zu verfolgen und sie schließlich in einem Gasthaus im Süden verhaften zu lassen. ${ }^{57}$ War hier nicht die Grenze des Sinnvollen endgültig überschritten worden? In den ersten akademischen Repliken auf den Fall hatte man den Teufel am Werk gesehen. ${ }^{58}$ Weder der Rückbezug auf vage qualitates occultae, noch die einfache Behauptung, Ausdünstungen, vapores, wären für die exorbitante Reichweite der Rute verantwortlich, konnten in vergleichbaren Fällen jedoch helfen, den Erfolg der Rute zu rekonstruieren, wie Lorrain de Vallemont deutlich macht, geschweige denn Dämonen, die an der Dingfestmachung eines Mörders wohl kaum ein Interesse haben konnten. Feinstoffliche Atome, die ständig abgesondert wurden und auf ihre Umwelt einwirkten, umgaben jedes materielle Objekt, wie Gassendi, und, so Vallemont, auch Descartes gelehrt hatten. Ihr Fluidum erklärte den Aktivitätsradius eines jeden Gegenstandes, seine sphaera activitatis. ${ }^{59}$ Freischwebende Atome drangen in andere Objekte ein, kollidierten in ihren Poren mit anderen Atomen und versetzten den anderen Gegenstand in Bewegung. Die Relation von Rute, Wasserquelle, Metallader, aber auch Handschuh und Mörder ließ sich auf dieser Ebene hinreichend erklären, wie Vallemont mit Nachdruck betont. Es war ein rein mechanischer Vorgang, der sich zwar der sinnlichen Wahrnehmung verweigerte, doch keine causae secundae in Anspruch nehmen musste. Schon auf der Ebene der Intuition, der groben Ahnung eines Gegenstandes, war die feinstoffliche Wirkung auf den menschlichen Tastsinn als vages und unbestimmbares Gefühl durchaus spürbar. Auch Jagdhunde brachten ihre Beute durch eine atomistische Affektion ihrer Sinnesorgane zur Strecke; Robert Boyle hatte gezeigt, dass der bloße Geruch bestimmter Pflanzen auf der Ebene der transportierten Atome bereits eine purgierende Wirkung haben konnte. Der weitere technische Fortschritt, der auch die Kleinstlebewesen Leuwenhoecks ans Licht gebracht hatte, würde daher, wie Vallemont betont, auch die Wechselwirkung der Atome zur

57 Im Unterschied zur mitteldeutschen Debatte hat die französische Diskussion der Wünschelrute inzwischen erhebliche Aufmerksamkeit erhalten. Ausführlich zum Kasus Aymars und seiner Aufarbeitung durch Vallemont vgl. Michael R. Lynn: Diving the Enlightenment. Public Opinion and Popular Science in Old Regime France. In: Isis 92 (2001), S. 34-54, und Koen Vermeir: The Physical Prophet and the Powers of Imagination II: a case study on dowsing and the naturalisation of the moral (1685-1710). In: Studies in the History and Philosophy of Science 36 (2005), S. 1-24. Die niederländische Reaktion auf Aymar und Vallemont und die Einlassungen Bayles rekonstruiert Koen Vermeir: Circulation Knowledge or Superstition? The Dutch Debate on Divination. In: Silent Messengers. The Circulation of Material Objects of Knowledge in the Early Modern Low Countries. Hrsg. von Sven Dupré und Christoph Lüthy. Berlin 2011, S. 293-328.

58 Johann Joachim Zentgraf, Johannes Georg Le Conte (resp.): Ex legibus Ebraeorum forensibus contra magiam de divinationibus magicis eaque occasione de virgula divina et divinatione nupera Jacopo Aymari. Straßburg 1694, Corrollarium, § 18-28, S. 22-28.

59 Lorrain de Vallemont: La physique occulte (Anm. 55), c. 3, S. 40-70, deutsch Lorrain de Vallemont: Der heimliche und unerforschliche Natur-Kündiger (Anm. 55), c. 3, S. 49-72. 
Gänze freilegen und in einen ausreichenden Erklärungszusammenhang stellen. ${ }^{60}$ Bereits in dieser Epoche wusste man, dass die ganze Erde von einer Hülle von kleinsten Partikeln umgeben war, die das Ausschlagen einer Kompassnadel erklärbar machte. Wie eine Wünschelrute legte sich auch diese Magnet-Nadel parallel zu den Atomen, die um die Erde fluktuierten. ${ }^{61}$

Schon jetzt bot die atomistische Perspektive also die Möglichkeit, so Vallemont, fast alle Fragen, die mit der Rute verbunden waren, mit neuer Bedeutung zu füllen. Unterirdische Wasserquellen sandten Atome aus, drangen an die Erdoberfläche, fanden Eingang in die mikroskopisch kleinen Poren der Haselstaude, kollidierten mit ihren Elementarpartikeln und sorgten für die Bewegung der Rute. ${ }^{62}$ Dass Wasseradern, vom Erdfeuer angetrieben, vergleichbare Ausdünstungen produzieren konnten, war auch den Jesuiten, darunter Kircher, Jean François, Claude François Milliet de Chales oder Caspar Schott, die sich mit dem unterirdischen Kreislauf des Wassers und dem Brunnenbau befasst hatten, schon bewusst gewesen. ${ }^{63}$ Das innere Feuer der Erde, das die Metallbildung im Erdinneren forcierte, veranlasste auch die unterirdischen Erze, in winzigen Partikeln atomare Transmissionen in die Luft $\mathrm{zu}$ treiben, die auf die Rute die gleiche Wirkung ausüben konnten. ${ }^{64}$ Auch vorher schon hatten Theoretiker der Erdwärme wie Jean-Baptiste Morin, Joseph Maria Maraviglia oder eben Kircher diese Exhalationen beschrieben, wie Vallemont bemerkt, aber noch nicht mit der Wünschelrute in Verbindung gebracht. ${ }^{65}$ In Wirklichkeit lag hier, auf der Ebene einer atomaren Ursächlichkeit, die Antwort auf alle Unklarheiten. Dass nicht jedes Holz auf jedes Metall ausschlug, verdankte sich dabei, wie Vallemont erklären kann, der unterschiedlichen Konsistenz der Poren, in die das metallische Atom Zugang zu finden hatte. Nach dem gleichen Prinzip - man ahnt es bereits - waren auch die Mörder des französischen Weinhändlers aufgespürt worden. Eine nur der Rute zugängliche transpiratio insensibilis, gleichsam der fein-

60 Lorrain de Vallemont: La physique occulte (Anm. 55), c. 4, S. 70-93, deutsch Lorrain de Vallemont: Der heimliche und unerforschliche Natur-Kündiger (Anm. 55), c. 4, S. 72-95.

61 Lorrain de Vallemont: La physique occulte (Anm. 55), c. 5, S. 93-109, deutsch Lorrain de Vallemont: Der heimliche und unerforschliche Natur-Kündiger (Anm. 55), c. 5, S. 96-113.

62 Lorrain de Vallemont: La physique occulte (Anm. 55), c. 6, S. 110-131, deutsch Lorrain de Vallemont: Der heimliche und unerforschliche Natur-Kündiger (Anm. 55), c. 6, S. 114-135.

63 Jean François: La science des eaux, qui explique en quatres parties leur formations, communications, movemens, et meslanges, avec les artes de conduire les eaux, et mesurer la grandeur des eaux que des terres. Rennes 1653, dort bes. Prèmiere Partie, §§ 1-9, S. 1-32; Claude François Milliet de Chales: Cursus seu Mundus mathematicus (3 Bde.). Lyon 1690, Bd. 3, Tractatus 17, S. 112-144, bes. Propositio 16, S. 123-126; Caspar Schott: Physica curiosa sive mirabilia naturae et artis libris XII comprehensa (2 Bde.). Nürnberg 1667, Bd. 2, Liber XI, c. 1, S. 1181-1186.

64 Lorrain de Vallemont: La physique occulte (Anm. 55), c. 7, S. 131-155, deutsch Lorrain de Vallemont: Der heimliche und unerforschliche Natur-Kündiger (Anm. 55), c. 7, S. 135-159.

65 Jean-Bapiste Morin: Nova mundi sublunaris anatomia. Paris 1619, Relatio de locis subterraneis, S. 116-144; Joseph Maria Maraviglia: Proteus ethicopoliticus seu de multiformi hominis statu ad normam virtutis concinnato. Venedig 1660, Lex XI, S. 56-62. 
stoffliche Schweiß des Verbrechens, war von Aymar als impression aufgenommen worden, so Vallemont, und hatte das Schlagholz auf den Gesuchten ausgerichtet. Die atomare Spur war stark genug gewesen, um die Täter durch halb Frankreich zu verfolgen. ${ }^{66}$ Auch hier hatte es Jesuiten wie Francesco de Lana Terzi gegeben, die in ihrer Theorie der Transpiration bereits das Fundament gelegt hatten. ${ }^{67}$

Lorrain de Vallemonts Ansatz war gleichsam selbsterklärend, zugleich bot er die Option auf die finale Aufklärung des Rutenphänomens, die sicher nur wenige Jahre auf sich warten ließ. Es kam wie erwartet: Die Wünschelrutengänger affirmierten die atomistischen Erklärungen Vallemonts mit Begeisterung, fanden sie hier doch die akademische Dignifizierung ihrer eigenen Tätigkeit; die Gegner konnte dieses Modell, das sich in den Autoritäten der Gegenwartsphysik sonnte, nicht von der Ernsthaftigkeit des Schlagholzes überzeugen. Einen seiner vielen Anhänger fand Vallemont im Schweden Johann Hermansson, der auf die skandinavische Erfolgsgeschichte der Wünschelrute, der slagruta, in einer eigenen akademischen Disputation in Uppsala antwortete. Keine drei Jahrzehnte nach den deutschen Arbeiten geht auch Hermansson in seiner Abhandlung nach dem Ausschlussverfahren vor; doch kommt er zu einem diametral anderen Ergebnis. Das Schlagen der Rute war nicht diabolischer in seiner Natur als das Gerinnen von Butter. ${ }^{68}$ Eine atomare Exhalation, das Hervorquellen der Partikel in Gestalt einer effluvia atomorum, stellte den Kontakt zwischen Rute und Metall her. Es waren die gleichen Atome, die auch die Phänomene der Faszination erklärten, die Tatsache, dass menstruierende Frauen den Gärungsprozess von Bier unterbrechen konnten, und die im Kern auch alle Erscheinungen des Magnetismus plausibel machten. ${ }^{69}$ Auch dass nicht jeder Mensch als Medium der Rute qualifiziert war, das Hauptargument der Dämonologen, ließ sich leicht durch den Atomismus entkräften. Blut, Muskeln und Körperwärme hatten eine feinstoffliche und fast individuierende Entsprechung, nicht in alle Poren drangen die atomaren Bestandteile des Metalls und waren in der Lage, eine Reaktion hervorzurufen. ${ }^{70}$ Kein Teufelspakt war vonnöten, wie Hermansson noch einmal betont. ${ }^{71}$

66 Lorrain de Vallemont: La physique occulte (Anm. 55), c. 8-9, S. 155-229, deutsch Lorrain de Vallemont: Der heimliche und unerforschliche Natur-Kündiger (Anm. 55), c. 8-9, S. 159-235.

67 Francesco de Lana Terzi: Magisterium Naturae et Artis opus physico-mathematicum (3 Bde.). Brixen 1684-92, Bd. 2, Tractatus IV, Liber II, c. 1-3, S. 54-87.

68 Johann Hermansson, Johannes Maehlin (resp.): Specimen cogitationum de virgula divinatoria. Uppsala 1718, c. 2, §§ 1-2, S. 10-12.

69 Hermansson, Maehlin: Specimen cogitationum (Anm. 67), c. 2, §§ 3-9, S. 12-24.

70 Hermansson, Maehlin: Specimen cogitationum (Anm. 67), c. 3, §§ 1-4, S. 24-35.

71 Hermansson, Maehlin: Specimen cogitationum (Anm. 67), c. 3, §§ 6-7, S. 37-39. 


\section{Die Wünschelrute als Witz: Johann Gottfried Zeidler}

Mit Vallemonts Anhängern hätte der Siegeszug der Wünschelrute an sein Ende gelangt sein können. Schon der gern als leichtgläubig gescholtene Kircher freilich hatte, wie wir sahen, eine Erklärung vorgelegt, die uns bis heute den gesunden Menschenverstand zu artikulieren scheint. Das Schlagen der Rute beruhte auf bloßer Einbildung. Eine Gruppe von Autoren konnte Kircher beipflichten, darunter Adolph Beyer in seinen Otia metallica, einer mit Anekdoten angereicherten Einführung in die Bergmannskunst, ${ }^{72}$ oder sein Namensvetter August Beyer in seinem Gründlichen Unterricht vom Berg-Bau. Der Träger der Rute hatte eine von dunklem Fachwissen getragene Ahnung, und die Rute schlug von seiner Phantasie geleitet aus; der Rutengänger hätte die Ader jedoch zum Ende auch ohne sein Instrument gefunden. ${ }^{73}$

Härter ins Gericht vor allem mit Lorrain de Vallemonts physikalischer Erklärung geht im Jahre 1700 der heute fast vergessene Wissenschaftssatiriker Johann Gottfried Zeidler, ${ }^{74}$ der dem Franzosen eine 600 -seitige von bizarrem Humor getragene Widerlegung schenkt. Zeidler verwirft den Erklärungsfuror Vallemonts in Bausch und Bogen, wenn auch nicht mehr durch neue Argumente, sondern indem er ihre Motive auf die Spitze treibt und sich selbst als großen Experimentator inszeniert. Der Gedanke, dass wenige aus dem Erdboden quellende Atome genügen sollten, um eine Rute in Schwung zu versetzen, war ähnlich absurd, wie der Plan, so Zeidler, einen westfälischen Bauern mit dem eige-

72 Adolph Beyer: Otia metallica, oder Bergmännische Neben-Stunden (3 Bde.). Schneeberg 1748-58, Bd. 3, Nr. 5, § 34, S. 250, Nr. 9, § 1, S. 430.

73 August Beyer: Gründlicher Unterricht vom Berg-Bau, nach Anleitung der MarckscheiderKunst. Schneeberg 1748, Pars I, c. 10, S. 9-11.

74 Johann Gottfried Zeidler hat bisher kaum Beachtung gefunden. Zu seinen erfolgreichsten Werken zählen, schon im Titel vielsagend, Johann Gottfried Zeidler: Ihre Praecellentz, die Noologia oder Versteherey, als Archiv-Secretarin, der 9. Kunstgöttinnen, wie auch ErtzSchreinhalterin der hochpreißwürdigen lateinischgesinnten Genossenschafft, allen Unlateinischen zur Verwunderung aus den lateinischen Grundtext in unsere hochdeutsche Frau Muttersprache getreulich übersetzet. Halle a.S. 1699, ders.: Die Wohl-Ehrwürdige, Grossachtbare und Wohlgelahrte Metaphysica oder Über-Naturlehre, als die Königin aller Wissenschafften, und hochbetraute Leib-Magd oder Kammer-Jungfer der Theologiae terminiloquae, allen Unlateinischen zur Verwunderung aus dem lateinischen Grund-Text übersetzet. Halle a.S. 1699; und ders.: Die Hoch-Edle, Veste und Hoch-Gelahrte Gnostologia oder Allwisserey, als Ober-Hoff-Marschallin und geheimde Räthin der Neun Kunst-Göttinnen, wie auch Vorsitzerin, Zunfftmeisterin und Regiments-Quartier-Meisterin der hoch-preiß-würdigen Lateinisch gesinneten Genossenschafft, allen Unlateinischen zur Verwunderung aus dem Lateinischen Grund-Text in unsere hochdeutsche Helden-Frau Mutter-Sprache getreulich übersetzet. Halle a.S. 1699. Die beiden letzten Werke sind 2008 in Klagenfurt neu herausgegeben worden. Eine kurze Einschätzung Zeidlers als Wissenschaftssatiriker gibt Nicola Roßbach: „die selbst-eigene Erfahrung zuhülffe nehmen“. Der Maschinenbauer Jacob Leupold und die epistemische Zäsur um 1700. In: Die Sachen der Aufklärung. Beiträge zur DGEJ-Jahrestagung 2010 in Halle a.S. Hrsg. von Frauke Berndt und Daniel Fulda. Hamburg 2012, S. 448-456, hier S. 448, S. 456. 
nen Mundgeruch aus der Kneipe zu ziehen. ${ }^{75}$ Wenn Atome auf Atome eine so subtile Wirkung ausüben konnten, mussten sie sich überall mit ähnlicher Intensität artikulieren. Die ersten sogenannten Versuche Zeidlers mit der Wünschelrute lassen den Rutengänger daher auch mit wild rotierender und um sich schlagender Rute über die Felder ziehen; auch Salatköpfe werden zerhämmert und sein vierjähriger Sohn erhält unfreiwillig eine gediegene Tracht Prügel, denn die feinstofflichen Membranen der Rute mussten Allerortens auf Elementarteilchen treffen, die sie in Bewegung hielten. ${ }^{76}$ Später gelingt es Zeidler, wie er berichtet, das System zu perfektionieren. Er findet einen Schatz mit Hilfe von Stricknadeln, ${ }^{77}$ baut Ruten aus Scheren und Knackwürsten, ${ }^{78}$ lernt, wie die Rute bei richtigen Syllogismen ausschlägt oder offenbart, ${ }^{79}$ ob der Hamster unter der Erde allein wohnt oder mit seinem Weibchen. ${ }^{80}$ Schließlich glückt es Zeidler auch, den Brudermord Kains anhand seiner Atomspur durch die Weltgeschichte $\mathrm{zu}$ verfolgen. ${ }^{81}$

Wie bei allen Witzen über 600 Seiten stellt sich beim Leser eine gewisse Ermüdung ein, doch hatte Zeidler deutlich gezeigt, zu welch' paradoxen Schlussfolgerungen das Atommodell Vallemonts in seinen Anwendungen im Detail führen musste, wenn man seine theoretischen Voraussetzungen akzeptieren wollte. ${ }^{82}$ Auch Zeidler fand zwar noch einmal einen Gegner, Johann Michael Weise, der Zeidlers Ironisierung der Rute nicht goutieren konnte, sondern sich, wiederum auf insgesamt 700 Seiten in seinem Entdeckten Idolum der Wünschelrute, noch einmal für den dämonischen Charakter der Rute stark machte. ${ }^{83}$ Weise, der seine Schriften schon unter dem Pseudonym Theophilus veröffentlichte, sollte einer der letzten gewesen sein, der dieser Meinung anhing, und musste sich in

75 Johann Gottfried Zeidler: Pantomysterivm, oder Das Neue vom Jahre in der Wündschelruthe, als einem allgemeinen Werckzeuge menschlicher verborgenen Wissenschafft, darinnen ihre Natur und Ursach ihrer Bewegung, auch weitläufftiger Gebrauch und Nutz aus des Autoris eigener Erfahrung, und Physicalischen Grundlehren philosophisch ausgeführet, und der gelehrten Welt zu weitern Nachsinnen übergeben wird. Halle a.S. 1700, Erstes Hauptstück, c. 1, S. 9f.

76 Zeidler: Pantomysterivm (Anm. 74), Erstes Hauptstück, c. 1, S. 28-30.

77 Zeidler: Pantomysterivm (Anm. 74), Viertes Hauptstück, c. 1, S. 119f.

78 Zeidler: Pantomysterivm (Anm. 74), Zweites Hauptstück, c. 2, S. 44.

79 Zeidler: Pantomysterivm (Anm. 74), Viertes Hauptstück, c. 4, S. 142f.

80 Zeidler: Pantomysterivm (Anm. 74), Erstes Hauptstück, c. 1, S. 34.

81 Zeidler: Pantomysterivm (Anm. 74), Viertes Hauptstück, c. 3, S. 136f.

82 Dass Zeidlers Traktat auch heute nicht mehr gründlich gelesen wird, zeigt z.B. die Arbeit von Heide Klinkhammer: Schatzgräber, Weisheitssucher und Dämonenbeschwörer: Die motivische und thematische Rezeption des Topos der Schatzsucher in der Kunst vom 15. bis zum 18. Jahrhundert. Berlin 1993, S. 120f., die das Werk für eine ,Verteidigungsschrift' der Wünschelrute hält.

83 Johann Michael Weise (Theophilus Albinus): Das entlarvte Idolum der Wünschelruthe, oder gründliche Untersuchung, was bishero historice mit derselben passiert, ob sie physice in der Natur gegründet und wiefern moraliter zu operiren sey. Dresden 1704, dort bes. Sectio III, c. 2, q. 8-10, S. 535-585. 
der Debatte um die Rute schon fast als Anachronismus begreifen lassen. Ein ähnlicher Streit um die dämonische Natur der Rute wurde im Anschluss an Weise noch 1734 in Wittenberg ausgetragen. ${ }^{84}$ Eine dritte Gruppe von Autoren rang sich in der Mitte des 18. Jahrhunderts schließlich endgültig dazu durch, das Schlagholz und seine sympathetische Funktion zur Gänze als Schwachsinn abzutun. Als der Geologe Johann Gottlob Krüger im Jahre 1746 abermals einen Selbstversuch mit der Wünschelrute unternimmt, kommt er zu einem ernüchternden Ergebnis: Der Träger drückte die Rute zusammen, doch nach einem gewissen Zeitraum waren seine Muskeln fast zwangsläufig genötigt, den Druck zu lockern, und die Rute schlug aus. Ihre Bewegungen waren ein Produkt des Zufalls. ${ }^{85}$ Auch der Verfasser eines anonymen Traktates aus dem Jahre 1757 teilt die Argumente Krügers. ${ }^{86}$

Es ist kein Geheimnis, dass die Kette der Verwissenschaftlichungen, die für die Wünschelrute unternommen wurden, auch in der Mitte des 18. Jahrhunderts nicht abbrechen sollte. 1764 macht der schwedische Chemiker Johann Wallerius, kein Unbekannter seines Fachs, den Vorschlag, den Faktor der Elektrizität in die Beurteilung der Rute mit einzuschließen. Vielleicht arbeitete das Schlagholz aufgrund von unterirdischen Stromstößen oder Energiefeldern, deren Reichweite erst noch erforscht werden musste. ${ }^{87}$ Dennoch war mit der Mitte des 18. Jahrhunderts der Teufel und die verbotene Magie endgültig aus dem Hypothesenkanon der Wünschelrutenfreunde und -gegner verschwunden, und, wie sich vielleicht zum Ende als Ergebnis festhalten lässt, mit ihr, wie die Rute symptomatisch zeigen kann, auch die Diskursfähigkeit der Magie als ganzer innerhalb der akademischen Debatten. Anders als noch fünfzig Jahre vorher, bedurfte es des Teufels nicht mehr, um Aberglauben, Dummheit und Wissenschaft voneinander zu trennen.

84 Gegen die Rute wandte sich Johann Friedrich Wernher, Friedrich Florens Rivinus (resp.): Dissertatio inauguralis de finibus per virgulam mercurialem non investigandis. Von Aufsuchung der Grenzen durch Wünschel-Ruthen. Wittenberg 1734, dort z.B. §§ 26-31, S. 31-36. Noch einmal geht Wernher mit einem neuen Respondenten auf die Angelegenheit ein, nachdem der Rechtsgelehrte Johann Christoph Meinig Zweifel an seinem Urteil geäußert hatte, dazu Johann Friedrich Wernher, Johannes Hiob Thilemann (resp.): Vindiciae dissertationis de finibus per virgulam mercurialem non investigandis. Wittenberg 1734, dort $\S \S 6-$ 20, S. 6-27, mit unveränderter Haltung.

85 Johann Gottlob Krüger: Geschichte der Erde in den allerältesten Zeiten. Halle a.S. 1746, § 55, S. 99-102.

86 Gedanken über das Schlagen der Wünschelruthe auf die in der Erde verborgenen Erze und Metalle, aufgesetzet von einem Liebhaber der Bergwerkswissenschaften. Eisenach 1757, dort bes. S. 13-18.

87 Johann Gottschalk Wallerius, Petrus Adolph Ahlbom (resp.): Dissertatio gradualis de virgula divinatoria. Stockholm 1764, § 6, S. 7f. 
(C) 2015, Otto Harrassowitz GmbH \& Co. KG, Wiesbaden ISBN Print: 9783447104951 - ISBN E-Book: 9783447194129 


\section{Farbabbildungen}

(C) 2015, Otto Harrassowitz GmbH \& Co. KG, Wiesbaden 
(C) 2015, Otto Harrassowitz GmbH \& Co. KG, Wiesbaden ISBN Print: 9783447104951 - ISBN E-Book: 9783447194129 
Abb. 1 zu Schnyder, Der vierte Sohn Noahs (S. 61)

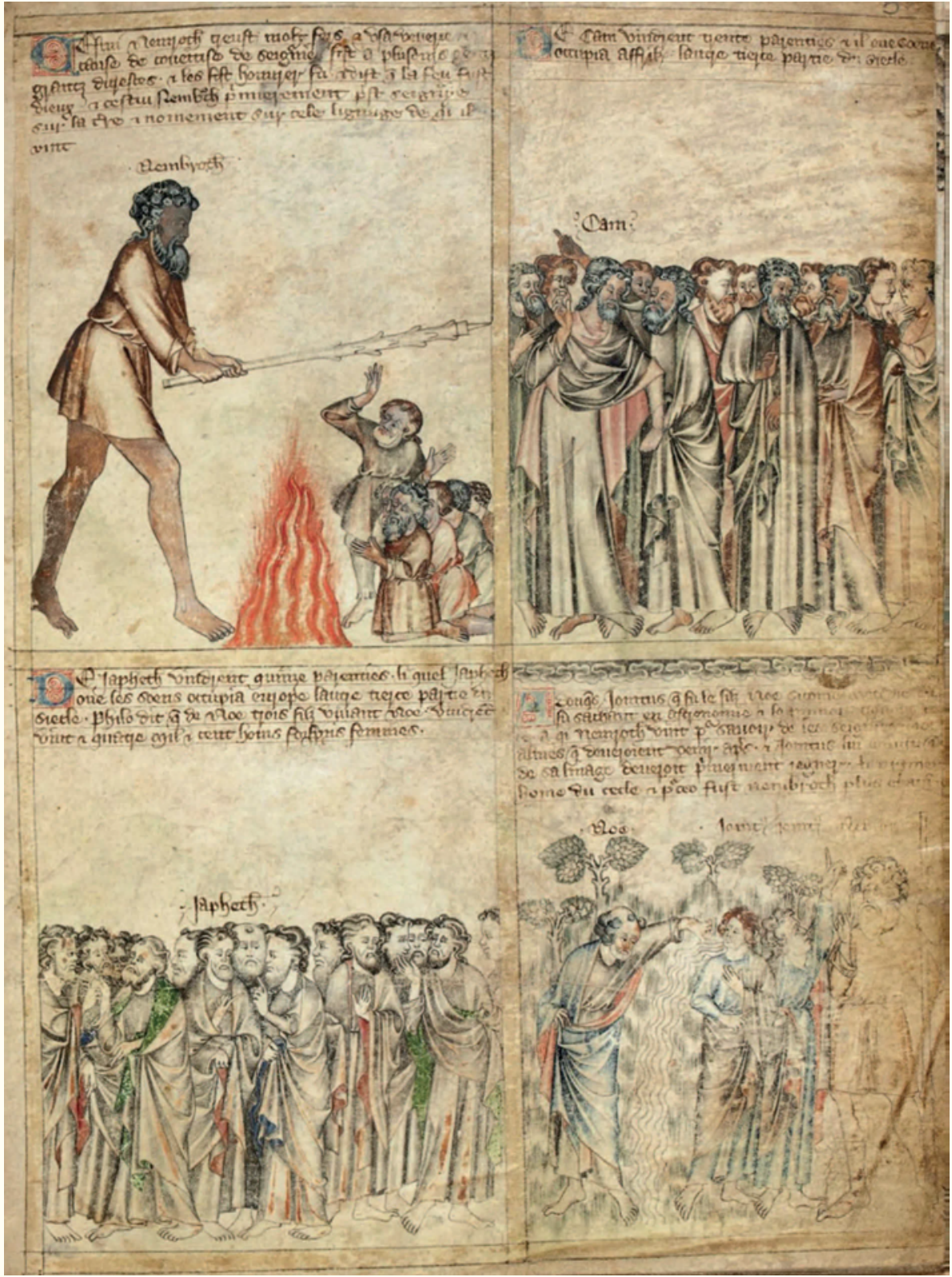

Ms. Egerton: Pictorial Illustrations of the Book of Genesis XIV. Century, 1894, fol.5r (letztes Drittel 14. Jh.), URL: http://www.bl.uk/manuscripts/Viewer.aspx?ref=egerton_ms_1894_f005r (22.10.2014). 
Abb. 2 zu Schnyder, Der vierte Sohn Noahs (S. 62)

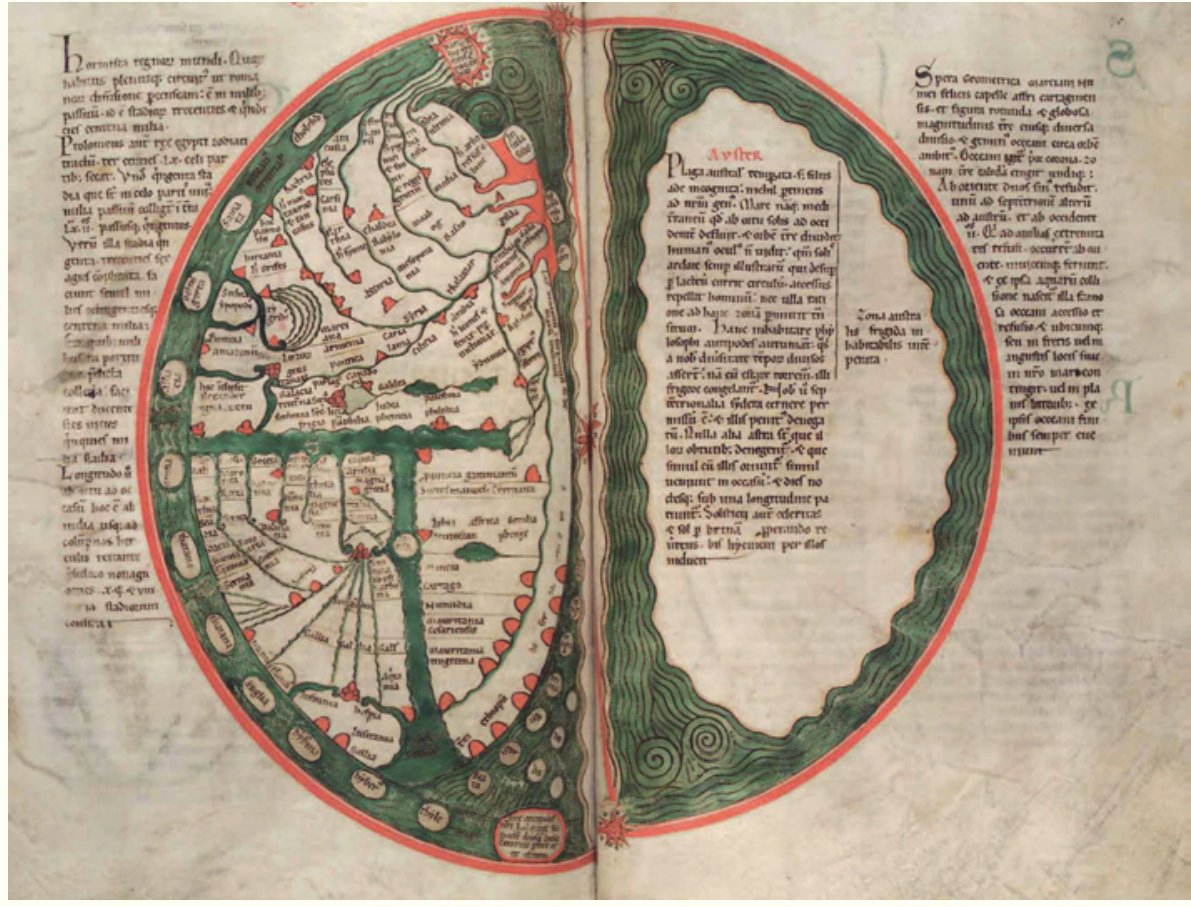

Lambert von Saint-Omer: Liber floridus, Cod. Guelf. 1 Gud. lat., fol. 69v-70r (ca. 1180); Wolfenbüttel Katalog-Nr. 4305), URL: 69v: http://diglib.hab.de/mss/1-gud-lat/start.htm?image=00144; 70r: http://diglib.hab.de/mss/1-gud-lat/start.htm?image=00145 (22.10.2014). 
Abb. 3 zu Schnyder, Der vierte Sohn Noahs (S. 63)

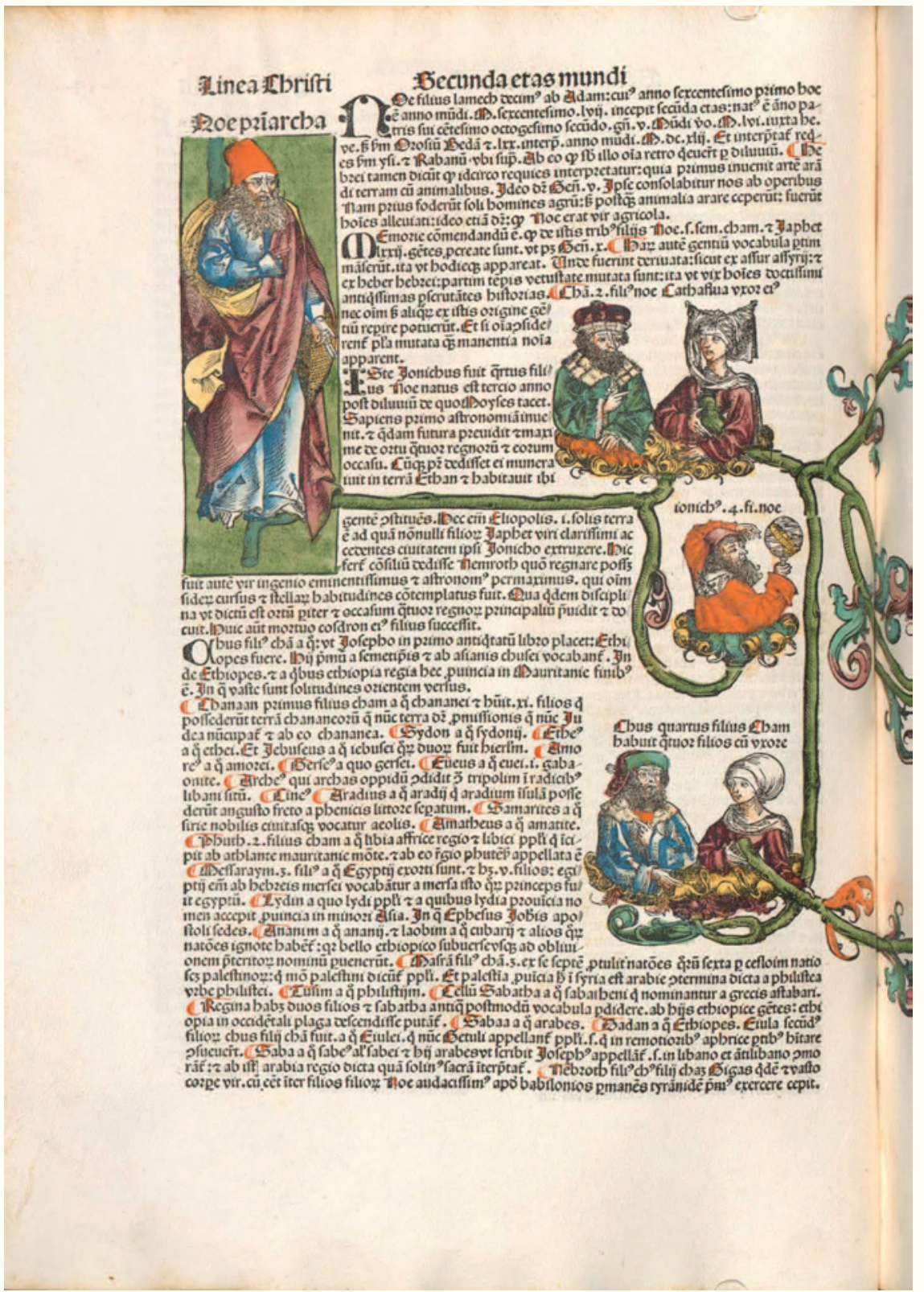

Schedelsche Weltchronik, Nürnberg 1493, xiiiiv: Hartmann Schedel, Michael Wolgemut und Wilhelm Pleydenwurff: Liber chronicarum, Nürnberg, 1493.07.12, xiiiiv, URL: http://daten.digitale-sammlungen.de/ db/0003/bsb00034024/image_99 (22.10.2014). 
Abb. 4 zu Wittstock, Transmutation und Veredelung (S. 116)

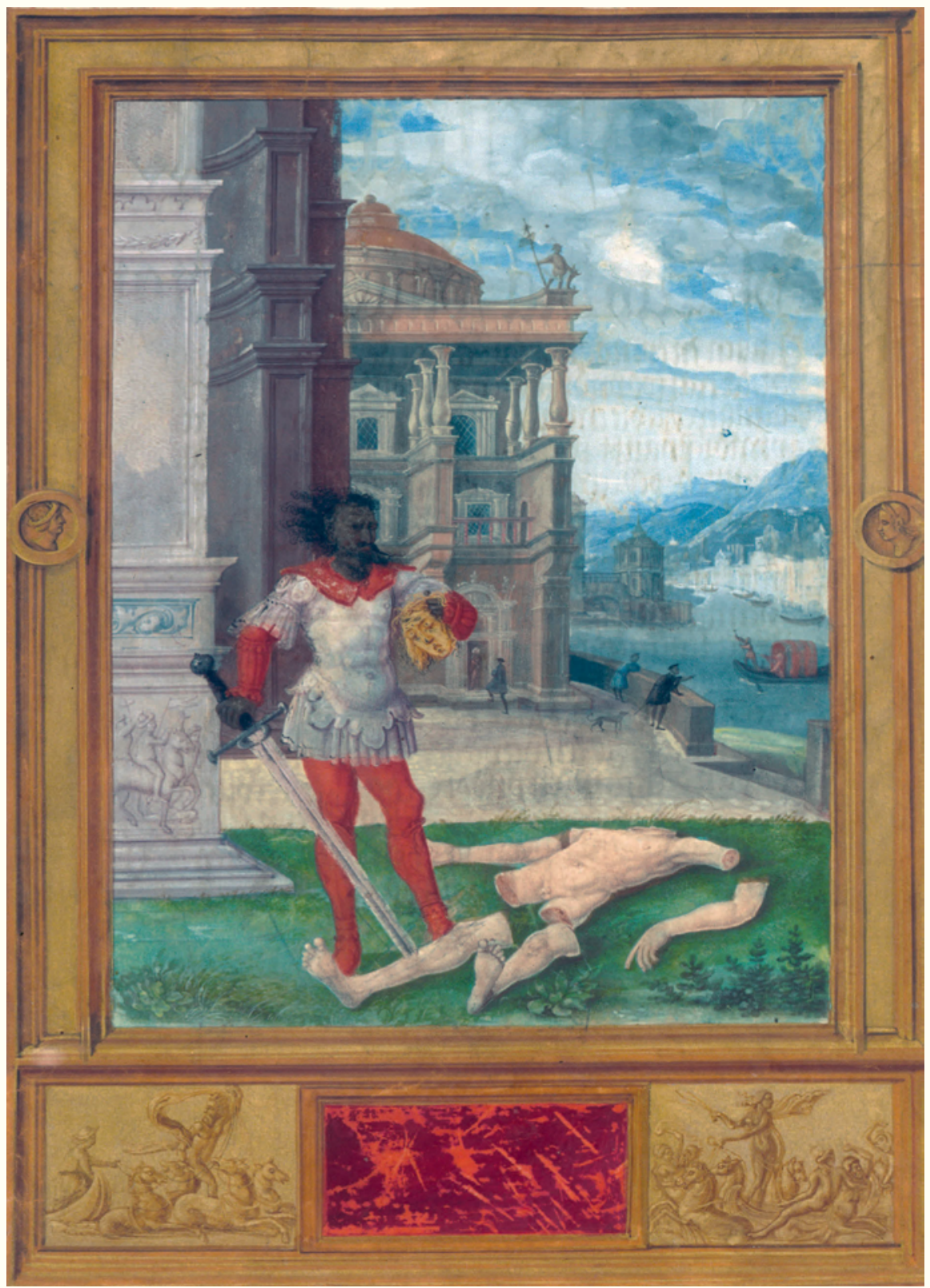

,Zerstückelung' im Splendor Solis, Berlin, Kupferstichkabinett, Cod. 78 D 3, fol. $18^{v}$. bpk / Kupferstichkabinett, SMB / Jörg P. Anders 
Abb. 5 zu Wels, Alchemie als Gegenstand der Wissensgeschichte (S. 256)

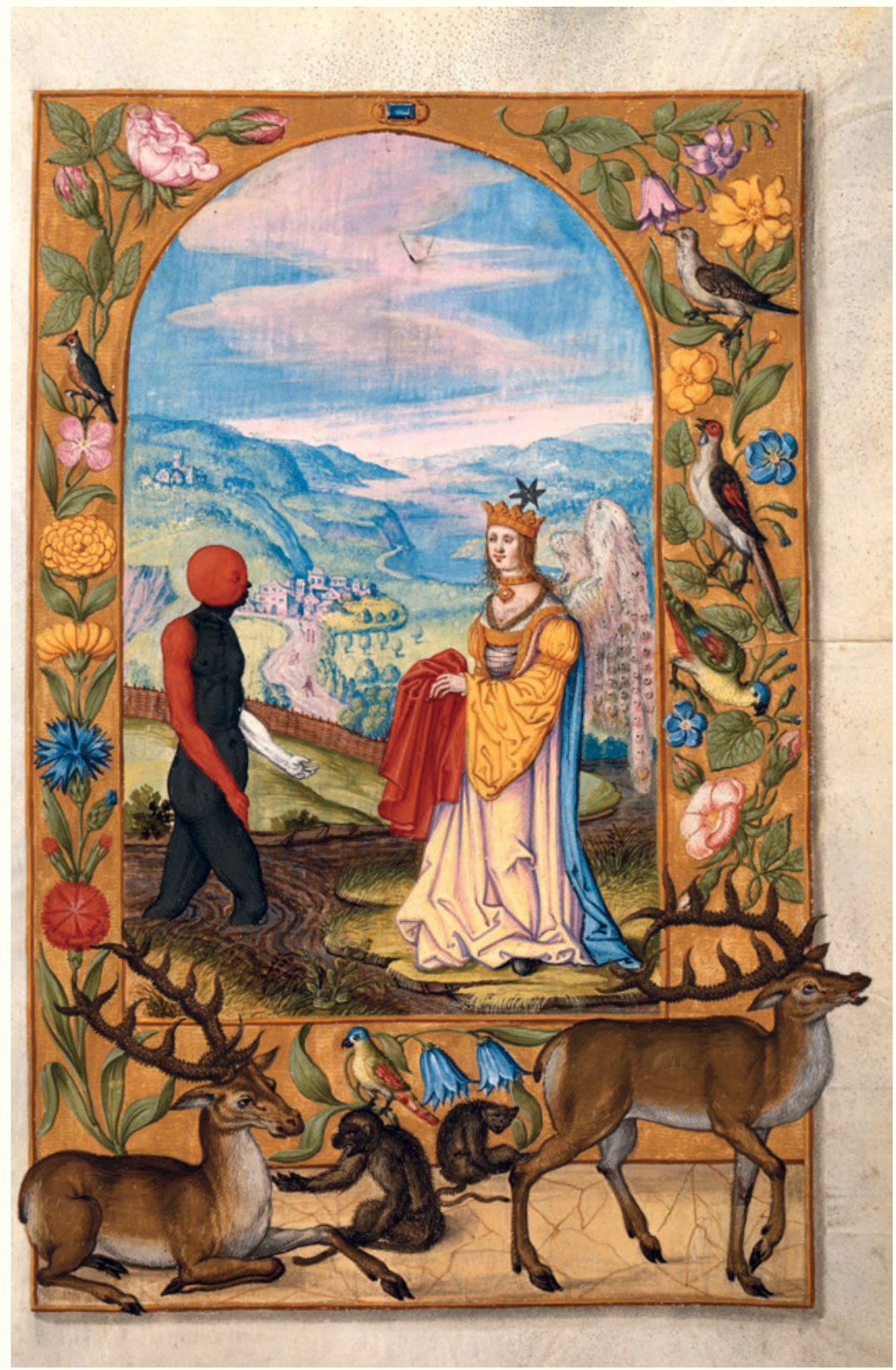

Splendor Solis, Staatsbibliothek zu Berlin, Ms. germ. fol. 42. Abbildung f. 9r , der „Sumpfmensch“. 
Abb. 6 zu Wels, Alchemie als Gegenstand der Wissensgeschichte (S. 256)

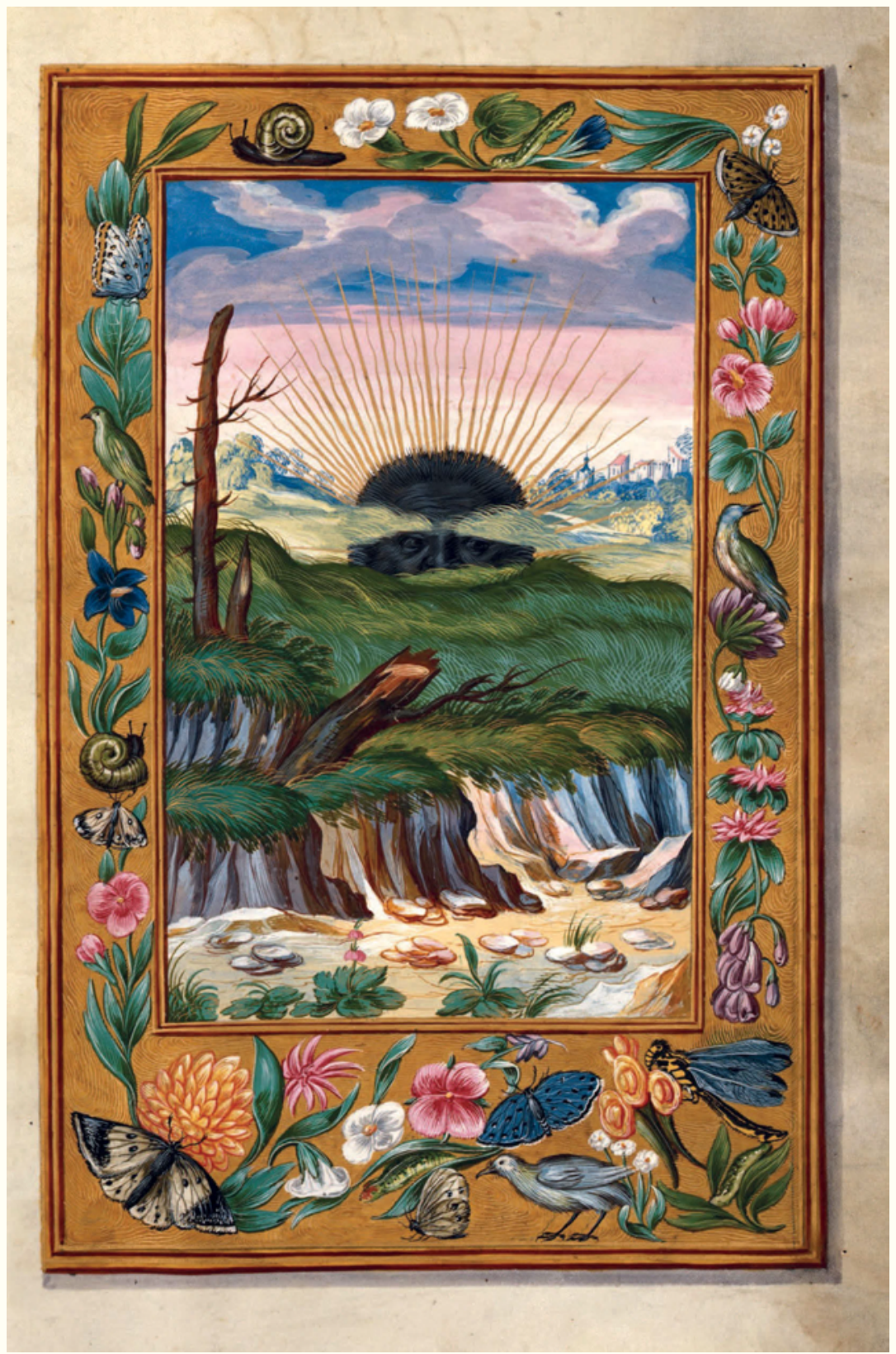

Splendor Solis, Staatsbibliothek zu Berlin, Ms. germ. fol. 42. Abbildung f. 25r , die ,schwarze Sonne'. 


\section{Episteme in Bewegung. Beiträge zu einer trans- disziplinären Wissensgeschichte}

Herausgegeben von Gyburg UhImann im Auftrag des Sonderforschungsbereichs 980 „Episteme in Bewegung. Wissenstransfer von der Alten Welt bis in die Frühe Neuzeit“

1: Eva Cancik-Kirschbaum,

Anita Traninger ( $\mathrm{Hg}$.)

\section{Wissen in Bewegung}

Institution - Iteration - Transfer

2015. Ca. 608 Seiten, $g b$

ISBN 978-3-447-10498-2

$\odot E-B o o k:$ ISBN 978-3-447-19414-3

je ca. $€ 78,-(D)$

Institutionen geraten normalerweise gerade nicht in den Blick, wenn es um Prozesse des Wissenswandels geht. Vielmehr ist es eine weithin geteilte Überzeugung, dass Wandel wenn, dann stets nur außerhalb dieser Kreativitätsblockierer stattfindet. Nun ist aber gerade dort, wo vermeintlich rigide und stur am Überkommenen festgehalten wird, stets auch Wandel feststellbar. Ganz offensichtlich bringen also Praktiken, die auf Wiederholung gepolt sind und so institutionelle Zusammenhänge stabilisieren sollen, zugleich auch Veränderung hervor. Dieses Zusammenspiel von Wiederholung und Veränderung wird in diesem Sammelband mit dem Begriff der ,Iteration' gefasst. Die Autorinnen und Autoren zeigen anhand einer breiten Palette historischer Fallbeispiele, welche Varianten des Wechselspiels von Wiederholung und Wandel zu beobachten sind und welche Befunde sich daraus für eine transdisziplinäre Wissensgeschichte ergeben.

Der Band eröffnet die Reihe „Episteme in Bewegung. Beiträge zu einer transdisziplinären Wissensgeschichte", in der die Ergebnisse der Zusammenarbeit im Sonderforschungsbereich 980 , angesiedelt an der Freien Universität Berlin, präsentiert werden.
2: Peter-André Alt, Jutta Eming, Tilo Renz, Volkhard Wels (Hg.)

\section{Magia daemoniaca, magia} naturalis, zouber (AT)

Schreibweisen von Magie und Alchemie in Mittelalter und Früher Neuzeit

2015. VI, 447 Seiten, 22 Abb., gb ISBN 978-3-447-10495-1

$\odot$ E-Book: ISBN 978-3-447-19412-9

je ca. $€$ 88,- (D)

3: Peter-André Alt, Volkhard Wels (Hg.)

Religiöses Wissen in der Lyrik der Frühen Neuzeit

2015. VI, 334 Seiten, 12 Abb., gb ISBN 978-3-447-10497-5

Ca. $€ 68,-(D)$

Der Band widmet sich religiösem Wissen in der Dichtung der Frühen Neuzeit, wobei der historische Schwerpunkt auf dem 17. und dem frühen 18. Jahrhundert liegt. Im Sinne des Sonderforschungsbereichs „Episteme in Bewegung" steht im Mittelpunkt die Frage, wie der Funktionswandel des religiösen Wissens, der sich in dieser Dichtung vollzieht, zu beschreiben ist. Von besonderer Bedeutung ist dabei die in der Literaturwissenschaft seit Langem debattierte These, dass die ,Subjektivität' als Kennzeichen der im selben Zeitraum entstehenden Gattung der ,Lyrik' sich in der geistlichen Dichtung der Frühen Neuzeit ankündige. Die Frage, in welcher konkreten Form tatsächlich von einer solchen Bewegung die Rede sein kann, gehört, genauso wie diejenige, ob und, wenn ja, in welchem Sinne diese Bewegung als Säkularisierung aufgefasst werden kann, zu den wiederkehrenden Themen des Bandes. 


\section{Episteme in Bewegung. Beiträge zu einer trans- disziplinären Wissensgeschichte}

Herausgegeben von Gyburg UhImann im Auftrag des Sonderforschungsbereichs 980 "Episteme in Bewegung. Wissenstransfer von der Alten Welt bis in die Frühe Neuzeit“

Im Einzelnen diskutieren die Beiträge die frömmigkeitsgeschichtlichen Voraussetzungen der geistlichen Dichtung und die Wirkung, die man von dieser Dichtung erwartete, genauso wie ihre konfessionsspezifischen Ausprägungen, ihre poetischen und rhetorischen Gestaltungsprinzipien, die Bedeutung antiker Mythologie und Religion, den Einfluss von Deismus und Pantheismus sowie die Frage nach den Anfängen der ,Naturlyrik؛. Im Fokus des gleichermaßen literaturwissenschaftlichen wie religionshistorischen Zugriffs stehen - neben Korpora wie den kirchlichen Gesangbüchern - Dichter wie Friedrich von Spee, Andreas Gryphius, Catharina Regina von Greiffenberg, Daniel von Czepko, Daniel Casper von Lohenstein, Johann Christian Günther, Barthold Heinrich Brockes, Albrecht von Haller, die galanten Dichter und die Autoren des „Parnassus Boicus“.

\section{4: Almut-Barbara Renger,} Alessandro Stavru (Eds.)

\section{Pythagorean Knowledge from the Ancient to the Modern World: askesis, religion, science}

2016. Ca. 554 pages, hc

Ca. $€ 89,-(D)$

In Vorbereitung / In Preparation

In both ancient tradition and modern research Pythagoreanism has been understood as a religious sect or as a philosophical and scientific community. Numerous attempts have been made to reconcile these pictures as well as to analyze them separately. The most recent scholarship compartmentalizes different facets of Pythagorean knowledge, but this offers no context for exploring their origins, development, and interdependence. This collection aims to reverse this trend, addressing connections between the different fields of Pythagorean knowledge, such as eschatology, metempsychosis, metaphysics, epistemology, arithmology and numerology, music, dietetics and medicine as well as politics. In particular, the contributions discuss how the Pythagorean way of life related to more doctrinal aspects of knowledge, such as Pythagorean religion and science. The volume explores the effects of this interdependence between different kinds of knowledge both within the Pythagorean corpus and in its later reception. Chapters cover historical periods from the Archaic Period ( $6^{\text {th }}$ century BC) to Neoplatonism, Early Christianity, the European and Arabic Middle Ages, and the Renaissance through to the Early Modern Period ( $17^{\text {th }}$ century AD). Contributions by E. Afonasin, L. Arcari, D. Baltzly, A. Barker, H. Bartoš, A. Bernabé, J. Bremmer, L. Brisson, F. Casadesús, M. Catarzi, S. Chrysakopoulou, G. Cornelli, E. Cottrell, S. Galson, M. Giangiulio, T. Iremadze, A. Izdebska, C. L. Joost-Gaugier, S. Kouloumentas, B. La Sala, R. McKirahan, C. Montepaone, H.-P. Neumann, A. Palmer, A. Provenza, I. Ramelli, D. Robichaud, B. Roling, W. Schmidt-Biggemann, E. Spinelli, I. F. Viltanioti, and L. Zhmud.

5: Angelika Neuwirth, Nora Katharina Schmid, Nora Schmidt (Hg.)

\section{Denkraum Spätantike}

Szenarien der Reflektion von „Antiken“ im Umfeld des Koran

2016. Ca. 432 Seiten, gb

Ca. $€ 68,-(D)$

In Vorbereitung / In Preparation 